der Historischen Kommission zu Berlin

Historische Kommission zu Berlin e.V. (Hrsg.)

\title{
Das Graue Kloster in Berlin
}

Perspektiven aus der Geschichte

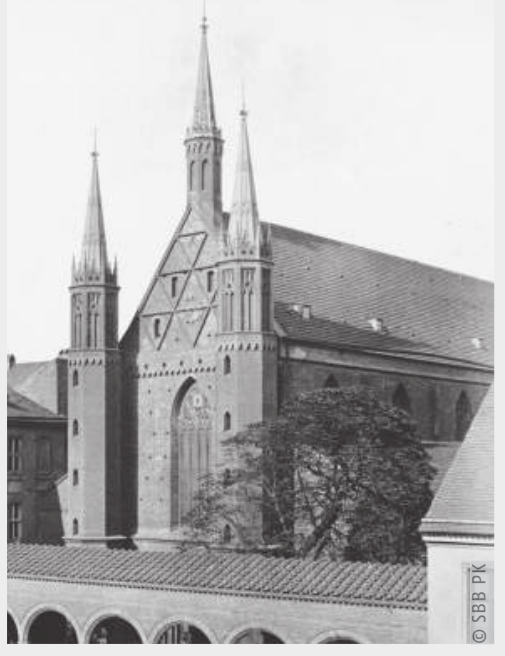



Das Graue Kloster in Berlin

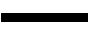




\section{KLEINE SCHRIFTENREIHE DER}

\section{HISTORISCHEN KOMMISSION ZU BERLIN}

Herausgegeben von Michael Wildt

\section{HEFT 11}


Historische Kommission zu Berlin e.V. (Hrsg.)

Das Graue Kloster in Berlin

Perspektiven aus der Geschichte 
Inhaltliche Konzeption

Doris Bulach, Benedikt Goebel, Guido Hinterkeuser, Wolther von Kieseritzky

und Matthias Wemhoff

Redaktion

Ellen Franke, Wolther von Kieseritzky, Annelies Scheel und Holger Schmidt

Gedruckt mit finanzieller

Unterstützung der Senatskanzlei -

Wissenschaft und Forschung

\begin{tabular}{|l|l|c|}
\hline $\begin{array}{l}\text { Der Regierende Bürgermeister } \\
\text { von Berlin } \\
\text { Senatskanzlei - Wissenschaft und Forschung }\end{array}$ & BERLIN & J \\
\hline
\end{tabular}

Historische Kommission zu Berlin e.V.

Jägerstraße 22/23 (BBAW),

10117 Berlin-Mitte

Kirchweg 33 (Der Mittelhof),

14129 Berlin-Nikolassee

E-Mail: info@hiko-berlin.de

Internet: www.hiko-berlin.de

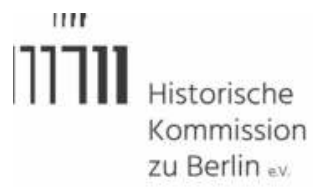

Dieses Buch ist eine 0pen-Access-Publikation.

\section{(c) $(1) \Theta$}

Dieses Werk ist lizenziert unter einer Creative Commons Namensnennung Nicht kommerziell - Keine Bearbeitungen 4.0 International Lizenz.

https://creativecommons.org/licenses/by-nc-nd/4.0/deed.de

Bibliografische Information der Deutschen Nationalbibliothek:

Die Deutsche Nationalbibliothek verzeichnet diese Publikation in der Deutschen Nationalbibliografie; detaillierte bibliografische Daten sind im Internet über http://dnb.d-nb.de abrufbar.

Dieses Werk einschließlich aller seiner Teile ist urheberrechtlich geschützt. Jede Verwertung außerhalb der engen Grenzen des Urheberrechtes ist unzulässig und strafbar.

(c) 2021 BWV | BERLINER WISSENSCHAFTS-VERLAG GmbH, Behaimstr. 25, 10585 Berlin,

E-Mail: bwv@bwv-verlag.de, Internet: http://www.bwv-verlag.de

Umschlagabbildung: @ Staatsbibliothek zu Berlin Preußischer Kulturbesitz, Kartenabteilung Layout und Herstellung durch den Verlag

Satz: DTP + TEXT Eva Burri, Stuttgart

Druck: docupoint, Magdeburg

Gedruckt auf holzfreiem, chlor- und säurefreiem, alterungsbeständigem Papier.

Printed in Germany.

ISBN Print 978-3-8305-5069-3

ISBN E-Book 978-3-8305-4233-9

https://doi.org/10.35998/9783830542339 


\section{Inhaltsverzeichnis}

Klaus Lederer

Grußwort des Senators für Kultur und Europa $\ldots \ldots \ldots \ldots \ldots \ldots \ldots \ldots \ldots \ldots \ldots \ldots \ldots$

Sabine Weißler

Grußwort der Bezirksstadträtin Bezirksamt Berlin-Mitte . .

Matthias Wemhoff

Einführung.

Heinz-Dieter Heimann

per totum orbem longe lateque diffudit angesichts des closters barfusser ordens

in unser stadt Berlin. Zur Geltung des Franziskanerkonvents im Mittelalter

und seiner Geschichte am Erinnerungsort ,Graues Kloster ' heute

Doris Bulach

Das Franziskanerkloster in Berlin als Ort christlicher Memoria im Mittelalter.

Andreas Stegmann

Das Graue Kloster von der Einführung der Reformation bis zur Begründung

des Gymnasiums (1540-1574)

Susanne Knackmuß

,Klostergeist'-Kontinuum in situ. Das Berlinische Gymnasium zum Grauen Kloster ......

Dirk Schumann

Die Berliner Franziskanerklosterkirche - eine Bettelordenskirche als markgräfliche

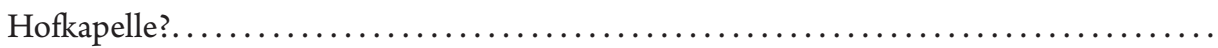

Gunnar Nath

Archäologische Bestandsaufnahme des Grauen Klosters

Michael Malliaris

Klostergründungen in Berlin. Die Ergebnisse der Ausgrabungen zum Dominikanerkloster in Cölln

Peter Lemburg

Das Graue Kloster und der Backsteinforscher Friedrich Adler . 


\section{Wolfgang Schäche}

Aufbruch in das 20. Jahrhundert. Der Umbau und die Erweiterung des Gymnasiums zum Grauen Kloster durch Ludwig Hoffmann. . .

\section{Sibylle Schulz}

Die Klosterkirche zu Berlin - Ruinendenkmal seit 1945.

\section{Guido Hinterkeuser}

Zum Umgang mit Ruinen kriegszerstörter Kirchen nach 1945 in Deutschland

Autorenverzeichnis.

Abbildungsnachweise 


\section{Klaus Lederer}

\section{Grußwort des Senators für Kultur und Europa}

Archäologie ist in. Zu diesem Fazit muss man kommen, wenn man die mannigfachen aktuellen Aktivitäten rund um die Archäologie in Berlin sieht: 2018 die große und publikumswirksame Ausstellung ,Bewegte Zeiten' im Martin-Gropius-Bau anlässlich des Europäischen Kulturerbejahrs; im Frühjahr 2019 der Beginn von archäologischen Grabungen am Mühlendamm, demnächst der Beginn der Grabungen am Molkenmarkt - beides schon jetzt unter großem Interesse der Presse und Öffentlichkeit; und gleichzeitig eine Vielzahl von Veranstaltungen - ob Führungen oder Buchpräsentationen -, bei denen die Geschichte unter der Erde im Fokus steht.

Angesichts dieses großen Interesses überrascht es nicht, dass wieder ein bedeutsamer Berliner Ort in den Fokus gerät - das sogenannte Graue Kloster.

Mit dem hiesigen Kolloquium - zu dem die Historische Kommission zu Berlin e. V. eingeladen hat und dessen Erträge nun in gedruckter Form vorliegen - soll die Bedeutung dieses besonderen Ortes für die Berlinerinnen und Berliner seit seiner Gründung bis heute erörtert werden: vom landesherrlichen Beginn im Mittelalter über das Berlinische Gymnasium zum Grauen Kloster und die ,Wiederentdeckung' der Anlage zu Beginn des 19. Jahrhunderts bis hin zum Schicksal im 20. Jahrhundert und seiner Perspektive im 21. Jahrhundert - die uns natürlich alle besonders interessiert.

Vieles, was einst das Graue Kloster ausmachte, ist heute nur noch als Fundamentrest im Boden vorhanden. Die Ruine der Klosterkirche ist der einzige bauliche Überrest, der vom Grauen Kloster bis heute überdauerte. Auch wenn sie angesichts der Vielzahl herausragender Denkmale in Berlin bisweilen im Hintergrund steht, darf die Bedeutung dieses Denkmals nicht unterschätzt werden: Das um 1250 begonnene gotische Kirchengebäude gilt als ältestes vollständig in Backstein ausgeführtes Bauwerk in Berlin. Stilistisch steht es am Anfang der regionalen Entwicklung der Backsteingotik. Es weist im Detail Verwandtschaften mit herausragenden Bauten wie dem Dom in Brandenburg oder der Zisterzienser-Klosterkirche in Chorin auf und ist gleichzeitig durch seine eigentümliche Chorlösung ein Unikum. Neben Objekten wie der Marienkirche und der Nikolaikirche gehört die Ruine der Klosterkirche zu den wenigen überlieferten Bauten des mittelalterlichen Berlin.

Gesteigert wird die Bedeutung der Klosterkirchenruine dadurch, dass diese - 75 Jahre nach Ende des Zweiten Weltkriegs - zu einer der bedeutendsten Ruinen in der Großstadt Berlin nach der Kaiser-Wilhelm-Gedächtniskirche geworden ist. Als Kulturdenkmal von nationaler Bedeutung hat sie Anerkennung und Förderung gefunden. Interessanterweise ist die im Grünraum inszenierte Ruine der Klosterkirche lange eine Art Geheimtipp für Berlinerinnen und Berliner sowie für unsere Gäste aus aller Welt geblieben. Mit den künstlerischen Interventionen, die das Kulturamt des Bezirks Mitte seit Kurzem an diesem besonderen Ort kuratiert, beginnt nun langsam ein Wandel. Immer mehr Menschen entdecken die Ruine der Klosterkirche (wieder). Als für Kultur und Denkmalschutz zuständiger Senator ist dies für mich natürlich ein wunderbares 
Beispiel, wie beides sich gegenseitig bereichern kann. Für diesen schönen Erfolg darf ich allen Beteiligten im Kulturamt Mitte sehr herzlich danken.

Dass die Klosterkirchenruine nicht immer im Fokus der Stadtgesellschaft war und ist, mag auch an ihrer Lage liegen. Etwas abgeschieden oder zumindest abgerückt von den Hauptverkehrsadern liegen das Parochialkirchviertel und die Klosterkirchenruine der Aufmerksamkeit bisweilen entzogen. Dieser Umstand war wahrscheinlich auch ein Grund, dass den Resten des berühmten Gymnasiums zum Grauen Kloster das traurige Schicksal anderer sakraler Denkmalruinen von Berlin erspart blieb, wie etwa der nahe gelegenen Sankt Petrikirche, deren Kriegsruine nach 1961 zugunsten eines Pkw-Stellplatzes vernichtet wurde. Die Klosterkirchenruine blieb - und entwickelte sich stattdessen zum ,Mahnmal für die Schrecken des Krieges‘.

In Kürze wird sich dieser Kontext verändern. Die vielen Baustellen auf dem Weg hierhin haben es angedeutet: Durch die Verlegung und Verschmälerung der Grunerstraße wird Platz für ein ganzes neues Stadtquartier zwischen historischem Molkenmarkt und Grauem Kloster entstehen. Ich freue mich auf dieses neue Quartier: Denn es wird durch Wohnen und öffentliche, zum Beispiel kulturelle Nutzungen Leben in ein Gebiet bringen, was von Vielen als überdimensioniert und unwirtlich empfunden wird.

Einst war hier die historische Mitte Berlins. Das Landesdenkmalamt Berlin wird deshalb vor Beginn der eigentlichen Bauarbeiten umfangreiche Grabungen zwischen Molkenmarkt und Grauem Kloster durchführen. Ich bin sehr gespannt, welche Ergebnisse und neuen Erkenntnisse diese Grabungen uns über unsere Stadt liefern werden, und setzte mich deshalb auch aktiv - und wie ich bisher meine auch erfolgreich - für die angemessene finanzielle Ausstattung dieser Grabungen ein. Gleichzeitig danke ich den hochmotivierten Kolleginnen und Kollegen im Landesdenkmalamt.

Bei so viel Geschichte stellt sich natürlich sofort auch die Frage, was dies für die zukünftige Gestaltung dieses neuen Quartiers bedeutet. Wichtig scheint mir, dass wir das neue Quartier nicht als Themenparcours durch die Geschichte entwickeln. Es soll ein neues, modernes Stadtviertel werden. Dies soll aber keinesfalls die Geschichte ausschließen. Vielmehr geht es meiner Meinung nach darum, genau zu identifizieren, was den Ort ausmachte und zukünftig ausmachen kann. Archäologische Fenster oder das Aneignen der historischen Stadtstruktur sind Beispiele, wie dies gelingen kann - ohne, dass wir in einen Historismus des 19. Jahrhunderts abgleiten müssen.

Mitte Mai 2019 fand ein Pressetermin statt, bei dem ich gemeinsam mit dem Landeskonservator Christoph Rauhut die Bauten der Internationalen Bauausstellung von 1987 als neue Berliner Denkmale präsentiert habe. Die sogenannte IBA Neu hatte sich damals das Ziel der ,Kritischen Rekonstruktion der Stadt' gesetzt. Im Fokus dieser - wirklich beeindruckenden - Planungen und Bauten stand also die kreative Aneignung und Weiterentwicklung der Stadt - meines Erachtens ein gutes Beispiel, von dem wir heute für die Entwicklung des neuen Quartiers lernen können.

Sicher ist, dass das Graue Kloster beziehungsweise die Klosterkirchenruine ein Höhepunkt dieses Quartiers bleiben wird. Dies heißt im Umkehrschluss aber auch, dass wir uns mit großer Sorgsamkeit diesem Ort widmen müssen. 
Ein Aspekt muss die Klosterkirchenruine sein: Seit der jüngsten umfassenden Sicherung und Restaurierung sind mehr als vierzehn Jahre vergangen. Unlängst diagnostizierte Schäden des Baubestands zeigen, dass es dringend einer Baupflege bedarf, die auf der Grundlage bewährter Wartungsintervalle und einer abgesicherten Finanzierung durchgeführt wird, um die Erhaltung der Kirche in ihrem Zustand für die nächsten Generationen zu gewährleisten. Ich weiß, dass die Denkmalpflege hierzu bereits im Dialog mit dem Bezirk Mitte als Eigentümer ist, was ich ausdrücklich begrüße und - wenn in Zukunft notwendig - auch versuchen will zu unterstützen.

Gleichzeitig gilt es natürlich auch, sorgsam über den ehemaligen Standort des einstigen Berlinischen Gymnasiums zum Grauen Kloster zu diskutieren. Ich meine, dass hier ein Ort entstehen muss, der baulich der Klosterkirche und durch eine öffentliche Nutzung dem Ort Respekt zollen sollte. Was dieses genau bedeuten mag, werden Sie ja im Laufe des heutigen Tages intensiv analysieren und diskutieren. Hierbei wünsche ich Ihnen Erfolg und bin gespannt auf die Impulse, die die Veranstaltung setzen wird. 



\section{Sabine Weißler}

\section{Grußwort der Bezirksstadträtin Bezirksamt Berlin-Mitte}

Ich freue mich sehr über die Gelegenheit, Ihnen ein paar Worte und Gedanken aus meiner Sicht als Bezirksstadträtin, in deren Fachvermögen und Zuständigkeit sich dieses einzigartige Baudenkmal Berlins sowie die umliegenden Grünflächen befinden, mit auf den Weg zu geben.

Mit dem neuen Bebauungsplan für den Bereich Klosterviertel/Molkenmarkt war das Baudenkmal der Kirchenruine des ehemaligen Franziskanerklosters aus seinem Schattendasein zwischen dem Palais Podewil und dem Berliner Rathaus herausgetreten.

Das Kolloquium ist für mich ein willkommener Anlass, über die Folgen dieser raumgreifenden Stadtveränderung für das Ensemble der ehemaligen Klosteranlage nachzudenken. Mir ist vollkommen bewusst und Ihnen ist es bestimmt auch sehr gegenwärtig, dass wir vor einem Moment stehen, der die Perspektive der Ruine der ehemaligen Klosterkirche der Franziskaner entscheidend prägen wird.

Was wird passieren? Der Bebauungsplan sieht zahlreiche Neubauten und eine Blockrandbebauung vor, mit der die Klosterruine in eine neue stadträumliche Situation eingebettet werden soll. Vorgesehen ist auch, dass sich Straßenzüge verengen, um den Stadtraum des Klosterviertel neu $\mathrm{zu}$ ordnen.

Ein Bebauungsplan aus der Mitte des 20. Jahrhunderts, gegen den sich schon Denkmalfachleute des frühen 21. Jahrhunderts ausgesprochen hatten, will den Kolonnadengang wieder auferstehen lassen. Das ist absurd, da diese Art der Fassung des Kirchengebäudes den historischen Wert des Bauwerks schmälert und verengt. Natürlich haben wir seinerzeit dagegen Einspruch erhoben. Die Klosterruine, gerade als wichtiges Zeugnis der Berliner Stadtgeschichte, muss eindeutig sichtbar Teil des öffentlichen Raums bleiben und darf nicht durch die Rekonstruktion eines Erweiterungsbaus aus dem 19. Jahrhundert eingeschränkt werden.

Die geplante Gebietsentwicklung zielt darauf ab, Molkenmarkt und Klosterviertel als Teil der mittelalterlichen Stadtgründung wieder erfahrbar zu machen, und will dazu beizutragen, die noch vorhandenen Fragmente und Spuren Alt-Berlins in einen nachvollziehbaren historischstadträumlichen Kontext zu stellen. ${ }^{1}$ Aber es ist dem Bezirksamt damals nicht gelungen, seine Forderung zur Änderung des Bebauungsplanes Nr. 1-14 durchzusetzen. Deshalb halte ich es für dringend notwendig, die Diskussion, was für diesen kulturgeschichtlich so wertvollen Standort angemessen und richtig ist, viel offensiver als zuvor zu führen.

Die Klosterkirchenruine des ehemaligen Franziskanerklosters blickt auf eine jahrhundertealte Geschichte zurück. Gegründet im Mittelalter, durchlief der Bau an der Berliner Stadtmauer eine höchst abwechslungsreiche Nutzungs- und Wirkungsgeschichte. Er war Andachts- und Zu-

1 Senatsverwaltung für Stadtentwicklung und Wohnen 2020 (online unter https://www.stadtentwicklung.berlin. de/planen/staedtebau-projekte/molkenmarkt/de/planung/index.shtml [abgerufen am: 23. Oktober 2020]). 
fluchtsraum, die erste Druckerei in Berlin und sogar ein Kornspeicher. Hier widmete sich im 16. Jahrhundert der kurfürstliche Leibarzt Leonhard Thurneysser seinen alchimistischen Experimenten und exotischen Gärten, hier fühlten sich ehemalige Schüler des historischen Gymnasiums zum Grauen Kloster, wie unter anderem Karl Friedrich Schinkel, zu einem neuen Denken in der Baukultur animiert, das Generationen nach ihnen versucht haben, aufzugreifen.

Heute haben wir es mit einer Kriegsruine zu tun. Dass es kein Dach mehr gibt und auch sonst jedwede Einrichtung von Schule und Kloster fehlt, macht diesen Raum nicht weniger bedeutsam. Im Gegenteil: Vielmehr verdichten sich hier die Zeitschichten und Zeugnisse der Stadtgeschichte ohne einen musealen deskriptiven Kontext, hin zu einem offenen und freien Denk- und Wahrnehmungsraum. Das kann ein glücklicher Umstand sein, denn nirgendwo anders in Berlin trifft sich die mittelalterliche Gründungsgeschichte der Stadt mit dem Wandel der Zeiten durch die Jahrhunderte. Und dieser Wandel besteht fortwährend, denn die Zukunft dieses einzigartigen Baus ist ungewiss und deshalb ergeben sich spannende Herausforderungen. Noch prägte den Ort eine seltene Offenheit. Schauen wir, was wir daraus machen können. Der radikale Umbau hat jetzt begonnen. Aber die Sicherungsmaßnahmen für das Baudenkmal aus dem Mittelalter, im Verbund mit dessen unmittelbarem Umfeld der ehemaligen Klosteranlage, stehen noch aus.

Die Perspektive des Bezirks ist es, die Ruine der Klosterkirche für nachfolgende Generationen und als ,öffentliches und lebendiges Baudenkmal' zu sichern und weiter auszugestalten. Der Fachbereich Kultur meiner Abteilung hat vor Jahren schon begonnen, mit Ausstellungen und Veranstaltungen ein neues Zeitfenster für die Nutzung der Kirchenruine zu öffnen. Mit dem Sommerprogramm zum Thema ,mittelalterlicher Garten' und mit der Winterbespielung, unfinished histories' versuchen wir gemeinsam mit internationalen Künstlerinnen und Künstlern, Anregungen für den Umgang mit diesem Ort zu geben und zu einem öffentlichen Nachdenken und Nachspüren der Aura zwischen Geschichte und Gegenwart zu inspirieren.

Ein Anfang ist also gemacht. Nun muss es weitergehen. Dafür brauchen wir den Austausch und die Unterstützung - insbesondere für die bauhistorische Sanierung und Sicherung und den Ausbau des Baudenkmals zu einem lebendigen öffentlichen Ort. 


\section{Matthias Wemhoff}

\section{Einführung}

\section{Das Graue Kloster in Berlin. Perspektiven aus der Geschichte}

Das Graue Kloster, das dem Viertel zwischen Spree und Rathaus beziehungsweise Molkenmarkt und Stadtmauer seinen Namen gab, ist im öffentlichen Raum kaum noch sichtbar. Darin zeigt sich nicht nur, wie sich lang tradierte und historisch bedeutende Strukturen und Identitäten sukzessive verflüchtigen können, sondern auch, insbesondere vor dem Hintergrund der spärlichen baulichen Überreste, welches Schicksal das Graue Kloster in sich trägt: Es wurde zu einem „gebrochenen Erinnerungsort". ${ }^{1}$ Der Berliner Bürgerschaft aufgrund der Verheerungen des Zweiten Weltkriegs sowohl ideell als auch materiell entrissen, wurde es beim Ausbau Berlins zur ,Hauptstadt der Deutschen Demokratischen Republik' weiter marginalisiert und so fristet das isoliert gelegene Ruinendenkmal an der stark befahrenen Grunerstraße gegenwärtig ein Schattendasein. Während Baukörper, die über Jahrhunderte existieren und im Laufe der Zeit verschiedene Nutzungen erfuhren (freilich zumeist mit Umbauten versehen), üblicherweise die vielfältigen Zeitschichten mit den dazugehörenden Transformationsprozessen widerspiegeln, lädt das Graue Kloster im stadträumlichen Gefüge derzeit weder zur Erinnerung ein, noch strahlt es Lebendigkeit oder Atmosphäre aus. Auch seiner ureigensten Aufgabe, die 800-jährige Geschichte dieses Areals zu vermitteln, kann das Ruinenensemble heute kaum gerecht werden. Dabei ist diese Funktionszuschreibung kaum zu überschätzen, mangelt es der Mitte Berlins doch an Zeugnissen seiner mittelalterlichen Geschichte. Zusammen mit der Sankt Marienkirche, der Nikolaikirche, der Kapelle des Heiliggeistspitals und den in der Nähe befindlichen Resten der Stadtmauer gehört es zu der sehr kleinen Gruppe der obertägig sichtbaren Baudenkmäler mit mittelalterlichen Ursprüngen. In den letzten Jahren ist dieser lange vergessene Bereich wieder stärker in den Fokus gerückt. Der Bereich an der Grunerstraße, die verlegt werden wird, wird neu gegliedert und damit besteht die Chance, dieses Areal mit historischen Bezügen neu zu gestalten. Der Umgang mit dem Areal des Grauen Klosters bildet dabei eine besondere Herausforderung, der unsere Generation nur gerecht werden kann, wenn die historische Bedeutung und die vielen Zeitschichten dieses Ortes in Erinnerung gerufen werden. Nur aus dieser Kenntnis heraus können angemessene Vorgaben für den Umgang mit dem Ruinendenkmal und dem gesamten Areal entwickelt werden.

Vor diesem Hintergrund erscheint es umso dringlicher, sich mit der historischen Entwicklung sowie den archäologischen und baulichen Positionen zum Grauen Kloster im Detail auseinanderzusetzen, um überzeugende Argumente für die Diskussion über die zukünftige Gestaltung zu entwickeln. Dazu gehört auch, existierende Forschungsdefizite zu benennen und sich darüber hinaus die in der Vergangenheit geführten Auseinandersetzungen über den Umgang mit dem

$1 \quad$ Heinz-Dieter Heimann, per totum orbem longe lateque diffudit angesichts des closters barfusser ordens in unser stadt Berlin. Zur Geltung des Franziskanerkonvents im Mittelalter und seiner Geschichte am Erinnerungsort ,Graues Kloster' heute, in diesem Band, S. 25. 
Areal zu vergegenwärtigen. Mit diesem Ziel veranstaltete die Historische Kommission zu Berlin e. V. am 20. Mai 2019 ein eintägiges wissenschaftliches Kolloquium, aus dem der vorliegende Band hervorgegangen ist. Die Historische Kommission führt damit ein seit Anfang der 1990erJahre bestehendes Tätigkeitsfeld weiter. Sie sieht ihre Aufgabe darin, in den Gestaltungsprozess der historischen Mitte die geschichtswissenschaftlichen, archäologischen und bauhistorischen Kenntnisse so einzubringen, dass sie im Dialog mit Städteplanern, Architekten sowie der Stadtgesellschaft präsent sind und wirksam werden. ${ }^{2}$ Es gehört zu ihren Kernanliegen, die städtebaulichen Veränderungen der nächsten Jahre, die sich mit den am Molkenmarkt stattfindenden archäologischen Untersuchungen ankündigen und die auf das Klosterviertel ausgedehnt werden, zu begleiten, indem sie auf die Bedeutung dieser Areale für das historische Berlin hinweist, ihre wissenschaftliche Expertise in die laufenden Diskussionen einbringt und somit als Anwalt der baulichen und archäologischen Zeugnisse in einer immer stärker von funktionalen und nutzungsoptimierten Gesichtspunkten bestimmten Gegenwart fungiert.

Das Kolloquium folgte den von der Arbeitsgruppe ,Historische Mitte innerhalb der Historischen Kommission zu Berlin formulierten Leitfragen, die sich zum einen auf den historischen, archäologischen und baugeschichtlichen Wissensstand zum Grauen Kloster bezogen, zum zweiten auf die historischen Perspektiven, die daraus für die Stadtgesellschaft bedeutsam werden, und drittens auf die Auswirkungen auf die künftige Gestaltung. Der vorliegende Band präsentiert Überlegungen und Ergebnisse der fachübergreifenden Diskussion nun einer breiteren Öffentlichkeit.

Zwar sind die großen, insbesondere (bau-)historischen Linien schnell erzählt und der Forschung bekannt, ${ }^{3}$ doch beabsichtigte die Arbeitsgruppe, nicht nur den aktuellen Forschungsstand darzulegen, sondern zugleich den Blick auf das Verhältnis von Berlinerinnen und Berlinern zu ,ihrem Kloster' zu lenken. Damit sollten geschichts- und kulturwissenschaftlich inspirierte Fragen gestellt werden. Welchen Stellenwert besaß dieser Raum für die Stadtgesellschaft in den verschiedenen Epochen? Der Bogen spannte sich vom Mittelalter über die Frühe Neuzeit und das 19. Jahrhundert bis zu den Verheerungen des 20. Jahrhunderts und dem Schicksal des Areals bis heute. Mit dieser epochenübergreifenden Gesamtsicht - so die Intention - sollte der Blick auf mögliche Perspektiven für die zukünftige Gestaltung des Areals geweitet werden. Das Kolloquium und die hier versammelten Beiträge verdeutlichen, dass der Prozess der Wiedergewinnung der ,Mitte' als der historischen Herzkammer Berlins und ihrer Aneignung durch die Stadtgesellschaft keineswegs abgeschlossen ist und auch von unterschiedlich streitbaren Positionen begleitet wird. ${ }^{4}$

2 Siehe dazu u. a. folgende Bände der Historischen Kommission zu Berlin e.V.: Helmut Engel/Wolfgang Ribbe (Hrsg.), Hauptstadt Berlin - Wohin mit der Mitte? Historische, städtebauliche und architektonische Wurzeln des Stadtzentrums (Publikationen der Historischen Kommission zu Berlin), Berlin 1993; Helmut Engel/Jörg Haspel/Wolfgang Ribbe (Hrsg.), Geschichtswerkstatt Spree-Insel. Historische Topographie - Stadtarchäologie - Stadtentwicklung (Publikationen der Historischen Kommission zu Berlin/Beiträge zur Denkmalpflege in Berlin, Sonderbd.), Berlin 1998; Historische Kommission zu Berlin e.V. u.a. (Hrsg.), Alte Mitte - Neue Mitte? Positionen zum historischen Zentrum von Berlin (Kleine Schriftenreihe der Historischen Kommission zu Berlin, H. 10), Berlin 2012.

3 Landesdenkmalamt Berlin (Hrsg.), Kirchenruine des Grauen Klosters in Berlin. Geschichte - Forschung - Restaurierung (Beiträge zur Denkmalpflege in Berlin, Bd. 23), Petersberg 2007.

4 Siehe dazu auch die Beiträge des Vereins für die Geschichte Berlins in: Wolther von Kieseritzky (Hrsg.), Fokus Berlin Mitte. 775 Jahre Historischer Stadtkern, Berlin 2012. 
Das Franziskanerkloster in Berlin (um 1250 dürfte vermutlich bereits ein kleiner Konvent bestanden haben) spielte innerhalb der mittelalterlichen Stadt Berlin von Anfang an eine herausgehobene Rolle, wie Heinz-Dieter Heimann in seinem Beitrag anschaulich darlegt. Zwar fließen die historischen Quellen nur spärlich, doch Heimann kann verdeutlichen, welche Strahlkraft der europäischen religiösen Ordensbewegung mit den Franziskanern als treibenden Akteuren im hohen Mittelalter innewohnte und wie diese wiederum in die Berliner Stadtgesellschaft hineinwirkte. Zugleich offenbart sich mit Blick auf eine „ordens- und kulturhistorisch geleitete Aneignung der Bedeutung der Franziskanerklosterkirche und des Konvents" eine beklagenswerte Forschungslücke, die - und dies war weder Intention des Verfassers noch der Herausgeberin in diesem Rahmen freilich nicht geschlossen werden konnte. Vielmehr ebnen die Überlegungen Heimanns den Weg, sich methodisch und konzeptionell mit dem Erinnerungsort Graues Kloster auseinanderzusetzen. Zugänge wären über verschiedene Wege möglich - zunächst über die franziskanische Ordensgeschichte in Verbindung zur mittelalterlichen Stadtgesellschaft oder zweitens durch die Beleuchtung der „Raumordnungsansprüche“, die sich in der Betrachtung von Klostertopografie und Stadtgestalt offenbaren. Nicht zuletzt könnte - drittens - der franziskanische Rechtfertigungsdruck und Geltungsanspruch der Klostergemeinschaft innerhalb der Stadt und des machtpolitischen Umfelds herausgeschält werden.

Während Heimann mit geschichts- und kulturwissenschaftlichen Zugriffen verdeutlicht, wie der Erinnerungsort Graues Kloster für die Gegenwart konzeptionell aufgeschlüsselt werden könnte, gelingt es Doris Bulach, den mittelalterlichen Erinnerungsort zu beleuchten. Sie nimmt die enge Verbindung der Franziskaner zur landesherrlich-weltlichen Macht, eingebettet in das städtischobrigkeitliche Umfeld Berlins, vor der Folie der religiösen Sorge der Menschen um ihr Seelenheil, der memoria, in den Blick. Obwohl die schriftliche Überlieferung nur wenige Aussagen zulässt, vermag die Autorin anhand der Klosterausstattung, wie Altäre, Gemälde, Grablegen, Inschriften und Stiftungen, vier Personengruppen herauszuarbeiten, die den Franziskanerkonvent für ihre Jenseitsvorsorge standesübergreifend nutzten (Markgrafen, Adlige, Geistlichkeit, darunter auch die Mönche selbst, sowie Berlinerinnen und Berliner). Sie zeichnet das Bild von einem Ort, der im Mittelalter „viele, ganz unterschiedliche Personengruppen zusammenführte“. Diese Funktion - Gemeinschaftsort für Personen unterschiedlicher Herkunft - zog sich als roter Faden durch die Geschichte und prägte das Areal auch nach der reformationsbedingten Aufhebung des Klosters beziehungsweise nach dessen Umwidmung zur Schule.

Hier setzt Andreas Stegmann ein und veranschaulicht, wie dieser Wandlungsprozess sowie „das Hineinwachsen der Klosterkirche in das städtische Kirchenwesen“ vonstattengingen. Angesichts der äußerst unzureichenden Quellenüberlieferung und des überholten Forschungsstands führt der Autor die daraus resultierenden Forschungslücken zur Berliner Stadt- und Reformationsgeschichte des 16. Jahrhunderts sehr eindrücklich vor Augen. Der Beitrag offenbart, welche Kraftanstrengungen notwendig sind, um die Stadtgeschichtsforschung für Berlin an aktuelle Fragestellungen der Frühneuzeitforschung anzuschließen. Dies gilt - bezogen auf die Schul- und Bildungsgeschichte - sogar bis in das 20. Jahrhundert, worauf der Beitrag von Susanne Knackmuß verweist. Die Autorin konzentriert sich in ihren Ausführungen auf die Bildungstradition, die dank einer fast 400-jährigen Kontinuität von Lehre und Unterricht im Grauen Kloster für Berlinerinnen und Berliner geschaffen wurde. Sie hebt hervor, mit welchem Selbstverständnis, 
aber auch mit welchen Ansprüchen sowohl die Lehrer als auch die Schüler in die Stadtgesellschaft hinein- und darüber hinauswirkten. Zugleich unterstreicht sie den bildungsbürgerlichen Verlust, den der Wegfall der Institution für die Mitte Berlins bedeutete.

Zwar zeigen die geschichtswissenschaftlichen Beiträge insgesamt, in welchem Umfang noch Forschungen zum Grauen Kloster erforderlich und wünschenswert sind, insbesondere auch in vergleichender Perspektive, eine Erkenntnis aber ist festzuhalten: Dieser Ort - egal, ob als Mönchskloster oder als Schule - war nicht nur fest verankert in seinem städtischen Umfeld, vielmehr schuf er geistig-kulturelle Angebote und strahlte auf diese Weise in seine Umgebung hinein. Als lebendiger Ort von und für Menschen zum intellektuellen Austausch geschaffen, zog er standesübergreifend Individuen an und ermöglichte damit vielfältige Denk- und Gestaltungsräume. Auf diese Weise prägte er nicht nur das nach ihm benannte (Kloster-)Viertel, sondern auch Berlin über die Jahrhunderte hinweg. Hinzu kommt die Bündelung der Gewalten auf engstem Raum; die kommunalen, geistlichen sowie die landesherrlichen Standorte der Macht mit ihren jeweiligen Interessen befanden sich, zumindest im Mittelalter, im Klosterviertel. In unmittelbarer Nachbarschaft zum Grauen Kloster befand sich das ,Hohe Haus', der Sitz der Landesherren in ihrer Stadt Berlin. Bis zur Mitte des 15. Jahrhunderts, bis zum Bau des hohenzollerischen Residenzschlosses auf der Cöllner Spreeinsel, beherbergte es also eines der landesherrlichen Zentren der Mark Brandenburg. In der Klosterkirche nahm der erste Hohenzoller, Kurfürst Friedrich I., 1415 die Huldigungen der märkischen Stände entgegen; hier fand 1441 ein Hoftag statt. Diese räumliche sowie ideelle Verbindung zwischen Stadt, Geistlichkeit und Landesherrschaft schuf die mittelalterliche Blütephase dieses Areals mit einer ganz besonderen atmosphärischen Mischung aus Macht, Kultur und Bildung.

Diese Funktionen sowie die herausgehobene Lage reflektierend, übersetzten vorangegangene Generationen die kulturell-politische Strahlkraft des Ortes in eine beeindruckende Architektursprache, wovon die bauhistorischen sowie archäologischen Beiträge des Bandes zeugen. Mit guten Argumenten geht Dirk Schumann der Frage nach, ob die Bauart der Franziskanerklosterkirche ihre Nutzung als askanische Hofkapelle nahelegt, und beantwortet sie positiv. Vergleichend zu anderen Franziskanerklosterkirchen, zum Zisterzienserkloster in Chorin sowie aus der Konkurrenz der johanneischen und ottonischen Markgrafenlinie schließend, entwickelt Schumann die These von der Klosterkirche als „Hofkirche der Landesherren, deren Architektur nicht hinter dem Bau der neuen Grablege der konkurrierenden ottonischen Markgrafenlinie in Chorin zurücksteht.“ Damit nahm der Konvent - anknüpfend an seine Funktion als Memorialträger herrschaftsnahe Aufgaben wahr, was einmal mehr die besondere Prägung dieses Ortes als markgräfliche sowie als städtisch-bürgerliche Kirche unterstreicht.

Diese Bedeutung für die herrschaftliche Führungsschicht im Verbund mit der stadträumlichen Prägung, die vom Kloster ausging, lässt sich im archäologischen Befund heute nur noch erahnen. Gunnar Nath gibt einen Überblick über die zu erwartenden archäologischen Funde und Befunde auf der Basis der seit dem späten 18. Jahrhundert durchgeführten Umbaumaßnahmen. Die Nutzung des Klosters als Schule stellte die Verantwortlichen zu verschiedenen Zeiten vor die Herausforderung, die baulichen Gegebenheiten jeweils modernen Ansprüchen entsprechend anzupassen. So zeigen die Ergänzungs- und Umbauten, insbesondere ab dem späten 18. Jahrhun- 
dert bis um 1900, wie die Anlage sich wandelte, um die neuen Funktionen (beispielsweise eine Turnhalle) integrieren zu können oder höhere Platzkapazitäten zu schaffen. Es wird deutlich, dass die baulichen Herausforderungen bewältigt wurden, um der Schule innerhalb der Klostermauern den Fortbestand zu sichern. Anders erging es dem benachbarten Dominikanerkloster, quasi dem Schwesterkloster in Cölln auf der anderen Spreeseite - es fiel bereits im 18. Jahrhundert einem vom Landesherrn initiierten Transformationsprozess zum Opfer, indem 1747 „K̈̈nig Friedrich II. den zuletzt freistehenden Kirchenbau abreißen ließ und die Domkirche in den Lustgarten verlegte“, wie Michael Malliaris ausführt. Der Autor legt anhand der archäologischen Ergebnisse, die die Grabungen auf der Cöllner Spreeinsel zu Tage förderten, eine in der Nähe des Berliner Schlosses zu verzeichnende und im späten 12. Jahrhundert beginnende Siedlungskontinuität offen. Malliaris verdeutlicht, welche innerstädtischen Wandlungsprozesse sich im Erdreich ablesen lassen, und hebt zugleich hervor, wie wertvoll die Sicherung dieser Zeugnisse für die Nachwelt innerhalb von entstehenden Neubauten ist. So lässt sich fragen, auf welche Weise dieser historische Raum heute vermittelt werden könnte? Mit der „geplante[n] Schaffung eines ,archäologischen Pfades', der verschiedene Geschichtsorte der Doppelstadt Berlin-Cölln miteinander verbinden soll“, ließe sich die Ruine der Franziskanerklosterkirche in den Vermittlungspfad einbinden, um die mittelalterliche Doppelstadt Berlin-Cölln für Besucher und Besucherinnen erfahrbar zu gestalten.

Überraschend ist der Befund von Peter Lemburg, dass Friedrich Adler, als einer der angesehensten (wenngleich nicht unumstrittenen) Backsteinforscher des 19. Jahrhunderts, eher wenig bis gar kein Interesse zeigte, den spätmittelalterlichen Kapitelsaal sowie den Nordflügel des Klosters zu untersuchen. Der Franziskanerklosterkirche vermochte Adler noch einige Untersuchungen abzugewinnen, den Konventsbauten jedoch entzog er sich ganz. Wie dieser Befund zu erklären und einzuordnen ist, muss an dieser Stelle offenbleiben, doch offenbart der Beitrag, welchen Überformungen die Klosteranlage im 19. Jahrhundert unterworfen war und welche Namen als verantwortlich handelnde Akteure in der damaligen wie auch heutigen Forschung für diese Umbauten und Ergänzungen ins Spiel gebracht wurden (und werden). Erst um 1900 kann wieder sicheres Terrain gewonnen werden - mit dem zwischen 1900 und 1904 vorgenommenen Um- und Ausbau unter der Leitung von Stadtbaurat Ludwig Hoffmann. Wolfgang Schäche präsentiert diese wichtigen Erweiterungsbauten, darunter auch die neue Turnhalle; ebenso ordnet er die historisierenden Ansprüche Hoffmanns sowie die stilistischen Details ein. Hoffmann schuf, so der Autor, ein das Klosterviertel prägendes Gebäudeensemble, das „in seiner programmatischen Klarheit und stilistischen Vielfalt [...] , unverwechselbar hoffmannsch, impressionistisch, fortschrittlich, beruhigend und (im Sinne des gesellschaftlichen Selbstverständnisses) dabei durchaus autoritär " "`5 war.

Die Hoffmannschen Umbauten waren die letzten nennenswerten baulichen Veränderungen „vor den kruden Zerstörungen des Zweiten Weltkriegs“, mit deren Folgen sich Sibylle Schulz in ihrem Beitrag befasst. Sie beschreibt die nach 1945 in Ost- wie West-Berlin zum Durchbruch gelangenden neuen städtebaulichen Tendenzen, die auf die Schaffung, autogerechter Städte zielten und dabei bewusst gewachsene Strukturen ignorierten. Letzteres war allerdings bereits vor 1945 
der Fall gewesen. Seit den 1920er-Jahren entwickelt, kam nun eine ,moderne' Städteplanung zum Zuge, die nach den großflächigen Zerstörungen des Zweiten Weltkrieges nicht nur den städtebaulichen Freiraum erhielt, um ganze Viertel und Stadtteile neu zu gliedern, sondern auch getragen von einem Teil der Gesellschaft - daran ging, noch vorhandene Altbausubstanz und überkommene Grundrisse großflächig abzuräumen. Rechtfertigt wurden diese Vorgänge mit dem Argument, als negativ verstandene städtebauliche und gesellschaftliche Entwicklungen der Vergangenheit durch radikalen Umbau gleichsam zu ,bewältigen'. In Ost-Berlin kam eine ideologische Formierung hinzu, in der - unter der Ägide eines sozialistischen Stadtbaus für eine ,neue Gesellschaft - explizit bildungsbürgerliche (wie das Gymnasium zum Grauen Kloster) und religiös konnotierte Orte keinen Platz mehr hatten, wodurch das Schicksal der einstigen Eliteschule im Herzen Berlins besiegelt war. Übrig blieb die Klosterkirchenruine, die nun als Ruinendenkmal an die Schrecken des Krieges erinnern sollte.

In welchem Umfang Erinnerungsorte von der jeweiligen historischen Sinngebung und gesellschaftlichen Verfasstheit abhängen, also auch geschichtspolitisch bestimmt sind, legt abschließend Guido Hinterkeuser dar. Ihm geht es darum, „einen Begriff von den verschiedenen Möglichkeiten im Umgang mit Ruinen kriegszerstörter Kirchen zu vermitteln“. Der Autor skizziert mehr als 20 Kirchenbaubeispiele und unterstreicht, wie eng der Umgang mit den Kirchenruinen nicht nur durch die jeweilige geschichtspolitische Deutung, sondern ebenso durch ihre Nutzungsgeschichte sowie die Erwartungshaltungen in der Gesellschaft und der verantwortlich handelnden Akteure auf kommunaler und staatlicher Ebene bedingt ist. Ruinen verlangen eine Stellungnahme, Ruinen sind aber zugleich auch Positionsbestimmungen der Gesellschaft und auch dies macht der Beitrag deutlich - Ruinen müssen nicht immer Ruinen bleiben.

Die Beiträge im Band können sicher kein ganzheitliches und abschließendes Bild der Geschichte des Grauen Klosters im Sinne einer Gesamtschau seiner sozialen, kulturellen, herrschaftlichen und bauhistorischen Wirkungen im Stadtgefüge bieten. Jedoch zeigen bereits die hier ausgeführten Facetten, welche immense Bedeutung die mittelalterlichen Ursprünge Berlins für die Entwicklung der Stadtgesellschaft besaßen und wie das Graue Kloster bis weit in das 20. Jahrhundert hinein zu den zentralen und im kollektiven Bewusstsein fest verankerten Kristallisationspunkten städtischen Lebens gehörte. Dies ist gemeint, wenn von diesem Areal als einem Erinnerungsort der Zivilgesellschaft die Rede ist.

Auf die Frage, wie mit diesem Raum umzugehen ist, gibt es, auch dies verdeutlichen die Beiträge im Band, unterschiedliche Antworten. Während die einen - vor dem Hintergrund der bereits 2007 erfolgten wissenschaftlich-denkmalpflegerischen Bestandsaufnahme - ein Ruinendenkmal bevorzugen, plädieren andere für einen geschützten, bestenfalls baulich überformten Ort, der die Ruine verantwortungsvoll integriert und der Geschichtsvermittlung sowie Erinnerung dient. Dabei kommt auch den im Boden noch erhaltenen Baustrukturen, wie dem Kreuzgang, dem bedeutenden Kapitelhaus und dem Nordflügel, eine besondere, möglicherweise auch zukünftige bauliche Vorhaben prägende Bedeutung zu. Die Einbeziehung in das Konzept der archäologischen Fenster, das am Humboldt Forum im Berliner Schloss bereits realisiert ist, sich am Petriplatz in der baulichen Umsetzung befindet und am Roten Rathaus gerade geplant wird, liegt dabei nahe. Die Vorstellungen über mögliche Nutzungen knüpfen insbesondere an die Bedeutung der Schule 
an dieser Stelle an. Konsens scheint nach den Ergebnissen des Kolloquiums darüber zu bestehen, diesen Raum wieder in seiner historischen Bedeutung bewusst und erfahrbar zu machen, ihn der gegenwärtigen und zukünftigen Stadtgesellschaft wieder ,zurückzugeben'. Das heißt zuallererst, das Areal als einen lebendigen Ort des offenen Austausches und der Partizipation, als Beispiel einer demokratischen Erinnerungskultur und Geschichtsvermittlung zu begreifen. Nimmt man das historische Erbe, das von einer beeindruckenden Entwicklung und Vielfalt der Berliner Stadtgesellschaft zeugt, sowie den verantwortungsvollen Umgang mit der eigenen Geschichte zum Ausgangspunkt künftiger städtebaulicher Überlegungen, könnte dies zu gesellschaftlich tragfähigen, zukunftsweisenden und bürgernahen Entscheidungen von hoher Akzeptanz führen. Dies ist gerade vor dem Hintergrund der so weitgehend ausgelöschten Zeugnisse der Geschichte Berlins vor dem 19. Jahrhundert eine große Chance und eine Verpflichtung.

Die Historische Kommission zu Berlin e.V. dankt allen Autorinnen und Autoren, den Referentinnen und Referenten sowie allen Personen, die zum Gelingen des Kolloquiums und der Publikation dieses Bandes beigetragen haben, sehr herzlich. Ein großer Dank richtet sich auch an den Berliner Wissenschafts-Verlag, der den Band innerhalb der Kleinen Schriftenreihe der Historischen Kommission umgesetzt und betreut hat. Für die großzügige finanzielle Förderung des wissenschaftlichen Kolloquiums sowie der Publikation danken wir der Senatskanzlei - Wissenschaft und Forschung. 



\section{per totum orbem longe lateque diffudit angesichts des closters barfusser ordens in unser stadt Berlin. Zur Geltung des Franziskanerkonvents im Mittelalter und seiner Geschichte am Erinnerungsort ,Graues Kloster' heute}

\section{Geschichtskulturelle Annäherungen}

Die Tagung ,Das Graue Kloster in Berlin' wirbt für eine neu bedachte Aneignung der Gestaltung der ,Alten Mitte 'Berlins. ${ }^{1}$ Welche Perspektiven und Ansprüche dabei auch immer zur Geltung zu bringen sind, zur unabweisbaren Herausforderung wird die Aufgabe, mit dem Ort des Grauen Klosters eigentlich das Wirken der Barfusser inhaltlich und konzeptionell anschlussfähig an weitere Kontexte zu vermitteln.

Dazu bietet die bisherige Wahrnehmung des Grauen Klosters kaum Raum. Wer sich die Geschichte der Stadt und die der Franziskaner vergegenwärtigt, wird jenseits der Aussagen zur Baugeschichte eher auf blinde Flecken in der Wahrnehmung dieser Beziehungsgeschichte stoßen. Es ist daher die eine Sache, die gegenwärtige Ruine der Klosterkirche, die einen prominenten Rest authentischer Architektur darstellt, als Denkmal neu zu sichern oder sie - was mir geboten scheint - als beziehungsreiches Kirchengebäude in der historischen Mitte in Gänze kultur- und stadtraumgeschichtlich neu zu gestalten.

Doch Geschichte lässt sich nicht so einfach zurückholen. Vielmehr stellen die mit der Sinnhaftigkeit der Geschichte des Grauen Klosters verbundene Distanz und Sehnsucht zugleich besondere Aufgaben für ein geschichtskulturelles Konzept dieses Ortes dar. Bei einer derartigen Aufwertung des Ortes wird es letztlich darum gehen, ein der Kontinuität des Ortes angemessenes Narrativ mit durchaus verschiedenartigen Bedeutungen auszumachen, das dem offenen wissenschaftlichen Erkenntnisprozess historischer Forschungen ebenso folgt wie einer historischen Bewusstseinsbildung. Das mag in vielerlei Perspektiven geschehen, aber nicht ohne den Blick auf die Anfänge der Stadt und die Bedeutung der Franziskaner in diesem Geschehen.

Um dorthin zu kommen, ist es notwendig, die bisher vorherrschende Adressierung des Ortes mit der Klosterkirchenruine als gotischem Bauensemble oder als städtischem Gymnasium, eben

1 Historische Kommission zu Berlin e. V.u.a. (Hrsg.), Alte Mitte - Neue Mitte? Positionen zum historischen Zentrum von Berlin, Berlin 2012. Die in dieser Initiative vermittelten Anstrengungen zur Wahrnehmung der Genese der historischen Stadt Berlin widersprechen aus guten Gründen einer verbreiteten - und touristisch gern bedienten - Nabelschau der jüngeren Geschichte der Stadt. Daher ist es weiterhin geboten, konsequent komplementäre Perspektiven dieser städtischen Geschichte im Mittelalter und in der Frühen Neuzeit herauszuarbeiten. Harald Bodenschatz/Benedikt Goebel, Stadt ohne Altstadt, in: Dominik Bartmann/Franziska Nentwig (Hrsg.), Berlins vergessene Mitte. Stadtkern 1840-2010, Bönen 2010, S. 16-36; Harald Bodenschatz, Berlin - Rom der Zeitgeschichte? - Sharing Heritage. Was heißt das in einer Stadt, die Europa im 20. Jahrhundert in Brand gesetzt und gespalten hat?, in: Forum Stadt 4 (2018), S. 372-378. 
als Grauem Kloster, aufzubrechen. Die Bewahrung und Deutung des Ortes als Graues Kloster ist signifikant mit kunsthistorischen und kulturpolitischen Aneignungsansprüchen verbunden, die die Gesellschaft des 19. Jahrhunderts an die Geschichte entwickelte und auf diesen Ort projizierte. Diesem Umstand situativer und soweit verkürzender Wahrnehmung der Geschichte des Grauen Klosters steht eine vielseitige Geltungsgeschichte der Klosterkirche als Gotteshaus sowie die Wirkungsgeschichte der Brüder der franziskanischen Ordensfamilie in Berlin gegenüber. Das gilt bis in die Gegenwart.

Als Teil der sogenannten Bettelorden, eines neuen Ordenstyps, der aus der vielgliedrigen religiösen Armuts- und kirchlichen Reformbewegung hervorging, leiteten die ,Minderen Brüder', die in Franziskus von Assisi (1181/2-1226) ein charismatisches Vorbild besaßen, die Forderung eines Lebens nach dem Evangelium und die Spiritualität vollkommener Armut in der Nachfolge Christi ab. So erreichten sie in ihrer Seelsorge die Ansprüche vieler Menschen. Ihr Wirken endete nicht mit den kirchlichen Umbrüchen des 16. Jahrhunderts, auch wenn mit Einführung der Reformation in der Mark Brandenburg ihre Konvente vielfach aufgelöst worden sind und ihre Kirchen und Klöster nach und nach umgenutzt wurden.

Seit dem sogenannten Ordensfrühling der 1840er-Jahre und den folgenden konfessionellen Behauptungen engagierten sich wieder mehrheitlich franziskanische Schwestern in den in Berlin neu errichteten Krankenhäusern, in der Sozialarbeit und in der Jugendbetreuung. 1919 errichte-
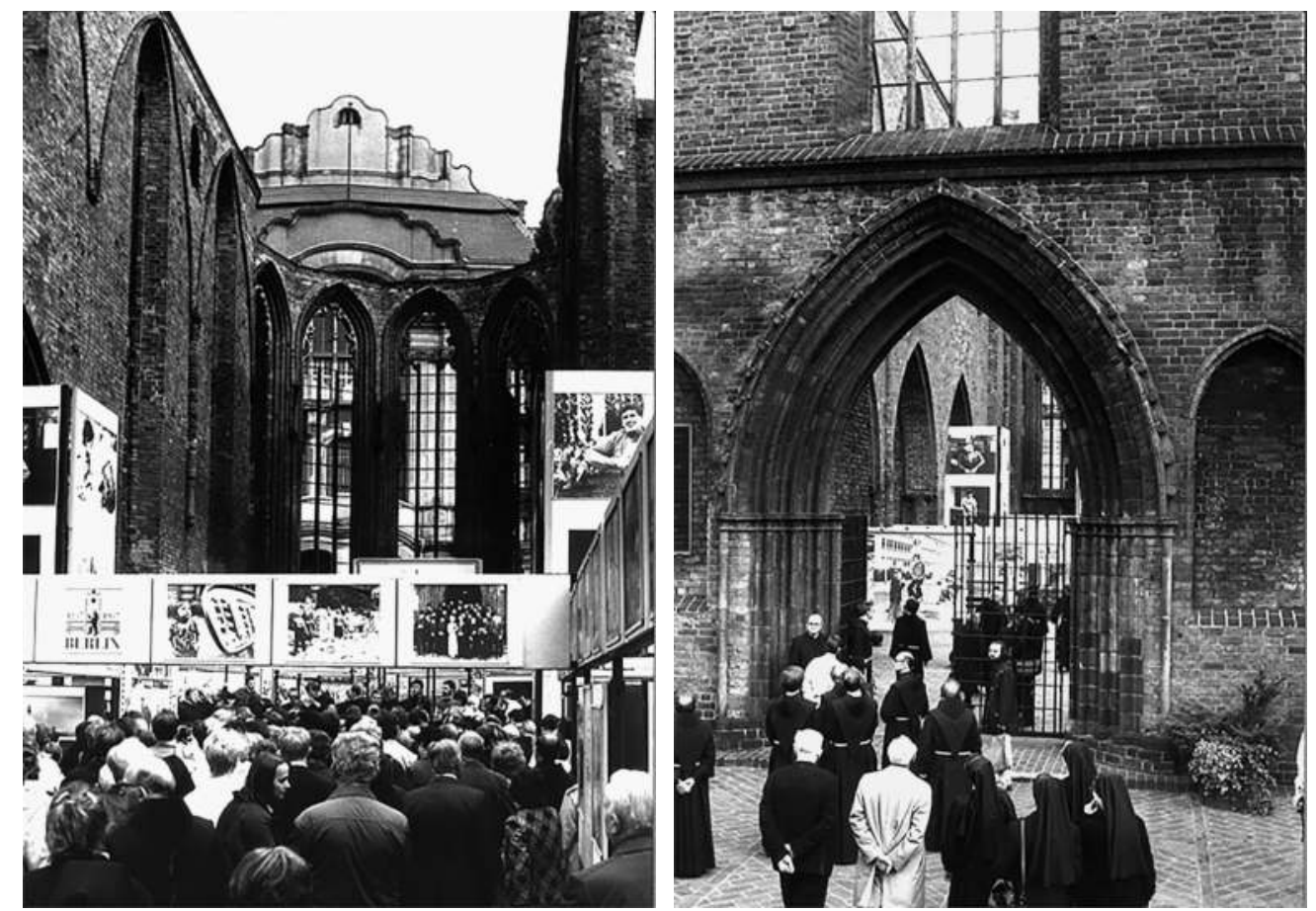

Abb. 1 und 2: Treffen von Schwestern und Brüdern der franziskanischen Ordensfamilie aus acht europäischen Ländern und Besuch der Ruine des Kirchengebäudes der Franziskanerkirche, Berlin 1987 anlässlich des 750-jährigen Stadtjubiläums. 
ten Brüder der Schlesischen Ordensprovinz in Pankow einen Konvent (zur Heiligen Hedwig), der bis heute durch seine Sozial- und religiöse Betreuungsarbeit in alle Schichten der Stadtbevölkerung hineinwirkt. Im Westteil der Stadt, zunächst in Tempelhof, gründeten sie 1967 eine weitere Kommunität, deren Brüder sich 1986 der Sächsischen Provinz vom Heiligen Kreuz eingliederten und seit 1990 die Pfarrei Sankt Ludwig in Wilmersdorf leiten und betreuen. ${ }^{2}$ Später unterstützte auch die in Bonn ansässige Missionszentrale der Franziskaner von Berlin aus eigens die Seelsorge in Ostmitteleuropa.

Präsenz und das caritativ-seelsorgliche Wirken der Franziskaner in Berlin wird bis heute von einem starken Geschichtsbewusstsein in Bindung an ihre mittelalterlichen Kirchengebäude, eben dem Grauen Kloster, mitbestimmt. Begleitet von einer großen Öffentlichkeit bewiesen Brüder und Schwestern dieses Geschichtsbewusstsein und ihr religiöses Selbstverständnis auch 1987. Damals trafen sich hier aus Anlass des 750-jährigen Stadtjubiläums Berlins über die Grenzen der damals geteilten Stadt hinweg Ordensbrüder und Ordensschwestern aus acht europäischen Ländern. ${ }^{3}$ Solches Geschichtsbewusstsein und heute veränderte Ansprüche an die Aneignung und Vermittlung der Geschichte der mittelalterlichen und frühneuzeitlichen Stadt Berlin fordern dazu auf, den Platz der Franziskaner in dieser Beziehungsgeschichte deutlicher sichtbar zu machen. Damit ist es auch geboten, die mit deren Wirken verbundenen kulturellen Zeugnisse an dieser Stelle öffentlich zu machen, wo sie so Teil des unverwechselbaren Gesichts dieses franziskanisch mitgeprägten Erinnerungsorts sein könnten. Ein solches Beispiel städtisch-franziskanischer Beziehungsgeschichte machte aus dem bisherigen Grauen Kloster einen Ort vermittelter Geschichtskultur in der Mitte der Stadt.

Bisher haben vor allem die Baugeschichte und die Klosterruine des Grauen Klosters die Denkmalpflege angezogen, ebenso der damit verbundene Gotik-Diskurs. Eine ordens- und kulturhistorisch geleitete Aneignung der Bedeutung der Franziskanerklosterkirche und des Konvents sowie der des Grauen Klosters aus einer integrierten Perspektive fehlt bislang. Die Sinndeutung dieses Ortes erschöpft sich nicht in der Wahrnehmung als ,Denkmal der Denkmalpflege. Die Denkmalpflege selbst unterliegt dem Wandel. Geschichtswissenschaft und Historische Kulturgeschichtsforschung stellen mit dem fortschreitenden Wandel eben auch an Letzteren stets neue Fragen aus methodisch geleiteten Erkenntnisinteressen. Und ihre Antworten sowie Deutungen sind, angemessen erinnerungsgeschichtlich reflektiert, in ihrem Gesamtverlauf öffentlich zu ver-

2 Relinde Meiwes, Arbeiterinnen des Herrn. Katholische Frauenkongregationen im 19. Jahrhundert (Geschichte und Geschlechter, Bd. 30), Frankfurt am Main/New York 2000; Harald Schwillus/Matthias Brühe, Erzbistum Berlin. Eine junge Diözese in langer Tradition, Kehl am Rhein 2009, S. 213, 249; Urban Hachmeier OFM (Hrsg.), 100 Jahre St. Ludwig. Berlin Wilmersdorf 1897-1997, Berlin 1997; Roland Pieper/Jürgen Werinhard Einhorn (Hrsg.), Franziskaner zwischen Ostsee, Thüringer Wald und Erzgebirge. Bauten - Bilder - Botschaften, Paderborn 2005, S. 55-59.

3 Ralf Nickel, Die Minderbrüder in Berlin, in: Dieter Berg (Hrsg.), Franziskanisches Leben im Mittelalter. Studien zur Geschichte der rheinischen und sächsischen Ordensprovinzen (Saxonia Franciscana, Bd. 3), Werl 1994, S. 1-26. 


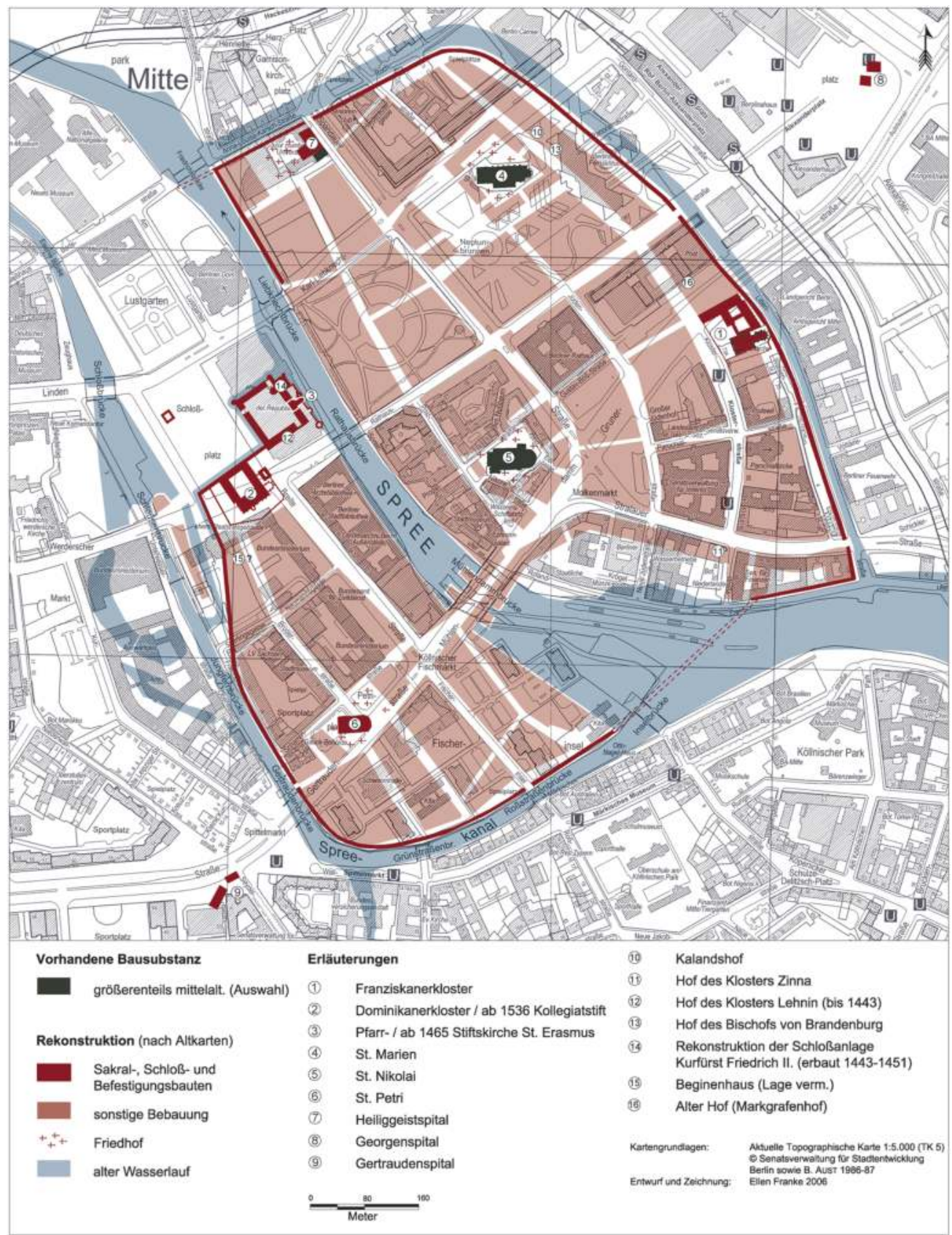

Abb. 3: Die mittelalterliche Doppelstadt Berlin-Cölln mit dem Franziskanerkloster auf dem Berliner Stadtgebiet. 
mitteln. Entsprechende Perspektiven gehen über das hinaus, was als „merkwürdiges Monument früher Baukunst und Gotteshaus“4 1827 die Verantwortlichen bewegte und was zuletzt, 2007, vor allem Kunsthistoriker, Bauforscher und Archäologen an dieser Ruine verantworteten.

Eine solchen Anstrengungen vorausgehende Frage lautet immer wieder, wie weit hier ,Mittelalter' als kulturelle Bezugsfolie verstanden und genutzt wurde. Angefangen mit der frühen Stadtgeschichte und der Wirkungsgeschichte der Franziskaner bis zur gegenwärtigen Funktion des Grauen Klosters stellen sich deshalb Fragen nach der Kontinuität seiner Deutung. Diese zielen weniger auf heile Oberflächen rekonstruierter Gebäude als vielmehr auf Anstrengungen, den gegenwärtigen Zeitgenossen im Grauen Kloster einen disparaten Erinnerungsort zu erschließen, daran eine Vergessens- und Wiederaneignungsgeschichte zu exemplifizieren sowie darüber kontextbezogen die Sinndeutungsgeschichte eines konfessions- und sozialgeschichtlich sowie erinnerungspolitisch gebrochenen Erinnerungsorts nachzuerzählen.

Eine Diskursanalyse der Wahrnehmungsgeschichte des Grauen Klosters sollte wiederum mit der Aneignungsgeschichte der historischen Mitte und den Anforderungen zeitgemäß vermittelter Erinnerungsgeschichte korrespondieren. ${ }^{5}$ Wie erweitert ein Erinnerungsort ,Franziskanerkonvent/ Graues Kloster' und seine nicht nur steingewordene Monumentalität die öffentlich verantwortete Erinnerungskultur im heutigen Berlin? Zur Beantwortung dieser Frage bieten sich verschiedene Vorgehensweisen an. Leitende Gedanken könnten dabei die Problematisierung der Brüche in der Kontinuität der verschiedentlichen Aneignungen des Grauen Klosters sowie die dabei jeweils leitende Sinnhaftigkeit der Deutung dieses Ortes sein. Nicht allein die Nutzungsgeschichte bietet das angemessene Narrativ. Es gehört ebenso dazu, die Wege der Ausstattungsstücke des Konvents und

4 Landesdenkmalamt Berlin (Hrsg.), Kirchenruine des Grauen Klosters in Berlin. Geschichte - Forschung - Restaurierung (Beiträge zur Denkmalpflege in Berlin, Bd. 23), Berlin 2007 mit folgenden Beiträgen: Jörg Haspel/Sibylle Schulz, Ein ,merkwürdiges Monument früher Baukunst und ein Gotteshaus' - Schlussbetrachtung, S. 216220; Petra Marx, Zur Geschichte der bauhistorischen Forschung und denkmalpflegerischen Bemühungen - ein fachgeschichtlicher Rückblick, S. 31-49; Birgit Neumann-Dietzsch, Die Ausmalung der Franziskaner-Klosterkirche, S. 73-88; Andreas Cante, Die Klosterkirche als Berliner Gedächtnisort, S. 54-68. Cante arbeitet eine bemerkenswerte memorialgeschichtliche Perspektive heraus. Zur Innenausstattung der Kirche Stefan Breitling, Ferdinand Quast und die Franziskaner-Klosterkirche in Berlin - ein Beitrag zur Geschichte der Denkmalpflege im 19. Jahrhundert, in: Auch die Denkmalpflege hat Geschichte. Ferdinand von Quast (1807-1877). Konservator zwischen Trier und Königsberg (Beiträge zur Denkmalpflege in Berlin, Bd. 29), Berlin 2008, S. 77-87; Manfred Kühne, Impulsreferat: Fragen der Stadtplanung an Historiker und Archäologen, in: Historische Kommission, Alte Mitte - Neue Mitte, S. 109-113; Felix Escher, Fragen der Stadtgeschichte an Planer und Architekten, in: Historische Kommission, Alte Mitte - Neue Mitte, S. $183 \mathrm{f}$. Unter den Beiträgen dieses anregenden Bandes vermisst man freilich Angebote der geschichts- und kulturhistorischen Diskurse öffentlich verantworteter Geschichtsvermittlung.

5 Cante, Die Klosterkirche, verdeutlicht - im Gegensatz zu vorherrschenden denkmalpflegerischen Wahrnehmungen - in der Totenmemoria die religiösen Ansprüche an die Nutzung des nachmittelalterlichen Kirchenraums; Tilmann Robbe, Historische Forschung und Geschichtsvermittlung. Erinnerungsorte in der deutschsprachigen Geschichtswissenschaft (Formen der Erinnerung, Bd. 39), Göttingen 2009; Marianne Pollak, Vom Erinnerungsort zur Denkmalpflege. Kulturgüter als Medien des kulturellen Gedächtnisses (Studie zu Denkmalschutz und Denkmalpflege, Bd. 21), Wien u. a. 2010; Stefan Berger/Joana Seiffert (Hrsg.), Erinnerungsorte. Chancen, Grenzen und Perspektiven eines Erfolgskonzeptes in den Kulturwissenschaften, Essen 2014; Heinz-Dieter Heimann, Franziskus im Museum. Historische Ausstellungen und Perspektiven neuer ordensgeschichtlicher Erinnerungsräume, in: Thomas T. Müller/Bernd Schmies/Christian Löfke (Hrsg.), Für Gott und die Welt. Franziskaner in Thüringen. Text- und Katalogband zur Ausstellung in den Mühlhäuser Museen, Paderborn u. a. 2008, S. 16-22. 
der Kirche in die öffentlichen Sammlungen und in verschiedene Berliner Museen und Kirchen zu ermitteln und zu vermitteln. Ein solches komplementäres Vorgehen zielt auf die Erschließung der jeweiligen Neuordnungsansprüche der Materialität und auf die damit jeweils verbundene erinnernde Deutung, sei es als Gotteshaus, als Ort der Totenmemoria, ${ }^{6}$ als Laboratorium, als Objekt mit (Teil-)Abriss, als Schulgebäude, als Ruine und Mahnzeichen. Zugleich fände damit die Problematisierung des jeweiligen Willens zur kulturellen Überlieferung, zu Kontinuitäten und Brüchen statt, um gebotene und nachvollziehbare wissenschaftsgeschichtliche Antworten zu suchen.

Entsprechende deutungsgeschichtliche Argumentationen entfaltete Otto Gerhard Oexle. Sie regen dazu an, die mit dem Ort ,Graues Kloster' verbundenen Denkkonstrukte und Sinnformationen gedeuteter Geschichte entsprechend zu ordnen und so zu vermitteln. ${ }^{7}$ Ein wesentlicher Gedankengang erschlösse diesen Ort entlang jener Ansprüche, die daran die jeweilige Moderne als ihr Verständnis von Mittelalter und Gotik formulierte. Mit diesem Konzept ließen sich schlüssig und systematisiert die Wahrnehmung der Spiritualität der Franziskaner, die weitere Aneignungsgeschichte ihrer religiösen Kulturzeugnisse sowie stadtraumgeschichtliche Kontexte verbinden. Diesen Weg zu gehen, heißt, der Wirkungsgeschichte der Franziskaner von Anfang an und bis in die Gegenwart konzeptionell und deutungsgeschichtlich mehr Raum zu geben. Folglich wird in diesem Beitrag wenig mit Daten der Klosterbaugeschichte argumentiert. Stadt und Kloster werden als Bedeutungsträger von Wechselseitigkeit verstanden und es werden zu drei Feldern Argumente aufgenommen, die die Beziehungsgeschichte der ,Berliner Barfusser ${ }^{`}$ zu der sie umgebenden Welt exemplifizieren.

\section{„Berliner Barfusser' statt Graues Kloster}

Die Begriffsgeschichte versteht Sprache als Faktor vorgefundener Realität sowie als Faktor dieser Realitätsfindung. ${ }^{8}$ Die Erfolgsgeschichte des Begriffsgebrauchs Graues Kloster zeigt, dass dann überspitzt gesagt - die mittelalterlichen Berliner Franziskaner eine schlechte Presse erhielten. Die Ortsbezeichnung Graues Kloster, so heißt es vielfach, nehme die Farbe des Habits der Franzis-

6 Cante, Die Klosterkirche, S. 54-68; siehe dazu auch den Beitrag von Doris Bulach in diesem Band.

7 Gerd Althoff (Hrsg.), Die Deutschen und ihr Mittelalter. Themen und Funktionen moderner Geschichtsbilder vom Mittelalter, Darmstadt 1992; Otto Gerhard Oexle, Geschichtswissenschaft in einer sich ständig verändernden Welt, in: Akademie der Wissenschaften zu Göttingen (Hrsg.), Wissenschaften 2001. Diagnosen und Prognosen, Göttingen 2001, S. 89-116; ders. (Hrsg.), Bilder gedeuteter Geschichte. Das Mittelalter in der Kunst und Architektur der Moderne, 2 T., Göttingen 2004; ders., Die gotische Kathedrale als Repräsentation der Moderne, in: ders./Michail A. Bojcov (Hrsg.), Bilder der Macht in Mittelalter und Neuzeit. Byzanz - Okzident - Rußland (Veröffentlichung des Max-Planck-Instituts für Geschichte, Bd. 226), Göttingen 2007, S. 631-674; ders., Die Gegenwart des Mittelalters (Das mittelalterliche Jahrtausend, Bd. 1), Berlin 2013. Zum Mythos des Terminus Gotik die einleitenden Kapitel des Katalogs der Thüringer Ausstellung ,Der Naumburger Meister؛ Hartmut Krohm/ Holger Kunde (Hrsg.), Bildhauer und Architekt im Europa der Kathedralen, Bd. 1.2, Petersberg 2011; Dietmar Schiersner, Räume der Kulturgeschichte - Räume der Landesgeschichte. Affinitäten, Divergenzen, Perspektiven, in: Sigrid Hirbodian/Christian Jörg/Sabine Klapp (Hrsg.), Methoden und Wege der Landesgeschichte (Landesgeschichte, Bd. 1), Stuttgart 2015, S. 149-160.

8 Reinhart Koselleck, Begriffsgeschichte, in: Stefan Jordan (Hrsg.), Lexikon Geschichtswissenschaft. Hundert Grundbegriffe, Stuttgart 2002, S. 40-44; Matthias Untermann, Fehlbenennungen von Klosterräumen und ihr Effekt auf die Forschung, in: Gert Melville/Leonie Silberer (Hrsg.), Die Klöster der Franziskaner im Mittelalter. Räume, Nutzungen, Symbolik (Vita regularis, Abhandlungen, Bd. 63), Münster 2014, S. 19-43. 
kaner auf. Für diese Ableitung aber findet sich zum Berliner Konvent nahezu keine Bestätigung. Im Brandenburgischen Klosterbuch werden aus den Schriftzeugnissen spezifische (Selbst- und Fremd-) Bezeichnungen zitiert. ${ }^{9}$ Offenbar erst nachreformatorisch wurde der Begriff Graues Kloster in Berlin umdeutend üblich. Das Verständnis dieser Benennung und des Gemeinten verengte sich im 19. Jahrhundert im Zuge der Mittelalterentdeckung, der Gotik-Rezeption und mit der Eigentumsübertragung der Immobilie bevorzugt auf das Gymnasium als prominenten Ort Berliner Schulgeschichte. Im Ergebnis heißt das auch, dass der Begriff Graues Kloster heute nahezu keine Merkmale franziskanischen Wirkens transportiert oder erinnert. Zwischen Begriff und vor Augen gestellter Sache, das heißt zur mittelalterlichen beziehungsweise vorreformatorischen Vergangenheit und Bedeutung des Konvents, besteht eine gravierende sachlich-inhaltliche Wissenslücke. Sie aufzuarbeiten, führt zu einer ausdrücklichen franziskanischen Perspektive.

Diese Perspektive muss nicht weitläufig abgeleitet werden. Im Gegenteil. Sie steht eigentlich allen vor Augen, gut dokumentiert in den - im Titel des Beitrags zitierten - Inschriften an der Rückwand des Chorgestühls der Klosterkirche. Die bisherige Forschung hat im Brandenburgischen Landesdenkmalamt verwahrte Fotodokumente dieser Inschriften bisher kaum beachtet. Die Inschriften, die im späten 15. Jahrhundert angebracht wurden, sind so etwas wie Selbstzeugnisse der Brüder. ${ }^{10}$ In diesen Selbstzeugnissen und in weiteren dort zitierten Quellen werden das reklamierte Selbst- und Geschichtsverständnis der Brüder sichtbar. Nach diesen Zeugnissen lautete die übliche Benennung der Franziskaner in Berlin gemeyne bruder des closters barfussen ordens, oder Barfusser, an anderer Stelle auch fratres barvoti. Diese Eigen- und zugleich Fremdbenennungen besagten damals und besagen heute, dass man mit Barfussen gerade keine Vorstellung von einem Gebäude verband, sehr wohl aber das Barfuß-Gehen als Aussage ihrer religiösen Identität wahrnahm. ${ }^{11}$ Diese Benennung enthielt also eine Botschaft. Sie nutzte auch Kurfürst Friedrich II.

9 Peter Riedel u. a., Berlin Franziskaner, in: Heinz-Dieter Heimann u. a. (Hrsg.), Brandenburgisches Klosterbuch. Handbuch der Klöster, Stifte und Kommenden bis zur Mitte des 16. Jahrhunderts (Brandenburgische Historische Studien, Bd. 14), 2 Bde., 1. Aufl., Berlin 2007, Bd. 1, S. 146-157.

10 Die Forschung zitierte dazu zumeist Patricius Schlager, Inschriften auf Chorgestühlen im mittelalterlichen Franziskanerkirchen, in: Beiträge zur Geschichte der sächsischen Franziskanerprovinz vom Heiligen Kreuze, Düsseldorf 1908, S. 1-15, hier S. 12 f. Eine bau- und bildhistorische Dokumentation hat sich in ca. 20 Fotografien wohl aus den dreißiger und vierziger Jahren des 20. Jahrhunderts im Bildarchiv des Brandenburgischen Landesdenkmalamts und Archäologischen Landesmuseums, Wünsdorf, erhalten, darunter Aufnahmen des Chorgestühls mit den Stiftungsinschriften. Siehe die in diesem Band nun veröffentlichten Abbildungen 4 bis 7. Diese Bildquelle nutzte Winfried Schich, Die Markgrafen von Brandenburg und die Ansiedlung der Franziskaner in den Städten östlich der Elbe im 13. Jahrhundert, in: Landesdenkmalamt Berlin, Kirchenruine des Grauen Klosters, S. 13-23, hier S. 19, Abb. 16. Dagegen ohne diese Bildquellen Roland Pieper, Mittelalterliche Chorgestühle und Dreisitze, in: ders. (Hrsg.), Kunst. Von den Anfängen bis zur Gegenwart (Geschichte der Sächsischen Franziskaner-Provinz von der Gründung bis zum Anfang des 21. Jahrhunderts, Bd. 5), Paderborn 2012, S. 407-416.

11 Peter Bell, Gewand(t). Vestimäre Kommunikation und Bildrhetorik in mittelalterlichen Franziskanerzyklen, in: Heinz-Dieter Heimann u. a. (Hrsg.), Gelobte Armut. Armutskonzepte der franziskanischen Ordensfamilie vom Mittelalter bis in die Gegenwart, Paderborn 2012, S. 81-100. Der Chronist des Augustinerchorherrenstifts Petersberg bei Halle registrierte um 1225 das Auftreten von duo nove conversacionis ordines und kritisierte sie als primitivi ordinis. Dazu Bernd Schmies/Volker Honemann, Die Franziskanerprovinz Saxonia von den Anfängen bis 1517. Grundzüge und Entwicklungslinien, in: Volker Honemann (Hrsg.), Vom Mittelalter bis zur Reformation. (Geschichte der Sächsischen Franziskaner-Provinz von der Gründung bis zum Anfang des 21. Jahrhunderts, Bd. 1), Paderborn 2015, S. 21-43, bes. S. 31. 


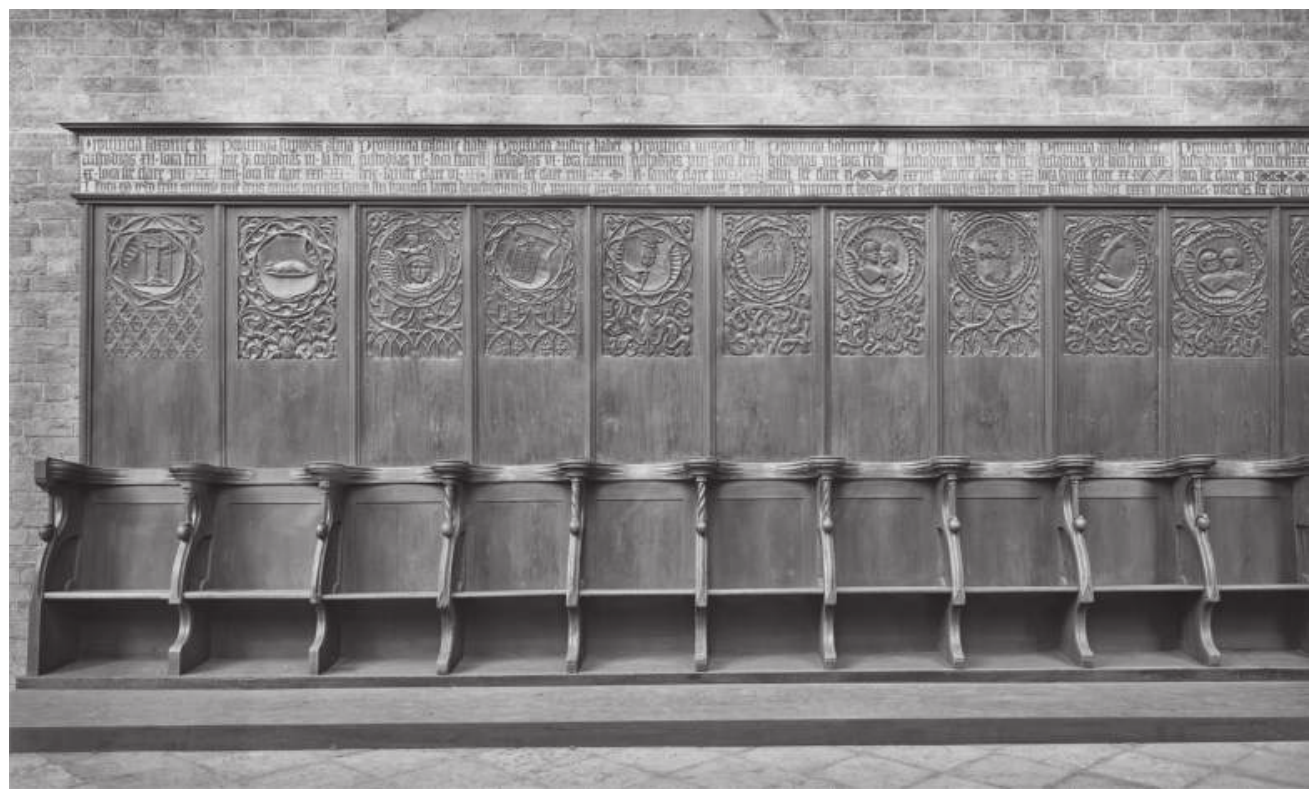

Abb. 4: Chorgestühl der Klosterkirche mit Schriftfeld (Abb. 4 und 5 zusammengehörig), Brandenburgisches Landesamt für Denkmalpflege und Archäologisches Landesmuseum (BLDAM).

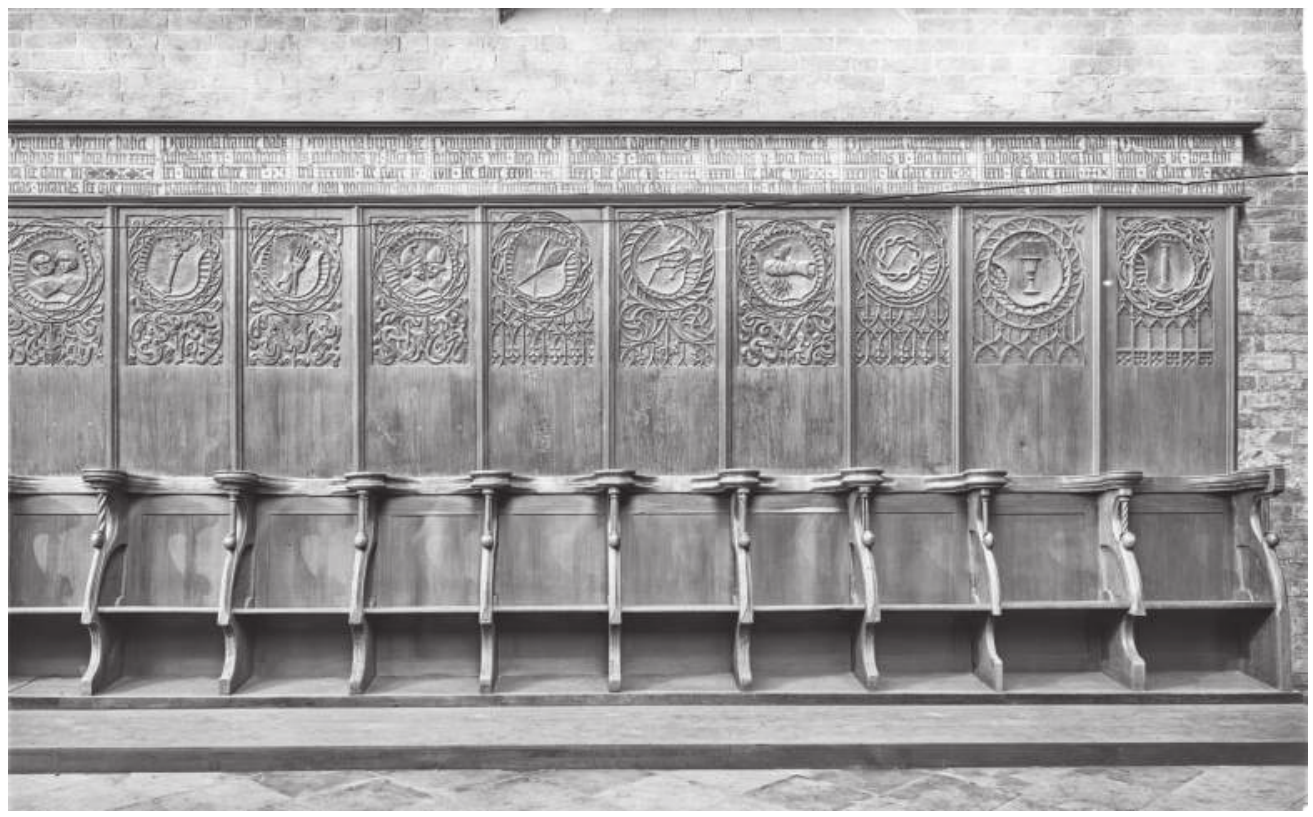

Abb. 5. 


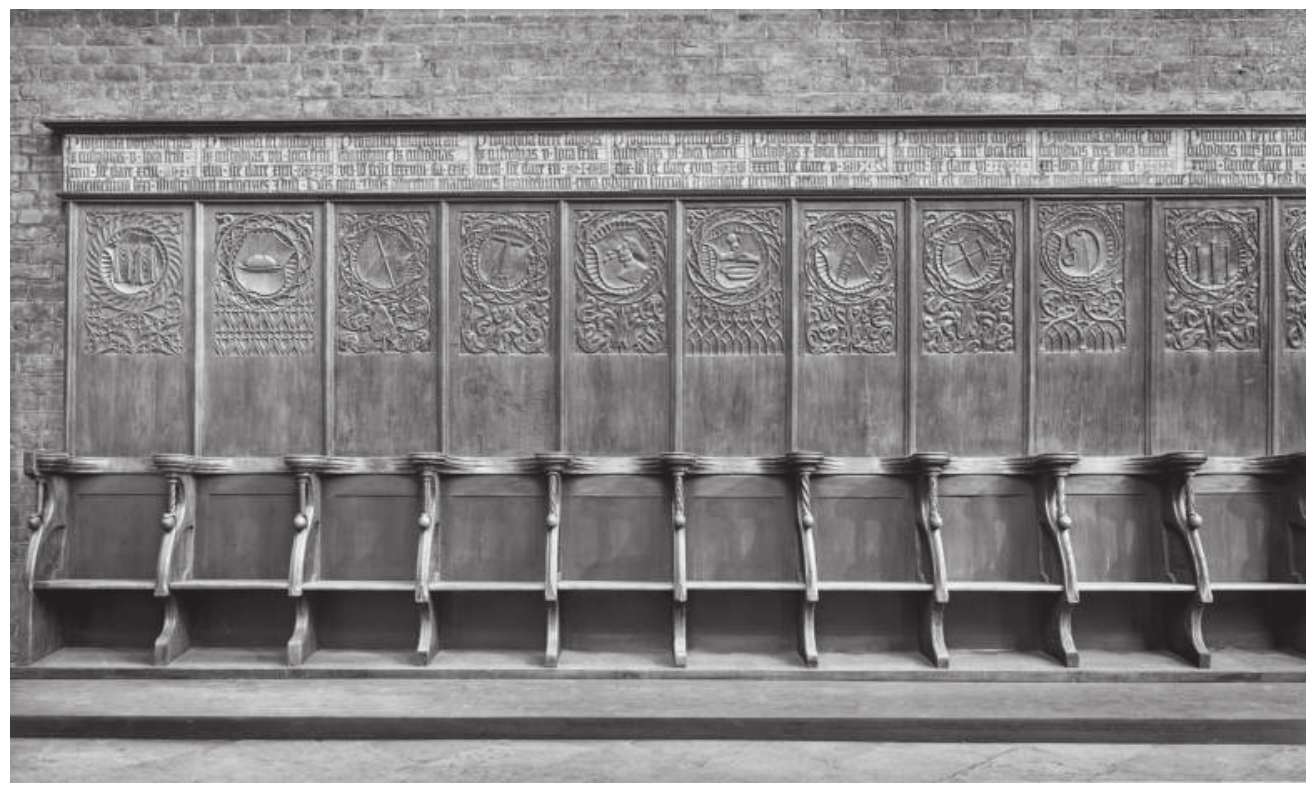

Abb. 6: Chorgestühl der Klosterkirche mit Schriftfeld (Abb. 6 und 7 zusammengehörig), Brandenburgisches Landesamt für Denkmalpflege und Archäologisches Landesmuseum (BLDAM).

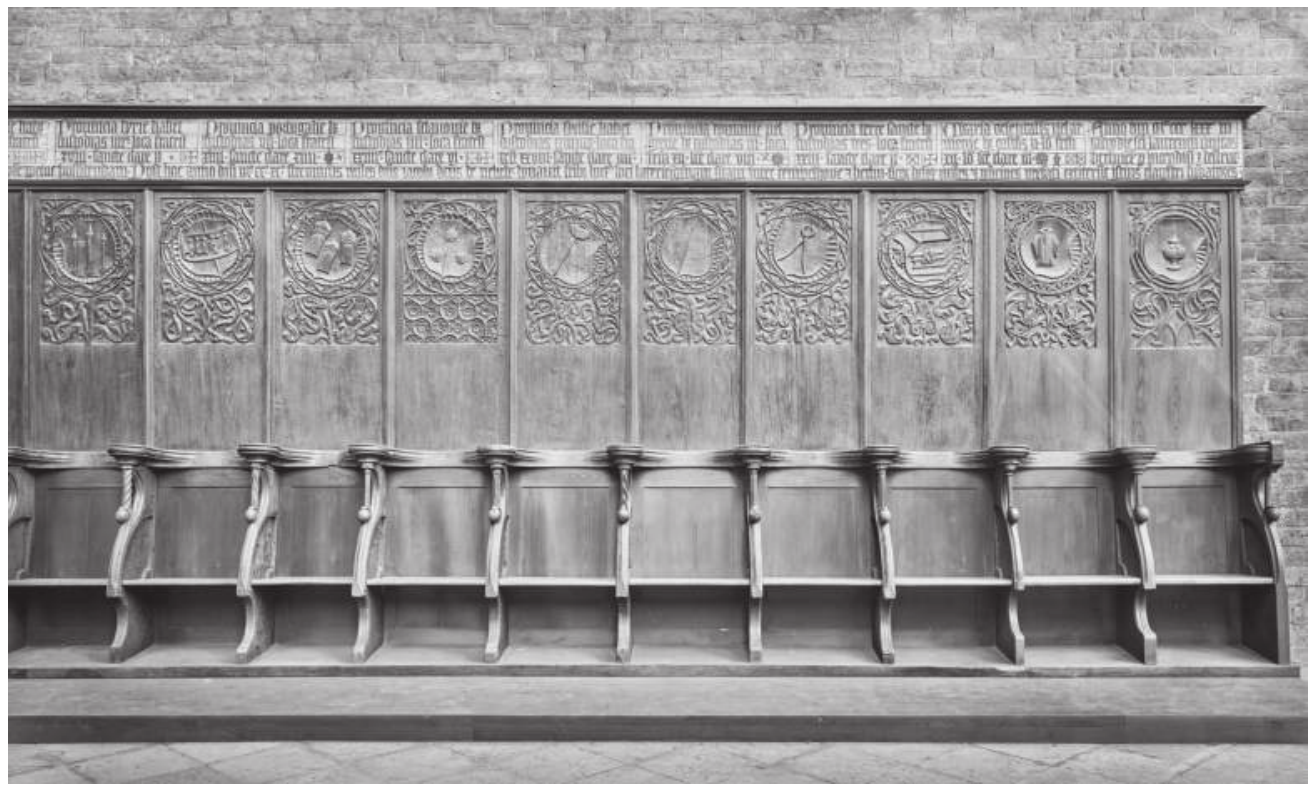

Abb. 7. 
von Brandenburg (1440-1470) ${ }^{12}$ in einer in den Inschriften an der Chorwand ebenfalls zitierten Schenkungsurkunde.

Das Interesse der Hohenzollern an dem Franziskanerkonvent wird oft angeführt. Aus franziskanischer Perspektive bleibt anderes hervorzuheben, denn die Franziskaner wiesen in jenen Inschriften ihr mendikantisches Selbst- und Sendungsverständnis aus. Um diese Spur geht es also. Prägnant schrieben die Franziskaner ihren Anspruch in den Inschriften weiter aus, per totum orbem longe lateque diffudit, frei übersetzt ,zahlreich über den weiten Erdkreis verbreitet. Deshalb führten sie dort auch namentlich alle Provinzen und Kustodien ihrer Ordensfamilie zwischen Schottland, Italien und dem Baltikum sowie die Anzahl der dort lebenden Brüder und Schwestern an. Vor allem wohl an sie selbst und mittelbar auch an ihre Kirchenbesucher gerichtet, besagt dieses Selbstzeugnis, das Wirken der ,Barfussen 'in Berlin erschöpft sich nicht in lokaler Bindung. Die Brüder wollten ihr Dasein und Wirken als Teil einer größeren Bewegung innerhalb der römischen Kirche verstanden wissen, die nach dem Vorbild ihres Ordensgründers Franziskus in der Nachfolge Christi allerorten auf die Menschen zugeht. ${ }^{13}$

Es spricht historisch und konzeptionell viel dafür, dementsprechend das Verständnis über den Standort des Grauen Klosters für eine franziskanische Perspektive zu öffnen und Letztere - auch im Sinn eines interaktiven Museums - so für eine zeitgemäße Vermittlung franziskanischer Wirkungsgeschichte öffentlich zu machen. Dafür bieten sich weitere Argumente. Die frühe Brüdergemeinschaft und die franziskanische Ordensfamilie setzten sich von Anfang an und mit Blick auf das Vorbild ihres Ordensgründers Franziskus vehement mit sich und gegenüber der Papstkirche darüber auseinander, wie denn ihr Kloster zu verstehen sei. Ein bezeichnendes Beispiel bietet dazu die frühe Schrift, Sacrum commercium', der ein Gespräch von Brüdern mit der ,Herrin Armut' zugrunde liegt. Auf die Bitte der ,Herrin Armut', die Brüder mögen ihr das Kloster zeigen, heißt es im Text: ,Die Brüder führten sie auf einen Hügel, zeigten ihr die ganze Welt, soweit man sehen konnte, und sprachen: Das ist unser Kloster, Herrin!! ${ }^{14}$ In Kapitel 6 der Regula bullata

12 Sascha Bütow, Kurfürst Friedrich II. Vom Werden der fürstlichen Residenz in Berlin-Cölln, in: Thomas Fischbacher (Hrsg.), Die Hohenzollern in Brandenburg. Gesichter einer Herrschaft (Einzelveröffentlichung des Brandenburgischen Landeshauptarchivs, Bd. 15), Regensburg 2015, S. $28-37$.

13 Dieter Berg (Hrsg.)/Bernd Schmies/Kirsten Rakemann (Bearb.), Spuren franziskanischer Geschichte. Chronologischer Abriß der Geschichte der sächsischen Franziskanerprovinzen von den Anfängen bis zur Gegenwart (Saxonia Franciscana, Sonderbd.), Werl 1999; Kaspar Elm, Vitasfratrum. Beiträge zur Geschichte der Eremitenund Mendikantenorden des zwölften und dreizehnten Jahrhunderts. Festgabe zum 65. Geburtstag, hrsg. von Dieter Berg (Saxonia Franciscana, Bd. 5), Werl 1994; ders., ,Sacrum Commercium: Über Ankunft und Wirken der ersten Franziskaner in Deutschland, in: Paul-Joachim Heinig (Hrsg.), Reich, Regionen und Europa in Mittelalter und Neuzeit. Festschrift für Peter Moraw (Historische Forschungen, Bd. 67), Berlin 2000, S. 389-412; Gert Melville, Quoniam ubicumque sumus et ambulamus, habemus cellam nobiscum. Franziskus von Assisi und die räumlichen Muster der ,vita eremitica', in: ders./Leonie Silberer (Hrsg.), Die Klöster der Franziskaner im Mittelalter. Räume, Nutzungen, Symbolik (Vita regularis, Bd. 63), Münster 2014, S. 105-123; Heinz-Dieter Heimann, Unterwegs zu einem orbis christianus. Zum kulturellen Umgang mit Nichtchristen in der mittelalterlichen und reformationszeitlichen Missionstätigkeit der Franziskaner, in: Historisches Jahrbuch 135 (2015), S. 9-26.

14 Zentrale Quellen und Texte der Geschichte der Gemeinschaft finden sich im Band ,Franziskus-Quellen 'übers. und kritisch kommentiert. Der geheiligte Bund des seligen Franziskus mit der Herrin Armut, übers. von Johannes Schlageter, in: Dieter Berg/Leonhard Lehmann (Hrsg.), Franziskus-Quellen. Die Schriften des Heiligen Franziskus, Lebensbeschreibungen, Chroniken und Zeugnisse über ihn und seine Orden, Kevelaer 2009, S. 654-686, bes. S. 683 . 
von 1223 heißt es dazu und zur Frage des Erwerbs von Eigentum: ,Die Brüder sollen sich nichts aneignen, weder Haus noch Ort noch sonst eine Sache. Und gleich wie Pilger und Fremdlinge $(=1$ Petr 2,11) in dieser Welt, die dem Herrn in Armut und Demut dienen, mögen sie voll Vertrauen um Almosen bitten gehen und sollen sich dabei nicht schämen, weil der Herr sich für uns in dieser Welt arm gemacht hat. ${ }^{\prime 15}$ Die Brüder verstanden soweit ihr Mendikantensein, ihre Mobilität und Ausbreitung auch nicht als linear ubiquitär. Nach jenen Quellen sahen sich die Brüder eher als ,Pilger', als ,Gehende' und - ausgerichtet auf Assisi - als ,Zurückkommende'. Ihre Gemeinschaft breitete sich, so fasste es Kaspar Elm zusammen, also nicht weg vom Ursprungsort Assisi aus, sondern in einer zirkulierenden Bewegung. Will sagen: Nichts gegen eine Aneignung der Bedeutung der Gotik an dieser Franziskanerkirche, aber sie relativiert sich angesichts der Kraft des religiösen Unterwegsseins und der Wirkungsgeschichte der Franziskaner.

Nicht also das Gebäude der Kirche, oder gar die Ruine selbst, auch nicht allein die lokale Bindung der Brüder an sich, sondern diese zugleich als Teil religiös motivierter Mobilität und der Kommunikation franziskanischen Sendungsbewusstseins bleiben als Ausweise franziskanischer Identität an dieser Stelle den Heutigen verständlich zu machen. Das kann auf ganz verschiedene Weise geschehen. Nachfolgend sei es an zwei Phänomenen verdeutlicht - zunächst an dem Stadtsässig-Werden der Franziskaner im Kontext der von neuen normativen Setzungen geprägten Ausbreitung der Gemeinschaft im 13. Jahrhundert und ferner an der von ihnen durch religiöse Medien kommunizierten Deutung des Franziskanisch-Seins aus dem späten 15. Jahrhundert. Beides führt zugleich die Semiotik franziskanischer Räume in der Stadt und darüber hinaus vor Augen.

\section{Klostertopografie und Stadtgestalt}

Zu den Anfängen Berlins und Cöllns gibt es keine schriftlichen Quellen, auch gibt es - im Unterschied zu anderen Städten ringsum - keine Gründungsurkunden. Früheste Siedlungsbefunde der Stadtentstehung lassen es zu, den Beginn um oder auch deutlich vor $1200 \mathrm{zu}$ datieren. ${ }^{16}$ Sie resultieren in der Hauptsache aus jüngeren bauarchäologischen Untersuchungen. In deren Zusammenhang werden auch jüngere Arbeiten zur Siedlungs- und Stadtentstehungsgeschichte von Spandau und zur Doppelstadt Brandenburg sowie Verbindungen zu der ab 1157 von den

15 Regula bullata, in: Berg/Lehmann, Franziskus-Quellen, S. 98; ähnlich im Testament des Franziskus, ebd. S. 61. Die geforderte absolute Armut blieb ein Anspruch. In Wirklichkeit gehörte dazu die Hilfe ,geistlicher Freunde;, Kap. 4, ebd. S. 97; Gert Melville/Jörg Oberste (Hrsg.), Die Bettelorden im Aufbau. Beiträge zu Institutionalisierungsprozessen im mittelalterlichen Religiosentum (Vita regularis, Bd. 11), Münster 1999; Werner Maleczek, ,Nackt dem nackten Christus folgen. Die freiwillige Armut in den religiösen Bewegungen der mittelalterlichen Gesellschaft, in: Heimann, Gelobte Armut, S. 17-35.

16 Winfried Schich, Das Vordringen der Markgrafen von Brandenburg auf den Barnim und die Anfänge Berlins, in: Historische Kommission, Alte Mitte - Neue Mitte?, S. 71-80; ders., Die Markgrafen von Brandenburg, S. 13-23; Michael Lindner, Copnic - Köpenick und die Anfänge von Colonia - Cölln und Berlin, in: Historische Kommission, Alte Mitte - Neue Mitte?, S. 93-102; Dietrich Kurze, Auf schriftlicher Überlieferung basierende Kirchengeschichte und ihr diskussionsbedürftiger Beitrag zur Beantwortung der Frage nach den Anfängen von Berlin-Cölln, in: Historische Kommission, Alte Mitte - Neue Mitte?, S. 103-108; ders., Die Berliner Kirche des Mittelalters, in: ders., Berlin-Brandenburgische Kirchengeschichte im Mittelalter. Neun ausgewählte Beiträge, hrsg. von MarieLuise Heckmann/Susanne Jenks/Stuart Jenks (Bibliothek der Brandenburgischen und Preußischen Geschichte, Bd. 9), Berlin 2002, S. 185-207, bes. S. 193-195. 
Askaniern herrschaftspolitisch gezielt vorgetragenen Ausbildung der Markgrafschaft Brandenburg für die Entwicklungen Berlins bedeutsamer. ${ }^{17}$ Aufs Ganze gesehen, erweisen sich diese Vorgänge östlich der Elbe als Merkmale und Teilgeschehen binneneuropäischer Entwicklungen des 12. Jahrhunderts, die mit grundbildenden Prozessen gesteigerter Mobilität, kultureller Vernetzung und Welterschließung rechtlich und sozial komplexer sich organisierender Gemeinschaften verbunden waren und - eingebettet in kirchliche Erneuerungsanstrengungen und in intensivierte politische Raumordnungsansprüche - wirksam wurden. ${ }^{18}$ Einer der augenfälligsten Indikatoren dieser Dynamik ist neben der Einbindung der Gebiete östlich der Elbe in den Verband des Heiligen Römischen Reichs die dort neu angesetzte Christianisierung mit Niederlassung nun von Bettelordensgemeinschaften im Prozess zeitgleicher Ausbildung der Städtelandschaft. Die rasche Ausbreitung der seit dem 11. Jahrhundert aus religiösen Armutsbewegungen, Reform- und Seelsorgeanstrengungen hervorgehenden ,neuen Orden', vorzugsweise Dominikaner und Franziskaner, gelten - wie die Ausbildung neuer Städte mit neuen (Rats-)Verfassungen - als Schlüsselprozesse des weiteren modernen Europas. ${ }^{19}$

Stadthistoriker interessiert die Ansiedlung von Bettelorden zumeist deshalb, weil deren Konvente als Kristallisationskerne und Prosperitätsfaktoren sowie auf Dauer als Ausweise kommunaler Selbstbehauptung, der Repräsentation sowie herrschaftlicher wie kommunaler Verdichtungsinteressen wirksam wurden. ${ }^{20}$ Dabei musste die Stadt- wie auch die Bettelordensforschung erst erkennen, dass diese neuen Orden, die in enger Bindung an die päpstliche Zentralgewalt standen,

17 Lutz Partenheimer, Albrecht der Bär. Gründer der Mark Brandenburg und des Fürstentums Anhalt, Köln u.a. 2003; Michael Lindner, Jacza von Köpenick. Ein Slawenfürst des 12. Jahrhunderts zwischen dem Reich und Polen. Geschichten aus einer Zeit, in der es Berlin noch nicht gab, Berlin 2012; Clemens Bergstedt/Heinz-Dieter Heimann (Hrsg.), Wege in die Himmelsstadt. Bischof, Glaube, Herrschaft 800-1550 (Veröffentlichungen des Museums für brandenburgische Kirchen- und Kulturgeschichte des Mittelalters, Bd. 2), Berlin 2005; Joachim Müller/Klaus Neitmann/Franz Schopper (Hrsg.), Wie die Mark entstand. 850 Jahre Mark Brandenburg (Forschungen zur Archäologie im Land Brandenburg, Bd. 9), Wünsdorf 2009.

18 Michael Borgolte, Europa entdeckt seine Vielfalt 1050-1250 (Handbuch der Geschichte Europas, Bd. 3), Stuttgart 2002; Gisela Drosbach/Hans-Joachim Schmidt (Hrsg.), Zentrum und Netzwerk. Kirchliche Kommunikation und Raumstrukturen im Mittelalter, Berlin 2008; Gabriele Köster/Christina Link/Heiner Lück (Hrsg.), Kulturelle Vernetzung in Europa. Das Magdeburger Recht und seine Städte. Wissenschaftlicher Begleitband zur Ausstellung,Faszination Stadt', Dresden 2018.

19 Winfried Schich, Die ,Christianisierung' der Kulturlandschaft zwischen Elbe und Oder im 12. und 13. Jahrhundert, in: Siedlungsforschung. Archäologie, Geschichte, Geographie 20 (2002), S. 93-116. Mit neu erstellten Karten zur Ausbreitung der Konvente der franziskanischen Ordensfamilie nach Zeitstufen seit dem Mittelalter Lars Schulenburg, Franziskanertum als Karte, in: Heimann, Gelobte Armut, S. 589-603. Siehe ferner die Ausbreitungskarten, in: Christoph Stiegemann/Bernd Schmies/Heinz-Dieter Heimann (Hrsg.), Franziskus. Licht aus Assisi. Katalog zur Ausstellung im Erzbischöflichen Diözesanmuseum und im Franziskanerkloster Paderborn, München 2011; Dirk Schumann (Hrsg.), Brandenburgische Franziskanerklöster und norddeutsche Bettelordensbauten. Architektur - Kunst - Denkmalpflege, Berlin 2010; Hans-Joachim Schmidt, Klöster, Stifte und Orden in der Mark Brandenburg, in: Heimann, Brandenburgisches Klosterbuch, Bd. 1, S. 18-46; Matthias Untermann/ Leonie Silberer, Die Kirchenbauten bis 1400, in: Pieper, Kunst, S. 93-143; Heinz-Dieter Heimann, ErinnerungsNeuland: Markgrafschaft - Bettelordenslandschaft. Zur Bedeutung der brandenburgischen Klosterlandschaft in Anbetracht historischer Jubiläen, in: Müller/Neitmann/Schopper, Wie die Mark entstand, S. 421-430.

20 In verschiedenen Perspektiven Achim Todenhöfer, Kirchen der Bettelorden. Die Baukunst der Dominikaner und Franziskaner in Sachsen-Anhalt, Berlin 2008, bes. S. 303-321; Leonie Silberer, Architektur der Franziskanerklöster. Annäherungen, Forschungsfragen und Baubefunde, in: Melville/Silberer, Die Klöster der Franziskaner, S. 3-18. 
mit der persönlichen Armut der Brüder sowie mit ihren Ansprüchen in der Seelsorge in überlieferte Strukturen der Kirche einbrachen; sie stellten zudem kein ausschließlich städtisches Phänomen dar. Die Franziskaner sprachen seelsorglich von Anfang an Herrschaftsträger, die Menschen der sich ökonomisierenden Stadtgesellschaft sowie jene im Umland der Städte an. Diese Einsicht in die Wirkungsreichweite der Franziskaner verdanken wir auch Kaspar Elm, dem Doyen der Ordensforschung in Deutschland, und seinen im letzten Viertel des vergangenen Jahrhunderts angeregten Forschungen zu den Termineien der Franziskaner. ${ }^{21}$

Mit der erfolgreichen Ausbreitung der Brüder, die recht früh auch nach Deutschland gingen, mussten sie ihr Stadtsässig-Werden als eine Herausforderung ihrer religiösen Armutsbewegung erfahren. Folglich richteten sie in einem spannungsvollen Vorgang ihr regelkonformes mendikantisches Wirken dann auch erst daraufhin aus. Vor diesem Hintergrund erst erschließt sich auch das Wirken der frühen Franziskaner in der werdenden Stadt Berlin. Zugleich steht diese Entwicklung wiederum in einem engen Zusammenhang mit Entwicklungen des Gesamtordens, sodass Klostertopografien anderer Städte Rückschlüsse auch auf Berlin ermöglichen können. ${ }^{22}$

Wie hielt es zunächst der Ordensgründer mit Kloster- und Kirchenbauten seiner Brüder? Welche Unterkünfte fanden schließlich die aus Assisi kommenden Brüder nördlich der Alpen vor oder suchten sie? Die Regulata bullata von 1223 und auch das Testament des Ordensgründers waren da eindeutig, denn dort standen Besitz und entsprechende Anforderungen an Häuser oder Kirchen unter der Geltung freiwilliger Armut als Ausweis der Christusnachfolge. So lesen sich denn auch die ersten Berichte über die Ausbreitung der Brüder kaum als Erfolgsgeschichten. Die Chronik über die Ankunft der Brüder in Deutschland des Augenzeugen Jordan von Giano erhellt, wie fern ihnen Vorstellungen von Klöstern lagen. Als die Brüder, die 1223/25 nach Erfurt kamen, von der Bürgerschaft unvermittelt gefragt wurden, ob sie ,ein Haus nach Art eines Klosters gebaut haben möchten', erwiderte Bruder Jordan, ,ich weiß gar nicht, was ein Kloster ist. Baut uns das Haus nur nahe am Wasser, damit wir zum Füßewaschen hineinsteigen können.23 Ähnliche Umstände und Situationen, die auch die Erstdatierung der Ankunft der Brüder in den Städten erschweren, finden sich für Mühlhausen oder Magdeburg. Danach kamen, und das ist hinlänglich belegt, die ersten Brüder in den Städten auch nicht in festen oder gar in eigenen Konventen unter. Das dürfte auch in Berlin gelten. Entsprechend bleibt das Stadtsässig-Werden der Franziskaner zu erklären.

Jene normativen Setzungen, die den Franziskanern das sichtbarere Stadtsässig-Werden ermöglichten, erweisen sich als Teil einer von heftigen internen Spannungen gekennzeichneten Ver-

21 Peter Riedel, Termineien im ,Bettelordensland‘'Brandenburg. Zugleich ein Beitrag über Nutzen und Grenzen von Klosterbüchern, in: Sascha Bütow/Peter Riedel/Uwe Tresp (Hrsg.), Das Mittelalter endet gestern. Beiträge zur Landes-, Kultur- und Ordensgeschichte. Heinz-Dieter Heimann zum 65. Geburtstag (Studien zur brandenburgischen und vergleichenden Landesgeschichte, Bd. 16), Berlin 2014, S. 191-223; Arend Mindermann, Das franziskanische Termineisystem, in: Honemann, Vom Mittelalter bis zur Reformation, S. 195-264.

22 Todenhöfer, Kirchen der Bettelorden, S. 302-310.

23 Lothar Hardick OFM (Hrsg.), Nach Deutschland und England. Die Chroniken der Minderbrüder Jordan von Giano und Thomas von Eccleston (Franziskanische Quellenschriften, Bd. 6), Werl 1957, Kap. 43-45, S. 73-77; Johannes Schlageter, Die Chronica des Bruders Jordan von Giano. Einführung und kritische Edition nach den bisher bekannten Handschriften, in: Archivum Franciscanum Historicum 104 (2011), S. 3-63. Ferner Schmies/ Honemann, Die Franziskanerprovinz Saxonia, S. 26-37. 
rechtlichung der brüderlichen Armutsbewegung. Nach und nach rechtlich strukturiert und schließlich normativ verfasst, erlangte jene von der römischen Kirche den Status als anerkannte Ordensgemeinschaft. Diesen Weg, wie auch die Bedeutung der Armutstheologie, spiegeln die Genese der Ordensregel und die Beschlüsse der Ordenskapitel, insbesondere die 1260 unter dem Ordensgeneral Bonaventura (1217/1221? -1274) in Narbonne verabschiedeten Generalstatuten, die die Franziskusregel auf veränderte Zeitverhältnisse hin aktualisierte, wider. Dazu gehört auch, dass erst eine päpstliche Bulle von 1230 den Brüdern - unter Berücksichtigung des Eigentumsverbots - den Bau von Konventen ausdrücklich gestattete. Wohl infolge solcher zentral veranlasster und nach Ortslage rezipierter neuer Normen nahm auch die Bautätigkeit von Franziskanerkonventen und Bettelordenskirchen in den Städten bis zum ersten Höhepunkt um 1250 rapide $\mathrm{zu}^{24}$

Die so nach und nach auf neue rechtliche Grundlagen gestellte Stadtsässigkeit der Franziskaner schlug sich in der Klostertopografie nieder, doch wurde darum in den Gemeinschaften auch weiter gerungen. Wie sie über die Stadtsässigkeit argumentierten, lassen ihre ,Determinationes erkennen, eine um 1260 entstandene Lehrschrift. Stadtsässigkeit wird dort damit begründet, gerade in Städten den dort zahlreichen Menschen predigen zu können. Dort sei der Lebensunterhalt der Brüder besser zu sichern. Ferner böten ihnen Städte besseren Schutz. Und weiter, Klosterbauten seien inter muros besser, weil die Bürger befürchten, Gebäude außerhalb könne der Feind bei Belagerungen ausnutzen. Schließlich reagierte man 1268 in der päpstlichen Bulle, Quia plerumque' auf die Konkurrenz der Bettelorden in den Städten. Darin legte Papst Clemens VI. (1265-1268) fest, dass innerhalb eines Ortes die Abstände zwischen Bettelordenskonventen beziehungsweise Bettelordenskirchen mindestens 140 cannae, etwa 240 Meter, betragen sollten. ${ }^{25}$

Was bedeutet das hier und heute? Erinnerungsgeschichtlich genügt es hier und in Zukunft nicht, mit Blick auf das Graue Kloster dessen ursprüngliche Randlage im Stadtraum oder die damit verbundene Nähe der Franziskaner zu hier wohnenden ärmeren Bevölkerungsgruppen oder zum Stadttor zu wiederholen. Am Anfang des Weges der Franziskaner in die Gebiete östlich von Magdeburg stand 1226 Ziesar $^{26}$ im Bistum Brandenburg und von dort bald, 1237, Brandenburg/ Neustadt ${ }^{27}$ und vor 1250 Berlin. Dort erhielten die Franziskaner am Ostrand ihren Platz, die Dominikaner am Nordrand von Cölln, auf der Spreeinsel.

Unverzichtbar ist es daher, in Zukunft zusammen mit den normativen Voraussetzungen der Stadtsässigkeit der Franziskaner die Genese der Kloster- und Stadttopografie in Berlin detailliert zu vermitteln. Dabei trafen jene Ansprüche der Franziskaner zeitgleich auf wachsende Ansprüche der Standortökonomie in Gestalt aufgesiedelter Grundstücke, von der die Stadtarchäologie

24 Schmies/Honemann, Die Franziskanerprovinz Saxonia, S. 26 f. Siehe dazu die Tabelle bei Todenhöfer, Kirchen der Bettelorden, S. 307, 318.

25 Helmut G. Walther, Bettelordenskloster und Stadtgründung im Zeichen des Landesausbaus. Das Beispiel Kiel, in: Dieter Berg (Hrsg.), Bettelorden und Stadt. Bettelorden und städtisches Leben im Mittelalter und in der Neuzeit (Saxonia Franciscana, Bd. 1), Werl 1992, S. 19-32; Todenhöfer, Kirchen der Bettelorden, S. 316 f.

26 Peter Riedel, Ziesar Franziskaner, in: Heimann, Brandenburgisches Klosterbuch, Bd. 2, S. 1345-1347.

27 Petra Weigel, Brandenburg Franziskaner, in: Heimann, Brandenburgisches Klosterbuch, Bd. 1, S. $278-288$. 
sagt, dass sie in Berlin und Cölln planmäßig eingerichtet und bebaut wurden. ${ }^{28}$ Wenn die Ordensprovinz 1252 ihr Kapitel in Berlin feierte, wie es die Inschrift im Chor der Klosterkirche ausweist, so sicherlich (noch) nicht in ihrem Gebäude. Von 1250/1257 datiert die Nennung eines Hermann de Lengele, lector fratrum minorum de Berlin, der wohl auch als Beichtvater der askanischen Markgrafen wirkte. Danach ist zu vermuten, dass die Brüder im Umfeld der Markgrafen in Berlin für eine gewisse Zeit eine Art ,Provisorium' erhielten und um die Mitte des Jahrhunderts auch schon ein Hausstudium organisierten, was auf eine schon gefestigte Bedeutung des Konvents hindeuten könnte. ${ }^{29}$ Erst 1271 erhielten die Franziskaner von den askanischen Markgrafen Otto V. (1267-1298) und Albrecht III. (1284-1300) ein Grundstück zur Errichtung einer Kirche zugewiesen. Es handelte sich um eine Parzelle an der Stadtmauer, die vom Gelände des landesherrlichen Hofes abgetrennt und für den Bau der Kirche sowie dann eines Konventsgebäudes genutzt wurde. Die Markgrafen könnten mit dieser Maßnahme zugunsten der Franziskaner die Absicht eingeleitet haben, Berlin einen geistlichen Mittelpunkt zu implantieren, der ihnen auch die Möglichkeit bot, die Klosterkirche als dynastische Grablege zu nutzen ${ }^{30}$ und damit ihren Herrschaftssitz zu verdichten.

Siedlungs- und klostertopografisch sowie ordensspezifisch wird man aus diesen Umständen mitnehmen, für die Franziskaner und ihre im Kirchenbau zentral sichtbar gemachte Stadtsässigkeit auf die Vorgeschichte und die Geltung der jüngeren Ordensstatuten in der Gemeinschaft zu achten. Bauhistorische Befunde des Kirchenbaus deuten zunächst auf einen Feldstein- und dann Backsteinbau hin, dessen Langhauskonsolen und Formsteinversatz auf die Klosterkirche der Zisterzienser in Chorin verweisen. ${ }^{31} 1290$ schenkte der Ritter Jacob von Nybede dem Franziskanerorden eine Ziegelei bei Tempelhof, was den Bau einer Backsteinkirche begünstigt haben dürfte. Solche Konstellationen hatten die Franziskaner wohl vor Augen, als sie im 14. Jahrhundert rückblickend in den Inschriften ihres Chorgestühls auch den Ritter Jacob als fundator ihres Klosters öffentlich auswiesen. Sie schrieben damit ihr Geschichtsverständnis als historisches Argument und zur eigenen Legitimation an die Wand (siehe Abbildungen 4 bis 7).

Die aufragende dreischiffige Backsteinbasilika der Franziskaner wirkt bis heute raumgreifend und imponierend. Damit nicht genug. Mehr noch bildeten die gebauten Zeichen zusammen mit dem Konvent, Kreuzgang, Klosterfriedhof und dem Vorplatz städtische Binnenräume, deren Funktion und öffentliche Zugänglichkeit wesentlich aus der kommunizierten Anwesenheit der Franziskaner resultierte. Weitere Ausgrabungen zu den Grablegen innerhalb der Kirche wie auf dem Friedhof könnten diese Situation noch verdeutlichen und damit eine ordens- und stadtkulturgeschichtliche Forschung befruchten, die Friedhöfe und Vorplätze an Bettelordenskirchen als Predigtorte sowie Konvente als auch städtische Identifikationsmedien befragt. Die gegenwärtige Kulturgeschichtsforschung interessiert sich für solche ,Zeichen' und damit funktional markierte

28 Winfried Schich, Der Ausbau Berlins im 13. Jahrhundert und der überlieferte Stadtgrundriss, in: Historische Kommission, Alte Mitte - Neue Mitte, S. 113-123.

29 Riedel, Berlin Franziskaner, S. 146; Dirk Schumann, Die Franziskaner und die märkische Backsteinarchitektur um 1300, in: ders., Brandenburgische Franziskanerklöster, S. 83-104.

30 Vgl. dazu den Beitrag von Dirk Schumann in diesem Band.

31 Schumann, Die Franziskaner, S. 89. 
Räume sozialer Gruppen. ${ }^{32}$ Angesichts der anstehenden Projekte rund um die stadtarchäologische Erschließung des Grauen Klosters erscheint es geboten, alle Zeugnisse, nicht nur die bisher zumeist kunsthistorisch bewerteten Kulturzeugnisse der Bettelordenskirche, als Elemente der Semiotik franziskanischer Räume und als Teil erinnerter Berliner Geschichte deutlicher wahrzunehmen und so vor Ort museal sichtbar zu machen.

\section{Grenzübergreifende Geltungsbehauptungen}

Die Franziskaner besaßen bis in die Mitte des 16. Jahrhunderts hinein gefestigte Bindungen an das religiöse Leben in der Stadt und darüber hinaus. Die bis in diese Zeit nachgewiesenen Stiftungen, Grablegen sowie die Ausstattung der Franziskanerklosterkirche spiegeln dies ebenso wider wie der Ausbau des Konvents im späten 15. Jahrhundert. Statt eines allgemeinen ,Verfalls des Mönchtums, ehedem gern als Kennzeichen einer epochenspezifischen Krise angeführt, stellt die jüngere Spätmittelalterforschung gerade bei den Franziskanern ein vielstimmiges Erneuerungsstreben fest. ${ }^{33}$ Nach der Inschrift auf der Chorwand fanden im Berliner Konvent mindestens zehn Provinzkapitel statt (siehe Abbildungen 4 bis 7). Von diesen rechtsweisenden Versammlungen datieren drei ins 13. Jahrhundert, sechs ins 14. und je eine ins 15. und 16. Jahrhundert. Die zeitliche Lücke zwischen 1429 und 1515 markiert eine Phase intensiv ausgetragener ordensinterner Auseinandersetzungen um Anspruch und Form einer Erneuerung des Ordens, die ein papaler Befehl zur Aufspaltung des Gesamtordens 1517 nur bedingt beendete. Jene Reformanstrengungen und die Durchsetzung der Neuordnung auf der einen Seite, das Interesse der städtischen und landesherrlichen Obrigkeiten an beaufsichtigten Konventen und deren Ressourcen sowie die theologische Aufkündigung des hergebrachten Mönchtums auf der anderen Seite führten je nach konfessioneller Disposition der Städte und der Landesherren zu Auflösungen beziehungsweise zu zeitlich gestreckten Aufhebungen der Bettelordenskonvente. ${ }^{34}$ Auch in Berlin bildete

32 Riedel, Berlin Franziskaner, S. 153 f.; Otto Gerhard Oexle, Die Stadtkultur des Mittelalters als Erinnerungskultur, in: Thomas Schilp/Barbara Welzel (Hrsg.), Dortmund und Conrad von Soest im spätmittelalterlichen Europa, Bielefeld 2004, S. 11-28; Susanne Rau/Gerd Schwerhoff (Hrsg.), Topographien des Sakralen. Religion und Raumordnung in der Vormoderne, München 2008; Susanne Ehrich/Jörg Oberste (Hrsg.), Städtische Räume im Mittelalter, Regensburg 2009; Karl-Joachim Hölkeskamp, ,Performative turn' meets ,spatial turn'. Prozessionen und andere Rituale in der neueren Forschung, in: Dietrich Borschung/Karl-Joachim Hölkeskamp/Claudia Sode (Hrsg.), Raum und Performanz. Rituale in Residenzen von der Antike bis 1815, Stuttgart 2015, S. 15-74; Walburga Knorr, Bestattungen im Kloster am Beispiel Regensburg und die Frage öffentlicher Zugänglichkeit, in: Melville/Silberer, Die Klöster der Franziskaner, S. 165-191; Cante, Die Klosterkirche, S. 54-68; Todenhöfer, Kirchen der Bettelorden, S. $320 \mathrm{f}$.

33 Kaspar Elm, Verfall und Erneuerung des Ordenswesens im Spätmittelalter. Forschungen und Forschungsaufgaben, in: Untersuchungen zu Kloster und Stift (Veröffentlichungen des Max-Planck-Instituts für Geschichte, Bd. 68/Studien zur Germania Sacra, Bd. 14), Göttingen 1980, S. 188-238; Volker Honemann, Die Reformbewegungen des 15. und frühen 16. Jahrhunderts in der Saxonia, in: ders., Von den Anfängen bis zur Reformation, bes. S. 158-163; Heinz-Dieter Heimann, Gescheiterte Vereinheitlichung und nachwirkende Anerkennung. Der zisterziensische Papst Benedikt XII. (1335-1342) und die Mönchs- und Bettelordensgemeinschaften, in: Andreas Sohn (Hrsg.), Benediktiner als Päpste, Regensburg 2018, S. 193-210.

34 Schmies/Honemann, Die Franziskanerprovinz Saxonia, S. 44. 
dafür die 1540 von Kurfürst Joachim II. erlassene Brandenburgische Kirchenordnung nur eine gewisse Richtschnur. ${ }^{35}$

Im Gegensatz zur älteren Forschung warnen Historiker heute davor, den unserem Verständnis von Reformen und Reformbedarf näherstehenden Argumenten der seinerzeitigen Reformer spätmittelalterlicher Ordenskonvente vorschnell anzuhängen. ${ }^{36}$ Auch überzeugt es heute nicht, allein aus bestimmten baulichen Raumdaten die Größe des Berliner Konvents zu berechnen und daraus seine Blüte abzuleiten, um der Raumgröße schließlich die Umnutzung des Kirchengebäudes durch den kurfürstlichen Leibarzt Leonhard Thurneysser und ab 1571/74 die Einrichtung einer Schule als neuem Zeitzeichen gegenüberzustellen.

Lässt man derlei verengende Bezüge beiseite, bleibt nach der Ordensforschung festzustellen, dass die einzelnen Konvente im 15. Jahrhundert teils ihr Armutsgebot neu zur Wirkung brachten, sie teils in diversen rechtlichen Verfahren ihren Status und ihre materiellen Grundlagen sicherten, womit sie sich auch gegen Zugriffe durch das städtische oder landesherrliche Regiment wehrten. Die Franziskanergemeinschaft geriet freilich aufgrund solcher Herausforderungen zunehmend unter Rechtfertigungsdruck und musste deshalb auch gegen wachsende Kritik ihre Legitimität und ihr mendikantisches Selbstverständnis offensiver reklamieren. Damit verbunden kam eine Dynamik in Gang, in die als zeittypisch erachtete Ansprüche nach bildgeleiteter Christusfrömmigkeit und Heilsgewissheit einwirkten. Das späte 15. Jahrhundert erweist sich so als eine Zeit intensivierter Frömmigkeit und religiös motivierten Mediengebrauchs. Das Rosenkranzgebet und der Rosenkranz als populäre Gebetshilfe stehen dafür. Der Franziskanerorden verband derlei Anliegen mit Initiativen eigener Geltungsbehauptung und der Vermittlung der ihnen eigenen Spiritualität.

Solche Behauptungsstrategien verbinden auch den Berliner Konvent und dessen umfänglichen Bestand an religiösen Kulturgütern mit einer grenzübergreifenden franziskanischen Frömmigkeitskultur. Sie gehören integriert in die Wahrnehmung der Eigentypik des Grauen Klosters als heute insgesamt disparater Erinnerungsort.

Zwischen dem 13. und 16. Jahrhundert mögen vielleicht 500 Barfüsser zum Berliner Konvent gehört haben, die hier wohnten, beteten, bettelten, predigten, Seelsorge leisteten, beerdigten. Aber nach dem Brandenburgischen Klosterbuch kennen wir gerade mal gut zwei Dutzend von ihnen mit Namen. Dass die Wittelsbacher als Nachfolger der Askanier in der Landesherrschaft und Kurwürde in der Franziskanerklosterkirche ihre Grablege bestimmten, ${ }^{37}$ verweist auf die

35 Riedel, Berlin Franziskaner; Andreas Stegmann, Die brandenburgische Kirchenordnung von 1540, in: Enno Bünz/Heinz-Dieter Heimann/Klaus Neitmann (Hrsg.), Reformationen vor Ort. Christlicher Glaube und konfessionelle Kultur in Brandenburg und Sachsen im 16. Jahrhundert (Studien zur brandenburgischen und vergleichenden Landesgeschichte, Bd. 20), Berlin 2017, S. 235-288; Heinz-Dieter Heimann, Frömmigkeit transferieren? Traditionskerne und Wandel der Prämonstratenser-Domkapitel Brandenburg und Havelberg in den Herausforderungen der Reformation des 16. Jahrhunderts, in: Analecta Praemonstransia XCV (2019), S. 65-94.

36 Hans-Joachim Schmidt, Status quo gegen Reform. Streit um Legitimationen von Klosterreformen, in: Saeculum. Jahrbuch für Universalgeschichte 66 (2016), S. 17-28.

37 Cante, Die Klosterkirche als Berliner Gedächtnisort. Cante führt als leitende Motive für den Erhalt der Kirche im 16. Jahrhundert deren Bedeutung als Grablege und Gedächtnisort an - auch für Leonhard Thurneysser, der also aus religiösen Gründen die Renovierung des Kircheninneren initiierte, ebd. S. 57 f. 
Nähe zwischen Bettelorden und Dynastie sowie auf den Rang dieser Kirche für die dynastische Memoria und Repräsentation im Gefüge der Stadt. Die frühen Hohenzollern knüpften daran in Berlin auch aus Gründen politisch motivierter Erinnerung an. Ihre Bindung an den Konvent zeigt sich weiter darin, dass sie ihm ihre Urkunden anvertrauten und das Refektorium für politische Anlässe wie Hoftage und Erbhuldigungen nutzten. Persönlich engere religiöse Bindungen lassen sich aus der Nutzung der Klosterkirche auch als Hofkapelle ableiten. Daneben - und dies jenseits zeittypischer Kritik an den Bettelorden - suchten bürgerliche Familien religiös motiviert die Bindungen an die Franziskanerklosterkirche und den Konvent in Memorialstiftungen, darunter prominent die Familie Blankenfelde. Derlei Beziehungen von Laien zum Konvent sind gerade im Licht der Bedeutung der verschiedenen Reformbewegungen in der Saxonia Gegenstand aktueller Forschung. ${ }^{38}$ Dieser Spur wird auch für den Berliner Konvent weiter nachzugehen sein. Jene Konstellationen des sozialen Wandels wirkten neben der Kritik an den Bettelorden auf den Konvent und die Gläubigen. Zugleich gab es um 1500 offenbar besonders überzeugende religiöse Gründe, dass Familien ihr Totengedächtnis mit der franziskanischen Frömmigkeit verbanden.

Aus franziskanischer Perspektive ist auf ihr irenisches Wirken in zeittypischen Auseinandersetzungen zwischen Bürgerschaft, Stadtherrschaft und Kirchenregiment hinzuweisen. Die Franziskaner wirkten mit ihren Möglichkeiten der Seelsorge oft friedenstiftend auf die Erlangung von kommunalem Konsens hin. Das zeigt sich 1324 in der Vermittlung zugunsten der Gemeinde während des päpstlichen Interdikts, oder 1412, als sich die Gemeinde gegen die Ratsherrschaft im Kloster versammelte, oder auch in Schutzverpflichtungen des Rats zugunsten der Brüder. Solche Beispiele sind für andere Städte bekannt, was auch für Berlin zeigt, in welch gutem Ruf der Konvent bei den Bürgern stand und warum Berliner Familien dem Franziskanerkonvent immer wieder Stiftungen und Totengedenken anvertrauten. Diese Kirche war offensichtlich vielen Berliner Familien ein religiös bestimmter Identifikationsort, ihr städtisches Zentrum.

Zur Frömmigkeit: Die Franziskaner waren ein Orden der neuen Mündlichkeit, was sich auf ihre ausgebildete und ausgedehnte Predigttätigkeit bezieht. Deshalb entfalteten sie auch in bevorzugten Konventen ein Hausstudium, organisierten gemäß der Ordensregel eine hohe Bildungsmobilität, besetzten bedeutende theologische Lehrstühle an den Universitäten, ebenso wie sie Nichtchristen im muslimischen Orient, im Baltikum oder in Fernost missionierten. ${ }^{39}$ Aus gutem Grund besetzten sie auch Lehrstühle an der durch den brandenburgischen Kurfürsten gegründeten Universität in Frankfurt (Oder).$^{40}$ Daneben trugen und förderten sie in der Seelsorge neue

38 Leonie Silberer, Domus fratrum minorum, in: Melville, Die Klöster der Franziskaner, S. 275-325; Bernd Schmies, Brüder ohne Stimme. Auf der Suche nach den Laienbrüdern unter den Sächsischen Franziskanern im Mittelalter und in frühreformatorischer Zeit, in: Archivum Franciscanum Historicum 112 (2019), S. 169-214.

39 Andreas Sohn, Studium und Universität im Zeichen der Armut? Zu den Franziskanern in der europäischen Bildungsgeschichte, in: Heimann, Gelobte Armut, S. 155-182; Giancarlo Collet/Johannes Meier (Hrsg.), Geschichte der Sächsischen Franziskaner-Provinz von der Gründung bis zum Anfang des 21. Jahrhunderts, Bd. 4: Missionen, Paderborn 2013.

40 Michael Höhle, Universität und Reformation. Die Universität Frankfurt (Oder) von 1506 bis 1550 (Bonner Beiträge zur Kirchengeschichte, Bd. 25), Köln 2002, bes. S. 44-46, 138-145, 276-282. 
Formen gelebter Frömmigkeit, wobei die Franziskaner von Anfang an als ein Orden der Bilder wirkten, ${ }^{41}$ - auch in Berlin.

Das Wilsnacker Wunderblut motivierte im 15. Jahrhundert viele Pilger selbst aus entfernteren Regionen. Der zwischen Theologen ausgetragene Streit um dieses Wunder und die angemessene Verehrung der Hostien bewegten nicht weniger, wobei die Franziskaner die fromme Verehrung der Hostien verteidigten und darüber mit anderen Kirchenvertretern konkurrierten. Als Prediger und Gelehrter wirkte daran von Berlin aus der Franziskaner Johannes Kannemann mit. Promoviert in Erfurt kam er über den Magdeburger Konvent als Seminarleiter nach Berlin. Er starb 1469 im Frankfurter Konvent. 1458 nahm er an den Inquisitionsprozessen gegen die Waldenser in der Mark Brandenburg teil, wirkte in der Ordensprovinz als Reformer und predigte landesweit einem offenbar großen Publikum. ${ }^{42}$ Kannemanns Wirken von Berlin aus ist nur ein Beispiel dafür, wie sehr der Orden wissenschaftliche Bildung in seinen Reihen förderte und über die Stadt hinaus kommunizierte. Kannemanns theologisches Wirken, erweitert dann um das Wirken der Franziskaner an der Universität Frankfurt (Oder), repräsentiert die franziskanische Wissenskultur der Zeit. Seine Mobilität markiert den Berliner Konvent als Teil einer nicht allein ordensspezifisch bemessenen Bildungslandschaft. Die Lehrschriften Kannemanns haben sich bis heute erhalten. Sie aus den Archiven an die Öffentlichkeit zu bringen, sie neu zu lesen und zu deuten, würde neue Wege und Räume einer europäischen Bildungs- und Ordensgeschichte vor Augen stellen und zugleich die franziskanische Geschichte Berlins bereichern. Eine Schulgeschichte des Grauen Klosters mag man im letzten Quartal des 16. Jahrhunderts beginnen lassen, eine Studienund Wissensgeschichte der Barfüßer mit Berliner Bürgern beginnt bereits im späten Mittelalter. Das gilt auch für eine konfessionskulturelle Mediengeschichte.

Illustrieren lässt sich dies mit der religiösen Kunst im Berliner Konvent um 1500. Es geht dabei nicht um Stilmerkmale. Vielmehr gilt es, die Art und Weise sowie signifikante Themen der kommunizierten Frömmigkeit der Franziskaner an diesem Ort neu öffentlich zu machen. Bisher sind diese Zeugnisse an diversen Orten über die Stadt Berlin verteilt und daher in ihren franziskanischen Bezügen kaum angemessen wiedererkennbar. Es ist wohl an der Zeit, diese Seite der Franziskaner- und Frömmigkeitsgeschichte bevorzugt in die Erinnerungsarbeit aufzunehmen und darin auch die Ausstattung anderer Franziskanerkirchen in der Mark Brandenburg aufzunehmen.

Die jüngere Landes-, Kirchen- und Kulturgeschichtsforschung konnte bereits die tatsächliche Vielfalt und die Bedeutung der Ausstattung der spätmittelalterlichen Kirchen in der Mark Brandenburg mit hochwertigen Kunst- und Kulturgegenständen herausarbeiten. ${ }^{43}$ Doch die Perspek-

41 Dieter Blum, Der Orden und die Bilder, in: Stiegemann/Schmies/Heimann, Franziskus. Licht aus Assisi, S. 114124.

42 Johannes Schlageter OFM, Franziskanische Theologie des Mittelalters in der Saxonia, in: Honemann, Von den Anfängen bis zur Reformation, S. 489-501; Volker Honemann, Bücher und Bibliotheken der Saxonia von ihren Anfängen bis zur Reformation, in: ders., Von den Anfängen bis zur Reformation, S. 521-601, bes. S. 557 f., mit Nachweisen eines Hausstudiums auch im Berliner Konvent und mit Hinweisen auf die dort 1467 entstandenen Handschriften. Einige der Handschriften finanzierte der Berliner Thomas Blankenfelde, Honemann, Bücher und Bibliotheken, S. 557, Anm. 143.

43 Ernst Badstübner u. a. (Hrsg.), Die Kunst des Mittelalters in der Mark Brandenburg. Tradition, Transformation, Innovation, Berlin 2008; Clemens Bergstedt/Heinz-Dieter Heimann/Hartmut Krohn (Hrsg.), Die Bischofsre- 
tive der Kunstgeschichte ist nur eine neben anderen. Vielmehr bieten die Mentalitäts-, Frömmigkeits- und Mediengeschichte weitere Argumente, die Franziskanerklosterkirche und den Konvent in einem erweiterten Kontext zu zeigen. ${ }^{44}$

Ein Beispiel: Die in der Berliner Franziskanerklosterkirche eingebrachten Bildwerke und Kultgegenstände „zeugen von einer regelrechten Ausstattungskampagne in den letztem Jahrzehnten des 15. Jahrhunderts" ${ }^{\text {" } 5}$ die zusammen mit dem Neubau des vergrößerten Konventsgebäudes religiöse Leitvorstellungen des Ordens adressierten. Sie weisen stadtraumbezogene und grenzübergreifende heilsgeschichtlich verdeutlichte Anstrengungen der Geltung des Ordens aus. Auch gegen zeittypische Kritik an den Bettelorden brachte dieser gezielt heilsbezogen Alleinstellungsmerkmale mit dem reklamierten Vorbild ihres Ordensgründers vor. Die verbundene ordens- und frömmigkeitsgeschichtliche Perspektive verweist auf einen Konvent, dessen Angehörige sich in einer überregionalen Ordenskultur vernetzt ausweisen. Der betrieb intensiviert heilsgeschichtlich ausgerichtete Bildpropaganda.

Dafür ist die sogenannte Tafel mit dem Ordensbaum des heiligen Franziskus von Assisi aus der Franziskanerklosterkirche anzuführen. An dieser Tafel, deren exakte Datierung schwankt, aber sicherlich ins ausgehende 15. Jahrhundert gehört, lässt sich die vom Konvent mitgetragene religiöse Produktivität ablesen. Dafür spricht das Motiv des Franziskanerstammbaums, das Christus am Kreuzesstamm zeigt, darunter Franziskus von Assisi, der mit den Wundmalen des Gekreuzigten stigmatisiert, seitlich von heiligen Männern und Frauen aus seinem Orden und einem Stif-

sidenz Burg Ziesar und ihre Kapelle. Dokumentation der Wandmalereien im Kontext der spätmittelalterlichen Kunst- und Kulturgeschichte der Mark Brandenburg und angrenzender Regionen (Veröffentlichungen des Museums für brandenburgische Kirchen- und Kulturgeschichte des Mittelalters, Bd. 4), Berlin 2009; Clemens Bergstedt u. a. (Hrsg.), Im Dialog mit Raubrittern und Schönen Madonnen. Die Mark Brandenburg im späten Mittelalter. Begleitband zum Ausstellungsverbund ,Raubritter und Schöne Madonnen' (Studien zur brandenburgischen und vergleichenden Landesgeschichte, Bd. 6), Berlin 2011; Jan Richter/Peter Knüvener/Kurt Winkler (Hrsg.), Karl IV. Ein Kaiser in Brandenburg, Berlin 2016. Neben den entsprechenden Beiträgen des Brandenburgischen Klosterbuchs Jan Raue, Farbigkeit franziskanischer Feldsteinarchitektur. Die Klosterkirchen in Angermünde und Prenzlau, in: Schumann, Brandenburgische Franziskanerklöster, S. 105-141; siehe ferner die folgenden Beiträge im soeben zitierten Sammelband von Schumann, Brandenburgische Franziskanerklöster: Maria Deiters, Die Ausstattung der Franziskanerklosterkirche in Berlin. Franziskanische Bildthemen in der Ausstattung der Berliner Klosterkirche, S. 142-165; Peter Knüvener, Das Retabel aus der Granseer Franziskanerkirche, S. 166-178; Jens Christian Holst/Joachim Müller, Die Johanniskirche der Franziskaner in der Altstadt Brandenburg, S. 291-368; Detlev von Olk, Das Kyritzer Franziskanerkloster. Entdeckungen am Kyritzer Klostergebäude, S. 405-414; Wolfgang Blaschke, Die Nutzung der Angermünder Franziskanerklosterkirche im Wandel der Zeiten. Von der Reformation bis heute, S. 415-428. Ferner Pieper, Kunst, S. 347-527.

44 Berndt Hamm/Thomas Lentes (Hrsg.), Spätmittelalterliche Frömmigkeit zwischen Ideal und Praxis (Spätmittelalter und Reformation, N. R., Bd. 15), Tübingen 2001; Sebastian Scholz, Öffentliche Frömmigkeit im 15. Jahrhundert. Stiftung, Memoria und Repräsentation auf Denkmälern, in: Jörg Rogge (Hrsg.), Religiöse Ordnungsvorstellungen und Frömmigkeitspraxis im Hoch- und Spätmittelalter, Korb 2008, S. 115-134; Berndt Hamm/ Volker Leppin (Hrsg.), Media salutatis. Gnaden- und Heilsmedien in der abendländischen Religiosität des Mittelalters und der Frühen Neuzeit (Spätmittelalter, Humanismus, Reformation, Bd. 58), Tübingen 2011.

45 Deiters, Die Ausstattung der Franziskanerklosterkirche, S. 157; Heinz-Dieter Heimann, Franziskusbilder in populären Heilsmedien und ordenskritischen Polemiken des 15. und 16. Jahrhunderts. Beispiele aus der, iconographia franciscana' als Wegweiser zu einer kulturellen Konfessionsgeschichtsforschung, in: Michaela Sohn-Kronthaler/ Jacques Verger (Hrsg.), Europa und Memoria. Festschrift für Andreas Sohn zum 60. Geburtstag, Ostfildern 2019, S. 99-119. 
terehepaar zu seinen Füßen umgeben ist. Das Motiv geht auf den Theologen und Ordensheiligen Bonaventura zurück und wurde im 14. Jahrhundert neu gedeutet und im späten 15. Jahrhundert aktualisiert in unterschiedlichen Medien vervielfältigt. Diese Entwicklung verdankt sich sehr wahrscheinlich dem Franziskanerhistoriografen Nikolaus Glasberger. Bildmotive des Franziskuslebens erfuhren vor und nach 1500 eine von Nürnberger Künstlern wie Max Traut getragene überregionale Verbreitung; sie waren von und durch franziskanische Spiritualität und persönliche christusbezogene Gebetsfrömmigkeit gekennzeichnet. ${ }^{46}$ Jenes Stammbaummotiv findet sich so von Flandern bis Böhmen, nicht nur in Kirchen der Franziskaner. In dieser Bildverbreitung wird ein franziskanisch mitbestimmter religiöser Kommunikationsraum erkennbar, an dem auch der Berliner Konvent partizipierte. Will sagen: Dieser Konvent förderte offenbar Ansprüche franziskanisch geleiteter Christusfrömmigkeit, die - im Rückblick - lutherisch-reformatorisch anmutet. Tatsächlich aber bewarben damit die Franziskaner ihre oft reforminteressierten Gruppen öffentlich und erzeugten so ein religiös unterlegtes Alleinstellungsmerkmal des Ordens. Letzterer versuchte, sich hiermit theologisch-seelsorglich und medial modern gegen zeitübliche Kritik am Ordensleben zu behaupten. Der Berliner Konvent betrieb also mit diesem Gemälde und anderen Zeugnissen, darunter Einblattdrucke, religiös motivierte Meinungsbildung, die mehr als nur medientechnisch modern war. Der Berliner Konvent, ein von der Stadtbevölkerung geschätzter Memorialort, wirkte offenbar auch als ein Ort religiöser Produktivität. Diese Wirkungsgeschichte der Franziskaner erreicht unsere Gegenwart. Sie ließe sich am Grauen Kloster auch (wieder) sichtbar vermitteln.

\section{Stadt und Konvent - eine Zusammenfassung}

Mehr als bereits geschehen, lassen sich die Ruine ,Graues Kloster' als Denkmal und die gepflegten Steine der Gotik noch deuten und zum Sprechen bringen. Erinnerung unterliegt dem Wandel. Erinnerung ist zudem Konstruktion, die jeweils zu vermitteln bleibt. Nutzt man dazu die franziskanische Perspektive im Kontext, so erweitert sie die bisher verengte Wahrnehmung des Grauen Klosters und öffnet den Blick auf die Vielfalt und Ambivalenz der für und an diesem Ort jeweils reklamierten Erinnerungen. Neben der Wirkungs- und Geltungsgeschichte der Franziskaner sind es die Brüche in der Geschichte des Ortes und die auf ihn bis in die Gegenwart projizierten verschiedenen (Be-)Deutungssetzungen, die das Graue Kloster heute als Ort - eingangs skizzierter - disparater Erinnerungen in der historischen Mitte der Stadt besonders bedeutsam machen. Die Wirkungs- und Geltungsgeschichte des Berliner Franziskanerkonvents bietet mannigfache Anknüpfungsmöglichkeiten, aus der Intensität der Beziehungen zwischen Bevölkerung und Franziskanerkonvent sowie der Sachkultur der Gemeinschaft bisher nicht beachtete soziale und kulturelle Stadträume und damit verbundene überregionale Beziehungen sichtbarer als bis-

46 Jürgen Werinhard Einhorn OFM, Franziskus und die Autoritäten in Beispielen mittelalterlicher Buchmalerei zu Bonaventuras Großem Franziskusleben, in: Dieter Berg (Hrsg.), Könige, Landesherren und Bettelorden. Konflikt und Kooperation in West- und Mitteleuropa bis zur Frühen Neuzeit (Saxonia Franciscana, Bd. 10), Werl 1998, S. 3-34; ders., Überregionale Bildkontakte. Ein Franziskusleben im ostsächsischen Kamenz, in: Verum, pulchrum et bonum: miscellanea di studi offerti a Servus Gieben in occasione del suo 80 compleanno (Bibliotheca seraphico-capuccina, Bd. 81), Rom 2006, S. 251-274; Heimann, Franziskusbilder in populären Heilsmedien, S. 111 . 
her zu vermitteln. Damit nicht genug. Um die verschiedenen mit diesem Ort verbundenen und auf ihn projizierten Erinnerungen konzeptionell deutungsgeschichtlich zu erschließen und zu vermitteln, bietet das von Otto Gerhard Oexle problematisierte Verhältnis von Mittelalter und Moderne einen probaten Schlüssel und ein Gerüst. Danach ließen sich hier jenseits herkömmlichen Verständnisses historischer Epochen ,Sinnformationen' gedeuteter Geschichte in Erinnerung bringen. Für diesen Weg plädiere ich vehement, weil dazu auch eine auf dem Areal zu realisierende Museumsspur konfessioneller Kulturgeschichte beiträgt. Und in jedem Fall würde so verständlich werden, wieso Franziskaner seit den Anfängen Berlins hier seelsorglich wirkten und ihre mittelalterlichen Selbstzeugnisse auf der Wand des Chorgestühls auch für die Stadt bis heute gelten: per totum orbem longe lateque diffudit. 


\section{Doris Bulach}

\section{Das Franziskanerkloster in Berlin als Ort christlicher Memoria im Mittelalter}

Kaum eine historische oder kunsthistorische Darstellung von adeligen Familien, städtischen Gruppen oder kirchlichen Einrichtungen kommt heute noch ohne einen Beitrag zur Memoria, also zur Sorge von Menschen um ihr Seelenheil, um die Armenfürsorge, aber auch der mit beidem verbundenen persönlichen Repräsentation im Kirchenraum, aus. ${ }^{1}$ Seit den Forschungen von Gerd Tellenbach wurden nicht nur unzählige Totenbücher, Anniversarien oder Stiftungen, sondern auch Grabmäler, Kapellen, Altäre, Altarbilder oder weiteres Kirchengerät unter Einbeziehung dieser Parameter in historischen, aber auch kunstgeschichtlichen Studien ediert, ausgewertet oder untersucht. ${ }^{2}$ In diesen Studien geht es nicht darum, anerkannte Thesen „zum wiederholten Male exemplarisch zu belegen“. ${ }^{3}$ Vielmehr sagt die Untersuchung der Memoria von Personen oder Gruppen mit ihrem Wunsch, auch nach dem Tod als Subjekte im Kirchenraum unter den Lebenden gegenwärtig zu bleiben, viel über die Sozialstruktur dieser Gruppen, ihre individuellen oder gruppenspezifischen Möglichkeiten und Strategien oder ihre Beziehungen zu

1 Vgl. dazu u.a. ausgewählte in den letzten Jahren erschienene Untersuchungen: Barbara Welzel, Memoria und Bildende Kunst. Überlegungen zu einer postsäkularen Kunstgeschichte, in: Thomas Schilp (Hrsg.), Die Dortmunder Dominikaner und die Propsteikirche als Erinnerungsort (Dortmunder Mittelalter-Forschungen, Bd. 8), Bielefeld 2006, S. 71-98; Doris Bulach, Handwerk im Stadtraum: Das Ledergewerbe in den Hansestädten der südwestlichen Ostseeküste (13. bis 16. Jahrhundert) (Quellen und Darstellungen zur Hansischen Geschichte, Bd. 65), Köln 2013 (v. a. Kapitel 3: Religiöse Räume des Handwerks); Marco Bogade, Memoria in der spätmittelalterlichen und frühneuzeitlichen bürgerlichen Sepulkralkultur von Hermannstadt und Nürnberg, in: Zeitschrift für siebenbürgische Landeskunde 39 (2016), S. 2-18; Enno Bünz, Die mittelalterliche Pfarrei. Ausgewählte Studien zum 13.-16. Jahrhundert (Spätmittelalter, Humanismus, Reformation, Bd. 96), Tübingen 2017 (darin die Kapitel 5: Memoria auf dem Dorf. Pfarrkirche, Friedhof und Beinhaus als Stätten bäuerlicher Erinnerungskultur im Spätmittelalter und 6: Vikariestiftungen verändern den Kirchenraum. Zum Wandel spätmittelalterlicher Pfarrkirchen im deutschsprachigen Gebiet); Rüdiger von Schnurbein, Seelenheil und Selbstdarstellung - Wiederverwendung und Memoria unter den frühen Hohenzollern, in: ders. (Hrsg.), Altlust. 1000 Jahre Nachnutzung im Dom zu Brandenburg, Berlin 2017, S. 62-68; Thorsten Fischer, Adelige Memoria im regionalen Kontext. Zum liturgischen Totengedenken der Grafen von der Mark im 13. und 14. Jahrhundert, in: Stefan Pätzold/Felicitas Schmieder (Hrsg.), Die Grafen von der Mark. Neue Forschungen zur Sozial-, Mentalitäts- und Kulturgeschichte (Veröffentlichungen der Historischen Kommission für Westfalen, N. F., Bd. 41), Münster 2018, S. 79-102; Katja Putzer, Totenkalender, Grabplatten, Totenschilde. Zur Memoria der Familie von Wolfstein im Kloster Seligenporten, in: Georg Schrott/Christian Malzer (Hrsg.), Mors. Tod und Totengedenken in den Oberpfälzer Klöstern, Kallmünz 2019, S. 265-277.

2 Zum aktuellen Forschungsüberblick: Michael Borgolte, Zur Lage der deutschen Memoria-Forschung, in: ders. u. a. (Hrsg.), Memoria. Erinnern und Vergessen in der Kultur des Mittelalters = Memoria. Ricordare e dimenticare nella cultura del medioevo, Bologna 2005, S. 21-28; ders., Stiftung und Memoria. Ein mediävistisches Forschungskonzept in universalhistorischer Perspektive, in: Thomas Schilp/Caroline Horch (Hrsg.), Memoria - Erinnerungskultur - Historismus. Zum Gedenken an Otto Gerhard Oexle (Memoria and remembrance practices, Bd. 2), Turnhout 2019, S. 75-92.

3 So die Rezension von Gregor Rohrmann zu Michael Borgolte (Hrsg.), Stiftungen und Stiftungswirklichkeiten. Vom Mittelalter bis zur Gegenwart, Berlin 2000, in: Zeitschrift für Geschichtswissenschaft 50 (2002), S. 75 f., hier S. 75 . 
kirchlichen Institutionen aus. All dies war von Person zu Person, Gruppe zu Gruppe oder Ort zu Ort sehr unterschiedlich, sodass die Einbeziehung von Fragen nach sozialer und liturgischer Memoria ${ }^{4}$ in Untersuchungen immer interessante und oft unerwartete Teilaspekte zutage fördert.

An dieser Stelle soll darauf verzichtet werden, erneut die „Grundzüge der Memoria“ ausführlich zu charakterisieren. ${ }^{5}$ Festzuhalten bleibt, dass die auf ewige Dauer angelegten Gebete von Geistlichen, aber auch Mitchristen, für die spätmittelalterlichen Gläubigen unabdingbar waren, sollten dadurch doch ihre Seelen beim Warten auf das Jüngste Gericht Erleichterung finden. ${ }^{6}$ Um aber auf solche Weise im Gedächtnis nachfolgender Generationen zu bleiben, brauchte und braucht es finanzielle Mittel, mit denen die Erinnerung, die Memoria, an die eigene Person wachgehalten werden kann. Entsprechend der jeweiligen Möglichkeiten konnten daher Stiftungen von Kerzen, Almosen, Bildern sowie von ganzen Altären oder Kapellen in Pfarr- oder Klosterkirchen mit dort angestellten Priestern getätigt werden, was sich unter anderem in Totenbüchern, Testamenten, Stadtbucheinträgen, Stiftungsurkunden oder Kapital- und Rentenverschreibungen niederschlug. Diese und weitere Quellen sowie Relikte wie die Kapellen, Altäre, Altarbilder oder kirchliche Gerätschaften selbst können - sofern sie erhalten sind - dazu genutzt werden, Einblicke in das mittelalterliche Gebetsgedenken und den damit verbundenen Repräsentationswillen von Individuen und Gruppen in einzelnen Kirchen zu gewinnen. Auf diese Weise entsteht zugleich ein Bild von der sozialen Zusammensetzung, den kulturellen und religiösen Vorstellungen sowie den finanziellen Möglichkeiten derjenigen, die ihre Memoria an die jeweiligen Kirchen banden.

Wer waren nun die Menschen, die ihre Memoria und Jenseitsvorsorge in die Hände der franziskanischen Mönche in Berlin legten? Woher kamen sie? Wie gelang es ihnen, in das Kircheninnere vorzudringen und welche Motive lassen sich für die Anbindung ihrer Memoria an das Franziskanerkloster erkennen? Und lassen sich damit verbundene Strategien feststellen, um das auf ewige Dauer angelegte Vorhaben gelingen zu lassen? Anhand der verschiedenen Personengruppen, die sich mit ihrer Memoria an das Franziskanerkloster banden, soll versucht werden, diese Fragen zu beantworten.

Einer umfassenden Beantwortung steht allerdings eine sehr disparate Quellenlage entgegen. So sind für das Berliner Franziskanerkloster aufgrund der nachreformatorischen Veränderungen, vor allem aber durch verschiedene Brände und Zerstörungen der städtischen und kirchlichen Archive kaum zeitgenössische schriftliche Quellen überliefert. ${ }^{7}$ Jedoch können spätere Chroniken des 15./16. Jahrhunderts mit aller Vorsicht herangezogen werden. Nur auf der Basis allein dieser Schriftquellen fiele eine Untersuchung der Anbindung der Memoria an das Franziskanerkloster sehr kurz aus, würde man hier nicht auf die noch in größerer Zahl überlieferten bildlichen Denkmale zugreifen können. Diese Relikte überlebten nicht nur die kirchenrechtlichen Verände-

4 Dazu ausführlich Otto Gerhard Oexle, Die Gegenwart der Lebenden und der Toten. Gedanken über Memoria, in: Karl Schmid (Hrsg.), Gedächtnis, das Gemeinschaft stiftet, München/Zürich 1985, S. 74-107, hier S. 78.

5 Vgl. dazu zusammenfassend u. a. Bünz, Die mittelalterliche Pfarrei, S. 188-198.

6 Dazu sehr anschaulich Peter Jezler, Jenseitsmodelle und Jenseitsvorsorge. Eine Einführung, in: ders. (Hrsg.), Himmel, Hölle, Fegefeuer. Das Jenseits im Mittelalter, 2. durchges. Aufl., München 1994, S. 13-26.

7 Vgl. dazu Peter Riedel u.a., Berlin Franziskaner, in: Heinz-Dieter Heimann u. a. (Hrsg.), Brandenburgisches Klosterbuch. Handbuch der Klöster, Stifte und Kommenden bis zur Mitte des 16. Jahrhunderts (Brandenburgische Historische Studien, Bd. 14), 2 Bde., 1. Aufl., Berlin 2007, Bd. 1, S. 146-159, hier S. 155, Abschnitt 9. 
rungen nach der Reformation, sondern dank ihrer rechtzeitigen Evakuierung auch den Zweiten Weltkrieg mit Zerstörung des gesamten Klosterareals. Heute sind sie in verschiedenen evangelischen Kirchen untergebracht.

Erleichtert wird die Untersuchung der Anbindung der Memoria an das Berliner Franziskanerkloster dadurch, dass es neben der zusammenfassenden Darstellung der Geschichte durch Peter Riedel im Klosterbuch mehrere kunstgeschichtliche Untersuchungen zu den bildlichen Darstellungen gibt, die durch Peter Knüvener, Andreas Cante und Maria Deiters in den letzten Jahren erfolgt sind. ${ }^{8}$ Dazu kommen Beschreibungen der Kirchenausstattung seit dem 18. Jahrhundert, die meist mit umfassenden Umbaumaßnahmen in der Kirche in Verbindung stehen. ${ }^{9}$ Auch diese können als Quellen dienen, wenn sie beispielsweise ältere, heute verlorene Inschriften oder Bildwerke beschreiben.

\section{Das Franziskanerkloster als Memorialort der Markgrafen}

Die Etablierung des Franziskanerordens in Berlin ging, so eine wohl um 1500 im Gestühl der Kirche angefertigte Inschrift, auf die beiden askanischen Markgrafen Otto IV. und dessen Cousin Albrecht III. zurück, die 1271 aus besonderer Verehrung dem Orden gegenüber (erga ordinem speciali devotione permoti) das Grundstück zum Bau eines Klosters zur Verfügung stellten. ${ }^{10}$

Im Norden angrenzend an das Grundstück lag der erstmals 1261 genannte Hof der Markgrafen, somit wurden die Franziskaner durch die Schenkung zu deren unmittelbaren Nachbarn. Dieser Hof blieb bis zur Fertigstellung des neu errichteten Schlosses an der Spree Mitte des 15. Jahrhunderts der Sitz aller folgenden Markgrafen in Berlin. ${ }^{11}$

8 Dazu (in chronologischer Reihung) u. a. Peter Knüvener, Die Skulptur des Retabels aus der Berliner Marienkirche im Märkischen Museum und die Kunst in Berlin im späten 15. Jahrhundert, in: Jahrbuch Stiftung Stadtmuseum Berlin 10 (2004/2005), S. 96-146; Riedel, Berlin Franziskaner; Andreas Cante, Die Klosterkirche als Berliner Gedächtnisort. Zur Bedeutung ihrer Grabdenkmäler, in: Landesdenkmalamt Berlin (Hrsg.), Kirchenruine des Grauen Klosters in Berlin. Geschichte - Forschung - Restaurierung (Beiträge zur Denkmalpflege in Berlin, Bd. 23), Petersberg 2007, S. 54-67; Maria Deiters, Die Ausstattung der Franziskanerklosterkirche in Berlin. Franziskanische Bildthemen in der Ausstattung der Berliner Klosterkirche, in: Dirk Schumann (Hrsg.), Brandenburgische Franziskanerklöster und norddeutsche Bettelordensbauten. Architektur - Kunst - Denkmalpflege, Berlin 2010, S. 142-165; Peter Knüvener, Die spätmittelalterliche Skulptur und Malerei in der Mark Brandenburg (Forschungen und Beiträge zur Denkmalpflege im Land Brandenburg, Bd. 14), Worms 2011.

9 Zu den Umbauarbeiten Petra Marx, Zur Geschichte der bauhistorischen Forschung und denkmalpflegerischen Bemühungen - ein fachgeschichtlicher Rückblick, in: Landesdenkmalamt Berlin, Kirchenruine des Grauen Klosters, S. 31-53, hier S. 52 f.

10 Codex diplomaticus Brandenburgensis. Sammlung der Urkunden, Chroniken und sonstigen Quellenschriften für die Geschichte der Mark Brandenburg und ihrer Regenten, Hauptt. III, Bd. 1, hrsg. von Adolph Friedrich Riedel, Berlin 1859 [im Folgenden CDB], S. 13, Nr. 11.

11 Winfried Schich, Das mittelalterliche Berlin (1237-1411), in: Wolfgang Ribbe (Hrsg.), Geschichte Berlins, Bd. 1: Von der Frühgeschichte bis zur Industrialisierung (Berlin-Forschungen der Historischen Kommission zu Berlin, Bd. 2/1), München 1987, S. 139-248, hier S. 172 f.; Knut Schulz, Vom Herrschaftsantritt der Hohenzollern bis zum Ausbruch des Dreißigjährigen Krieges (1411/12-1618), in: Ribbe, Geschichte Berlins, Bd. 1, S. 249-340, hier S. 274; Dirk Schumann, Hohes Haus, in: Franziska Nentwig (Hrsg.), Mittelalterliche Kunst aus Berlin und Brandenburg im Stadtmuseum Berlin, Berlin 2011, S. 323 f., Nr. 128. 
Die räumliche Nähe führte aber - zumindest im Spiegel der vorhandenen Quellen - nicht zu einer besonderen Bevorzugung des Klosters durch die Askanier bei ihrer Wahl von Grablegen oder weiteren Zustiftungen. Der Klosterstifter Otto IV. fand seine letzte Ruhestätte in der askanischen Familiengrablege in Chorin, während Albrecht III. erst in Lehnin, dann in Himmelpfort bestattet wurde. ${ }^{12}$ Die Nachricht von zumindest einer askanischen Grablegung findet sich aber für das Kloster: Die vierte Tochter Ottos V., Kunigunde, die wohl als einziges seiner Kinder unverheiratet geblieben und Nonne geworden war, starb 1317 in Berlin und wurde laut einer Chronik des 14. Jahrhunderts ehrenvoll bei den Minderbrüdern bestattet. ${ }^{13}$

Anders als die Askanier verfügten deren Nachfolger als Markgrafen, die bayerischen Wittelsbacher, im fernen Brandenburg über keine traditionellen Familiengrablegen, eine solche musste sich erst innerhalb der schon bestehenden Klosterlandschaft etablieren. Dafür bot sich das unmittelbar an den markgräflichen Hof grenzende Franziskanerkloster regelrecht an. Und tatsächlich wählte der erste wittelsbachische Markgraf Ludwig der Ältere für seine im Jahr 1340 verstorbene dänische Frau Margarethe diesen Ort als Grabstätte. ${ }^{14}$ Er selbst, der 1351 die Mark an seinen gleichnamigen Bruder übergeben hatte, ${ }^{15}$ starb 1361 bei München und wurde in der dortigen Frauenkirche bei seinem Vater bestattet. ${ }^{16}$ Sein Nachfolger in der Mark, Ludwig der Römer, ließ dagegen seine 1357 verstorbene polnische Frau Kunigunde wieder bei den Franziskanern bestatten, wo auch er 1365 seine letzte Ruhe fand. Zu diesen Jahren vermerkte der 1572 verstorbene Chronist Paul Creusing den Tod der beiden, die, laut eines Epitaphiums, dessen Inschrift er nach einem Gewährsmann zitiert, vor dem Altar (sub altari) nebeneinander begraben worden seien. ${ }^{17}$ Zacharias Gartz, 1586 verstorben, notierte kurze Zeit später, dass diese Inschrift auf einer an der linken Wand im Chor befindlichen Tafel (tabula) stehe. ${ }^{18}$ Andreas Angelus, der sich 1592 einige Monate in den Gebäuden des seit 1571 profanierten Klosters aufhielt, ${ }^{19}$ fand die Taffel dort jedoch nicht vor. ${ }^{20}$ Von den Gräbern vor dem Altar selbst überliefert die Chronistik keine wei-

12 Felix Escher, Otto IV., in: Neue Deutsche Biographie, Bd. 19, Berlin 1999, S. 677, online unter https://daten. digitale-sammlungen.de/0001/bsb00016337/images/index.html id=00016337\&groesser $=\&$ fip $=$ qrseneayaqrs xseayaensdasxdsydenxdsyd\&no=14\&seite=691 [abgerufen am: 26. April 2020]; Johannes Schultze, Die Mark Brandenburg, Bd. 1-3, 3. Aufl., Berlin 2004, hier Bd. 1, S. 196.

13 CDB IV 1, S. 15; vgl. auch Andreas Angelus, Annales Marchiae Brandenburgicae. Das ist ordentliche Verzeichniß und Beschreibung der fürnemsten und gedenckwirdigsten märckischen Jahrgeschichten und Historien [...], Frankfurt am Main 1598, S. 126.

14 Angelus, Annales Marchiae Brandenburgicae, S. 139, mit Berufung auf Marchia Autoris.

15 Schultze, Die Mark Brandenburg, Bd. 2, S. 115.

16 Hans Rall/Marga Rall, Die Wittelsbacher. Von Otto I. bis zu Elisabeth I., Wien 1994, S. 65.

17 Friedrich Holtze (Hrsg.), Creusings Märkische Fürsten-Chronik (Schriften des Vereins für die Geschichte Berlins, Bd. 23), Berlin 1886, S. 106; dazu Hermann Pieper, Die Grabstätte Ludwigs des Römers, in: Brandenburgia. Monatsblätter der Gesellschaft für Heimatkunde der Provinz Brandenburg zu Berlin 6/7 (1896/1897), S. 235240, hier S. 236.

18 Zacharias Gartz, Successiones Familiarum Lib. 1, in: Johann Gottlieb Krause, Scriptorum de rebus Marchiae Brandenburgensis maxime celebrium [...], Bd. 2, Frankfurt am Main 1729, S. 133 (mit separater Zählung im Band).

19 So Pieper, Die Grabstätte Ludwigs des Römers, S. 237.

20 Angelus, Annales Marchiae Brandenburgicae, S. 159. Allerdings berichtet Michael Herfurth in seiner handschriftlichen Chronik von 1728 zu den markgräflichen Gräbern nach Ausweisung einer alten Taffel, so zu Angeli Zeiten und noch bis diese Stunde vorhanden ist; zitiert nach Pieper, Die Grabstätte Ludwigs des Römers, S. 237, Anm. 5. Diese offenbar eher als Gedenktafel denn als Reste der Grabsteine anzusprechende Tafel war bis Ende des 19. Jahrhun- 
teren Einzelheiten. Im 19. Jahrhundert deckte jedoch Ferdinand von Quast vor dem Hauptaltar im Chor im Boden zwei gestörte, leere Grüfte auf ${ }^{21}$ und 2004 wurden hier erneut Gruftüberreste gesichert, deren Backsteinziegel ins 14. Jahrhundert weisen. ${ }^{22}$

Die vier Grablegungen, die der askanischen Markgrafentochter Kunigunde und die der drei Wittelsbacher, sind die einzigen überlieferten Grabstätten von Markgrafen in der Klosterkirche. Bis auf Kurfürst Joachim I. fanden alle nachfolgenden mittelalterlichen Markgrafen aus dem Hause Luxemburg und Hohenzollern ihre letzte Ruhe außerhalb der Mark. ${ }^{23}$

Markgraf Friedrich II. nutzte zumindest die Transsumierung einer Stiftungsurkunde im Jahr 1443 dazu, Gebete für sein eigenes Seelenheil und das seiner Nachkommen von den Mönchen zu erhalten: So stellte er die Urkunde aus, umb uns und unser nachkomen selen selickeit willen. ${ }^{24}$

\section{Das Franziskanerkloster als Memorialort des Adels}

Zur Übertragung des Grundstückes durch die Markgrafen im Jahr 1271 gesellte sich rund zwanzig Jahre später 1290 die Stiftung eines Ortes, den die Franziskaner zur Errichtung ihrer Gebäude dringend benötigten: einer Ziegelei, zwischen Tempelhof und Berlin gelegen, die ihnen der Ritter Jacob von Nybede überließ. ${ }^{25}$ Während die Stiftung der beiden Markgrafen lediglich durch die genannte Inschrift überliefert ist, findet sich die aus dem Lateinischen ins Mittelniederdeutsche übersetzte Stiftungsurkunde des Ritters in dem erwähnten Transsumpt Markgraf Friedrichs II. von 1443 wieder. ${ }^{26}$ Jakob hatte demnach seine Stiftung 1290 schriftlich niedergelegt, der zufolge er dem Kloster eine materielle Gabe (die Ziegelscheune) als Gegenleistung für eine immaterielle, und zwar für Gebete für sein Seelenheil und das seiner Frau, überlassen hatte. An diese herrschaftlich-private Partnerschaft, der das Kloster seine Gründung verdankt, erinnerte die um 1500 mit der Errichtung des Gestühls angebrachte lateinische Inschrift an der Nordseite im Chor $^{27}$ bis zu ihrer Zerstörung im Zweiten Weltkrieg.

derts dann endgültig verloren gegangen: Richard Borrmann, Die Bau- und Kunstdenkmäler von Berlin. Mit einer geschichtlichen Einleitung von Paul Clauswitz (Die Bauwerke und Kunstdenkmäler von Berlin, Bd. 8), Berlin 1893, S. 189.

21 Cante, Die Klosterkirche als Berliner Gedächtnisort, S. 55, Abb. 74.

22 Uwe Michas, Archäologische Untersuchungen an der Berliner Franziskaner-Klosterkirche, in: Landesdenkmalamt Berlin, Kirchenruine des Grauen Klosters, S. 88-98, hier S. 96; Riedel, Berlin Franziskaner, S. 152.

23 Zu Heilsbronn als Familiengrablege der Hohenzollern bis zu Albrecht Achilles u. a. Schultze, Die Mark Brandenburg, Bd. 3, S. 159; Michael Diefenbacher, Heilsbronn. Die Grablege der Hohenzollern, in: Georg Seiderer u. a. (Hrsg.), Vielfalt fränkischer Geschichte. Gedenkschrift für Gerhard Rechter, 1951-2012 (Jahrbuch des Historischen Vereins für Mittelfranken, Bd. 104), Ansbach 2016, S. 329-370, hier S. 344-348. Joachim I. war der erste Kurfürst, der wieder in der Mark bestattet wurde, zuerst in Lehnin, dann in den Berliner Dom überführt; Schultze, Die Mark Brandenburg, Bd. 3, S. 226.

24 Codex Diplomaticus Brandenburgensis Continuatus. Sammlung ungedruckter Urkunden zur Brandenburgischen Geschichte, hrsg. von Georg Wilhelm von Raumer, Bd. 1, Berlin u. a. 1831 [im Folgenden: Raumer, Codex 1], S. 4, Nr. 3.

25 CDB III 1, S. 13, Nr. 11.

26 Raumer, Codex 1, S. 4, Nr. 3.

27 CDB III 1, S. 13, Nr. 11; Angelus, Annales Marchiae Brandenburgicae, S. 108. Zur Inschrift u. a. Martin Diterich, Berlinsche Closter- und Schul-Historie. Welche die Stifftung und Merckwürdigkeiten des Franciscaner-Closters in Berlin [...] in sich fasset [...], Berlin 1732, S. 8-13 (mit der gesamten Wiedergabe der Inschriften im Chorge- 
Die Zustiftung Jacobs von Nybede kann als die erste adelige Initiative zugunsten des Franziskanerklosters gelten. Danach sind erst wieder für das 15. Jahrhundert adelige Initiativen, aus dem Umkreis des hohenzollerischen Hofes, überliefert. Im Sommer 1411 hatte König Sigismund den Burggrafen Friedrich VI. von Nürnberg zum Verweser der Mark Brandenburg eingesetzt, was dort auf teilweise heftige Gegenwehr bei Adel und Städten stieß. ${ }^{28}$ Eine entscheidende Wende brachten Kampfhandlungen am Kremmener Damm. Trotz des burggräflichen Sieges am 24. Oktober 1412 starben dabei jedoch auch drei Friedrich eng verbundene fränkische Adelige: Graf Johann von Hohenlohe, Philipp von Uttenhofen und Kraft von Lentersheim, über deren Tod, so der Zeitzeuge Engelbert von Wusterwitz, Herr Friedrich mit seinem gantzen Hofe nicht wenig bekümmert und betrübt ist worden. ${ }^{29}$ Mitglieder dieses Hofes waren es sicherlich, die für die Memoria der drei Ritter bei den benachbarten Berliner Franziskanermönchen sorgten. Graf Johann, Enkel Kaiser Ludwigs des Bayern, ${ }^{30}$ stand Friedrich offenbar so nahe, dass er ihm auf dem Kremmener Damm zusätzlich ein hölzernes Kreuz errichten ließ, dass mehrfach erneuert und im Jahr 1845 von König Friedrich Wilhelm IV. durch ein heute noch vorhandenes Steinkreuz ersetzt wurde. ${ }^{31}$ Das Epitaph Johanns bei den Franziskanern, das mit Inschrift zum ersten Mal Andreas Angelus im 16. Jahrhundert genauer beschrieb, ${ }^{32}$ ist bis heute in der Dorfkirche von Berlin-Buckow erhalten und weist Namen, Todestag und die entscheidende Bitte nach der Gnade Gottes auf (Abbildung 1).33

Für das ewige Gedächtnis des am 28. Oktober 1412 verstorbenen Philipp von Uttenhofen sorgte ebenfalls eine Tafel bei den Franziskanern, die allerdings schon zu Beginn des 18. Jahrhunderts nicht mehr vorhanden war. ${ }^{34}$ Daher liefert die Beschreibung samt Wiedergabe der Inschrift bei Angelus die einzige Nachricht über sie. ${ }^{35}$ Grabsteine der beiden werden in der Chronistik nicht erwähnt.

stühl); Joachim Bellermann, Das graue Kloster in Berlin, mit seinen alten Denkmälern, T. 1, Berlin 1823, S. 17 f.; Franz Kugler, Die Klosterkirche zu Berlin, in: Allgemeines Archiv für die Geschichtskunde des preußischen Staates 4 (1831), S. 257-272, hier S. 259; Siegfried Mauermann, Die Geschichte des Grauen Klosters zu Berlin, Berlin 1909, S. 13; Cante, Die Klosterkirche als Berliner Gedächtnisort, S. 54.

28 Dazu ausführlich Schultze, Die Mark Brandenburg, Bd. 2, S. 225-235.

29 CDB IV 1, S. 51.

30 Rall/Rall, Die Wittelsbacher, S. 60.

31 Zu finden auf der linken Seite der Straße von Kremmen nach Sommerfeld, mit der Inschrift [am 23. April 2020 gelesen]: Im Jahre des Herrn 1412 d. 24. Oct. am St. Columbani Tage fiel hier der edle Herr Johannes Graf zu Hohenloh, Friedrich I. Markgraf v. Brandenburg des H. R. Reiches Erzkämmerer u. Kurfürst setzte zu seinem Andenken ein hölzernes Kreuz welches 1666 zuerst dann 1796 erneuert A. 1845 aus Stein neu errichtet wurde durch Friedrich Wilhelm IV. König von Preußen.

32 Angelus, Annales Marchiae Brandenburgicae, S. 190.

33 Zur Bildbeschreibung Wilhelm Hugo von Schmelzing, Grabdenkmäler von Landfremden in der Klosterkirche zu Berlin, in: Familiengeschichtliche Blätter/Deutscher Herold 68/10 (1937), Sp. 305-326, hier Sp. 305-307, Nr. 1; Cante, Die Klosterkirche als Berliner Gedächtnisort, S. 55 mit s/w Abb. 75; Maria Deiters, Bettelorden und Landesherr, in: Cranach und die Kunst der Renaissance unter den Hohenzollern - Kirche, Hof und Stadtkultur, Berlin 2009, S. 258-263, hier S. 258, Nr. VII.1 mit Farbabb.; dies., Die Ausstattung der Franziskanerklosterkirche, S. 143 f. mit s/w Abb. 1; dies., Gedächtnismale, Einzelgemälde und -skulpturen aus der Berliner Franziskanerklosterkirche. Bemerkungen zu Programm und Bedeutung im Gesamtbestand, in: Roland Pieper (Hrsg.), Geschichte der Sächsischen Franziskaner-Provinz von der Gründung bis zum Anfang des 21. Jahrhunderts, Bd. 5: Kunst: von den Anfängen bis zur Gegenwart, Paderborn u. a. 2012, S. 401-406, hier S. 401 f. mit s/w Abb. 507.

34 Diterich, Berlinsche Closter- und Schul-Historie, S. 19.

35 Angelus, Annales Marchiae Brandenburgicae, S. 190. 


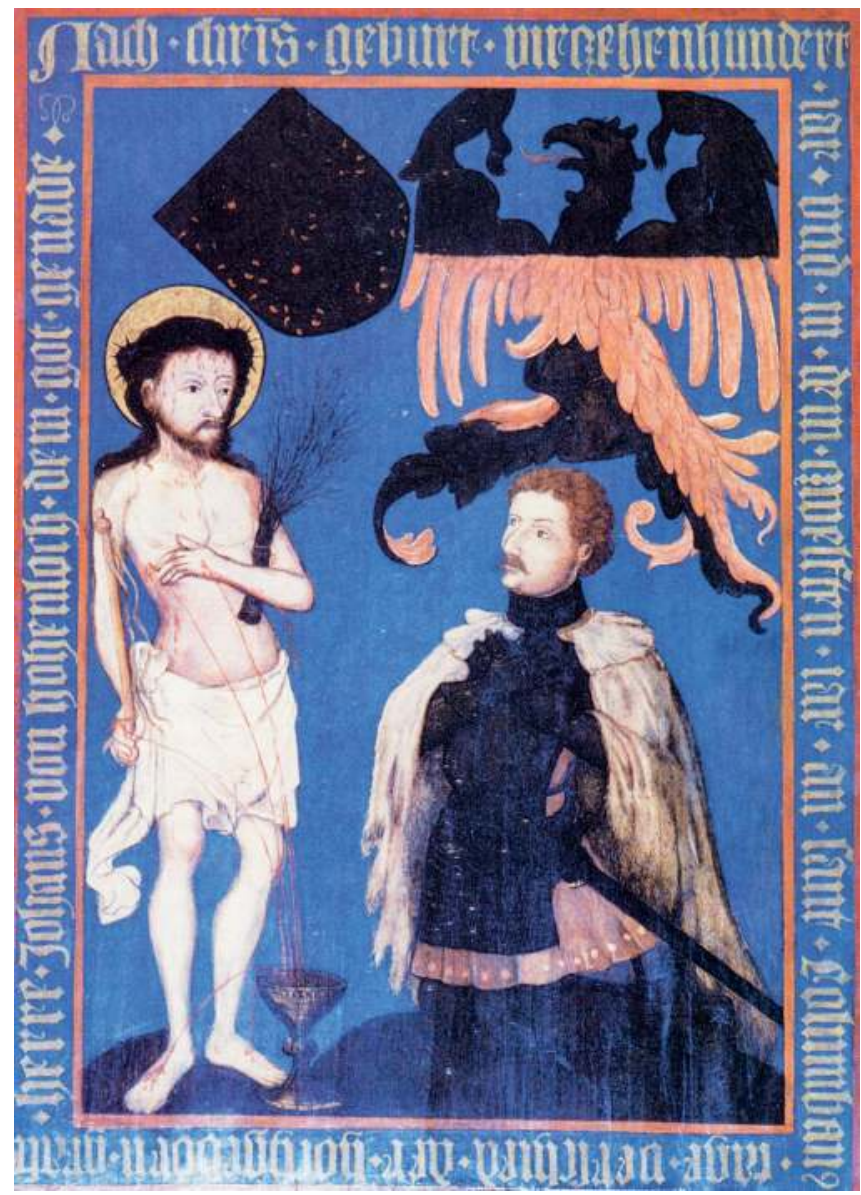

Abb. 1: Epitaph für Johann von Hohenlohe, 1412, Dorfkirche von Berlin-Buckow.

Anders sieht es dagegen bei dem dritten am Kremmener Damm Gefallenen Kraft von Lentersheim aus, der vor der Schlacht als Rat Burggraf Friedrichs gewirkt hatte. ${ }^{36}$ Angelus erwähnt ihn in seiner Chronik lediglich als in der Schlacht umbkommen. ${ }^{37}$ Die materielle Überlieferung bietet hier jedoch zusätzliche Informationen: Für Kraft ist zwar kein Epitaph überliefert, ein Grabstein war dagegen bis zur Zerstörung im Zweiten Weltkrieg in der Kirche vorhanden. In der Mitte zeigte er das Wappen der Familie, während umlaufend eine nicht überlieferte, verlorengegangene Umschrift eingelegt war. ${ }^{38}$ Kraft war also offenbar tatsächlich im Kloster begraben worden.

36 Schmelzing, Grabdenkmäler von Landfremden, Sp. 308, Nr. 2.

37 Angelus, Annales Marchiae Brandenburgicae, S. 190.

38 Zum Grabstein Borrmann, Die Bau- und Kunstdenkmäler, S. 198 f.; Julius Kurth, Die Altertümer der St. Nikolai-, St. Marien- und Klosterkirche zu Berlin [...], Berlin 1911, S. 142 f. mit s/w Abb.; Schmelzing, Grabdenkmäler von Landfremden, Sp. 308 f., Nr. 2 mit s/w Abb.; Cante, Die Klosterkirche als Berliner Gedächtnisort, S. 55 f. mit s/w Abb. 76. 
Ein weiterer, ebenfalls in hohenzollerischen Diensten stehender Adeliger, Georg von Stein (de Lapide), fand Ende des 15. Jahrhunderts ebenfalls bei den Franziskanern seine letzte Ruhe. Von Stein stammte aus dem süddeutschen Raum, von der schwäbischen Burg Rechtenstein an der Donau, ${ }^{39}$ stand im Dienste verschiedener hochrangiger Herren und fungierte als Rat für Kurfürst Johann Cicero. ${ }^{40} 1493$ erwarb er in Berlin von Bürgermeister Thomas Blankenfelde ein Haus mit Garten bey der barfusser kirchhofe $e^{41}$ und wählte (vielleicht wegen der räumlichen Nähe) das Kloster als seinen Begräbnisort. Zur Memoria erhielt er dort nach seinem Tod am 3. Dezember 1497 ein heute im evangelischen Konsistorium in Berlin erhaltenes Wappenepitaph mit seinen Todesdaten und der Bitte, seine Seele möge in Frieden ruhen (Abbildung 2). ${ }^{42}$

Auch sein Zeitgenosse, der aus dem Harz stammende Ratgeber und Freund Kurfürst Albrecht Achilles', Graf Johann von Hohnstein, der am 30. November 1498 verstarb, erhielt ebenso wie seine vor ihm, am 8. April 1492 verstorbene Frau, Anna von Anhalt, ein Epitaph im Kloster. ${ }^{43}$ Wer die Tafeln oder Grab-Schrifften ${ }^{44}$ stiftete, auf denen jeweils die Bitte, Gott möge der Seelen der Verstorbenen gnädig sein, vermerkt war, bleibt unklar. Im Gedächtnis der Familie waren sie aber noch rund hundert Jahre später, als der Enkel des Paares, Graf Martin von Hohnstein, Letzter seines Geschlechts, ${ }^{45}$ beide Tafeln im Jahr 1583 renovierte, laut einer nicht mehr erhaltenen, aber 1732 beschriebenen Beischrift. ${ }^{46}$ Im Laufe der folgenden zwei Jahrhunderte verschwanden sowohl die Tafel von Anna als auch die Beischrift ihres Enkels, nur das Epitaph des Grafen selbst ist bis heute im evangelischen Konsistorium in Berlin vorhanden (Abbildung 3). ${ }^{47}$

Lediglich aus der Chronistik des 16. Jahrhunderts ist ein Gedächtnisbild überliefert, von einem Friedrich [von] Stein (Steinio), vielleicht ein Verwandter Georgs. ${ }^{48}$ Kurfürst Joachim II. hatte ihn gegen Kost und Logis um 1537 an seinen Hof gezogen, wo Friedrich aber kurz darauf starb, im

39 Schmelzing, Grabdenkmäler von Landfremden, Sp. 309, Nr. 2.

40 Ausführlich Schmelzing, Grabdenkmäler von Landfremden, Sp. 309-312, Nr. 3; Cante, Die Klosterkirche als Berliner Gedächtnisort, S. $55 \mathrm{f}$.

41 Historisch-diplomatische Beiträge zur Geschichte der Stadt Berlin, T. 4: Berlinische Urkunden von 1232 bis 1700, hrsg. von Ernst Fidicin, Berlin 1842, S. 221 f., Nr. 203; dazu Schmelzing, Grabdenkmäler von Landfremden, Sp. 312, Nr. 3.

42 Zur Bildbeschreibung Diterich, Berlinsche Closter- und Schul-Historie, S. 17; Schmelzing, Grabdenkmäler von Landfremden, Sp. 309-314, Nr. 3 mit s/w Abb.; Borrmann, Die Bau- und Kunstdenkmäler, S. 198; Kurth, Die Altertümer, S. 126 f.; Wilhelm Schubring, Die Klosterkirche zu Berlin, Berlin 1936, S. 10, Nr. 32; Cante, Die Klosterkirche als Berliner Gedächtnisort, S. 55 f.; Deiters, Die Ausstattung der Franziskanerklosterkirche, S. 144; Deiters, Gedächtnismale, Einzelgemälde und -skulpturen, S. 404.

43 Diterich, Berlinsche Closter- und Schul-Historie, S. 15 (dort auch zur Person und Bildbeschreibung); Schmelzing, Grabdenkmäler von Landfremden, Sp. 314-316, Nr. 4; Cante, Die Klosterkirche als Berliner Gedächtnisort, S. 55 f. mit s/w Abb. 77; Deiters, Die Ausstattung der Franziskanerklosterkirche, S. 144.

44 So Diterich, Berlinsche Closter- und Schul-Historie, S. 15.

45 Detlev Schwennicke, Europäische Stammtafeln, N. F. 17: Hessen und das Stammesherzogtum Sachsen, Marburg 1998, Tafel 92.

46 Zitiert bei Diterich, Berlinsche Closter- und Schul-Historie, S. $15 \mathrm{f}$.

471893 befand sich die heute oberhalb des Wappens angebrachte Inschrift offenbar unterhalb davon: Borrmann, Die Bau- und Kunstdenkmäler, S. 198.

48 Zur Person Schmelzing, Grabdenkmäler von Landfremden, Sp. 313, Nr. 3. 
Franziskanerkloster begraben und dort mit einer als Epitaphium bezeichneten Tafel, die offenbar schon Anfang des 18. Jahrhunderts nicht mehr vorhanden war, geehrt wurde. ${ }^{49}$

Über das Begräbnis eines Herzog Ernsts von Sachsen zum Jahr 1300, angeblich ein Zeitgenosse Bischof Johannes' von Brandenburg, berichtet ebenfalls nur die spätere Chronistik und in ihrer Folge die Literatur. ${ }^{50}$ Ein Bischof Johannes ist für Brandenburg erst 1415-1420 überliefert, während es einen Ernst von Sachsen zu beiden Zeiten nicht gab. ${ }^{51}$ Hier muss also offenbleiben, wer gemeint gewesen sein könnte.

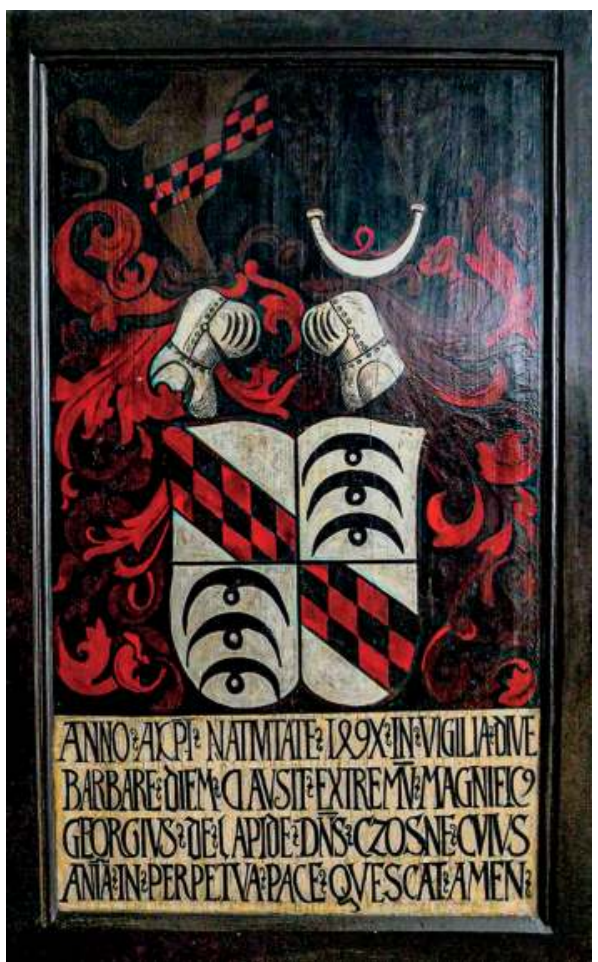

Abb. 2: Epitaph für Georg von Stein, 1497, Konsistorium der Evangelischen Landeskirche.

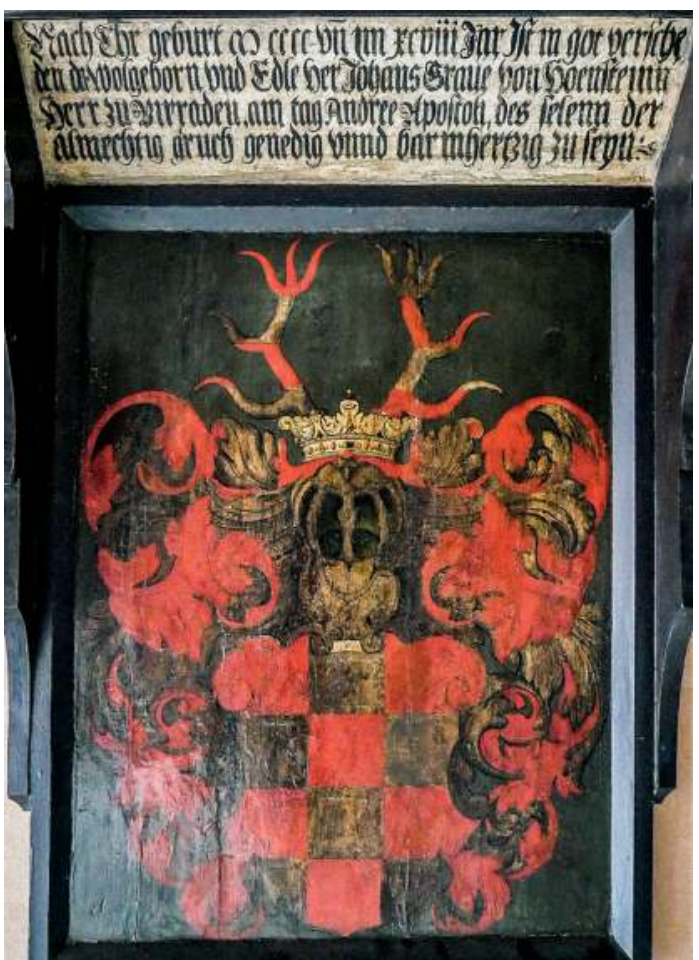

Abb. 3: Epitaph für Johann von Hohnstein, 1498, Konsistorium der Evangelischen Landeskirche.

49 Nikolaus Leuthinger, De Marchia Brandenburgensi, ejusque statu, Joachimo I. et Joachimo II. princip. electoribus Brandenburg. Commentariorum, in: Johann Gottlieb Krause, Scriptorum de rebus Marchiae Brandenburgensis maxime celebrium [...], Bd. 1, Frankfurt am Main/Leipzig 1729, S. 155 (mit separater Zählung im Band); dazu Diterich, Berlinsche Closter- und Schul-Historie, S. 17 f., der ebenso wie Georg Gottfried Küster, Altes und Neues Berlin. Das ist: Vollständige Nachricht von der Stadt Berlin [...], Bd. 2, Berlin 1752, S. 604 nur die Stelle bei Leuthinger zitiert.

50 Angelus, Annales Marchiae Brandenburgicae, S. 120; Diterich, Berlinsche Closter- und Schul-Historie, S. 15; Mauermann, Die Geschichte des Grauen Klosters, S. 16.

51 Kurfürst Ernst von Sachsen wurde 1486 im Dom in Meißen bestattet. 


\section{Das Franziskanerkloster als Memorialort von Bürgerinnen und Bürgern}

Nur wenige Grabsteine aus der Franziskanerkirche haben sich erhalten, sicherlich auch, weil viele von ihnen sekundären Nutzungen zugeführt wurden. Von Berliner Bürgerinnen und Bürgern, die ihre Memoria in die Hände der grauen Mönche legten, existieren immerhin zwei Grabsteine bis heute, die zu den ältesten erhaltenen in Berlin gehören. Fragmente eines Grabsteins mit Ritzzeichnungen und ehemals umlaufender Schrift eines unbekannten bürgerlichen Ehepaares, die 1982 in den Treppenstufen des Chorraumes geborgen wurden, ${ }^{52}$ stammen wohl aus dem Ende des 13. Jahrhunderts. Allerdings sind auf den heute im Märkischen Museum aufbewahrten Fragmenten nur wenige Details, darunter wohl der Todestag des Mannes (31. März oder Juli), erkennbar. ${ }^{53}$

Ein weiterer komplett erhaltener Ritzgrabstein des Berliner Bürgers Konrad von Beelitz hat sich dagegen bis heute im Märkischen Museum erhalten. ${ }^{54}$ Auch Konrad fand nach seinem Tod am 17. April 1308 offenbar im Franziskanerkloster seine letzte Ruhe, mit dem in Stein gemeißelten Wunsch, seine Seele möge in Frieden ruhen. ${ }^{55}$

Von den zu anderen Pfarr- oder Bettelordenskirchen so zahlreich überlieferten Stiftungen, aus deren Kapital Renteneinkünfte für bestimmte Zwecke und/oder Gegenstände bestimmt wurden, findet sich für das Franziskanerkloster nur ein schwacher Reflex: Eine unbekannte Person hatte vor 1400 die Verwaltung des Stiftungskapitals und die Auszahlung der Einkünfte an den Berliner Rat übertragen. Der Rat vermerkte nun unter seinen Ausgaben für ewige renten, dass er den Barfüßern eine bestimmte Summe für ein ewiges Licht auszuzahlen hatte. ${ }^{56}$ Ein Licht, durch das der unbekannte Stifter hoffte, weiterhin für die Gebete der Mönche und Gläubigen präsent zu bleiben.

Abgesehen von Grablegen oder zweckgebundenen Stiftungen eröffnete sich vor allem mit der Stiftung eines im Spätmittelalter so populären Epitaphs für die Bürgerschaft die Möglichkeit, in das Kircheninnere vorzudringen. Von diesen religiösen Bildwerken, in die sich meist zu Füßen des biblischen Geschehens die Stiftenden als betende Gläubige samt ihren Namen und Sterbedaten einschrieben, ${ }^{57}$ sind nur wenige über die Reformation hinaus in den Quellen oder den Kirchen selbst bis heute präsent geblieben..$^{58}$

52 Heinz Seyer, Ein neuer mittelalterlicher Grabstein aus der Berliner Franziskaner-Klosterkirche, in: Archäologie in Deutschland 9/2 (1993), S. 43 f., hier S. 44; Deiters, Gedächtnismale, Einzelgemälde und -skulpturen, S. 402, Anm. 99.

53 Dazu umfassend Karl Heinz Priese, Grabplatte eines ,bürgerlichen' Ehepaares aus der Berliner Franziskanerklosterkirche, in: Nentwig, Mittelalterliche Kunst aus Berlin, S. 134 f., Nr. 18 mit s/w Abb.

54 Zum Grabstein Hans Martin, Die Wiederherstellung der Klosterkirche. Mit 10 Aufnahmen, in: Mitteilungen des Vereins für die Geschichte Berlins 44 (1927), S. 17-23, hier S. 22; Cante, Die Klosterkirche als Berliner Gedächtnisort, S. 54 mit s/w Abb.; Deiters, Die Ausstattung der Franziskanerklosterkirche, S. 147; umfassend und mit s/w Abb. Karl Heinz Priese, Grabplatte des Konrad von Beelitz aus der Berliner Franziskanerkirche, in: Nentwig, Mittelalterliche Kunst aus Berlin, S. 131-134, Nr. 17; Deiters, Gedächtnismale, Einzelgemälde und -skulpturen, S. $401 \mathrm{f}$.

55 Borrmann, Die Bau- und Kunstdenkmäler, S. 198; Kurth, Die Altertümer, S. 138f. mit s/w Abb.

56 Paul Clauswitz, Berlinisches Stadtbuch. Neue Ausgabe [...], Berlin 1883, S. 233, Nr. 11.

57 Paul Schoenen, Epitaph, in: Reallexikon zur Deutschen Kunstgeschichte, Bd. 5, Stuttgart 1967, Sp. 872-921, online unter http://www.rdklabor.de/w/ ?oldid=93211 [abgerufen am: 26. April 2020].

58 Bünz, Die mittelalterliche Pfarrei, S. 235. 
Erfolgreich war darin die Bürgermeisterfamilie Blankenfelde mit ihren vier aus dem Kloster überlieferten Bildern. ${ }^{59}$ Diese Epitaphien aus dem 15. Jahrhundert sind wohl vor allem deshalb teilweise bis heute überliefert, weil Mitglieder der Familie die enge Verbindung zur Klosterkirche auch nach der Reformation bis ins 17. Jahrhundert fortsetzten. ${ }^{60}$ Eindrücklich beschreibt diese enge Verbindung die Inschrift eines heute nicht mehr vorhandenen großen Steins, die erstmals 1732 überliefert wird ${ }^{61}$ In ihr hielt 1673 ein in der weiblichen Linie mit den Blankenfeldes verwandter Johann Tieffenbach zu Ehren seiner verstorbenen Frau die Familiengeschichte der Blankenfeldes fest, die er 1453 mit dem Bürgermeister Wilke als Ahnherr beginnen lässt. ${ }^{62}$ Wilkes Wappen in Bronze, das in der Umschrift seine Sterbedaten (13. November 1474) wiedergab, war im Zentrum des Steins platziert. ${ }^{63}$ Ziel des Steines war es, $[. .$.$] bey der Ober-Eltern und Vorfahren$ Grabschriften seiner seligen Liebsten werthes Andencken zu erneuern. ${ }^{64}$

Bei den drei erhaltenen und in der Marienkirche hängenden mittelalterlichen Epitaphien der Familie Blankenfelde, die zu den wichtigsten Vertretern dieser Gattung in Berlin gezählt werden, steht die Kreuzigung Christi beziehungsweise die Beweinung Christi im Zentrum, der die jeweiligen Stifterpaare zu Füßen der Szenen kniend beiwohnen. ${ }^{65}$ Das älteste überlieferte Tafelbild der Familie entstand wohl um 1440 und erinnert an ein männliches Familienmitglied, das mit einer Frau der Bürgermeisterfamilie Strohband verheiratet war, wie die unterhalb der Knie des Stifterpaares angebrachten Wappen belegen. Unter Christus am Kreuz, das flankiert wird von Maria und Johannes, kniet das betende Paar, auf der linken Seite unter Maria der Mann mit fünf Söhnen, seine Frau mit fünf Töchtern auf der rechten Seite (Abbildung 4). ${ }^{66} \mathrm{Da}$ ein Blankenfelde, der Bürgermeister Paul, wohl um 1336 verstarb und dessen Sohn Wilke im gleichen Jahr zum Bürgermeister gewählt wurde, erscheint es naheliegend, Paul als den Stifter des Bildes anzusehen, zusammen mit seiner namentlich unbekannten Ehefrau Strohband. ${ }^{67} \mathrm{Ihr}$ Sohn Wilke war es dann, dessen im erwähnten nachreformatorischen Stein gedacht wurde.

59 Zum Haus der Familie ausführlich Eberhard Kirsch/Peter Knüvener/Dirk Schumann, Berlin, Haus Spandauer Straße 49, im Mittelalter Mittelstraße, Haus Blankenfelde, in: Nentwig, Mittelalterliche Kunst aus Berlin, S. 333335, Nr. 134.

60 Deiters, Die Ausstattung der Franziskanerklosterkirche, S. 149.

61 Zitiert bei Diterich, Berlinsche Closter- und Schul-Historie, S. 19-21.

62 Carl Brecht, Die Familie von Blankenfelde (Tafel 1), in: Verein für die Geschichte Berlins (Hrsg.), Vermischte Schriften im Anschlusse an die Berlinische Chronik und an das Urkundenbuch, Bd. 1, Berlin 1888 [ohne Seitenzählung], [S. 2] (mit s/w Abb. der Tafel); Borrmann, Die Bau- und Kunstdenkmäler, S. 199; Kurth, Die Altertümer, S. 135 f. mit Wiedergabe der Inschrift und daraus erschlossenem Stammbaum; Schubring, Die Klosterkirche zu Berlin, S. 9, Nr. 23.

63 Nach Borrmann, Die Bau- und Kunstdenkmäler, S. 199.

64 Diterich, Berlinsche Closter- und Schul-Historie, S. 21.

65 Cante, Die Klosterkirche als Berliner Gedächtnisort, S. 57.

66 Zur Bildbeschreibung Andrea Theissen, Das Leben in den Städten, in: Geraldine Saherwala/Andrea Theissen (Hrsg.), Berlin im Mittelalter. Bürger, Bauer, Edelmann, Berlin 1987, S. 94-114, hier S. 103 mit Farbabb. 43; Cante, Die Klosterkirche als Berliner Gedächtnisort, S. 57; Deiters, Die Ausstattung der Franziskanerklosterkirche, S. 147; Deiters, Gedächtnismale, Einzelgemälde und -skulpturen, S. 403; Knüvener, Die spätmittelalterliche Skulptur und Malerei, S. 174 mit Farbabb. 456.

67 Zu Paul Blankenfelde: Brecht, Die Familie von Blankenfelde [S. 2 f.] (mit der Angabe „Der Name der Gattin Paul Blankenfelds ist unbekannt"); Theissen, Das Leben in den Städten, S. 102 (ohne Sterbedaten Pauls); Knüvener, Die spätmittelalterliche Skulptur und Malerei, S. 174 mit Anm. 1006 gibt das Jahr 1436 als Sterbejahr an; Deiters, 


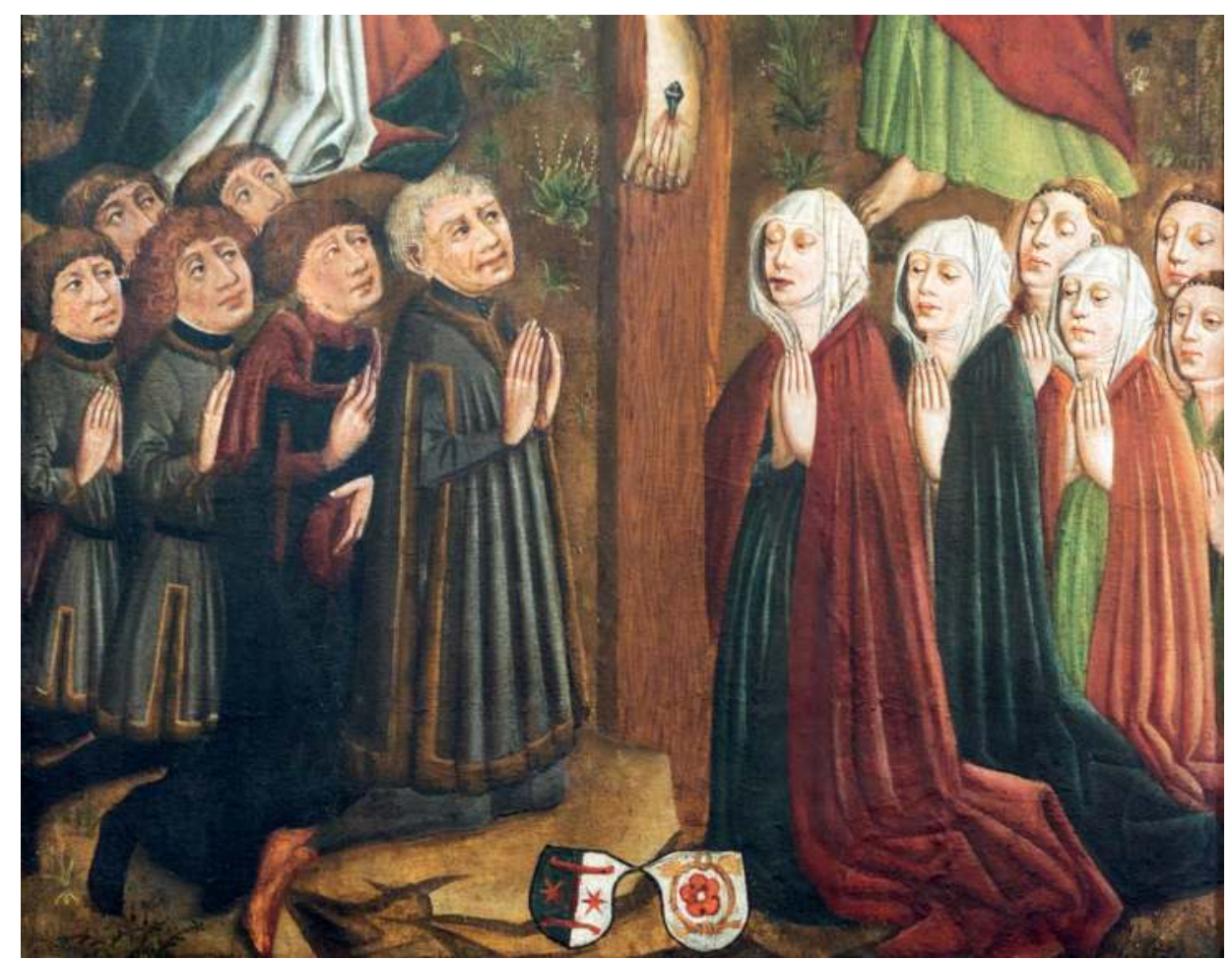

Abb. 4: Epitaph für Paul Blankenfelde und seine Frau aus der Familie Strohband, um 1436, Marienkirche Berlin (Ausschnitt).

Die Kriegszerstörungen ebenfalls überlebt hat ein weiteres Epitaph der Familie Blankenfelde. ${ }^{68}$ Auch hier kniet zu Füßen der Kreuzigungsszene ein Stifterpaar: links der Mann aus der Familie Blankenfelde, am Wappen zu seinen Füßen identifizierbar, mit zehn betenden Söhnen hinter sich, rechts die Frau, deren Wappen sie als ein Mitglied der aus Frankfurt/Oder stammenden Familie Buchholtz ausweist, ${ }^{69}$ mit zwölf Töchtern (Abbildung 5).

Die Ausstattung der Franziskanerklosterkirche, S. 147 „um 1445“. Für die gelegentlich in der neueren Literatur zu findende Vermutung, der Vorname der Frau sei Anna gewesen, gibt es keine Belege.

68 Zum Bild Schubring, Die Klosterkirche zu Berlin, S. 8, Nr. 10; Cante, Die Klosterkirche als Berliner Gedächtnisort, S. 56 f. mit s/w Abb. 78 und S. 61, Abb. 86 (Aufhängung); Deiters, Bettelorden und Landesherr, S. 259, Nr. VII.2 mit Farbabb.; Deiters, Die Ausstattung der Franziskanerklosterkirche, S. 146 f. mit s/w Abb. 3; Deiters, Gedächtnismale, Einzelgemälde und -skulpturen, S. 402 f. mit s/w Abb. 508; Knüvener, Die spätmittelalterliche Skulptur und Malerei, S. 186.

69 Die Zuordnung des Wappens zur Familie Buch (so bei Brecht, Die Familie von Blankenfelde, [S. 3]) ist nicht richtig. Das Wappen lässt sich eindeutig der Frankfurter Familie zuordnen; Peter Knüvener, ,Kreuzigung Christi‘, Epitaph für die Familie Christian Buchholtz und Benigna Kemnitz, in: Maria Deiters/Gotthard Kemmether (Hrsg.), Bürger, Pfarrer, Professoren. St. Marien in Frankfurt (Oder) und die Reformation in Brandenburg, Dresden 2017, S. 345. [Im Titel wurde der im eingereichten Text stehende Familienname ,Buchholtz in der Redaktion zu ,Buchholtzer` verfälscht. Für diesen Hinweis danke ich Dr. Peter Knüvener.] 


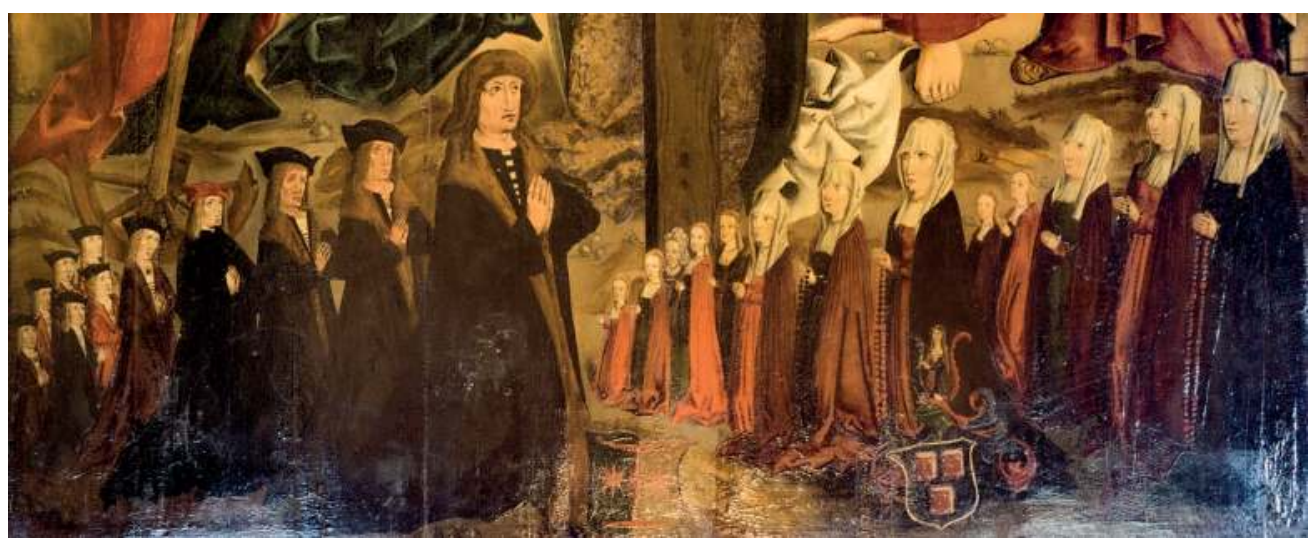

Abb. 5: Epitaph für Thomas Blankenfelde und seine Frau aus der Familie Buchholtz, um 1504, Marienkirche Berlin (Ausschnitt).

Wer war aber nun dieses Stifterpaar? Darauf gaben im Gegensatz zu dem älteren BlankenfeldeEpitaph, das ohne Inschriften überliefert ist, bei diesem Bild unterwerts stehende Worte genauer Auskunft, die 1732 zum ersten Mal dokumentiert wurden, heute aber verloren sind. Wie es sich für ein klassisches Epitaph gehört, sind hier neben der Bitte, Gott möge dem Toten ewige Glückseligkeit schenken, alle wichtigen Informationen - allerdings nur zu dem Mann - zusammengefasst: Der Stifter wird als der Fernhändler Thomas Blankenfelde benannt, der am 22. Februar 1504 im Alter von 68 Jahren verstorben war und 15 Kinder sowie viele Enkel hinterließ. ${ }^{70}$ Von den 24 im Stifterbild dargestellten Kindern des Paares hatten neun also offenbar nicht überlebt. Bei der Ehefrau von Thomas handelte es sich wohl um Margarete Buchholtz/Blankenfelde, die auch nach dem Tod ihres Mannes noch lange geschäftlich aktiv blieb und vermutlich erst nach 1351 verstarb. ${ }^{71}$ Weitere Zusatzinformationen erhält man aus dem 19. Jahrhundert: Laut der Beschreibung des Bildes 1823 war es „ein Weihegeschenk von der von Blankenfeldischen Familie, vom Jahr 1554"72 ohne dass dabei klar wird, woher diese Informationen stammen. Möglicherweise schon zu diesem Zeitpunkt, spätestens aber 1888 scheint die oben genannte Inschrift verloren gewesen zu sein. ${ }^{73}$

Ein drittes, weibliches Mitglied der Familie hatte ebenfalls wohl zeitnah zu ihrem Tod eine eigene alte Tafel erhalten, die 1732 noch nahe bei dem Gedenkstein der Familie von 1673 hing und deren Überschrift Namen und Sterbedaten der Frau wiedergab. ${ }^{74}$ Sie war der am 18. Dezember 1503 verstorbenen Barbara, Ehefrau eines weiteren Wilke Blankenfeldes und Tochter Peter Otts aus

70 Diterich, Berlinsche Closter- und Schul-Historie, S. 21. Zur Person, es handelte sich um einen Urenkel von Paul und Enkel von Wilke Blankenfelde: Brecht, Die Familie von Blankenfelde [S. 3 und Stammbaum nach Tafel 3]; Johannes Papritz/Hugo Rachel/Paul Wallich, Berliner Großkaufleute und Kapitalisten, Bd. 1: Bis zum Ende des dreißigjährigen Krieges, Berlin 1936, S. 25-28; Knüvener, Die spätmittelalterliche Skulptur und Malerei, S. 186.

71 Zu Margarete Blankenfelde: Papritz/Rachel/Wallich, Berliner Großkaufleute, Bd. 1, S. 28 f. und Stammtafel im Anhang.

72 Bellermann, Das graue Kloster in Berlin, T. 1, S. 38, Nr. 11.

73 Brecht, Die Familie von Blankenfelde, [S. 3].

74 Diterich, Berlinsche Closter- und Schul-Historie, S. 21. 
Herzberg, gewidmet, ${ }^{75}$ womit sie sich als Schwiegertochter Thomas Blankenfeldes identifizieren lässt. ${ }^{76} \mathrm{Ob}$ zu diesem Zeitpunkt noch ein zugehöriges Bild vorhanden war, lässt sich nicht mehr feststellen; 1893 wird lediglich „eine hölzerne Inschriftentafel, ohne Wappen oder sonstigen Schmuck" beschrieben. ${ }^{77}$

Bei einem vierten noch erhaltenen und ebenfalls als Epitaph zu bezeichnendem Bild der Familie steht die Kreuzabnahme im Mittelpunkt. Maria, zu Füßen des Kreuzes mit ihrem verstorbenen Sohn, wird links von Johannes, rechts von Maria Magdalena flankiert, die durch ihre Namen im Heiligenschein identifiziert werden. Zu Füßen Johannes' kniet ein einzelner Stifter, zu Füßen Maria Magdalenas die Stifterin, deren Wappen sie als Mitglied der Familie Blankenfelde ausweist, während das Wappen des Ehemannes fehlt (Abbildung 6). ${ }^{78}$ Kinder hatte das Paar offenbar keine. Zeitlich passend könnte hier eine der vielen Töchter des Paares Buchholtz/Blankenfelde in Betracht kommen, die auf deren Epitaph festgehalten wurden. Im hölzernen Rahmen des Bildes, das auf Ende des 15. Jahrhunderts datiert wird, ${ }^{79}$ steht auf der Seite des Mannes der Heilige Franziskus (mit Stigmata), hinter der Frau die Heilige Elisabeth (mit Krug und Schale), während ein Schriftband im oberen Bereich die Betrachtenden ermahnt, der Stifter zu gedenken. ${ }^{80}$ Damit ist dieses Epitaph dasjenige der Familie, das sich sowohl durch die Themenwahl als auch durch die beiden Heiligen Franziskus und Elisabeth explizit in den Kontext der franziskanischen Frömmigkeitspraxis einordnen lässt. ${ }^{81}$

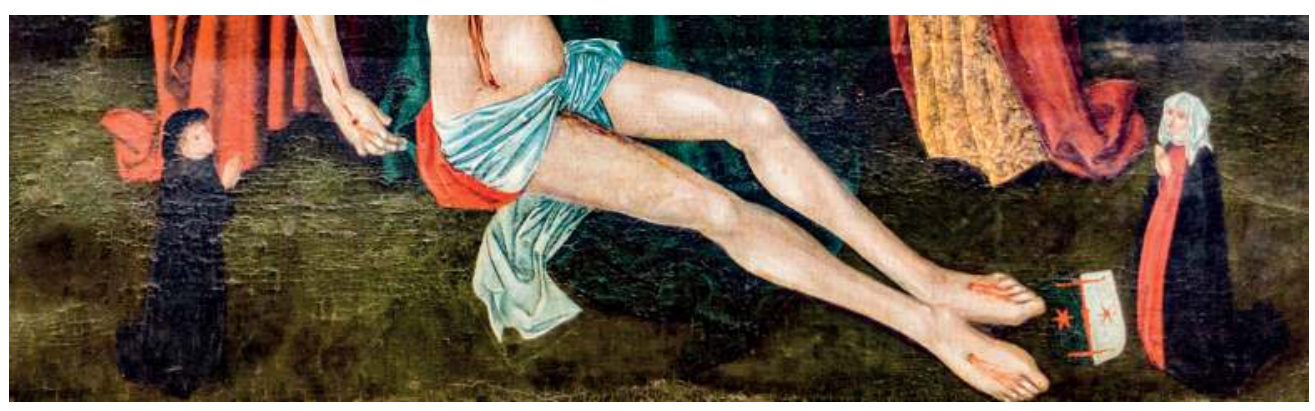

Abb. 6: Epitaph für eine Frau aus der Familie Blankenfelde und ihren unbekannten Mann, um 1500, Marienkirche Berlin (Ausschnitt).

75

76 Brecht, Die Familie von Blankenfelde [S. 4], mit dem Zitat der Inschrift offenbar aus Diterich, Berlinsche Closterund Schul-Historie, S. 21.

77 Borrmann, Die Bau- und Kunstdenkmäler, S. 198; Brecht, Die Familie von Blankenfelde [S. 4] scheint diese Tafe ein paar Jahre zuvor übersehen zu haben: ,und besagt über Letztere [Barbara Ott] eine früher in der Klosterkirche vorhanden gewesene Tafel [...]“ [mit Zitat der Inschrift].

78 Cante, Die Klosterkirche als Berliner Gedächtnisort, S. 57 mit Anm. 20; Deiters, Die Ausstattung der Franziskanerklosterkirche, S. 147 f. mit Farbabb. (Farbtafel 6); Knüvener, Die spätmittelalterliche Skulptur und Malerei, S. 185 f. mit Farbabb. 494.

79 Cante, Die Klosterkirche als Berliner Gedächtnisort, S. 57 („Ende 15. Jahrhundert oder 1516“); Deiters, Die Ausstattung der Franziskanerklosterkirche, S. 147 („um 1490“).

80 Zitiert bei Kugler, Die Klosterkirche zu Berlin, S. 267 f.; Borrmann, Die Bau- und Kunstdenkmäler, S. 197; Kurth, Die Altertümer, S. 134; Schubring, Die Klosterkirche zu Berlin, S. 9, Nr. 25.

81 Ausführlich dazu Deiters, Die Ausstattung der Franziskanerklosterkirche, S. 148. 


\section{Das Franziskanerkloster als Memorialort der Geistlichkeit}

Die Franziskanermönche waren sowohl für Markgrafen, Adelige als auch für Bürgerinnen und Bürger Ankerpunkt für die für unabdingbar erachteten Gebete für das eigene Seelenheil, die sie durch Stiftungen für die Ewigkeit zu erhalten hofften. Aber nicht nur weltliche Personen banden ihre Grablege und/oder Seelenheilstiftungen an das Kloster. Selbstverständlich hatten auch Geistliche und darunter die Mönche selbst das Bedürfnis, über die kollektiven Gebete ihrer Mitbrüder hinaus als Individuen für die Gebete ihrer Mitmenschen präsent zu bleiben.

Bis heute hat sich ein bischöflicher Grabstein in der Klosterkirche erhalten, der seit dem 19. Jahrhundert Liborius von Schlieben, Bischof von Lebus (gestorben 1486), zugesprochen wird. ${ }^{82} \mathrm{Al}-$ lerdings verzeichnet Angelus Ende des 16. Jahrhunderts zwar den Tod des Bischofs zu diesem Jahr in Berlin, begraben wurde er laut Chronik aber im Dom zu Fürstenberg, wo sein Grab jedoch ganz vergangen sei. ${ }^{83}$ Vielleicht täuschte sich der Autor rund hundert Jahre später ebenso wie die Chronistik, der er folgte, und Liborius' Leichnam blieb in Berlin. Für welchen Bischof die Grabplatte tatsächlich geschaffen wurde, muss wohl offenbleiben. ${ }^{84}$

Wohl ebenfalls eher aus Zufall fand ein weiterer hochrangiger Geistlicher im Kloster seine letzte Ruhe, der am 20. Juni 1521 verstorbene Nikolaus von Bach, Großkomtur des Deutschen Ordens in Preußen. ${ }^{85}$ Er war kurz zuvor bei den Franziskanern abgestiegen, um in Berlin mit Kurfürst Joachim I. wegen der Stellung von Truppen für den stark gefährdeten Ordensstaat zu verhandeln. ${ }^{86}$ Bach starb jedoch vor Abschluss der Verhandlungen und wurde in der Klosterkirche beigesetzt. Die Ausführung seines letzten Willens hatte der ihn offenbar begleitende Ordensritter Jost Truchsess von Wetzhausen übernommen, der sein Nachfolger im Amt des Großkomturs wurde. Jost sorgte zum einen für eine Sandsteingrabplatte mit eingelassenem Bronzewappen und bronzener Inschriftentafel, die neben Namen und Sterbedaten auch die Aufforderung enthielt, Gott möge der Seele Bachs gnädig sein. ${ }^{87}$ Zum anderen gab er ein Epitaphgemälde in Auftrag, in

82 Woher diese Vermutung stammt, bleibt unklar; seit der ersten Erwähnung des Grabsteines wird dabei immer von ,angeblich' gesprochen: Borrmann, Die Bau- und Kunstdenkmäler, S. 198; Schubring, Die Klosterkirche zu Berlin, S. 8, Nr. 5.

83 Angelus, Annales Marchiae Brandenburgicae, S. 252. Peter Hafftiz berichtet in seiner Chronik des 16. Jahrhunderts zum Jahr 1486 nur über die Wahl des neuen Bischofs, CDB IV 1 S. 75.

84 Zur Lage und Beschreibung der Platte: Borrmann, Die Bau- und Kunstdenkmäler, S. 198; Schubring, Die Klosterkirche zu Berlin, S. 8, Nr. 5. Die Inschrift lässt sich kaum mehr entziffern. Lesbar ist lediglich das Jahrhundert: $[A]$ nno d $[$ omi $]$ ni M cccc [...]. Für ihre diesbezüglichen Bemühungen danke ich Dr. Christine Magin von der Arbeitsstelle Inschriften, Greifswald.

85 Zu diesem Schmelzing, Grabdenkmäler von Landfremden, Sp. 316f., Nr. 5; Dieter Heckmann, Amtsträger des Deutschen Ordens in Preußen und in den hochmeisterlichen Kammerballeien des Reiches bis 1525/Dostojnicy zakonu niemieckiego w Prusach i baliwatach-kamarich wielkomistrowskie imperiumu do 1525 r, voraussichtlich Toruń 2021 [Manuskriptzählung: S. 206, 232].

86 Das Folgende nach Schmelzing, Grabdenkmäler von Landfremden, Sp. 317 f., Nr. 5; zur Person ebd. und Heckmann, Amtsträger des Deutschen Ordens [u. a., S. 197, 206].

87 Cante, Die Klosterkirche als Berliner Gedächtnisort, S. 57 mit fotografischer Abb. 79. Zur Grabplatte Borrmann, Die Bau- und Kunstdenkmäler, S. 199; Kurth, Die Altertümer, S. 138; Schmelzing, Grabdenkmäler von Landfremden, Sp. 316-318, Nr. 5 (mit s/w Abb. nach Sp. 308); Cante, Die Klosterkirche als Berliner Gedächtnisort, S. 57; Deiters, Die Ausstattung der Franziskanerklosterkirche, S. 145, 147 mit s/w Abb. 2; Knüvener, Die spätmittelalterliche Skulptur und Malerei, S. 226 f. mit Farbabb. 603. 
dem er sich als Testamentarius und als fast gleichwertiger Stifter verewigen ließ. Dieses Epitaph zeigt den Abschied Jesus' von seiner Mutter am Gründonnerstag. ${ }^{88}$ Im Vordergrund knien links Klaus von Bach sowie rechts etwas kleiner Jost von Wetzhausen als Stifter, beide in Rüstung mit abgelegtem Helm, an ihren Wappen im Vordergrund identifizierbar (Abbildung 7). Auf einem links in der Ecke befindlichen stilisierten Pergament wird der christliche Betrachter direkt angesprochen und aufgefordert, um selbst ein gutes Ende zu nehmen, jeden Donnerstag des Schmerzes Marias - und dabei sicherlich auch der Stifter - zu gedenken. ${ }^{89}$ Dieses Bild, auf dem außer den Wappen jegliche Hinweise auf die Namen der beiden Männer fehlen, ist bis heute in der Berliner Marienkirche erhalten. Die Aufforderung zum Gebet im Bild selbst war aber nicht die einzige Beischrift, sondern es gehörte ein weiterer zeitgenössischer Text zum ehemaligen Gesamtkunstwerk. Auf einer offenbar gesonderten Tafel hielt Jost für die Betrachtenden die Sterbedaten des Ritters parat, bat Gott darum, dem Toten gnädig und barmherzig zu sein, forderte dazu auf, ein inichck Pater Noster und Ave Maria vor di vorstorben Seelen zu beten, und wies sich namentlich als Testamentsvollstrecker aus. Beschrieben und zitiert wird die gesamte Inschrift zum ersten Mal 1732, jedoch ohne weitere Erklärung zu ihrer Anbringung, ${ }^{90} 1823$ als Unterschrift des Bildes genannt, ${ }^{91}$

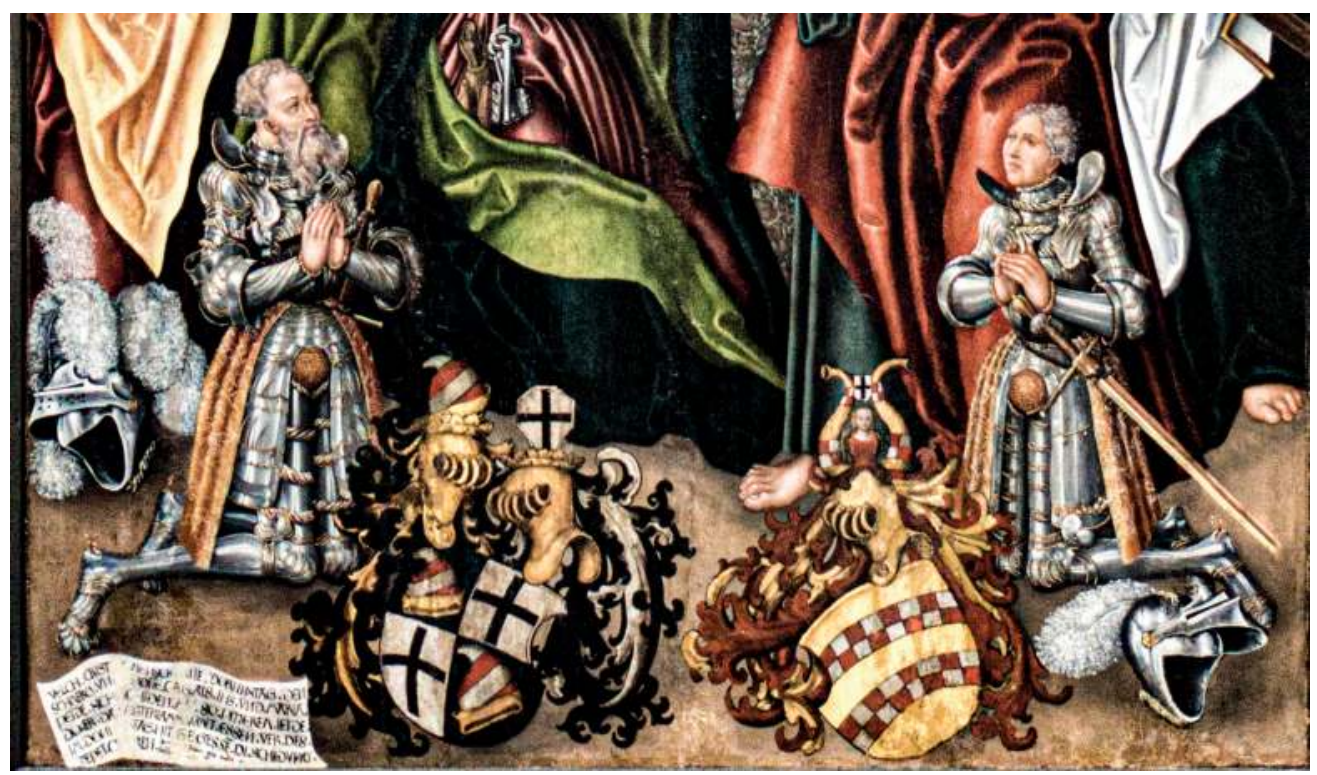

Abb. 7: Epitaph für Klaus von Bach und Jost von Wetzhausen, 1521, Marienkirche Berlin (Ausschnitt).

88 Zum Epitaph Cante, Die Klosterkirche als Berliner Gedächtnisort, S. 57; Deiters, Die Ausstattung der Franziskanerklosterkirche, S. 145, 147; Deiters, Gedächtnismale, Einzelgemälde und -skulpturen, S. 402 f.

89 Kurth, Die Altertümer, S. 132.

90 Das Epitaphium am Pfeiler lautet also [...], Diterich, Berlinsche Closter- und Schul-Historie, S. 16 f.

91 Ebd.; Kugler, Die Klosterkirche zu Berlin, S. 269 (hier zitiert nach Kugler). 
während 1891 die Beischrift nicht mehr vorhanden gewesen zu sein scheint. ${ }^{92}$ Der erklärende Text war wohl nicht mehr für überlieferungswürdig gehalten worden.

Selbst nach der Reformation banden Geistliche ihre Memoria an das Kloster. So machte 1558 der achtzigjährige Priester und Dechant des Havelberger Domes, Peter Conradus, sein Testament und verfügte, dass er in der dort durch ihn errichteten und ausgestatteten Marienkapelle begraben werden wolle. ${ }^{93}$ Gebete für sein Seelenheil sollten jedoch von einer Institution gewährleistet werden, auf deren Dauerhaftigkeit Peter trotz Reformation setzte, auf die barfusser munnichen in Berlin, die dort zu diesem Zeitpunkt ja weiterhin lebten. ${ }^{94}$ Ihnen vermachte er fünf Gulden, das sie bald nach meinen tode meiner in ihrem gebett und kirchen empteren gedencken. ${ }^{95}$

Die meisten Niederschläge des Wunsches von Geistlichen, in Erinnerung zu bleiben, lassen sich aber naheliegenderweise für die Mönche selbst finden. Eine ausgefeilte und erfolgreiche Strategie, um über den Tod hinaus - jenseits von Pergament und Papier - einer gewissen Öffentlichkeit in Erinnerung zu bleiben, dachten sich dabei einige Mönche aus. Sie verewigten sich namentlich und mit ihren religiösen Bitten an dem Ort, an dem sie und eventuell weitere Personen regelmäBig zusammentrafen, dem Saal des um 1470 neu errichteten sogenannten Kapitelhauses. ${ }^{96}$ Auf dessen vier tragenden Säulen finden sich die Gebete und Namen von Mönchen sowie Jahreszahlen zum Bau in Tonfriese gemeißelt, die heute im Märkischen Museum aufbewahrt werden. ${ }^{97}$ Auf der südlichsten Säule bat im oberen Fries ein Bruder Adam Gott, dieses Haus und sich selbst zu segnen, ${ }^{98}$ während unten auf der nächsten Säule die Namen von sieben Brüdern verewigt sind. Auf der dritten Säule baten oben die Brüder Benedikt und Markus Gott, dieses Gebäude vor aller Unbill zu bewahren, während der untere Schaft der Säule kundtat, dass Meister Bernhard dieses Werk 1474 vollendet hatte. Auf der vierten Säule auf dem oberen Schaft verewigte sich ein Bruder Hieronymus mit der Anrufung Marias im Rosenkranzgebet, während der untere Schaft der Vergegenwärtigung von Jesus, Maria und vier Ordensheiligen, darunter Bernhardin [von Siena], vorbehalten blieb. Mindestens elf Brüder aus dem Konvent, der möglicherweise zu diesem Zeitpunkt aber auch nicht mehr Brüder umfasste, blieben damit, letztlich bis heute, an repräsentativer Stelle in Erinnerung der Nachwelt. hauptstadt in kulturhistorischen Schilderungen, Berlin 1891, S. 228.

93 CDB I 3, S. 157-164, Nr. 75, hier S. 161.

94 Bis zum Tod des letzten Mönchs im Jahre 1571; Riedel, Berlin Franziskaner, S. 147.

95 CDB I 3, S. 157-164, Nr. 75, hier S. 161.

96 Joachim Bellermann, Das graue Kloster in Berlin, mit seinen alten Denkmälern, T. 2, Berlin 1824, S. 40-47; Borrmann, Die Bau- und Kunstdenkmäler, S. 200 f. (mit Teilabb. des Saals), Mauermann, Die Geschichte des Grauen Klosters, S. 21 (mit Abb. eines Ausschnitt des Saals); Peter Knüvener/Dirk Schumann, Berlin, Franziskanerkloster, in: Nentwig, Mittelalterliche Kunst aus Berlin, S. 326-329, Nr. 131, hier S. 326 mit s/w Abb. S. 44, Abb. 16.

97 Umfassend dazu Knüvener/Schumann, Berlin, Franziskanerkloster, S. 327 f. mit Abb.

98 Das Folgende nach Julius Heidemann, Geschichte des grauen Klosters zu Berlin. mit vier Tafeln, Berlin 1874, S. 326; Bellermann, Das graue Kloster in Berlin, T. 2, S. 41-45; Borrmann, Die Bau- und Kunstdenkmäler, S. 200 f. 


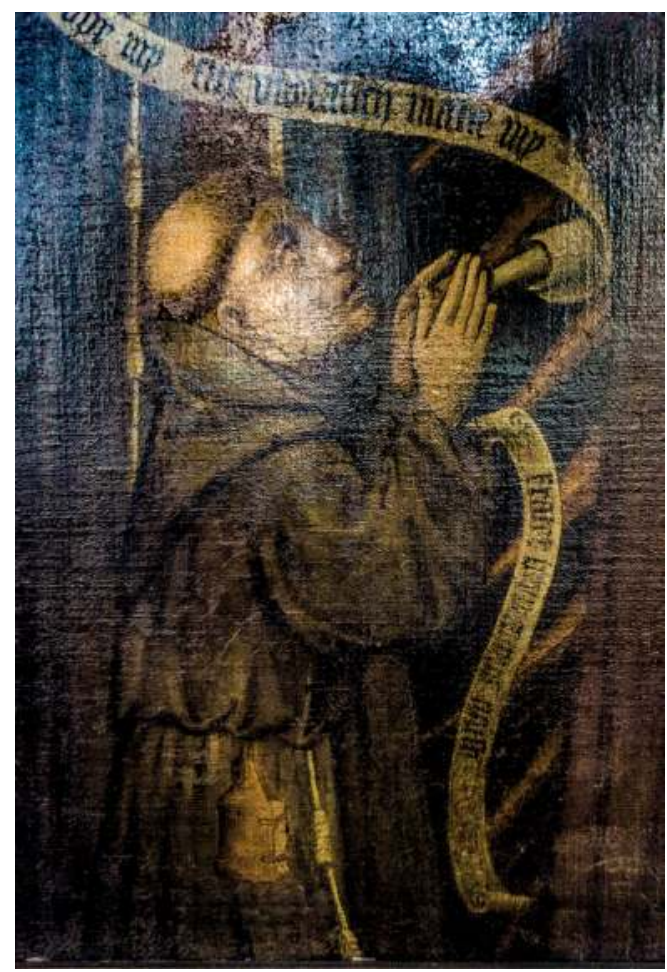

Abb. 8: Epitaph für Hieronymus Musa, nach 1450, Marienkirche Berlin (Ausschnitt).

Neben diesen in Stein gemeißelten Bitten an Gott sind bildliche Zeugnisse erhalten, die auf einzelne Brüder oder den Konvent als Stifter deuten. So zeigt ein heute in der Marienkirche hängendes, kurz nach 1450 entstandenes Leinwandgemälde Maria im Kreis von insgesamt fünf franziskanischen Heiligen, darunter der 1450 heiliggesprochene Bernhardin von Siena (mit Buch und Strahlensonne) ${ }^{99}$ sowie Klara (mit Monstranz). ${ }^{100}$ Maria wird durch eine goldene Inschrift über ihrem Haupt als alderschoeneste machet Maria und als pulcherrima virgo Maria verehrt, ${ }^{101}$ während gegenüber der Heiligen Klara ein eindeutig als Stifter dargestellter Franziskanermönch eine Schriftrolle zwischen den betenden Händen hält. Darauf richtet der in einer weiteren Schriftrolle entlang seines Körpers ausgewiesene frater Hironimus Musa seine Bitte nach jenseitiger Seligkeit an die Vermittlerin Maria (schoneste Maria bidde ihesum vor my,

99 Auf der Sonne und im Buch sind noch mittelalterliche Textfragmente erkennbar, die aber kaum entzifferbar sind.

100 Zum Bild Diterich, Berlinsche Closter- und Schul-Historie, S. 25; Bellermann, Das graue Kloster in Berlin, T. 1, S. 37 f., Nr. 6; Kugler, Die Klosterkirche zu Berlin, S. 268; Borrmann, Die Bau- und Kunstdenkmäler, S. 197; Schubring, Die Klosterkirche zu Berlin, S. 8, Nr. 15; Riedel, Berlin Franziskaner, S. 153 f.; Knüvener, Die Skulptur des Retabels, S. 136f.; Cante, Die Klosterkirche als Berliner Gedächtnisort, S. 61, Abb. 86 (Aufhängung); Deiters, Bettelorden und Landesherr, S. 259 f., Nr. VII.3 mit Farbabb.; dies., Die Ausstattung der Franziskanerklosterkirche, S. 158 f. (mit Farbtafel 7); dies., Gedächtnismale, Einzelgemälde und -skulpturen, S. 403 f. mit s/w Abb. 509; ausführlich Knüvener, Die spätmittelalterliche Skulptur und Malerei, S. 172 f. mit Farbabb. 453.

101 Zuerst zitiert bei Diterich, Closter S. 25. Die Inschriften des Bildes sind aber auch heute noch gut lesbar. 
sunt und salich make my) (Abbildung 8). ${ }^{102}$ Es scheint nun zeitlich naheliegend, diesen Bruder Hieronymus als denjenigen zu identifizieren, der sich im Säulenschaft mit der Anrufung Mariens verewigte. ${ }^{103}$ In welchem Kontext und Ort dieses durch die Inschrift wohl als Epitaph zu bezeichnende Gemälde im Mittelalter präsentiert wurde, bleibt unklar, was auch der späteren Neurahmung geschuldet ist, die nur die rechte Seite des Originalrahmens übrig ließ.

Ebenso unklar sind Aufstellungsort und Präsentationskontext bei einer großformatigen Relieftafel, die heute ebenfalls in der Marienkirche hängt. ${ }^{104}$ Auf dieser Tafel, die um die gleiche Zeit wie das vorige Bild zu datieren ist, steht Bernhardin von Siena ganz im Zentrum, auch hier mit seinen Attributen, der Strahlensonne mit Christusmonogramm in der einen, ein Buch (mit einer später zugefügten Inschrift) in der anderen Hand. ${ }^{105} \mathrm{Zu}$ Füßen des Heiligen knien betend fünf weltliche Personen: halb kniend rechts ein Paar mit eventuell einem Sohn sowie links ein älterer und ein jüngerer Mann (Abbildung 9). Ob es sich bei diesen Figuren um die Darstellung von Stiftenden oder um Andächtige handelt, die auch die Betrachtenden zum Gebet anregen sollten, ${ }^{106}$ muss wegen des Fehlens weiterer schriftlicher Hinweise auf der Tafel offenbleiben. Aber jemand, sei es von außerhalb oder aus dem Konvent selbst, hat den Auftrag zur Fertigung des Bildes gegeben, es bezahlt und im Kloster oder der Kirche anbringen lassen.

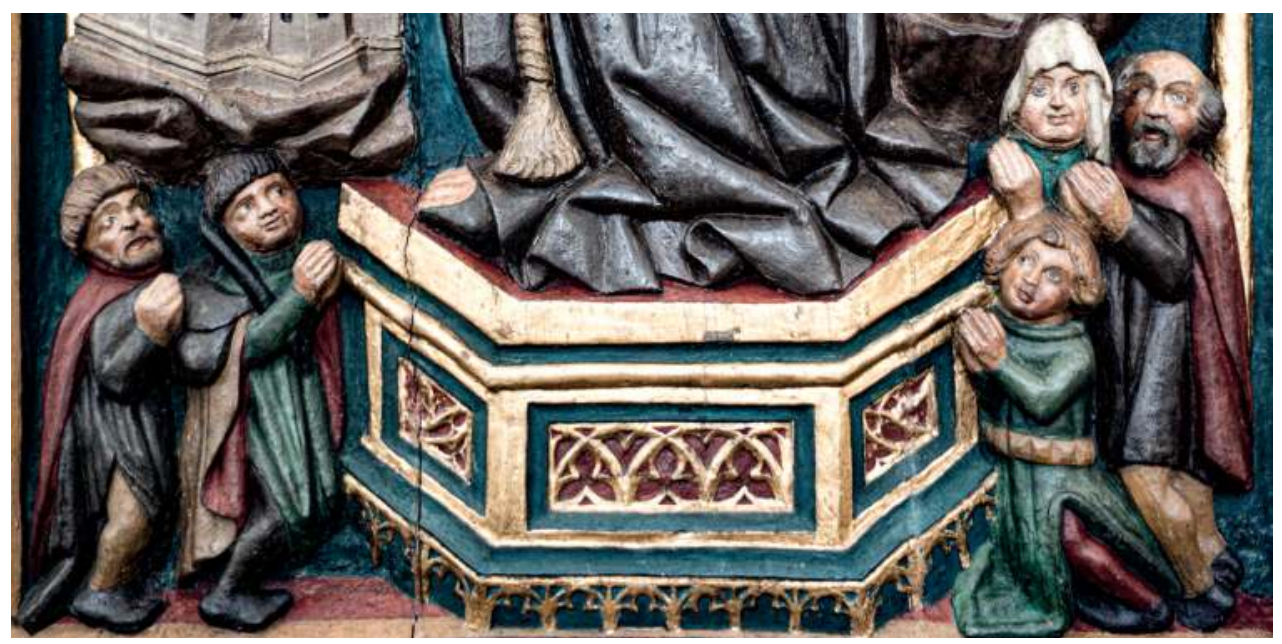

Abb. 9: Tafel mit Bernhardin von Siena und knienden Personen, nach 1450, Marienkirche Berlin (Ausschnitt).

102 So die Lesart bei Deiters, Die Ausstattung der Franziskanerklosterkirche, S. 158; Knüvener, Die spätmittelalterliche Skulptur und Malerei, S. $172 \mathrm{f}$.

103 So auch Knüvener/Schumann, Berlin, Franziskanerkloster, S. 329 Anm. 3.

104 Als Altarflügel diente es nicht, es gibt auf der Rückseite keine Hinweise auf Scharniere oder Fassungen, so Deiters, Die Ausstattung der Franziskanerklosterkirche, S. 158 f. Anm. 39; Deiters, Gedächtnismale, Einzelgemälde und -skulpturen, S. 404, Anm. 123; Knüvener, Die spätmittelalterliche Skulptur und Malerei, S. 174.

105 Riedel, Berlin Franziskaner, S. 154; Deiters, Bettelorden und Landesherr, S. 260 f., Nr. VII.5 mit Farbabb.; dies., Die Ausstattung, S. 158f. mit s/w Abb. 16; dies., Gedächtnismale, Einzelgemälde und -skulpturen, S. 404 mit s/w Abb. 510; ausführlich zum Inhalt Knüvener, Die spätmittelalterliche Skulptur und Malerei, S. 173 f. mit Farbabb. 454.

106 So Deiters, Die Ausstattung der Franziskanerklosterkirche, S. 158 f. Anm. 39; Knüvener, Die spätmittelalterliche Skulptur und Malerei, S. 174. 
Ebenfalls zum franziskanischen Kontext ist die in das Ende des 15. Jahrhunderts zu datierende Bildtafel des Baumes der Franziskaner zu rechnen. ${ }^{107}$ Wahrscheinlich lag dem Bild, das sich heute in der Marienkirche befindet, ein Einblattholzschnitt von 1484 aus Nürnberg zugrunde, ${ }^{108}$ der bei dem Berliner Baum jedoch eine starke Reduktion erfuhr. In den Wurzeln des Berliner Baumes sitzen zwei (statt drei) Nonnen, die von einem Schriftband umschlungen werden, auf denen auch hier die drei franziskanischen Tugenden festgehalten sind. ${ }^{109}$ Den Tugenden folgt eine Schrifttafel mit dem lateinischen Text der Johannesoffenbarung 7,2, ${ }^{110}$ die die Franziskaner auf sich bezogen. ${ }^{111}$ Darüber steht im Stamm Franziskus, über ihm hängt Christus am Kreuz. Den fünf Ästen des Berliner Baumes folgen zu beiden Seiten des Stammes jeweils zwölf (im Nürnberger Baum 17) mit ihren Attributen und zusätzlich mit Namen gekennzeichnete Heilige des Ordens, wobei die meisten der hier genannten Heiligen auch in der Nürnberger Version erscheinen. ${ }^{112}$ Links der Schrifttafel knien zwei (in der Nürnberger Version vier) als Heilige gekennzeichnete Frauen, die erste mit einem Kelch in den Händen, ${ }^{113}$ rechts davon sind ebenfalls von vier nur zwei Personen übriggeblieben: eine Heilige mit Krone, gefolgt von einem männlichen Heiligen mit fürstlicher Kopfbedeckung und Kleidung, ${ }^{114}$ deren Namen wohl ehemals in den unter ihnen angebrachten Schrifttafeln zu lesen waren (Abbildung 10). Hinweise auf Stiftende finden sich in diesem Bild also keine, es scheint wohl vom Konvent selbst in Auftrag gegeben worden zu sein.

107 Diterich, Berlinsche Closter- und Schul-Historie, S. 25; Bellermann, Das graue Kloster in Berlin, T. 1, S. 30 f., Nr. 5 ; Borrmann, Die Bau- und Kunstdenkmäler, S. 196 f.; Deiters, Bettelorden und Landesherr, S. 259 f., Nr. VII.4 mit Farbabb.; dies., Die Ausstattung der Franziskanerklosterkirche, S. 160 f. mit s/w Abb. 17; dies., Gedächtnismale, Einzelgemälde und -skulpturen, S. 404 f. mit s/w Abb. 511; Knüvener, Die spätmittelalterliche Skulptur und Malerei, S. 171, ferner S. 344, Anm. 1008.

108 Deiters, Die Ausstattung der Franziskanerklosterkirche, S. 160. Zum Baum im Einblattholzschnitt von 1484: Hanna Egger, Rosarium beati Francisci, in: Johannes Gründler (Hrsg.), 800 Jahre Franz von Assisi. Franziskanische Kunst und Kultur des Mittelalters (Katalog des Niederösterreichischen Landesmuseums, N.F., Bd. 122), Wien 1982, S. 658-660, Nr. 13.21 mit s/w Abb. 107 (Original: Graphische Sammlung Albertina [Wien], Inventarnr. DG1930/190, Digitalisat: https://sammlungenonline.albertina.at [abgerufen am: 24. April 2020]) und dem fast identischen Baum (mit leeren Schriftbändern) in einem Graduale von 1494/97: Elisabeth Vavra, Rosarium beati Francisci, in: Gründler, 800 Jahre Franz von Assisi, S. 596-598, Nr. 10.72 mit Farbtafel Nr. 45 (Original: Bayerische Staatsbibliothek, Clm 23042, Digitalisat: http://www.manuscripta-mediaevalia.de [abgerufen am: 24. April 2020]).

109 Dazu auch Deiters, Die Ausstattung der Franziskanerklosterkirche, S. 160. Auf dem Band des Nürnberger Baumes steht: Castitas pudorosa, Paupertas zelosa und Obediencia studiosa. Auf dem Berliner Baum ist rechts eindeutig oboedientia studio [sa] zu lesen, in der Mitte scheint die Schrift durch einen Restaurator sehr verfälscht, aber Castitas [pudoro] sa lässt sich dort lesen, auf der linken Seite sind keine verwertbaren Buchstaben mehr erkennbar. Für die Transkriptionsunterstützung danke ich meiner Kollegin Dr. Magdalena Weileder, München. Die von Bellermann, Das graue Kloster in Berlin, T. 1, S. 31 genau an dieser Stelle zitierten und von Borrmann, Die Bau- und Kunstdenkmäler, S. 197 übernommenen Worte virgo formosa mater dei sind dort nicht erkennbar.

110 Zitiert bei Bellermann, Das graue Kloster in Berlin, T. 1, S. 31.

111 Ausführlich dazu Deiters, Die Ausstattung der Franziskanerklosterkirche, S. 162 f.

112 Vgl. die Aufzählung der Heiligen in der Nürnberger Version: Egger, Rosarium beati Francisci, S. 658; Vavra, Rosarium beati Francisci, S. 596. Zu den unterschiedlichen Personifizierungsversuchen der Heiligen im Berliner Baum Bellermann, Das graue Kloster in Berlin, T. 1, S. 32-37; Kurth, Die Altertümer, S. 132 f.

113 Deiters, Die Ausstattung der Franziskanerklosterkirche, S. 160 identifiziert sie mit Klara und Elisabeth (mit Kelch). Geht man von der Vorlage aus, könnten Klara (hier mit Kelch statt Monstranz) und ihre Schwester Agnes übriggeblieben sein.

114 Bellermann, Das graue Kloster in Berlin, T. 1, S. 31 sieht in dem Mann den Klosterstifter Otto; geht man von der Vorlage aus, könnten von den vier Personen hier die Heilige Elisabeth (dort wie hier mit Krone) und der selige Elzearius, Graf von Ariano (dort mit ähnlicher Kleidung wie hier), übriggeblieben sein. 


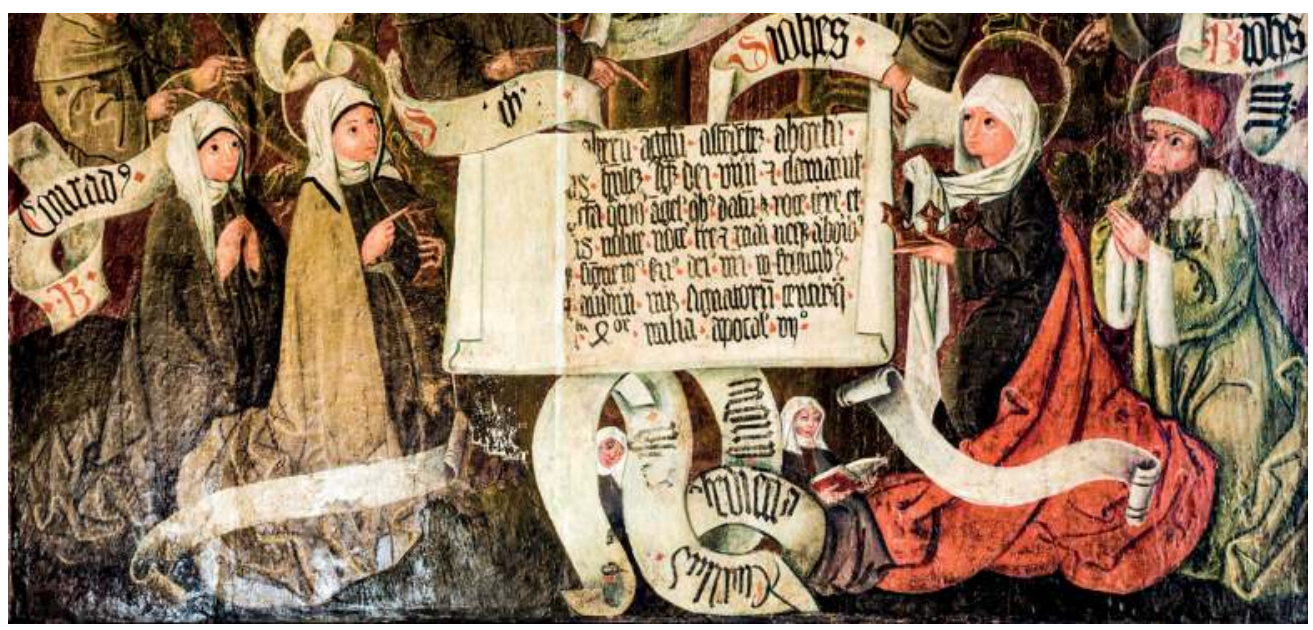

Abb. 10: Baum der Franziskaner, Ende 15. Jahrhundert, Marienkirche Berlin (Ausschnitt).

Ein viertes, um 1480 entstandenes Tafelbild, in dem der Tod Jesu' im Beisein des ,guten Hauptmanns' im Zentrum steht, ${ }^{115}$ lässt sich eindeutig als eine Stiftung aus dem Konvent interpretieren. Während der Hauptmann im Kreise seiner Untergebenen auf der rechten Seite steht, trauert links Maria, gestützt und begleitet von weiteren Heiligen. ${ }^{116} \mathrm{Zu}$ Füßen des Kreuzes knien in Stifterposition zwei betende Mönche (Abbildung 11). Ob es sich dabei wirklich um zwei Stifterpersönlichkeiten aus dem Konvent handelte oder um Stellvertreter für eine Stiftung des ganzen Konventes, muss wohl offenbleiben, da auch hier jegliche erklärenden Inschriften fehlen. Während alle bisherigen Bilder als Einzelbilder angesehen werden dürfen, scheint es sich bei diesem, das heute auf dem Altar der Dahlemer Sankt Annen-Kirche steht, um den Mittelteil eines Triptychons gehandelt zu haben, wie Aussparungen für eine baldachinartige Maßwerkarchitektur am oberen Bildrand vermuten lassen. ${ }^{117}$ Dieses Bild leitet über zu einer großen Gruppe an weiteren überlieferten Stiftungen von geistlichen Bildern, den Altarbildern selbst. Sie, die als die teuersten und repräsentativsten Bilder des Kirchenraumes gelten können, waren aber nur die sichtbare Spitze eines ,Eisberges'. Denn hinter jedem Bild standen in der Regel hohe Kapitalsummen mit Einkünften beispielsweise für Priester, Altargerät und regelmäßige Messen. ${ }^{118}$ Trotz aller Umbauarbeiten haben sich bis heute Reste von mindestens sieben zur Klosterkirche gehörenden Retabeln erhalten, die alle Ende des 15./Anfang des 16. Jahrhunderts entstanden. ${ }^{119}$ Alle wurden in Auftrag gegeben und finanziert von jemandem, seien es einzelne Personen, Gruppen oder der Konvent selbst gewesen. Ähnliches gilt für

115 Nach Markus 15,39; nach Lukas 23,47.

116 Riedel, Berlin Franziskaner, S. 154; Deiters, Die Ausstattung der Franziskanerklosterkirche, S. 157 mit s/w Abb. 15 (die das Bild als „eine Art Anleitung zur Bildbetrachtung“ deutet); Knüvener, Die Skulptur des Retabels, S. 118, Abb. 17; ausführlich zur Bildgestaltung Knüvener, Die spätmittelalterliche Skulptur und Malerei, S. 180 mit Farbabb. 475.

117 Dazu Deiters, Die Ausstattung der Franziskanerklosterkirche, S. 157; Knüvener, Die spätmittelalterliche Skulptur und Malerei, S. 180.

118 U. a. Jezler, Jenseitsmodelle und Jenseitsvorsorge, S. 13.

119 Zu diesen Retabeln u. a. Bellermann, Das graue Kloster in Berlin, T. 1, S. 29; Borrmann, Die Bau- und Kunstdenkmäler, S. 196 f.; Kurth, Die Altertümer, S. 123-125, ferner S. 140, Anm. 1; Riedel, Berlin Franziskaner, S. 153; 
die materielle Ausstattung der Altäre mit Kirchengerät. Einiges wurde bald nach der Reformation inventarisiert, ${ }^{120}$ einiges hat bis heute überdauert. ${ }^{121}$ Da aber die Stifterpersönlichkeiten dieser Bilder und Gegenstände ebenso wenig wie der Kontext ihrer Entstehung rekonstruierbar sind, sollen hier nur zwei Bilder mit direkten Bezügen zum Orden und ein weiteres, das den Memorialwunsch sehr deutlich zum Ausdruck bringt, kurz vorgestellt werden. So hat sich bis heute das Relief mit der Darstellung der Anbetung durch die Heiligen Drei Könige erhalten, das um 1470 entstanden ist und sich heute im Chor der Marienkirche befindet. ${ }^{122}$ Der Bezug zu den Franziskanern darauf ist eindeutig: So wird der bei Ochs und Esel im Hintergrund sitzende Josef als Mönch dargestellt, ein weiterer Mönch ist im Hintergrund des Bildes in einer Gruppe von fünf Reitern zu erkennen. ${ }^{123}$

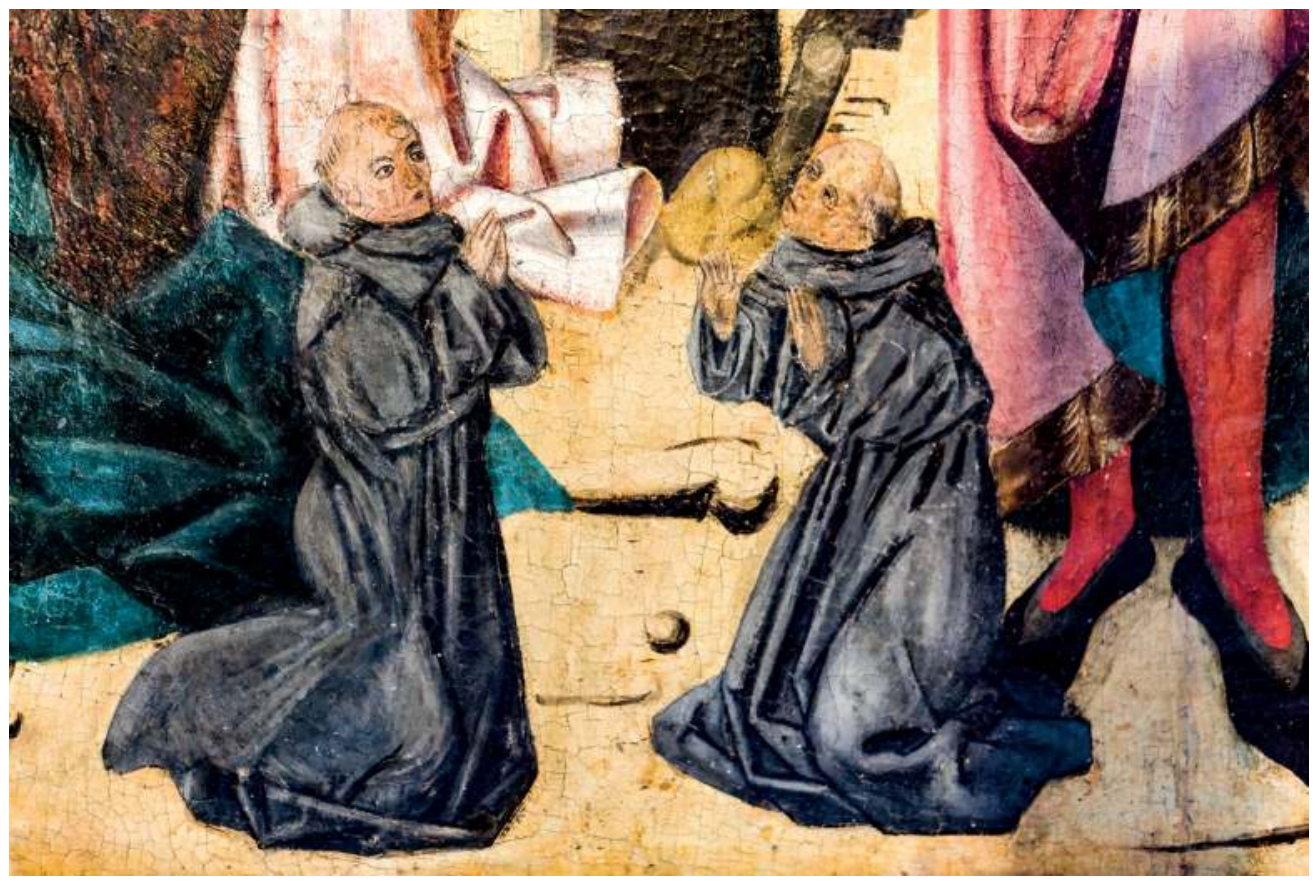

Abb. 11: Tafelbild Kreuzigung mit ,gutem Hauptmann' sowie zwei Franziskanermönchen, um 1480, Dorfkirche Berlin-Dahlem (Ausschnitt).

Deiters, Die Ausstattung der Franziskanerklosterkirche, S. 149, 154f.; Knüvener, Die spätmittelalterliche Skulptur und Malerei, S. 180 f., 195.

120 Vgl. dazu CDB III 3, S. 501, Nr. 351 (Uebersicht des abgelieferten Kirchengeräthes aus dem grauen Kloster zu Berlin) und Historisch-diplomatische Beiträge zur Geschichte der Stadt Berlin, T. 2: Berlinische Urkunden von 1261 bis 1550, hrsg. von Ernst Fidicin, Berlin 1837, S. 350-353, Nr. 211, hier S. 353.

121 Zu Beschreibungen des Kirchengeräts Borrmann, Die Bau- und Kunstdenkmäler, S. 193; Riedel, Berlin Franziskaner, S. 153; Knüvener/Schumann, Berlin, Franziskanerkloster, S. 326; Peter Knüvener, Ziborium, in: Nentwig, Mittelalterliche Kunst aus Berlin, S. 356-358.

122 Zum Bild und den wohl zugehörigen Flügeln, die heute in der Dorfkirche von Zehlendorf hängen: Bellermann, Das graue Kloster in Berlin, T. 1, S. 29 f., 44 f.; Borrmann, Die Bau- und Kunstdenkmäler, S. 196; Riedel, Berlin Franziskaner, S. 154; Deiters, Die Ausstattung der Franziskanerklosterkirche, S. 151-153 (mit s/w Abb. 7a-b, 8, 9a-b); Knüvener, Die spätmittelalterliche Skulptur und Malerei, S. 175 f. mit Farbabb. 459 a-b.

123 Dazu Bellermann, Das graue Kloster in Berlin, T. 1, S. 45. 
Von einem weiteren Altarbild, das ebenfalls eindeutig dem franziskanischen Kontext zuzuordnen ist, sind heute noch zwei um 1480 datierte Flügel vorhanden, die in der Dorfkirche von BerlinBuckow hängen. ${ }^{124}$ Auf den äußeren Flügeln findet sich die Darstellung der Gregorsmesse, auf den Innenseiten die zwölf Apostel, wobei auf dem rechten Innenflügel einer der Apostel (wohl Judas) durch Franziskus ersetzt wurde. Auch hier wurde also von den Auftraggebern bewusst eine Beziehung zum Kloster hergestellt.

Ein weiteres Flügelretabel, auf Anfang des 16. Jahrhunderts datiert, ist fast vollständig erhalten. ${ }^{125}$ Das Zentrum dieses Retabels, das heute in der Klosterkirche von Heiligengrabe auf dem Hauptaltar steht, bildet die Strahlenkranzmadonna mit Kind. Interessant sind nun die deutlich auf eine Stiftung weisenden Inschriften: So steht im Heiligenschein des links neben Maria stehenden Heiligen Petrus: Sanctus Petrus ora pro [nobis], ebenso bei dem rechts von ihr stehenden Andreas: Sanctus Andrews ora [pro nobis], die gleiche Bitte findet sich wohl insgesamt acht Mal auf den breiten Kleidersäumen der Heiligen (Abbildung 12). ${ }^{126}$ Zwar werden auch hier die Stiftenden wahrscheinlich nie identifiziert werden können, ihre Bitten auf Goldgrund sind aber bis heute nachvollziehbar.

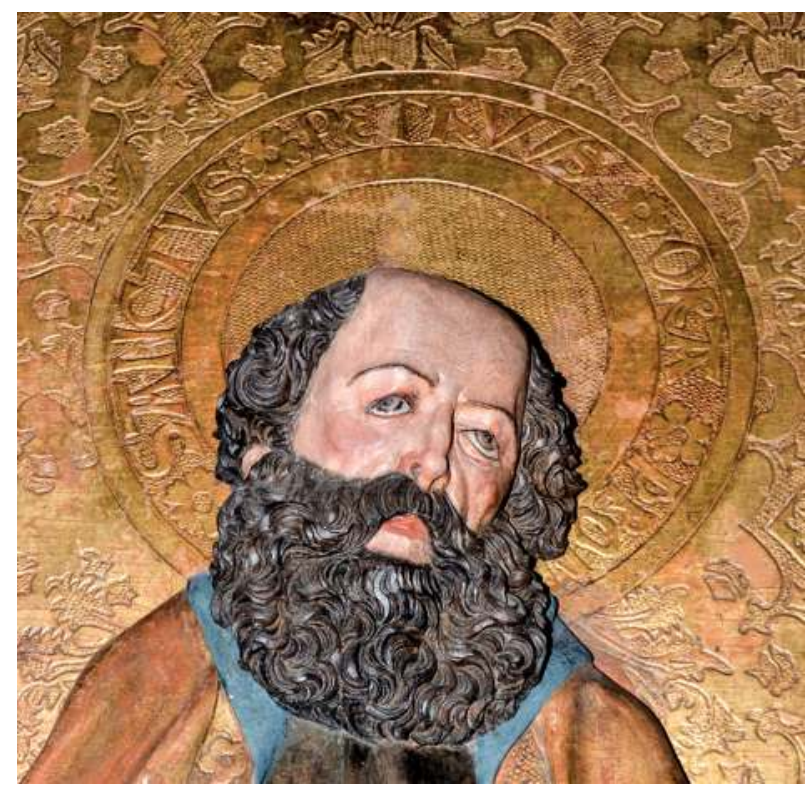

Abb. 12: Strahlenkranzmadonna, Inschriften, Anfang 16. Jahrhundert, Kloster Heiligengrabe (Ausschnitt).

124 Riedel, Berlin Franziskaner, S. 154; ausführlich Deiters, Die Ausstattung der Franziskanerklosterkirche, S. 153 f. mit s/w Abb. 10a-b und 11a-b.

125 Ausführlich dazu Bellermann, Das graue Kloster in Berlin, T. 1, S. 46 f., Nr. 4; Kurth, Die Altertümer, S. 106 f.; Deiters, Die Ausstattung der Franziskanerklosterkirche, S. 155 f. mit s/w Abb. 13 und 14; Knüvener, Die spätmittelalterliche Skulptur und Malerei, S. 237-239 mit Farbabb. 644, $646 \mathrm{f}$.

126 So Bellermann, Das graue Kloster in Berlin, T. 1, S. 47; vgl. auch Borrmann, Die Bau- und Kunstdenkmäler, S. 196. 


\section{Resümee}

Aus dem Franziskanerkloster haben sich wenige schriftliche Zeugnisse des Mittelalters erhalten, darunter kaum solche, die die Anbindung der Jenseitsvorsorge von Personen an das Kloster belegen würden. Weder haben Verzeichnisse zu den Todestagen von Stiftenden im Kloster selbst noch Testamente, Stadtbucheinträge oder Stiftungsurkunden für das Franziskanerkloster, die sicherlich in irgendeiner Form vorhanden gewesen sind, bis heute überdauert. Nur rückblickende Chroniken des 15./16. Jahrhunderts sowie Bau- und Einrichtungsbeschreibungen des 18. bis 20. Jahrhunderts lassen sich hier vorsichtig als historische Quellen nutzen. Die erstaunlich zahlreich erhaltenen Monumente aus dem Berliner Franziskanerkloster bilden also die Hauptquelle bei der Untersuchung der Anbindung von Memoria an diese Dauerhaftigkeit garantierende Institution. Anhand beider Quellengattungen war es möglich, zumindest einen Ausschnitt der mittelalterlichen Memoria auf der einen Seite und der mit ihr stets verbundenen Repräsentation von Einzelpersonen und Familien auf der anderen Seite im Kloster zu betrachten. Wie groß dieser Ausschnitt aber ist, hängt auch davon ab, ob diese Überlieferung nur einen kleinen oder großen Prozentsatz des gesamten Inventars ausmacht. ${ }^{127}$

Schon bei der Gründung und ersten Ausstattung des Klosters fällt auf, dass dieser Ort durch das Zusammenwirken verschiedener Herrschaftsträger ermöglicht wurde. Sowohl die beiden Markgrafen als auch der Ritter Nybede waren daher im Gedächtnis der Mönche als Klostergründer (claustri fundatores) präsent. ${ }^{128}$ Auch in den folgenden Jahrhunderten bis zur Auflösung der monastischen Gemeinschaft blieb das Kloster ein Ort, an dem ein breites Spektrum an gesellschaftlichen Gruppen, Markgrafen, Adel, Geistlichkeit, das Berliner Bürgertum und die Mönche selbst, nicht nur durch ihre Grablegen und Stiftungen, sondern damit verbunden sicherlich durch persönliche Anwesenheit aufeinandertraf.

Während die Askanier ihre Jenseitsvorsorge außer durch die Gründung des Klosters nur mit der Bestattung einer Tochter Ottos V. an die Mönche banden, spiegeln die Quellen vor allem eine engere Bindung der ihnen nachfolgenden Markgrafengeschlechter, der Wittelsbacher und der Hohenzollern, wider. Immerhin zwei wittelsbachische Markgräfinnen und ein Markgraf fanden im Kloster ihre letzte Ruhestätte. Die Hohenzollern beauftragten das Kloster zwar nachweislich nur durch Friedrich II. in einer Urkunde von 1443 mit ihrem Gebetsgedenken, aber zwischen Mitgliedern des hohenzollerischen Hofes und den Franziskanern bestanden enge Kontakte. Insgesamt sechs Vertraute der Markgrafen erhielten Epitaphien und wurden mit großer Wahrscheinlichkeit auch hier bestattet.

Von Berliner Bürgerfamilien sind immerhin zwei der ältesten Berliner Grabsteine aus dem Kloster erhalten, der älteste in Fragmenten überlieferte reicht sogar bis ins Jahrhundert der Klostergründung zurück. Nach einer großen zeitlichen Lücke erfährt man erst wieder um die Mitte des 15. Jahrhunderts von der Anbindung bürgerlicher Memoria an das Kloster, allerdings nur durch die überlieferten Epitaphien der Familie Blankenfelde. Eine enge Verflechtung von Bürgern,

127 Ausgegangen wird davon, dass gerade einmal fünf Prozent der mittelalterlichen Retabeln bis heute überdauerten; dazu mit weiterer Literatur Bünz, Die mittelalterliche Pfarrei, S. 235.

128 CDB III 1, S. 13, Nr. 11. 
Markgrafen und den Mönchen selbst deutet auch die Bestätigungsurkunde Friedrichs II. von 1443 an. So traten neben Guardian, Lesemeistern und allen Mönchen vier namentlich genannte Bürger als Intervenienten auf, die den Markgrafen baten, dem Kloster ihre Urkunde zur Übertragung der Ziegelei zu bestätigen. ${ }^{129}$

Hohe Geistliche, ein Bischof und ein Großkomtur des Deutschen Ordens, fanden am Ende des 15./Anfang des 16. Jahrhunderts ihre letzte Ruhe im Kloster, auch wenn dabei eher der Zufall bestimmend gewesen zu sein scheint. Und selbstverständlich sorgten auch einzelne Mönche oder der Konvent für ihre Jenseitsvorsorge vor Ort. Auffällig ist dabei, dass alle vier franziskanischen Bildwerke der zweiten Hälfte des 15. Jahrhunderts und damit der Zeit entstammen, in der das Kapitelhaus errichtet und um 1500 das Kloster vergrößert sowie die Kirche renoviert wurden. ${ }^{130}$ Auch die sieben Retabel entstanden ebenso wie weitere Bilder mit unklarer Funktion in dieser Zeit. Dazu kamen prächtige Ausstattungsgegenstände, wie das im Krieg zerstörte Gestühl der Mönche, das ebenfalls um 1500 gefertigt wurde ${ }^{131}$ und neben Hauptaltar und Nebenaltären der Kristallisationspunkt der monastischen Gebete war. Auch die beiden aus dem Ende des 15. Jahrhunderts stammenden Kreuzigungsgruppen ${ }^{132}$ sowie ein eventuell ebenfalls aus der Franziskanerkirche herrührendes Kruzifix gehören in diesen Zusammenhang. ${ }^{133}$

Möglicherweise ging mit diesen Umgestaltungen im Kloster auch die Entfernung älterer Bildwerke und Grabstätten einher, die durch die moderneren Epitaphien und durch neue Altarbilder abgelöst worden sein könnten. Den zahlreichen Umbauten und Umgestaltungen der Kirche, die mit dem Tod des letzten Mönches 1571 und der Übertragung des Areals an Leonhard Thurneysser und dessen ,Renovierung' der Kirche 1583/84 begannen und mit der umfassenden Neugestaltung der Kirche 1936 endeten, sind zahlreiche weitere Bildwerke und - wie gezeigt - auch Inschriften zum Opfer gefallen.

Festzuhalten bleibt, dass sich angesichts der diese Umgestaltungen überdauernden Bildwerke und der wenigen schriftlichen Quellen das Berliner Franziskanerkloster als Kristallisationspunkt der Memoria eines breiten Querschnitts der mittelalterlichen Gesellschaft präsentiert: Sowohl einheimische als auch zugezogene oder zufällig in Berlin weilende Menschen fanden hier ihre

129 Raumer, Codex 1, S. 4, Nr. 3.

130 Marx, Zur Geschichte der bauhistorischen Forschung, S. 51; vgl. dazu auch Knüvener, Die Skulptur des Retabels, S. 129-131.

131 Zum Gestühl Bellermann, Das graue Kloster in Berlin, T. 1, S. 39-43, Nr. 1; Heidemann, Geschichte, S. 38-40; Schubring, Die Klosterkirche zu Berlin, S. 6; Winfried Schich, Die Markgrafen von Brandenburg und die Ansiedlung der Franziskaner in den Städten östlich der Elbe im 13. Jahrhundert, in: Landesdenkmalamt Berlin, Kirchenruine des Grauen Klosters, S. 13-22, hier S. 19, Abb. 16.

$132 \mathrm{Zu}$ den beiden Kreuzigungsgruppen, eine mit Maria und Johannes als Assistenzfiguren (heute in Sankt Johannis in Moabit), Heidemann, Geschichte, S. 38; Borrmann, Die Bau- und Kunstdenkmäler, S. 196; Deiters, Die Ausstattung der Franziskanerklosterkirche, S. 149 f. mit s/w Abb. 5a-c; Deiters, Gedächtnismale, S. 405 f.; Knüvener, Die spätmittelalterliche Skulptur und Malerei, S. 187 mit Farbabb., S. 187 (Abb. 497), S. 194 (Abb. 509 ), S. 196 (Abb. 519); zur zweiten Kreuzigungsgruppe, mit dem Wappen Leonhard Thurneyssers zu Füßen des Kreuzes, die sich heute in der Kirche am Stölpchensee (Wannsee) befindet, Borrmann, Die Bau- und Kunstdenkmäler, S. 196; Kurth, Die Altertümer, S. 129; vgl. zu einem der Kreuze: Bellermann, Das graue Kloster in Berlin, T. 1, S. 39, Nr. 17.

133 Peter Knüvener, Kruzifix aus der Berliner Franziskanerklosterkirche (?), in: Nentwig, Mittelalterliche Kunst aus Berlin, S. 208 f., Nr. 49. 
letzte Ruhe und blieben dank ihrer Familien oder anderer Personen, die für den Erhalt der Kunstwerke sorgten, teilweise bis heute in Erinnerung. Es waren Menschen sowohl aus markgräflichem, adeligem oder bürgerlichem Hause als auch Menschen, die sich für den geistlichen Stand entschieden hatten. Das Graue Kloster war im Mittelalter ein Ort, der viele, ganz unterschiedliche Personengruppen zusammenführte. Wünschenswert wäre es, wenn sich dies auch in einem Nutzungskonzept für den gegenwärtigen Ort widerspiegeln würde. 


\section{Andreas Stegmann}

\section{Das Graue Kloster von der Einführung der Reformation bis zur Begründung des Gymnasiums (1540-1574)}

\section{Die Reformation in Berlin}

Dass es für Deutschlands mittlerweile größte und seit dem 18. Jahrhundert auch kirchengeschichtlich bedeutsamste Stadt keine verlässliche Darstellung ihrer Reformationsgeschichte gibt, ist eine bemerkenswerte Leerstelle wissenschaftlicher Geschichtsforschung, die auch das Desinteresse städtischer Erinnerungskultur am Reformationsjahrhundert widerspiegelt. Wer sich für die kirchliche Erneuerung in der Doppelstadt Berlin-Cölln, die sich rasch und umfassend in den Jahrzehnten in der Mitte des 16. Jahrhunderts vollzog und die Geschichte der Stadt im Allgemeinen und die ihres Kirchenwesens im Besonderen langfristig bestimmte, interessiert, muss bis 1839 zurückgehen, um eine akzeptable Überblicksdarstellung zu finden. ${ }^{1}$ Die allerdings krankt wie viele andere jüngere, forschungsgeschichtlich irrelevante Überblicke - daran, dass die städtische Reformationsgeschichte mit der territorialen, die sich wegen der Residenzstadtfunktion von Berlin-Cölln eben auch in dieser Stadt abgespielt hat, vermischt wird und hinter diese zurücktritt. Wer noch einmal ein Jahrhundert zurückgeht, erhält mit dem von Johann Christoph Müller und Georg Gottfried Küster zusammengestellten Werk, Altes und Neues Berlin' die einzige wirklich an der städtischen Kirchengeschichte interessierte Darstellung, die zudem eine Fülle von heute verlorenen Quellen verarbeitet, allerdings nicht modernen Erfordernissen an eine Darstellung städtischer Reformationsgeschichte entspricht. ${ }^{2}$ Auch wenn man nach wissenschaftlich relevanten Einzelstudien zur Berlin-Cöllner Kirchengeschichte des 16. Jahrhunderts sucht, fällt die Ausbeute mager aus, selbst wenn sich mittlerweile ein vermehrtes Interesse an diesem Thema feststellen lässt, das sich in biografisch-bibliografischen Studien ${ }^{3}$ und der Erschließung wichtiger Quellen ${ }^{4}$ niederschlägt.

$1 \quad$ Ludwig Frege, Berlin unter dem Einflusse der Reformation im sechszehnten Jahrhundert, Berlin 1839.

2 Johann Christoph Müller/Georg Gottfried Küster, Altes und Neues Berlin. Das ist: Vollständige Nachricht von der Stadt Berlin [...], vier Bde., Berlin 1737-1769.

3 Adolf Laminski, Georg Buchholzer. Erster evangelischer Prediger in Buckow, Schöna und Arnswalde sowie Propst an St. Nikolai in Berlin, in: Jahrbuch für brandenburgische Landesgeschichte 50 (1999), S. 62-112; Lothar Noack/Jürgen Splett, Bio-Bibliographien. Brandenburgische Gelehrte der Frühen Neuzeit. Mark Brandenburg mit Berlin-Cölln 1506-1640, Berlin 2009; Christiane Schuchard, Die Geistlichkeit am Hof der Kurfürsten von Brandenburg im 16. Jahrhundert, in: Frank Göse (Hrsg.), Reformation in Brandenburg. Verlauf, Akteure, Deutungen (Schriften der Landesgeschichtlichen Vereinigung für die Mark Brandenburg, N. F. 8), Berlin 2017, S. 113-134; dies., Stiftspersonen. Das Personal des ,Domstifts‘ oder ,Neuen Stifts‘ zu Cölln an der Spree (1536-1608), in: Berlin in Geschichte und Gegenwart. Jahrbuch des Landesarchivs Berlin 2017, S. 7-75.

4 Adolf Laminski, Notizen zur ältesten Berliner Bibliothek. Ein Forschungsbericht, in: Evangelische Kirche BerlinBrandenburg-schlesische Oberlausitz. Archivbericht 18 (2013), S. 61-68; Christiane Schuchard, Die ältesten Rechnungsbücher der Berliner Pfarrkirchen St. Nikolai und St. Marien, in: Berlin in Geschichte und Gegenwart. Jahrbuch des Landesarchivs Berlin 2013, S. 7-60; dies., Das ,Domstift‘ oder ,Neue Stift' zu Cölln an der Spree im Lichte seiner Rechnungsbücher-Überlieferung aus dem letzten Drittel des 16. Jahrhunderts, in: Berlin in Ge- 
Diese modernen Erfordernisse wurden vor allem in der zweiten Hälfte des 20. Jahrhunderts formuliert und in Gestalt der von den 1970er- bis zu den 1990er-Jahren blühenden historischen Forschung zum Thema ,Stadt und Reformation' in einer Fülle von Arbeiten an einzelnen Beispielen veranschaulicht. ${ }^{5}$ In dreierlei Hinsicht ist die städtische Reformationsgeschichte zu erforschen: hinsichtlich des Verlaufs der Reformation (diachron-prozessuale Perspektive), hinsichtlich der Akteure (synchron-strukturelle Perspektive) und hinsichtlich der den Verlauf und den Erfolg der Reformation bestimmenden Faktoren (interpretativ-analytische Perspektive). Während die ältere stadtgeschichtliche Forschung vor allem an der diachron-prozessualen Perspektive interessiert war, hat die neuere sozialgeschichtlich inspirierte Forschung die synchron-strukturelle Perspektive als gleichberechtigtes Forschungsinteresse etabliert und damit die eigenständige Thematisierung der interpretativ-analytischen Perspektive angeregt. Dass die Doppelstadt Berlin-Cölln von der lange boomenden Forschung zum Thema ,Stadt und Reformation' übersehen wurde, hängt nicht nur mit dem Desinteresse an der brandenburgischen Landes- und der Berliner Stadtgeschichte des 16. Jahrhunderts zusammen, sondern auch mit der schwierigen Quellenlage. Während andere deutsche Städte reiches Material für die Behandlung aller drei Perspektiven bieten, sodass die Schwierigkeit eher darin besteht, die Fülle der Quellen zu bändigen, ist für BerlinCölln nur wenig überliefert und scheint auch im Reformationsjahrhundert selbst wenig vorhanden gewesen zu sein. ${ }^{6}$ Die heute verfügbaren Quellen erlauben nur, den Verlauf der kirchlichen

schichte und Gegenwart. Jahrbuch des Landesarchivs Berlin 2015, S. 7-54; dies., Die ältesten Rechnungsunterlagen der Pfarrkirche St. Petri zu Cölln an der Spree (1558-1604). Mit neuen Quellenfunden zur Tätigkeit des kurfürstlichen Hofmalers Michel Ribestein, in: Evangelische Kirche Berlin-Brandenburg-schlesische Oberlausitz. Archivbericht 20 (2017), S. 47-56. Mittlerweile ist der Band mit den Visitationsakten zu Berlin-Cölln erschienen: Die brandenburgischen Kirchenvisitations-Abschiede und -Register des XVI. und XVII. Jahrhunderts, Bd. 4: Die Mittelmark, T. 1: Mittlere Mittelmark. Aus dem Nachlass von Victor Herold [...], bearb. von Christiane Schuchard (Veröffentlichungen der Historischen Kommission zu Berlin, Bd. 109/1), Berlin/Boston 2019 [im Folgenden: BKVAR 4/1].

$5 \quad$ Einen guten Überblick über die Forschung der 1970er- und 1980er-Jahre gibt Bernhard Rüth, Reformation und Konfessionsbildung im städtischen Bereich. Perspektiven der Forschung, in: Zeitschrift der Savigny-Stiftung für Rechtsgeschichte, Kanonistische Abteilung 77 (1991), S. 197-282. Das Büchlein, das die Forschungsdiskussion in den 1960er-Jahren entscheidend angeregt hat, ist mit einem die Forschungsgeschichte skizzierenden Vorwort neu aufgelegt worden: Bernd Moeller, Reichsstadt und Reformation, bearb. Neuausgabe, hrsg. von Thomas Kaufmann, Tübingen 2011.

6 Drei Archive sind wichtig: Die Bestände des Archivs des Berliner Magistrats sind durch die Ungunst der Zeitläufte stark zusammengeschmolzen. Heute gibt es im Landesarchiv Berlin [im Folgenden: LAB] nur noch wenige Urkunden und Akten aus dem Reformationsjahrhundert, z. B. die Akten zu den Visitationen und zum Schulwesen (LAB, A Rep. 4, Nr. 9; Rep. 20-2, Nr. 553). Günstiger ist die Überlieferungslage im Archiv der Territorialobrigkeit, dessen Berlin-Cölln betreffende Bestände sich heute ganz überwiegend im Geheimen Staatsarchiv PreuBischer Kulturbesitz [im Folgenden: GStA PK] befinden (GStA PK, I. HA, Rep. 21, Nr. 23-26, mit zahlreichen Faszikeln, die vor allem das 17. und 18. Jahrhundert betreffen). Allerdings findet sich hier - abgesehen von den Akten zu den Visitationen (GStA PK, I. HA, Rep. 47, Nr. 15; Rep. 47, Tit. B 4; Rep. 47, Tit. C 4; Rep. 99, Nr. 174, Nr. 184, Nr. 458 u. a.) - nicht allzu viel kirchengeschichtlich Relevantes. Die Archive der Kirchengemeinden St. Marien-St. Nikolai Berlin und St. Petri Cölln, die heute als Depositum im Evangelischen Landeskirchlichen Archiv Berlin [im Folgenden: ELAB] verwahrt werden (ELAB 10109/11), weisen ebenfalls erhebliche Verluste auf. Was erhalten ist, setzt vielfach erst im 17. oder gar im 18. Jahrhundert ein und ist darum für die Erforschung der Reformationsgeschichte von geringem Interesse. Gleiches gilt für das in der Berliner Zentral- und Landesbibliothek verwahrte Archiv des Gymnasiums zum Grauen Kloster (Sonderbestand, Streitsche Stiftung). Die er- 
Erneuerung in groben Zügen nachzuzeichnen, und geben allenfalls punktuell Einblick in die sozial- und mentalitätsgeschichtlichen Tiefendimensionen dieser Entwicklung.

Die reformatorische Verkündigung drang schon in den 1520er-Jahren vom benachbarten Kursachsen in die Mark Brandenburg ein und dürfte auch in der Residenz- und Handelsstadt BerlinCölln auf Interesse gestoßen sein. ${ }^{7}$ Vereinzelte Hinweise zeigen, dass das städtische Kirchenwesen, das unter dem Schutz des die Reformation bekämpfenden kurfürstlichen Patrons stand, bis Mitte der 1530er-Jahre zwar stabil blieb, aber auch schon Auflösungserscheinungen zeigte. Doch diese Hinweise lassen es nicht zu, eine anfängliche ,Inkubations-' und eine darauffolgende ,Konfliktphase` zu rekonstruieren, wie sie für die städtische Reformation andernorts typisch sind. Die Öffnung für die Reformation in der Bevölkerung scheint sich untergründig vollzogen zu haben und bis Ende der 1530er-Jahre nur verklausuliert geäußert worden zu sein. Erst der Antrag der Bürgerschaften und Repräsentanten beider Städte an Kurfürst Joachim II. im Februar 1539, beim bevorstehenden Osterfest das Abendmahl unter beiderlei Gestalt, also mit Brot und Wein für die Gemeinde, zu feiern, ist ein unzweifelhaftes Zeugnis für reformatorische Sympathien. ${ }^{8}$ Erst mit der offiziellen Einführung der Reformation zwischen Herbst 1539 und Sommer 1540 beginnen die Quellen etwas reichlicher zu fließen. Über die dritte und vierte Phase städtischer Reformation - die ,Institutionalisierungs- und die ,Konfessionalisierungsphase ‘ - sind wir dank der Visitationsabschiede der Jahre 1540, 1551, 1574 und 1600 gut informiert. ${ }^{9}$ Die Etablierung der Reformation vollzog sich in den 1540er- und 1550er-Jahren rasch und ohne erkennbare Widerstände - Berlin und Cölln wurden binnen einer Generation zu evangelischen Städten, die am Aufblühen der lutherischen Konfessionskultur in der Mark Brandenburg von Anfang an teilhatten.

heblichen Lücken können nur teilweise durch Quellenabdrucke oder Paraphrasen und Zusammenfassungen von Aktenstücken in der Literatur geschlossen werden (vgl. die nützliche Übersicht: Regesten der Urkunden zur Geschichte der Stadt Berlin 1500 bis 1815, bearb. von Gaby Huch [Berlin-Forschungen der Historischen Kommission zu Berlin, Bd. 5], Berlin 2004). Neben den Schriftquellen sind die Sachquellen wichtig: die Kirchengebäude und ihre Ausstattung, besonders die sozial- und frömmigkeitsgeschichtlich aufschlussreichen Epitaphien (vgl. den Katalog: Cranach und die Kunst der Renaissance unter den Hohenzollern. Kirche, Hof und Stadtkultur, hrsg. von der Generaldirektion der Stiftung Preußische Schlösser und Gärten Berlin-Brandenburg und der Evangelischen Kirchengemeinde St. Petri-St. Marien, Berlin 2009, sowie den Beitrag von Doris Bulach in diesem Band).

7 Zur Geschichte der Reformation in der Mark Brandenburg: Andreas Stegmann, Deutung und Bedeutung der brandenburgischen Reformation, in: Göse, Reformation in Brandenburg, S. 63-92; ders., Die Reformation in der Mark Brandenburg, Leipzig 2017; ders., Die Kirchenpolitik des brandenburgischen Kurfürsten Joachim II. (1535-1571), in: Jahrbuch für Berlin-Brandenburgische Kirchengeschichte [im Folgenden: JBBKG] 71 (2017), S. 42-148; ders., Konfessionelle Kultur im frühneuzeitlichen Brandenburg, in: JBBKG 72 (2019), S. 211-213 (vgl. die Beiträge, die das Thema an einzelnen Beispielen veranschaulichen: ebd., S. 214-276); Quellen zur brandenburgischen Reformationsgeschichte (1517-1615), bearb. von dems., Tübingen 2020 (hier sind auch wichtige Quellen zur Berliner Reformationsgeschichte abgedruckt [im Folgenden: QBR]).

8 QBR, Nr. 54.

9 Abdruck der vier Dokumente: BKVAR 4/1, S. 31-39, 96-98, 157-186, 186-208; QBR, Nr. 91, 154, 194, 217. 


\section{Das Graue Kloster in Berlin zwischen 1540 und $1574^{10}$}

Der Berliner Franziskanerkonvent war im späten Mittelalter zwar nicht Teil des städtischen Kirchenwesens, wohl aber stand seine Konventskirche den Stadtbürgern offen, gehörten doch die religiöse Unterweisung und die seelsorgerliche Betreuung der Bevölkerung zu den Aufgaben dieses Mendikantenordens. Die Franziskanerklosterkirche kann durchaus als Bürgerkirche gelten, war doch das geistliche Angebot der Franziskaner selbstverständlicher Teil des kirchlichen Lebens der Stadt. Als sich die Sympathien für die Reformation in der Stadtbevölkerung auszubreiten begannen, war der Franziskanerkonvent davon unmittelbar betroffen, ohne dass wir wissen, wie sich das Verhältnis der Brüder zur Bevölkerung im Laufe der 1520er- und 30er-Jahre veränderte.

Zwei Vorgänge aus der Zeit um 1540 sind bekannt, von denen aber unklar ist, ob man in ihnen Spuren eines grundlegenden Wandels im Verhältnis von Konvent und Bevölkerung sehen kann. So widmete Katharina Butenius 1538 die Erträge einer Wiese, die bislang den Mendikantenkonventen in Berlin und Cölln zugeflossen waren, um: Sie kamen in Zukunft der Finanzierung eines Prädikanten an der Cöllner Petrikirche zugute. ${ }^{11}$ Zwei Jahre später gab es eine Auseinandersetzung zwischen dem Berliner Franziskanerkonvent und der Stadt Spandau: In Spandau hatten die Berliner Franziskaner ein Terminierhaus, das wegen des Armutsgebots formal nicht in ihrem Besitz war, aber von den Brüdern genutzt wurde. Als der Spandauer Rat den Berliner Franziskanern die Nutzung des Terminierhauses entziehen wollte, baten der Guardian und die Ältesten des Konvents, das Haus weiterhin für die Brüder offenzuhalten. ${ }^{12}$ Sie rechneten wohl damit, dass der Konvent seinen Finanzbedarf auch weiterhin durch den Bettel decken konnte.

Ein deutlicheres Indiz für den Wandel, der sich um 1540 vollzog, bietet die Nachricht über die Inobhutnahme des Kirchensilbers des Konvents. Nachdem Anfang August in den Kirchengemeinden von Berlin und Cölln mit der kurfürstlichen Kirchenvisitation begonnen worden war, musste

10 In der einschlägigen Literatur zum Berliner Franziskanerkonvent und zum Gymnasium zum Grauen Kloster wird die Periode zwischen Einführung der Reformation und Schulgründung oft nur kursorisch behandelt (Johann Joachim Bellermann, Das graue Kloster in Berlin, mit seinen alten Denkmälern [... ], T. 1, Berlin 1823, S. 60-70; T. 3, Berlin 1825, S. 4-15; Gustav Abb/Gottfried Wentz, Das Bistum Brandenburg, T. 1, Berlin 1929, S. 371-378; Peter Riedel u. a., Berlin Franziskaner, in: Heinz-Dieter Heimann u. a. (Hrsg.), Brandenburgisches Klosterbuch. Handbuch der Klöster, Stifte und Kommenden bis zur Mitte des 16. Jahrhunderts (Brandenburgische Historische Studien, Bd. 14), 2 Bde., 1. Aufl., Berlin 2007, Bd. 1, S. 146-159). Am ausführlichsten ist die Darstellung von Julius Heidemann, Geschichte des Grauen Klosters zu Berlin, Berlin 1874, S. 43-117. Heidemanns Darstellung ist nicht überholt und dürfte angesichts der seither eingetretenen Quellenverluste auch nicht mehr überholt werden können, weshalb sich der vorliegende Beitrag auf einen knapp gehaltenen Überblick beschränken kann. Zum Schicksal des Klosterwesens in der Mark Brandenburg siehe neben dem eben angeführten Brandenburgischen Klosterbuch auch die Überblicksdarstellung von Walter Ziegler, Klosteraufhebung im Zeitalter der Reformation in der Mark Brandenburg, in: ders., Die Entscheidung deutscher Länder für oder gegen Luther. Studien zur Reformation und Konfessionalisierung im 16. und 17. Jahrhundert, Münster 2008, S. 247-274.

11 Johann Gustav Reinbeck, Umständliche Nachricht/Von dem erschrecklichen Brande In der Königl. ResidenzStadt Berlin/Durch welchen in der Nacht zwischen dem zweyten und dritten Pfingst-Tage dieses 1730sten Jahres nicht nur der an der St. Petri-Kirche neuerbaute und bald fertige, aber mit seinem völligen Gerüste noch versehene Hohe Thurm [...] sondern auch die Kirche [...] in einen Stein- und Aschen-Hauffen verwandelt worden. Nebst einer Beschreibung gedachter Kirchen, Berlin 1730, S. 73.

12 Historisch-diplomatische Beiträge zur Geschichte der Stadt Berlin, T. 4: Berlinische Urkunden von 1232 bis 1700, hrsg. von Ernst Fidicin, T. 4, Berlin 1842, S. 219 f., Nr. 202, S. 256-258, Nr. 224 f., S. 261 f., Nr. 227. 
der Franziskanerkonvent Monstranzen, Kreuze, Kelche und Patenen an die kurfürstlichen Silberknechte abliefern. ${ }^{13}$ Die Wertgegenstände gingen anschließend in die Verfügungsgewalt des Berliner Rats über. Vermutlich ging es bei diesem Vorgang nicht darum, die Wertgegenstände zu sichern, um sie auf Anfrage dem Konvent für die liturgische Nutzung zu überlassen, sondern um eine Enteignung zugunsten der kurfürstlichen Kasse. Dieser Eingriff war aber nicht die größte Gefährdung des Konvents. Entscheidend war, dass die von Kurfürst Joachim II. 1539/40 verfügten kirchlichen Reformen den Konvent seines institutionellen Rückhalts beraubten. Zwar wurden im Kurfürstentum Brandenburg die Klöster nicht einfach aufgelöst und die Mönche und Nonnen entlassen, aber es wurde den Klosterinsassen freigestellt, die Konvente zu verlassen. Gottesdienst und geistliches Leben wurden im Sinne der Reformation umgestaltet und das Klostervermögen wurde vielfach entfremdet. ${ }^{14}$ Drastische Folgen hatten diese Veränderungen vor allem für die städtischen Konvente der Bettelorden, denen mit einem Mal die religiöse Funktion und damit die ökonomische Basis abhandenkam, lebten die Mendikanten doch von Zuwendungen, die sie im Gegenzug für ihre religiösen Dienstleistungen erhielten. Auch in Berlin scheint der Konvent seit dem Ende der 1530er-Jahre rasch zusammengeschmolzen zu sein, sodass sich seit den 1540er-Jahren nur noch eine Handvoll Franziskaner auf dem großen Areal fand, die den Konvent nicht verlassen wollten oder konnten und auf die Mildtätigkeit von Bürgern und Stadt angewiesen waren. Es ist anzunehmen, dass diese verbliebenen Brüder - wie wir auch von anderen Rumpfkonventen wissen - ihre Messen und Stundengebete weiterzuführen versuchten und eine Zeitlang noch dem weiterhin der Papstkirche treuen Teil der Stadtbevölkerung Rückhalt boten. ${ }^{15}$ Der letzte Berliner Franziskaner soll chronikalischen Nachrichten zufolge 1571 verstorben sein. ${ }^{16}$ Mangels Quellen lässt sich zu den mehr als dreißig Jahren zwischen Einführung der Reformation und Versterben des letzten Bruders aber nichts Genaueres sagen.

13 Historisch-diplomatische Beiträge zur Geschichte der Stadt Berlin, hrsg. von Ernst Fidicin, T. 2: Berlinische Urkunden von 1261 bis 1550, Berlin 1837, S. 350-353, Nr. 211.

14 Was für den Franziskanerkonvent in der Altstadt Brandenburg galt, dem Kurfürst Joachim II. im November 1539 die Feier der römischen Messe untersagte und auf die neue reformatorische Gottesdienstordnung - die allerdings noch gar nicht veröffentlicht war - verpflichtete (Konzept: GStA PK, I. HA, Rep. 47, Lit. B, Nr. 2 [Paket 15763], Fasz. 1, Bl.3r-5r; Abdruck der Ausfertigung: Urkunden des Magistrats-Archivs zur Reformations-Geschichte der Stadt Brandenburg, hrsg. von Rudolf Grupp, in: Jahresbericht über den historischen Verein zu Brandenburg a. d.H. 13-16 (1884), S. 93-109, hier S. 99-101; QBR, Nr. 73), dürfte auch für die Berliner Franziskaner gegolten haben. Zur Geschichte des Brandenburger Konvents: Johannes H. Gebauer, Zur Geschichte der letzten Mönche in der Mark, in: Zeitschrift für Kirchengeschichte 21 (1901), S. 380-398.

15 Noch 1558 stiftete der altgläubige Havelberger Domdekan Peter Conradi in seinem Testament Geld, damit die Berliner Franziskaner ihn in ihre Totenmemoria einschlossen (Codex diplomaticus Brandenburgensis. Sammlung der Urkunden, Chroniken und sonstigen Quellenschriften für die Geschichte der Mark Brandenburg und ihrer Regenten, Hauptt. I, Bd. 3, hrsg. von Adolph Friedrich Riedel, Berlin 1843, S. 157-164, Nr. 75, hier S. 161). Als aber der päpstliche Nuntius Giovanni Franceso Commendone zwei Jahre später durch die Mark reiste und gezielt der Papstkirche loyale Konvente aufsuchte, ließ er die Berliner Franziskaner aus (Reisebericht von Fulvio Ruggieri: Biblioteca Apostolica Vaticana, Chigiano M I 2, Bl. 1r-69v, hier Bl. 13rv; QBR, Nr. 174). Möglicherweise hielt es der Nuntius auch für unangebracht, einen solchen Besuch unter den Augen des Kurfürsten in dessen Residenzstadt zu machen.

16 Den vierden Januarij [1571] ist der letzte Mönch im grawen Closter zum Berlin/Bruder Peter genandt/gestorben/vnd folgendes tages gar ehrlich zur Erden bestattet worden (Andreas Angelus, Annales Marchiae Brandenbvrgiae, Frankfurt [Oder] 1598, S. 368 [VD16 E 1181]). 
Entscheidend für das Schicksal des Grauen Klosters war aber eine andere Entwicklung: die Vereinnahmung des Gebäudekomplexes durch die kurfürstliche Verwaltung und die Nutzung der Klosterkirche für den evangelischen Gottesdienst. Offensichtlich betrachtete der Kurfürst die Baulichkeiten des Franziskanerkonvents als sein - nunmehr an den Stifter zurückgefallenes - Eigentum, jedenfalls nutzte er die Gebäude für seine eigenen Zwecke. Der franziskanische Rumpfkonvent scheint noch für einige Zeit dort geduldet worden zu sein, der Großteil der Baulichkeiten diente aber anderen Zwecken, etwa der Lagerung von Gütern ${ }^{17}$ oder der Unterbringung von kurfürstlich geförderten Einrichtungen. ${ }^{18}$ Die Klosterkirche wurde weiter als kirchlicher Raum genutzt: zum einen für besondere Versammlungen wie Disputationen ${ }^{19}$ oder Amtsträgersynoden, ${ }^{20}$ zum anderen für Gemeindegottesdienste. Während der 1560er-Jahre sollten im Gebäudekomplex des Franziskanerkonvents ein fürstliches Hospital ${ }^{21}$ und eine neu $\mathrm{zu}$ gründende Stadtschule ${ }^{22}$ untergebracht werden, wobei weder die Initiative des Landesherrn noch die der Stadtbürger zum Ziel kam.

Wie sich das Hineinwachsen der Klosterkirche in das städtische Kirchenwesen vollzog, lässt sich anhand der spärlich überlieferten Quellen nicht erkennen, nur das Ergebnis ist klar: Bei der Visitation im Jahr $1574^{23}$ war die Klosterkirche die fünfte Gottesdienststätte neben den beiden Pfarrkirchen Sankt Nikolai und Sankt Marien und den beiden Hospitalkapellen Heiliggeist und Sankt Georg; es gab dort eine Orgel, die vom Nikolai-Organisten gespielt wurde; die Kapläne (Diakone) von Sankt Nikolai übernahmen die Predigtpflichten; und der Klosterkirche wurde ein Pfarrbezirk zugeordnet, nämlich die Straßenzüge am östlichen Rand der Stadt. Die im Geheimen

17 Wahrscheinlich wurden die Klostergebäude vom Amt Mühlenhof mitgenutzt, das für die Versorgung des Hofs (und auch der Kirchengemeinden) mit Naturalien verantwortlich war (Friedrich Holtze, Das Amt Mühlenhof bis 1600, in: Schriften des Vereins für die Geschichte Berlins 30 [1893], S. 19-39).

18 So wurde für anderthalb Jahrzehnte Leonhard Thurneysser im Klosterkomplex untergebracht, wo er ein Labor und eine Druckerei betrieb (Heidemann, Geschichte des Grauen Klosters, S. 104-117).

19 Im Zusammenhang des Streits um die Himmelfahrt Mariens, in dem sich der Berliner Propst Georg Buchholzer und der kurfürstliche Hofprediger Johannes Agricola gegenüberstanden, lud Agricola 1558 die Geistlichen aus Stadt und Umland in die Klosterkirche zu einer Disputation ein, die dann allerdings vom Kurfürsten untersagt wurde. Die Aktensammlung Buchholzers zum Vorgang ist erhalten: GStA PK, VI. HA, Nl. Johann Christoph Beckmann, Nr. 21, Bl. 1100r-1106v (vgl. Müller/Küster, Altes und Neues Berlin, Bd. 1, S. 297-299). Der Vorgang zeigt, dass die Klosterkirche für solche Versammlungen genutzt wurde, dass das Hausrecht jedoch beim Kurfürsten lag.

20 So trafen sich am 22. Juli 1577 mehr als 200 Geistliche aus der Mittelmark in der Klosterkirche, um sich über die Konkordienformel informieren zu lassen (Bericht in einer Sammelhandschrift des 17. Jahrhunderts: Forschungsbibliothek Gotha, Cod. Chart. A 282, Bl. 5r-6v; QBR, Nr. 195).

21 In seinem Testament kündigt Kurfürst Joachim II. 1562 an, noch bei unserm leben in unserm grauen closter zu Berlin ein ansehenlich und furstlich spittal anzurichten, zu vorordnen und zu stiften, das der Armenfürsorge dienen soll (Die Testamente der Kurfürsten von Brandenburg und der beiden ersten Könige von Preußen, hrsg. von Hermann von Caemmerer, München/Leipzig 1915, S. 98; QBR, Nr. 178).

22 Matthaeus Flaccus, Ein Erinnerung: was die Oberkeit zur Pestilentz zeit bestellen/vnd wie sich menniglich fur solcher grausamer Seuch preseruiern/auch aus rechtem grund der Ertzney curirn sol/der gantzen Marck zu Brandeburg/Sonderlich aber beiden Stedten/Berlin vnd Cöln an der Sprew zu nutz gestellet, Wittenberg 1566, B1. E 3r [VD16 F 1615]. Der Berliner Stadtarzt wirbt hier mit dem Verweis auf die Spendensammlung für die Stadtschule unter den Bürgern für die Unterstützung seiner ambitionierten Pläne zur Seuchenvorsorge und -bekämpfung.

23 Visitationsabschied: GStA PK, I. HA, Rep. 99, Nr. 184 (korrigierter und gesiegelter, wohl für die Konsistorialakten bestimmter Entwurf der Visitatoren [Abdrucke: BKVAR 4/1, S. 157-186; QBR, Nr. 194]); LAB, F Rep. 238-1, Nr. 1574/2 (Ausfertigung für die Kirchengemeinde). 
Staatsarchiv Preußischer Kulturbesitz überlieferte Fassung des Visitationsabschieds von 1574 sie bietet den endgültigen Text, weist aber zahlreiche Bearbeitungsspuren auf - verrät, dass die Visitatoren sich unsicher waren, wie der Status der Klosterkirche im kirchlichen Gefüge Berlins zu bestimmen war: Ursprünglich wurden im Text an mehreren Stellen drei Pfarrkirchen aufgezählt - Sankt Nikolai, Sankt Marien, Klosterkirche ${ }^{24}$-, was auf eine Gleichrangigkeit der drei Kirchen hindeutet. Bei der abschließenden Bearbeitung wurde bei diesen Dreieraufzählungen die Klosterkirche gestrichen, wodurch sie zu einer Art Filialkirche von Sankt Nikolai herabgestuft wurde und die traditionelle Zweizahl der Pfarrkirchen bestehen blieb. ${ }^{25}$

Der 1574 festgeschriebene Rechtszustand blieb über Jahrhunderte hinweg erhalten: Die Klosterkirche war eine den beiden Pfarrkirchen nachgeordnete, aber über einen eigenen Pfarrbezirk und Kirchenvorsteher verfügende und für alle Haupt-, Neben- und Kasualgottesdienste zuständige Predigtstätte innerhalb der einen Berliner Kirchengemeinde. Dass das Kirchengebäude auch dem im selben Gebäudekomplex ansässigen Gymnasium als Gottesdienstraum diente - übrigens anfangs nur ergänzend zu den beiden Pfarrkirchen, in denen die Schüler als Chor zu singen hatten -, dürfte gegenüber der Funktion als Gemeindekirche minder wichtig gewesen sein. Die Klosterkirche war nicht Schul-, sondern Bürgerkirche. Diese Funktion hatte sie übrigens sowohl nach als auch vor der Reformation: vor der Reformation als Konventskirche der Minderbrüder, nach der Reformation als Gemeindekirche. Über den Umbruch der Reformation führt also eine Kontinuitätslinie. Anschaulich wird diese Kontinuität auch in den erhaltenen Zeugnissen der Totenmemoria, die sich zwar in Form, Gehalt und Funktion vom Spätmittelalter zur Frühen Neuzeit stark wandelte, aber im Kern dieselbe blieb: Das Kirchengebäude war der Ort, wo die Gemeinschaft der christlichen Gemeinde anschaulich wurde, zu der die Lebenden wie die Verstorbenen gehören, und wo die hier versammelten Menschen im Angesicht ihrer in den Epitaphien vergegenwärtigten Vorfahren Gottesdienst feierten. ${ }^{26}$ Das Kirchengebäude war nur die äußere Hülle für die sich in ihm vollziehende religiöse Praxis, die das Gebäude erhielt und umformte. Diese Verankerung des Grauen Klosters im religiösen Leben der Stadt sollte für die historische Forschung Grund genug sein, die Klosterruine nicht mehr nur archäologisch und baugeschichtlich zu untersuchen, sondern den Blick zu weiten, etwa auf die Geschichte der Klostergemeinde vom 16. bis zum 20. Jahrhundert.

24 GStA PK, I. HA, Rep. 99, Nr. 184, Bl. 13rv.
Das spiegelt sich auch in den kirchlichen Rechnungsbüchern des 16. Jahrhundert wider (zu dieser Quellengattung siehe Schuchard, Die ältesten Rechnungsbücher der Berliner Pfarrkirchen St. Nikolai und St. Marien). Die erhaltenen Rechnungsbücher enthalten nur wenige verstreute Hinweise auf die Klosterkirche. Das hängt möglicherweise auch damit zusammen, dass Kurfürst und Stadt für die bauliche Unterhaltung des Klosterkomplexes sorgten, sodass sich damit in Zusammenhang stehende Ausgaben nicht in den kirchlichen Rechnungsbüchern finden.

Vertraut man den Hinweisen bei Bellermann, Das graue Kloster, T. 1, S. 38, dann wurden schon in den 1550erJahren Epitaphien mit lutherischem Bildprogramm angebracht, was darauf deutet, dass die Klosterkirche von der Stadtbevölkerung als Memorialort in Anspruch genommen wurde. Siehe auch den Ausblick auf die Folgezeit bei Andreas Cante, Die Klosterkirche als Berliner Gedächtnisort. Zur Bedeutung ihrer Grabdenkmäler, in: Landesdenkmalamt Berlin (Hrsg.), Kirchenruine des Grauen Klosters in Berlin. Geschichte - Forschung - Restaurierung (Beiträge zur Denkmalpflege in Berlin, Bd. 23), Petersberg 2007, S. 54-67, sowie den Katalog der Grabdenkmäler ebd., S. 68-72. Die Verstorbenen waren nicht nur symbolisch in Gestalt von Epitaphien präsent, sondern einige wurden auch im Kirchenraum bestattet: „Nach der Reformation wurde der gesamte Kirchenraum offenbar auch in der frühen Neuzeit noch intensiv als Bestattungsplatz genutzt“ (Riedel, Berlin Franziskaner, S. 152). 



\section{Susanne Knackmuß}

\section{,Klostergeist'-Kontinuum in situ. Das Berlinische Gymnasium zum Grauen Kloster}

daß unsere Schul= und Kloster Gebäude von der Art sind, daß wir es nirgends wieder werden so finden können \& sind dieselben von derjenigen Festigkeit, [...], werden biß an den Jüngsten Tage stehen können (Lehrerkollegium des Grauen Klosters 1705)

Die Klosterstraße zwar bestand Noch heimlich, still und leise; Sie war auch noch nicht umbenannt Ganz sonderbarerweise.

Das Graue Kloster stand noch da In wesentlichen Teilen; Die Schönheitsfehler, die ich sah, Wird wohl die Zukunft heilen (Klosteraner 1946) ${ }^{1}$

Unter dem Kurznamen Graues Kloster war das Berlinische Gymnasium zum Grauen Kloster bis in das 20. Jahrhundert jedem gebildeten Berliner ein Begriff und damit en passant das mittelalterliche Franziskaner- oder Barfüßerkloster. Das Graue Kloster ${ }^{2}$ blieb mit seinen Bauten und nicht zuletzt durch Tausende von Schülern und Abiturienten in der Öffentlichkeit präsent. Ein Kontrast zu dem Schwarzen Kloster der Dominikaner in Cölln, welches durch die Umwandlung 1536 in ein Stift, später in eine protestantische Domkirche und den Abriss der Konventsgebäude heute aus dem Bewusstsein der breiteren Öffentlichkeit verschwunden ist.

Ab 1574 war das Graue Kloster in seinen vom Kurfürsten geschenkten Gebäuden seiner Bildungsbestimmung, seit 1923 erweitert um Schülerinnen, nachgekommen. Niemanden verwunderte die in einer protestantisch geprägten Stadt bemerkenswerte Aussage: ,Ich gehe aufs Graue Kloster. Der Kurzname erschien den gelehrten Rektoren um 1800, die sich der (Berliner) Aufklärung und der Fortschrittspädagogik verschrieben hatten, zwar unzeitgemäß, doch er blieb. Erst die politisch Verantwortlichen in der Deutschen Demokratischen Republik (DDR) tilgten den Schulnamen 1958, da die Kombination aus Gymnasium (diese Schulform wurde als sogenannte Standesschule in der DDR generell aufgelöst) und der christlichen Grundierung beziehungsweise Herkunft (des Namens) für das Bildungssystem der DDR untragbar erschien. Das Berlinische Gymnasium zum Grauen Kloster war die letzte Schule in der DDR, die das althergebrachte Wort im offiziellen Schulnamen führte.

1 Als Klosteraner werden die Schüler des Grauen Klosters bezeichnet, die Lehrkräfte wurden Klosterlehrer beziehungsweise Klosterrektoren genannt, ab 1767 Klosterdirektoren. Die Zitate entstammen Archivalien in den Sammlungen des Berlinischen Gymnasiums zum Grauen Kloster (Streitsche Stiftung) [im Folgenden: SGK1 (St St)], GKl Archiv I/3/12 und NL Kurt Bernhard, darin: Hans Jäckel, Urian, 1946 (Typoskript). Dieser Eigenname findet hier, wie seit der Frühen Neuzeit üblich, nur für die Schule Verwendung. 
Die Zerstörung der zum Teil noch mittelalterlichen Schulgebäude in der Klosterstraße in den letzten Kriegsmonaten 1945, die Ausweichquartiere seit Juni 1945 in der Weinmeister- und Niederwallstraße (seit 1949), die Umbenennung des Gymnasiums 1958 in ,Oberschule II BerlinMitte, später ,2. EOS Berlin-Mitte', die bewusst mit dem Bruch des Althergebrachten einherging, waren dazu geeignet, der Schultradition ein Ende zu bereiten. Dennoch stellte sich der ,Klostergeist' 1958 den sozialistischen Bemühungen im DDR-Schulwesen offenbar derart auffällig in den Weg, dass eine Zeitung im Zuge der Umbenennung erwartungsfroh postulierte, Klostergeist wird ausgetrieben. ${ }^{3}$ Explizit wurde so anerkannt, dass es einen solchen lebendigen Geist der Schule und ihrer Schüler über alle historischen Brüche hinweg gegeben hat und erst dessen Beseitigung die vollständige Eingliederung in das staatliche DDR-Bildungsgefüge ermöglichen würde. Der ,Klostergeist' war für seine Verehrer, die ihn in Liedern besangen ${ }^{4}$ und zu fördern suchten, aber auch für seine bildungspolitischen Gegner nach 1945 ein Faktum.

\section{,Klostergeist' - Traditionsbewusstsein und genius loci}

Karl Kinzel, von 1875 bis 1921 Klosterlehrer, definierte ihn als eine Art Traditionsbewusstsein, das sich aus den alten Gemäuern sowie der Zugewandtheit und allgemeinen Liberalität im Umgang zwischen Lehrern und Schülern ergab. Diese bewusst gepflegte, sorgsam tradierte Liberalität hatte ihren Ursprung im Selbstverständnis und der Bedeutung frühneuzeitlicher Gymnasien. Das Wohnen der Lehrerfamilien auf dem Gelände, es zog Eheschließungen einstiger Spielkameraden und somit eine Verschwägerung der Klosterlehrerfamilien (,Des Klostergeistes weibliche Linie $^{\text {(5) }}$ nach sich, strahlte aus. Kinzel beschrieb vielfältige Faktoren, denn obwohl der Direktor die Lehrer gewähren ließ, schnitt das Graue Kloster bei Revisionen und beim Abiturienten-Examen immer ziemlich gut ab. Und: Überraschend war es mir, daß Schüler, die von uns auf andere Schulen gingen, stets versicherten, im Kloster würde mehr verlangt und mehr geleistet. Es muß wohl daran gelegen haben [...], daß [...] über dem Ganzen eine geheime Macht schwebte, die man als Klostergeist bezeichnete. Es ist mir damals klar geworden, wieviel solch täglicher Anblick altehrwürdiger Gebäude und wertvolle Überlieferungen [Archiv-, Bibliotheks- und Kunstbestände, SK] auf Lehrer und Schüler wirken können. ${ }^{6}$ Kinzel sah die Geschichte, die Tradition und die alten mit Kunstwerken verzierten Gemäuer als eine Art Kraftquelle, die Bildungserfolge bewirkte. Die starke Verbundenheit der Lehrer drückte sich im Widerstand gegen jedwede Verlegungspläne, auch in modernere Gebäude, aus. Und im Ankauf angrenzender Grundstücke um 1900 aus schulischen Stiftungsmitteln zur Erweiterung des Schulgeländes, um, so der Direktor, die Schule auf lange Zeit, vielleicht auf Jahrhunderte in den Stand zu setze[n], ihre segensreiche Wirksamkeit an der alten Stätte, an der tausende von Schülern mit Liebe und Verehrung hängen ausüben zu können. ${ }^{7}$ Die Anhänglichkeit

3 Klostergeist wird ausgetrieben, in: Die Junge Welt, 19. Juni 1958.

4 Zum Beispiel Der alte gute Klostergeist: Wer einmal Klosteraner war, Der bleibt es für sein Leben, Den wird, verjüngend immerdar, Der Klostergeist umschweben. Vgl. auch: Ausschuß für die Klosterfeste (Hrsg.), Klosterlieder 18261885. Zur 25jährigen Jubelfeier der Klosterfeste am 4. Dezember 1885 [Berlin 1885].

5 Titel der Lehrerfamilien-Stammtafel, in: Harald Scholtz, Gymnasium zum Grauen Kloster 1874-1974. Bewährungsproben einer Berliner Gymnasialtradition in ihrem vierten Jahrhundert (Bibliothek für Bildungsforschung, Bd. 8), Weinheim 1998, S. 74.

6 Karl Kinzel, Kloster-Erinnerungen 1875-1920, zit. nach Abdruck in: Scholtz, Gymnasium, S. 52-66, hier S. 53.

7 Ludwig Bellermann, Zur Verhandlung am 24.11.1904 (Typoskript), in: SGKl (St St), GKl Archiv II/4/36, S. 5. 
der Schüler zeigte sich in Kommersen und in tätiger Unterstützung (testamentarische Verfügungen und Alumni-Stiftungen seit dem 17. Jahrhundert). Diese Stiftungen trugen dann durch die Förderung begabter, zumeist ärmerer Knaben, die mit Intelligenz und Fleiß ihre Bildungs- und Aufstiegschancen nutzten, en passant zum guten Ruf dieser nur in Bezug auf die fachliche Leistung strengen Schule bei. Der Klosterdirektor Friedrich Hofmann, zuvor Berliner Stadtschulrat, resümierte zur Disziplin 1876 gegenüber dem Provinzialschulkollegium: Die alte Tradition, den Schülern möglichst viel Freiheit zu laßen, ist sorgfältig aufrecht erhalten worden und es ist durchaus keine Veranlaßung gewesen, eine genauere Ueberwachung oder strengere Behandlung eintreten zu laßen. Die Klosteraner haben von jeher eine große Anhänglichkeit an ihre Schule gehabt und eine recht vorgebrachte Ermahnung, daß sie dem Kloster nicht Schande machen möchten, ist stets wirksamer gewesen als Strafen. So ist es leicht gewesen, Zucht und Ordnung aufrecht zu erhalten. ${ }^{8}$ Kinzel, kein Klosteraner, staunte über die lockere Disziplin und die größte Freiheit in der ehrwürdigen Anstalt. Schwere Strafen seien selten, denn die Weisheit der Lehrer tat natürlich hier viel, aber doch sicher auch die Tradition, der Klostergeist. Es schien, als wenn hier die Schüler nicht von der so weit verbreiteten Vorstellung beherrscht wurden, daß der Lehrer ihr natürlicher Feind wäre. ${ }^{9}$

Die Schulatmosphäre prägte, dass viele Klosterlehrer die Anstalt und die angestammten Freiheiten ihrer Gymnasiasten zuvor selbst in ihrer Jugend als Klosteraner kennen- und schätzen gelernt hatten. Freiheit, Lebensfreude, Tradition und ein Bildungsanspruch, der mit fachlich-inhaltlicher Strenge verbunden gewesen zu sein scheint, schlossen sich hier offenbar nicht aus. Scholtz sah ein Problem darin, dass nicht nur die Gebäude, sondern auch der Archiv-, Bibliotheks- und Kunstbesitz des Grauen Klosters nach 1945 teilweise vernichtet worden war und der Rest von der Schule getrennt wurde. Dies habe eine Störung der gesellschaftlichen Funktion dieser Anstalt nach sich gezogen, da diese „identitätsstiftend und traditionsbildend“ gewirkt hatten, obgleich dieses Erbe der Schule „weniger die Heranwachsenden als die historisch bewußte Öffentlichkeit“ herausgefordert habe und nun nurmehr als ein „Zeugnis einer längst abgerissenen Beziehung zwischen Bürgertum und Schule an eine vergangene Schulkultur" erinnere. ${ }^{10}$

Aus diesem Traditionsbewusstsein, diesem seit dem 17. Jahrhundert immer wieder nach innen und außen postulierten Bewusstsein, die älteste Schule Berlins, das älteste an der immer gleichen Stelle in der ständig größer werdenden Stadt bestehende Gymnasium zu besuchen, erwuchs eine spezielle Haltung. Sie spiegelt sich im Vertrauen des Klosteraners Jäckel 1946 auf die Wiederherstellung der zerstörten Schule. Die Schulgebäude standen mit ausgebrannten Dächern zum Teil noch bis in die zweite Etage, zumal die mittelalterlichen Gewölbe Bomben und Feuer standgehalten hatten, wie Fotos der frühen Nachkriegszeit vor Augen führen. Die Klosterschulgebäude, deren Backsteine nach Ansicht der Lehrer 1705 Festigkeit biß zum Jüngsten Tag verleihen würden, waren schwer beschädigt, nicht aber zum Untergang verdammt, wie die Bemühungen der Denkmalschützer bis zum endgültigen Abriss 23 Jahre später - 1968 - belegen. Mittelalterliche märkische Backsteingebäude stehen bis heute; die Prognose des Kollegiums wäre berechtigt, könnte man die Verheerungen des von Berlin ausgehenden Krieges und die politisch motivier-

8 Brandenburgisches Landeshauptarchiv [im Folgenden: BLHA], Rep. 34 PSK, Nr. 1497, Bl. 164.

9 Kinzel, Kloster-Erinnerungen, S. 53 f.

10 Scholtz, Gymnasium, S. 202 f. 
ten stadtplanerischen Entscheidungen der DDR außen vor lassen. Sogar im Trümmermeer war der Schulkomplex rund um die Kirchenruine noch erkennbar. Selbst Hans Scharoun kündigte noch im Januar 1946 an, das Graue Kloster würde aufgebaut, und zum Beispiel beschäftigten sich 1953/54 mehrere Ostberliner Behörden ernsthaft mit dem Wiederaufbau der Anstalt in der Klosterstraße. ${ }^{11}$

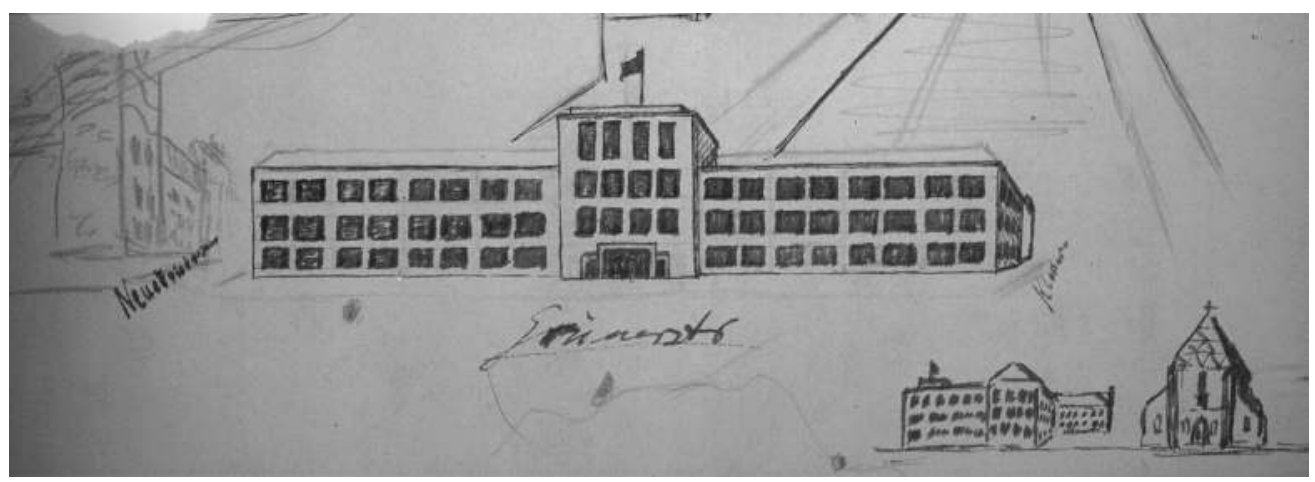

Abb. 1: Schulneubau in der Klosterstraße/Ecke Grunerstraße unter Einbeziehung des Kapitelhauses Entwurf des jungen Klosteraners Wolfram Schulz während seiner Schulzeit auf dem Grauen Kloster (Abitur 1953).

Aber nicht zuletzt der Abbruch des letzten steinernen ,überirdischen Schulzeugen' des Grauen Klosters, also des spätmittelalterlichen Kapitelhauses 1968, hat die Erinnerung an diesen die Berliner Bildungsgeschichte so prägenden Ort verblassen lassen. Nicht nur sein gewölbtes Erdgeschoss hatte den Bomben getrotzt, aber es verlor bei der Verbreiterung der Grunerstraße, die im sozialistischen Stadtzentrum den Weg in eine autogerechte Zukunft bahnen sollte, seinen angestammten Platz im Stadtgefüge, obgleich es, nachdem es während der offenen Verlegung von U-Bahngleisen touchiert wurde, in der Nachkriegszeit zum Teil wieder aufgemauert worden war. Schon durch die Gestaltung eines schmaleren Gehweges dieser neuen Magistrale hätte das Kapitelhaus auch nach 1968 Bestand haben können.

Die Ruine der Klosterkirche steht heute als einziger überirdischer Sachzeuge für Kloster und Schule. Sie repräsentiert die räumliche Kontinuität beider Institutionen: Seit 1271 das Kloster (die Konventsgründung um 1249 erfolgte an anderer Stelle) bis zur Umwandlung in ein Aussterbekloster 1539 und dem Tod des letzten Mönches 1571 sowie die Zeit des Gymnasiums von 1574 bis 1945. Unter Einbeziehung der Schuljahre bis 1958 unter dem traditionellen Namen Berlinisches Gymnasium zum Grauen Kloster in den Ausweichquartieren ergeben sich über 375 Jahre Schultradition. Aber selbst dieser eindrucksvollen Ruine fehlt heute die Verankerung im Sprachgebrauch der Berliner. Seit der Reformation sprach man schlicht von ,der Kloster-

11 Vgl. ,Das Graue Kloster“ vom 23. Januar 1946 (ohne Angabe der Zeitung): Unter den Gebäuden, die wieder hergerichtet werden sollen, befindet sich, wie Professor Scharun [sic] mitteilte, auch das Graue Kloster in der Klosterstraße, in: SGKl (St St), GKl Archiv NL Kurt Bernhard sowie in: News of Germany, Vol. 1, 1946 January 17, Nr. 78: to rebuild a number of well-known buildings of former days such as the Brandenburger Tor, the ,Graues Kloster', a boy's school. 
kirche; denn Berlin hatte nur noch diese eine. Heute liefert man Erklärungen wie ,Franziskaner Klosterkirche' (zumeist in dieser fehlerhaften Orthografie) oder spricht von ,Klosterruine Berlin' Obwohl von den einstigen Klostergebäuden kein Stein mehr sichtbar ist, führt das Bestreben, es dem Kloster Chorin oder Lehnin gleichzutun zu dieser ahistorischen, inkorrekten Benennung, die nicht Schule machen sollte.

Wünschenswert wäre ein Umgang mit den archäologischen Sachzeugen, den Fundamenten der Kloster- und Schulbauten, die die DDR und die baufreudige Nachwendezeit ,unter der Grasnarbe überdauert haben, der eine Zukunft mit Erinnerung ermöglicht. Eine Wiedererrichtung des Berlinischen Gymnasiums zum Grauen Kloster im Herzen der wiedervereinigten Stadt könnte den genius loci und die humanistische Bildungstradition für das 21. Jahrhundert wiederbeleben. Die Kombination mit einem neuen Kapitelhaus auf den meterdicken Fundamenten verwiese zugleich auf die franziskanische Tradition des Ortes.

\section{Fokus}

Im Fokus steht hier die Relevanz von Geschichte und Tradition für das Selbstverständnis des Grauen Klosters, da die Schule nicht zuletzt immer wieder auf die Gründungsgeschichte als erstes Gymnasium in Berlin, welches der Landesherr in den säkularisierten Konventsgebäuden gestiftet hatte, zurückgriff. Zugleich nahmen die Rektoren und Lehrer die Bezeichnung Fürsten- und Landesschule für ihr Gymnasium in Anspruch und insistierten darauf, die älteste höhere Bildungsanstalt Berlins zu sein. Deshalb sollen nachfolgend Aspekte des Geschichtsfundus, auf den die Schule zur Untermauerung ihres Anspruches zurückgriff, durch Heranziehung dafür relevanter Quellenbestände verdeutlicht werden. Zahlreiche Veröffentlichungen zur Schulgeschichte, die im 17. Jahrhundert einsetzten, belegen das durchgängige Interesse an der eigenen Tradition, die mit einer Art Selbstvergewisserung einherging. Die historiografischen Bemühungen märkischer Geschichtsschreiber zur Frühgeschichte der Schule müssen hier außen vor gelassen werden.

Neben einem Hinweis zur Fürsten- und Landesschulfrage wird im Folgenden anhand der Punkte ,Schulkirche', ,Historia communes' und ,Schule konserviert' der Versuch unternommen, Aspekte zur Beantwortung der Frage zusammenzutragen, ob die von der Schule ausgehenden geistigen und pädagogischen Entwicklungen auch an einer anderen Stelle der Stadt, in einem anderen, weniger geschichtsträchtigen Berliner Gebäudekomplex möglich gewesen wären oder ob die Ansiedlung zur Gründungszeit in den säkularisierten Konventsgebäuden mit Schulkirche, Friedhof, Lehrerwohnungen und einer Kommunität - in Kombination mit der jahrhundertelangen Ortskontinuität - für die Schulentwicklung nicht vielmehr fundamental und bestimmend geworden ist. $^{12}$

12 Weitere frühneuzeitliche Themen: das Patronat Berlins bei der Lehrervozierung, die Streitigkeiten zwischen dem Propst/Ephorus und der Stadt bei der Kantorenberufung (die Marien- und Nikolaikantoren waren Klosterlehrer), die Schulproblematik in den Visitationsabschieden bis 1600 und das Wirken der Schulprovisoren. Die Auswirkungen von theologisch-geistesgeschichtlichen Strömungen wie Pietismus oder Aufklärung auf den Schulalltag und den Lehrplan harren ebenso einer Untersuchung. 


\section{Forschungsstand zur Geschichte des Grauen Klosters - Veröffentlichungen}

Bis heute fehlt eine moderne Gesamtschulgeschichte des Grauen Klosters (1574-1945/58). ${ }^{13}$ Andererseits ist die Forschungs- und Sekundärliteratur so umfangreich, dass hier keine vollständige Erfassung möglich, sondern die Beschränkung auf die wichtigste Literatur zur (frühneuzeitlichen) Schulgeschichte und einige relevante Quellenbestände unumgänglich ist. Neben Klosterlehrern und Klosteranern legten auch Historiker oder Bildungswissenschaftler Untersuchungen vor.

Obwohl nicht zuletzt die theologisch und philologisch gebildeten Klosterlehrer sich seit Jahrhunderten ${ }^{14}$ mit der Stätte ihrer Berufsausübung, die auch Ort ihres Wohnens war, auseinandergesetzt haben - und dabei immer auch die Geschichte des Franziskanerkonventes einbezogen -, ${ }^{15}$ gibt es keine ausführliche Darstellung der Kloster- und Schulgebäude oder der komplexen Umund Neubauten vom 16. bis zum 20. Jahrhundert. Die bis 1945 in der Schule und bis heute gebräuchlichen Namen für einzelne Konventsbauten, wie Kapitelhaus, gehen auf den Klosterdirektor Johann Joachim Bellermann 1824 zurück, der den schönen gewölbten Klostergebäuden Wertschätzung entgegenbrachte. ${ }^{16}$ Ein Manuskript, in dem der Lehrersohn und Anarchist Johannes Nohl, ein Freund Erich Mühsams, die geistesgeschichtliche Wirkung seiner Schule in einer Art intellektuellen Biografie der Bildungsanstalt schildern wollte, ist im Zweiten Weltkrieg zerstört worden. Dabei wären nicht zuletzt (pädagogische) Neuerungen, die auch auf das Wirken von Klosterlehrern zurückgehen oder mit diesen ihren Anfang nahmen, zur Sprache gekommen. $\mathrm{Zu}$ nennen sind unter anderem das allgemeinverbindliche Abitur zum Nachweis der Universitätsreife (Friedrich Gedike), die gemeinsame Bürgerschule im Gegensatz zu Privatlehrern und

13 Aber materialreich der Klosterlehrer Julius Heidemann, Geschichte des Grauen Klosters zu Berlin, Berlin 1874; der Erziehungswissenschaftler Scholtz, Gymnasium, deckt das vierte Säkulum und die Traditionsübernahme durch das Evangelische Gymnasium (zum Grauen Kloster ab 1963) ab.

14 Das erste schulgeschichtliche Werk für Berlin überhaupt: Gottfried Weber, Secularis Recordatio Gymnasii Berlinensis A. O. R. [MDC] LXXIV a.d. XXII. Novembr. publica autoritate intimatur à M. Gottfried Weber, Berlinense Rectore, Berlin [1674].

15 M.D. [Martin Diterich], Summarische Schul=Historie des Berlinischen Gymnasii, in: Zufällige Anmerckungen von allerhand zum Schul-Wesen und Grundlegung der Gelahrtheit gehörigen Sachen 3 (1716), S. 230-240; 4 (1717), S. 311-354; 5 (1717), S. 406-426; 6 (1718), S. 494-505. (Vorarbeit zu): Martin Diterich, Berlinsche Closter- und Schul-Historie welche die Stifftung und Merckwürdigkeiten des Franciscaner-Closters in Berlin, die Aufrichtung des Gymnasii in demselben, Ingleichen Die Rectores, Magistros und Schul-Collegen [...], Berlin 1732 [im Folgenden: Diterich, Historie]. Bei der Aufl. von 1750 wurde nur das Titelblatt verändert. Ferner ders., Berlinische Kloster- und Schulhistorie, Berlin 1997 [ND der Ausgabe 1732]; Anton Friedrich Büsching, Geschichte des Berlinischen Gymnasii im grauen Kloster. Sammlung aller Schriften, welche bey der zweyten hundertjährigen Jubel=Feyer des Berlinschen Gymnasii zum Grauen Kloster [...] geschrieben [...], 1.-2. Abt., Berlin 1775; die vierteilige Schulschrift über Konvent und Schule: Johann Joachim Bellermann, Das graue Kloster in Berlin, mit seinen alten Denkmälern [...], T. 1-4, Berlin 1823-1826.

16 Bellermann, Das graue Kloster, T. 2, S. 5. Schon 1809 bezeichnete er die Klosterkirche als werthvolles gothisches Gebäude. Seine Schulschriften fanden große Verbreitung (ND 1828). Als Dr. theol. aber: Eine genauere Kenntniß der Alterthümer [...], vermehrt die Vaterlandsliebe zumal, wenn man mit den römisch=katholischen Klostersatzungen die deutsch=evangelische Lehre vergleicht, und so der große Unterschied zwischen der Gewissens= und Glaubens=Freiheit, und dem Zwang des mönchischen Aberglaubens sichtbar werde. Ders., Das graue Kloster, T. 1, S. 5. 


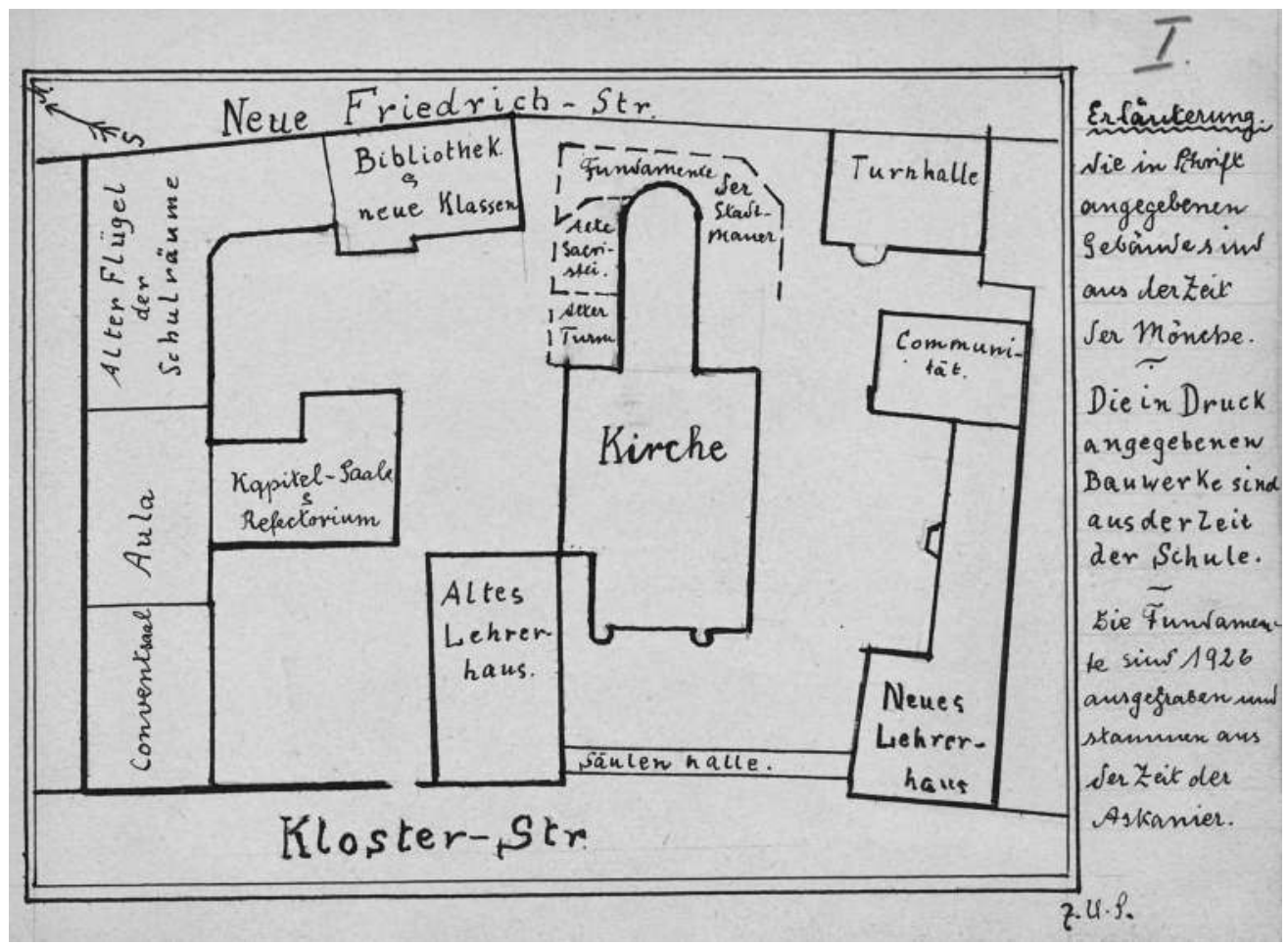

Abb. 2: Berliner Klosterplan einer Untertertianerin. Die Zeichnung der Klosteranerin Eva Samel für eine Projektarbeit zur Kloster- und Schulgeschichte mit den auf Johann Joachim Bellermann zurückgehenden Benennungen, nach 1926.

Privatschulen seit dem 18. Jahrhundert (Anton Friedrich Büsching), Gesangsunterricht als ordentliches Schulfach - und nicht zur Ausbildung als Kurrendaner oder zum Gottesdienstgesang (Johann Joachim Bellermann) - sowie nicht zuletzt die Verkürzung der Schulstunde (Ludwig Bellermann). ${ }^{17}$

Neuere Forschungen zur Geschichte des Grauen Klosters beschäftigen sich zumeist mit zeitlich begrenzten Teilaspekten, ${ }^{18}$ Lehrerpersönlichkeiten, deren wissenschaftliche oder pädagogische Tätigkeit eine große Bandbreite aufwies, ${ }^{19}$ sowie nicht zuletzt mit der Biografie oder den Schul-

17 Scholtz, Gymnasium, S. 82.

18 Susanne Knackmuß, Frau Musica am Grauen Kloster. Schüler und Kantoren zwischen Schulbank, Chorempore und Leichenstein, in: Ingeborg Allihn/Wilhelm Poeschel (Hrsg.), Wie mit vollen Chören. 500 Jahre Kirchenmusik in Berlins historischer Mitte, Beeskow 2010, S. 116-139; Agnes Winter, Das Gelehrtenschulwesen der Residenzstadt Berlin in der Zeit von Konfessionalisierung, Pietismus und Frühaufklärung (1574-1740) (Quellen und Forschungen zur brandenburgischen und preußischen Geschichte, Bd. 34), Berlin 2008 bietet eine Kontextualisierung, die in Bezug auf das Joachimsthalsche Gymnasium ab 1607 (erst ab 1649/50 in Berlin ansässig) und die Schwesteranstalt Cöllnisches Gymnasium relevant ist.

19 Zahlreiche Klosterlehrer vertreten in der vierbändigen ,Bio-Bibliographien-Reihe von Lothar Noack und Jürgen Splett, zuletzt dies., Bio-Bibliographien - brandenburgische Gelehrte der Frühen Neuzeit, T.: Mark Brandenburg und Berlin-Cölln 1506-1640, Berlin 2008; Susanne Knackmuß, ,Scholae columba' und ,Berlinische Siren und 
erfahrungen von Klosteranern, deren Bedeutung für die brandenburgisch-preußische oder auch deutsche (Kultur-) Geschichte unbestritten, wenngleich zum Teil umstritten, ist. ${ }^{20}$ Der Bestandsgeschichte der bis heute gepflegten Sammlungen des Berlinischen Gymnasiums zum Grauen Kloster wurde seit dem 18. Jahrhundert Aufmerksamkeit zuteil. ${ }^{21}$ Schon ab 1810 wurden auch retrospektiv alle Werke von und über Klosterlehrer in der Litteratura gymnasii gesammelt. ${ }^{22}$ Insbesondere die bedeutendste Alumnistiftung am Grauen Kloster, die Streitsche Stiftung, ist intensiver erforscht worden. ${ }^{23}$ Charakteristisch im Gymnasialkontext sind die oft belletristisch gefärbten Schülererinnerungen, die dennoch nicht nur für historisch versierte Erziehungswissenschaftler relevant sind. ${ }^{24}$

KirchenNachtigall: Johann Crüger am Berlinischen Gymnasium zum Grauen Kloster. Schüler (1616-1620) und Lehrer (1622-1662), in: Günter Balders/Christian Bunners (Hrsg.), ,... die Edle und niemals genug gepriesene Musicá. Johann Crüger - (nicht nur) der Komponist Paul Gerhardts, Berlin 2014, S. 145-246; Peter Hoffmann, Anton Friedrich Büsching (1724-1793). Ein Leben im Zeitalter der Aufklärung, Berlin 2000; Frank Tosch (Hrsg.), Friedrich Gedike (1754-1803) und das moderne Gymnasium, Berlin 2007; Susanne Knackmuß, Quo vadis - oder wo steckt Vasallus? Wilhelm von Humboldt und der Direktor des Grauen Klosters Johann Joachim Bellermann, in: Das Altertum 54 (2009), S. 141-188.

20 Neben Klosteranern wie Otto von Bismarck oder Friedrich Ludwig Jahn, vgl. Peter Rohrlach, Der Berliner Mäzen James Simon (1851-1932) als Schüler des Berlinischen Gymnasiums zum Grauen Kloster, in: Wolfgang Voigt/Kurt Wernicke (Hrsg.), Stadtgeschichte im Fokus von Kultur- und Sozialgeschichte. Festschrift für Laurenz Demps, Berlin 2006, S. 327-337; Mario Zadow, Karl Friedrich Schinkel - ein Sohn der Spätaufklärung. Die Grundlagen seiner Erziehung und Bildung, Stuttgart 2001; Meno Burg, Geschichte meines Dienstlebens. Autobiographie, hrsg. von Ludwig Geiger, Leipzig 1916 (ND mit Vorwort von Hermann Simon [Jüdische Memoiren, Bd. 1], Berlin 1998).

21 So in der ersten Geschichte einer Schulbibliothek in Berlin: Martin Georg Christgau, De Initiis Incrementis Et Statv Hodierno Bibliothecæ Scholasticæ In Gymnasio Berolinensi [...], Berlin 1738; Heinrich Bellermann, Verzeichniß der größtentheils von Sigismund Streit dem grauen Kloster geschenkten Musikalien, in: Zur Feier des Wohltäterfestes im Berlinischen Gymnasium zum Grauen Kloster 1856 [...], Berlin 1856, S. 5-18; Maximilian Dinse, Katalog der Bibliothek des Grauen Klosters zu Berlin, Berlin 1877; Hermann Nohl, Die Leichenpredigten der Bibliothek des Grauen Klosters, in: Vierteljahrsschrift für Wappen-, Siegel- und Familienkunde 31 (1903), S. 191-291 und 36 (1908), S. 220-241; Peter P. Rohrlach, Die Kartensammlung von Regemann in der Bibliothek des ehemaligen Berlinischen Gymnasiums zum Grauen Kloster, in: Lothar Zögner (Hrsg.), Kartographische Sammlungen in Berlin, Gotha 2001, S. 53-58; Susanne Knackmuß, Ein preußischer ,helluo librorum des 17. Jahrhunderts und seine, animadversiunculae. Eine bibliotheksgeschichtliche Entdeckung [...], in: Wolfenbütteler Notizen zur Buchgeschichte 29 (2004), S. 83-108; Holger Nickel, Buchbesitz um 1500 in Berlin. Das Graue Kloster, in: Barbara Schneider-Kempf u. a. (Hrsg.), Habent sua signa libelli. Beiträge zum Bucheinband [...] (Beiträge aus der Staatsbibliothek zu Berlin Preußischer Kulturbesitz, Bd. 48), Berlin 2015, S. 55-68.

22 Geheimes Staatsarchiv Preußischer Kulturbesitz [im Folgenden: GStA PK], I. HA Rep. 76 VI. Sek. 14x, Nr. 4a, B1. 42.

23 U.a.: Gemäldegalerie zu Berlin (Hrsg.), Blick auf den Canal Grande. Venedig und die Sammlung des Berliner Kaufmanns Sigismund Streit, Ausstellung und Katalog [...], Berlin 2002; Sigismund Streit, Verzeichnüß Aller Bücher, Gemählde und Andere Sachen so ich von Venedig und Padua aus, am Gymnasio zum Grauen Closter in Berlin [...] gesand habe, ediert von Susanne Knackmuß und Peter P. Rohrlach (Veröffentlichungen aus den Sammlungen des Berlinischen Gymnasiums zum Grauen Kloster, Bd. 1), Berlin 2006; Susanne Knackmuß, Frisch ans Werk oder ein ,nicht gemeiner Schul-Mann' in Berlin. Das Gedächtnisbild des Johann Christoph Frisch auf den Klosterrektor Johann Leonhard Frisch (1666-1743), in: Herold. N. F. 61 (2018), S. 69-102; Halgard Kuhn, Daniel Alexander Benda (1786-1870), der zweite jüdische Stadtrat Berlins, in: Berlin in Geschichte und Gegenwart. Jahrbuch des Landesarchivs 2009, S. 101-140.

24 Bücher der Schüler stellen die „Schulwirklichkeit“ (Wolfgang Neugebauer) bewusst subjektiv dar, so wie sein erstes Solo Hermann Prey, Premierenfieber, München 1981; Margarethe von Olfers, Berliner Gymnasiastenleben zur Zeit Friedrichs des Großen. Aus den Erinnerungen Ernst Gottliebs von Gossow, in: Mitteilungen des Ver- 
Die Visitationsabschiede der Jahre 1540, 1551, 1574 und 1600 bieten Aussagen zur Schulsituation in Berlin. Alle verdeutlichen die Relevanz des Schülergesanges in den Pfarrkirchen. Diese Funktion musste ab 1574 das Graue Kloster fortführen. Die Abschiede führen die Durchsetzung der reformatorischen Bestrebungen sowie die Organisation des Kirchen- und Schulalltags in der Mark, kurz der ,Reformation vor Ort, ${ }^{65}$ vor Augen; sie liegen ebenso wie die Abschiede von 1574 und 1600 für Cölln zusammen mit den Visitationsregistern von 1540 und 1551 in einer Edition von Christiane Schuchard ${ }^{26}$ vor, die das von Herold nachgelassene Manuskript ergänzt hat. So sind auch die Berlin und das Graue Kloster betreffenden Abschiede, die zumeist seit Langem ediert vorlagen, beigefügt worden. ${ }^{27}$

Den durchaus inspirierenden Entwürfen, die bislang zumeist Architekturstudenten für ein Gymnasium zum Grauen Kloster, ${ }^{28}$ einen Studienort oder eine Akademie zum Grauen Kloster ${ }^{29}$ am Traditionsstandort anfertigten, ging kaum eine intensivere Beschäftigung mit dem Funktionswandel der Gebäude, etwa anhand der Quellenüberlieferung, voraus. Die im Laufe des 16. bis 20. Jahrhunderts hinzugewonnenen neuen Aufgaben (Bau einer Kommunität, der Ausbau von Lehrerwohnungen, die Errichtung des Streitschen Direktorenwohnhauses, der Fachräume, der Turnhalle, einer Bibliothek und Galerie) müssten in historisch-architekturkritische Untersuchungen einfließen. Zukünftige Arbeiten sollten über die Zusammenstellung älterer Pläne oder

eins für die Geschichte Berlins 51 (1934), S. 41-53, 74-77; Siegfried Mauermann, Die Geschichte des Grauen Klosters zu Berlin. Gymnasium Leucophaeum utrique carum 1271 - 1574 - 1909, Berlin 1909; Joachim Hoffmeister, Unser altes Graues Kloster, Berlin 1976; Ursula Matthias, Das Kloster der Grauen Mönche und das Berlinische Gymnasium zum Grauen Kloster, Gernrode 2002; zur 2. EOS: Knut Elstermann, Klosterkinder. Deutsche Lebensläufe am Gymnasium zum Grauen Kloster in Berlin, Berlin 2012.

25 Vgl. Christiane Schuchard, Entstehung, Überlieferung und Inhalt brandenburgischer Visitationsakten, in: Dagmar Blaha/Christopher Spehr (Hrsg.), Reformation vor Ort. Zum Quellenwert von Visitationsprotokollen (Schriften des Hessischen Staatsarchivs Marburg, Bd. 29/Schriften des Thüringischen Hauptstaatsarchivs, Bd. 7), Leipzig 2016, S. 250-261.

26 Die brandenburgischen Kirchenvisitations-Abschiede und -Register des XVI. und XVII. Jahrhunderts, Bd. 4: Die Mittelmark, T. 1: Mittlere Mittelmark. Aus dem Nachlass von Victor Herold [...], bearb. von Christiane Schuchard (Veröffentlichungen der Historischen Kommission zu Berlin, Bd. 109/1), Berlin/Boston 2019 [im Folgenden: BKVAR 4/1].

27 So der für das Graue Kloster relevante Abschied von 1574 im Corpus Constitutionum Marchicarum, oder königl. Preußis. und Churfürstl. Brandenburgische [...] Ordnungen, Edicta, Mandata, Rescripta [...], T. 1, hrsg. von Christian Otto Mylius, Berlin und Halle [1737]; Die evangelischen Kirchenordnungen des XVI. Jahrhunderts, Bd. 3: Die Mark Brandenburg [...], hrsg. von Emil Sehling, Leipzig 1909 [ND Tübingen 1970]; Adalbert Kuhn (Hrsg.), Die Visitationsabschiede für die Schulen von Berlin und Kölln aus den Jahren 1541 und 1574. Festgabe zur dritten Saekularfeier des Berlinischen Gymnasiums zum grauen Kloster [...], Berlin 1874; Heidemann, Geschichte, passim. Auch für weitere Visitationen liegen Dokumente zum Grauen Kloster vor, u. a. für 1719 mit nur teilweise edierten Antworten der Lehrer. Ein Vergleich mit den in BKVAR 4/1 edierten erfolgt durch die Autorin.

28 Alexander Pellnitz, Eine neue Schule am historischen Ort. Das Gymnasium zum Grauen Kloster zu Berlin, in: Das Altertum 50 (2005), S. 47-57; Graues Kloster, Berlin Mitte. Neue Schule auf historischem Standort. Diplomarbeiten Wintersemester 2003/04, Universität Karlsruhe, Lehrstuhl für Gebäudelehre und Entwerfen Arno Lederer sowie Robert Niess [...], Karlsruhe 2004.

29 Studienort Graues Kloster. Entwurf eines Studiengebäudes für die Sammlungen des Grauen Klosters in BerlinMitte. Architektur-Wettbewerb der Rudolf Lodders Stiftung, Hamburg 2005; Akademie zum Grauen Kloster. Master Abschlussentwurf 2011/12 [...]. Aufgabensteller: Prof. Robert Niess, Düsseldorf 2012. 


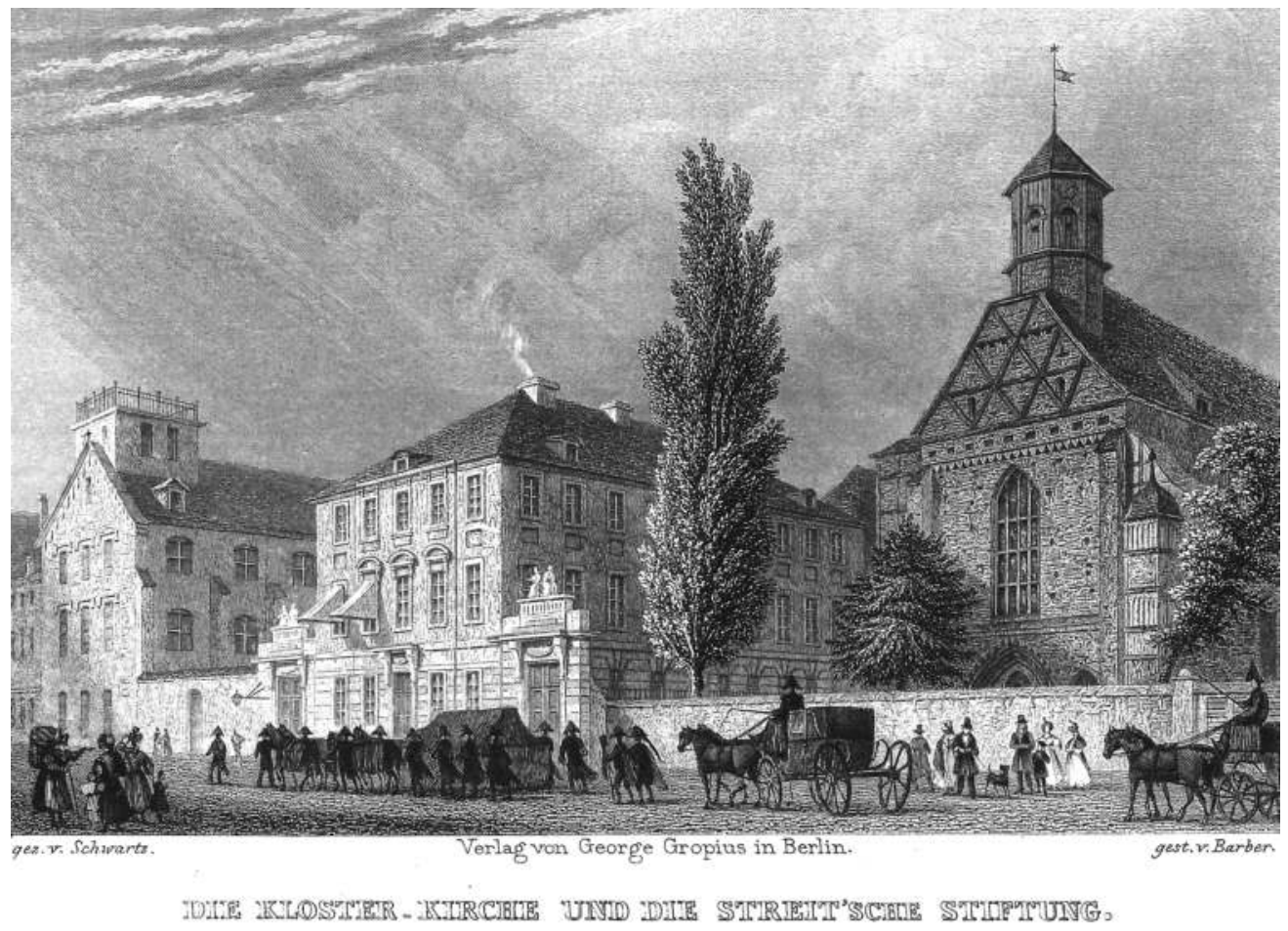

Abb. 3: Gustav Schwartz, Die Kloster-Kirche und die Streit'sche Stiftung, 1832, Stahlstich von Barber. In der Mitte das Streitsche Direktorenwohnhaus (erbaut 1786) eine Bauinkunabel des privaten Bildungsmäzenatentums in Berlin.

Fotografien hinausgehen und sich nicht nur an den bei Julius Heidemann und Richard Borrmann ${ }^{30}$ überlieferten Plänen orientierten. Ein Band über die Klosterkirchenruine lässt die Klostergebäude, in denen nach dem Konvent die Schule beheimatet war, außen vor. ${ }^{31}$ Der Untersuchungszeitraum im Brandenburgischen Klosterbuch verwehrte die Erforschung der schulischen Nachnutzung seit $1574 .^{32}$

Trotz der vielfältigen Forschungsliteratur rund um das Graue Kloster, seine Lehrer, Schüler und Bauten, die die Relevanz des Themas belegen, gibt es Forschungslücken und nicht zuletzt im

30 Richard Borrmann, Die Bau- und Kunstdenkmäler von Berlin, Berlin 1893, S. 188-203, vgl. Ludwig Hoffmann, Gymnasium zum Grauen Kloster, in: ders. (Hrsg.), Neubauten der Stadt Berlin, Bd. 3, Berlin 1904; Otto Sarrazin/Friedrich Schultze, Die Um- und Erweiterungsbauten des berlinischen Gymnasiums zum Grauen Kloster, in: Zentralblatt der Bauverwaltung 24 (1904), Nr. 93, S. 577-579.

31 Landesdenkmalamt Berlin (Hrsg.), Kirchenruine des Grauen Klosters in Berlin. Geschichte - Forschung - Restaurierung (Beiträge zur Denkmalpflege in Berlin, Bd. 23), Petersberg 2007. Zuvor der Klosteraner Julius Kurth, Die Altertümer der St. Nikolai-, St. Marien- und Klosterkirche zu Berlin, Berlin 1911.

32 Heinz-Dieter Heimann u.a. (Hrsg.), Brandenburgisches Klosterbuch. Handbuch der Klöster, Stifte und Kommenden bis zur Mitte des 16. Jahrhunderts (Brandenburgische Historische Studien, Bd. 14), 2 Bde., 1. Aufl., Ber$\operatorname{lin} 2007$ [ND 2010]. 
Hinblick auf eine Neubebauung Forschungsfragen, da jede Veränderung des Areals die steinernen Fundamente der Kloster- und Schulgeschichte integrieren muss.

\section{Fürsten- und Landesschule? Eine frühneuzeitliche Grundsatzfrage}

Beim Berlinischen Gymnasium zum Grauen Kloster handelte es sich, trotz der Stiftung durch den Kurfürsten 1574, nicht um eine echte Fürstenschule. Das Gymnasium verfügte über zu geringe materielle Grundlagen (Kapital) und Einkünfte (wie Zehntabgaben), um, wie die sächsischen Fürstenschulen, eine Internatsschule sein zu können, die ihren Schülern kostenloses Wohnen, Essen und Lernen bieten konnte. Das Gymnasium zum Grauen Kloster sollte dennoch als Landesschule territoriale Funktionen erfüllen: Wenn wir denn befunden, dass diess Christl. Werck die Schule und derselben Ordnung nicht allein dieser Stadt, sondern gemeiner Jugend unsers Churfürstentums und Lande der Marcke zu Brandenburg auch andern fremden aussländischen Knaben, Arm und Reich, zu Nutz und besten aufgerichtet und gereichen wird, so der Kurfürst $1579 .{ }^{33}$ Seine großzügige Stiftung bewirkte das in den Grundbüchern bis ins 20. Jahrhundert festgehaltene Eigentum des Berlinischen Gymnasiums zum Grauen Kloster an dem Schulgrundstück mit den Gebäuden. In einer im Zweiten Weltkrieg vernichteten Urkunde heißt es: Und wir der Landesfürst vereignen und perpetuiren gedachtem Rathe unser Stadt Berlin solche Kirche und Schule sambt den zugehörigen Gebäuden, Kreuzgange und darein gelegenen Garten, Beichthause und Kirchhofe, auch allen der Schulen Einkommen, so itzo allbereits darzu seyn und künffig dazu gegeben und vereignet werden möchten, nichts aussgenommen, für und für zu derselben Schulen, ohne Jemandes Einrede zu gebrauchen. ${ }^{34}$

Die Etablierung der Bildungsanstalt in der Residenz verstärkte die Ausstrahlung; bis 1945 war die Zahl der Schüler, die nicht nur aus der Kur- und Mittelmark kamen, erheblich. Dass das Gymnasium im Grauen Kloster keine Fürstenschule gewesen ist, belegt sein Patron, also die Institution, die für die Lehrervozierung zuständig war - Berlin. Aber der Anspruch, dennoch keine Stadt-, sondern eine Landesschule für das Kurfürstentum, ein schola provincialis zu sein, bestand immer, auch als sich die Bedingungen durch die Gründung des Joachimsthalschen Gymnasiums (1607) und den Konfessionswechsel im Herrscherhaus verändert hatten. Das Interesse des ,FundatorKurfürsten' war indessen groß; er teilte dem Rat und den Schulprovisoren oft seine Wünsche in Berufungsfragen, die landesherrliche Befehle waren, mit.

Selbst das Wort Gymnasium illustre oder academicum unterlag einem Bedeutungswandel. Um 1800 sollen rund 1,3 Prozent der männlichen Bevölkerung in preußischen Städten ,gelehrte Schulen ' besucht haben; von denen allerdings nur ein Bruchteil die Universität bezog. ${ }^{35}$ So waren die gelehrten Schulen in ihrer Zeit herausgehobene Bildungseinrichtungen. ${ }^{36}$ Die eigentlichen Gymnasien galten als eine Art halbakademische Institution zwischen Schule und Universität, wie auch die eigenständigen Disziplinarstrafen (Karzer) oder das teilweise Gerichtsprivileg belegen.

33 Heidemann, Geschichte, S. 336.

34 Ebd.

35 Karl-Ernst Jeismann, Das preußische Gymnasium in Staat und Gesellschaft (Industrielle Welt, Bd. 15/16), 2 Bde., 2. vollst. überarb. Aufl., Stuttgart 1996 [zuerst 1974], Bd. 1, S. 52.

36 Vgl. Wolfgang Neugebauer, Absolutistischer Staat und Schulwirklichkeit in Brandenburg-Preußen (Veröffentlichungen der Historischen Kommission zu Berlin, Bd. 62), Berlin/New York 1985, S. 517. 
Allgemein war die Elementarbildung, die die Dorf- und Pfarrschulen boten. Diese Sonderstellung der Gymnasien war den Zeitgenossen bewusst. Über das Graue Kloster und seine studirende Jugend urteilte zum Ende des 18. Jahrhunderts Klosterdirektor Büsching: Das Gymnasium ist ein Mittelding zwischen einer gemeinen Stadtschule, und zwischen einer Universität. ${ }^{37}$

\section{Aspekte des Geschichtsfundus - Beispiele für Quellen und Geschichtsargumentation}

Die Materialfülle für die 1574 als Landesschule des Kurfürstentums im aufgelösten Franziskanerkloster eröffnete Anstalt ist groß - im Gegensatz zur schriftlichen Überlieferung des Konventes (nicht einmal das Patrozinium der Klosterkirche ist bekannt). Dazu trug die seit dem 17. Jahrhundert einsetzende Geschichtsschreibung der Klosterlehrer, deren Druckwerke auch verlorene Quellen überliefern, bei. Sie thematisierten neben der Schulgeschichte (Abfolge der gelehrten Rektoren, Lehrplan, Wissensvermittlung) immer die Gebäude des Grauen Klosters sowie die räumliche Verortung in der Stadt. Die Ansiedlung einer Schule in den Klostergebäuden 1574 führte zur Bewahrung der mittelalterlichen Gebäude, wenn auch, vor allem seit dem Brand der Schulgebäude 1712, dann Um- und Neubauten hinzutraten. Die Situierung hatte Rückwirkungen auf das Selbstverständnis des Gymnasiums - bis in das 20. Jahrhundert. Die Lehrer argumentierten schon 1705, da die Verlegung des Gymnasiums zur Erweiterung des Lagerhauses drohte, daß die Schule mit dem Kloster so genau verbunden ist, daß es gantz wil unmöglich scheinen beyde von einander zu trennen. Denn: der Ort der Schule sei angewisen sowie von dem löbl. Churfürsten von Brandenburg also fundiret, daß Sr. Churfl. Durchl. hiezu gegeben vereiniget und perpetuiret zu sambt dem Kloster, auch die gantze Kirche etc. oder wie mans [...] in denen documenten findet: ,einen Theil des grauen Klosters zu Berlin, mit der gantzen Kirchen, Kreütz-Gange, samt denen gelegenen Gewölben, Garten, Beichthause, Kirchhof und anderen Zugehörigen'. Die Fundation sei zu nichts anders, als zur KlosterSchule zu ewiger Zeit getätigt worden. ${ }^{38}$

Anhand dreier Punkte soll der Geschichtsfundus, der - ähnlich wie die Bauten - auf die Schule zurückwirkte, illustriert werden.

\section{Schulkirche des Grauen Klosters oder Schule und Kirche}

Das Gymnasium war weder Rechtsnachfolger des Aussterbeklosters, wozu es 1539 durch das landesherrliche Verbot von Neuaufnahmen erklärt worden war, noch hat es dessen Buchbestände übernommen. Es gab seit 1572 in dem weitläufigen Gelände eine Druckerei, die sich der eingeführten ,Landmarke im Stadtraum bediente, sodass viele Drucke der Hinweis Gedruckt im Grawen Kloster ziert. Die Druckerei war - wie die Schule - in den einstigen Konventsräumen und nicht, wie in Unkenntnis der verspäteten, jedenfalls keineswegs bilderstürmerischen Reformation in der Mark geäußert, in der Klosterkirche untergebracht. Letztere wurde aber als Unterrichts- oder Festraum für die Klosteraner genutzt. Die Klosterkirche fungierte seit dem Visitationsabschied 1574 (nachdeme die Closterkirche widder zugerichtett wirdett, und eine feine kirche ist,

37 Anton Friedrich Büsching, Geschichte des Berlinischen Gymnasii im grauen Kloster [...], Berlin 1774, S. 29.

38 SGKl (St St), GKl Archiv I/3/12. 
auch [...] darein gepredigtt, getauffet und die hochwirdige sacramentt, wie in andern pfarkirchenn, vorreichett werden sollen) ${ }^{39}$ einerseits als Gemeindekirche (Filial von Sankt Nikolai), wofür der von Leonhard Thurneysser gestiftete Taufstein ${ }^{40}$ Zeugnis ablegt, und andererseits - trotz der Einpfarrung der Bewohner der gancze [n] Klosterstraße - als Schulkirche. Der Propst an Sankt Nikolai als Ephorus der Schule oder wen man sonst daczu dienstlich achtet sollte mittwochs um 9 Uhr eine predigt im Closter thuenn und die gancze schule mit allen praeceptoribus unnd knaben daselbst erschienenn, solemniter singen und die predigtt horenn. ${ }^{41}$ Diese schülergerechte Predigt in der Klosterkirche sollte das Gemeinschaftsgefühl stärken; Predigttexte scheinen nicht überliefert zu sein. Ob der Forderung: Auch sollen die schuldiener und schuler alle tage, wann sie auß der schule gelassen, sembtlich in die Klosterkirche gehen, ein psalm Gott zu lobe und ehren anstadt der andern gesenge, so hievor zu verseumnus der knaben in den kirchen gehalten worden singen, und ein stucke oder responsorium de tempore figurirenn Folge geleistet worden ist, lässt sich nicht abschätzen. ${ }^{42}$ Figuralgesang gemäß der Konsistorial- und Visitationsordnung im Gottesdienst der beiden Berliner Pfarrkirchen gehörte - wie bei den einstigen mittelalterlichen Pfarrschulen - zu den Aufgaben der Klosteraner. Die Berliner Visitationsdokumente vor 1600 bieten dafür detaillierte Vorgaben, so 1574 zur Einrichtung einer Marien- und Nikolaus-Partei, die zuichtigik und ordentlich an pahrenn zur Kirchen gehen, also nona das amptt und tertia die vesper halttenn, deß gleichen des sontags die metten, messe und vesper singen, auch wann funera in einer parttei vorhanden und nur eine schule begerett wirdett, also gehalten werden. ${ }^{43}$ Durch diese Zweiteilung wurden Schüler und Lehrer entlastet und das Begräbnis sollte allewege umb 3 schlege gewißlichen geschenen, damitt die knaben an iren studiis nicht mogen verhindertt werden. Der Schülergesang bei Leichenbegängnissen war bis in das 18. Jahrhundert geschätzt. ${ }^{44}$ Aber die Visitatoren betonen 1574 auch: Deß werckeltags aber, wan in den pfarkirchen zu S. Niclauß oder Marien gepredigtt wirdett, sollen der Cantor und ein Baccalaurius mitt den knabenn auß einem classe daß aldo mitt singen bestellen und einn klass umb daß ander, neben den kleinen knaben, damitt sie auch der kirchenn gesenge gewonnett, daczu gebrauchett werdenn; aber so bald die Predigt angefangen, wider nach der schulen gehen und irer studia gewarten. ${ }^{45}$ Es galt, zeitraubende Gesangsverpflichtungen mit einem gymnasialen Lehrplan in Einklang zu bringen. Aber die offenen Kirchen brauchten Aufsicht. Der Warnhinweis betonte 1574 das Züchtigungsrecht: Derwegenn sollen auch die custer guette achttungen darauff gebenn, das die kirchenn reinlich gehaltten und nichts darauß voruntrauwett oder zurissen werde, auch nichtt gestadtenn, daß die lose buben und bachantenn darein ein gelauffe oder spiell halttenn und allen mudtwillen, wie bißhero geschehenn, uben. Sondern neben die todtengreber sie mitt der peiczke heraußtreiben, auch, do eß schuler sein, den Schulmeistern, sie zu czuchtigen, berichtenn. Die Kirchen waren öffentliche (Stadt-)Räume. Die Visitato-

40 Junge Klosteraner transportierten ab 1949 Stücke - wie den Taufstein - aus der Kirchen- und Schulruine in das Märkische Museum. Manches davon könnte in ein neues Schulgebäude integriert oder in einem wiederaufgebauten Kapitelhaus den angestammten Platz einnehmen.

41 BKVAR 4/1, Abschied von 1574, S. 174.

42 Ebd.

43 Ebd., S. 173.

44 Vgl. Knut Schulz, Der festliche Tod. Bemerkungen zu Selbstverständnis und Tradition der Familie Distelmeyer und der höfisch-bürgerlichen Gesellschaft in Berlin um 1600, in: Bernhart Jähnig/ders. (Hrsg), Festschrift zum 125jährigen Bestehen des Herold zu Berlin 1869-1994 (Herold-Studien, Bd. 4), Berlin 1994, S. 185-217. 
ren wünschten Zucht und guette disciplin, um ruhige Gebete zu ermöglichen: sol auch der Radt die lose buben, so in der Christnacht und Osternachtt inn den kirchen alle buberey treiben, durch die stadtdiener darauß jagen oder in die torme seczen laßen - neben dem Küster war städtisches Personal nötig. Jedenfalls betonen die Visitatoren gleicher gestaldt soll der custer im Closter [Klosterkirche, $\mathrm{SK}$ ] aufsehen thuen und zudem wan die schule darinne angerichtett, soll er des morgens allewege eine halbe stunde nach funff schlegenn des sommers anfangen und mitt der klockenn biß um sechssenn, des winters aber hal[ $[\mathrm{b}]$ wege siebenn und biß umb sieben. Nach der Mittagspause solle die Glocke eine halbe stunde von 11.30-12 Uhr leutenn, damitt die schuler es horenn und zue rechter czeitt zu schulen gehen. ${ }^{46}$ Nach dem Brand, der vom Lagerhaus auf Schule und Klosterkirche 1712 übergegriffen hatte, zierte die neue Kirchenglocke die Inschrift: Ecclesiae, gymnasio, civitati, portae servio. ${ }^{47}$

Noch 1750 stellte der Prorektor die Vorzüge seiner Anstalt heraus: Das deutlichste Merkmal der Gottseligkeit: das Gymnasium hat seine eigene Kirche. Unsere Todten werden nicht nur in derselben und auf ihrem Gottesakker begraben; sondern wir haben auch Recht, unsere Vorlesungen; bei erheischener Notwendigkeit, in dem Kirchen=Gebäude zu halten. Und: Wir gehen auch in keinem andern Gottes=Hause zur Beichte und zum Abendmahle. Ihn würden die brünstigen Empfindungen bei diesen heiligen Handlungen beherrschen; zumal wenn alle Hirten und die ganze Herde [...] zu Tische des Herrn nahen. Und er lobte die in der Klosterkirche vor Zeiten so erbaulichen, so heilsamen, Schul=Predigten ${ }^{48}$ Dieses Abendmahl in der Klosterkirche war später vor der Ablegung der Abiturprüfungen üblich, waren doch fast alle Klosteraner und Berliner in der Frühen Neuzeit evangelisch; es gab aber Jahrzehnte vor dem Judenedikt von 1812 schon jüdische Klosteraner. Noch 1844 verlangte Klosterdirektor August Ferdinand Ribbeck (Klosteraner 1805-1809) einen Sakristeineubau an einer Stelle, die nicht den Eingang versperre, dessen sich die Schule bei den halbjährlichen gemeinsamen Abendmahlsfeiern immer bedient habe; der Direktor führe den Zug von der Schule zur Kirche an: In dieser Art des Eintritts der Klosterschüler lag eine zur ganzen Feierlichkeit mitgehörige Andeutung, die ich ungern aufopfern möchte. ${ }^{49}$

Die Klosterlehrer betrachteten noch 1750 die Klosterkirche als Schulkirche: Die Lehrer erhalten bei dem Ende ihrer Walfahrt, eine freie Ruhe-Stelle in der Schul= oder so genannten Kloster=Kirche. ${ }^{50}$ Einer der Collegiis ultimis wählte den Closter=Kirchhoff; sein Leichen=Stein verkündete: Hier ruhet Johann Marggraff unter seiner Linde. ${ }^{51}$ Die Klosterkirche war als Schulkirche der gebührenfreie Begräbnisort für die Klosterlehrer, woran bis heute in der Ruine erhaltene Grabsteine erinnern. Die Schüler wurden westlich und südlich der Kirche beerdigt. ${ }^{52}$ Noch nach der Schließung der

46 Ebd., S. 175.

47 Diterich, Historie, S. 246 f.

48 Johann Jakob Wippel, Zu der Redeübung, mit welcher der iärliche Stiftungs=Tag des Berlinischen Gymnasii, zum grauen Kloster, [...] durch diese Abhandlung, von den Vorzügen des gedachten Gymnasii [...], Berlin 1750, S. 13f. Die Auswertung der Schulpredigten, vor allem auch bei Introduktionen der Rektoren, beginnend im 16. Jahrhundert, legt die Autorin an anderer Stelle vor.

49 GStA PK, I. HA, Rep. 137 I, Nr. 38.

50 Wippel, Zu der Redeübung, S. 10.

51 Diterich, Historie, S. $360 \mathrm{f}$.

52 In der Matrikel wurde 1730 Joh. Bucholz von Pritzwalk als Primaner eingetragen sowie: Er starb am 10. August 1731 und wurde in coemeterio nostro beerdigt. Hinter dem Namen seines Bruders Gottfried (11. April 1731) 


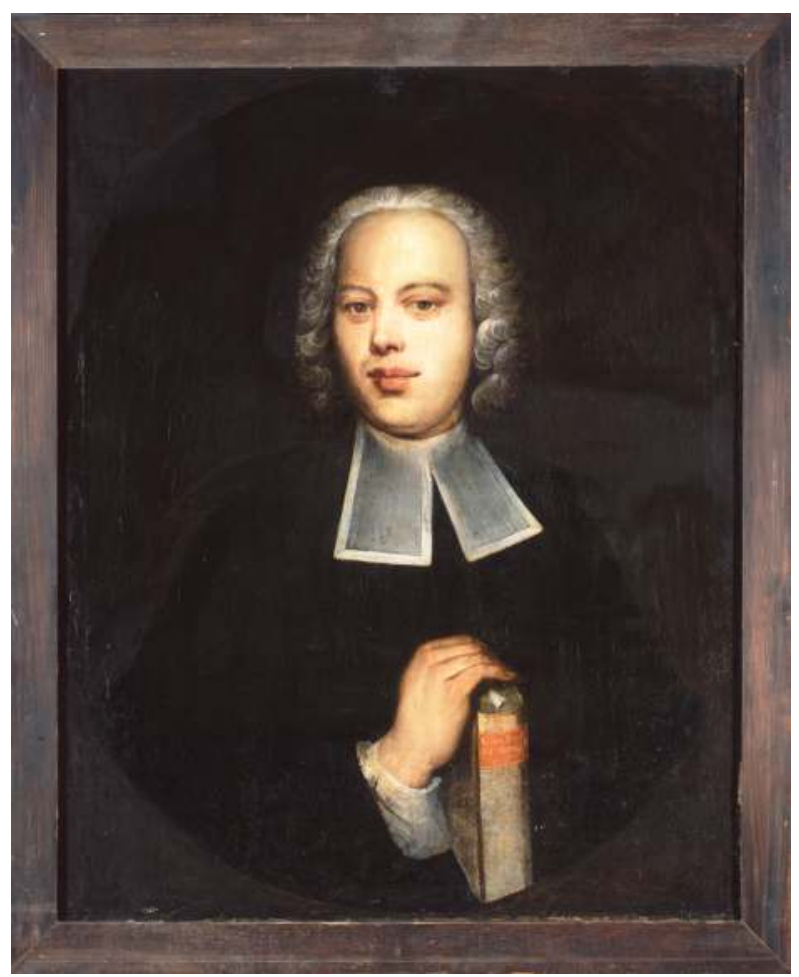

Abb. 4: Klosterrektor Johann Jakob Wippel (1717-1765), zeitgenössisches Porträt eines unbekannten Malers.

innerstädtischen Friedhöfe durch den Soldatenkönig wurde dieses Begräbnisprivileg (und das der Lehrerfamilien auf dem Kirchhof) nach einer Eingabe bestätigt - ein Beleg für die Wirksamkeit der in der Gründungszeit zugesprochenen Rechte. Die Schultradition stand den Amtsnachfolgern und Schülern anhand der alten Grabsteine in Kirche und Kirchhof täglich vor Augen.

\section{Historia communes oder loci communes - Ausweitung der Geschichtsschreibung}

Die Druckerei im Grauen Kloster initiierte der umtriebige Baseler Alchimist Leonhard Thurneysser (1531-1596), der als kurfürstlicher Leibarzt in Berlin ab 1571 reüssierte, nicht das Gymnasium, wenngleich dort Schulbücher, Schulschriften und Gymnasialprogramme gedruckt worden sind..$^{53}$ Nur um 1585 hatte sie ein Rektor gepachtet. Der - wie die Schule - in den Räumen des aufgelösten Klosters residierende ,Renaissancemensch' Thurneysser galt immer als Teil der Schulgeschichte. Seine vielseitige Biografie wurde beginnend mit dem ersten Historiografen der

steht: er sei drei Tage nach dem Bruder im August 1731 gestorben und neben diesem beerdigt, SGKl (St St), GKl Archiv Matrikel IV/1/2.

53 Gabriele Spitzer, ,... und die Spree führt Gold'. Leonhard Thurneysser zum Thurn. Astrologe - Alchemist - Arzt und Drucker im Berlin des 16. Jahrhunderts, 2. Aufl., Berlin 2001. 
Schule, dem Klosteraner und Klosterlehrer Diterich, aber auch von Bellermann und Heidemann in ihren Werken zur Schulgeschichte thematisiert, ebenso wie die Geschichte des Franziskanerkonvents als Vorgänger und Erbauer der Schulgebäude. ${ }^{54}$ Bellermann forderte 1824 Interesse ein: Die Inschriften, Gemälde, Denkmäler sind theils noch nicht beschrieben, theils unrichtig gedeutet worden. Der Zahn der Zeit nagt sie immer mehr ab, und doch sind sie, gleich andern Denkmälern der Vorzeit, der Erhaltung werth. Sie vertreten die Stelle anderer Urkunden, die hier fehlen. Auch dürften manche Nachrichten von der Verfassung des Ordens den Nichtunterrichteten, und besonders unsern Schülern, welche an die Stelle jener Minoriten getreten sind, und wohl gern wissen möchten, wer und was ihre Vorfahren gewesen sind, nicht gleichgültig sein..$^{55}$

Er zog eine Linie von den Minoriten zu den Klosteranern. So wurde die Erinnerung an die Franziskaner und den illustren Thurneysser innerhalb der Schule und in Berlin durch die geschichtsund schreibaffinen Lehrer, zumeist Theologen und Philologen, in Publikationen wachgehalten, aber auch durch Schulfeste und Lieder. Diese Erinnerung in reduzierter, auf bestimmte Merkmale des Ordenslebens verengter Form kann, vor dem Hintergrund, dass viele Klosteraner (märkische) Pfarrersöhne waren und evangelische Pastoren wurden, nicht verwundern. ${ }^{56}$

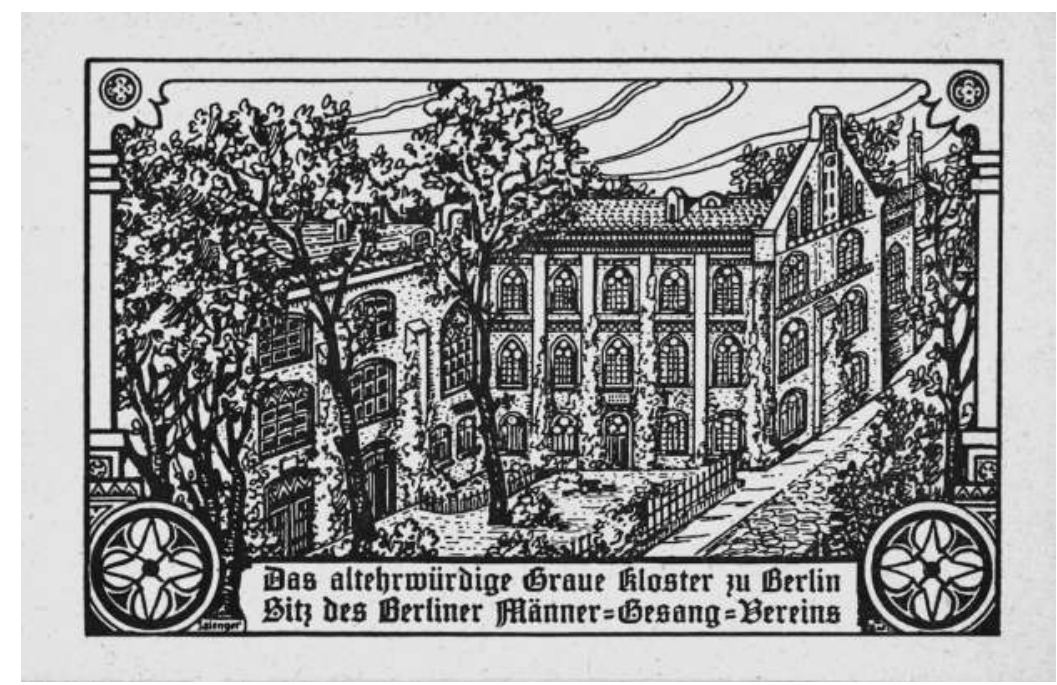

Abb. 5: Offen für die Stadtgesellschaft. Im Kapitelhaus des Grauen Klosters probte der Berliner Männer Gesangverein, der mit einer Postkartenserie (gezeichnet von Salenger) für sich warb.

54 Zuerst 1674 in Weber, Secularis Recordatio.

55 Bellermann, Das graue Kloster, T. 1, S. 4f.

56 Die ,Franziskanerregel' Minoritae non est studendum, Ed cum sacco circueundum, Si potest, et praedicandum hatte Bellermann, Das graue Kloster, T. 2, S. 8 eingeführt. Sie blieb lebendig: Fürwahr, das ist ein herrlich Ding Klosteraner sein auf Erden, Und wers nicht ist, der mag nur flink Nochmals geboren werden, Und wähle solchen Vater dann, der ihn aufs Kloster schicken kann, Nam sumus minoritae Fidelioris vitae! Es schuf vor manchem Säkulum Im Lande der Abbruzzen Franciscus von Assisium Die grauen Wollkapuzen Auch nach dem sündigen Berlin Sah man die Franziskaner ziehen Das waren minoritae Miserioris vitae! Vgl. Ausschuß für die Klosterfeste (Hrsg.), Klosterlieder 1826-1924. Zur Feier des 350jährigen Bestehen [...], Berlin 1924. 
Die unspektakuläre Geschichte des Proviant- oder Lagerhauses und der Erleuchtungsanstalt blieb außen vor, obwohl beide die mittelalterlichen Konventsgebäude genutzt hatten. Sie hatten die Räumlichkeiten, die 1819 als königliche Schenkung dem Grauen Kloster übereignet wurden, zuvor inne. Die Ausweitung des schulischen Geschichtsinteresses hatte Grenzen.

In ,Klosterliedern' wurden, ironisch-protestantisch eingefärbt, Gebäude und Vorgänger besungen, wie Ein gutes Refectorium darf keinem Kloster fehlen, da laben sich am Tisch herum der Mönche durstge Seelen. Die mittelalterlichen Berliner Bettelbrüder haben weitaus weniger getrunken, als es in den Liedern der geselligen Altschüler, im sündigen Berlin' beschworen wurde. In der Erinnerungskultur der Klosteraner entwickelten die Franziskaner ein Eigenleben, es hatte mit dem mittelalterlichen Berliner Guardian und seinem Barfüßerkonvent nur wenige Berührungspunkte. Nicht nur zur Säkularfeier 1874 fanden sich schulgeschichtliche Motive selbst auf Speisekarten oder Einladungen, die zeittypisch historistisch so durcheinandergewirbelt waren, dass die ,Nationalzeitung den Überblick verlor und den Schulprovisor (1574-1586), den Lehnssekretär Steinbrecher, zum Leiter der Klosterschule erhob: Die Speisen = und Wein=Karte [...] zeigt ein altes gothisches KlosterPortal unter dem der Bruder Kellermeister einen Humpen zum Willkommen bietet. Alles umrahmt von den Portraits griechischer, römischer und deutscher Klassiker, sowie der beiden reformatorischen Bahnbrecher Luther und Melanchthon, denen an den Ecken in größeren Medaillons die Bildnisse des Kurfürsten Johann Georg, seines Kanzlers Lamprecht Distelmeier, des Gründers und Leiters der Klosterschule Joachim Steinbrecher und des Wohlthäters derselben Sigismund Streit eingefügt sind. ${ }^{57}$

\section{Schule konserviert oder Bestandsschutz durch Sparsamkeit}

Die Überführung des größeren Teils der Konventsgebäude 1574 in das Eigentum einer eigenständigen Schule hatte auf die Bauten eine konservierende Wirkung, zumal der kurfürstliche Stifter unnötiges Abreißen und unnütze Bauten sofort verbot (eine effektive Form des Denkmalschutzes ${ }^{58}$ ), denn schon im ersten Handtczeichenn des Kurfürsten zur neuen Schule, als ,Urkundeninsert' dem Visitationsabschied 1574 einverleibt, wurde den Visitatoren und Provisoren aufgetragen, ein theill unsers Grawen Closters, in unser stadt Berlin gelegenn, [...] zu einer gemeinen Schule anczurichttenn und zu gebrauchenn, allerdings müssten seine kornboden und gemecher [...] frei pleibenn, auch nichts unnottigs abgebrochenn oder gebawett, sondernn alles ordentlich gebessertt und zugerichtett werden. Er habe bauhernn und provisornn derselbenn schulen im closter verordnet, damit sich auch ein jeder des regiments darein nichtt unternehmenn noch sonst unrichtigkeittenn hierauß erfolgen. ${ }^{59}$ Aber sämtliche Dächer - auch der Kirche - mussten neu gedeckt werden. Diese gezielte Umnutzung und kurfürstliche Sparsamkeit bewirkten ein nachhaltiges Bauen im Bestand und eine Art Denkmalpflege trotz des neuen (evangelischen) Lebens. Nicht nur im 16. Jahrhundert fehlte der Schule das Geld für eine Modernisierung (erst seit dem Ende des 18. Jahrhunderts

57 Bericht über die Säkularfeier des Grauen Klosters 1874, in: Nationalzeitung 29 (1874), 3. Juli 1874 (Beiblatt zur Nr. 304).

58 Mit Ernst Badstübner, Kirchen in Berlin [...], Berlin 1987, S. 29, könnte man versucht sein, durch Thurneyssers Bemühungen um Klosterkirche und Kunstwerke, in ihm einen „Restaurator und Denkmalpfleger zu sehen“. Dann wäre das Graue Kloster durch den postreformatorischen Erhalt seiner ,katholischen Bausubstanz' der Ausgangspunkt der Berliner Denkmalpflege - lange vor Schinkel und Quast. 
wurden Teile des Kreuzganges abgerissen, um der Kirche mehr Licht und Luft zu verschaffen), sondern zu allen Zeiten beschäftigten die Direktoren Bauprobleme. Büsching forderte Erweiterungsbauten, da unser Musensitz, [...] in Kellern bestehe, die mit Salpeter stark angefüllt waren. Die Unterrichtsräume waren 1767 alle kellermäßig, dunkel, unangenehm und ungesund, weil sie einige Ellen tiefer als die Straßen und Höfe in der Erde lagen - wie die Klosterkirche bis heute. Aber der König beschied 1784, das Graue Kloster habe zu seinem Bedarf hinlänglichen Gelass und auf dergleichen unnöthige Bauten verwendet kein Geld euer gnädiger König Friedrich. Auch 1786 verfing das Schülergesundheitsargument nicht, denn um den Salpeter aus den Klassen des Gymnasii zum grauen Kloster wegzubringen, und solche über der Erde und im Lichten zu bauen, nachdem solche schon einige Jahrhunderte, der Gesundheit unbeschadet, besuchet worden, dazu kann [...] einige tausend Thaler nicht verwilligen, euer sonst gnädiger König Friderich. ${ }^{60}$ Friedrich der Große betrieb wie sein Vorfahr Denkmalschutz durch Sparsamkeit, durch das Unterlassen von Um- oder Neubauten. Die neuen Eigentümer, die keine illiterati waren, thematisierten interessante Aspekte der Geschichte des Klosterareals; auch inhaltliches Interesse und Wissen kann Denkmäler (be)schützen - durch die Stimulierung öffentlicher Aufmerksamkeit.

Die Verschuldung des Kurfürsten Joachim II. und der späte Tod des letzten Berliner Barfüßers ebenfalls 1571 vereitelten sein im Testament 1562 bekundetes vorhaben, noch bei unserm leben in unserm grauen closter $\mathrm{Zu}$ Berlin ein ansehenlich und furstlich spittal anzurichten $[\ldots]$ und $z$ stiften. Gelänge es zu Lebzeiten, sollte der Sohn des stifters gedechntnus in ewigkeit erhalten und den armen leuten [...] ganz und gar nichts entziehen oder abbrechen ${ }^{61}$ Der Sohn räumte noch 1571 seinem neuen Leibarzt einen Teil der Konventsgebäude ein, gründete 1574 seine newe Schul, für die er 1579 Ewigkeitsgarantien gab: wir wollen, dass solche Schule für und für männiglichs, ungehindert, unverändert bleiben solle. Inmassen wir und unsere Erben unss hiermit verpflichten, dieselbe jederzeit mit Gnaden zu beforderen und fortsetzen $z u$ helffen. ${ }^{62}$ Verfolgte er die Schulidee der Visitatoren 1573/74 so engagiert, weil eine Landesschule im Kloster als mildtätige Stiftung keine Einbehaltung ehedem kirchlichen Vermögens bedeutete? War so der väterliche Wunsch leichter zu ignorieren? Dieses Gymnasium gehörte zu den piis corpora, wie noch der Große Kurfürst bei der Verzinsung des Schulkapitals in der Landschaft den Schulprovisoren zugestand. ${ }^{63}$ Die Nutzungsvorstellungen beider Kurfürsten stimmen mit den Erkenntnissen des 20. Jahrhunderts zur Klosternachnutzung überein. Klöster werden als „Meister der Disziplin" ${ }^{“ 64}$ charakterisiert, als eine durch Macht- und Raumstrukturen gekennzeichnete Institution der autoritären und umfassenden Disziplinierung des Menschen nicht nur in geistig-geistlicher Hinsicht. Deshalb wurden säkularisierte Klöster zu Spitälern, Irrenanstalten, Gefängnissen sowie Schulen, da ihre Baustruktur der Sicherung und Abschirmung der Bewohner beziehungsweise Insassen nach außen sowie der Disziplinierung nach innen dienen konnte. Innerstädtische Klosterkomplexe, auch der Bet-

60 Anton Friedrich Büsching, Eigene Lebensgeschichte [...], Halle 1789, S. 570; vgl. Heidemann, Geschichte, S. $341 \mathrm{f}$.

61 Hermann von Caemmerer (Hrsg.), Die Testamente der Kurfürsten von Brandenburg und der beiden ersten Könige von Preußen, München/Leipzig 1915, S. 98.

62 Heidemann, Geschichte, S. 337.

63 BLHA, Rep. 23A, C 2496.

64 Vgl. u. a. Michel Foucault, Überwachen und Strafen. Die Geburt des Gefängnisses (suhrkamp taschenbuch wissenschaft, Bd. 184), Frankfurt am Main 1977, S. 192. 
telorden, waren Bauten, die die Finanzkraft einzelner Einwohner zur alleinigen Bewirtschaftung zumeist überschritten. Die aus wirtschaftlichen Erwähnungen gebotene nachhaltige Nutzung prädestinierte sie - nach Foucault ${ }^{65}$ - zur Nutzung als Gefängnis et cetera. Der Erhaltungsbefehl des Kurfürsten und die Umnutzung als Schule mit schreibaffinen Lehrern legte den Grundstein für das ,Gesamtkunstwerk Gymnasium zum Grauen Kloster ' und für die Beschäftigung mit der und die Berufung auf die Schulgeschichte des Klosterareals.

Diese Traditionslinien und der für vielfältige Zwecke abrufbare Geschichtsfundus des Grauen Klosters waren in Berlin einzigartig, da das Joachimsthalsche Gymnasium erst seit der Mitte des 17. Jahrhunderts in Berlin ansässig und zudem mehrfach umgezogen war - zuletzt 1912 nach Templin. Auch das Cöllnische Gymnasium musste mehrere inhaltliche und räumliche Umbrüche verkraften. Die räumliche Schulkontinuität von 1574 bis 1945 ist ein Alleinstellungsmerkmal des Grauen Klosters.

Dennoch ist an der Spree eine Kontextualisierung, die Einbettung in die Bildungstopografie der frühneuzeitlichen Residenzstadt ein lohnendes Unterfangen, denn in Berlin-Cölln waren, im Kontrast zu den meisten deutschen Städten vor 1750, mehrere, nicht zuletzt durch konfessionelle Unterschiede geprägte Gymnasien ansässig. Das Graue Kloster stand um 1650 in gnesiolutherischem Ruf, dessen Nachklang kann man in den Paul-Gerhardt-Liedern, in der Vertonung der Klosterlehrer Crüger und Ebeling, hören. In ,Spree-Athen' war die gymnasiale Bildungskonkurrenz - bis 1810 von Studenten ungestört - Alltag, die für die Zeit bis 1740, ohne die Gesamtheit der zur Verfügung stehenden Quellen in Gänze ausschöpfen zu können, thematisiert worden ist. ${ }^{66}$ Die Gymnasien konkurrierten - in Rangfragen war man in der Frühen Neuzeit unerbittlich - nicht nur um den Vortritt oder die Reihenfolge bei Leichenbegängnissen, über Fragen der Anciennität, es kam auch zu blutigen Tätlichkeiten. ${ }^{67}$ Schüler konnten sich frei für ein Berliner Gymnasium - bis auf das Joachimsthalsche - entscheiden und nach bestandener Aufnahmeprüfung immatrikulieren. Der Ruf der Schule und der wissenschaftliche Ruf des Rektors entschieden die Wahl. Das ab 1707 nun königliche Joachimsthalsche Gymnasium stach das altehrwürdige Berlinische Gymnasium zum Grauen Kloster, das nie Gymnasium Regii wurde, aus. ${ }^{68}$ Das Joachimsthalsche war in Berlin nicht primus inter pares; zu stark unterschied es sich durch Organi-

65

66 Winter, Gelehrtenschulwesen, passim. Ein Beispiel: Die Drucklegung der Schulgeschichte 1732 regte um 1740 einen Joachimsthaler Lehrer zu seiner Schulmonografie an [Teiledition: Bernhard Ludwig Becmann, Nachrichten von dem Königlichen Joachimsthalischen Gymnasio, welche deßen Zustand vom Anfang bis auf gegenwärtige Zeiten in einem Zusammenhang vorstellen, hrsg. von Karl-Walter Beise u. a., Bad Heilbrunn 2012]. Darin diskreditierte er das Klostergymnasium als Berlinische Schule. Das lange ungedruckte, wichtige Becmannsche Manuskript erlangte im Kontrast zum Diterich'schen Werk keine öffentliche Wirkung. Becmann postulierte, dass dieses Gymnasium ohne alle wiedersprache eine von den herrlichsten Stiftungen in ganz deutschland ist. Und: Es wird hier aber als eine ausgemachte Sache voraus gesetzt, daß diesem Gymnasio in corpore der Vorzug vor allen anderen Schulen und Gymnasiis in der Mark zustehe (Becmann, Nachrichten, S. 30) - ein unblutiger Seitenhieb gegen das Graue Kloster.

67 Susanne Knackmuß, ,Grau ist nur die Theorie. Bibliothekspraxis am Berlinischen Gymnasium zum Grauen Kloster in der Frühen Neuzeit, in: Britta Klosterberg (Hrsg.), Frühneuzeitliche Schulbibliotheken, Halle 2020, S. 67-93; Mathis Leibetseder, ,Callvinsche Füchse und Hunde. Konfessionelle Aspekte schulischer Ehrenhändel im Berlin des späten 17. Jahrhunderts, in: Jahrbuch für Historische Bildungsforschung 15 (2009), S. 127-153. 
sation, reichhaltige Dotierung und Patronat. Schon im Adreß-Kalender der Königlich Preußischen Haupt- und Residenz-Städte ist sein Vorrang deutlich, ebenso wie der des Berlinischen vor dem Cöllnischen. Eine vergleichende Arbeit über die Berliner Gymnasien während des ,pädagogischen' 18. Jahrhunderts, in der Aufklärung oder der Humboldtschen Bildungsreform fehlt. ${ }^{69}$ Überblickswerke ziehen das Graue Kloster zum Vergleich heran. ${ }^{70}$ Dieser Umstand ist der - ungeachtet der Kriegsverluste - guten Quellenlage, aber auch der frühen, die Quellen popularisierenden und konservierenden Beschäftigung der Lehrer mit der Schulgeschichte ab dem 17. und den Sammlungsbeständen ab dem 18. Jahrhundert geschuldet. Die Sammlungen des Berlinischen Gymnasiums zum Grauen Kloster stehen heute pars pro toto für die Bildungs-, Kulturund Stiftungsgeschichte der Berliner Gymnasien und deren, wenn nicht so alte, so doch vielfältige Bestände, die im Zweiten Weltkrieg und der Nachkriegszeit zerstört und zerstreut worden sind.

\section{Fazit oder Klostergeist quo vadis?}

Erinnerung bedeutete am Grauen Kloster immer Kontinuität und Geschichte. Aus der Geschichtsschreibung (der Klosterlehrer) erwuchs die Erinnerung an Kloster und Schule. Das Berlinische Gymnasium zum Grauen Kloster wurde durch die Ansiedlung als landesherrliche Stiftung in den Klostergebäuden in der Residenz geprägt; und von dort aus prägte es, eng verwoben mit der Stadtgeschichte, die Bildungsgeschichte nicht nur Berlins. Über die Jahrhunderte haben die Lehrer die enge Verwobenheit ihrer Anstalt mit dem Kloster-Schul-Areal betont und sich bemüht, die franziskanischen Vorgänger neben der spätreformatorischen kurfürstlichen Gründung 1574 als Landesschule in die eigene Geschichtsschreibung einzubeziehen. Ohne den großzügigen Gebäudekomplex des Grauen Klosters, der neben der Schulfunktion das gemeinsame Wohnen der Lehrerfamilien mit Kostschülern, die Schulkirche, die sowohl dem Schulgottesdienst als auch der Bestattung der Klosterlehrer diente, und eine Schülerkommunität umfasste, wäre eine in bildungsgeschichtlicher Hinsicht so weitreichende Wirkung nicht möglich gewesen. Der ,Berlinische Klostergeist' konnte nur dort gedeihen.

Archäologen als radikale Fundamentalisten (radix, Wurzel) werden die Fundamente des Grauen Klosters (aus fundare, anknüpfen, errichten, gründen und mens, mentis Sinn, Geist) ausgraben. Damit werden sie einen Beitrag zur Belebung des ,Klostergeistes' leisten, vorausgesetzt, die Fundamente aus der Kloster- und der Schulzeit werden sichtbar in der Klosterstraße in situ bewahrt. Neben der schriftlichen Überlieferung steckt in den steinernen Zeugnissen der Franziskaner und der Klosteraner der ,Klostergeist. Unterirdische Spuren der Steine gibt es, ein Auferstehen aus Ruinen ist nicht mehr möglich. Jedoch der Wiederaufbau als humanistisches Gymnasium könnte eine Renaissance, nicht zuletzt des ,Klostergeistes', bewirken. Nur die Berücksichtigung der Fundamente in situ ist hier ein ,Bauen im Bestand' und wird diesem historisch doppelt ,kontaminierten' Areal Alt-Berlins gerecht. Die backsteinernen Schulgebäude des Grauen Klosters waren immerhin der Prototyp, an dem sich bis in das 20. Jahrhundert hinein der Berliner Schulneubau orientierte.

69 Für Sachsen Jonas Flöter/Günther Wartenberg, Die sächsischen Fürsten- und Landesschulen. Interaktion von lutherisch-humanistischem Erziehungsideal und Eliten-Bildung, Leipzig 2004.

70 So Jonas Flöter, Eliten-Bildung in Sachsen und Preußen. Die Fürsten- und Landesschulen Grimma, Meißen, Joachimsthal und Pforta (1868-1933) (Beiträge zur Historischen Bildungsforschung, Bd. 38), Köln 2009. 


\title{
Dirk Schumann
}

\section{Die Berliner Franziskanerklosterkirche - eine Bettelordenskirche als markgräfliche Hofkapelle?}

\author{
,Im Jahr 1271 haben die erlauchten Fürsten und Herren Otto und Albert, Markgrafen von \\ Brandenburg, aus besonderer Verehrung des Ordens, den Platz, auf welchem dieses Kloster \\ erbauet ist, den Ordens-Brüdern zum ewigen Besitz gnädigst übergeben.'
}

\section{Der Bauplatz des Berliner Franziskanerklosters}

Die Frage nach der Entstehung des Berliner Franziskanerklosters scheint eng mit dem markgräflichen Hof verbunden zu sein, denn die erste Erwähnung der Berliner Franziskaner erfolgte 1250 mit dem Urkundenzeugen Frater Hermann, der als Lektor und zugleich in prominenter Stellung als Beichtvater der beiden Markgrafenbrüder Johann I. und Otto III. überliefert ist. ${ }^{2}$ In dieser Funktion riet er den Markgrafen zur Stiftung des Zisterziensernonnenklosters Zehdenick, für das er 1257 noch einmal als Urkundenzeuge in einer markgräflichen Besitzbestätigung erscheint. ${ }^{3}$ Einer unsicheren Überlieferung zufolge soll bereits 1252 bei den Franziskanern in Berlin ein Provinzialkapitel stattgefunden haben. ${ }^{4}$ Das setzt ein funktionierendes Kloster voraus. Allerdings ist bisher unklar, ob sich das Kloster vor Übertragung des Grundstücks, das offenbar vom Gelände des markgräflichen Hofes abgetrennt wurde, bereits an der Stelle befand, an dem später die Klausurgebäude des Berliner Franziskanerklosters errichtet wurden (Abbildung 1). ${ }^{5}$ Die Grundstücksübertragung vollzogen die Söhne Ottos III., die Markgrafen Otto V. und Albrecht III., die entsprechend der Landsteilung von 1258/60 in Berlin die Herrschaft ausübten. Da ihr Vater Otto III. offenbar der jüngere der beiden Brüder war, verblieben Kurwürde und das Amt des Erzkämmerers bei der älteren Linie, obwohl sich die jüngere Linie ebenfalls darum bemühte. ${ }^{6}$ So kam es zwischen den beiden Familienlinien der brandenburgischen Markgrafen mehrfach zu Rivalitäten, in deren Folge die Markgrafen bei Auseinandersetzungen mit den Nachbarn auf unterschiedlichen Seiten standen. ${ }^{7}$

1 Übersetzt nach der bei Johann Joachim Bellermann abgedruckten Inschrift im ehemaligen nördlichen Chorgestühl, ders., Das graue Kloster in Berlin, mit seinen alten Denkmälern [... ], T. 1, Berlin 1823, S. 17.

2 Vgl. Regesten der Markgrafen von Brandenburg aus askanischem Hause, Lfg. 1-12, bearb. von Hermann Krabbo/Georg Winter (Veröffentlichungen des Vereins für Geschichte der Mark Brandenburg), Leipzig/München/ Berlin 1910-1955, S. 165, Nr. 728 [im Folgenden: Krabbo/Winter, Regesten]; Peter Riedel u. a., Berlin Franziskaner, in: Heinz-Dieter Heimann u. a. (Hrsg.), Brandenburgisches Klosterbuch. Handbuch der Klöster, Stifte und Kommenden bis zur Mitte des 16. Jahrhunderts (Brandenburgische Historische Studien, Bd. 14), 2 Bde., 1. Aufl., Berlin 2007, Bd. 1, S. 146-159, hier S. 146.

3 Codex diplomaticus Brandenburgensis. Sammlung der Urkunden, Chroniken und sonstigen Quellenschriften für die Geschichte der Mark Brandenburg und ihrer Regenten, Hauptt. I, Bd. 13, hrsg. von Adolph Friedrich Riedel, Berlin 1857 [im Folgenden: CDB I 13], S. 128, Nr. 1.

4 Riedel, Berlin Franziskaner, S. 146.

$5 \quad$ Krabbo/Winter, Regesten, S. 250, Nr. 1007; Riedel, Berlin Franziskaner, S. 146.

6 Johannes Schultze, Die Mark Brandenburg, Bd. 1, Berlin 1961, S. 176 f., 187 f. und 192.

7 Schultze, Die Mark, S. $188 \mathrm{f}$. 


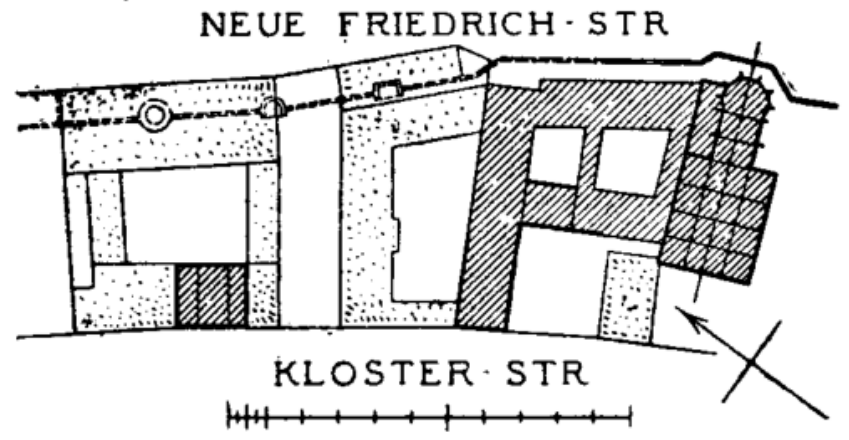

Abb. 1: Berlin, Ausschnitt aus einem historischen Katasterplan mit dem ehemaligen landesherrlichen Grundstück.

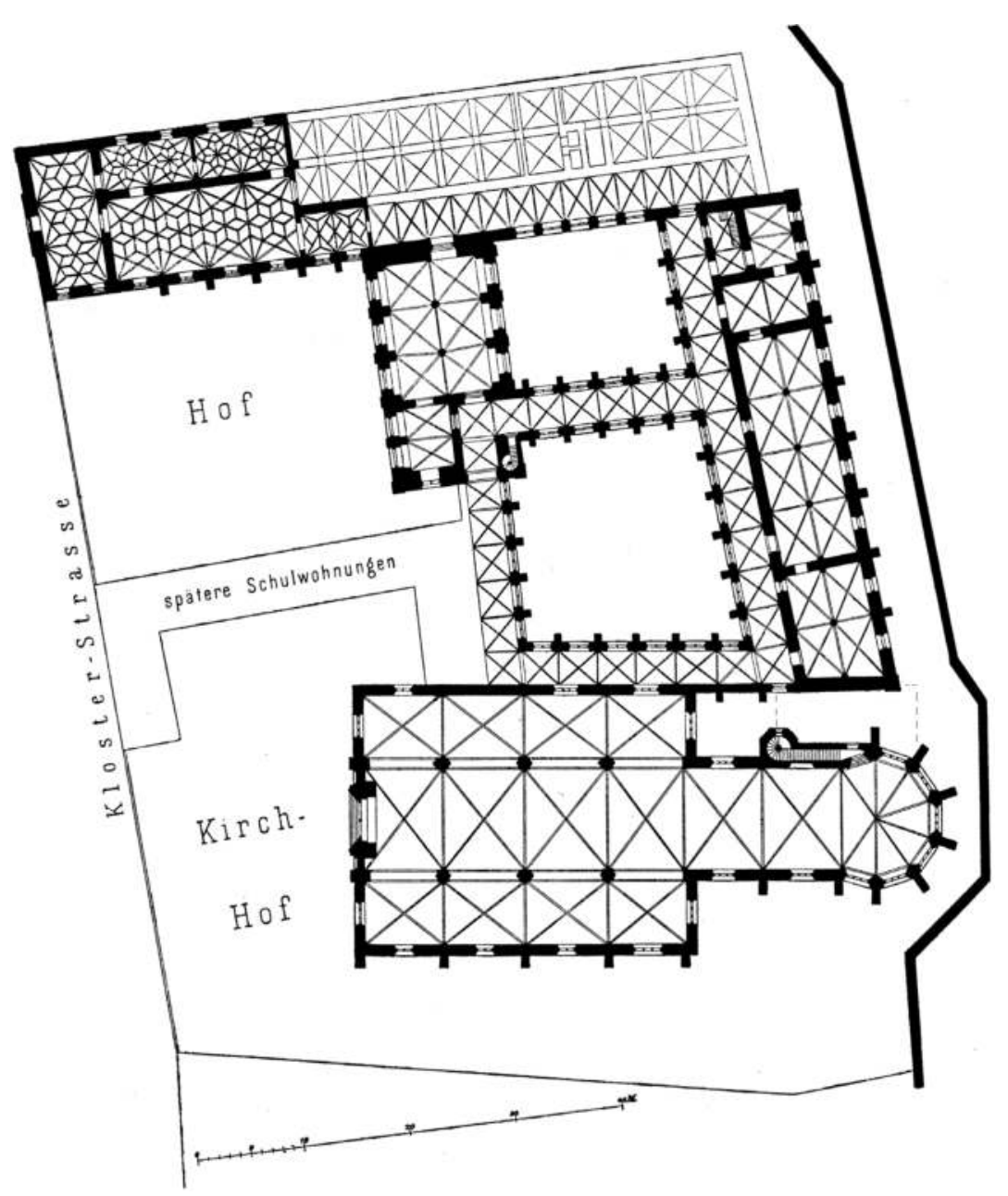

Abb. 2: Berlin, Grundriss der Klosteranlage. 
Schließlich setzte auch das nachweisbare Baugeschehen auf dem Gelände des Berliner Franziskanerklosters erst nach der Teilung der Mark zwischen den beiden Familienlinien ein (Abbildung 2). Die beim Abbruch eines Hofkomplexes in der Berliner Klosterstraße 1931 festgestellten Reste eines repräsentativen hallenartigen mittelalterlichen Gebäudes, ${ }^{8}$ das offenbar einst das Herzstück des markgräflichen Hofes in Berlin gewesen war, lassen sich anhand der Baudetails frühestens in das ausgehende 13. Jahrhundert datieren (Abbildung 3a und b). ${ }^{9}$

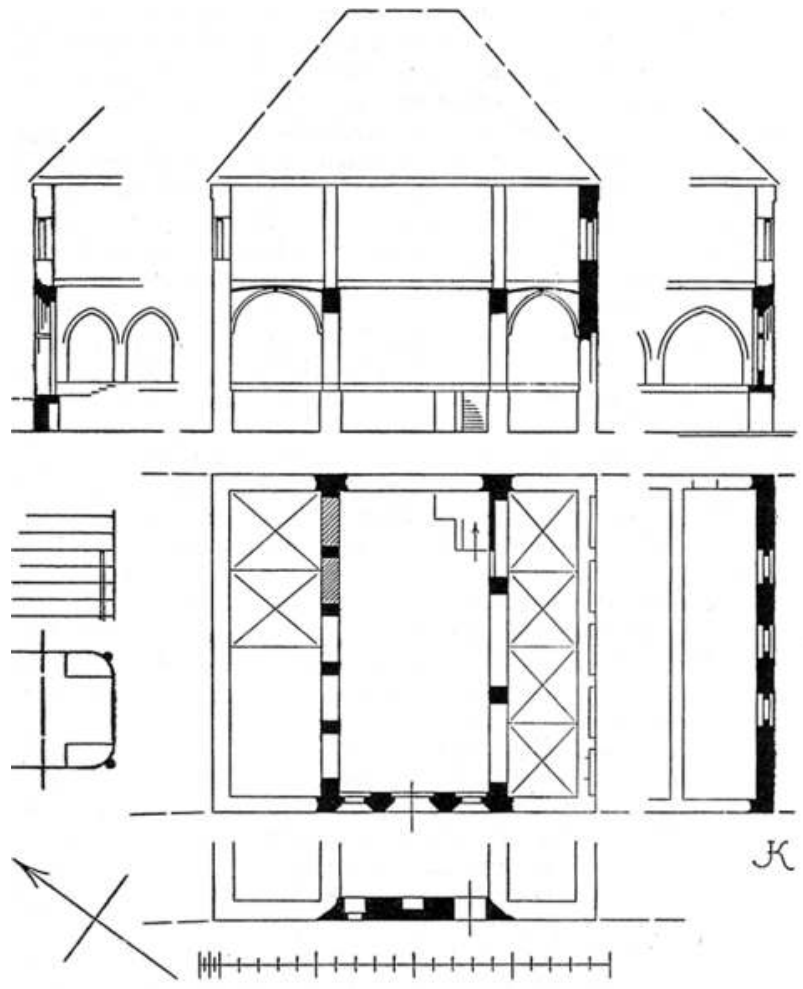

Abb. 3a: Berlin, ehemaliges Hohes Haus, 1931 festgestellte Baudetails eines repräsentativen Backsteinbaus. (1936), S. 148-163.

9 So tritt erst in dieser Zeit der charakteristische Blattdekor mit den gratigen Blattrippenauflagen auf, wie er sich an den zum Haus gehörigen Portalkämpfern erhalten hat, welche sich heute in der Sammlung der Stiftung Stadtmuseum Berlin befinden. Schließlich zeigen die Formsteine des dazugehörigen Portalgewändes Choriner Profile sowie darauf aufbauende Formen, bei denen es sich jedoch bereits um reduzierte Weiterentwicklungen handelt. Auch die festgestellten Bogenformen der Obergeschossfenster gehören frühestens in das späte 13. Jahrhundert, könnten jedoch auch auf das frühe 14. Jahrhundert verweisen. Allerdings lässt sich heute nicht mehr sicher klären, ob Erd- und Obergeschoss der gleichen Bauzeit angehörten. Vgl. auch Dirk Schumann, Die mittelalterliche Bauskulptur im Märkischen Museum, in: Franziska Nentwig (Hrsg.)/Peter Knüvener (Bearb.), Mittelalterliche Kunst aus Berlin und Brandenburg im Stadtmuseum Berlin, Berlin 2011, S. 36-46, hier S. 38. 


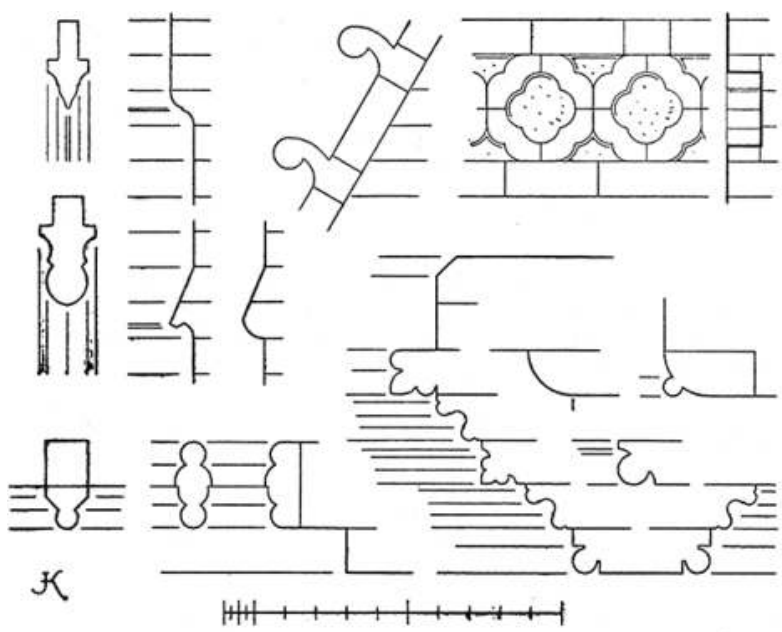

Abb. 3b: Berlin, ehemaliges Hohes Haus, 1931 festgestellte Baudetails eines repräsentativen Backsteinbaus.

Die Reste des mittelalterlichen Gebäudes gehörten zu einem unterkellerten und darüber zweigeschossigen Gebäude, das offenbar vollständig in Backstein errichtet worden war. Das Erdgeschoss bestand aus einem dreischiffigen Saal, dessen 7,65 Meter breites Mittelschiff von den Seitenschiffen durch Spitzbogenarkaden abgeteilt wurde. An der Klosterstraße konnten vor dem Abbruch noch die Reste einer auffällig repräsentativen Fassadengliederung freigelegt werden, bei der sich ein reich gestuftes Spitzbogenportal in der Mitte zweier ebenfalls reich profilierter spitzbogiger Fenstergewände befand, während die darüber liegenden Obergeschossfenster in Segmentbogenblenden saßen. Der Portalkämpfer entstand in einer für die Mark im Mittelalter eher seltenen Technik aus Gipsstuck (Abbildung 4). ${ }^{10}$ Eine zunehmende Bedeutung dieses landesherrlichen Hofes, der in späteren Quellen (1429) auch als ,Hohes Haus ' bezeichnet wurde, ${ }^{11}$ spiegelt sich erst in den 1280 einsetzenden Aufenthaltsbelegen der Söhne Ottos III. für Berlin wider, die eine verstärkte Nutzung des markgräflichen Hofkomplexes in dieser Zeit nahe legen. ${ }^{12}$ Zwar ist der markgräfliche Hof in Berlin bereits im Jahr 1261 mit der Bezeichnung aula Berlin urkundlich belegt, ${ }^{13}$ doch gibt es keinen Hinweis, dass die beiden Markgrafenbrüder Johann I. und Otto III. diesen Hof auch persönlich nutzten. ${ }^{14}$

10 Weitere Beispiele gab es nur noch an einer Säule der Berliner Gerichtslaube und an einigen ehemaligen Kapitellen der Berliner Marienkirche, alles Befunde aus dem späteren 13. Jahrhundert.

11 Kohte, Das Hohe Haus, S. 147, FN 3.

12 Ebd., S. 146 f. und Hans-Joachim Fey, Reise und Herrschaft der Markgrafen von Brandenburg (Mitteldeutsche Forschungen, Bd. 84), Köln/Wien 1981, S. $187 \mathrm{f}$.

13 Krabbo/Winter, Regesten, S. 205, Nr. 863.

14 Fey, Reise und Herrschaft, S. 59 f. Neben Spandau diente 1264 Köpenick als Ausstellungsort einer Urkunde. Die nächstgelegenen Ausstellungsorte für Urkunden der beiden Brüder Johann I. und Otto III. sind ansonsten Liebenwalde und Strausberg. 


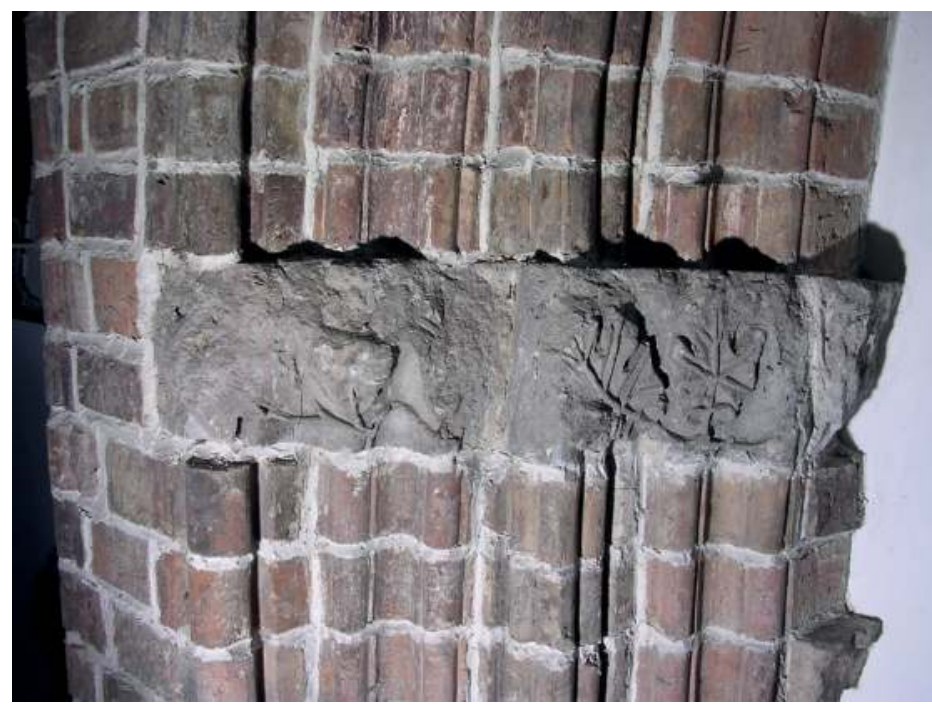

Abb. 4: Berlin, Kämpferdetail des rekonstruierten Portalgewändes des 1931 abgebrochenen Hohen Hauses in der sogenannten Kapelle im Märkischen Museum.

Ihre Regierungsgeschäfte führten die beiden Brüder offenbar von der Spandauer Burg aus, denn von den 18 überlieferten Urkunden aus ihrer Regierungszeit (1220-1266/67), die im Berliner Raum ausgestellt wurden, belegen 17 den Ausstellungsort Spandau, keine einzige kam dagegen in Berlin zustande. ${ }^{15}$ Dementsprechend entstand die markgräfliche Urkunde von 1257, in der der Franziskanerbruder Hermann als Zeuge auftrat, nicht etwa am Standort seines Berliner Klosters, vielmehr befand sich der Beichtvater der beiden Markgrafen zu diesem Zeitpunkt offenbar in deren Reisegesellschaft und weilte mit ihnen in Spandau. ${ }^{16}$ Doch nicht nur die Existenz eines franziskanischen Beichtvaters spricht für den hohen Stellenwert, den dieser Bettelorden bei den Markgrafenbrüdern einnahm. Vielleicht ging bereits die Verlegung des ältesten märkischen Franziskanerkonventes von Ziesar in die Brandenburger Altstadt auf die Initiative der beiden Landesherren zurück. ${ }^{17}$ Diese erfolgte in der Mitte des 13. Jahrhunderts, war 1258 abgeschlossen und lag damit genau in jener Zeit, in der sich die beiden Landesherren um den Ausbau der Doppelstadt bemühten. ${ }^{18}$

16 CDB I 13, S. 128.

17 Vgl. Petra Weigel mit Marcus Cante/Thomas Ertl, Brandenburg/Havel Franziskaner, in: Heimann, Brandenburgisches Klosterbuch, Bd. 1, S. 278-288, hier S. 278 f. sowie Winfried Schich, Die Markgrafen von Brandenburg und die Ansiedlung der Franziskaner in den Städten östlich der Elbe im 13. Jahrhundert, in: Landesdenkmalamt Berlin (Hrsg.), Kirchenruine des Grauen Klosters in Berlin. Geschichte - Forschung - Restaurierung (Beiträge zur Denkmalpflege in Berlin, Bd. 23), Petersberg 2007, S. 13-22, hier S. $13 \mathrm{f}$.

18 Weigel, Brandenburg/Havel Franziskaner, S. 278 f. sowie Winfried Schich, Die Markgrafen, S. 13 f. 


\section{Ordensarchitektur und Landesherrschaft}

Anders als in Berlin sind in Brandenburg an der Havel markgräflicher Hof und Franziskanerkloster räumlich getrennt, denn der Hof lag in der Neustadt und wurde 1286 schließlich den Dominikanern geschenkt, ${ }^{19}$ die hier ihre repräsentative Klosteranlage errichteten. In der 1248 offenbar mit konzeptionellen Absichten - gegründeten Stadt Neubrandenburg (Brandenborch Novam ${ }^{20}$ hingegen befanden sich die um 1260 in Feldstein begonnenen Kirchen- und Klausurgebäude in unmittelbarer Nähe zu den kurz zuvor errichteten markgräflichen Wohn- und Herrschaftsgebäuden und waren auch baulich mit diesen verbunden (Abbildung 5). ${ }^{21}$ Vielleicht könnte
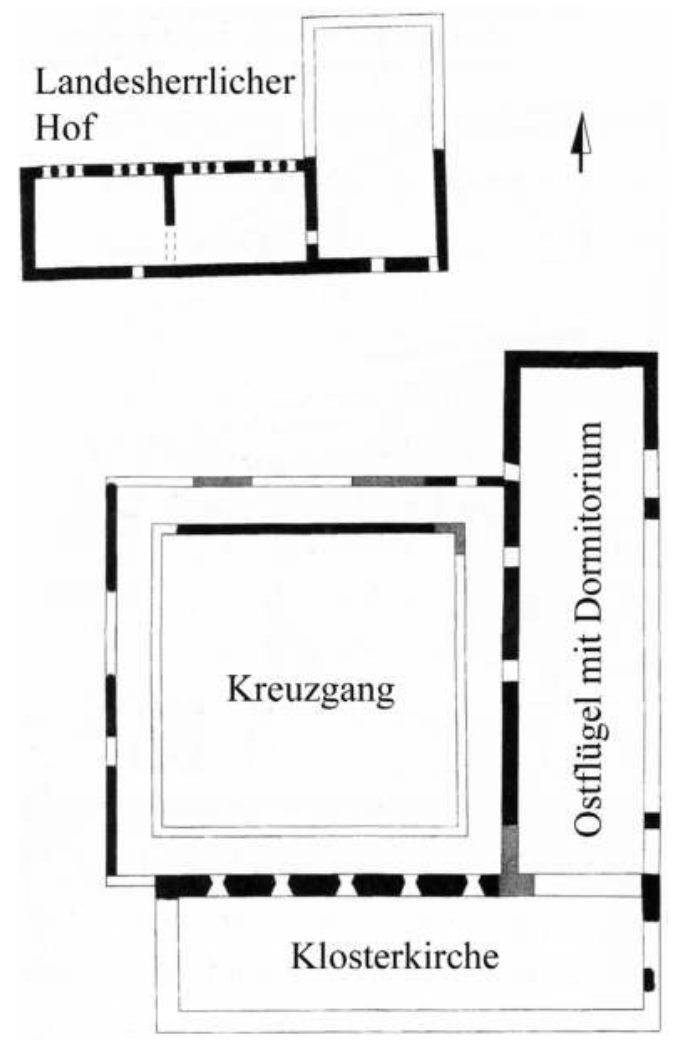

Abb. 5: Neubrandenburg, Grundrissrekonstruktion des markgräflichen Hofes und der Klausur der ersten Klausurgebäude in der zweiten Hälfte des 13. Jahrhunderts.

19 Vgl. Klaus-Bernward Springer mit Marcus Cante, Brandenburg/Havel Dominikaner, in: Heimann, Brandenburgisches Klosterbuch, Bd. 1, S. 289-306, hier S. 289.

20 Krabbo/Winter, Regesten, S. 162, Nr. 717.

21 Vgl. Rainer Szczesiak, Die baulichen Anfänge des Neubrandenburger Franziskanerklosters unter sakralen und weltlichen Aspekten, in: Dirk Schumann (Hrsg.), Brandenburgische Franziskanerklöster und norddeutsche Bettelordensbauten, Berlin 2010, S. 369-389, hier S. 375 f. und Ingo Ulpts-Stöckmann/Jens Christian Holst/Rainer Szczesiak, Neubrandenburg Kloster St. Johannis, in: Wolfgang Huschner u. a. (Hrsg.), Mecklenburgisches Klosterbuch. Handbuch der Klöster, Stifte, Kommenden und Prioreien (10./11.-16. Jahrhundert), 2 Bde., Rostock 2016, Bd. 1, S. 581-615, hier S. 581 f., 588 f. 
diese Klosteranlage eine Ahnung von der Berliner Situation vor der Grundstücksübertragung von 1271 geben. In der Zeit des Besitzüberganges des Landes Stargard und der Stadt Neubrandenburg an die Mecklenburger Landesherrschaft gingen anscheinend die markgräflichen Gebäude in den Besitz des Klosters über, denn der überlieferte Stadthof der mecklenburgischen Herzöge befand sich weiter östlich in Richtung des Friedländer Tores. ${ }^{22}$ In der laut Markgrafenchronik von Johann I. und Otto III. gegründeten Stadt Angermünde erfolgte die Ansiedlung der Franziskaner wahrscheinlich ebenfalls auf Initiative dieser Landesherren. ${ }^{23}$ Die erste steinerne Klosterkirche wurde dort um 1260 und damit noch zu ihren Lebzeiten begonnen. Die Stadt Gransee ist ebenfalls eine markgräfliche Gründung. 1262 erhielt sie von Johann I. Brandenburger Stadtrecht. ${ }^{24}$ Auch hier ist es nicht unwahrscheinlich, dass der dortige franziskanische Bettelordenskonvent bald darauf im Zuge der Anlage der Stadt angesiedelt wurde, obwohl seine erste urkundliche Nennung erst für das Jahr 1302 überliefert ist. ${ }^{25}$ Während mit den Stadtgründungen von Neubrandenburg und von Gransee vor allem Johann I. verbunden war und die dortige Ansiedlung der Franziskaner vielleicht auch auf seine Initiative zurückging, trat sein Bruder Otto III. schließlich 1254 mit der Gründung eines Dominikanerklosters in der Stadt Strausberg hervor, dem er das Gelände des dortigen landesherrlichen Stadthofes (curia) stiftete und das er auch als seine Grablege bestimmte. ${ }^{26} \mathrm{Im}$ Dezember 1259 weilte er nachweislich in den Räumen dieses Klosters. ${ }^{27}$ Deutlich wird schließlich ein enges Verhältnis der beiden Markgrafenbrüder zu den Bettelorden, deren Klosteranlagen über das Leben hinaus eng mit den Aufenthalten der Landesherren in den jeweiligen Städten verbunden waren.

Für Berlin gibt es keinerlei Belege eines solchen Aufenthalts der beiden Brüder. Das könnte jedoch einer lückenhaften Überlieferung geschuldet sein, denn auch im Fall von Neubrandenburg, wo die baulichen Hinterlassenschaften eine deutliche Sprache sprechen, gibt es keine urkundliche Überlieferung, die einen Aufenthalt der beiden Markgrafenbrüder in dieser Stadt belegen. ${ }^{28}$ Wahrscheinlich setzte bereits in der letzten Regierungszeit der beiden Markgrafenbrüder jener Prozess ein, in dem die Bettelordensklöster an die Stelle der separaten landesherrlichen Höfe treten und einen Teil von deren Aufgaben übernehmen. Dazu gehörten etwa die Beherbergung der Landesherren bei ihren Aufenthalten in den jeweiligen Städten und die Bereitstellung repräsentativer Wohn- und Herrschaftsräume, auch wenn die Nachweise dafür in der Regel erst aus späterer Zeit stammen. So wird im Falle des Franziskanerklosters Gransee bei dessen Verkauf an die Stadt 1561 deutlich, dass sich darin die landesherrlichen Wohnräume befanden, die auch weiterhin für ihre Nutzung instand zu halten waren. ${ }^{29}$

22 Georg Krüger (Bearb.), Kunst- und Geschichtsdenkmäler des Freistaates Mecklenburg-Strelitz, Bd. 1: Das Land Stargard, Abt. 3, Neubrandenburg 1929, S. 4.

23 Vgl. Paul Eichholz/Friedrich Solger (Bearb.), Die Kunstdenkmäler der Provinz Brandenburg, Bd. 3, T. 3: Kreis Angermünde, Berlin 1934, S. 2 f. und Wolfgang Blaschke mit Dirk Schumann, Angermünde Franziskaner, in: Heimann, Brandenburgisches Klosterbuch, Bd. 1, S. 96-105, hier S. 96.

24 CDB I 4, S. 426 f., Nr. 1.

25 Vgl. Peter Riedel mit Dirk Schumann, Gransee Franziskaner, in: Heimann, Brandenburgisches Klosterbuch, Bd. 1, S. 536-542, hier S. 536.

26 Vgl. Matthias Friske mit Blandine Wittkopp, Strausberg Dominikaner, in: Heimann, Brandenburgisches Klosterbuch, Bd. 2, S. 1243-1254, hier S. 1243.

27 Krabbo/Winter, Regesten, S. 200, Nr. 844.

28 Fey, Reise und Herrschaft, S. $56 \mathrm{f}$.

29 Vgl. CDB I 4, S. 436 f., Nr. 19 und Riedel/Schumann, Gransee Franziskaner, S. 536. 


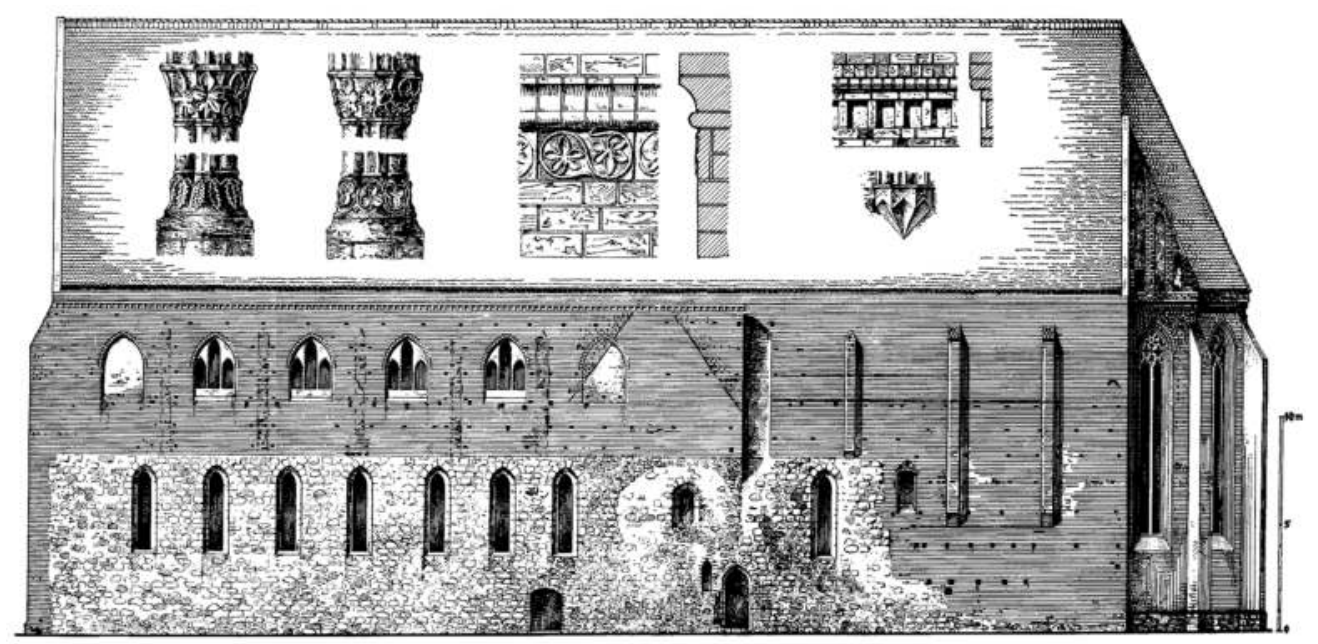

Abb. 6: Angermünde, Franziskanerklosterkirche, Baudetails und Backsteinzierrat um 1300 und 15. Jahrhundert.

Mit Ausnahme der in der Mitte des 13. Jahrhunderts errichteten Franziskanerklosterkirche in der Brandenburger Altstadt und der landesherrlichen Räume in unmittelbarer Nähe des Neubrandenburger Franziskanerklosters setzte der repräsentative Ausbau der landesherrlich gestifteten beziehungsweise geförderten märkischen Franziskanerklöster mit ihrer charakteristischen Backsteinarchitektur jedoch erst unter der nachfolgenden Markgrafengeneration ein. Dabei sind es vor allem die Söhne von Johann I., die mit dem repräsentativen Um- bzw. Neubau von Ordenseinrichtungen in ihren Herrschaftsgebieten begannen, nachdem sie den repräsentativen Neubau ihres Hausklosters und ihrer Grablege in Chorin vollendet hatten. So entstand das um 1271 gegründete Zisterzienserinnenkloster Boitzenburg offenbar unter Mitwirkung Choriner Ziegler und Bauleute unter Verwendung jenes charakteristischen Backsteinzierrats, der am Familienkloster Lehnin seinen Ausgang nahm und in der Choriner Klosterarchitektur virtuos weiterentwickelt wurde. ${ }^{30}$ Doch blieb diese charakteristische Backsteingestaltung nicht auf Klausurbauten des Zisterzienserordens beschränkt. In der Nachbarschaft zu Chorin begann im ausgehenden 13. Jahrhundert der Umbau der Kirche und der Klausur des Franziskanerklosters in Angermünde. Auch hier legen die detaillierten Übereinstimmungen zum Choriner Backsteindekor (Abbildung 6), der bis in die modelgeformten Reliefplatten der Friese reicht, ${ }^{31}$ eine Beteiligung Choriner Ziegler und Bauleute nahe. ${ }^{32}$ Schließlich spielten entsprechende Fähigkeiten in

30 Vgl. Dirk Schumann, Herrschaft und Architektur, Otto IV. und der Westgiebel von Chorin (Studien zur Backsteinarchitektur, Bd. 2), Berlin 1997, S. 21 f. und Winfried Schich mit Dirk Schumann/Blandine Wittkopp, Boitzenburg Zisterzienserinnen, in: Heimann, Brandenburgisches Klosterbuch, Bd. 1, S. 212-228, hier S. 219.

31 Zwar wurde bei einem Vergleich deutlich, dass die Friesplatten nicht aus demselben Model stammten, doch wurde das Model relativ genau nachgefertigt, was eine detaillierte Kenntnis des Vorbildes nahelegt.

32 Vgl. Dirk Schumann, Die Franziskaner und die märkische Backsteinarchitektur um 1300, in: ders., Brandenburgische Franziskanerklöster, S. 83-104, hier S. 93 f. 
der Herstellung dieses Backsteinzierrats und in der Ausführung eines verwandten Architekturdekors auch bei der Errichtung des 1275 von Markgraf Johann II. gestifteten Prenzlauer Dominikanerklosters eine wichtige Rolle, für dessen Errichtung ebenfalls Teile eines landesherrlichen Hofes zur Verfügung gestellt wurden. ${ }^{33}$ Das Auftreten Choriner Reliefplatten an einem Tor der Befestigung der landesherrlichen Stadt Templin belegt schließlich, dass diese charakteristische Gestaltung nicht nur auf Ordensbauten beschränkt blieb. Gemeinsam ist den in gleicher Weise ausgezeichneten Bauten, dass sie von den Landesherren gestiftet beziehungsweise gefördert wurden, ja der charakteristische Backsteinzierrat fast ausschließlich an den mit der Landesherrschaft verbundenen Bauten anzutreffen ist. Da dieser Backsteindekor nach dem Aussterben der Markgrafen aus askanischem Hause in der Mark Brandenburg nicht mehr verwendet wurde, ${ }^{34}$ liegt der Verdacht nahe, dass es sich hier um absichtsvoll eingesetzte Gestaltungen handelt, die nicht nur ganz allgemein einen hohen repräsentativen Anspruch und einen großen Gestaltungsaufwand verkörpern, sondern in der Wiedererkennbarkeit dieser architektonischen Form schließlich auch für die Landesherrschaft selbst stehen mögen. ${ }^{35}$

Unter einem solchen Gesichtspunkt wird auch der im späten 13. Jahrhundert errichtete repräsentative Backsteinbau der Marien- und Magdalenenkirche in Eberswalde (Abbildung 7), der dortigen Stadtpfarrkirche, verständlich.

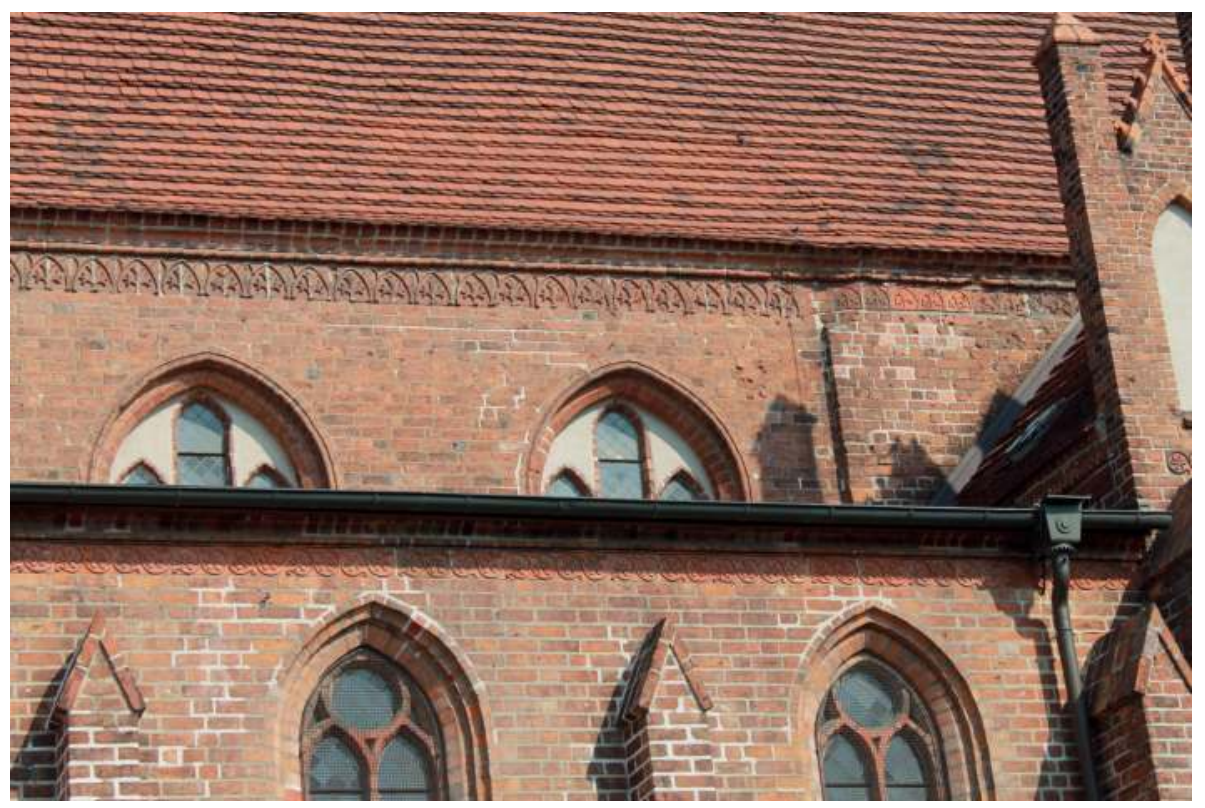

Abb. 7: Eberswalde, nach 1282 errichtete Stadtkirche Sankt Maria-Magdalena, Langhausobergaden von Süd.

33 Falko Neininger mit Katja Hillebrand/Blandine Wittkopp, Prenzlau Dominikaner, in: Heimann, Brandenburgisches Klosterbuch, Bd. 2, S. 978-990, hier S. 978.

34 Bereits unter dem letzten askanischen Markgrafen lässt sich ein Abwandern der Formen und damit auch der Ziegler und Bauleute dieser Architektur nach Nordwesten und nach Nordosten beobachten.

35 Vgl. Schumann, Franziskaner, S. 97 f. 
Archäologische und siedlungsgeschichtliche Untersuchungen sowie die vorhandenen Quellen weisen auf einen Ausbau der Stadtanlage um beziehungsweise nach 1275. ${ }^{36}$ Albrecht III. hatte sich um 1282 aus der Herrschaft der ottonischen Familienlinie gelöst und eine eigene Landesherrschaft geschaffen, ${ }^{37}$ in der die Stadt Eberswalde eine wichtige Stellung einnahm. Mit maßgeblicher Unterstützung Albrechts wurde in dieser Zeit der Neubau der dortigen Pfarrkirche in seinen Ostteilen begonnen..$^{38}$ Die baukünstlerische Qualität dieser Kirche ist relativ hoch und das Auftreten eines Choriner Relieffrieses weist auf den engen Zusammenhang mit dem Baubetrieb des dortigen Zisterzienserklosters. Doch das Eberswalder Baugeschehen setzte offensichtlich erst mit den bauund backsteintechnischen Kenntnissen ein, die auf der Baustelle der Choriner Klosteranlage erworben und - wie es scheint - in Eberswalde weiterentwickelt wurden. ${ }^{39}$ So treten hier reiche figürliche Portalkämpfer aus Backstein auf, die relativ einzigartig in der Backsteinarchitektur dieser Zeit sind.

Der repräsentative Umbau des Franziskanerklosters in der Brandenburger Altstadt, der vielleicht noch vor 1300 einsetzte, besaß offenbar einen ähnlichen Hintergrund. ${ }^{40}$ Während die ,Hauptstadt der Mark' 1258 vorerst nicht von der Landesteilung betroffen war, erhielt die ottonische Markgrafenlinie 1260 die Brandenburger Neustadt und die johanneische Linie die dortige Altstadt mit dem Franziskanerkloster. ${ }^{41}$ Otto V. stiftete auf dem Platz der ehemaligen landesherrlichen Burg in der Neustadt im Jahr 1286 das dortige Dominikanerkloster, dessen bald darauf begonnene Architektur deutliche Bezüge zur ab 1275 errichteten Prenzlauer Anlage aufweist. Im späten 13. Jahrhundert waren offenbar Teile des repräsentativen Neubaus des Dominikanerklosters in der Brandenburger Neustadt vollendet und konnten als Herberge der ottonischen Markgrafenlinie dienen. ${ }^{42}$ Für eine standesgemäße Unterbringung Ottos IV. und seiner Brüder in der Brandenburger Altstadt kam vor allem das dortige Franziskanerkloster in Frage. So ist es sicher kein Zufall, dass in dieser Zeit auch die Umbauarbeiten an der dortigen Franziskanerkirche

36 Vgl. Ilona Rohowski (Bearb.), Denkmale in Brandenburg, Bd. 5: Landkreis Barnim, T. 1: Stadt Eberswalde (Denkmaltopographie Bundesrepublik Deutschland), Worms 1997, S. 12 und Alexander Sachse, Eberswalde. Entstehung und Entwicklung einer märkischen Stadt im Mittelalter, unveröff. Magisterarbeit Humboldt-Universität zu Berlin 2000.

37 Schultze, Die Mark, S. 191.

38 Vgl. Rohowski, Denkmale in Brandenburg, hier S. 42. Der romanisierende Dekor der Backsteinkapitelle im Langhaus war dafür verantwortlich, dass der Baubeginn des aufgehenden Baus ursprünglich für die Mitte des 13. Jahrhunderts oder zumindest für die Zeit um 1260 angenommen wurde. Vgl. Heinrich Trost u.a. (Bearb.), Eberswalde-Finow, in: Institut für Denkmalpflege (Hrsg.), Die Bau- und Kunstdenkmale in der DDR, Bezirk Frankfurt/Oder, Berlin 1980, S. 147-152, hier S. 149.

39 So zeigen die östlichen Langhauspfeiler in Eberswalde einen systematischeren Versatz als in Chorin und es gibt bei den Pfeilern abwechselnde Formsteinlagen mit wenigen nachträglichen Bearbeitungen der Formsteine. Die Portalgewände bestehen im Wesentlichen aus der rhythmischen Wiederholung gleicher Formen wie zwei verschiedenen, jeweils wechselnd versetzten Formsteinblöcken, die über zwei Backsteinlagen reichen und auch sonst größer sind als die hier verwendeten Backsteinformate.

40 Vgl. Dirk Schumann, Die Johanniskirche in der Brandenburger Altstadt. Zur Baugeschichte der ehemaligen Franziskanerklosterkirche, in: Johanniskirche Brandenburg an der Havel. Erforschung - Sicherung - Restaurierung (Arbeitshefte des Brandenburgischen Landesamtes für Denkmalpflege und Archäologischen Landesmuseums, Nr. 43), Worms 2017, S. 69-105, hier S. 84 f.

41 Fey, Reise und Herrschaft, S. 158.

42 Allerdings wurde nur noch 1297 eine Urkunde durch Otto V. in Brandenburg an der Havel ausgestellt, vgl. Fey, Reise und Herrschaft, S. 201. 
Johanniskirdje.
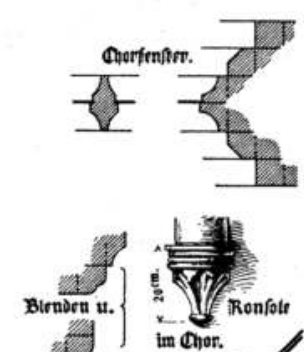

in Chor.
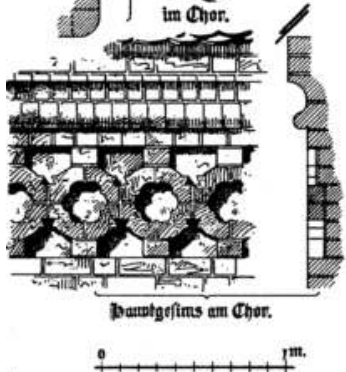

? $1^{\mathrm{m}}$

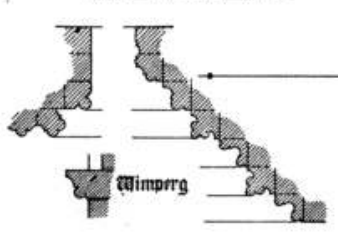

thunifortor.
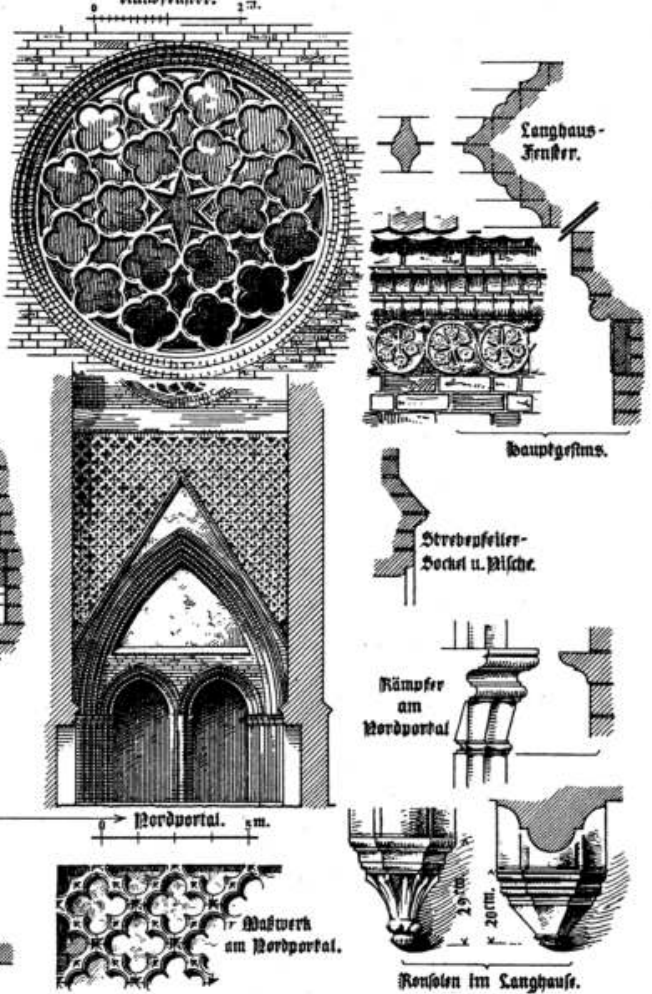

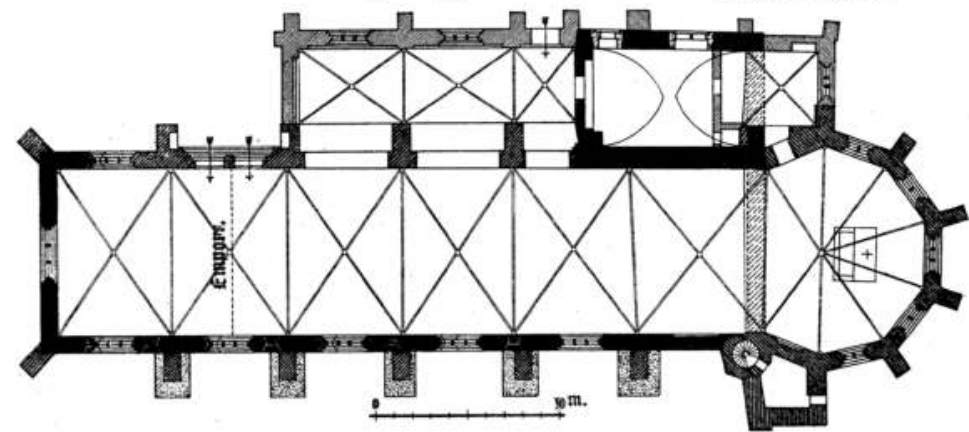

Abb. 8: Brandenburg an der Havel, Franziskanerklosterkirche, Baudetails und Backsteinzierrat um 1300 und 15. Jahrhundert.

begannen (Abbildung 8). ${ }^{43}$ Schließlich weisen die erhaltenen Urkundenbelege nach, dass auch die Aufenthalte Ottos IV., des führenden Markgrafen der johanneischen Linie, in Brandenburg an der Havel im späten 13. Jahrhundert zunahmen. ${ }^{44}$ Bei der Dominikanerklosterkirche der Bran-

43 Vgl. auch Jens Holst/Joachim Müller, Die Johanniskirche der Franziskaner in der Altstadt Brandenburg, in: Schumann, Brandenburgische Franziskanerklöster, S. 291-368, hier S. 316.

44 Fey, Reise und Herrschaft, S. 158 f. 
denburger Neustadt kam es im Bauverlauf um 1300 offenbar zu einer einschneidenden Planänderung, in deren Folge erst die heutige Gestalt des dreischiffigen Hallenlanghauses entstand. ${ }^{45}$ Möglicherweise reagierten die Dominikaner nun ihrerseits auf die repräsentative Erweiterung der Klosterkirche der Franziskaner in der Brandenburger Altstadt, bei der man an dem Konzept der Saalkirche festhielt. Ob sich in den baulichen Reaktionen der beiden konkurrierenden Bettelorden aufeinander auch das teilweise spannungsvolle Verhältnis der beiden Markgrafenlinien zueinander niederschlug, wie es in dieser Zeit in den Quellen greifbar wird, muss hier offenbleiben. Vielleicht weisen die Planänderungen in der frühen Baugeschichte der Berliner Franziskanerklosterkirche in eine solche Richtung.

\section{Der Baubeginn der Berliner Franziskanerklosterkirche nach 1271 und die Spuren einer Planänderung ${ }^{46}$}

Wie das enge Ineinandergreifen von Bettelordensklausur und markgräflichen Gebäuden im Fall von Neubrandenburg nahelegt, könnte es auch in Berlin bereits vor 1271 ein Konventsgebäude der Franziskaner in unmittelbarer Nähe der markgräflichen Aula gegeben haben. So wurde immer wieder vermutet, dass die in Feldstein ausgeführte nördliche Seitenschiffswand der Klosterkirche älter ist als der übrige Kirchenbau (Abbildung 9). Ein höheres Alter nahm für dieses Mauerwerk bereits Friedrich Adler an, allerdings vermutete er hier den „Rest eines markgräflichen Gebäudes",47 während Gerhard Bronisch in seiner umfangreichen Arbeit einen rechteckigen Saal aus Feldstein als Vorgängerkirche postulierte, ${ }^{48}$ wie er sich auch in Angermünde rekonstruieren lässt. Tatsächlich fällt die Datierung dieses Feldsteinmauerwerks auch unter den gegenwärtigen bauhistorischen Möglichkeiten nicht so leicht. Wichtig ist die Beobachtung, dass die auf der Nordseite dieser Wand befindlichen Gewölbeschildbögen aus Backstein erst nachträglich eingebracht worden sind, der Feldsteinverband also älter ist als der über einem Feldsteinfundament in Backstein ausgeführte südliche Kreuzgangarm, dessen Reste unlängst im Auftrag des Landesamtes für Denkmalpflege sondiert wurden. ${ }^{49}$ Bei dem teilweise überformten und neu verfugten Feldsteinmauerwerk fällt auf, dass im unteren Bereich hauptsächlich Feldsteine verwendet wurden, die in der Fläche und an den Kanten bearbeitet wurden. Sie weisen jedoch kaum rechteckige Formen auf und konnten deshalb auch nicht passgerecht vermauert werden. Dementsprechend war der Einsatz zusätzlicher Ausgleichssteine (Auszwickelungen) erforderlich, sodass kein so sorgfältiger Verband entstand, wie er von einigen Dorfkirchen des Berliner Umlands

45 Möglicherweise wurde die Dominikanerklosterkirche der Brandenburger Neustadt als Saalkirche begonnen. So finden sich dort an der nördlichen Schiffsarkade Abbruchspuren eines Wandpfeilers. Spätestens mit dem Bau des dreischiffigen Langhauses wurde dieser Plan aufgegeben. Vgl. Springer/Cante, Brandenburg/Havel Dominikaner, S. 297.

46 Die vorliegenden Ausführungen basieren auf den bereits 2007 publizierten Überlegungen und führen diese weiter. Vgl. Dirk Schuman, Die Franziskaner-Klosterkirche - Formsteine und Formsteinsysteme einer repräsentativen askanischen Architektur, in: Landesdenkmalamt Berlin, Kirchenruine des Grauen Klosters, S. 127-140.

47 Friedrich Adler (Hrsg.), Mittelalterliche Backstein-Bauwerke des Preussischen Staates, Bd. 2, Berlin 1898, S. 41.

48 Gerhard Bronisch, Die Franziskaner-Klosterkirche in Berlin, in: Mitteilungen des Vereins für die Geschichte Berlins 50 (1933), S. 89-142, hier S. 99.

49 Vgl. den Beitrag von Gunnar Nath in diesem Band. 


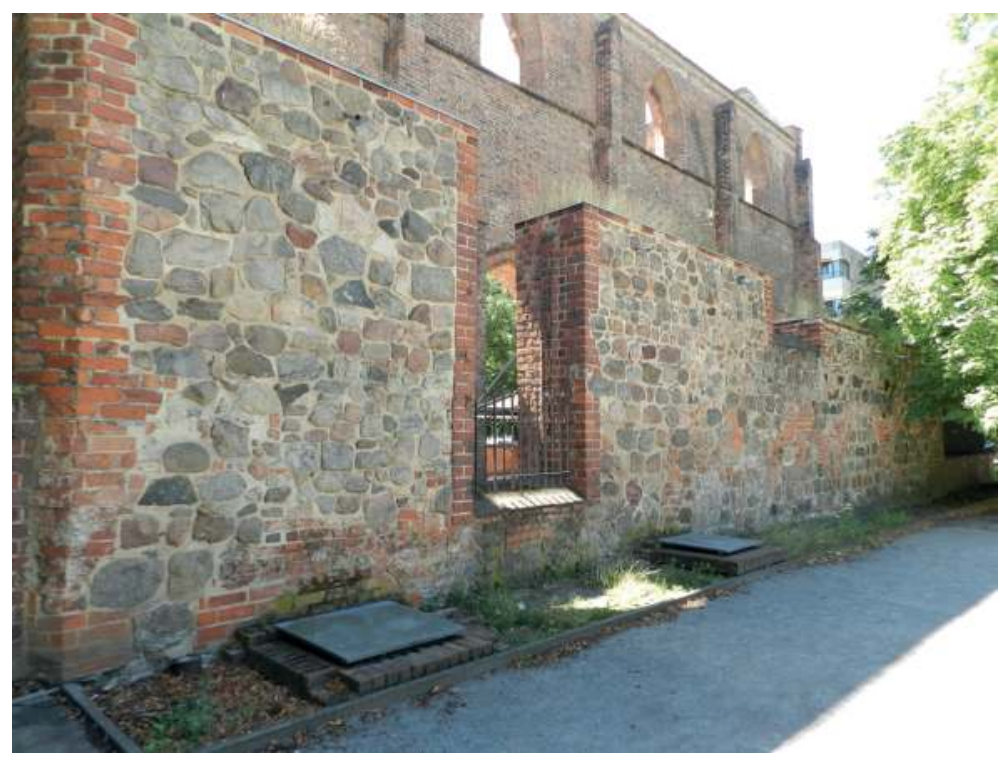

Abb. 9: Berlin Franziskanerklosterkirche, nördliche Seitenschiffsmauer der Kirche, die zugleich als Kreuzgangswand diente.

aus der Mitte oder der frühen zweiten Hälfte des 13. Jahrhunderts bekannt ist. Bei der zur Kirche gerichteten südlichen Innenseite des Feldsteinmauerwerks handelt es sich dem Verband und der Steinbearbeitung zufolge um eine Innenwand, da diese von vornherein für einen Flächenverputz vorgesehen war. ${ }^{50}$

Zudem konnte im Zuge der bauhistorischen Untersuchungen im östlichsten Joch des Seitenschiffs das schräge Gewände einer Portalblende festgestellt werden, die ebenfalls die Südseite der Feldsteinwand als Innenwand ausweist. Wie bereits Gerhard Bronisch vermutete auch Stefan Breitling einen langgestreckten Feldsteinbau, der dem Backsteinbau der Klosterkirche vorausging und dem Mauerwerk zufolge in eine Zeit vor der Mitte des 13. Jahrhunderts gehört. Allerdings datieren Analogien dieses weniger sorgfältig ausgeführten Feldsteinmauerwerks eher in eine Zeit um 1270. ${ }^{51}$ Zudem stellte Uwe Michas bei den zwischen 2001 und 2004 durchgeführten archäologischen Untersuchungen fest, dass jenes bereits 1926 im Chor festgestellte Feldsteinfundament, das in der Verlängerung der Ostwand der Sakristei verlief und bisher als Rest der abgebrochenen Ostwand eines Vorgängerbaus angesehen wurde, zwar der Errichtung

50 Vgl. Stefan Breitling, Die Franziskaner-Klosterkirche in Berlin: Ergebnisse der bauhistorischen Untersuchungen 1999-2004, in: Landesdenkmalamt Berlin, Kirchenruine des Grauen Klosters, S. 99-126, hier S. 102 f.

51 So konnten bei Reihenuntersuchungen brandenburgischer Dorfkirchen durch den Autor im Zusammenhang mit dem Forschungsprojekt mittelalterliche Wandmalereien im Land Brandenburg Nord-Ost einige dieser Kirchen mittels dendrochronologischer Untersuchungen genauer datiert werden, wie die Dorfkirche in Kerkow (Uckermark). Die dazugehörige Publikation ist in Vorbereitung. 
des polygonalen Chorabschlusses vorausging, ${ }^{52}$ jedoch seine Fundamentoberkante in derselben Höhe wie die anderen Chorfundamente lag und sich damit offensichtlich auf einen einheitlich planierten Bauhorizont bezog. ${ }^{53}$ Möglicherweise markiert dieses Fundament die ursprüngliche Planung eines geraden Chorabschlusses. Es wurde jedoch nie bis zur Flucht der Außenwand des südlichen Seitenschiffes geführt, denn während der Grabungen zeigte sich am südlichen Fundament des Chorpolygons zwar die Fortsetzung einer einheitlichen Planierschicht, darin befanden sich jedoch keine weiteren mittelalterlichen Fundamente. ${ }^{54}$ Auch die anderen archäologischen Sondagen erbrachten keine Hinweise auf Feldsteinfundamente eines Vorgängerbaus, die bei dessen Vorhandensein dort jedoch hätten angetroffen werden müssen. ${ }^{55}$ Tatsächlich bleibt die in Feldstein ausgeführte nördliche Seitenschiffswand erklärungsbedürftig. Aber vielleicht war diese vielmehr von einer bereits vorhandenen Klausur aus gedacht. Auch wenn sie zwar als Seitenschiffswand geplant war, sollte sie vor allem erst einmal die bereits vorhandenen Klausurgebäude vom Bauplatz der Klosterkirche abtrennen, wodurch plausibel wird, dass diese Mauer noch vor den anderen Mauern der Klosterkirche entstand. ${ }^{56}$

Allerdings wird damit noch nicht die Existenz des Feldsteinfundamentes einer geraden Ostwand unter dem polygonalen Chor verständlich. Archäologische Sondagen an den Fundamenten der heutigen südlichen Chorwand führten zu überraschenden Einblicken, die das gerade verlaufende Feldsteinfundament unter dem Chor in einem anderen Licht erscheinen lassen. So kamen bei diesen Sondagen keine Indizien für einen Vorgängerbau der heutigen Klosterkirchenruine zutage, sondern vielmehr Hinweise auf einen komplizierten Planungs- und Bauvorgang. Zwar erfolgte eine einheitliche Vorbereitung des Bauplatzes durch eine Planierung des Kirchenareals, ${ }^{57}$ doch belegen mehrere Fundamente, dass die heutige Chorgestalt der Kirche ursprünglich gar nicht vorgesehen war, sondern das Ergebnis von Planänderungen ist. So stellte Uwe Michas bei den archäologischen Sondagen unter der südlichen Chorwand drei rechteckige Fundamentblöcke fest, die bereits vor dem übrigen Fundament ausgeführt und offensichtlich als Pfeilerfundamente konzipiert worden waren..$^{8}$ Sie liegen genau an den Endpunkten der späteren Gewölbejoche und können nicht zur Konzeption eines einschiffigen Chores gehören. Passend zu diesem Befund zeigte die Sondage im Fundamentbereich zwischen nördlicher Chorwand und Langhaus eine trommelartige Fundamenterweiterung, auf der wohl ein kräftiges Vorlagenbündel vorgesehen

52 Bei diesen Untersuchungen konnten auch die noch vorhandenen Reste des 1926 freigelegten Fundamentes angetroffen werden. Vgl. Uwe Michas, Archäologische Untersuchungen an der Berliner Franziskaner-Klosterkirche, in: Landesdenkmalamt Berlin, Kirchenruine des Grauen Klosters, S. 88-98, hier S. 92, Schnitt 7 und S. $94 \mathrm{f}$.

53 Für den freundlichen Hinweis auf die einheitliche Planierung und die Höhe der Fundamentoberkante danke ich Uwe Michas.

54 Vgl. Michas, Archäologische Untersuchungen, S. 92, Schnitt 5.

55 So gab es keinen Hinweis auf einen schmaleren Saalbau, wie ihn Bronisch rekonstruierte, vgl. Bronisch, Die Franziskaner-Klosterkirche, S. 97-104, denn im Nord-Südschnitt am westlichen Ende des Chores traten keinerlei Hinweise auf ein solches Fundament auf. Vgl. Michas, Archäologische Untersuchungen, S. 94, Schnitt 9 sowie Breitling, Die Franziskaner-Klosterkirche [...]: Ergebnisse, S. 103.

56 Bei den Sondagen im Klausurbereich konnte die Planierschicht vom Gelände der Klosterkirche bisher nicht angetroffen werden, für die Klärung dieser Frage wären jedoch wegen der bisher zu geringen Einblicke umfassendere Untersuchungen notwendig. Für diesen freundlichen Hinweis danke ich Gunnar Nath.

57 Vgl. Michas, Archäologische Untersuchungen, S. $91 \mathrm{f}$.

58 Vgl. ebd., S. 96. 


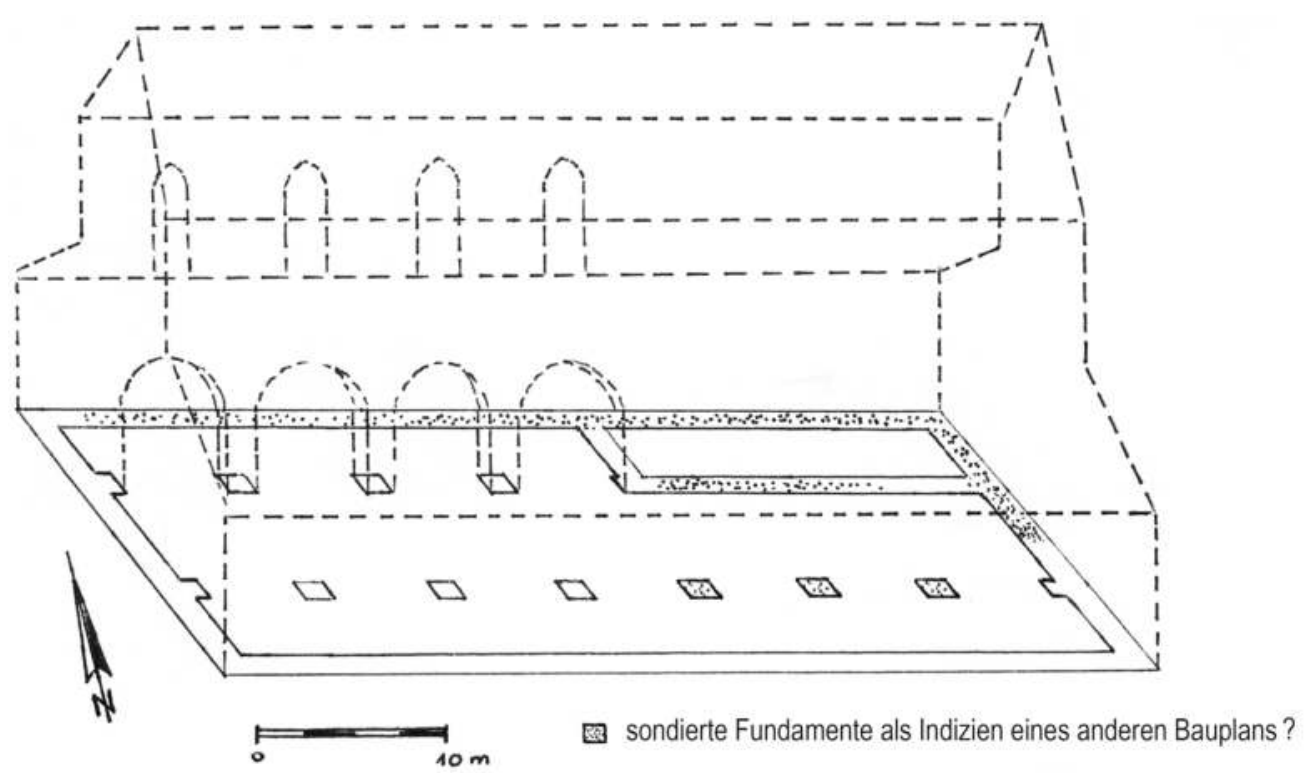

Abb. 10: Isometrischer Rekonstruktionsvorschlag einer ursprünglichen Planung der Franziskanerklosterkirche mit geradem Chorschluss und südlichem Nebenchor.

war. ${ }^{59}$ Dieses sollte möglicherweise den Pfeilern der Langhausarkade entsprechen und ist als Bindeglied zwischen Langhaus und den geplanten Pfeilern der südlichen Chorwand zu verstehen. Die Vorlage wurde jedoch bei der Ausführung des aufgehenden Mauerwerkes aufgegeben. Vielleicht kann man sich die ursprünglich geplante, aber nie vollständig gegründete Baugestalt als zweischiffige Choranlage vorstellen, zu der auch eine nördliche Chorkapelle mit ihrem heutigen Grundriss gehören sollte. ${ }^{60}$ In der Außengestalt wäre sie als dreischiffige basilikale Anlage mit geradem Ostabschluss in Erscheinung getreten (Abbildung 10). Bei der Frage nach den Vorbildern einer solchen Konzeption muss man die Mark Brandenburg gar nicht verlassen. Die ergrabene Vorgängerkirche des Zisterzienserklosters Chorin in Mariensee wurde offenbar mit einer entsprechenden Grundrisskonzeption begonnen. ${ }^{61}$ So gehören die dort noch vorhandenen Fundamente zu einer dreischiffigen Choranlage mit geradem Ostabschluss, dessen auskragende wie auch eingezogene Strebepfeiler die Konzeption eines gotischen Gewölbebaus nahelegen (Abbildung 11). Die Proportionen der dortigen Grundrissanlage mit einem etwa 8,5 Meter breiten Mittelschiff und 5,3 Meter breiten Seitenschiffen hätten der angenommenen dreischiffigen Berliner Konzeption entsprochen, denn hier wäre ein wohl 9,5 Meter breites Mittelschiff von etwa

59 Vgl. ebd., S. 90, Schnitt 3 und S. 96.

60 So ist das Motiv einer asymmetrischen Zweischiffigkeit in der Bettelordensarchitektur des 13. Jahrhunderts grundsätzlich nicht ungewöhnlich. Vgl. Wolfgang Schenkluhn, Die Architektur der Bettelorden. Die Baukunst der Dominikaner und Franziskaner in Europa, Darmstadt 2000, S. 119 f.

61 Vgl. Adler, Mittelalterliche Backstein-Bauwerke, Bd. 2, S. 39 und Josef Adolf Schmoll gen. Eisenwerth, Das Kloster Chorin und die Askanische Architektur in der Mark Brandenburg 1260-1320 (Veröffentlichungen der Berliner Historischen Kommission beim Friedrich-Meinecke-Institut der Freien Universität Berlin, Bd. 2), Berlin 1961, S. 26. 

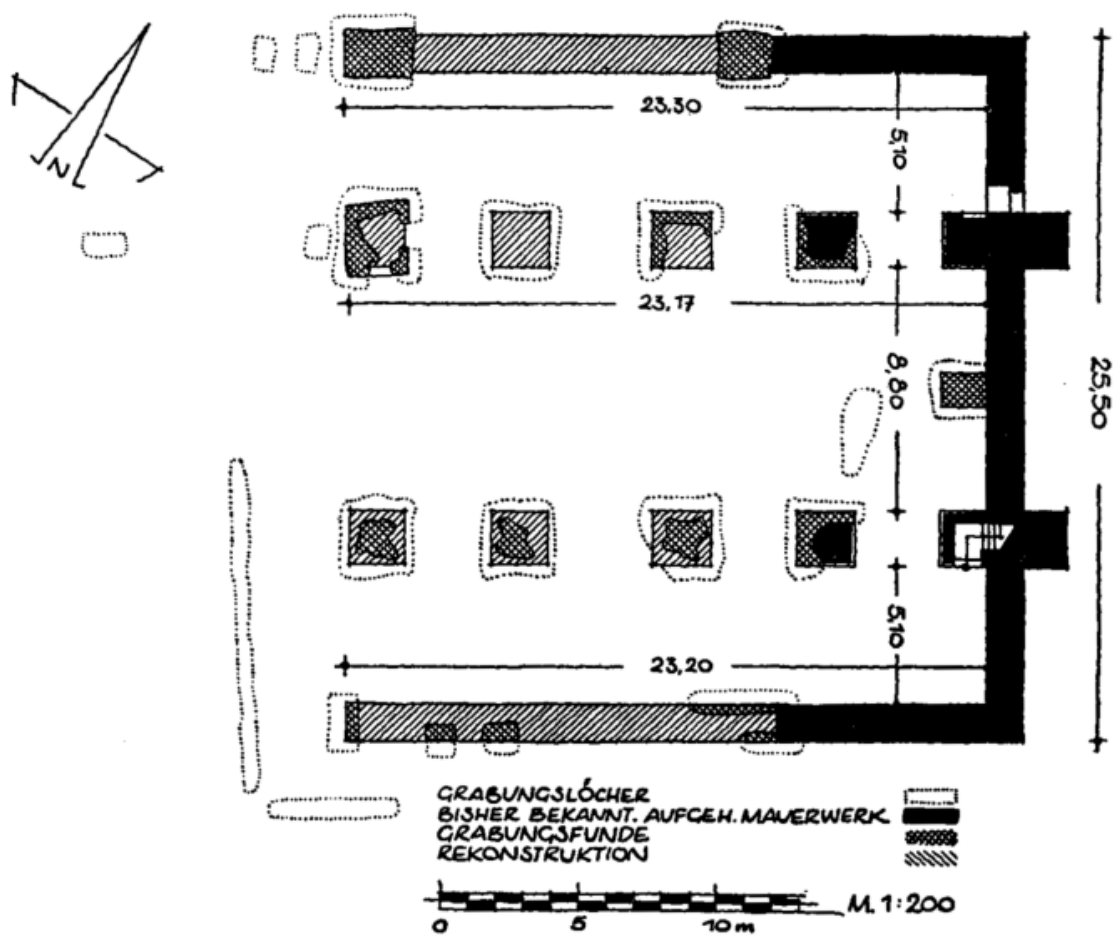

Abb. 11: Ergrabene Chorfundamente der in Mariensee begonnenen Zisterzienserklosterkirche.

sechs Meter breiten Seitenschiffen begleitet worden, ${ }^{62}$ was in beiden Fällen für das Mittelschiff annähernd die anderthalbfache Breite der Seitenschiffe ergibt. Wie bei den ältesten Fundamenten der Berliner Franziskanerkirche wurden auch in Mariensee annähernd quadratische Pfeilerfundamente angetroffen. In Berlin wurde der anders geplante Ostabschluss der Franziskanerklosterkirche noch vor der Ausführung des aufgehenden Mauerwerkes aufgegeben. Denn bereits das untere Mauerwerk der Sakristeikapelle berücksichtigt die Grundrisslösung des ausladenden Chorpolygons. So wird der hier zwischen Sakristei und Chor eingeschobene Gang zum Treppenturm verständlich. ${ }^{63}$ Es gibt auch keinen bauhistorischen Hinweis, dass die Sakristeikapelle bereits vorhanden war und bei der Errichtung des vorhandenen Chores teilweise wieder abgebrochen wurde. ${ }^{64}$ So deuten die Fotos von der Freilegung der Mauerreste der Sakristeikapelle

62 Da für diese erste Berliner Grundrisskonzeption die südliche Seitenschiffswand fehlt, wurde hier die Breite der ehemaligen nördlichen Sakristeikapelle beziehungsweise die Breite des südlichen Seitenschiffs am Langhaus dafür angenommen.

63 Ein Hinweis, dass das ausladende Chorpolygon und der trotz seiner Rekonstruktion im Kern noch mittelalterliche Gang in den Treppenturm zwischen Sakristeikapelle und Chor nicht von Anfang an in ihrer heutigen Form vorgesehen worden sein könnten, liegt vielleicht in den unterschiedlichen Breiten der Sakristeikapelle. So ist diese im dreiseitigen Chor 20 Zentimeter breiter als dort, wo der Gang zum Treppenturm eingefügt worden ist.

64 Auch die Existenz der hauptsächlich in Feldstein ausgeführten nördlichen Seitenschiffswand kann aus der vorhandenen Befundlage nicht als sicherer Nachweis für einen Vorgängerbau angesehen werden. Möglicherweise 
aus dem Jahr 1926 auf einen einheitlichen Verband von äußerer Feldsteinmauer und dem System aus Backsteinblenden und Vorlagen im Kapelleninneren. ${ }^{65}$ Ein wichtiger Hinweis sind auch die Runddienste, die zusammen mit dem Backsteinmauerwerk der beiden Kapellenwände ausgeführt wurden. Sie entsprechen den schlankeren Diensten des Mittelschiffs und wurden mit den gleichen Formsteinen und in derselben Verbandstruktur ausgeführt. Dementsprechend liegt hier eines der wichtigsten Argumente für den zeitlichen Zusammenhang von Langhaus, Chor, Sakristeikapelle sowie Gang und Treppenturm. Ein Argument für den baulichen Zusammenhang ist schließlich die Bausubstanz dieser Elemente selbst, die die nachträgliche Anfügung des Polygons an einen bereits vorhandenen Chor unwahrscheinlich macht. ${ }^{6}{ }^{6}$ Wenn man entsprechend der jüngsten bauhistorischen Ergebnisse davon ausgeht, dass die Aufbereitung des Bauplatzes und der Beginn der Fundamentierung erst nach der Übertragung des Grundstücks einsetzten, ${ }^{67}$ dann wären die ersten Fundamente der Berliner Franziskanerklosterkirche frühestens 1272 begonnen worden und die angenommene Planänderung erst danach möglich. Dabei handelt es sich genau um jenes Jahr, in dem erstmals die Verlegung des Klosters von Mariensee nach Chorin in den Urkunden greifbar wird, welche spätestens 1273 abgeschlossen war, und der Neubau der dortigen Zisterzienserklosterkirche begonnen wurde. ${ }^{68}$ Bei diesem Baugeschehen gab man die zeitgemäße Grundrisskonzeption des Vorgängerbaus in Mariensee auf und wählte nun den romanischen Grundriss des Mutterklosters und der dynastischen Grablege in Lehnin als Vorbild für die Errichtung der neuen Familiengrablege in Chorin. Allerdings entstand auf diesem romanischen Grundriss eine gotische Backsteinarchitektur, zu deren Gliederung Strebepfeiler, queroblonge (querrechteckige) Gewölbe, ein polygonaler Ostabschluss sowie Maßwerkfenster nach französischem Vorbild gehörten. ${ }^{69}$ Die Bezüge in der Backsteintechnik sowie die bereits mehrfach festgestellten stilistischen und baulichen Bezüge der Architektur der Berliner Franziskanerklosterkirche zur Choriner Klosterkirche machen deutlich, dass es sich bei dem in den Fundamenten greifbaren Planwechsel nicht um einen Zufall handelt, sondern der Choriner Planwechsel demjenigen in Berlin vorausgeht. Die Änderung in Berlin stellt offenbar eine ganz bewusste Reaktion auf den Wechsel in Chorin dar. Der Blick auf die Berliner Franziskanerklosterkirche zeigt, dass dieses Baugeschehen wiederum als eine architektonische Steigerung gegenüber Chorin zu verstehen ist.

hatte man mit Baubeginn hier noch höhere sockelartige Feldsteinbereiche vorgesehen, wie sie auch den zeitgleichen Bau der Berliner Marienkirche kennzeichnen. Dass der Feldsteinverband ein Joch vor dem heutigen Westabschluss der Kirche endet, könnte auch dem Bauablauf geschuldet sein, indem man hier erst einmal nur die für die Länge des - zu diesem Zeitpunkt ungewölbten - Kreuzganges notwendige Langhauswand vollendete. Vielleicht war aber an dieser Stelle auch ein erster westlicher Abschluss der Kirche vorgesehen.

65 Vgl. Hans Martin, Die Wiederherstellung der Klosterkirche, in: Mitteilungen des Vereins für die Geschichte Berlins 44 (1927), S. 19 f. So wurde bei der Kartierung das freigelegte nördliche und östliche Mauerwerk der Kapellen als zusammenhängender Baubefund wahrgenommen und dargestellt.

66 Vgl. Breitling, Die Franziskaner-Klosterkirche [...]: Ergebnisse, S. $110 \mathrm{f}$.

67 Vgl. ebd., S. $118 \mathrm{f}$.

68 Schumann, Herrschaft und Architektur, S. 38 f. und Gunther Nisch, Urkunden der ehemaligen Zisterzienserabtei Chorin, T. 1: Askanierzeit (Choriner Kapitel, H. 10), Chorin 2007, S. 50 f.

69 Vgl. Schumann, Herrschaft und Architektur, S. 80 f. und 90 f. 


\section{Der Baubestand der Franziskanerklosterkirche - Inspirationen gotischer Vorbilder}

Die Berliner Franziskanerkirche lässt ihre architektonischen Besonderheiten vor allem im Innenraum erkennen, denn hier zeigt sich ein deutlicher Gestaltungsgegensatz von Chor und Langhaus, der in der Vergangenheit immer wieder zur Annahme unterschiedlicher Bauzeiten geführt hat. ${ }^{70}$ So sind das dreischiffige, basilikale Langhaus und der eingezogene Langchor altertümlicher gestaltet als das auskragende Chorpolygon, dessen fast vollständig in Formsteingewänden aufgelöste Wandflächen gegenüber dem Langhaus ungewöhnlich modern wirken (Abbildung 12). Doch bereits Richard Borrmann kam nach eingehender Betrachtung der vermeintlichen Baunähte zum Schluss, dass es „keine Spur eines nachträglichen Anbaus“ des Chores der Berliner Franziskanerklosterkirche gibt. ${ }^{71}$ Auch die zwischen 1999 und 2004 erfolgte bauhistorische Dokumentation an den aufgehenden Wänden der Kirche stellte eine relativ einheitliche Struktur des aufgehenden mittelalterlichen Mauerwerkes fest, ${ }^{72}$ was für eine zügige Errichtung des Bauwerks spricht, auch wenn sich einzelne Planänderungen und damit verbundene Zäsuren nicht völlig ausschließen lassen. Zudem legen die Untersuchungen nahe, dass der Bau der Klosterkirche mit dem ambitioniertesten Teil, dem auskragenden siebenseitigen polygonalen Chor, begonnen und von Ost nach West weitergeführt wurde. Während die Wandflächen des Polygons oberhalb der Fenstersohlbänke durch reich profiliert gestufte Fenstergewände fast vollständig aufgelöst werden, liegen in den Wandflächen darunter tiefe spitzbogige Wandblenden mit einem teilweise freistehenden Maßwerk; feingliedrige Dienste verlaufen in den Knickpunkten der Wand. Durch die abweichende Aufrissgestaltung der Innenwände erhält der eigentliche Altarraum den Charakter eines separaten Zentralbaus und wird vom Langchor mit dem Chorgestühl des Konventes deutlich geschieden. Mit seinem ganz allgemeinen Zitat der Grabeskirche in Jerusalem, deren östlicher Zentralbau das Grab Christi enthält, wird der Altarraum der Berliner Franziskanerkirche mit Bedeutung aufgeladen, bei der die Architektur auf den Tod und die Auferstehung Christi verweist. Zudem besitzt die Wandgestaltung des Altarraumes eine Entsprechung in der bedeutendsten Palastkapelle der Hochgotik, der in der Mitte des 13. Jahrhunderts fertiggestellten Sainte Chapelle in Paris.

Dagegen bildet der Langchor mit seinen glatten Wandflächen, die allein durch die gotischen Fensteröffnungen und die Gewölbevorlagen gegliedert werden, eine deutliche Zäsur. Die anschließenden Langhausarkaden wiederum weisen auffällige Bezüge zu dem um 1240 begonnenen Langhaus des Magdeburger Domes auf. ${ }^{73}$ So zitieren die Arkaden trotz eines abweichenden

70 Adler, Mittelalterliche Backstein-Bauwerke, Bd.2, S. 41; Schmoll, Das Kloster Chorin, S. 86; zuletzt: Landesdenkmalamt (Hrsg.), Denkmale in Berlin, Bezirk Mitte: Ortsteil Mitte (Denkmaltopographie Bundesrepublik Deutschland), Petersberg 2003, hier S. 211.

71 Vgl. Richard Borrmann (Bearb.), Klosterkirche, in: Magistrat der Stadt Berlin (Hrsg.), Die Bau- und Kunstdenkmäler von Berlin, Berlin 1893, S. 188-203, hier S. $188 \mathrm{f}$.

72 Vgl. Breitling, Die Franziskaner-Klosterkirche in Berlin - Zur Rekonstruktion der Bauabschnitte, in: Johannes Cramer/Dorothée Sack (Hrsg.), Technik des Backsteinbaus im Europa des Mittelalters, Berlin 2005, S. 113-124 sowie Breitling, Die Franziskaner-Klosterkirche [...]: Ergebnisse, S. $106 \mathrm{f}$.

73 Zu dieser Bauphase zusammenfassend: Michael Süßmann, Zu den Bauphasen und der Bautechnik des Magdeburger Doms, in: Matthias Puhle (Hrsg.), Aufbruch in die Gotik. Der Magdeburger Dom und die späte Stauferzeit. Landesausstellung Sachsen-Anhalt aus Anlass des 800. Domjubiläums, Bd. 1: Essays, Mainz 2009, S. 126-141, hier S. $132 \mathrm{f}$. 


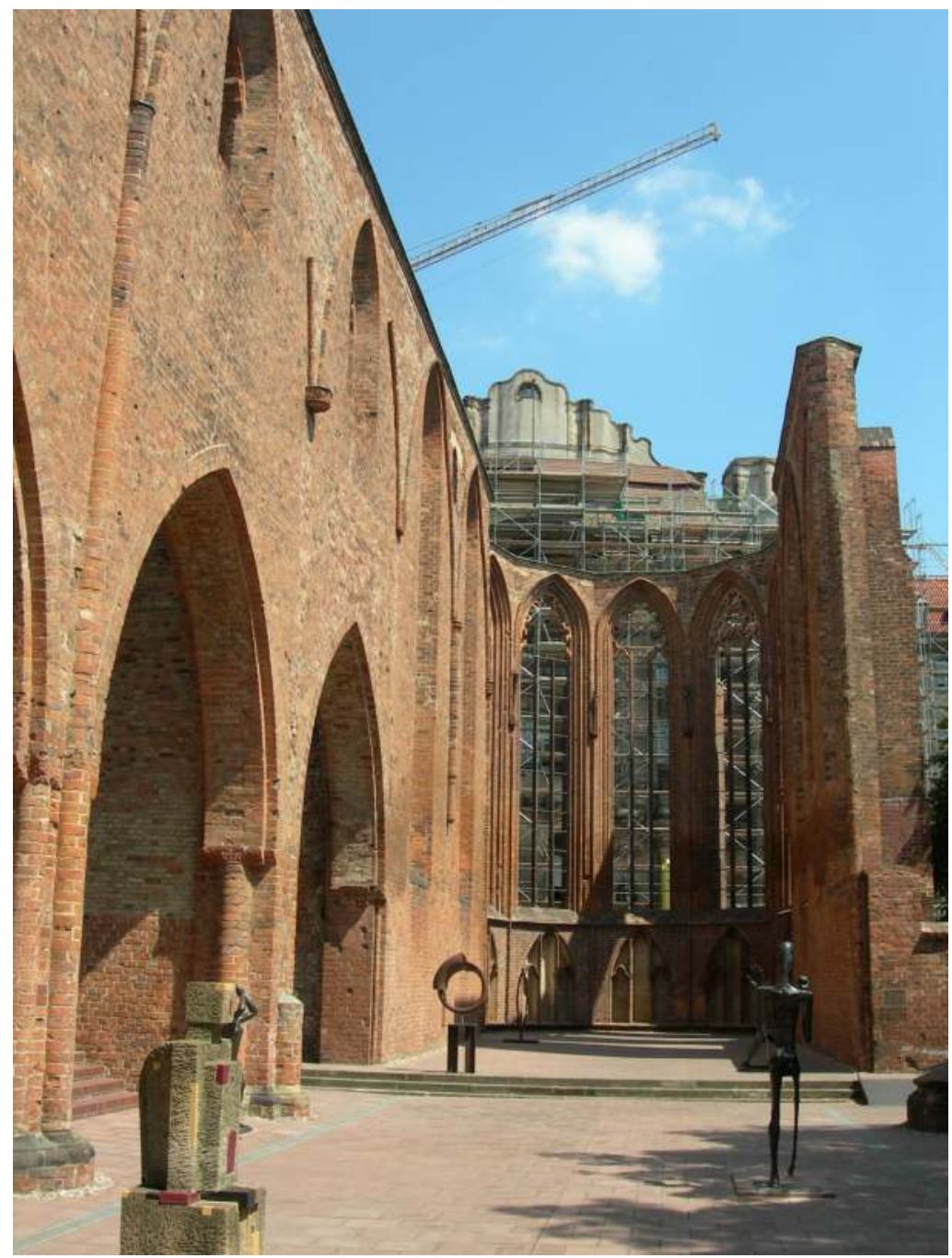

Abb. 12: Berlin, Franziskanerklosterkirche, Ruine von Chor und Langhaus, Blick nach Osten.

Stützenwechsels und eines anderen Kämpferdekors relativ detailliert das Magdeburger Vorbild mit durchlaufenden Diensten, der darunter flächig gehaltenen Mittelschiffswand, den Arkadenunterzügen und dem erst in der Leibung einsetzenden Kämpferdekor. Denn wie in Magdeburg liegt bei den Berliner Langhausarkaden neben dem dekorierten Innenbereich des Kapitells ein unvermittelt scharfgeschnittener Versprung, der dem Bogenunterzug folgt (Abbildung 13). Ganz nach Magdeburger Vorbild enden die Kämpferkapitelle schließlich in der Ebene der Wand und verstärken so absichtsvoll den monumentalen Charakter der Wandfläche, ein Gestaltungsprinzip, das bereits bei sächsischen und niedersächsischen Bauten der Romanik zu finden ist. Ein charakteristisches Merkmal des Langhausaufrisses der Berliner Franziskanerkirche ist der mit dem Pfeiler angelegte Gewölbedienst, der ohne Unterbrechung in den Gewölbekämpfer reicht. 


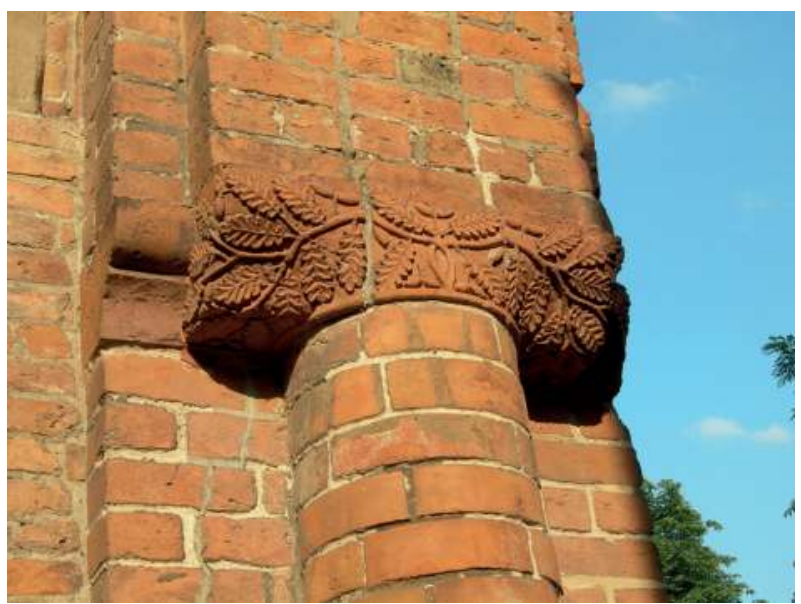

Abb. 13: Berlin, Franziskanerklosterkirche, Kämpferkonsole der nördlichen Langhausarkade und Querschnitte der Langhauspfeiler.

Anders als beim Magdeburger Vorbild ist der Dienst hier mit den anderen Halbrundvorlagen zu einer gleichmäßigen bündelartigen Gestalt des Pfeilers zusammengezogen worden. Dabei variiert nicht nur die Gestalt der Pfeiler, auch die Stärke der Vorlagen ist unterschiedlich. ${ }^{74}$ Für die Errichtung der Vierkantpfeiler war nur ein einziger spezieller Formstein notwendig. Der bündelartige Pfeiler mit den acht Rundvorlagen wurde dagegen, soweit erkennbar, aus drei verschiedenen Formsteinen gebildet (Abbildung 14). Ein einfacher Versatzwechsel führt dazu, dass sich jede

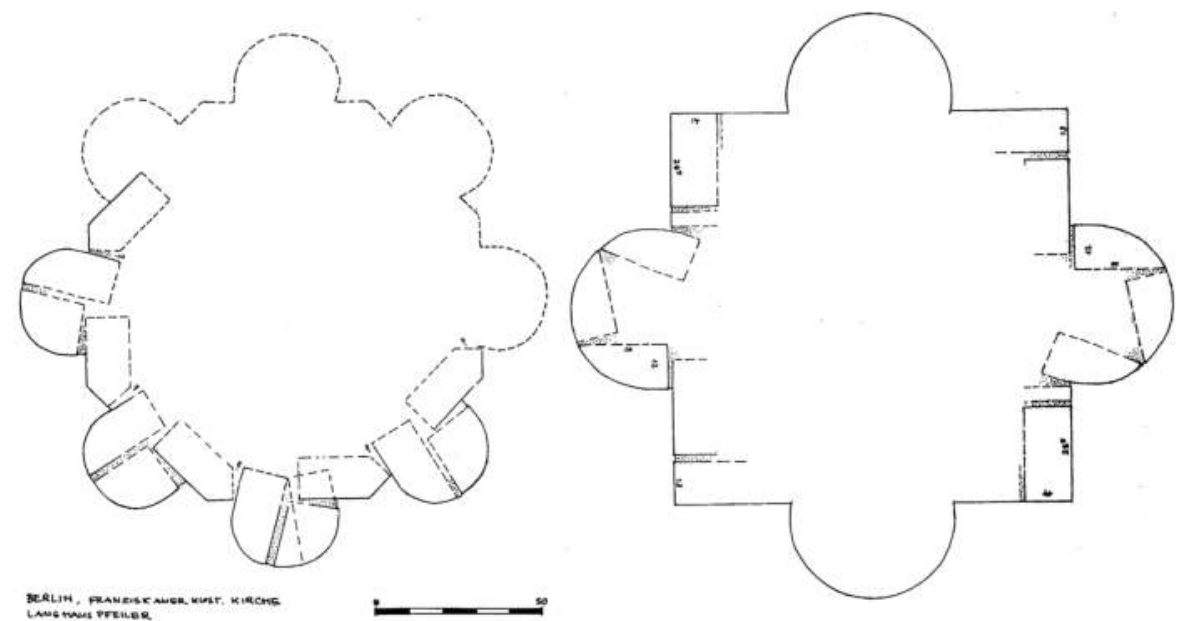

Abb. 14: Berlin, Franziskanerklosterkirche, Kämpferkonsole der nördlichen Langhausarkade und Querschnitte der Langhauspfeiler.

74 So gibt es je nach Pfeilerquerschnitt einen 50 oder einen 30 Zentimeter breiten Gewölbedienst. Die variierenden Pfeilertypen erfordern so jeweils unterschiedliche Formsteine zur Ausführung ihres Querschnittes. Die hier verwendeten, aus dem Normalformat entwickelten, Formsteine wurden offensichtlich ebenfalls mittels hölzerner Schablonen aus den noch feuchten Backsteinrohlingen herausgeschnitten. 
zweite Steinlage im Verband gleicht. Damit zeigen sich die Berliner Bündelpfeiler im Verband etwas reduzierter als die kurz zuvor am östlichen Langhaus der Klosterkirche Chorin entwickelten Formsteinsysteme.

An den um 1272 begonnenen Ostteilen der Choriner Klosterkirche gibt es (wie auch im Chor der Berliner Franziskanerklosterkirche) wechselnde Formsteinprofile, die aus normalformatigen Backsteinen entwickeltwurden. ${ }^{75}$ Doch beim Bau des ersten Choriner Langhausabschnittes kamen noch vor der Vollendung von Chor und Querhaus Formsteine zum Einsatz, die die Höhe von zwei Backsteinlagen besitzen und auch in der Länge und der Breite über die Maße der zum Teil relativgroßen Choriner Normalformate hinausgehen (Abbildung 15). Besonders große Formsteinblöcke

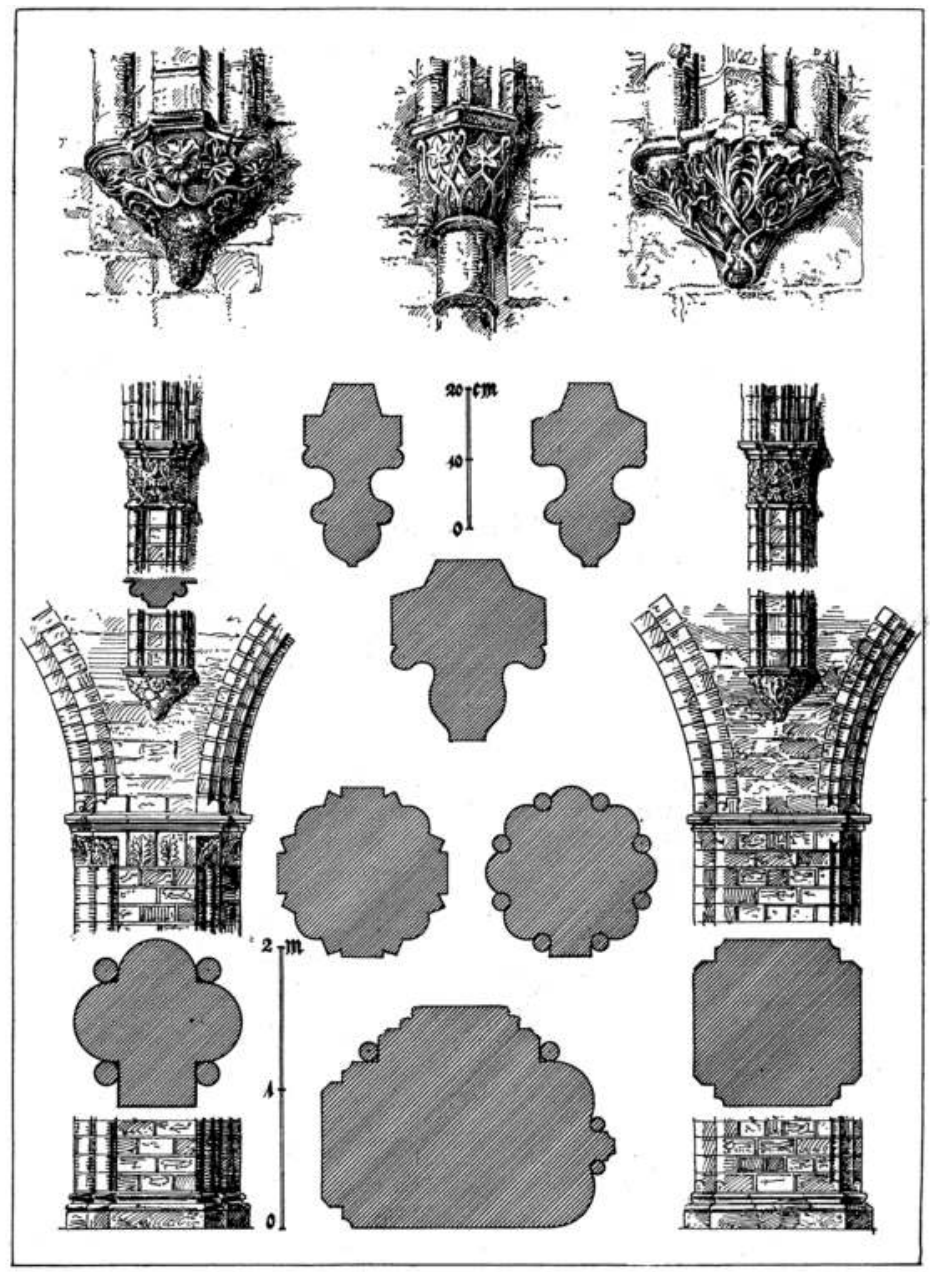

Abb. 15: Zisterzienserklosterkirche Chorin, Langhaus, Mittel- und Seitenschiffskonsolen, Gewölberippenprofile und Pfeilerquerschnitte.

75 So das Sakristeiportal und das Gewändeprofil zwischen Querhaus und Seitenschiff der Choriner Klosterkirche. 
treten in der Obergadenwand des Choriner Langhauses auf. Diesen entsprechen schließlich in der Größe und im Anspruch die Konsolformsteine der Arkadenkämpfer am Langhaus der Berliner Franziskanerkirche, ${ }^{76}$ auch wenn es im Detail mehrere Unterschiede gibt. ${ }^{77}$ Die große Herausforderung in der Herstellung und dem Versatz solcher über 80 Kilogramm schweren Formstücke aus Backstein setzt die Annahme eines spezialisierten Baubetriebes voraus, der über eine eigene Ziegelherstellung verfügte, da die Formstücke direkt für die Stelle ihres Versatzes im Mauerwerk gefertigt wurden. ${ }^{78}$ Im Gegensatz zur perfektionierten Herstellungstechnik bleiben die Blatt- und Rankenmotiven des Berliner Kämpferdekors auffällig ornamental und stark stilisiert. Verschiedentlich zeigen sie eine Verwandtschaft zu Choriner Blattmotiven, weisen jedoch grundsätzlich darüber hinaus und zeigen beispielsweise eine gratige Binnenzeichnung wie auffällige Blattrippen. Ein weiteres wichtiges architektonisches Element an der Berliner Franziskanerkirche ist das zusammen mit dem westlichen Langhausjoch entstandene Westportal. ${ }^{79}$ Ursprünglich war es zweigeteilt und mit einer Reliefdarstellung des Weltenrichters versehen (Abbildung 16). Es gehört zu einer ganzen Reihe ehemals gleichartiger repräsentativer Laienportale märkischer Bettelordenskirchen wie in Angermünde, Brandenburg und Prenzlau. Insgesamt trat die Außengestaltung der Berliner Franziskanerkirche gegenüber der Gliederung des Innenraums zurück und trug zu einer Vereinheitlichung der Architekturelemente bei. So bestimmen einfache schräge Fenstergewände den gesamten Außenbau und verleugnen geradezu die repräsentative Innengestaltung des Chores. Dieser Gestaltungsdualismus zwischen dem Formenreichtum im Chorinnenraum und der sachlichen Außenhülle des Baukörpers dürfte schließlich ein weiteres Indiz für eine einheitliche Ausführung des Baus sein, der von Anfang an als Franziskanerklosterkirche vorgesehen war.

76 Die Berliner Kämpferformsteine erreichen Ausmaße von $60 \times 40 \times 24$ Zentimetern und dürften damit zu den eindrucksvollsten Beispielen dieser Herstellungstechnik in der Mark gehören.

77 Die Choriner Konsolformsteinblöcke besitzen Seitenlängen von 50-55 Zentimetern sowie Höhen von ca. 24 Zentimetern.

78 Auch beim Bau des Zisterzienserklosters im schweizerischen Sankt Urban wurden in der ersten Hälfte des 13. Jahrhundert Formsteine mit den Ausmaßen von $54 \times 30 \times 22$ Zentimetern hergestellt. Ein interdisziplinäres Forschungsprojekt untersuchte 1996-98 die Steine und ihre Herstellungsbedingungen. Vgl. Sophie Wolf, Die Herstellungstechnik der Backsteine des Zisterzienserklosters St. Urban, in: Ernst Badstübner/Dirk Schumann (Hrsg.), Backsteintechnologien in Mittelalter und Neuzeit (Studien zur Backsteinarchitektur, Bd. 4), Berlin 2003, S. 227-239. Die Tonmasse musste hier über einen Winter hinweg aufwendig vorbereitet werden. Nach der Anfertigung des Rohlings wurde dieser unter ganz speziellen Feuchtigkeitsverhältnissen über drei Monate lang getrocknet und schließlich acht Tage lang gebrannt. Wie in Chorin hat man auch bei der Berliner Franziskanerkirche die endgültige Form der Formsteine aus dem noch relativ feuchten Tonrohling herausgeschnitten. Zudem erhielten einige der Formstücke der Langhauskämpfer offenbar durch Polieren vor dem Brand eine leicht glänzende Oberfläche.

79 Friedrich Adler nahm an, dass das Westportal im 14. Jahrhundert durch das vorhandene ersetzt wurde, ohne jedoch eine nähere Begründung dafür anzugeben, vgl. Adler, Mittelalterliche Backstein-Bauwerke, Bd. 2, S. 41. Bei den Sanierungen des westlichen Mauerwerkes haben sich auf der Innenseite von der Einbindung des Portalgewändes in die Mauerblende nur noch wenige mittelalterliche Mörtelfugen erhalten. Diese sprechen jedoch eher für eine zusammenhängende Entstehung von Portalgewände und Westwand. 


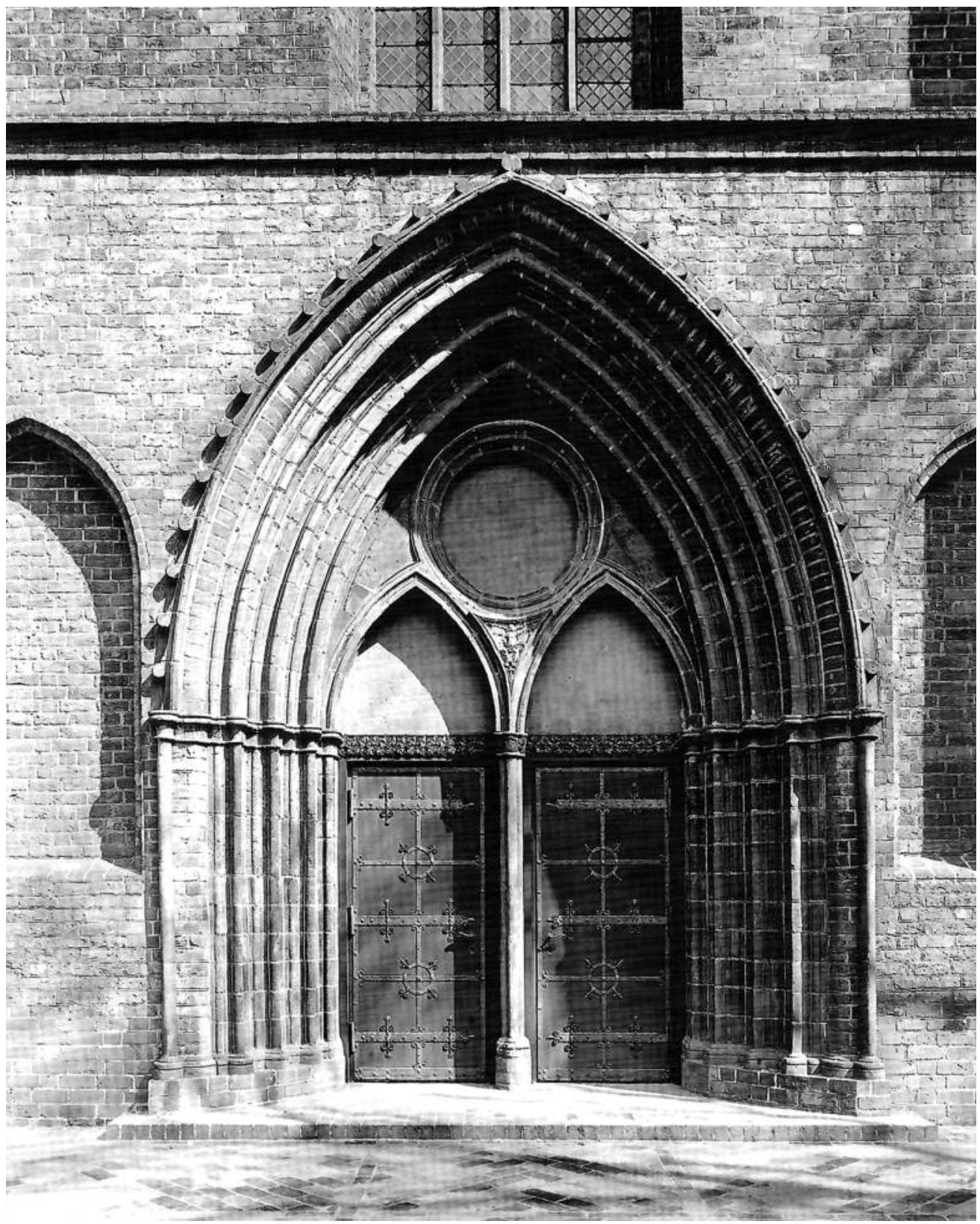

Abb. 16: Berlin Franziskanerklosterkirche, Westportal vor der Zerstörung, historisches Foto 1933/36. 


\section{Schlussbemerkungen und Überlegungen zur Datierung der Architektur der Berliner Franziskanerklosterkirche}

Gerhard Bronisch ging 1933 von einem einheitlichen Bauverlauf der Berliner Klosterkirche von West nach Ost aus. Er sah ihren Baubeginn im Anschluss an die Fertigstellung der Choriner Ostteile um 1280, wobei er für die Beisetzung Herzog Albrechts von Sachsen im Jahre 1300 nutzbare Teile der Kirche voraussetzte. ${ }^{80}$ Da der Chorschluss der Stettiner Franziskanerkirche dem Berliner Vorbild folgt, musste aufgrund der damals etablierten stilistischen Datierung Stettins „der Chorschluss der Berliner Franziskanerkirche spätestens in der ersten Hälfte des 14. Jahrhunderts entstanden sein".81 Josef Adolf Schmoll setzte dieser Ansicht eine Datierung in die Zeit vor dem Baubeginn der Choriner Klosterkirche entgegen. ${ }^{82}$ Allerdings datierte er das nun ungewöhnlich moderne Chorpolygon in eine spätere Bauzeit. Dessen Errichtung brachte er mit der Schenkung einer Ziegelei im Jahre 1290 in Verbindung. ${ }^{83} \mathrm{Ihm}$ nachfolgende Autoren teilten diese Auffassung. ${ }^{84}$ Ausgangspunkt für die Datierung Schmolls ist die auffällige Bezugnahme der Berliner Langhausarkaden auf den Magdeburger Dom, allerdings nicht bezogen auf den heutigen Zustand, sondern auf die ursprüngliche, 1274 aufgegebene Planung. ${ }^{85}$ Doch auch seine Argumentation einer stilistischen Abhängigkeit der Choriner Ornamentik von der Berliner Klosterkirche würde keinesfalls eine sichere Datierung rechtfertigen. Vielmehr gebietet das bereits von Bronisch aufgezeigte gleichzeitige Auftreten von altertümlichen und modernen Formen, „bei der Festlegung des Baubeginns besonders vorsichtig zu sein“ ${ }^{86}$

Doch welche Anhaltspunkte für eine Datierung bleiben, wenn stilistische Kriterien riskant, die Quellen lückenhaft und bauarchäologische Datierungsmethoden wie die Dendrochronologie nunmehr unmöglich sind? Neue Ausgangspunkte für eine zeitliche Einordnung des Baugeschehens bieten jüngere bauhistorische Ergebnisse. Mit der Konkretisierung des mittelalterlichen Bauablaufs zeigt sich das Baugeschehen in einem neuen Licht, denn anhand verschiedener Befunde des Mauerverbandes lässt sich eine grundsätzliche Baurichtung von Ost nach West wahrscheinlich machen. ${ }^{87}$ So steht nun die moderne Chorlösung in einem engen Bauzusammenhang mit dem Langhaus, auch wenn dessen Aufriss und Gestaltung altertümlicher erscheinen. Zwar ergibt sich daraus noch keine Datierung, das Baugeschehen lässt sich jedoch in den Kontext anderer bedeutender Baustellen dieser Zeit einordnen, deren charakteristischer Formsteindekor einen Vergleich mit der Backstein- und Formsteintechnik des Berliner Baus ermöglichen. ${ }^{88}$ Die

80

81

82

83

84

44

Berlin 1983, S. 70; Georg Dehio. Handbuch der deutschen Kunstdenkmäler, Bezirke Berlin/DDR und Potsdam,
Berlin 1983, S. 17 f.; Carljürgen Gertler, Zur Geschichte und Gestalt der Berliner Franziskanerkirche, in: Katalogalmanach. Das Baudenkmal, die Skulpturen-Ausstellung, die Veranstaltungen, Berlin 1997, S. 174.

85 Für Schmoll ist nur ein Bezug auf diese Planung zu einem Zeitpunkt vor ihrer veränderten Ausführung denkbar. Vgl. Schmoll, Das Kloster Chorin, S. $84 \mathrm{f}$.

86 Bronisch, Die Franziskaner-Klosterkirche, S. 114.

87 Vgl. Breitling, Die Franziskaner-Klosterkirche [... - Zur Rekonstruktion, S. $117 \mathrm{f}$.

88 Breitling setzt den Bau in eine Zeit zwischen den Experimenten der ersten Hälfte des 13. Jahrhundert und den „formenreichen Bauten am Anfang des 14. Jahrhunderts, bei denen der Steinversatz bereits detailliert geplant wurde“. 
seriellen Möglichkeiten der Backsteintechnik bildeten in der Mark in der zweiten Hälfte des 13. Jahrhunderts die Grundlage für eine Architektur, deren gestalterische Innovationen bewusst in den Dienst komplexer Architekturbezüge gestellt wurden. ${ }^{89}$ So stellt es sich auch für die vollständig durch Blenden und Gewändeprofile aufgelösten Innenwände des Chorpolygons der Franziskanerkirche dar. Neben dem ganz allgemeinen Bezug des ausladenden Chorpolygons auf die Jerusalemer Grabeskirche steht für den Wandaufriss und die gotische Durchfensterung des ehemals kreuzrippengewölbten Chores das Vorbild der in der Mitte des 13. Jahrhunderts vollendeten Pariser Sainte-Chapelle im Raum, deren Verbindung von Palast- und Reliquienkapelle für die Sakralisierung von Herrschaft Maßstäbe setzte.

Beim Langhaus handelt es sich dagegen um einen auffällig deutlichen Bezug auf das Langhaus des von Kaiser Otto dem Großen gestifteten und seit 1209 neugebauten Magdeburger Doms, ${ }^{90}$ zu dessen Erzsprengel auch Berlin gehörte. Dieser Bezug dürfte nicht nur mit Blick auf die imperiale Bedeutung dieser Kathedrale zu verstehen sein, sondern der Auslöser könnte auch die Einverleibung des Amtes des Magdeburger Erzbischofs durch ein Familienmitglied der askanischen Markgrafen gewesen sein. So gelang es Markgraf Otto IV. schließlich nach mehreren Anläufen und mit starkem politischen Druck, 1283 seinen Bruder Erich auf den Magdeburger Erzbistumsthron zu bringen. ${ }^{91}$ Allerdings ist mit dem Erzbischof Erich von Brandenburg auch jene Bautätigkeit am Obergaden des Magdeburger Langhauses verbunden, die bereits sein Vorgänger um 1274 einleitete und die zu einem Planwechsel und der Aufgabe quadratischer Langhausjoche führte. Denn nun sitzen über einem Arkadenbogen des Magdeburger Mittelschiffes jeweils zwei Fensteröffnungen und zwei queroblonge Gewölbefelder. ${ }^{92}$ Dementsprechend bliebe vor allem die Zeit zwischen 1271 und 1274 für den Bezug auf die dortige ursprüngliche Langhausplanung. ${ }^{93}$ Allerdings lässt sich auch ein späteres Aufgreifen dieser um 1274 in Magdeburg verworfenen Konzeption nicht vollständig ausschließen.

Die in Berlin angewendete Backsteintechnik setzt den technischen Stand der Choriner Baustelle voraus, da neben direkten Bezügen und Entsprechungen in Berlin auch Weiterentwicklungen greifbar werden. ${ }^{94}$ Wie in Chorin wurden in Berlin zu Beginn der Bauarbeiten am Chor Gewändeformsteine verwendet, die aus dem Normalformat entwickelt und in einem systematischen Wechsel verbaut wurden; in Berlin allerdings noch als asymmetrische Profilfolge, die verschiedentlich sogar zwei unterschiedliche Formsteine für ein und dieselbe Stelle erforderten. Im Lang-

Vgl. Breitling, Die Franziskaner-Klosterkirche [... - Zur Rekonstruktion, S. 123. Er bezieht sich damit auf die Veränderungen in den Formsteinverbänden, die im späten 13. Jahrhundert eine serielle Rationalisierung erfuhren und aufwendige Profile mit immer weniger Formsteinen in einem immer systematischeren Versatz ermöglichten. Vgl. Dirk Schumann, Die Berliner Franziskanerklosterkirche und der Dekor - Formsteine und Formsteinsysteme im märkischen Backsteinbau des 13. Jahrhunderts, in: Badstübner/Schumann, Backsteintechnologien, S. 109-128.

89 Vgl. Schumann, Herrschaft und Architektur, S. 89 f.

90 Vgl. Schmoll, Das Kloster Chorin, S. 85 f.

91 Schultze, Die Mark, S. $183 \mathrm{f}$.

92 Vgl. Süßmann, Bauphasen und Bautechnik, S. $136 \mathrm{f}$.

93 So wies bereits Schmoll auf den um 1274 erfolgten Planwechsel am Obergaden des Magdeburger Domlanghauses und dessen mögliche Relevanz für die Datierung des Baugeschehens an der Berliner Franziskanerkirche hin. Vgl. Schmoll, das Kloster Chorin, S. $85 \mathrm{f}$.

94 Es sind anscheinend ähnliche Veränderungen im technischen Erfahrungshorizont, die das Baugeschehen der Franziskanerklosterkirche in eine zeitliche Nähe zum Baufortgang am Kloster Chorin um 1270/80 rücken. 
haus entschied man sich bei der Berliner Klosterkirche für glatte Wandflächen und riesige Formsteinblöcke aus Backstein im Kämpfer- und Sockelbereich. Diese fertigte man eigens für ihren Platz im Mauerwerk an und versah sie mit einem romanisierenden Dekor, der im Detail jedoch ebenfalls den Choriner Blattdekor voraussetzte. Erscheint die Gestaltung der Langhausarkaden mit ihren Bezügen auf das Magdeburger Domlanghaus durchaus traditionell, befand sich die an der Berliner Klosterkirche angewandte Backsteintechnik an einem fortgeschrittenen Punkt in der Konzeption und Herstellung der einzelnen Bauelemente, wie es sich auch für die Baustelle des Klosters Chorin nachweisen lässt. ${ }^{95}$ Neben den Übereinstimmungen mit dem Gewändeprofil eines um 1300 entstandenen Choriner Portals (Kirche/Fürstensaal) stellt ein heute in Berlin nicht mehr vorhandener Befund ein weiteres Indiz für einen Zusammenhang mit dem Choriner Baubetrieb dar. Bei der Sanierung der Mauerkrone der kriegszerstörten Klosterkirche im Jahr 1959 wurden im Traufbereich Reste quadratischer Backsteinplatten beseitigt (Abbildung 17), die auf dem mittelalterlichen Mauerverband aufsaßen. ${ }^{96}$ Dabei kann es sich eigentlich nur um die Reste

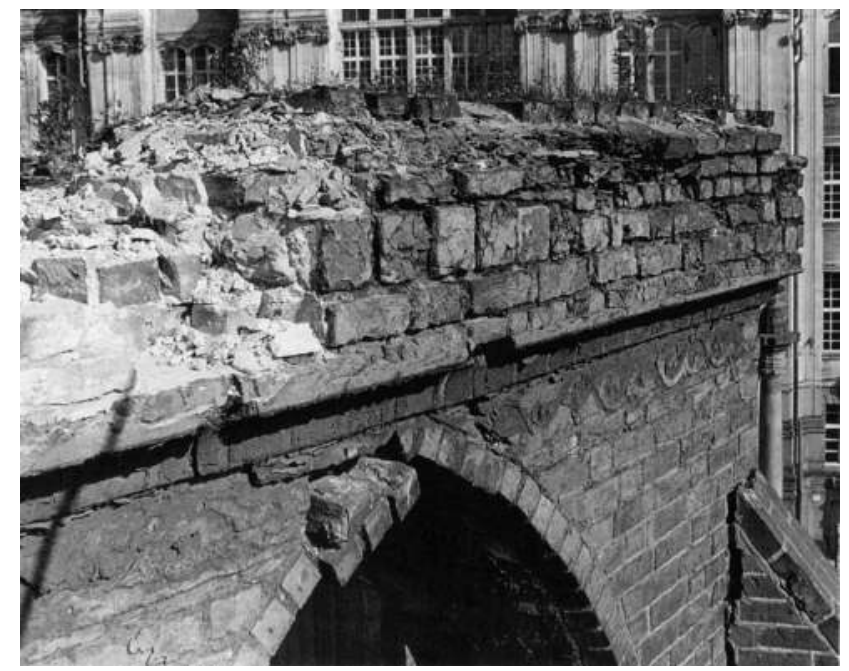

Abb. 17: Berlin, Franziskanerklosterkirche, Traufe nach der Kriegszerstörung, historisches Foto vor 1959.

95 Die Herstellung solcher Backsteinformstücke von Seitenlängen bis zu 60 Zentimetern erforderte ein hohes technisches Können beim Herstellen, Trocknen, Brennen und im Versatz. Möglicherweise handelte es sich hier um technische Erfahrungen, die vor allem von zisterziensischen Baustellen stammten, die in Lehnin vorbereitet und schließlich in Chorin weiterentwickelt wurden. Diese Fähigkeiten und Erfahrungen haben in der Mark Brandenburg im späten 13. Jahrhundert eine Verbreitung über die Ordensgrenzen hinaus gefunden. Bauten wie die Franziskanerklosterkirche in Angermünde, das Zisterzienserinnenkloster Boitzenburg und die Pfarrkirche in Eberswalde weisen auf einen engen Zusammenhang mit dem Baubetrieb in Chorin und entstanden im Umfeld der askanischen Landesherrschaft. Die Ausführung von Portalen mit großen Gewändeformsteinen erfuhr eine Verbreitung bis in die Neumark hinein. Auch die zeitgleichen, in Mecklenburg anzutreffenden bautechnischen Fähigkeiten wären auf diesen Zusammenhang hin zu überprüfen.

96 So belegt es ein historisches Foto aus der Zeit vor der Sanierung 1959. Vgl. Dirk Schumann, Die FranziskanerKlosterkirche und der Dekor - Formsteine und Formsteinsysteme einer repräsentativen askanischen Architektur, in: Landesdenkmalamt Berlin, Kirchenruine des Grauen Klosters, S. 127-140, hier S. 138. 
eines ehemaligen Reliefplattenfrieses handeln, der durch Verwitterung sein Relief verlor. ${ }^{97} \mathrm{Ob}$ die im Hof des Märkischen Museums verbauten, teils figürlich gestalteten Reliefplatten aus der Sammlung des märkischen Provinzialmuseums vielleicht ehemals aus diesem Kontext stammten oder eher zur bald darauf im Bau befindlichen Dominikanerklosterkirche gehörten, lässt sich heute jedoch nicht mehr klären. ${ }^{98}$

Die ehemals vorhandenen aufwendigen mittelalterlichen Fenstermaßwerke der Berliner Franziskanerkirche besaßen ihre Entsprechungen dagegen nicht in Chorin, ${ }^{99}$ sondern in nachfolgenden Bauten der Choriner Schule wie in dem im späten 13. Jahrhundert neugebauten Chor der Angermünder Franziskanerklosterkirche oder dem um 1300 erfolgten Umbau der Franziskanerklosterkirche in Brandenburg. Doch ist damit nicht gesagt, dass die Berliner Maßwerke zur gleichen Zeit mit denen in Angermünde und Brandenburg entstanden sein müssen. Vielmehr könnte die konzeptionelle Architektur der Berliner Franziskanerkirche zumindest im Fall der Maßwerke das Vorbild für die Umbauten in Angermünde und Brandenburg geliefert haben, auch wenn dort ansonsten vor allem Choriner Formen präsent sind. Die bis zur Zerstörung der Berliner Bettelordenskirche vorhandenenfigürlichgestalteten Gewölbekonsolen im Bereich des Triumphbogens schließen sich stilistisch an die um 1270/80 entstandenen Beispiele figürlicher Backsteinskulpturen des Klosters Chorin an (Abbildungen 18 und 19), auch wenn der an der Unterkante der Konsole aufgelegte Blattdekor eine

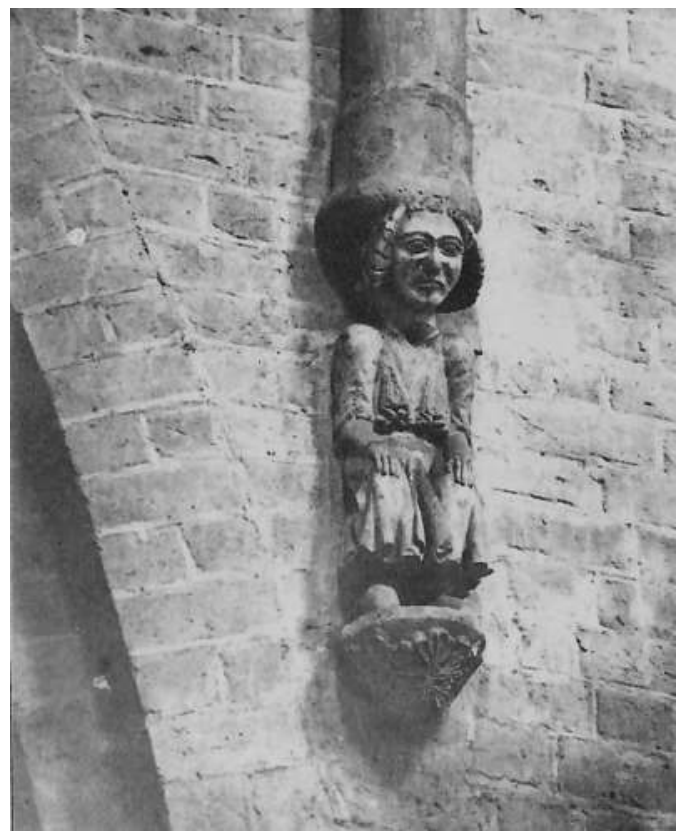

Abb. 18: Berlin Franziskanerklosterkirche, ehemaliger figürlich gestalteter Dienstanfänger im Langchor, historische Postkarte vor 1945.

97 Möglicherweise sollte der später im Traufbereich dort aufgeputzte Ornamentfries an jenen Relieffries erinnern.

98 Vgl. Schumann, Die mittelalterliche Bauskulptur, S. 37.

99 Zur Rekonstruktion der ursprünglichen mittelalterlichen Maßwerke im Chor der Berliner Franziskanerkirche siehe Breitling, Die Franziskaner-Klosterkirche [...]: Ergebnisse, S. 112 f. 


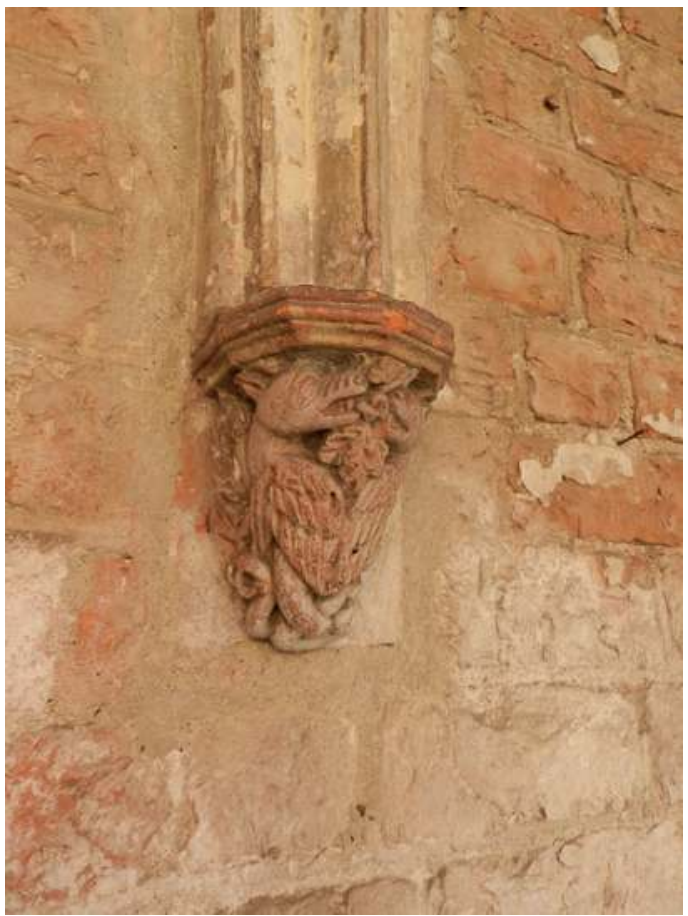

Abb. 19: Zisterzienserkloster Chorin, mit einem Fabelwesen gestaltete Konsole im östlichen Kreuzgang.

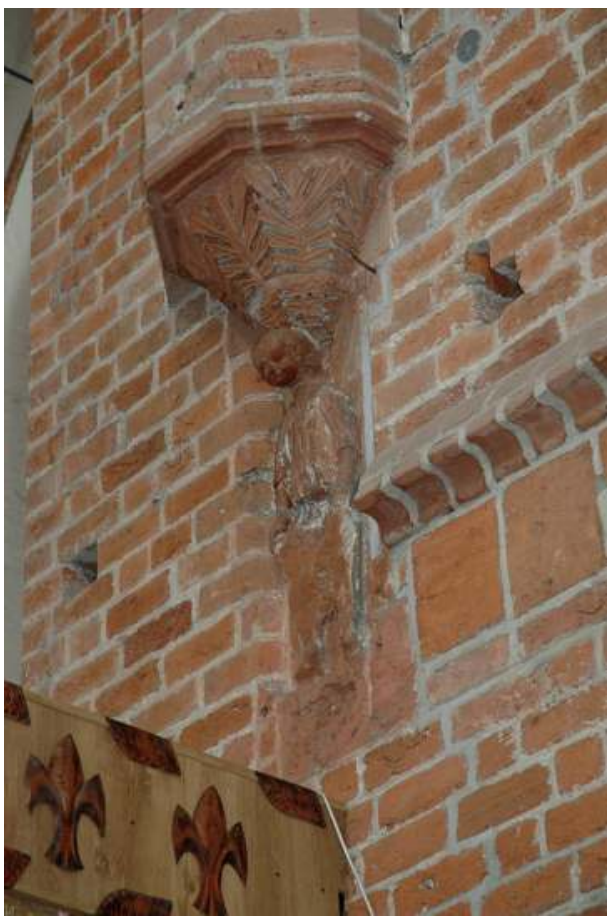

Abb. 20: Stettin Franziskanerklosterkirche, figürliche Terrakottaskulptur am Choranfang.

gratige Binnenzeichnung aufweist, wie sie die im Langhaus der Franziskanerklosterkirche verbauten Konsolen besitzen und damit auf das späte 13. Jahrhundert verweisen. ${ }^{100}$ Der Chor der Stettiner Franziskanerklosterkirche, ${ }^{101}$ der jüngeren bauhistorischen Beobachtungen zufolge bald nach 1300 als direkte Kopie der Berliner Choranlage begonnen wurde, setzt das Vorhandensein des Berliner Baus voraus (Abbildung 20). Er wurde über einem ähnlichen Chorgrundriss errichtet und besaß im Außenbereich ebenfalls einen ornamentalen Reliefplattenfries. ${ }^{102}$ Schließlich ergibt sich für die Datierung der Berliner Franziskanerklosterkirche aus den verschiedenen architekturhistorischen Beobachtungen, dass ihre Errichtung zwar erst nach dem Baubeginn der Choriner Klosterkirche einsetzte, aber auch nicht allzu lange nach der Übertragung des Grundstückes im Jahr 1271 begonnen worden sein kann, da die stilistischen und backsteintechnischen Details auf

100 Von den entsprechenden Konsolen im Triumphbogen der Stettiner Franziskanerkirche, die offenbar im frühen 14. Jahrhundert deutlich dem Vorbild der Berliner Konsolen entsprechend ausgeführt wurden, unterscheiden sich diese jedoch stilistisch und weisen in eine vorausgehende Zeit.

101 So musste die Stettiner Franziskanerkirche im Zuge der im späten 13. Jahrhundert erfolgten Auffüllung des Siedlungsareals neu errichtet werden. Indizien zufolge dürfte dieser Neubau um 1300 begonnen worden sein. Vgl. Agnieszka Lindenhayn-Fiedorowicz, Die Architektur der Franziskanerkirche St. Johannis in Stettin, in: Schumann, Brandenburgische Franziskanerklöster, S. 261-281, hier S. 263.

102 Bei den Platten des Frieses handelt es sich heute um Rekonstruktionen, die jedoch ursprünglichen Vorbildern folgen sollen. 
eine Fertigstellung des Berliner Baus um 1300 weisen. Selbst wenn man von einem zügigen Bauverlauf ausgeht, kann nicht erst die Schenkung der am Weg nach Tempelhof gelegenen Ziegelei im Jahr 1290 für den Baubeginn an der Klosterkirche verantwortlich gemacht werden, ${ }^{103}$ sondern es ist ein Baubeginn spätestens um 1280/85 anzunehmen.

Die konzeptionelle Architektur der Berliner Franziskanerkirche zeigt, dass es sich bei vielen bauund backsteintechnischen Bezügen zur Choriner Baustelle nicht um einen Zufall handelt. ${ }^{104}$ Die Aufgabe der Planung eines gerade geschlossenen mehrschiffigen Chores ließe sich in Berlin als Reflexion auf den Planwechsel in Chorin sehen, bei dem mit der Verlegung des Zisterzienserklosters nach Chorin um 1272 die ganz ähnlich begonnene Vorgängerkirche schließlich zugunsten einer anspruchsvollen Konzeption aufgegeben wurde, in der das Zitat des Grundrisses der bisherigen Grablege in Lehnin bedeutungsvoll mit einer anspruchsvollen gotischen Backsteinarchitektur verschmolzen wurde und die im Chor statt einer Apsis einen zeitgemäßen fünfseitigen Chorpolygon als Ostabschluss erhielt. ${ }^{105}$ Dass schließlich die in Berlin verwirklichte Konzeption der Franziskanerkirche die Choriner Anlage in der Architekturgestaltung sowie in den architektonischen Bezügen sogar noch zu überbieten suchte, lässt sich in keiner Weise aus der Aufgabe eines franziskanischen Bettelordensklosters heraus erklären. Vielmehr zeigt sich auch in der Architektur die besondere Funktion der Berliner Franziskanerklosterkirche, die sich bereits durch ihre Lage neben dem markgräflichen Palast und der in den Urkunden greifbaren Bedeutung des Konvents abzeichnete: die Aufgabe einer Hofkirche der Landesherren, deren Architektur nicht hinter dem Bau der neuen Grablege der konkurrierenden ottonischen Markgrafenlinie in Chorin zurücksteht. Auch in Berlin entstand ein polygonaler Chor, der moderne französische Anregungen aufgreift. Doch ging man mit der ausladenden siebenseitigen Anlage sogar noch einen Schritt weiter und löste deren Wände schließlich fast vollständig mit aufwendigen Backsteingliederungen auf. So entsteht der Eindruck, dass in Berlin eine direkte Reaktion auf die Planänderungen in Chorin erfolgte. War die Planänderung in Chorin das Ergebnis des Funktionszuwachses als neue Familiengrablege der ehrgeizigen Angehörigen des johanneischen Familienzweiges der askanischen Markgrafen, dürfte der Berliner Bau unter nicht geringerem konzeptionellen Anspruch des ottonischen Familienzweiges der Markgrafen entstanden sein. ${ }^{106}$

103 So zuletzt von Stefan Breitling angenommen. Vgl. Breitling, Die Franziskaner-Klosterkirche [...]: Ergebnisse, S. 120. Wie bei vergleichbaren Bauprojekten dieser Zeit ist auch hier die Ziegelproduktion in der Nähe der Baustelle anzunehmen, da es unwahrscheinlich ist, dass die riesigen Formblöcke der Kapitelle auf dem langen Weg von Tempelhof über Land transportiert wurden.

104 Auch wenn sich die Anwesenheit spezialisierter Bauleute und Ziegler von der Choriner Baustelle in Berlin nicht konkret belegen lässt, liegt sie doch nahe.

105 Den bisherigen bauhistorischen Untersuchungen zufolge ist mit der dendrochronologisch abgesicherten Vollendung der westlichen Teile der Kirche um 1300 der Bau der gesamten Klausur abgeschlossen. Die Ausführung dieses umfangreichen Bauvolumens ist jedoch nur vorstellbar, wenn bereits 1273 oder kurz danach mit dem Neubau der Choriner Klosteranlage begonnen worden ist. Vgl. Stefanie Wagner, Beobachtungen zur Baugeschichte des Klosters Chorin während der Sanierungsarbeiten am Westgiebel der Kirche, in: Denkmalpflege im Land Brandenburg 1990-2000. Bericht des Brandenburgischen Landesamtes für Denkmalpflege und Archäologischen Landesmuseums (Forschungen und Beiträge zur Denkmalpflege im Land Brandenburg, Bd. 5), 2 Bde, Worms 2001, Bd. 2, S. 729-734 und Schumann, Herrschaft und Architektur, S. 35 f. und 58 f.

106 So ist es vor allem Otto V., der ab 1280 aufgrund des Ausstellungsortes von Urkunden in Berlin nachweisbar ist. Vgl. Fey, Reise und Herrschaft, S. 185 f. 
Ein solch unmittelbares Reagieren auf ein anderes Bauprojekt ist jedoch nur plausibel, wenn es auch einen Austausch zwischen den daran arbeitenden Bauleuten gegeben hat. Dass es sich aus landesherrlicher Sicht hierbei um zwei konkurrierende Baustellen handelte, stellte offenbar keine Einschränkung dar, denn nur wenig später wurde unter dem brandenburgischen Markgrafen Albrecht III. das Repräsentationsprojekt der Marien- und Magdalenenkirche in Eberswalde begonnen, hier unter maßgeblicher Beteiligung von Choriner Bauleuten, in dem gerade erst neu gebildeten Territorium der dritten Landesherrschaft eines brandenburgischen Markgrafen aus askanischem Hause. Offensichtlich wurde die repräsentative Backsteinarchitektur von den askanischen Markgrafen vor allem auch als gegenständlicher Träger inhaltlicher Ansprüche verstanden. Somit zeigen sich die deutlichen Parallelen nicht nur in den mehrfachen Planänderungen zur Aufwertung der Architektur, sondern es fallen auch die gestalterischen Ambitionen auf, mit denen die Anlagen in Berlin und Chorin durch den gezielten Einsatz von Bau- und Schmuckformen zu einem architektonischen Bildgefüge avancieren, das aus seiner Funktion als Ordensarchitektur nicht mehr zu erklären ist, sondern bei dem vielmehr konkrete inhaltliche Bezüge im Vordergrund standen. 


\section{Gunnar Nath}

\section{Archäologische Bestandsaufnahme des Grauen Klosters}

Mit dem Beitrag wird das Ziel verfolgt, die archäologischen Befunde im Areal des ehemaligen Franziskanerklosters und späteren Berlinischen Gymnasiums zum Grauen Kloster zu prognostizieren und, dem Thema der Tagung folgend, den an der Entwicklung des Ortes Beteiligten eine Plangrundlage zu geben. Der vom Berliner Abgeordnetenhaus beschlossene Bebauungsplan sieht vor, die isolierte Lage des Klosterviertels zu korrigieren und das Viertel an die benachbarten Straßen und Plätze anzubinden. ${ }^{1}$ In diesem Zusammenhang erfährt die Ruine der Franziskanerklosterkirche große Aufmerksamkeit. Geplant ist eine kulturelle Nutzung der Gebäudereste, die $\mathrm{zu}$ den wenigen verbliebenen mittelalterlichen Bauten Berlins gehören und aufgrund ihrer einmaligen Bedeutung für die Berliner Stadtgeschichte besondere Aufmerksamkeit erlangen sollen.

Durch die schulische Nachnutzung des Klosters kam es seit dem späten 18. Jahrhundert zu tiefgreifenden Umbaumaßnahmen. In Folge des Zweiten Weltkrieges und der Nachkriegszeit ist ein Totalverlust aller oberirdischen Bauten zu verzeichnen. Einzig die Klosterkirchenruine ist noch als sichtbares Zeugnis vorhanden. Im Boden sind hingegen noch Bauteile und Funde aus unterschiedlichen Zeiten verborgen. Mit der folgenden Bestandsaufnahme sollen die Geschichte des Areals sowie die wahrscheinlich unterirdisch erhaltenen Zeugnisse vorgestellt und visualisiert werden. Die Arbeit basiert auf umfangreichem Quellenmaterial, das im Rahmen der Restaurierung der Kirchenruine in den Jahren 1999 bis 2004 zusammengetragen wurde. Zusätzlich erweitern Entwurfszeichnungen für ein Gästehaus des Magistrats aus dem Jahre 1951, die sich im Archiv des Landesdenkmalamtes befinden, Pläne und Schnitte der Berliner Verkehrsbetriebe sowie ein Leitungsbestandsplan der Senatsverwaltung für Stadtentwicklung und Wohnen die Quellen. Es werden erstmalig acht Phasenpläne präsentiert, die die bauliche Entwicklung darstellen. In diesen sind sowohl die ehemaligen Kloster- und Schulgebäude als auch Leitungstrassen und bereits durchgeführte Ausgrabungen kartiert.

Das Gelände des Franziskanerklosters und späteren Berlinischen Gymnasiums zum Grauen Kloster befand sich am östlichen Rand der mittelalterlichen Stadt und wird heute begrenzt von der Grunerstraße im Norden, der Klosterstraße im Westen und der Littenstraße im Osten. Der brandenburgische Landesherr war der Eigentümer eines großen Grundstücks, auf dem sich das Hohe Haus, eine bis zum Jahre 1451 genutzte Residenz, befand. ${ }^{2}$ Im Jahre 1271 überließ er einen Teil seines Besitzes dem Bettelorden der Franziskaner. ${ }^{3}$ Die beeindruckende Architektur der Klosterkirche spricht für seine Einflussnahme beim Bau der Klosterkirche. Im 14. Jahrhundert wurde die Kirche mehrfach als Begräbnisstätte für die Landesherren genutzt. Bis zu ihrer

1 https://www.stadtentwicklung.berlin.de/planen/staedtebau-projekte/molkenmarkt/de/planung/bebauungs planung.shtml [abgerufen am: 27. August 2020].

2 Julius Kohte, Das Hohe Haus in Berlin. Ein Beitrag zur Baugeschichte Berlins im Mittelalter, in: Forschungen zur Brandenburgischen und Preußischen Geschichte 48 (1936), S. 146-163.

3 Siehe den Beitrag von Heinz-Dieter Heimann in diesem Band. 
Zerstörung im Zweiten Weltkrieg war sie das „bedeutendste gothische Denkmal zu Berlin“. Klausur des Klosters lag nördlich der Kirche. Der Nordflügel ist heute von der Grunerstraße überbaut. Südlich und westlich der Kirche befand sich der Kirchhof. Um 1900 wurde das Gelände nach Süden erweitert und mit einem Direktoren- und Lehrerwohnhaus und einer Turnhalle bebaut. Dadurch gruppierte sich das bauliche Ensemble erstmals um die Klosterkirche als Mittelpunkt. Die Gesamtfläche summierte sich auf ca. 8.700 Quadratmeter.

\section{Das mittelalterliche Franziskanerkloster}

Die bauhistorischen Untersuchungen von 1999 bis 2004 ergaben, dass die Backsteinbasilika mit vierjochigem Langhaus, einschiffigem Langchor und polygonalem Chorabschluss in die Jahre um 1300 datiert und ihr Bau einheitlich ausgeführt wurde. ${ }^{5}$ Es gibt zudem Hinweise, dass am Anfang des Baugeschehens eine Planänderung erfolgte. Unter den Wänden des Langchores liegen Pfeilerbankette, die einen ersten Entwurf mit offenen Arkaden deutlich machen. ${ }^{6}$ Gesichert ist, dass der Backsteinbau älteres Feldsteinmauerwerk eines Vorgängerbaues in der Seitenschiffnordwand integrierte (Abbildung 1). Der Bereich der Klausur ist bisher wenig erforscht. Zudem ist

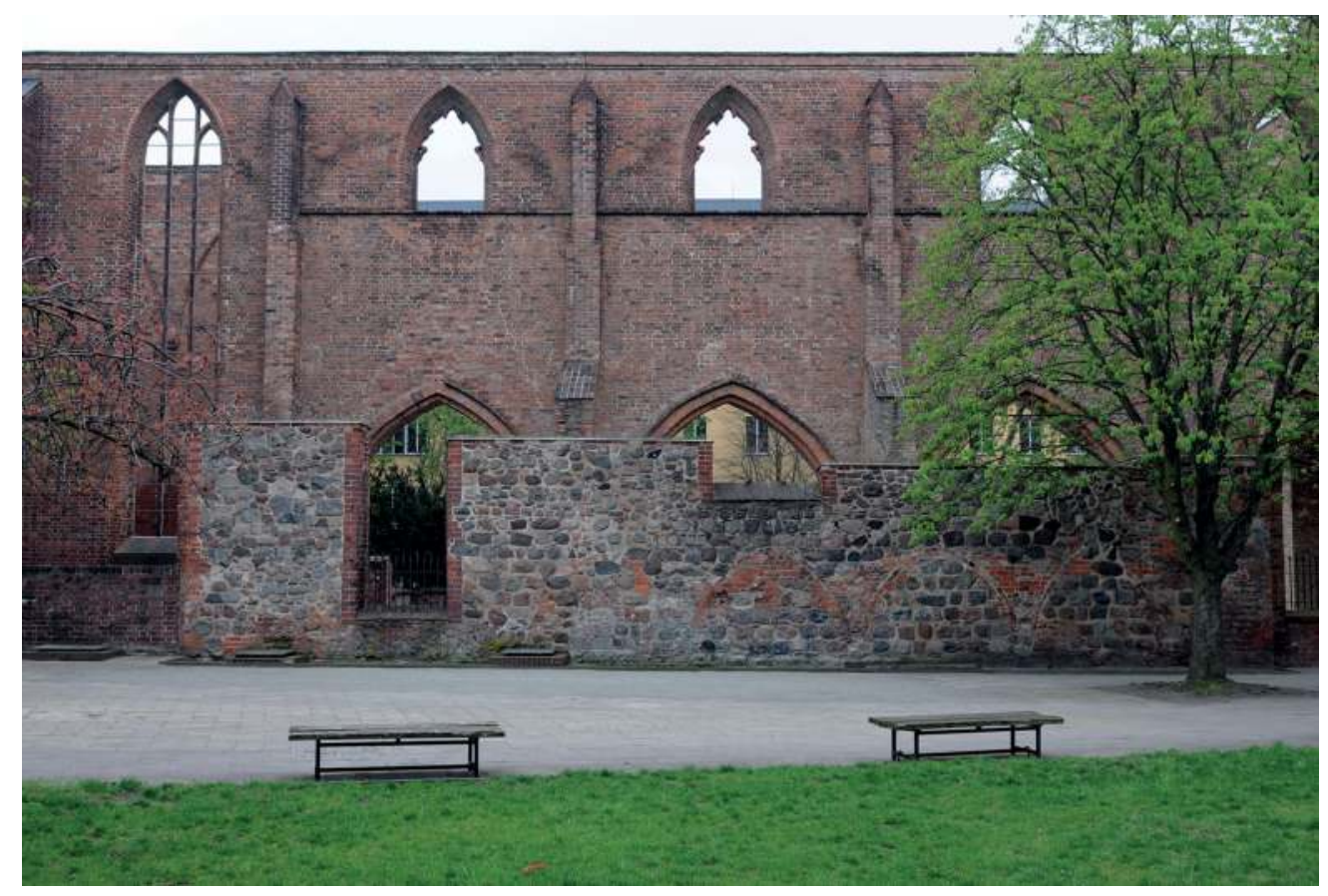

Abb. 1: Nordwand aus Feldsteinmauerwerk.

4 Richard Borrmann, Die Bau- und Kunstdenkmäler von Berlin, Berlin 1893, S. 188-203, bes. S. 188.

5 Stefan Breitling, Die Franziskaner-Klosterkirche in Berlin: Ergebnisse der bauhistorischen Untersuchungen 1999-2004, in: Landesdenkmalamt Berlin (Hrsg.), Kirchenruine des Grauen Klosters in Berlin. Geschichte - Forschung - Restaurierung (Beiträge zur Denkmalpflege in Berlin, Bd. 23), Petersberg 2007, S. 99-126, hier S. 120.

6 Dirk Schumann, Die Franziskaner-Klosterkirche - Formsteine und Formsteinsysteme einer repräsentativen askanischen Architektur, in: Landesdenkmalamt Berlin, Kirchenruine des Grauen Klosters, S. 127-140. 
er durch Fundamente neuzeitlicher Schulbauten und einen U-Bahnverbindungstunnel stark verändert. 2014 wurden in diesem Bereich erstmals Ausgrabungen durchgeführt und dokumentiert (siehe unten). Ein historischer Plan von 1700 zeigt, dass sich die Gebäude der Klausur um zwei Höfe gruppierten (Abbildung 2). Der Ostflügel lag nur wenige Meter hinter der mittelalterlichen Stadtmauer und schloss direkt nördlich an die Sakristei an. Das Gebäude wurde vermutlich im frühen 14. Jahrhundert errichtet, zeitgleich mit dem Kreuzgang, der nachträglich an die nördliche Außenwand der Kirche angefügt worden ist. Vermutlich befanden sich im Ostflügel bereits alle zum Betrieb des Klosters erforderlichen Räume, wie Refektorium, Dormitorium und Kapitelsaal. ${ }^{7}$ An der Nordseite der Kirche lagen eine Chorkapelle und ein Treppenturm. Im 15. und 16. Jahrhundert wurde die Anlage in nördlicher und westlicher Richtung erweitert. Das Kapitelhaus entstand zwischen 1471 bis 1474 und der Nordflügel wurde zwischen 1516 und 1518 gebaut.

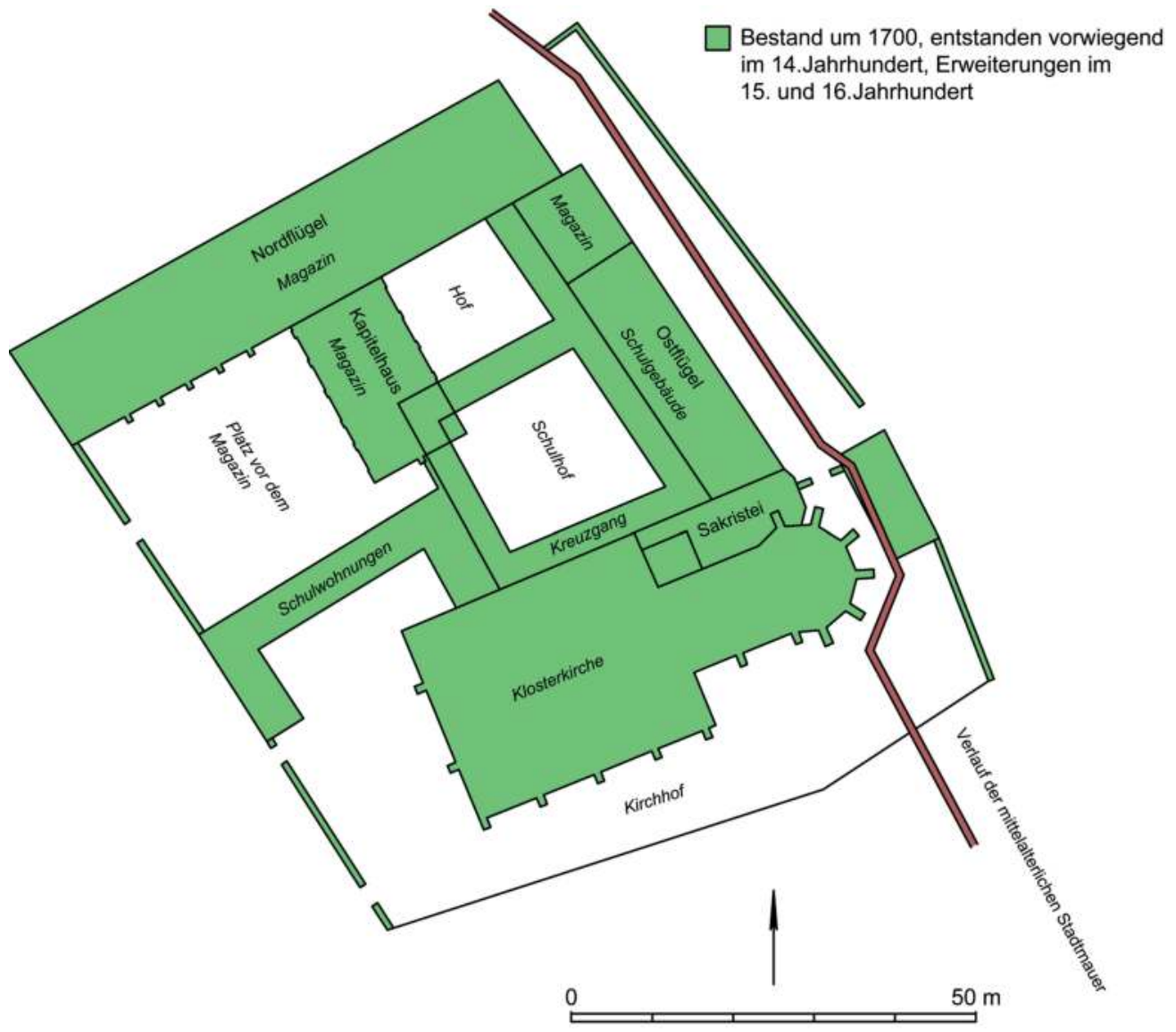

Abb. 2: Graues Kloster um 1700, Plan auf der Grundlage eines Planes von 1700 (Evangelisches Landeskirchliches Archiv Berlin, ELAB 7.2/02), historische Eintragungen in Kursiv.

7 Peter Riedel u. a., Berlin Franziskaner, in: Heinz-Dieter Heimann u. a. (Hrsg.), Brandenburgisches Klosterbuch. Handbuch der Klöster, Stifte und Kommenden bis zur Mitte des 16. Jahrhunderts (Brandenburgische Historische Studien, Bd. 14), 2 Bde., 1. Aufl., Berlin 2007, Bd. 1, S. 146-157, bes. S. 151. 


\section{Bauliche Zäsuren im 18. und 19. Jahrhundert}

Nachdem die katholischen Güter 1540 säkularisiert wurden, bezog der Leibarzt des Kurfürsten Leonhard Thurneysser 1571 den Nordflügel des enteigneten Klosters und richtete dort ein Laboratorium und eine Druckerei ein. Durch Verordnung des Kurfürsten Johann Georg von Brandenburg wurde der südliche Teil 1574 zum Standort des Berlinischen Gymnasiums zum Grauen Kloster bestimmt. ${ }^{8}$ Bis zur zweiten Hälfte des 18. Jahrhunderts bestand das bauliche Ensemble des Klosters fast unverändert. Nur die Türme der Klosterkirche und die Treppenaufgänge wurden im 17. und 18. Jahrhundert erneuert. ${ }^{9} \mathrm{Zu}$ welchem genauen Zeitpunkt der mittelalterliche Treppenturm und die Sakristei abgebrochen wurden, ist nicht mehr feststellbar. Das Jahr 1712 verzeichnete eine Brandkatastrophe im östlichen Teil der Anlage. Es gibt Hinweise, dass die Sakristei mit einem bis an den Kirchenchor heranreichenden Schulgebäude überbaut wurde, das wiederum unter Direktor Anton Friedrich Büsching zwischen 1786 und 1788 abgebrochen wurde. Das Bodenniveau im Kircheninneren wurde erhöht, um in den Seitenschiffen Gruftgewölbe anzulegen. ${ }^{10}$ Im Laufe der Zeit erhöhte sich das Außenterrain, dadurch lagen viele Räume unterhalb des Straßenniveaus, was zu Feuchtigkeit und Bauschäden führte. Ab der zweiten Hälfte des 18. Jahrhunderts nahmen mehrere Schuldirektoren energisch die Verbesserung der baulichen Situation von Klassenräumen und Lehrerwohnungen in Angriff. Den Anfang machte Schuldirektor Büsching. In den Jahren 1786 bis 1788 ließ er den größten Teil des Kreuzganges abbrechen (Abbildung 3). Im Bereich des nördlichen Kreuzgangflügels entstand ein Schulgebäude mit Klassenzimmern und Räumen für physikalische Geräte und die Streitsche Gemäldesammlung. ${ }^{11}$ Sigismund Streit, 1687 in Berlin geboren, lebte seit 1709 in Venedig, wo er durch kaufmännische Tätigkeit ein Vermögen erlangte, das er dem Berlinischen Gymnasium zum Grauen Kloster vermachte. Da er Kunstsammler war, umfasste die Schenkung unter anderem wertvolle Gemälde des bekannten Malers Canaletto mit Stadtansichten Venedigs. Ende des 18. Jahrhunderts wurde an Stelle des westlichen Kreuzgangflügels ein neues Gebäude für Lehrerwohnungen errichtet, direkt zwischen Kirche und Kapitelhaus, und an der Klosterstraße entstand ein stattliches Direktorenwohnhaus, von zwei neuen Eingangsportalen flankiert. Eine neue Ausstattung mit großem Hörsaal, Bibliothek und Wohnungen für Lehrer erhielt der Ostflügel, an der Neuen Friedrichstraße (heute Littenstraße) gelegen. ${ }^{12}$

Direktor Büsching folgten als Bauherren Georg Christoph Samuel Köpke (Direktor von 1828 bis 1837) und Johann Friedrich Bellermann (Direktor von 1847 bis 1867). In diese Zeit fallen auch die Anfangsjahre der Denkmalpflege in Preußen. ${ }^{13}$ Die im 16. Jahrhundert aus dem Klosterbestand herausgelösten Gebäude beziehungsweise Gebäudeteile (Kapitelhaus, Nordflügel) erhielt die Schule in der ersten Hälfte des 19. Jahrhunderts zurück. König Friedrich Wilhelm III. übereignete 1819 der Schule das Kapitelhaus und den westlichen Teil des Nordflügels. Direktor Köpke

8 Borrmann, Die Bau und Kunstdenkmäler, S. 189-191.

9 Gerhard Bronisch, Die Franziskaner-Klosterkirche in Berlin, in: Mitteilungen des Vereins für die Geschichte Berlins 50 (1933), S. 89-142, bes. S. 126.

10 Petra Marx, Zur Geschichte der bauhistorischen Forschung und denkmalpflegerischen Bemühungen - ein fachgeschichtlicher Überblick, in: Landesdenkmalmt Berlin, Kirchenruine des Grauen Klosters, S. 31-53, bes. S. 36.

11 Julius Heidemann, Geschichte des Grauen Klosters zu Berlin, Berlin 1874, S. 240.

12 Borrmann, Die Bau- und Kunstdenkmäler, S. 191.

13 Bronisch, Die Franziskaner-Klosterkirche, S. 129. 


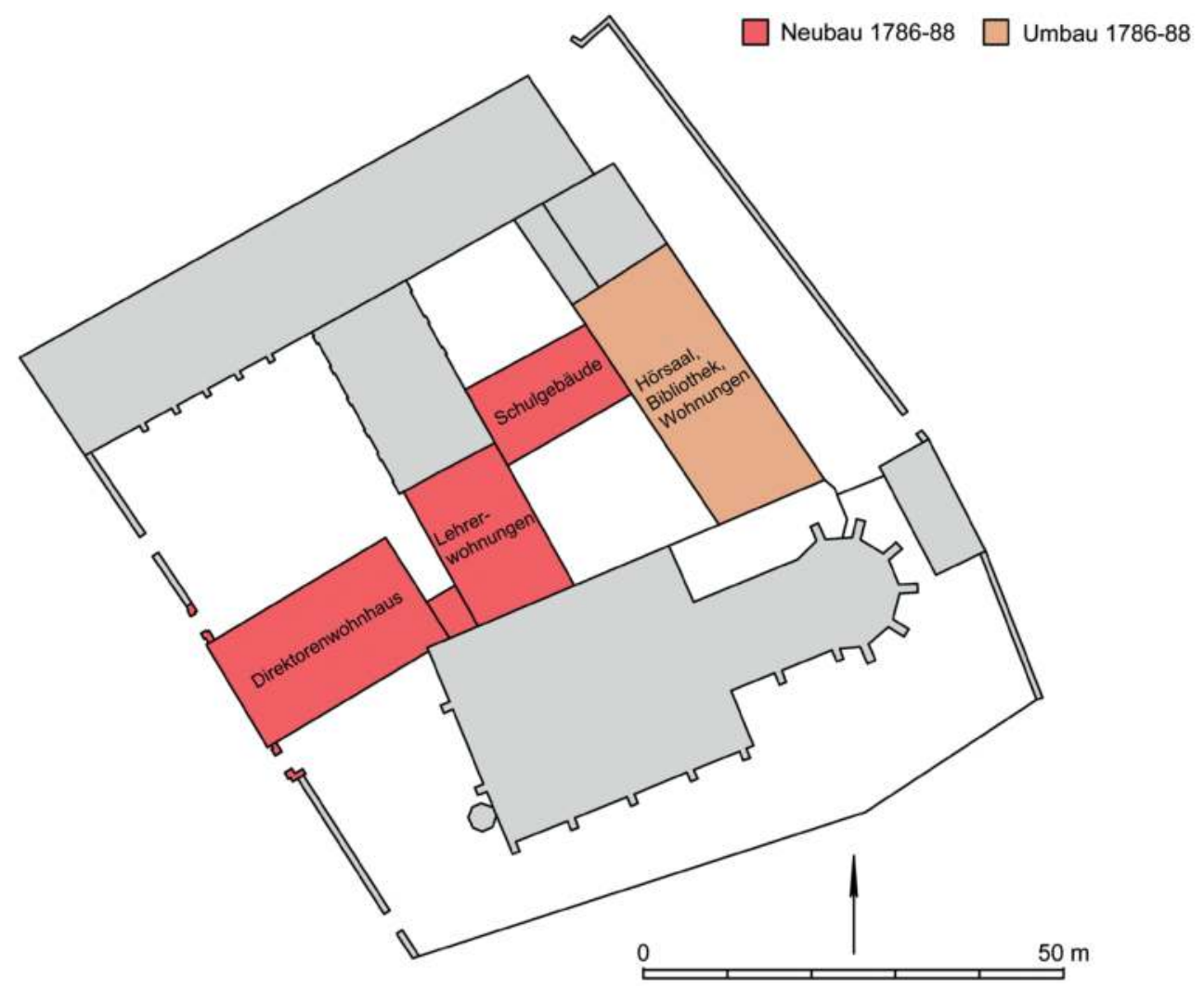

Abb. 3: Graues Kloster mit den baulichen Veränderungen von 1786 bis 1788.

begann 1828 mit dem Umbau des westlichen Gebäudeteils. Es kam zu einer denkmalpflegerischen Debatte, die Karl Friedrich Schinkel auslöste, da er sich für den Erhalt des Gebäudes aussprach. ${ }^{14}$ Unter Beibehaltung der alten Fundamente wurde dieses unterkellert ${ }^{15}$ und 1829 nach Zeichnungen Schinkels eine Aula hinzugefügt. Bis zum Zweiten Weltkrieg blieb diese Bestandteil der Anlage.

1831 wurde der östliche Teil des Nordflügels der Schule übereignet. Da in den Räumen noch städtische Beleuchtungskörper lagerten, für die ein anderer Aufbewahrungsort gesucht werden musste, begannen die Baumaßnahmen erst Jahre später. Schließlich ließ Schuldirektor Bellermann von 1848 bis 1849 den Gebäudeteil durch ein dreistöckiges neues Schulgebäude mit Klassenzimmern ersetzen. Nur zehn Jahre später entstand ein neuer Ostflügel mit vier Lehrerwohnungen, dessen Lage um acht bis zehn Meter aus der alten Gebäudeflucht nach Osten verschoben wurde, um Platz für einen geräumigen Schulhof zu schaffen. Dass die Planungen Jahrzehnte älter waren, belegt ein Plan aus dem Jahre $1824 .{ }^{16}$ Der mittelalterliche Vorgängerbau wurde bis auf die Fundamente abgerissen.

14 Alexander Pellnitz, Vom Mittelalter bis ins 20. Jahrhundert. Die Baugeschichte des Grauen Klosters zu Berlin, in: Das Altertum 50 (2005), S. 33-46, bes. S. 40-43.

15 Heidemann, Geschichte des Grauen Klosters, S. 285.

16 Berlinisches Gymnasium (Graues Kloster), Berlin, 7. August 1824, Handzeichnung, Tusche aquarelliert auf Papier, Technische Universität Berlin, Architekturmuseum, Inv.-Nr. 7979. 
Die Neubauten führten auch zum Abriss der von Büsching errichteten Gebäude im Bereich der Kreuzgangflügel. ${ }^{17}$ Das kleine Gebäude östlich der Klosterkirche wurde abgebrochen. Das Kapitelhaus bekam von 1863 bis 1864 eine zusätzliche Etage und ein neues Treppenhaus in neogotischer Form. Der Kapitelsaal wurde restauriert (Abbildung 4).

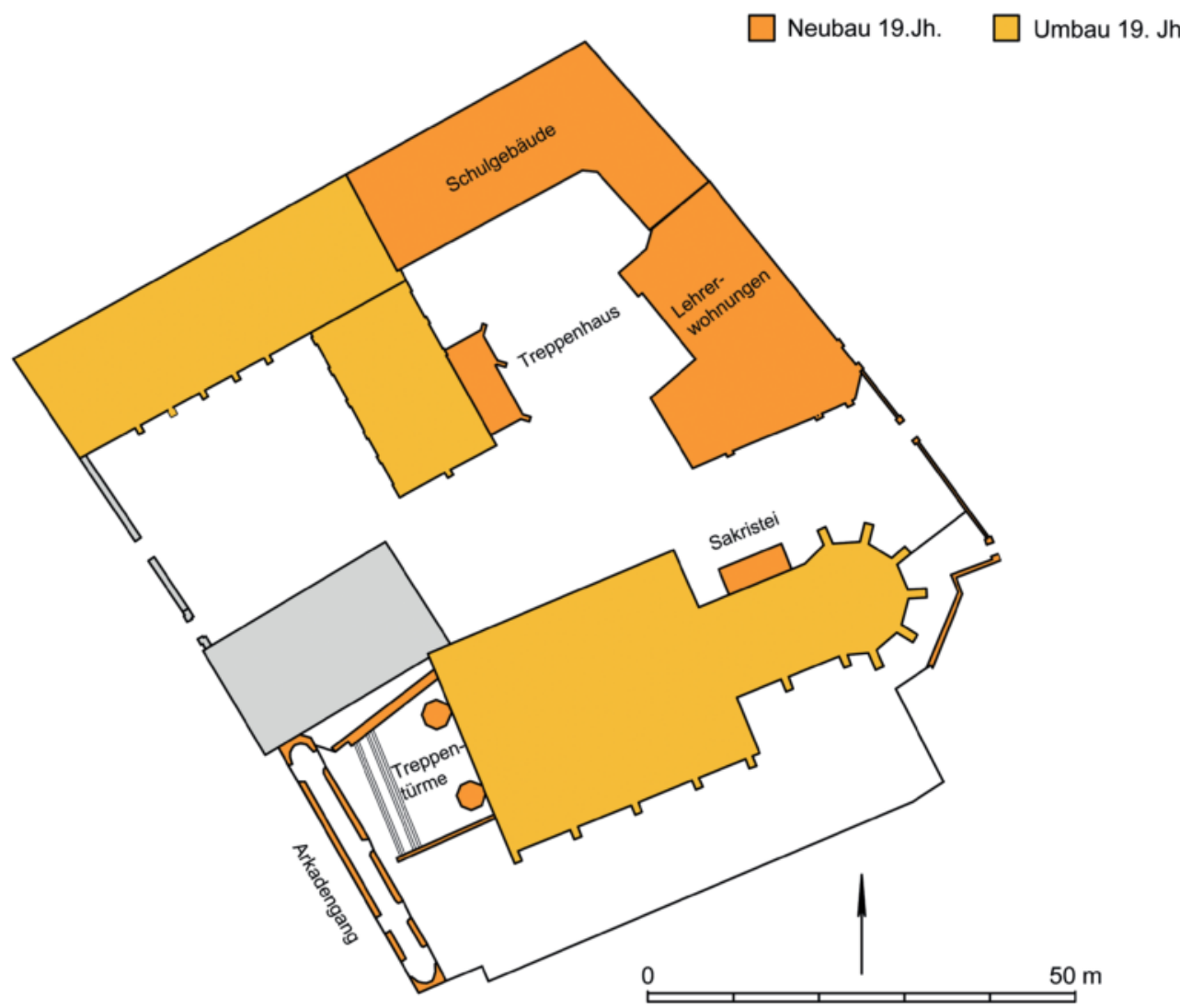

Abb. 4: Graues Kloster mit baulichen Veränderungen im 19. Jahrhundert.

Die 1842 bis 1845 beginnende Instandsetzung und Restaurierung der Klosterkirche übernahmen zuerst Wilhelm Berger und danach Theodor August Stein. Beteiligt war der spätere erste preußische Konservator Ferdinand von Quast, der 1842/43 eine Suchgrabung nach den Grüften Ludwigs des Römers und dessen Frau im Chorbereich der Kirche durchführte, die allerdings erfolglos blieb. ${ }^{18}$ Im 19. Jahrhundert wurde auch der Platz vor dem westlichen Portal der Kirche

17 Heidemann, Geschichte des Grauen Klosters, S. 298.

18 Breitling, Die Franziskaner-Klosterkirche [...]: Ergebnisse, S. 38. Siehe auch ders., Ferdinand von Quast und die Franziskaner-Klosterkirche in Berlin. Ein Beitrag zur Geschichte der Denkmalpflege im 19. Jahrhundert, in: Landesdenkmalamt Berlin/Schinkel-Zentrum für Architektur, Stadtforschung und Denkmalpflege der TU Berlin/ Architekturmuseum der TU Berlin in der Universitätsbibliothek (Hrsg.), Auch die Denkmalpflege hat Geschichte. Ferdinand von Quast (1807-1877). Konservator zwischen Trier und Königsberg (Beiträge zur Denkmalpflege in Berlin, Bd. 29), Berlin/Petersberg 2008, S. 77-87. 
tiefergelegt und an der Klosterstraße ein Arkadengang errichtet. Des Weiteren wurden die von Stein entworfene Sakristei und am Westportal zwei neue Treppentürme (Entwurf Wilhelm Berger) erbaut. Zugleich erfolgte der Abriss der Treppentürme aus Fachwerk.

\section{6 bis 1904}

Von 1896 bis 1904 wurde das bauliche Ensemble durch drei neue Gebäude im historistischen Stil ergänzt (Architekten Carl Roemert, Georg Matzdorff und Emil Högg). Der 1859 an der Neuen Friedrichstraße 84 errichtete Bau wurde ersetzt und südlich der Kirche, in der Klosterstraße 73, ein Direktoren- und Lehrerwohnhaus errichtet (Abbildung 5). An der Neuen Friedrichstraße 86 entstand eine neue Turnhalle, für die Stadtbaumeister Ludwig Hoffmann den Entwurf lieferte. ${ }^{19}$ Die Schnitte der Gebäude zeigen durchweg neue Fundamentgründungen von einer Tiefe bis zu drei Metern. ${ }^{20}$

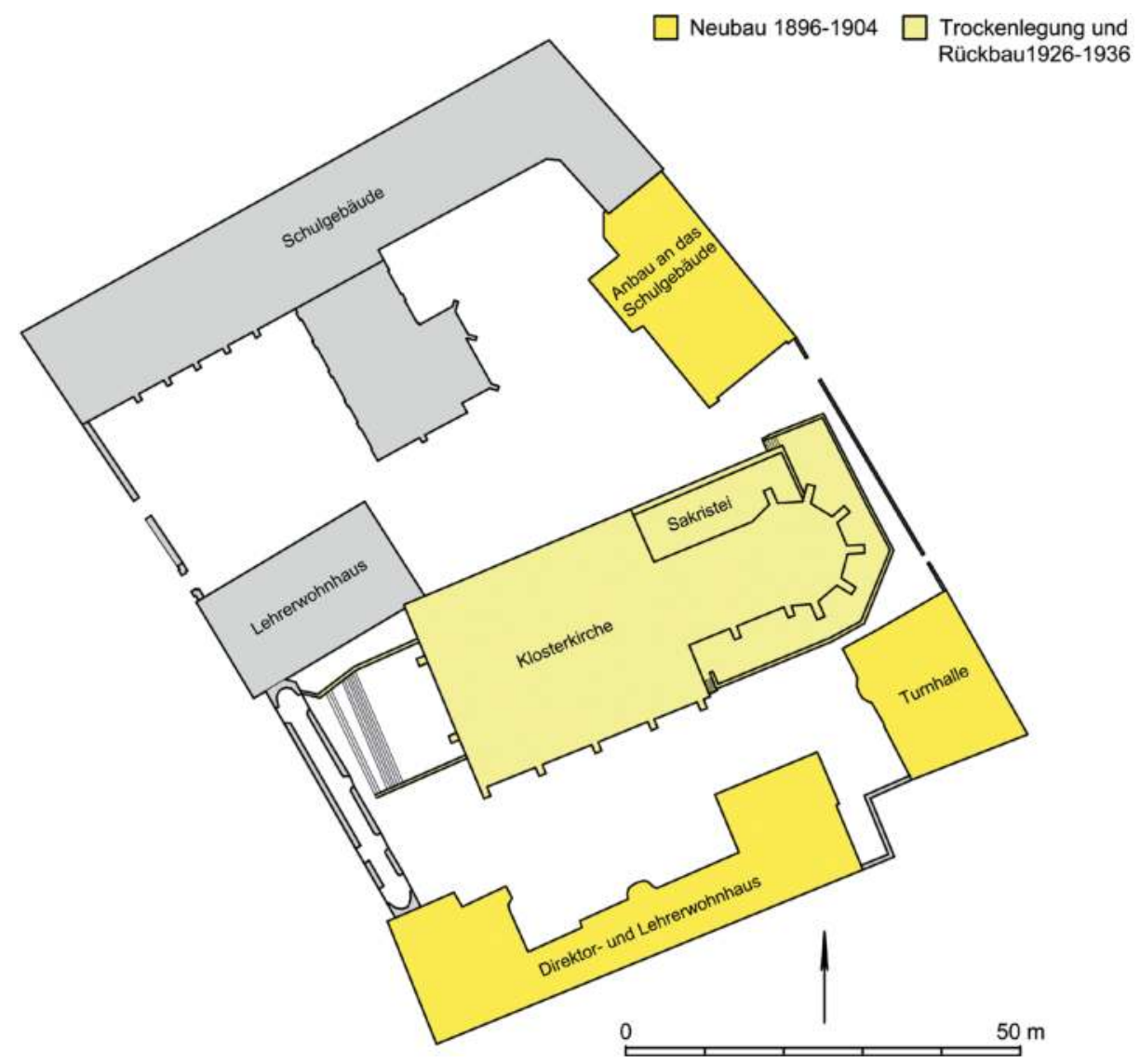

Abb. 5: Graues Kloster mit Erweiterungsbauten um 1900 und Trockenlegung sowie Umbau der Klosterkirche von 1926 bis 1936.

19 Siehe dazu den Beitrag von Wolfgang Schäche in diesem Band.

20 Otto Sarazzin/Friedrich Schultze, Die Um- und Erweiterungsbauten des Berlinischen Gymnasiums zum Grauen Kloster, in: Zentralblatt der Bauverwaltung 24 (1904), S. 577-579, 581. 


\section{Trockenlegung der Kirche von 1926 bis 1936, baugeschichtliche Forschungen}

Die Bau- und Instandsetzungsphase von 1926 bis 1936 konzentrierte sich auf die Klosterkirche, um die eindringende Feuchtigkeit zu reduzieren. ${ }^{21}$ Die Trockenlegungsarbeiten (1926 bis 1930) waren mit Ausschachtungen um den Chorbereich verbunden. Des Weiteren wurde die von Stein errichtete Sakristei abgerissen, die darunter liegenden Reste der mittelalterlichen Sakristei archäologisch freigelegt und später überdacht und zugänglich gemacht.

Die archäologischen Befunde im Chorbereich veranlassten Gerhard Bronisch, eine baugeschichtliche Dissertation zu verfassen, die sich kritisch mit Behauptungen Friedrich Adlers zum ursprünglichen Chorabschluss auseinandersetzte. ${ }^{22}$ Ferdinand von Quast hatte 1842 eine quer verlaufende Fundamentmauer im Chorbereich aufgedeckt, deren Lage - wie Bronisch nachweisen konnte - Adler unkorrekt dargestellt hat. Indem Adler die Fundamentmauer bündig an die Nahtstelle zwischen Langchor und Chorpolygon einzeichnete, begründete er einen älteren geraden Ostabschluss. Anhand der Grabungsbefunde korrigierte Bronisch diese These und rekonstruierte einen Vorgängerbau aus bearbeiteten Feldsteinen in Form einer Saalkirche. Deren Reste sind bis heute in der Außenwand des nördlichen Seitenschiffs, im Fundament der Sakristei sowie partiell unterhalb des Chores erhalten. ${ }^{23}$ Die Ausschachtungen um den Chorbereich führten auch zur Klärung des ursprünglich bogenförmigen Verlaufs der mittelalterlichen Stadtmauer um den Chor. Dieser Verlauf ist in den 1930er-Jahren bei der Freiraumgestaltung berücksichtigt worden.

Wie die Sakristei fielen auch die im 19. Jahrhundert am Westportal errichteten Treppentürme. Unter dem nördlichen Seitenschiff erfolgte der Einbau einer Warmluftheizung mit abzweigenden Warmluftkanälen in Richtung Kirchenraum, die tonnengewölbte Gruft aus dem 18. Jahrhundert wurde einbezogen. Auch die Verlegung eines unterirdischen Leitungskanals an der Nordwand der Sakristei war Teil der Maßnahme. Er ist vom Innenraum der Sakristei einsehbar.

\section{Nachkriegsjahre}

Die Bombardierung Berlins am Ende des Zweiten Weltkrieges hatte verheerende Auswirkungen auf das in Jahrhunderten gewachsene Bauensemble des Grauen Klosters. Nur wenige Jahre später, zwischen 1948 und 1949, fotografierte der junge Wolfgang Gehrke (geboren 1929), ein zukünftiger Mitarbeiter des Archäologischen Landesamtes in Westberlin, den Zustand (Abbildung 6). ${ }^{24}$

21 Hans Martin, Die Wiederherstellung der Klosterkirche, in: Mitteilungen des Vereins für die Geschichte Berlins 44 (1927), S. 17-23.

22 Siehe Bronisch, Die Franziskaner-Klosterkirche, S. 126. Vgl. auch die Ausführungen von Peter Lemburg dazu in diesem Band.

23 Ebd., S. 100. Die These wird durch die späteren Forschungen unter Stefan Breitling bestätigt und präzisiert, in: Breitling, Die Franziskaner-Klosterkirche [...]: Ergebnisse, S. 102.

24 Wolfgang Gehrke, Die Klosterkirche im November 1949. Faksimile und Abschrift, in: Landesdenkmalamt Berlin, Kirchenruine des Grauen Klosters, S. 142-150. 


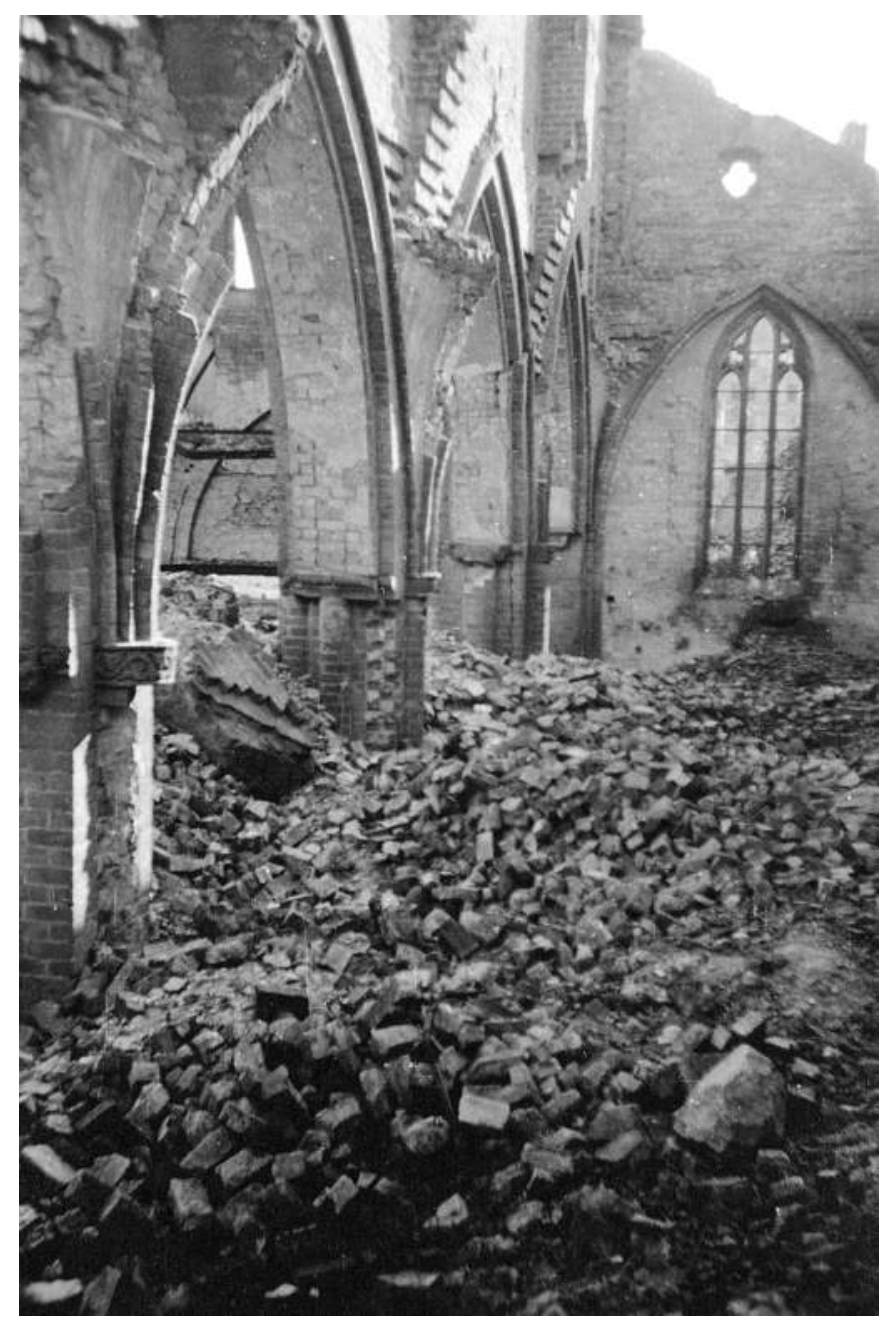

Abb. 6: Klosterkirche 1948.

In den kommenden Jahren wurden der Schutt und die Ruinen bis auf den mittelalterlichen Bestand abgetragen. Im Auftrag des Magistrats (Abteilung Aufbau) planten die Hauptämter Stadtplanung und Öffentliche Bauten 1951 den Wiederaufbau des Kapitelhauses und des Nordflügels als Gästehaus der Stadt Berlin, unter Einbeziehung des noch erhaltenen Restbestandes. Die Abbildung 7 zeigt einen Entwurf, der einen dreigeschossigen Ausbau des Kapitelhauses mit Blick von der Klosterstraße zeigt. ${ }^{25}$ In der Querschnittszeichnung des Kapitelhauses ist die Erhaltung unterhalb der Geländeoberkante mit 1,60 Meter angegeben. Des Weiteren belegen Planzeichnungen, dass eine Überdachung der Klosterkirchenruine vorgesehen war. Sie verdeutlichen das Ziel, die letzten Reste der mittelalterlichen Bausubstanz in eine neue Nutzung einzubeziehen und den Wiederaufbau mit historisierender Fassadengestaltung zu realisieren. Zur gleichen Zeit wurde 


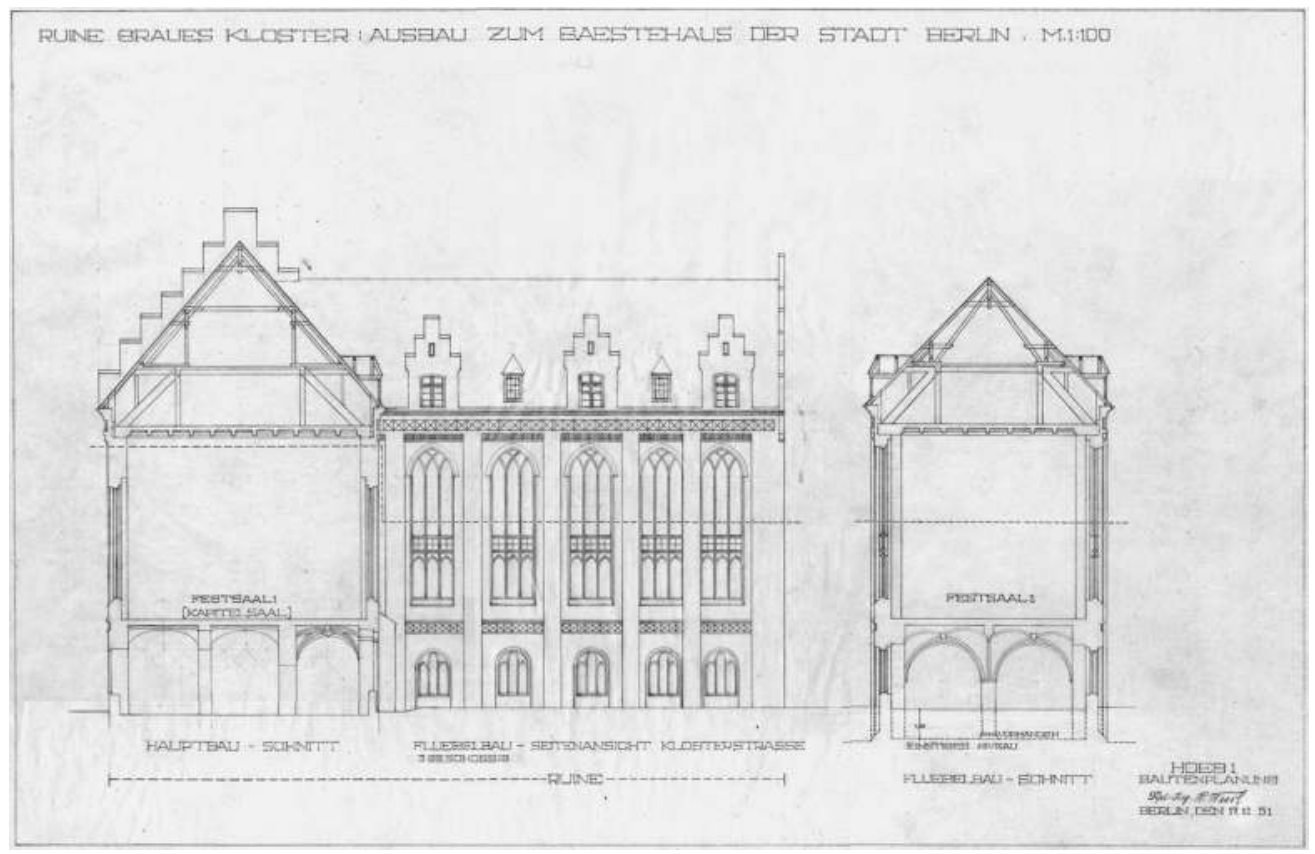

Abb. 7: Entwurf zum Ausbau des Kapitelhauses und des Nordflügels als Gästehaus der Stadt Berlin 1951.

das Gelände für den Bau eines Verbindungstunnels zwischen den U-Bahnlinien U2 und U5 gewählt. Es war bis dato der größte Eingriff in die unterirdische Substanz (ca. 1.300 Quadratmeter). Zwischen der Kirche und dem Kapitelhaus wurde ein ca. 130 Meter langer, elf Meter tiefer und sieben Meter breiter Tunnel gebaut. ${ }^{26}$ Die Grube wurde mit einer freien Böschung bis zur Grundwasserlinie ausgeschachtet. Sie tangierte unmittelbar die Gebäudeecken der Klosterkirche und des Kapitelhauses (Abbildung 8). Die Nordwestecke des nördlichen Seitenschiffs und ein Teil der Außenmauer wurden abgetragen. In Folge der Bauarbeiten brach die Spitze des Westgiebels herunter. Nachdem von 1958 bis 1963 Sicherungsmaßnahmen stattfanden, kam es im Rahmen der Verbreiterung der Grunerstraße vom 6. bis 20. Juni 1968 zum Abriss der letzten Reste des Kapitelhauses und des Nordflügels. Eine Tiefenenttrümmerung ist nicht erfolgt, aber leider kam es auf der Ostseite zur Verlegung eines 1,85 Meter breiten Fernwärmekanals in Nord-Südrichtung. Seine Oberkante liegt 1,5 Meter unter der Oberfläche. In dessen Verlauf ist mit einem kompletten Verlust archäologischer Substanz zu rechnen. Parallel zur verbreiterten Grunerstraße wurden zahlreiche Leitungen verlegt. Ungewiss ist, inwieweit die Fundamente der nördlichen Stirnwand des Kapitelhauses verschont geblieben sind und die Leitungen seitlich vorbeigeführt wurden.

26 Willy Fritsche, Berlins erster Nachkriegs-Tunnelbau, in: Bauplanung und Bautechnik 6 (1952), H. 8, S. 205-207; Karl Lufsky, Die Grundwasserabdichtung des U-Bahn Verbindungstunnels Klosterstraße-Littenstraße in Berlin, in: ebd., H. 15, S. 561-566. 


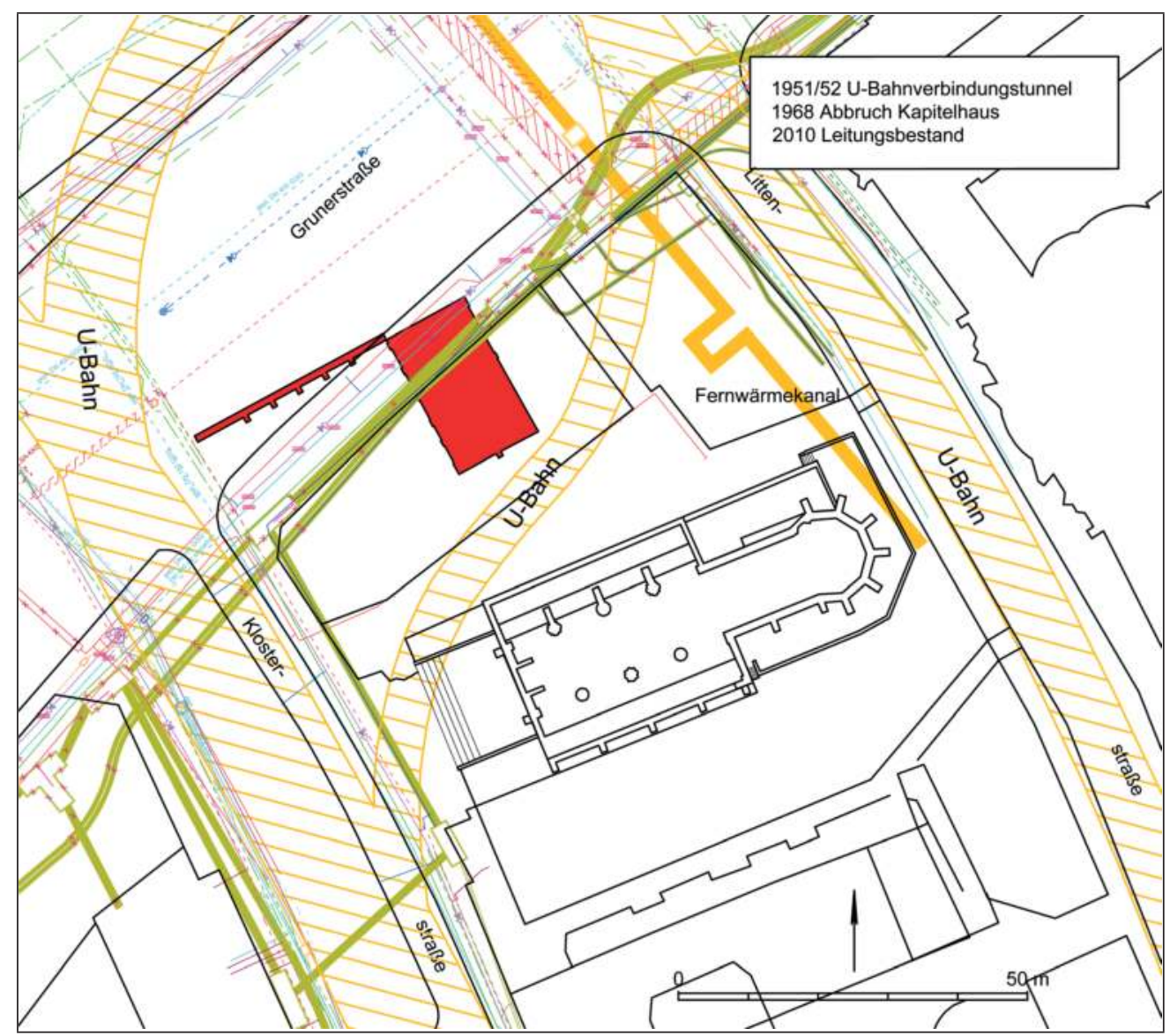

Abb. 8: Bauliche Eingriffe auf dem Areal des ehemaligen Grauen Klosters in der Nachkriegszeit.

\section{Untersuchungen zwischen 1999 und 2004}

Um das Jahr 2000 stand die Klosterkirche im Mittelpunkt einer weiteren Instandsetzungsmaßnahme. Durch das Landesdenkmalamt wurde die Ruine restauriert und in Zusammenarbeit mit der Technischen Universität Berlin bauhistorisch erforscht. Zwischen 2001 und 2004 wurden zehn kleinere Sondagen geöffnet (Abbildung 9). ${ }^{27}$ Die Grabungsflächen konzentrierten sich auf baugeschichtliche Fragestellungen, die an die Untersuchungen von 1926 bis 1936 und die Rekonstruktion von Gerhard Bronisch anknüpften. Dazu zählte die Suche nach der südlichen Außenwand des Vorgängerbaues im Kircheninneren. Wie schon bei Gerhard Bronisch blieb die Suche erfolglos. Dafür lokalisierte Stefan Breitling in der nördlichen Feldsteinwand eine Tür mit einem Gewände aus sorgfältig geglätteten Feldsteinen. ${ }^{28}$ Der ältere Bau verfügte demnach über

28 Breitling, Die Franziskaner-Klosterkirche [...]: Ergebnisse, S. 102. 


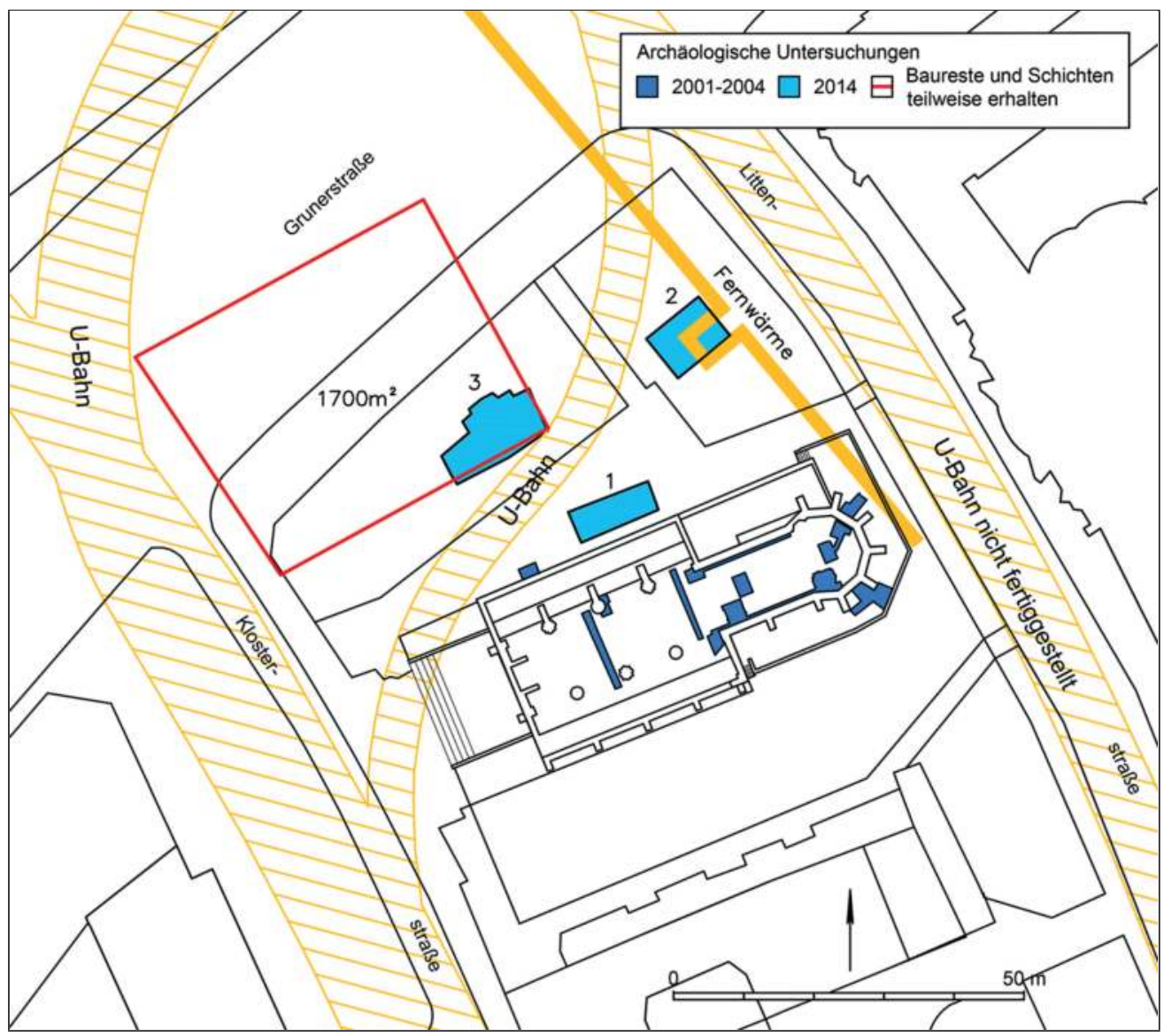

Abb. 9: Archäologische Untersuchungen 2001 bis 2004 und 2014.

einen nördlich liegenden Zugang aus Richtung des Hohen Hauses. Um den Westabschluss der Feldsteinnordwand zu klären, wurde ein Schnitt an der Außenseite der Nordwand angelegt. ${ }^{29}$ Die Feststellung, dass die Stadtmauer ursprünglich im Bogen um den Chor verlief, wurde bestätigt, und es gelang der Nachweis einer frühen Stadtbefestigung in Form eines Grassodenwalles. ${ }^{30}$ Die Baugeschichte der Backsteinbasilika wurde durch bisher unbekannte Baubefunde ergänzt. Unter den Wänden des mittelalterlichen Langchores lagen Pfeilerbankette, die auf einen ursprünglichen Bauplan mit offenen Arkaden hindeuten. ${ }^{31}$ Des Weiteren zeigte sich, dass die Fläche südlich der Kirche bis in die Neuzeit als Friedhof genutzt wurde.

29 Michas, Archäologische Untersuchungen, S. 89.

30 Ebd., S. 91.

31 Schumann, Die Franziskaner-Klosterkirche - Formsteine, S. 127-140. 


\section{Voruntersuchungen 2014, Bebauungsplan Molkenmarkt-Grunerstraße}

Im Zusammenhang mit dem Bebauungsplan Molkenmarkt-Grunerstraße fanden erstmalig archäologische Sondierungen im Bereich der ehemaligen Klausur statt, während sich die früheren Grabungen auf die Klosterkirche konzentrierten. Die zielgerichteten Untersuchungen sollten klären, ob im Boden noch Baureste vorhanden sind, in welcher Tiefe und in welchem Erhaltungszustand. Um diese Fragen zu klären, wurden drei Grabungsflächen geöffnet, die sich an den mittelalterlichen Gebäudegrundrissen orientierten. Im Sommer 2014 wurde die Ausgrabungsfirma Argepro mit der Durchführung beauftragt. Als Argepro im Herbst 2014 Insolvenz anmeldete, dokumentierte der Autor die Baubefunde vor der Wiederverfüllung der Schnitte. Ein baugeschichtliches Gutachten fertigte der Bauhistoriker Dirk Schumann an. ${ }^{32}$ Es diente als Quelle der folgenden Beschreibungen.

\section{Fläche 1, Südlicher Kreuzgangflügel}

In der neben der Nordwand der Kirche vorgenommenen Ausgrabung wurden in 1,70 Meter Tiefe Reste des südlichen Kreuzgangflügels freigelegt, die zum Fundament und Sockelbereich der Nordwand des Kreuzgangs gehören und in die Zeit um oder nach 1300 datieren. An der Nordseite der Kreuzgangwand waren zwei Strebepfeiler feststellbar, die in ihrer Lage mit den Schildbögen in der Kirchenaußenwand korrespondieren. Die Gewölbejochweite betrug etwa 3,20 Meter. Des Weiteren haben sich zwei Backsteinfußböden erhalten. Anhand der freigelegten Fußbodenreste ließ sich die Raumhöhe des Kreuzganges von vier Metern bis zum Gewölbescheitel rekonstruieren. Der unmittelbar an die Kirchenaußenwand angrenzende Bereich war bedingt durch einen Leitungskanal und frühere Abdichtungsarbeiten vollständig gestört. Im westlichen Abschnitt der Fläche 1 traten hingegen jüngere Kellermauern zu Tage, die von den hier im späten 18. Jahrhundert errichteten Lehrerwohnungen zeugen.

\section{Fläche 2, 0stflügel}

Die Fläche 2 wurde im Überschneidungsbereich von mittelalterlichem und neuzeitlichem Ostflügel angelegt (siehe Abbildung 10). Es zeigte sich, dass ein Fernwärmekanal nahezu den gesamten Bereich durchzog. Die Sondage erbrachte keinerlei mittelalterliche Mauerreste. Westlich des Fernwärmekanals wurde eine Ziegelmauer in sorgfältig ausgeführtem Blockverband gefunden. Sie wies eine Verkleidung auf, deren Schale einen halben Stein stark ist. Einige Ziegel waren mit dem Fabriknamen F. Michaelis gestempelt. Die Lage der Mauer und der Ziegelstempel sprechen dafür, dass die Mauer zum Treppenhaus des 1896 errichteten Ostflügels des Berlinischen Gymnasiums gehörte.

32 Dirk Schumann, Bauhistorischer Vorbericht zu den bisher freigelegten Fundamentbefunden von Klausurgebäuden des ehemaligen Franziskanerklosters in Berlin, 2014 (Archiv Landesdenkmalamt Berlin, Ortsakten, Nr. 1808 I). 


\section{Fläche 3, Kapitelhaus}

Die Fläche 3 wurde im Bereich der ehemaligen Stirnwand des Kapitelhauses platziert (siehe Abbildung 10 und 12). Knapp unter der Grasnarbe zeigten sich die ersten Baubefunde. Unterhalb eines Fußbodens aus dem 19. Jahrhundert kam die Nordwestecke der Kreuzgangwand zu Tage, die dem Befund aus Fläche 1 ähnelt und um das Jahr 1300 datiert. Über einem lagenweise aufgeschichteten Feldsteinverband folgte ein Backsteinverband mit einer pult- oder sattelförmigen Fugengestaltung. Auch die Überbauung der Kreuzgangecke mit dem Kapitelhaus (1471-1474) ließ sich anhand von Mauerbefunden belegen. Die Umfassungsmauer des Kapitelhauses war durch tiefe Wandnischen gegliedert, in denen Fensteröffnungen saßen. Das Mauerwerk dieser Bauphase zeichnete sich durch den für die Zeit charakteristischen Fugenstrich mit mehrfachen Ritzungen aus. Die Baubefunde in Fläche 3 belegten zudem den Bau eines Treppenhauses in neogotischer Form zwischen 1863 und 1865 sowie die Sicherung der Fundamente des Kapitelhauses während des U-Bahnbaus von 1950 bis 1951.

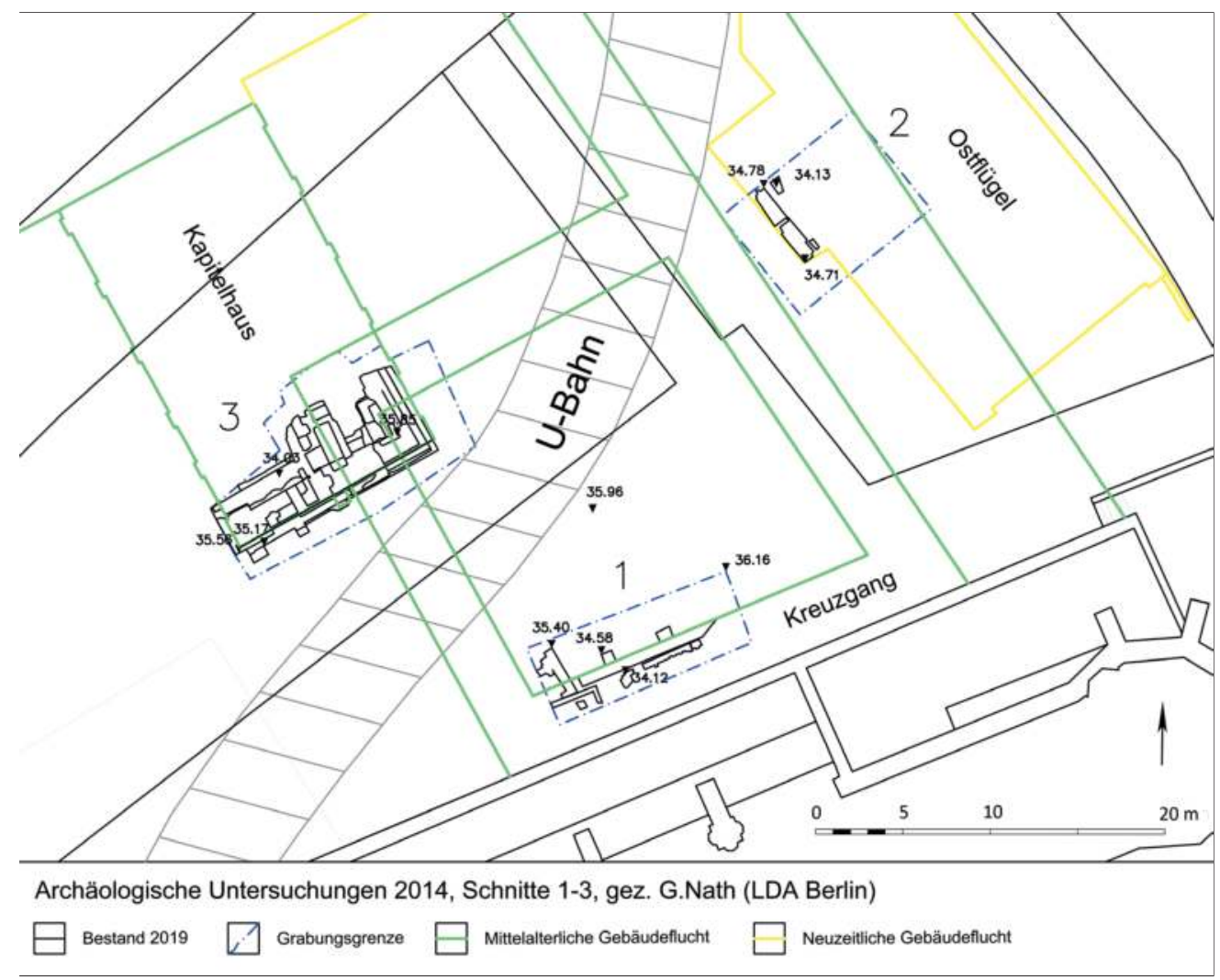

Abb. 10: Archäologische Befunde in den Schnitten 1 bis 3. 


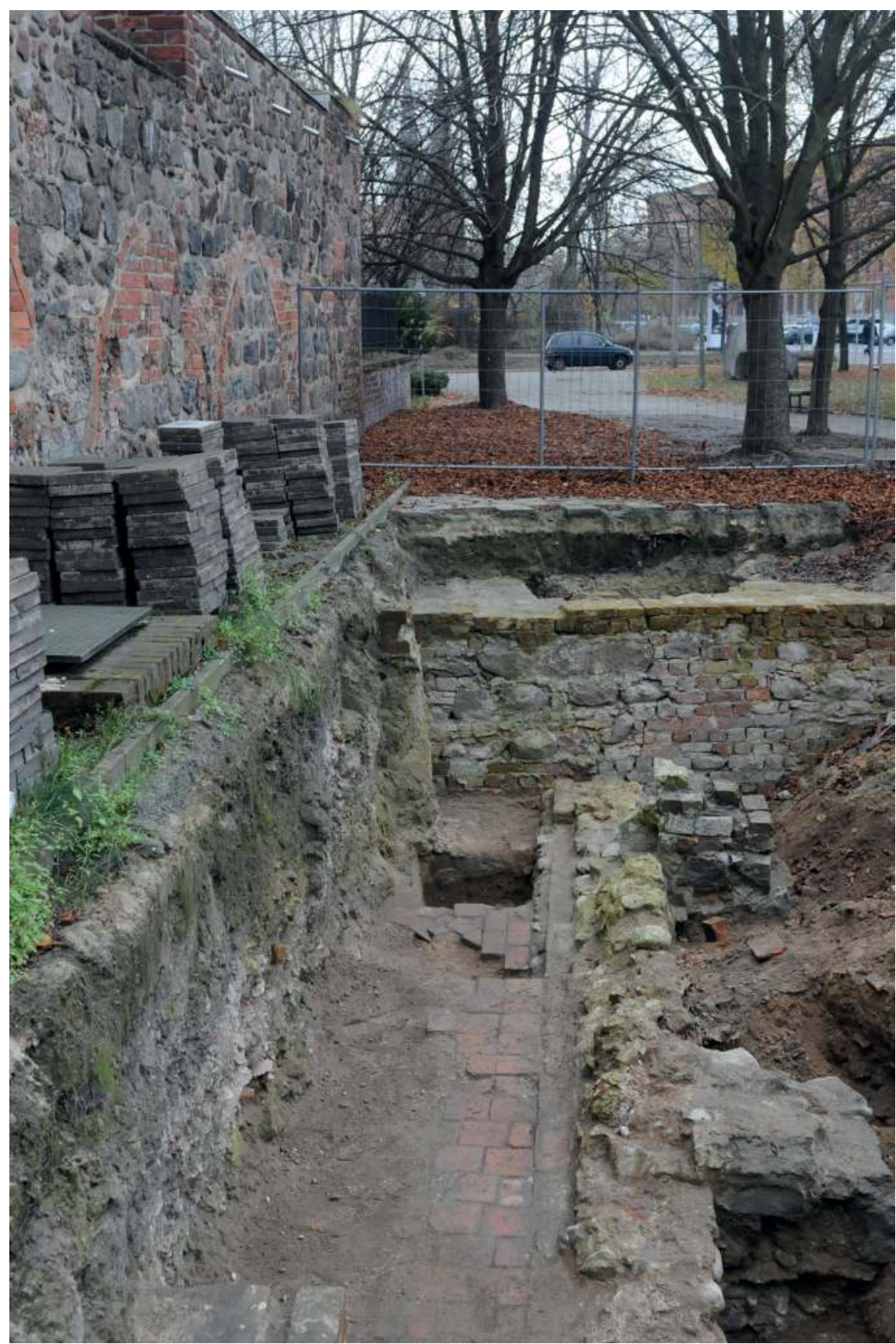

Abb. 11: Schnitt 1 mit den Resten der nördlichen Wand des südlichen Kreuzgangflügels, um 1300. 


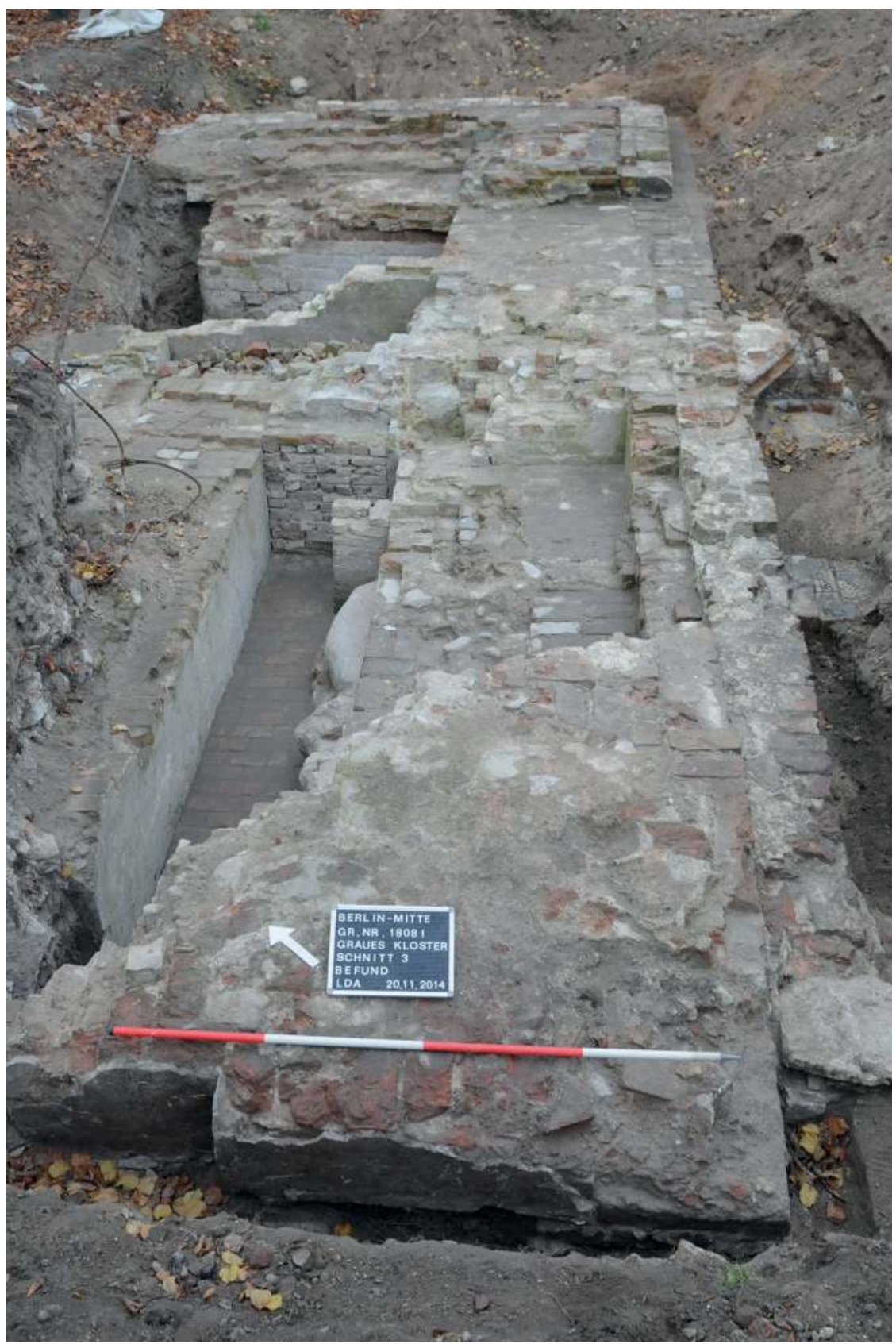

Abb. 12: Schnitt 3 mit den Fundamentresten der südlichen Umfassungsmauer des Kapitelhauses. 


\section{Fazit}

Die Neuerrichtung der Schulgebäude ab dem späten 18. Jahrhundert bis um 1900 hat zu starken Eingriffen in die ober- und unterirdische Bausubstanz des mittelalterlichen Klosterbestandes geführt. Denkmalpflegerische Interventionen gab es 1813, 1823 und von 1842 bis 1845 in der Klosterkirche, im Kapitelhaus und im Nordflügel. ${ }^{33}$ Nachdem der Kriegsschutt des Zweiten Weltkrieges abgetragen war, wurden die Reste der mittelalterlichen Gebäude zunächst gesichert. Planungen sahen vor, Kapitelhaus und Nordflügel wiederaufzubauen. Im Rahmen der Verbreiterung der Grunerstraße kam es aber zum Abbruch der letzten oberirdischen Reste und zur Gestaltung einer Grünanlage im Umfeld der Klosterkirchenruine.

Nach dem aktuellen Bebauungsplan sollen Teile der Grünanlage südlich und nördlich der Ruine bestehen bleiben. Damit bleiben auch Bodenfunde, unter anderem die Bestattungen des ehemals südlich liegenden Kirchhofes, vor einer Zerstörung bewahrt. Die für die Bebauung ausgewiesene Fläche nördlich der Ruine wurde 2014 archäologisch sondiert. Die Grabungsergebnisse und die Kartierung der Infrastrukturmaßnahmen des 20. Jahrhunderts zeigten, dass im mittleren und östlichen Bereich durch den U-Bahnbau und die Verlegung eines Fernwärmekanals viel archäologische Substanz verloren ging. In der nordwestlich des U-Bahntunnels liegenden Zone sind dafür noch ca. 1.700 Quadratmeter vom ehemals 4.500 Quadratmeter großen Areal der mittelalterlichen Klausur unterirdisch erhalten (rot umrandete Fläche in Abbildung 9). Hier sind auch Erdgeschossmauern des Kapitelhauses zu erwarten, da beim Abriss der Ruine in den 1950er-Jahren keine Tiefenenttrümmerung erfolgte. Die Ergebnisse der Voruntersuchung zeigen auch, dass die Baureste knapp unter der Erdoberfläche liegen. Es ist davon auszugehen, dass sich in nördlicher Richtung weitere Reste des Gebäudes und der westliche Teil des Nordflügels erhalten haben. Allerdings ist dort aufgrund von Leitungsverlegungen mit Teilzerstörungen zu rechnen. Durch die Ausgrabungen kamen auch archäologische Fundobjekte wie mittelalterliche Formsteine und Keramik, neuzeitliche Gefäß- und Ofenkeramik sowie Tonpfeifenreste zu Tage, die die wichtigsten Nutzungsphasen belegen.

Meines Erachtens sind die archäologischen Baureste des Kapitelhauses als Bezugspunkt zur mittelalterlichen Geschichte des Grauen Klosters und späteren Berlinischen Gymnasium zum Grauen Kloster geeignet. Diese könnten beispielsweise unter einem Schutzbau gezeigt oder in einen Neubau integriert werden. Grundsätzlich gilt, dass mit großer Sorgfalt vorgegangen werden muss, damit die fragilen Baubefunde der Überbauung standhalten. Für die wenigen Baureste des Kreuzganges scheint es aus konservatorischen Gründen hingegen ratsam, diese nicht offenzulegen, sondern unter der Erde zu belassen. Die Lage des Kreuzganges kann durch eine besondere Gestaltung der Erdoberfläche kenntlich gemacht werden. Im Hof westlich des Kapitelhauses gab es nach heutigem Kenntnisstand keine Bebauung. Dort haben sich mit großer Wahrscheinlichkeit mittelalterliche und frühneuzeitliche Nutzungsschichten erhalten. Bisherige Erfahrungen zeigen, dass sich Siedlungsschichten unter ehemaligen Höfen und Plätzen bis in die Frühzeit der Stadtgründung zurückverfolgen lassen. Hier könnten archäologische Forschungen sinnvoll sein, um weitere Fragestellungen zu klären, deren Beantwortung durch bauliche Zäsuren und neuzeitliche 
Bodeneingriffe bisher nicht möglich war. Es gilt aber auch hierbei, den denkmalpflegerischen Grundsatz nicht aus den Augen zu verlieren, denn Erdschichten, Abfallgruben, Brandhorizonte et cetera sind unwiederbringliche Quellen für die Stadtgeschichte. Nachfolgende Forschergenerationen werden es zu schätzen wissen, wenn sie unangetastete Bereiche vorfinden. 


\section{Michael Malliaris}

\section{Klostergründungen in Berlin. Die Ergebnisse der Ausgrabungen zum Dominikanerkloster in Cölln'}

Die Bettelordenskonvente der Doppelstadt Berlin und Cölln übten seit ihrer Ansiedlung im 13. Jahrhundert einen erheblichen spirituellen wie kulturellen Einfluss auf die mittelalterliche städtische Gesellschaft der Doppelstadt Berlin-Cölln an der Spree aus. Ihre außerordentlichen, von Stadt- und Klostermauern eingehegten Baukomplexe aus Kirche und Klausurbauten waren einst im steinernen Stadtgefüge unübersehbar. Grundlage des Erfolges der Mendikanten in den jungen Städten war gewiss nicht nur die straffe organisatorische Struktur der europaweit agierenden Orden, sondern auch die großzügige Förderung durch die brandenburgischen Landesherren und Vertreter bürgerlicher Fraktionen. Die Mönche vergalten es mit Predigt, Seelsorge und weitreichenden Beziehungen.

Nach Auflösung der Klöster im 16. Jahrhundert erfuhren die Baukörper unterschiedliche Nachnutzungen. Das ehemalige Berliner Franziskanerkloster nahm dauerhaft bis zum Zweiten Weltkrieg das Berlinische Gymnasium zum Grauen Kloster auf. In die Bauten der Cöllner Dominikaner zog zunächst das dem Heiligen Erasmus geweihte Domstift ein, die backsteinerne Hallenkirche der Prediger wurde darüber hinaus zur Hofkirche und Grablege der Hohenzollern umgebaut. Nur geringe Reste und Spuren der vielgliedrigen Baukomplexe haben sich bis heute erhalten. Von den Franziskanern zeugt im heutigen Stadtbild nur noch die Kirchenruine. Dominikanische Bausubstanz erhielt sich im Stadtbild gar nur bis 1747, als König Friedrich II. den zuletzt freistehenden Kirchenbau abreißen ließ und die Domkirche in den Lustgarten verlegte. Im Folgenden soll auf der Grundlage der archäologisch gewonnenen Quellen der Versuch unternommen werden, eine Grundlage zur vergleichenden Betrachtung der beiden Bettelorden in der Doppelstadt zu schaffen.

\section{Ausgrabung des Dominikanerklosterareals am Schlossplatz in Berlin-Mitte}

Die Ausgrabungen des Landesdenkmalamtes Berlin am Schlossplatz in Berlin-Mitte in den Jahren 2008 bis 2015 fanden im Vorfeld der Errichtung des Humboldt Forums statt. Dabei wurden auf einer Gesamtfläche von ca. 15.000 Quadratmetern nicht nur die Reste des Barockschlosses und des Großen Schlosshofs erfasst, sondern auch die heutige Platzfläche zwischen dem Sitz des Staatsrats der Deutschen Demokratischen Republik (DDR), heute European School of Management and Technology, sowie der rekonstruierten Barockfassade am Schlossplatz untersucht. Der letztgenannte Abschnitt ermöglichte die weitgehende archäologische Erforschung des Do-

1 Dieser Beitrag ist eine veränderte und erweiterte Fassung des am 20. Mai 2019 beim wissenschaftlichen Kolloquium gehaltenen Vortrags. 
minikanerklosterareals von der Zeit der Stadtgründung bis zum Abriss der ehemaligen Klosterkirche im Jahr 1747. ${ }^{2}$ Mit dieser vom Bund und vom Land Berlin finanzierten städtebaulichen Entwicklungsmaßnahme ,Hauptstadt Berlin - Parlaments- und Regierungsviertel' finanzierten Großgrabung lässt sich nunmehr in Verbindung mit den Ergebnissen vorangegangener Ausgrabungen und schriftlicher Quellen die Baugeschichte dieses Ortes über circa 550 Jahre hinweg nachzeichnen. Während der Untersuchungen wurden insgesamt 759 Gräber geborgen. Ihre Zeitspanne reicht von den Bestattungen des Dominikanerklosters ab dem späten 13. Jahrhundert bis zur Schließung des Friedhofs der Oberpfarr- und Domkirche im Jahr 1716. ${ }^{3}$ Die im Folgenden wiedergegebenen historischen Rahmendaten eignen sich für die Periodisierung der baulichen Entwicklung des Dominikanerklosterareals auf der Grundlage der archäologischen Untersuchungen.

\section{Vorklosterzeit (von der zweiten Hälfte des 12. Jahrhunderts bis um circa 1300)}

Die intensive neuzeitliche Bautätigkeit auf dem Areal, der Abriss sämtlicher Baulichkeiten im 18. Jahrhundert, die Ausgrabung des Jahres 1880 und etliche moderne Störungen durch Leitungsgräben und den Bau des Palastes der Republik rissen zwar erhebliche Lücken in das ursprüngliche Gesamtbild, doch die über die gesamte Fläche des späteren Klosters und darüber hinaus verteilten Siedlungsbefunde belegen ohne Zweifel eine rege und anhaltende Siedlungstätigkeit schon lange vor der Ankunft der Dominikaner. Diese drückt sich im archäologischen Befund durch Überschneidung und Überlagerung aus, die im Einzelfall zwingende Schlüsse zur Periodenzugehörigkeit und Datierung forderten: ein im Bereich des Vorchors freigelegter, im 13. Jahrhundert genutzter Holzkastenbrunnen muss vor der Errichtung dieses Abschnitts der Klosterkirche zugeschüttet worden sein. Als besonders aussagekräftige Quelle für die Interpretation des frühen städtischen Baugeschehens erwies sich der südwestliche Rand des Untersuchungsgebietes außerhalb der Kernbauten des Klosters und damit auch außerhalb der Ausgrabungsfläche des Jahres 1880. An mehreren Stellen konnte zweifellos eine mehrphasige Entwicklung festgestellt werden, die auch mit Nutzungswechseln (zum Beispiel mehrphasige Siedlungsgruben, die von zwei aufeinanderfolgenden Häusern geschnitten werden) einhergegangen war. Die dendrochronologisch ermittelten Daten der Siedlungsbefunde ergeben eine zeitliche Mindestspanne von über 100 Jahren Siedlungstätigkeit im späteren Klosterquartier zwischen dem mittleren 12. Jahrhundert bis mindestens in das Jahr 1264 (Eichendaube in einer Kloakenverfüllung). Die Tatsache, dass mehr als ein dendrochronologisches Datum in die Zeit um 1200 und davor fällt, mag als deutlicher Hinweis darauf gelten, dass die rege Nutzung dieses Areals schon in diese Zeit fallen dürfte.

2 Der Verfasser dieses Beitrags leitete die genannten Ausgrabungen im Auftrag des Landesdenkmalamtes Berlin. Der vorliegende Beitrag beruht auf den Ergebnissen der Doktorarbeit an der Freien Universität Berlin: Michael Malliaris, Die Baugeschichte des Dominikanerklosterareals in Cölln an der Spree vom 12. Jahrhundert bis zum Jahr 1747 nach den Ausgrabungen am Schlossplatz in Berlin-Mitte. Mit Beiträgen von Ulrich Haarlammert und Daniel Krebs (Beiträge zur Denkmalpflege in Berlin, Bd. 51), 2 Bde., Petersberg 2018.

3 Vgl. dazu besonders den Beitrag von Daniel Krebs, Archivalische und prosopografische Untersuchungen zu den Bestattungen der Dominikanerklosterkirche und des Alten Domes zu Berlin, in: Malliaris, Die Baugeschichte des Dominikanerklosterareals, Bd. 1, S. 316-392 sowie Bd. 2, S. 382-418. 
Verknüpft man die Mächtigkeit der vorklösterlichen Straten im Untersuchungsgebiet mit den wenn auch vereinzelten - frühen Dendrodaten aus der Mitte des 12. Jahrhunderts, kommt man nicht umhin, eine langsam, aber stetig aufbauende Siedlungstätigkeit im ausgehenden 12. Jahrhundert für plausibel zu halten. Vier im Bereich des Klosterareals nachgewiesene mittelalterliche Holzkastenbrunnen entsprechen, soweit ihre Herstellungstechnik geklärt wurde, vollständig den in der Region üblichen Brunnentypen des späteren 12. und 13. Jahrhunderts. Die Überlagerung verschiedener Häuser - greifbar an einem Doppelpfostenhaus, das von einem Steinhaus überlagert wurde - ist Ausdruck einer Platzkontinuität, die eher bei einer dichten Besiedlung und intensiven Nutzung des Areals zu erwarten ist. ${ }^{4}$ Die unterschiedliche Bauweise der Häuser auf einem Grundstück spiegelt eine Entwicklung vom schnell verfügbaren Holzbau zum dauerhaften Steinbau wider, die etwa in der Cöllner Breiten Straße, wo nur Holzbauten nachgewiesen werden konnten, nicht beobachtet wurde. ${ }^{5}$ Die Orientierung des Doppelpfostenhauses bezieht sich auf die Verlängerung der Achse der Brüderstraße. Innerhalb des Untersuchungsgebietes stießen die zwei von der späteren Brüderstraße und Breiten Straße auf die Parzellengrenzen übertragenen Achsensysteme aufeinander.

Im Bereich des Quartiers ist zunächst eine Landbewirtschaftung beziehungsweise eine Bearbeitung der Böden (Hack- und Spatenspuren) anzunehmen, der wohl eine Rodung vorausging. In den ältesten anthropogenen Schichten konnten an mehreren Stellen teilweise mehrreihige Spateneinstiche in analoger Ausrichtung dokumentiert werden. Sie lassen sich am besten mit der systematisch fortschreitenden Arbeitsweise eines Gärtners oder Erdarbeiters erklären. Siedlungstätigkeit ist nur an Holzkohlespuren geringer Konzentration im sandig-humosen Substrat ablesbar. In dieser Zeit wurden Zäune und Entwässerungsgräben angelegt, deren Orientierung nicht unbedingt den für die spätere Parzellierung gültigen Fluchten entsprach. Der Beginn der Pionierphase war vielleicht an der Topografie orientiert, führte aber noch nicht zu einer in größeren Zusammenhängen geplanten systematischen Parzellierung. Sie fällt mit Sicherheit noch in das 12. Jahrhundert und setzte möglicherweise schon in dessen Mitte ein. Sie muss jedoch schon vor 1200 abgeschlossen gewesen sein, da zu diesem Zeitpunkt so viele Bauwerke archäologisch gefasst werden können, dass sie ohne eine regulierende Struktur kaum angelegt werden konnten. Die sukzessive und intensive Nutzung der Grundstücke ist an mehreren Parzellen nachzuweisen. Die archäologisch erschlossenen, materiellen Zeugnisse des Dominikanerklosterareals vor 1300 ergeben das Bild eines Stadtrandviertels mit Mischnutzung. ${ }^{6}$ Dementsprechend beinhaltet das Fundspektrum des Stadtviertels außer den üblichen Tierknochen- und Keramikabfällen handwerkliche Produkte, vor allem Knochenobjekte und eiserne Schmiedeerzeugnisse.

4 Zahlreiche Beispiele mehrfacher baulicher Überlagerungen lassen sich etwa in Lübeck nachweisen: Gabriele Legant, Zur Siedlungsgeschichte des ehemaligen Lübecker Kaufleuteviertels im 12. und frühen 13. Jahrhundert. Nach den ältesten Befunden der Grabung Alfstraße -Fischstraße -Schüsselbuden, 1985-1990 (Lübecker Schriften zu Archäologie und Kulturgeschichte, Bd. 27), Rahden 2010.

5 Michael Hofmann/Frank Römer, Vom Stabbohlenhaus zum Haus der Wirtschaft. Ausgrabungen in Alt-Cölln, Breite Straße 21 bis 29 (Beiträge zur Denkmalpflege in Berlin, Bd. 14), Berlin 1999, S. 15-37, 88.

6 Als Vergleich dazu kann etwa ein Quartier der Cottbusser Altstadt herangezogen werden: Sebastian Heber, Zwischen Spremberger-, Burg- und Schlosskirchstraße - Archäologie eines Wohnquartiers im Südosten der Cottbusser Altstadt. Dissertation an der Philosophischen Fakultät der Humboldt-Universität zu Berlin, 2014, S. 35-92, online unter https://edoc.hu-berlin.de/handle/18452/21254 [abgerufen am: 15. September 2020]. 


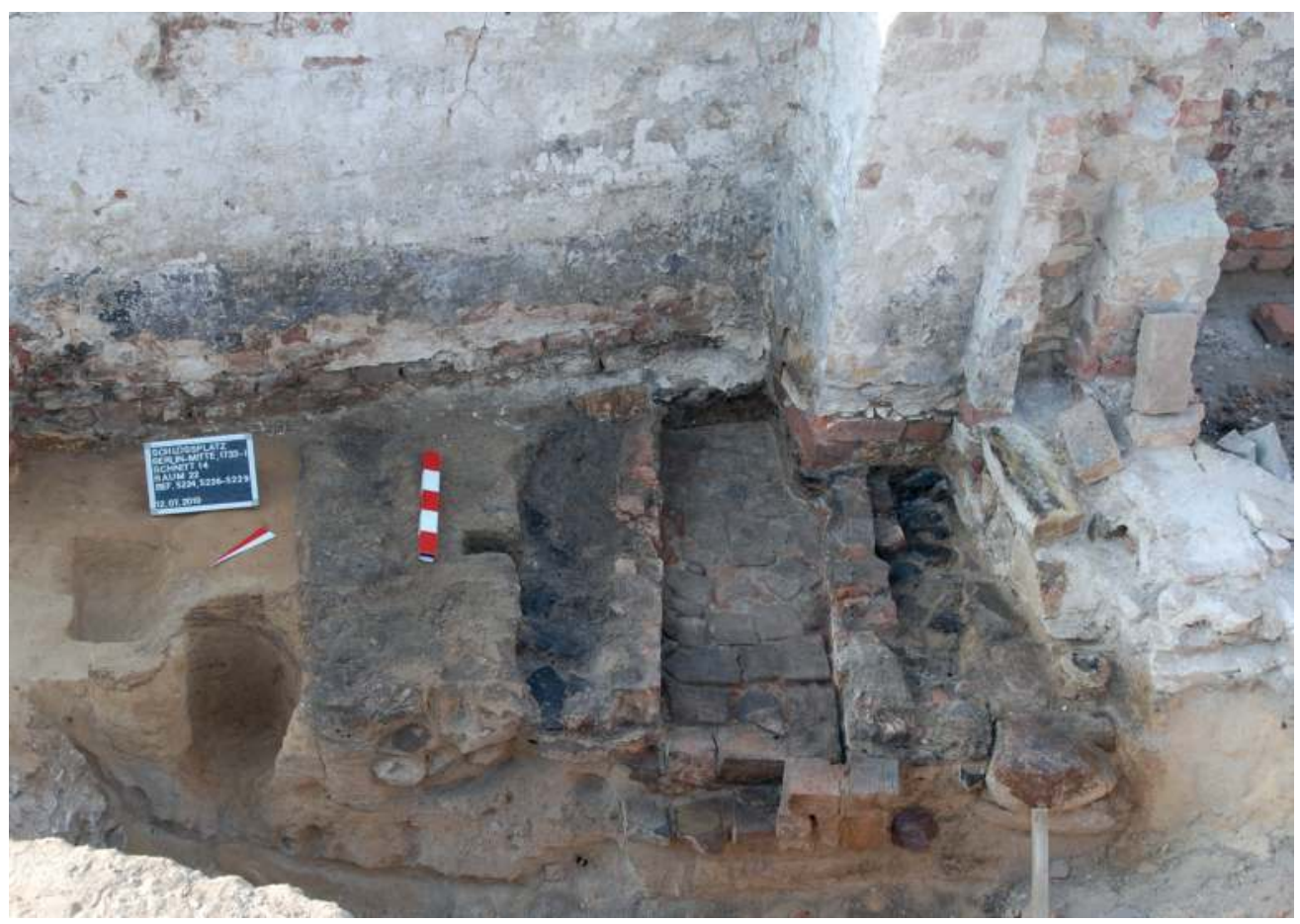

Abb. 1: Ofen mit Backsteintenne des 13. Jahrhunderts unter den Mauern eines frühneuzeitlichen Kaufladenkellers.

Auf den städtischen Parzellen betrieben die Quartiersbewohner ausweislich der Bodenbearbeitungsspuren Gartenbau, außerhalb der Stadt existierten sehr wahrscheinlich Felder. Botanische Reste aus einer Latrine des 13. Jahrhunderts belegen neben zahlreichen kultivierten und wilden Obstsorten die Getreidearten Roggen, Gerste, Rispenhirse, Hafer und Weizen. Darüber hinaus konnten darin Hanf, Leinsamen, Raps, Erbsen, Schlafmohn sowie auch Wildkräuter (,Ackerunkräuter') nachgewiesen werden. ${ }^{7}$ Die Baustrukturen des Stadtviertels orientierten sich an zwei Straßenachsen, die nicht im rechten Winkel aufeinanderstießen. Vorherrschend war die Ost-West-Achse in der Verlängerung der Langen Brücke (der heutigen Rathausbrücke) über die Spree. Auf diese Achse bezog sich das spätere Dominikanerkloster einschließlich der Klosterkirche. Die Bauten am westlichen Rand des Stadtviertels schmiegten sich an den östlichen Rand der erst später nach den Mönchen benannten Brüderstraße. Ein im rechten Winkel zur Brüderstraße angelegter unterirdischer Ofen mit Backsteintenne stach wegen seiner Größe und mutmaßlichen Funktion als Heizung eines Hauses aus der Vielzahl bescheidener Befunde heraus (Abbildung 1). Er deutet auf Nutzer oder Bewohner mit hervorgehobenem Status. In der Regel trifft man solche Heizanlagen nur in Burgen oder Klöstern an. Der Befund könnte vielleicht sogar als Indiz für ein temporäres Haus der Cöllner Dominikaner bis zur Bezugsfertigkeit des Neubaus angesehen werden. Südlich des Ofens befand sich das einzige nachgewiesene Steinhaus des

7 Für die Untersuchung der botanischen Proben danke ich Herrn Dr. Reinder Neef, DAI Berlin, ganz herzlich. 
Stadtviertels. Die Relikte des über älteren Arbeitsgruben sowie einem hölzernen Pfostenbau platzierten Steinhauses zeugen in jedem Falle davon, dass man im fortschreitenden 13. Jahrhundert zunehmend steinerne Profangebäude in Cölln und Berlin errichtete. Im Westen und Norden endete das Viertel an der zunächst wohl provisorischen Befestigung der Stadtgrenze. Zwischen Letzterer und der Randbebauung verliefen Entwässerungs- oder Straßengräben. Die endgültige Fortifikation der Stadtgrenze durch einen mit Grassoden vermischten Sandwall und einen feldseitigen Graben erfolgte erst nach 1232. Die Böschungssohle des Stadtgrabens hatte man mit Horizontalhölzern und senkrechten Doppelpfosten fixiert. Der den landestypischen Ressourcen angemessene, kostengünstige Bau einer Sandwallgrabenanlage war in der Mark Brandenburg zu dieser Zeit üblich.

Im letzten Viertel des 13. Jahrhunderts kamen wahrscheinlich die Dominikaner in das ihnen wohl von den Askaniern zugewiesene Quartier. Bis zur endgültigen Planierung des Stadtviertels für den Neubau des Klosters könnten die dominikanischen Mönche schon in provisorischen und vorhandenen Baulichkeiten vor Ort gewohnt haben. ${ }^{8}$ Spätestens kurz vor Baubeginn der Klostergebäude erfolgte der endgültige Abriss des über mehr als 100 Jahre gewachsenen Stadtviertels. Dieses radikale Ende der Baulichkeiten am nördlichen Rand von Cölln war zu dieser Zeit kein Einzelfall. Der gleiche Vorgang ereignete sich zum Beispiel auch beim Bau des Dominikanerklosters von Brandenburg an der Havel auf zuvor genutzten Stadtflächen. ${ }^{9}$

\section{Das Dominikanerkloster (um 1300 bis 1536)}

Früher als den Dominikanern in Cölln wurde den Berliner Minoriten schon im dritten Viertel des 13. Jahrhunderts ein Baugrundstück in unmittelbarer Nähe des Hohen Hauses der Askanier zugewiesen. ${ }^{10}$ Die Ersterwähnung eines dominikanischen Priors Wilhelm (frater Wilhelmus prior domus ordinis Predicatorum in Colonia ${ }^{11}$ ) fällt in einer Urkunde des askanischen Markgrafen Albrecht III. erst auf den 19 . November $1300 .{ }^{12}$

Die Annahme einer Ansiedlung der Cöllner Prediger schon im Laufe des letzten Viertels des 13. Jahrhunderts, die zunächst ohne größere bauliche Aktivitäten erfolgt sein kann, erscheint gleichwohl nicht ausgeschlossen. Eine Spanne mehrerer Jahre zwischen Ankunft der ersten Mönche und dem Baubeginn der stattlichen Klosterkomplexe kann sicher nicht nur für Ansiedlungen

8 Vgl. zu dieser These den Beitrag von Heinz-Dieter Heimann im vorliegenden Band.

9 Siehe dazu: Dietmar Rathert, Das Paulikloster in Brandenburg an der Havel, in: Kirchen des Mittelalters in Brandenburg und Berlin. Archäologie und Bauforschung, S. 286-292.

10 Peter Riedel u. a., Berlin Franziskaner, in: Heinz-Dieter Heimann u. a. (Hrsg.), Brandenburgisches Klosterbuch. Handbuch der Klöster, Stifte und Kommenden bis zur Mitte des 16. Jahrhunderts (Brandenburgische Historische Studien, Bd. 14), 2 Bde., 1. Aufl., Berlin 2007, Bd. 1, S. 146-159, bes. S. 146.

11 Codex diplomaticus Brandenburgensis. Sammlung der Urkunden, Chroniken und sonstigen Quellenschriften für die Geschichte der Mark Brandenburg und ihrer Regenten, Hauptt. I, Bd. 12, hrsg. von Adolph Friedrich Riedel, Berlin 1857, S. 284 f., Nr. 2, 3.

12 Michael de Nève mit Marcus Cante/Blandine Wittkopp, Berlin-Cölln Dominikaner, in: Heimann, Brandenburgisches Klosterbuch, Bd. 1, S. 160-171. 


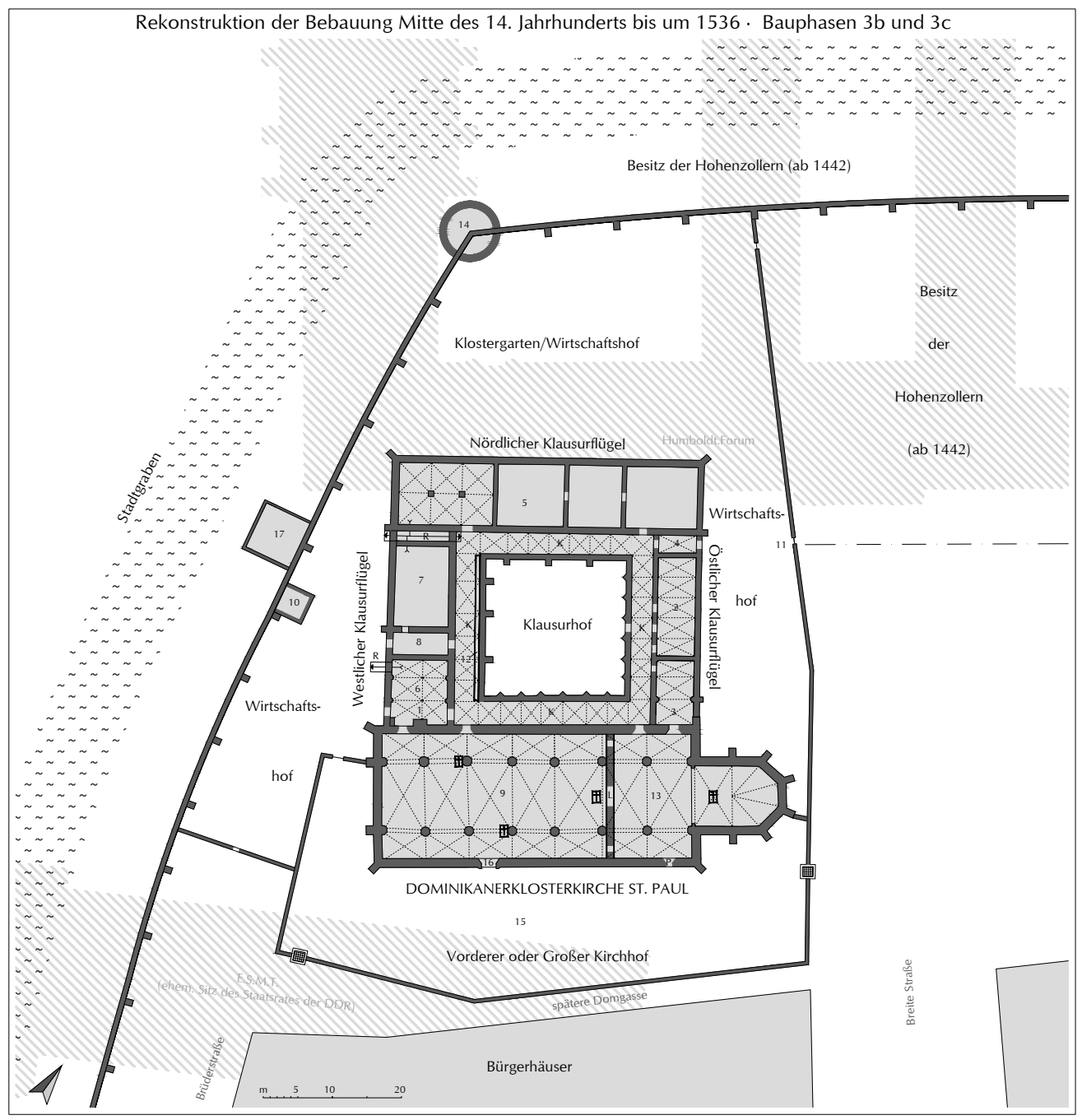

Abb. 2: Rekonstruktion der Bebauung des Dominikanerklosterareals von der Mitte des 14 . Jahrhunderts.

im deutschsprachigen Raum nachgewiesen werden. ${ }^{13}$ Eine längere Anfangsphase des Dominikanerklosters vor der Ersterwähnung des Priors Wilhelm erhält durch die naturwissenschaftliche, mit der C14-Methode gewonnenen Datierung von zwei frühen Gräbern auf dem Areal der Dominikaner Auftrieb. ${ }^{14}$ Grab 96 einer 25- bis 30-jährigen Frau, die im südöstlichen Winkel des

13 Achim Todenhöfer, Kirchen der Bettelorden. Die Baukunst der Dominikaner und Franziskaner in Sachsen-Anhalt, Berlin 2010, S. 198 f. (für die Klöster im heutigen Sachsen-Anhalt); Wolfgang Schenkluhn, Architektur der Bettelorden, Darmstadt 2000, S. 27-31; Panayota Volti, Les couvents des ordres mendiants et leur environnement à la fin du Moyen Age. Le nord de la France et les anciens Pays-Bas méridionaux, Paris 2003, S. 51-102.

14 Für die Aufnahme des Knochenmaterials von Grab 96 und 635 zur C14-Altersbestimmung in eine am 2. November 2015 im Klaus-Tschira-Archäometriezentrum an der Universität Heidelberg eingetroffene und am 18. De- 
vorderen Kirchhofs lag, sowie Grab 635 eines 17- bis 19-jährigen Mannes, das von der Fassadenmauer des östlichen Kreuzgangs überlagert worden war, ergaben für beide Individuen ein Sterbedatum zwischen den Jahren 1260 und 1280. ${ }^{15}$ Das Frauengrab gehörte zu einer kleinen Gruppe von frühen Gräbern, deren Orientierung nicht den baulichen Achsen der späteren Klosterbauten, sondern der an der Flucht der Brüderstraße ausgerichteten, ältesten westlichen Klostermauer folgte. Vorbehaltlich der zutreffenden naturwissenschaftlichen Datierung der Gräber könnte also im letzten Viertel des 13. Jahrhunderts auch eine zum Friedhof gehörige, archäologisch jedoch nicht nachgewiesene Kirche der Dominikaner vermutet werden.

Der großzügige Komplex des Dominikanerklosters am Stadtrand von Cölln wurde zur Stadt hin von der bei den Ausgrabungen partiell erfassten Klostermauer nach Osten und Süden, von der städtischen Befestigung jedoch im Norden und Westen begrenzt (Abbildung 2). Gemäß der durch die Grabungsbefunde möglichen Rekonstruktion des Stadtmauerverlaufs nahm das Dominikanerkloster eine Fläche von circa 8.000 Quadratmetern ein. Wie sich das Klosterareal von der Ankunft der Mönche über den Abriss der Altbauten bis zum Baubeginn der endgültigen Häuser entwickelte, zeichnet sich im archäologischen Befund dagegen kaum ab. Sicher ist, dass von Anfang an Bestattungen erfolgten. Kirche, Klausurbauten und verschiedene Nutzbauten errichtete man nicht alle gleichzeitig. Wichtigstes und größtes Bauwerk war die nach dominikanischer Vorschrift turmlose Klosterkirche. ${ }^{16}$ Die dreischiffige Hallenkirche erreichte ein stattliches Maß mit einer Länge von circa 64 Metern und einer Breite von 18 Metern. Anders als bei den Pfarrkirchen - in Berlin Sankt Nikolai und Sankt Marien, in Cölln Sankt Petri - wies der Hohe Chor nicht genau nach Osten, sondern folgte der städtischen Straßenachse, die vom Oderberger Tor über die Lange Brücke (heute Rathausbrücke) auf das Cöllner Klosterareal zulief. Diese gewissermaßen profane Axialität der Kirche garantierte einerseits gute Sichtbarkeit, verkörperte andererseits aber auch im übertragenen Sinne die Hinwendung der Prediger zu den Bürgern der Doppelstadt. Die Positionierung der Cöllner Dominikanerkirche muss als ungewöhnlich prominent und auch bevorzugt bezeichnet werden. Nicht weit vom Kloster entfernt lag das gemeinsame Rathaus von Cölln und Berlin an oder auf der Langen Brücke. Zwischen Predigerkloster und Spree befanden sich im 15. Jahrhundert der Stadthof des eng mit den Askaniern verbundenen Zisterzienserklosters Lehnin, bürgerliche Wohnhäuser sowie direkt am Wasser die Cöllnische Badestube. Das mauerumsäumte Klosterareal der Dominikaner wurde von der beherrschenden Kirche ungleich geteilt: in eine stadtseitige und eine der Stadtmauer zugewandte Teilfläche. Auf der ,öffentlichkeitswirksamen' Stadtseite des Klosters erstreckte sich ein Friedhof, der aber auch

zember 2015 beprobte Knochenserie aus Cöllner Gräbern vom Petriplatz danke ich Claudia Maria Melisch ganz herzlich.

15 Die in einem Bericht vom 18. Dezember 2015 mitgeteilte Altersbestimmung wurde von der CEZ Archäometrie gGmbH in Mannheim von Dr. Ronny Friedrich und Susanne Lindauer M. Sc. ermittelt. Grab 96: Labornr. MAMS 25781, Probename 20 - 1685/647-Pr. 1, C14-Alter 748 plus/minus 24; Cal 1 sigma: cal AD 1260-1280; Cal 2 sigma: cal AD 1227-1284. Grab 635: Labornr. MAMS 25780, Probename 19 - 1685/5013-Pr. 1, C14-Alter 745 plus/minus 24; Cal 1 sigma: cal AD 1261-1280; Cal 2 sigma: cal AD 1227-1285.

16 Diese Vorschrift wurde in den dominikanischen Konstitutionen formuliert. Der diesbezügliche Passus mit deutscher Übersetzung bei Katja Hillebrand, Das Dominikanerkloster zu Prenzlau. Untersuchungen zur mittelalterlichen Baugeschichte, München/Berlin 2003, S. 159. 


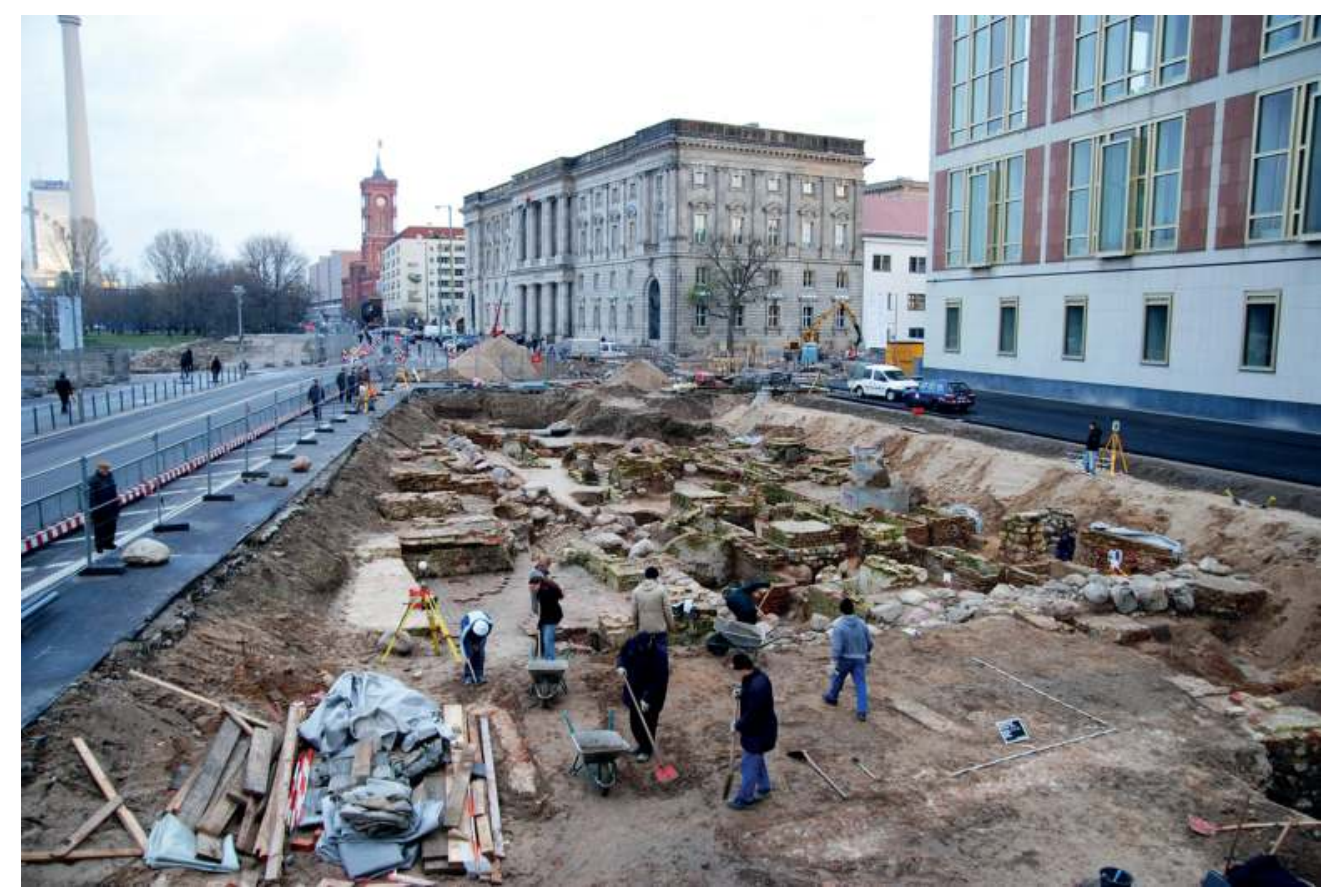

Abb. 3: Freigelegte Fundamente der Dominikanerklosterkirche und späteren Domkirche mit frühneuzeitlichen Grabkammern, Blick gegen Ost im Jahr 2008.

Schauplatz von Predigten im Freien gewesen sein dürfte. ${ }^{17}$ An der Südostfront der Kirche muss das Laienportal gelegen haben. An der ,stadtfernen', der Stadtmauer zugewandten Nordwestseite der Kirche befanden sich, vom städtischen Treiben abgeschirmt, die Klausurgebäude. Kirche und Klausur waren durch mehrere Pforten miteinander verbunden. Lang gestreckte Klausurflügel umschlossen den nahezu quadratischen Klausurhof mit einer Seitenlänge von knapp $20 \mathrm{Me}-$ tern. Den Hof umfasste ein in zwei Bauphasen gewachsener Kreuzgang. Zuerst entstanden der östliche und südliche Kreuzgang in reiner Backsteinbauweise; zu einem späteren Zeitpunkt wurden der westliche und nördliche Kreuzgang aus Mischmauerwerk errichtet. In den Kreuzgängen fanden unter anderem auch Lesungen und Versammlungen statt. Die jüngsten Ausgrabungen haben zahlreiche Bestattungen unter dem Backsteinpflaster des Kreuzgangs nachgewiesen. Der Ostflügel war der vornehmste Bereich der Klausur. In ihm befanden sich der repräsentative, für festliche Akte geeignete Kapitelsaal, daneben die Sakristei sowie der östliche Pfortenraum. Im Obergeschoss lag das Dormitorium. Der größer dimensionierte und unterkellerte Westflügel des Klosters, der ebenfalls eine Pforte besaß, nahm Vorratsräume sowie die Küche des Klosters auf. Im Keller des Westflügels konnte eine Steinkammerluftheizung nachgewiesen werden. Das zusammenhängende Brennkammer- und Kanalsystem des Westflügels durchzog im Kellergeschoss die gesamte Breite des Gebäudes. Die zehn Meter lange Anlage besaß einen direkten Zugang zur

17 Roland Pieper, Die Kirchen der Bettelorden in Westfalen. Baukunst im Spannungsfeld zwischen Landespolitik, Stadt und Orden im 13. und frühen 14. Jahrhundert (Franziskanische Forschungen, Bd. 39), Werl 1993, S. 216 und $264 \mathrm{f}$. 
Brennkammer von Westen her. Ein langer Heizkanal erstreckte sich von dort bis an die östliche Mauerkante des Westflügels, wo der Entrauchungskamin in die Außenwand integriert worden war. Reste von Fußböden, in denen die Heißluftkanäle endeten, hatten sich nicht erhalten. Im Nordflügel des Klosters, der vom späteren Barockschloss zum Teil überlagert wurde, sind im Erdgeschoss Refektorien und im Obergeschoss eine Bibliothek zu vermuten. ${ }^{18}$ Sein teilweise erhaltener, in das Archäologische Fenster des Humboldt Forums integrierter Keller diente ursprünglich als Lagerraum. Dort wurde nachträglich eine Steinkammerluftheizung eingebaut. Nördlich der Klausurgebäude mögen sich weitere Nutzbauten befunden haben, die jedoch der barocke Schlossbau des frühen 18. Jahrhunderts restlos beseitigte.

Der Klostergarten reichte - betrachtet man vergleichend das Brandenburger Dominikanerkloster - bis an die Stadtmauer. Der Nachweis eines in diesem Bereich angelegten Holzkastenbrunnens unterstützt die Annahme, dass die Wasserversorgung des Klosters dadurch unterstützt wurde. Der Entsorgung von Abwasser und Fäkalien diente sicher der wasserführende Stadtgraben jenseits der Stadtmauer. Bauliche Analogien sprechen dafür, dass zeitgleich mit dem Kloster die steinerne Cöllner Stadtmauer errichtet wurde - im Bereich des Klosters vielleicht durch die Mönche selbst. ${ }^{19}$

Die an die Nordseite der Kirche angelehnten Klausurgebäude folgen dem weithin gültigen Muster von Bettelordensanlagen, die Kirche mit Bezug auf das städtische Zentrum mit seinen Straßenachsen und die Klausur zur Stadtmauer hin zu platzieren. ${ }^{20}$ Die maximale ost-westliche Ausdehnung der Kirche im zur Verfügung stehenden Raum, ihre explizite Orientierung auf die Straßenachse zur Langen Brücke, die Platzierung des für Bestattungen und Predigten unter freiem Himmel geeigneten vorderen Kirchhofs zur südlichen Cöllner Stadtseite sowie die Hinwendung der Klausurbauten zur nahen Stadtmauer folgen der Idee einer selbst- und sendungsbewussten Einpassung der Konventsbauten in den „städtischen Organismus“ ${ }^{21}$

Die räumliche Gestalt der Klosterkirche folgt dem im ausgehenden 13. bis in das 14. Jahrhundert hinein weit verbreiteten Typus der dreischiffigen Hallenkirchen mit oktogonen Stützpfeilern und einschiffigem Chor mit Fünf-Achtel-Schluss in der Breite des Mittelschiffs. ${ }^{22}$ Ein Strebepfeilerkranz am Chor sowie Wandvorlagen und Strebepfeiler an verschiedenen Stellen des Cöllner

18 Die Annahme ergibt sich im Analogieschluss aus der Betrachtung der Baugestalt der Klosteranlagen: Marcus Cante, Bettelordensklöster in der Mark Brandenburg, in: Brandenburgische Denkmalpflege 14/2 (2005), S. 36-39.

19 Diese Annahme beruht auf der ungefähr gleichzeitigen Errichtung von Stadtbefestigungen und Konventen, die Achim Todenhöfer für eine Reihe von mitteldeutschen Städten aufgezeigt hat: Achim Todenhöfer, Kirchen der Bettelorden. Die Baukunst der Dominikaner und Franziskaner in Sachsen-Anhalt, Berlin 2010, S. 318.

20 Zur Stadtlage von Bettelordensklöstern allgemein s. Achim Todenhöfer, ebd., S. 315-319.

21 Pieper, Die Kirchen der Bettelorden in Westfalen, S. 263 f. Die von Roland Pieper für Westfalen erarbeiteten Kriterien für die Platzierung von Bettelordenskirchen im Gefüge der Stadt ist weitgehend auch auf das Cöllner Dominikanerkloster zu übertragen. Als Besonderheit der westfälischen Dominikanerkirchen nennt er ihre Lage „am Rande städtischer Adelshofgebiete, wobei die Klöster zu den Adelshöfen hin orientiert sind“ (ebd., S. 264). Die Nähe eines städtischen Hofes des Klosters Lehnin zum Dominikanerkloster Cölln lässt die Vermutung zu, dass die Askanier möglicherweise direkt in der Nachbarschaft ein Areal nutzten, das schon im 13. Jahrhundert dem Lehniner Kloster überlassen worden war. Es besteht also auch die Möglichkeit, dass die Dominikaner in ,adliger Nachbarschaft' platziert wurden.

22 Vgl. Ernst Badstübner, Stadtkirchen der Mark Brandenburg, Berlin 1982. 
Langhauses sind als sichere Hinweise auf eine Einwölbung anzusehen. In der bezeichneten Gestaltung findet die Cöllner Klosterkirche ihre nächste Parallele in der zeitlich vorangehenden, ein Joch kürzeren Prenzlauer Dominikanerkirche. Katja Hillebrand geht, ohne sich explizit festlegen zu wollen, von einem Baubeginn der Prenzlauer Kirche um das Jahr 1275 aus. ${ }^{23}$ Jenseits der Mark Brandenburg frappiert die vollständige Übereinstimmung des Cöllner Grundrisskonzepts mit demjenigen der ein Joch längeren Hallenser Dominikanerkirche, die - Achim Todenhöfer folgend - bald nach dem Jahr 1271 errichtet wurde. ${ }^{24}$ Die Klausur der Cöllner Dominikaner lehnte sich an die Nordseite der Kirche. Mit dieser Anordnung unterscheidet sie sich von den südlich an die Klosterkirchen stoßenden Klausurgebäuden der Prenzlauer und Brandenburger Dominikanerkonvente. Lagebestimmend war jedoch für Cölln - wie bei allen Bettelordensklöstern nahe der Stadtmauer - ausschließlich die Orientierung der Klosterkirche zum Stadtzentrum, die automatisch eine Abschirmung der Mönche im Schutz von Kirchenlanghaus und Stadtmauer mit sich brachte. ${ }^{25}$ Beim Cöllner Kloster korrespondiert der großzügig bemessene westliche Kreuzgang mit einem sehr breiten Westflügel, wohingegen der viel schmalere östliche Klausurflügel von einem Kreuzgang mit minimaler lichter Weite begleitet wird. Erst im Jahr 1443 bekamen die Prediger mit den Hohenzollern prominente Nachbarn, deren neue Residenz in Cölln an der Spree 1451 fertiggestellt war.

\section{Sitz des Niederstiftes Sankt Erasmus (1536 bis 1608)}

Der Verbundenheit von Hohenzollern und Dominikanern ${ }^{26}$ zum Trotz betrieb Kurfürst Joachim II. die im Jahr 1536 vollzogene Auflösung des Dominikanerklosters, also bereits drei Jahre vor der Reformation in Brandenburg. Die Gebäude fielen an das bis dahin im Schloss ansässige Niederstift Sankt Erasmus. Die Klosterkirche wurde unverzüglich unter hohem Aufwand zur Stifts- beziehungsweise Hofkirche der Hohenzollern mit Erbbegräbnis umgebaut. Damit hatte sich der Schlossbezirk um das ehemalige Klostergelände erheblich erweitert. Nach fast zweieinhalb Jahrhunderten endete dominikanisches Klosterleben in Cölln.

Die feierliche Einweihung der Stiftskirche am Fest des Heiligen Erasmus am Freitag vor Pfingsten des Jahres 1536 fand kurz nach der offiziellen Auflösung des Klosters statt. Zu Schutzheiligen des Stifts wurden neben Sankt Erasmus auch die Heilige Jungfrau Maria, Sankt Peter und Paul, Sankt Nikolaus und das Heilige Kreuz erhoben. Es kann keinen Zweifel daran geben, dass der Umzug des Domstifts in die alte Klosterkirche mit den Neubauplänen Joachims II. für das Schloss zu

23 Hillebrand, Das Dominikanerkloster zu Prenzlau, S. 154-158.

24 Todenhöfer, Kirchen der Bettelorden, S. 81-91, 328.

25 Katja Hillebrand führt die Nordlage der Cöllner Klausur auf Zwänge zurück, die sich aus bereits bebautem Terrain ergaben, obwohl auch sie die Priorität der Kirchenausrichtung nennt. Gemäß den Ergebnissen der jüngsten Ausgrabungen spricht jedoch davon abweichend alles dafür, dass die vorhandene Quartiersbebauung vollständig abgeräumt wurde und für die Anordnung der Klausur nur die Stadtlage entscheidend war (s. Hillebrand, Das Dominikanerkloster zu Prenzlau, S. 206).

26 Michael de Nève kennzeichnet das Verhältnis als symbiotische Nähe: siehe ders. mit Cante/Wittkopp, BerlinCölln Dominikaner, S. 161. 


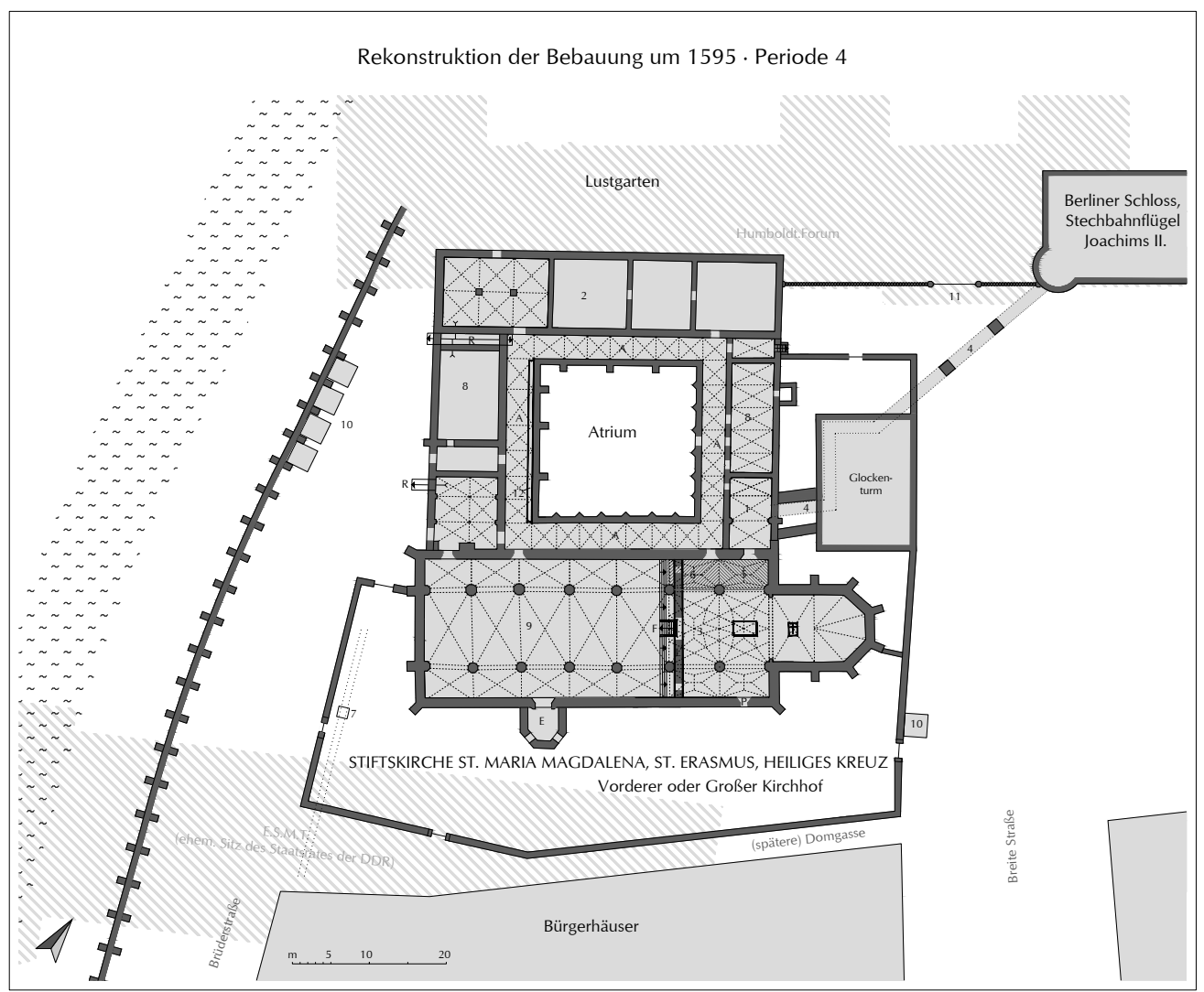

Abb. 4: Rekonstruktion der Bebauung des Dominikanerklosterareals um 1595. Nr. 4 ist der hölzerne Gang.

sammenhing. ${ }^{27}$ Durch den Neubau des Stechbahnflügels und die später angegangene Errichtung des Spreeflügels a primis fundamenti ${ }^{28}$ konnte der junge Kurfürst die gewachsene politische Bedeutung der Hohenzollern im Reich jedermann sichtbar vor Augen führen. ${ }^{29}$ Wohl schon im Jahr 1538 begann der Bau des Stechbahnflügels, dessen Ausstattung im Jahr 1540 vom polnischen Bischof Gorka lobend erwähnt wurde. ${ }^{30}$ Von der südwestlichen Ecke dieses Neubaus wurde ein hölzerner Verbindungsgang über den von Joachim II. errichteten mächtigen Glockenturm und den ehemaligen östlichen Klausurflügel zur kurfürstlichen Loge in der Hofkirche geführt (Abbildung 4). ${ }^{31}$ Die archäologisch untersuchten Relikte des Glockenturms und seiner Baugrube stüt-

27 Albert Geyer, Die Geschichte des Schlosses zu Berlin, Bd. 1: Die kurfürstliche Zeit bis zum Jahre 1698, T. 1 [Text], Berlin 1936, S. 22 f.

28 Ebd., S. 22.

29 Liselotte Wiesinger, Das Berliner Schloß. Von der kurfürstlichen Residenz zum Königsschloß, Darmstadt 1989, S. $29-48$.

30 Geyer, Die Geschichte des Schlosses, Bd. 1, T. 1 [Text], S. 22 f.

31 Ebd., S. $31 \mathrm{f}$. 
zen die Datierung des Turmes in das 16. Jahrhundert. Die offizielle Auflösung des Stifts besiegelte Kurfürst Joachim Friedrich nur 72 Jahre später am 25. Mai 1608. Die vergleichsweise kurzlebige landesherrliche Stiftung endete damit kurz vor der ,zweiten' Reformation, der Übernahme des reformierten Bekenntnisses durch die Hohenzollern.

\section{Vom Bau des Altangebäudes bis zur Entstehung des Eosanderflügels (1608 bis 1706)}

Die offizielle Auflösung des Kollegiatstifts im Jahr 1608 machte den Weg frei für die Neustrukturierung des Baukomplexes nördlich der Domkirche. Bis zum Baubeginn des Eosanderflügels im Jahr 1706, dessen Fertigstellung zehn Jahre später zum Abbruch aller Bauten des Untersuchungsgebietes bis auf die Kirche führen sollte, konnte der immer wieder für neue Nutzungen erschlossene Komplex noch in das zunehmend vom Schloss geprägte Gefüge integriert werden. Im Jahr 1613 trat Kurfürst Johann Sigismund, in dessen Regierungszeit die prachtvolle Kirche ihrer Ausstattung beraubt wurde, ${ }^{32}$ zum Calvinismus über. Dieser Schritt bedeutete das jähe Ende der von Joachim I. noch intensiv und von seinen Nachfolgern immer weniger geförderten katholischen Traditionen. So wird vom Markgrafen Johann Georg als Statthalter des abwesenden Kurfürsten Johann Sigismund berichtet, dass er noch im März des Jahres 1615 das große holzerne crucifix, so in dom vorm chor auf das eiserne gitter ist geheftet gewesen, haben abbrechen, zerschlagen und stuckweiß in die Sprew werfen lassen. ${ }^{33}$

Die Baumaßnahmen des Kurfürsten Joachim Friedrich zur Erweiterung und Neugestaltung des Großen Schlosshofes ab dem Jahr 1606 hatten maßgeblichen Einfluss auf die Umgestaltung des ehemaligen Klausurbereiches. Der Kurfürst ließ eine neue, diesmal steinerne Direktverbindung des Gotteshauses mit dem Schlosskomplex in Form einer Verlängerung des Altans oder Hochgangs um den neuen äußeren Schlosshof bauen. ${ }^{34}$ Der ehemalige Nordflügel des Klosters wurde somit in die Einfassung des Großen Schlosshofs einbezogen und trennte Schlosshof und Kleinen Kirchhof. Der gesamte westliche Klausurflügel wurde abgerissen und durch einen schlankeren Altanbau ersetzt, der an der Nordwand der Domkirche ansetzte und zur dortigen kurfürstlichen Loge führte. Sowohl der Bereich des ehemaligen Klausurhofes und Kreuzganges - nun Kleiner Kirchhof genannt - als auch der vordere Kirchhof südlich der Kirche nahmen weiterhin Bestattungen auf. Der Kunstagent Philipp Hainhofer erwähnt in seinem Bericht aus dem Jahr 1617 ein Gebäude, das nur als der ehemalige Nordflügel des Klosters identifiziert werden kann: An dieser Kürchen [der Domkirche] ware ein Kloster, da jetzo das Consistorium und Kammergericht ist, welcher Ort auf den ersten Platz des Schlosses stehet. Dieser Platz auf zwei Seiten gar lange Altanen, zwei Gaden hoch, hat, auf deren obristen Gaden man in die Kürchen gehet. ${ }^{35}$ Dieses ehemalige ,Lange Haus', das im 16. Jahrhundert vom Markgrafen und späteren Kurfürsten Johann Georg bewohnt

32 Philipp Hainhofers Reise-Tagebuch, enthaltend Schilderungen aus Franken, Sachsen, der Mark Brandenburg und Pommern im Jahr 1617, in: Baltische Studien 2 (1834), S. 13.

33 Andreas Tacke, Der Reliquienschatz der Berlin-Cöllner Stiftskirche des Kurfürsten Joachim II. von Brandenburg, in: Jahrbuch für Berlin-Brandenburgische Kirchengeschichte 57 (1989), S. 125-236, bes. S. 153 nach einem im Jahr 1897 publizierten Manuskript in dem Gräflich Dohnaschen Archiv zu Schlobitten in Ostpreußen.

34 Geyer, Die Geschichte des Schlosses, Bd. 1, T. 1 [Text], S. 49-53.

35 Philipp Hainhofers Reise-Tagebuch, S. 14. 
worden war, muss also zur Zeit Hainhofers von zwei kurfürstlichen Institutionen genutzt worden sein. In der Regierungszeit des Großen Kurfürsten wurde in den späten 1660er-Jahren zwei Joche östlich der Eingangshalle an der Südseite der Domkirche ein Treppenturm angebaut, der bis zum Dach aufragte (Abbildung 5). Die Wandlung des ehemaligen Klausurhofs und späteren Atriums zum Kleinen Kirchhof sprengte das alte Klostergefüge im frühen 17. Jahrhundert endgültig. Damit wurden zwei konstituierende Elemente des Klosters beseitigt: der Kreuzgang als Verbindungsscharnier aller Trakte und der geschlossene, nahezu quadratische Klausurhof. Als Hauptursache für die weitgehende Beseitigung der überwölbten Kreuzgangarme, den Abriss des Westflügels und den Bau des Altangebäudes als neuer westlicher Hofabschluss kann ohne Weiteres die Erweiterung der Friedhofsflächen angesehen werden. Die frühesten Grabbauten an der Stelle der ehemaligen Kreuzgangarme sind in den zwanziger Jahren des 17. Jahrhunderts entstanden; bei diesen frühen Anlagen verzichtete man auf eine unterirdische Grabkammer. Im Laufe des Jahrhunderts reihten sich zahlreiche weitere, archäologisch nachgewiesene Grabbauten an den Begrenzungsmauern des Kleinen Kirchhofs, teilweise auf alten Klostermauern gründend.

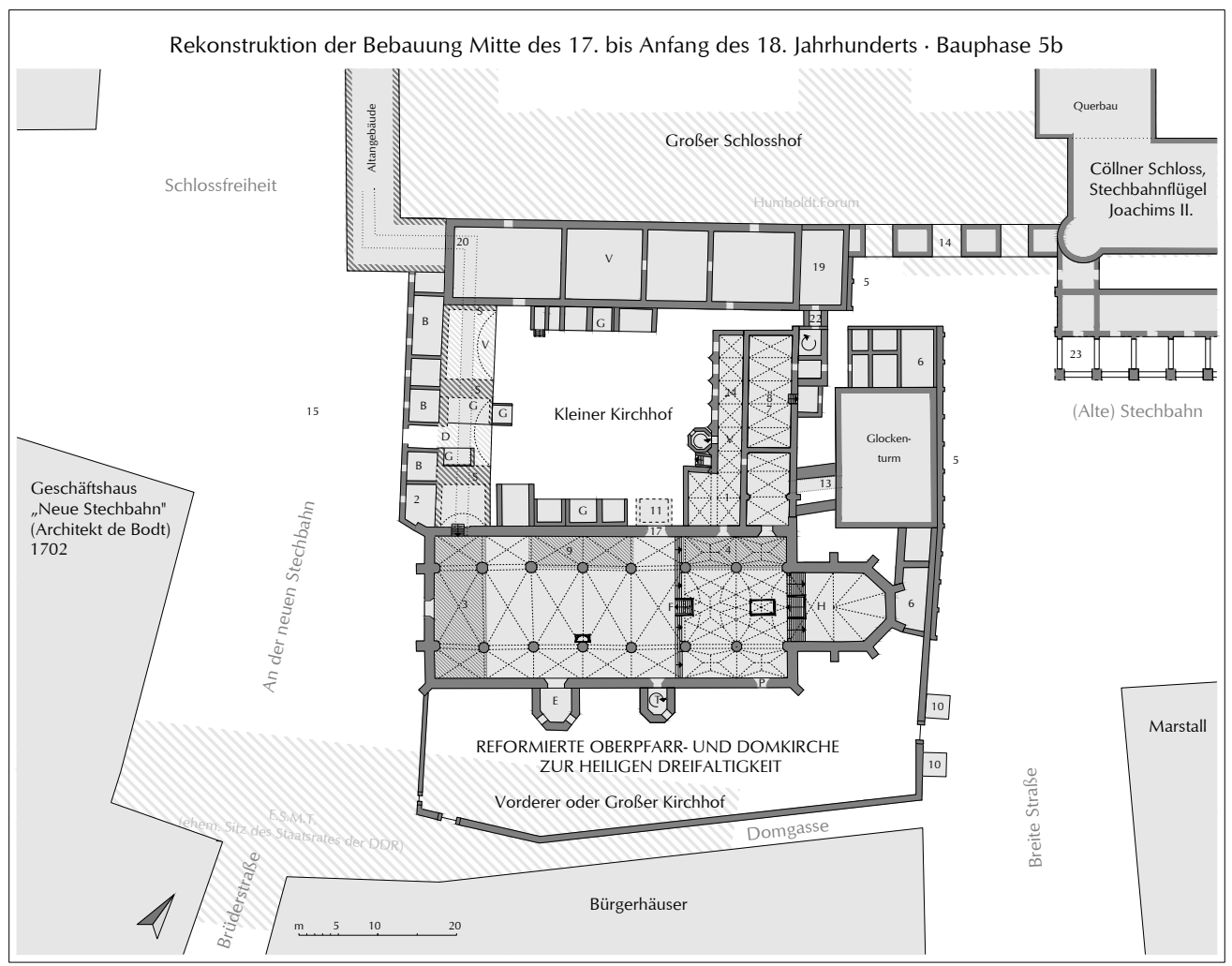

Abb. 5: Rekonstruktion der Bebauung des Dominikanerklosterareals

von der Mitte des 17. bis Anfang des 18. Jahrhunderts. G=Grabkammern, B=Boutiquen oder Kaufläden. 
Ende des 17. Jahrhunderts entstanden im Umfeld des Schlosses verschiedene Kaufladenzeilen oder Boutiquen. Dazu gehörten unter anderem die von Nehring 1679 erbauten Kaufläden an der Stechbahn, dem Glockenturm vorgeblendete Läden sowie nach 1688 schließlich ,französische Boutiquen' an der Westseite des Altangebäudes, die fortan die Durchfahrt zum Kleinen Kirchhof säumten. Mit ihnen erhielt der Komplex aus Domkirche und dazugehörigen Friedhofsflächen einen profanen Rahmen, der bis zum Jahr 1716 bestehen blieb.

\section{Vom Bau des Eosanderflügels bis zum Abriss der Domkirche (1706 bis 1747)}

Der Zeitraum zwischen 1706 (Baubeginn des Eosanderflügels) und 1718 (Abschluss der Ertüchtigung der Domkirche) brachte die Schließung des Friedhofs und den Abriss sämtlicher Gebäude bis auf die Domkirche im Jahr 1716 mit sich. Nach dem Abriss der angrenzenden Gebäude kam es zum Umbau und zur Ertüchtigung der Domkirche, der wieder zwei Türme über der Westfassade aufgesetzt wurden. ${ }^{36}$ Archäologisch deutlich zu fassen waren die Schuttverfüllungen der in Einzelfällen noch mit Bestattungen belegten Grabkammern und der Boutiquenkeller sowie Reste des Glockenturmfundaments, die von der neuen Pflasterung des Schlossplatzes um die Kirche herum überlagert wurden.

Der seit dem Ende des 17. Jahrhunderts im großen Stil vorangetriebene Residenzumbau ${ }^{37}$ zer- $^{-}$ störte den im Laufe der Jahrhunderte vielfach modifizierten physischen Verband von Kirche, Klausurbauten und Schlossbezirk. Die Schließung des Friedhofs wurde mit der allmählichen Verlegung der Gemeinde und ihrer Bestattungen an die um 1700 erbaute Parochialkirche in Berlin als neue Pfarrkirche der Reformierten eingeleitet. Mit der Fertigstellung des Schlossplatzflügels der Residenz zehn Jahre später ging der Abbruch aller Bauten des ehemaligen Klosterareals bis auf die Kirche einher. Die freigestellte Domkirche befand sich 1716 nicht nur altersbedingt, sondern auch durch die Abrissarbeiten in einem schlechten Zustand. Die Ertüchtigung der Kirche durch den Architekten Martin Heinrich Böhme schloss auch zwei neue Kirchtürme ein, die Ende des 17. Jahrhunderts abgerissen worden waren. Nach Abschluss dieser Arbeiten ließ König Friedrich Wilhelm I. die einzige überlieferte Bauinschrift der Kirche am Chor-Gewölbe anbringen: D. O. M. S. Hanc aedem Cathedr. Prisca relig. Sacram, pietate \& sepultura majorum illustrem Fridericus Wilhelmus, Rex Borussiae, Elect.Brand.Re-Novavit, \& duobus campanariis Instruxit M. D. C. C. XVIII. ${ }^{38}$ Bis zu ihrem Abriss im Jahr 1747 auf Geheiß von Friedrich II. stand die freistehende

36 Geyer, Die Geschichte des Schlosses, Bd. 1, T. 1 [Text], S. 21.

37 Guido Hinterkeuser, Das Berliner Schloss. Der Umbau durch Andreas Schlüter, Berlin 2003, S. 95-256; Albert Geyer, Die Geschichte des Schlosses zu Berlin, Bd. 2: Vom Königsschloß zum Schloß des Kaisers (1698-1918), bearb. von Sepp-Gustav Gröschel. Aus dem Nachlaß herausgegeben, T. 1 [Text], ND Berlin 2010, S. 1-34.

38 Johann Christoph Müller/Georg Gottfried Küster, Altes und Neues Berlin. Das ist: Vollständige Nachricht von der Stadt Berlin, derselben Erbauern, Lage, Kirchen, Gymnasiis; ingleichen von den Königlichen, und andern öffentlichen Gebäuden; dem Rath-Hause, dessen, und der Bürgerschaft Gütern, Vorrechten, Privilegiis und andern das Policey- und Stadt-Wesen betreffenden Sachen; Wobey dasjenige, so in Krieges- und Friedenszeiten von Anno 1106 biß itzo in hiesigen Residentzien merckwürdiges vorgegangen, aus Diplomatibus, guten und zuverläBigen, theils auch archivischen Nachrichten und den besten Auctoribus erzehlet wird; In fünff Theile verfasset, mit Kupffern gezieret, und nöthigen Registern versehen, Bd. 1, Berlin 1737, S. 51. 
Domkirche in circa 33 Meter Abstand zur Schlossplatzfassade der neuen Residenz gegenüber. Nach der 1749 erfolgten Überführung der Hohenzollerngräber in den neuen Dom im Lustgarten wurde das Pflaster des Schlossplatzes fortan auch über die Fundamente der ehemaligen Dominikanerklosterkirche hinweg verlegt.

\section{Perspektiven für das Franziskanerkloster}

Die komplexe Baugeschichte des Dominikanerklosterareals und die vielfältige Nutzung der Baulichkeiten aus fünf Jahrhunderten konnten mithilfe der archäologischen Ausgrabungen des Landesdenkmalamtes Berlin nachvollzogen werden. Durch den Bau des Humboldt Forums mit den eindrucksvollen Fassaden der barocken Residenz ist auch der historische Schlossplatz wiedererstanden. Äußerlich haben sich hier keine Relikte erhalten, die an die Existenz eines Dominikanerklosters an dieser Stelle erinnern würden. Dagegen konnten im begehbaren Keller des in seiner historischen Bausubstanz teilweise erhaltenen Eosanderflügels Mauern des Dominikanerklosters bewahrt werden (Abbildung 6). Sie gehören zu einem ehemals überwölbten Lagerkeller, in den eine Steinkammerluftheizung eingebaut worden war. Die klösterlichen Relikte erinnern unter anderem daran, dass sich an der Stelle beziehungsweise neben dem späteren Schloss ein Konvent nahe der mittelalterlichen Stadtmauer befand, dessen Bauten über Jahrhunderte neben der Residenz aufgeragt hatten.

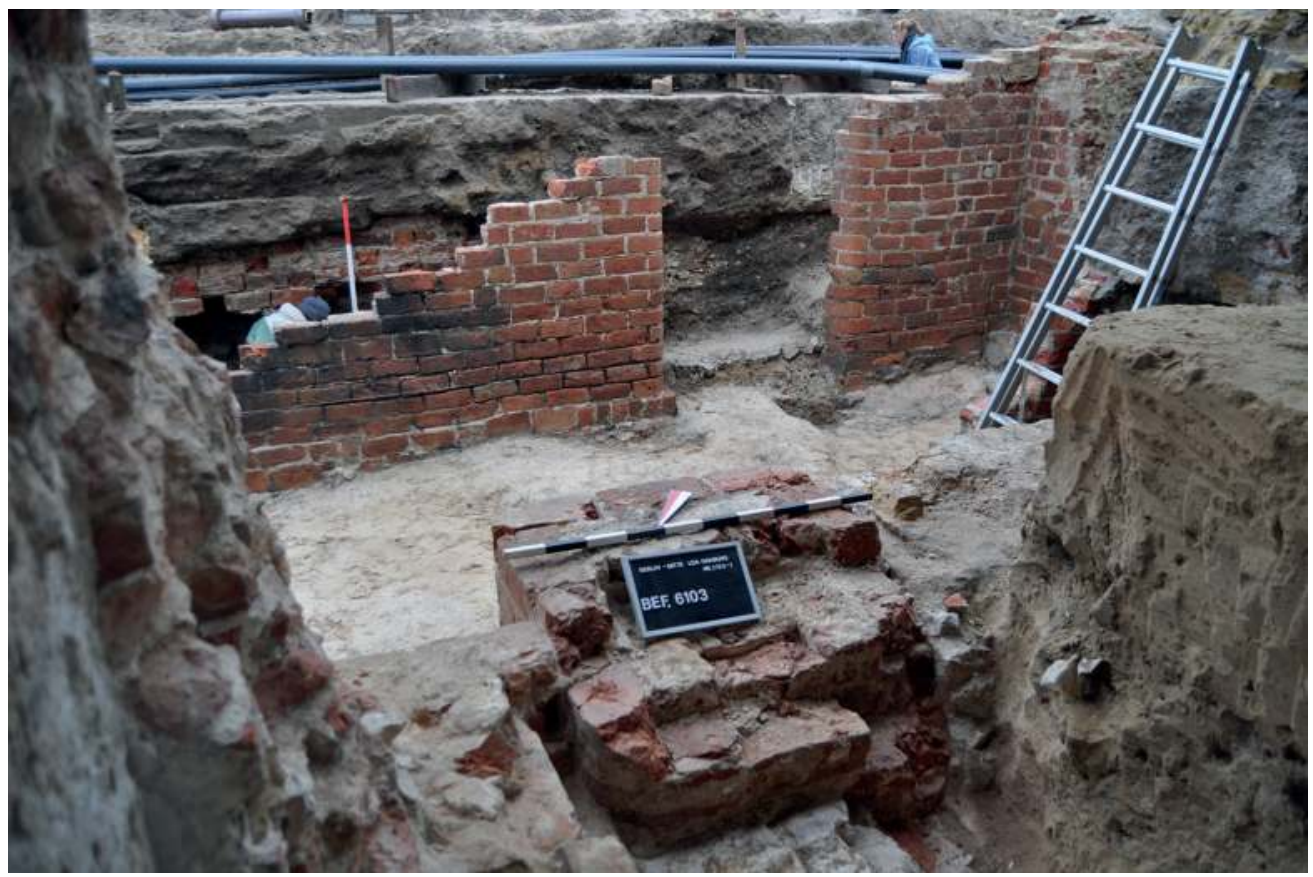

Abb. 6: Pfeiler und Mauern eines Kellerraums des 14. Jahrhunderts

im Nordflügel des Dominikanerklosters, heute integriert in den historischen Keller des Eosanderflügels im Humboldt Forum. 
Die in das Humboldt Forum, das als kultureller Leuchtturm bezeichnet werden kann, integrierten Relikte des Dominikanerklosters mögen als erfolgreiches Exempel dafür gelten, wie Geschichte anschaulich präsentiert werden kann. Warum sollte dies nicht auch für noch unter dem Erdboden schlummernde Bauglieder des Franziskanerklosters im Bereich der Klausurbauten möglich sein?

Bei einer archäologischen Ausgrabung freigelegte und dann dauerhaft gesicherte und erlebbare Bauzeugnisse des Franziskanerklosters würden die bislang isoliert stehende Klosterkirchenruine besser in der Topografie des ursprünglichen Klosterkomplexes verankern. In der Nachbarschaft moderner Großbauten würde die ,Geschichtsinsel' authentischer Klosterbauten so vergrößert und die Besonderheit dieses Ortes im Stadtbild durch originale Zeugnisse besser herausgehoben werden. Einer im Mittelalter gegründeten Metropole wie Berlin stünde es gut zu Gesicht, diesen bislang von Verkehrswegen überlagerten historischen Schatz ans Tageslicht zu heben und seine ältere Geschichte deutlicher im Stadtbild zu verankern. Die geplante Schaffung eines ,archäologischen Pfades', der verschiedene Geschichtsorte der Doppelstadt Berlin-Cölln miteinander verbinden soll, könnte die Einbindung dieses Ortes in die mittelalterliche Stadt und Gesellschaft vermitteln helfen. So wie der inzwischen fertig gestellte archäologische Keller im Humboldt Forum, die historischen Relikte im Archäologischen Haus am Petriplatz (im Bau) und der geplante archäologische Keller im mittelalterlichen Rathaus Berlins würde auch das Graue Kloster damit einen archäologisch erschlossenen Bezugspunkt erhalten. Gerade die beiden Klöster - Dominikanerkloster in Cölln einerseits und das Franziskanerkloster in Berlin andererseits - könnten sich mit ihren archäologischen Fenstern sehr gut dazu eignen, um zum Beispiel die Selbstständigkeit der jeweiligen Schwesterstädte vor Augen zu führen und die nachfolgende Nutzung der Baulichkeiten zu veranschaulichen. Hier wie dort könnten originale Relikte eindrucksvoll mit moderner Architektur kontrastieren.

Noch ist nicht klar, wie das heute noch von der Grunerstraße bedrängte und überlagerte Areal des ehemaligen Franziskanerklosters bebaut werden wird. Es zeichnet sich ab, dass auch hier Neubauten entstehen werden. Wenn diese Neubauten freigelegte und langfristig gesicherte Relikte des Franziskanerklosters berücksichtigten und vielleicht sogar integrierten, gewänne das Areal um die Ruine der Klosterkirche einen weiteren Ankerpunkt Berliner Geschichte. 


\section{Peter Lemburg}

\section{Das Graue Kloster und der Backsteinforscher Friedrich Adler}

Die Spuren des weit über die Baugeschichte hinaus bedeutenden Berliner Franziskanerklosters sind bis auf die eindrucksvolle Ruine seiner Kirche aus dem Stadtbild verschwunden. ${ }^{1}$ Mit seinen ausgedehnten Baulichkeiten war das Graue Kloster mit dem Hohen Haus der Markgrafen verflochten und die Position der Klosterkirche hart an der noch in bescheidenen Resten erhaltenen mittelalterlichen Stadtmauer ist ein weiteres Faktum von Bedeutung.

Die nachreformatorische Profanierung, Teilabrisse, Umnutzungen - letztendlich auch seine durchgreifende Umgestaltung zum Gymnasium lenkten das Interesse der Stadt- und Bauforschung lediglich auf den noch seinen ursprünglichen Charakter ausstrahlenden Kirchenbau. Den Sanierungs- und Umbauten der 1840er-Jahre auf Veranlassung Friedrich Wilhelm IV. gingen keine Bauforschungen zum Kloster voraus und selbst der zeitweilig mit den Arbeiten betraute vielseitig verdiente Ferdinand von Quast beschäftigte sich wissenschaftlich nur mit der Klosterkirche. Der subaltern eingebundene Theodor August Stein war dagegen auch mit kleineren Sanierungen an den Klosterbauten beschäftigt, doch ist wenig über den Umfang seiner Arbeiten bekannt. Auch der Bauforscher, Architekt und Kunsthistoriker Friedrich Adler (1828-1908), mit dem in den mittleren 1850er-Jahren erst die vertiefende Beschäftigung mit dem mittelalterlichen Baubestand Berlins begann, umging die Konventsbauten weitestgehend. Ihrer Klosterkirche räumte er dagegen einen hohen Rang im Gesamtkontext der Berlin-märkischen Backsteingotik ein.

Friedrich Adler galt seit Anbeginn seines Forscherlebens als der Spezialist des nordalpinen, somit auch des märkischen Backsteinbaus. Die Grundlage zu der bis heute andauernden Wertschätzung schuf sein Basiswerk, Mittelalterliche Backstein-Bauwerke des Preussischen Staates.2 1859 in ersten Teilen ediert, machte es den noch jungen Autor rasch über die Fachkreise hinaus bekannt. Als erst 24-Jähriger war er vom Fachverlag Ernst \& Sohn mit der großangelegten Arbeit betraut worden. Was befähigte einen gerade examinierten, zuvor noch nicht mit größeren publizistischen Arbeiten hervorgetretenen ,Königlichen Regierungsbaumeister' zu einem solch komplexen Unternehmen? Eine der Antworten lieferte seine bereits intensive Präsenz im einflussreichen Berliner Architektenverein, einem Nukleus für alle Fragestellungen des Bauens, Entwerfens, Konstruierens wie auch der Bauforschung, Architektur- und Kunstgeschichte. In der heute noch wirksamen Vereinigung konnte Friedrich Adler schon früh seine vielseitigen Veranlagungen unter Beweis stellen. ${ }^{3}$

1 Landesdenkmalamt Berlin (Hrsg.), Kirchenruine des Grauen Klosters in Berlin. Geschichte - Forschung - Restaurierung (Beiträge zur Denkmalpflege in Berlin, Bd. 23), Petersberg 2007. Dort die einschlägige Literatur zu Kloster und Kirche. Siehe ferner Peter Lemburg, Friedrich Adlers märkische Forschungen, in: Jahrbuch für brandenburgische Landesgeschichte 70 (2019), S. 169-187.

2 Friedrich Adler, Mittelalterliche Backstein-Bauwerke des Preussischen Staates, Bd. 1, Berlin 1862; Bd. 2, Berlin 1898.

31852 hatte er den erstmalig ausgetragenen,Schinkelwettbewerb' gewonnen, war Assistent Ferdinand von Arnims an der Bauakademie. Vgl. Peter Lemburg, Leben und Werk des gelehrten Architekten Friedrich Adler, Diss. phil. Freie Universität Berlin 1988; zuletzt ders., Johannes Heinrich Friedrich Adler, in: Jessica Hänsel u.a. (Hrsg.), Baumeister - Ingenieure - Gartenarchitekten (Berlinische Lebensbilder, Bd. 11), Berlin 2016, S. 119-138. 


\section{MITTELALTERLICHE \\ BACKSTEIN-BAU WERKE}

DES

\section{PREUSSISCHEN STAATES.}

GESAMMELT UND HERAUSGEGEBEN

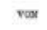

F. ADLER

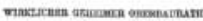

BAND II.

DIE MARK BRANDENBURG.

III. DIE PRIEGNITZ
IV. DIE MITTELMARK.
V. DIE UKERMARK.
VI. DIE NEUMARK.

MIT SIKBENZIG TAFELN.

BERLIN.

VERLAG VON WILHELM ERNST \& SOHN.

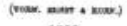

1898.

Seine kunstwissenschaftliche Förderung erhielt er vornehmlich durch den Bauakademieprofessor Karl Bötticher, die bauliche in den Ateliers der Schinkelerben Heinrich Strack und August Stüler. Bereits mit anspruchsvollen Arbeiten betraut, qualifizierte er sich vor allem unter Stüler schon zur eigenverantwortlichen Ausführung der in neugotischem Charakter konzipierten Bartholomäus-Kirche am Königstor. ${ }^{4}$ Darin bestärkt wurde Stüler möglicherweise durch einen Vor-

4 Für Strack war er als Bauleiter an der Berliner Petrikirche und am Schloss Babelsberg, für Stüler u. a. an der Innengestaltung des spätklassizistischen Neuen Museums eingesetzt. Friedrich Adler, Die Bartholomäuskirche zu 
trag Adlers vom August des Vorjahrs 1853. Erstmals hatte er sich nach einer Reihe von Beiträgen zur klassisch-antiken Baukunst der mittelalterlichen Backsteinthematik angenommen und über die Ordensburgen des nordöstlichen Preußen referiert. Er legte darin nicht nur deren Bedeutung für die mittelalterliche Backsteinarchitektur der baltischen Regionen dar, sondern widmete sich auch ihren,Wiederentdeckern' Friedrich Gilly und Karl Friedrich Schinkel. Zudem entspann sich eine enge kollegiale Freundschaft mit einem der wesentlichen Förderer der nachmaligen Marienburg-Wiederherstellungen und um die Berliner Franziskanerkirche verdienten Architekten und späteren Denkmalpfleger, Ferdinand von Quast. ${ }^{5}$

Getreu seinem später verlautbartem Credo wer Baudenkmäler lehren will, sei es schaffend induktiv, sei es forschend analytisch, muss sie gesehen haben, ${ }^{6}$ hatte Adler sich schon 1848 mit Aufnahme seines Bauakademie-Studiums auf Exkursionen begeben. Sie führten ihn über die märkische Umgebung hinaus auch in die Ostseeregionen mit ihren Backsteinkirchen und Klöstern. ${ }^{7}$ Julius Kohte fasste die sich also schon früh abzeichnende Vielseitigkeit Adlers 1909 in einer objektiven Analyse dessen Lebenswerks so zusammen: „Mag manches an den Forschungen Adlers als überholt gelten, so kann das seiner Bedeutung wenig Abbruch tun. Die Geschichte der Architektur ist zu einem weiten und so reich bestellten Felde geworden, daß es der Einzelne nicht mehr zu übersehen vermag. Aber unter den Männern, die das Ganze noch zu bestellen verstanden und die Jüngeren in die Arbeit unterwiesen, wird Friedrich Adler alle Zeiten an erster Stelle genannt werden." ${ }^{8}$ Und auf die Symbiose von Backsteinforschung und aktueller Architekturpraxis bezogen, hatte er schon ein Jahr zuvor verlauten lassen: „Wenn wir heute den Ziegelbau wieder beherrschen, so ist dies das Verdienst jenes umfangreichen Werkes“, ein Urteil, das explizit auf die ,Mittelalterlichen Backstein-Bauwerke des Preussischen Staates' seines Lehrers verwies. ${ }^{9}$

Diesem Werk lag also mit dem ersten Kirchenbau Adlers, Sankt Bartholomäus, eine reale Bauaufgabe zugrunde und die Verbindung von Forschen und Bauen sollte zu einem Wesensmerkmal dieses Architekten werden. ${ }^{10}$ Er stellte seine Ansprüche unter eine hohe Messlatte. Nicht nur die Beschreibung und stilistische Zuordnung des möglichst vollständig zu erfassenden Baubestan-

Berlin, in: Christliches Kunstblatt für Kirche, Schule und Haus 2 (1859), S. 81-87; Eva Börsch-Supan, Berliner Baukunst nach Schinkel. 1840-1870 (Studien zur Kunst des 19. Jahrhunderts, Bd. 25), München 1977, S. 165.

5 Ferdinand von Quast widmete sich der Marienburg gerade gutachterlich. Adler wurde später Ministerialkoordinator der dortigen Wiederherstellungen durch seinen Schüler Konrad Steinbrecht. Friedrich Adler, Friedrich Gilly - Schinkels Lehrer, in: Centralblatt der Bauverwaltung 1 (1881), S. 8-10, 17-19.

6 So Adler 1885 in seiner Dankesrede zur Feier seines 30. Professoren-Jubiläums an der Technischen Hochschule Charlottenburg. Handschriftliches Manuskript, Privatbesitz.

7 Am Ende seines Lebens hatte er Skandinavien ebenso wie Ägypten und Palästina bereist - und das jeweils vor dem Hintergrund, das Gesehene nicht nur für seine fünf Jahrzehnte umfassenden Lehrtätigkeiten auszuschöpfen, sondern in Schriften und Abhandlungen der Fachöffentlichkeit zur Diskussion zu stellen.

8 Julius Kohte, Friedrich Adler und seine Bedeutung für die Geschichte der Architektur, in: Zeitschrift für die Geschichte der Architektur 2 (1909), S. 220.

9 Ders., Zum 80 Geburtstag Friedrich Adlers, in: Wochenschrift des Architektenverein 3 (1907), S. 201.

10 Ein halbes Jahrhundert später schrieb er rückblickend auf seinen Erstling: Es drängte mich den Formenschatz und das Structursystem dieser heimischen Bauweise nicht nur für mich kennen zu lernen, sondern auch für die Praxis nutzbar zu machen, Adler, Mittelalterliche Backstein-Bauwerke, Bd. 1, Vorwort [o.S.]. Ein schlagendes Beispiel dafür lieferte Adler selbst mit seiner 1862 entworfenen Christuskirche an der Königgrätzer Straße. Siehe ders., ChristusKirche in Berlin, in: Zeitschrift für Bauwesen 16 (1866), S. 159-162. 
des war das Ziel, sondern das Herausarbeiten ihrer grundlegenden, eng miteinander verwobenen Hauptcharakteristika: die Historie, die Topografie, die Kultur. ${ }^{11}$ Mit seinem über Forschung und Wissenschaft hinausgehenden Anspruch, den ,werktätigen' Architekten auch eine Art Musterbuch vorbildlicher Bauwerke an die Hand zu geben, ging Adler an sein großes Werk. Es gelang ihm, besonders befähigte Hörer aus seinen Bauakademie-Kollegs einzubinden, die zunächst gemeinsam mit ihm, später auch selbstständig die regional verstreuten Bauwerke aufsuchten, aufmaßen und für die vereinbarte Veröffentlichung zeichnerisch aufbereiteten. ${ }^{12}$ Adlers tiefes Eindringen in die mittelalterliche Backstein-Welt führte ihn in dieser Zeit mit den ausgewiesenen Kennern der ,vaterländischen' Geschichte und Kunst, insbesondere für den Berliner Themenkreis mit Friedrich Wilhelm Holtze und Ernst Fidicin zusammen. ${ }^{13}$

Er trat auch schon um 1860 mit einigen beachtlichen Schriften und Thesen hervor, die man auch als ,Nebenprodukte' seines großen Backsteinwerks charakterisieren kann. ${ }^{14}$ Erstmals vertiefte er sich nun auch in das Berliner Mittelalter und damit auch in den Klosterkomplex der Franziskaner. Aber, wie oben schon angedeutet, sparten diese Schriften zur Berliner Baugeschichte (1861) und Befestigung (1863) die Konventsbauten nahezu vollends aus und beschränkten sich auf Angaben zu Standort, Charakter und Bedeutung der Klosterkirche.

Die Veröffentlichung des ersten zusammenhängenden Textes seines Backsteinwerkes mit eingestreuten Illustrationen erfolgte noch 1859, die Auslieferung des ersten gebundenen Konvoluts von 120 großformatigen Stahlstichen 1862. Davon waren 50 der Stadt Brandenburg, 70 der Altmark zugeteilt, den Regionen also, von denen die märkische Ziegelbaukunst mit ihren zum Teil noch romanischen Bauten den zeitlichen Ausgang nahm. Die zwischen Autor und Verleger abgestimmte Konzeption, eine umfassende zeichnerische Dokumentation des Baubestandes in einheitlichem Maßstab mit der Auswertung aller historischer Quellen und der Fachliteratur zu verknüpfen, türmte dem Unternehmen enorme Hürden auf. Friedrich Adler: Das in den ersten Jahren ziemlich gleichmäßig erschienene Werk, welches vertragsmäßig in fünf Jahren fertig sein sollte, ist dann zu meinem großen Bedauern immer langsamer gefördert worden und trotz der vielfachen Erinnerungen des Verlegers und befreundeter Fachgenossen seit dem Jahre 1868 beinahe ins Stocken gerathen. Beinahe - nicht ganz, denn die nothwendigen Aufnahmen wurden in aller Stille ebenso fortgesetzt wie die durch mehrfache Reisen nach Holland, Belgien, Italien und Dänemark geförderten Studien. ${ }^{15}$ Diese Schwierigkeiten sind auch der Grund dafür, dass sich die Bearbeitung aller nachfolgenden Kul-

11 Adler sah in Bauwerken treue unverfälschte Zeugnisse für das geistige wie materielle Leben eines Zeitalters, oder auch Bauwerke sind im eigentlichen Sinne des Wortes monumentale Illustrationen der Weltgeschichte, in: Friedrich Adler, Die Baugeschichte von Berlin. Vortrag, gehalten im Berliner Hilfs-Verein für das germanische Museum zu Nürnberg am 6. Februar 1861, Berlin 1861, S. 3.

12 Unter ihnen seien ausdrücklich Eduard Jacobsthal, August Tiede, Heinrich von Geymüller, Konrad Steinbrecht, Wilhelm Dörpfeld genannt, die durch erfahrene Kollegen von der Bauakademie wie Konrad Busse, Theodor August Stein, Paul Rudolph Brecht komplettiert wurden.

13 Mit Holtze deckte sich sein Interesse für die mittelalterliche Befestigung Berlin-Cöllns, mit Fidicin verfasste er die wertvolle Untersuchung zum mittelalterlichen Rathaus Berlins. Aber auch zu seinem Lehrer von der Gewerbeakademie Friedrich von Klöden, zu Adolph Friedrich Riedel, Leopold von Ledebur, Karl Theodor Odebrecht und Friedrich Voigt unterhielt er auch über die Geschichtsvereine enge kollegiale und freundschaftliche Beziehungen.

14 Friedrich Adler, Die Baugeschichte von Berlin; ders., Zur Geschichte der Befestigung Berlins, in: Märkische Forschungen 8 (1863), S. 213-220.

15 Adler, Mittelalterliche Backstein-Bauwerke, Bd. 1, Vorwort [o. S.]. 
turlandschaften, also auch der Mittelmark mit Berlin, um mehr als drei Jahrzehnte verzögerte. Die Skizzen des abschließenden zweiten Bandes von 1898 nämlich sind weit älteren Datums; die aus Adlers Hand, etwa zur Berliner Franziskanerkirche, datieren noch aus den 1860er-Jahren. Das lässt vermuten, dass viele Abbildungen der späteren Veröffentlichung, darunter eben auch die Berliner Vorlagen, ,veraltet' waren, worauf zurückzukommen sein wird. ${ }^{16}$

Adlers Auslassungen zum mittelalterlichen Backstein erzeugten sofort die schon angedeutete Aufmerksamkeit und sind im Gesamtzusammenhang seiner Thesen zur Baugeschichte wichtig. Sich auf die Slawenchronik Helmolds von Bosau berufend, nach der Markgraf Albrecht der Bär ,Nieder-, Seeländer und Flandern' in großer Zahl in den Marken angesiedelt hätte, entwickelte er unter Hinzuziehung aktueller Arbeiten Leopold von Ledeburs, Adolph Friedrich Riedels, August von Wersebes und anderer seine beiden Hauptthesen zum plötzlichen Auftreten der Backsteinarchitektur in der Mark Brandenburg: ihre Herkunft aus den erweiterten Niederlanden und ihre kurz vor der Mitte des 12. Jahrhunderts beginnende Verbreitung. In zwei nahezu zeitgleichen Studien über das großartige Figurenkapitell in der Krypta des Brandenburger Doms und die niederländischen Kolonien in der Mark von 1861 lieferte er vermeintliche Belege für seine Annahmen. ${ }^{17}$ Den architektonischen Beweis sah Adler in der Klosterkirche zu Jerichow, deren Baubeginn in das Jahr 1147 falle und die ohne die Niederländer und deren Technik nicht denkbar sei. Vehement und mit geografischen Ableitungen bekämpfte er etwa die Meinung seines Freundes und Gönners Ferdinand von Quast von einer Herkunft der Backsteinbaukunst aus Norditalien. ${ }^{18}$ Adlers nicht ungewagte Theorie wie auch die frühe Zeitbestimmung sollten die Forschung der nächsten Jahrzehnte beschäftigen. Den Baubeginn Jerichows sahen von Quast und Adler übereinstimmend um 1150, was beide zu den Begründern der nach wie vor umstrittenen ,Frühdatierung des märkischen Backsteins werden ließ. Aber über Ferdinand von Quast und die Zeitgenossen griff Adler mit seiner immens in die Tiefe gehenden, inventarähnlichen Abhandlung der ,Mittelalterlichen Backstein-Bauwerke' weit hinaus.

Bei allem erstaunt, wie eng sich die Forschung ihm doch anschloss, oder auch wie lange es dauerte, bis etwa mit den Veröffentlichungen des Hochschul-Kollegen Otto Stihl sein Thesengebäude erstmals merklich ins Wanken geriet. ${ }^{19}$ Ausgelöst von der 1884 beträchtlich staubaufwirbelnden Fehde zwischen Adler und Karl Schäfer um die Zeitstellung Jerichows, geriet die zuvor kaum angefochtene Forscherautorität Friedrich Adlers unter Druck. Das dabei die Ursache des Streits noch Überlagernde bestand darin, dass Schäfer unter seinem Ressortchef Adler als ,Hülfsarbeiter ${ }^{20}$ für Kirchenbau

16 Ein umfangreiches Konvolut der von Adler geschaffenen Zeichnungen befindet sich in der Stiftung Stadtmuseum Berlin. Der Klosterkirche werden elf Blätter zugeschrieben (einige sind nicht gesichert) sowie sechs Korrekturabzüge für den Fließtext des 2. Bandes der ,Mittelalterlichen Backstein-Bauwerke‘ 1898.

17 Friedrich Adler, Das Figurenkapitell in der Krypta des Doms zu Brandenburg und ein Elfenbein-Relief auf der Stadt-Bibliothek zu Hamburg, in: Märkische Forschungen 7 (1861), S. 183-191; ders., Die niederländischen Kolonien in der Mark Brandenburg, in: ebd., S. 110-127.

18 Adler, Die niederländischen Kolonien, S. 119. Ferdinand von Quast hatte in seiner fundamentalen Arbeit ,Zur Charakteristik des älteren Ziegelbaus in der Mark Brandenburg' (Berlin 1850) als einer der ersten Forscher den Import der Backsteinbaukunst aus dem Norden Italiens propagiert.

19 Otto Stihl, Backsteinbau romanischer Zeit, besonders in Oberitalien und Norddeutschland, Leipzig 1898.

20 Der ,Hülfsarbeiter' besaß einen relativ hohen Rang in der preußischen Bauverwaltung und ist nicht mit dem aktuellen ,Bauhilfsarbeiter' vergleichbar. 
im Ministerium für Öffentliche Arbeiten diente, beide aber auch hoch angesehene Lehrstühle an der Technischen Hochschule Charlottenburg besetzten. Wenn der Streit auch im Unentschiedenen versandete, so deckte er doch manche Unzulänglichkeit in den Bauanalysen Adlers auf und sorgte zukünftig für ein genaueres Nachprüfen seiner Zuschreibungen und Schlussfolgerungen. Zwischen diesen die Fachwelt nachweislich erschütternden Kontroversen und der Abschlussedition des Backsteinwerks lag noch einmal der Zeitraum von 15 Jahren, ein Abschnitt, in dem Adler eine Fülle von eigenen und ministeriell veranlassten Bauten errichtete und darin im Zenit seiner Wirksamkeit stand. Auch verfasste er zeitgleich ebenso zahlreiche Schriften, die, gefördert durch seine archäologischen Tätigkeiten, den Akzent mehr auf das klassische Altertum lenkten. ${ }^{21}$

Im so lange herausgeschobenen, letztendlich ,verspäteten' Backstein-Abschlusswerk von 1898 wurde die mittelalterliche Doppelstadt Berlin-Cölln nur mit drei Bauwerken gewürdigt, der Gerichtslaube als dem einzigen profanen Zeugnis, der mit einer gut gegliederten, altgothischen Ostfassade ausgezeichneten Heiliggeistkapelle an der Spandauer Straße und der Franziskanerklosterkirche. Die beiden Pfarrkirchen Sankt Nikolai und Sankt Marien überging er, anknüpfend an seine etwas geringschätzigen Bemerkungen zu den Kultus-Gebäuden in ,Berlin und seine Bauten'von 1877. Die theils vorhandenen [...] Kirchen des Mittelalters bieten ein mäßiges Interesse. Sie erscheinen dürftig und unbedeutend, wenn sie mit den entsprechenden Repräsentanten in anderen märkischen Städten - (Stendal, Brandenburg, Prenzlow) - verglichen werden. ${ }^{22}$

Das Graue Kloster, richtiger das Gymnasium zum Grauen Kloster, bot anscheinend ein ebenso mäßiges Interesse. Dabei war das Kloster als mittelalterliche Anlage mit Refektorium, Dormitorium, den Wandelhallen et cetera um die Wende zum 19. Jahrhundert trotz der nachreformatorischen Umbildungen zum Gymnasium immer noch erlebbar. Das Interesse der Bauforscher aber konzentrierte sich schon, wie eingangs erläutert, ausnahmslos auf die Klosterkirche. Auch Friedrich Adler, der seit seinen frühesten Schriften ihre außerordentliche Bedeutung nicht nur für Berlin, sondern für die gesamte märkische Baugeschichte betont hatte, hielt sich bezüglich der eigentlichen Konventsbauten deutlich zurück, indem er die alten Gebäude - so noch 1877 in ,Berlin und seine Bauten' - wenn auch nicht ganz überging, so doch lediglich summarisch zusammenfasste: In dem anstoßenden Gymnasium zum grauen Kloster existiren noch aus mittelalterlicher Zeit: 1) der [...] kreuzgewölbte Kapitelsaal; inschriftlich 1471-74 vom Meister Bernhard; 2) der [...] mit Sterngewölben erbaute Konventsaal [... $1516-18$ erbaut. ${ }^{23}$ Lässt sich daraus generell eine mangelnde Wertschätzung seitens der damaligen Berlin-Forschung zum Grauen Kloster ableiten? Auffallend jedenfalls ist, dass das Interesse im Architektenverein erst wieder um 1900 angesichts der historisierenden Schulerweiterungen an und in den alten Klosteranlagen unter anderem durch den Stadtbaurat und Adler-Schüler Ludwig Hoffmann geweckt wurde. ${ }^{24}$

21 Die wesentliche Adler-Literatur dieses Zeitraums bei Lemburg, Leben und Werk.

22 Architekten-Verein zu Berlin (Hrsg.), Berlin und seine Bauten, T. 1, Berlin 1877, S. 115.

23 Ebd., S. 120.

24 An der Klosterstraße entstanden um 1900 eine Erweiterung durch Georg Matzdorf und Emil Högg, durch den Stadtbaurat Ludwig Hoffmann eine Turnhalle am südlichen Chorpolygon. Siehe dazu den Beitrag von Wolfgang Schäche in diesem Band. 
Diese jedenfalls von der Architektenschaft an den Tag gelegte Ignoranz spiegelte sich aber auch im Verhalten der für das mehrhundertjährige Gymnasium verantwortlichen Schulmänner. Sie beklagten in erster Linie eine eingeschränkte Eignung der mittelalterlichen Restbauten für die schulischen Anforderungen und empfanden die stadt- und kunstgeschichtliche Bedeutung als eher nachrangig. ${ }^{25} \mathrm{Zu}$ diesen Stimmen gehörte der hochverdiente Johann Joachim Bellermann, der andererseits dem Kloster und seinen überkommenden Bauten eine ausführliche Abhandlung gewidmet hatte. ${ }^{26}$ Es fehlte allerdings nicht an konträren Haltungen. Als man etwa im beginnenden 19. Jahrhundert einige der überlieferten Klostergebäude durch Neubauten ersetzen wollte, trat niemand Geringeres als Karl Friedrich Schinkel deutlich für das Erbe ein. So sei es schade, die schönen Gewölbe niederzureißen, welche noch Jahrhunderte stehen könnten und ein Denkmal alter Baukunst sind. ${ }^{27}$ Natürlich war es nicht nur der Kunstwissenschaft bewusst, dass die Konventsbauten wesentlich jünger und baugeschichtlich nicht annähernd ranggleich mit der Klosterkirche waren. Deutlich war aber auch, dass Schulleitung und der Magistrat als Patron in der Vergangenheit ziemlich sorglos mit den Klosterbauten umgegangen waren, man sprach von Verwahrlosung und Vernachlässigung. Doch davon war auch die Klosterkirche nicht wirklich ausgenommen, denn selbst zu ihr vernahm man nach dem Abschluss der Umgestaltungen von 1845 bis auf marginale Nachrichten Adlers von 1863 aus dem Verein gar nichts mehr. ${ }^{28}$

\section{Die Franziskanerklosterkirche in Adlers Bearbeitung von 1898}

Die gesamte seit Adlers Finalband erschienene Literatur zur Franziskanerklosterkirche verweist auf die beiden darin enthaltenen Tafeln 32/33 mit Rissen und Schnitten und bringt sie völlig nachvollziehbar mit dem Erscheinungsdatum 1898 in Verbindung. Das verkennt aber die dahinter verschwommene Chronologie, was einen Hinweis wert erscheint. Zwischen dem ersten Band von 1862 und dem abschließenden von 1898 liegt unter Berücksichtigung der lange zuvor aufgenommenen Recherche ein Zeitraum von knapp vier Jahrzehnten. Der Erläuterungstext zur Klosterkirche wurde erst mit diesem späten Datum öffentlich. Die Darstellungen auf Tafeln 32 und 33 waren jedoch noch von Theodor August Stein gezeichnet worden, der bereits 1876 verstorben und nur von 1842-45 mit dem Grauen Kloster und der Kirche befasst war. Verkomplizierend kommt hinzu, dass Adler bereits 1877 in ,Berlin und seine Bauten' auf diese beiden schon identisch nummerierten Tafeln des erst zwei Jahrzehnte später erscheinenden Abschlusswerkes verwiesen hatte. ${ }^{29}$ Das bedeutet, dass Adler sie schon in seinen Tafelband von $1862 \mathrm{im}$

25 Die Vorgänge sind dokumentiert in: Paul Ortwin Rave, Karl Friedrich Schinkel. Berlin, T. 1: Bauten für die Kunst, Kirchen, Denkmalpflege, Berlin 1941, S. 356-359.

26 Johann Joachim Bellermann, Das graue Kloster in Berlin, mit seinen alten Denkmälern [...], T. 1-4, Berlin 18231826. Bellermann führt nach allgemeineren Ausführungen zum Franziskaner-Orden und kurzen Baugeschichtsabrissen die nach der Reformation vollzogenen Veränderungen an den überlieferten und sukzessive neu errichteten Berliner Baulichkeiten für das Gymnasium auf. Ausführlich zur Gymnasialgeschichte siehe auch: Julius Heidemann, Geschichte des grauen Klosters zu Berlin, Berlin 1874. Aufschlussreich aus Ost-Berliner Nachkriegsperspektive ist auch Gustav Leh, Das Franziskaner Kloster in Berlin, in: Berliner Heimat 3 (1958), S. 128-138.

27 Rave, Karl Friedrich Schinkel. Berlin, T. 1, S. 357.

28 Am 13. Mai 1863 legte Adler in der ,Brandenburgia‘ Kopien des bei der letzten Restauration zerstörten romanischen Frieses der Klosterkirche vor, der ältesten Wandmalerei Berlins, von der wir wissen. Protokollauszug in: Märkische Forschungen 9 (1865), S. 336.

29 Architekten-Verein, Berlin und seine Bauten, T. 1, S. 118. 
Vorgriff auf das erst Kommende aufgenommen hatte, ihre textliche Auswertung jedoch bis 1898 zurückhalten musste, was er in der dazugehörigen Einleitung hinsichtlich des Gesamtwerks mit einer ständigen Arbeitsüberlastung wortreich begründen zu müssen glaubte. Dieses Faktum ist insofern nicht nebensächlich, als die späteren Autoren, allen voran Gerhard Bronisch 1933, Adler Ungenauigkeiten und Fehler, vor allem im Grundriss auf Tafel 32, anlasteten, der auch in der Tat in seinen Erläuterungen die Steinsche Autorschaft nicht ausdrücklich mitgeteilt hatte. ${ }^{30}$ Die Tatsache, dass Adler bei der Berliner Franziskanerkirche auf altes Abbildungsmaterial zurückgreifen ,musste, offenbart die Schwierigkeiten, unter denen die Fertigstellung seines großen Werkes litt. Der zeitgenössischen Forschung waren sie nicht entgangen, was schon die Gegenüberstellung der Rezensionen von 1862 und 1898 verdeutlicht. Während Erstere noch voll des Lobes und der Anerkennung waren, vermeldeten die Letzteren schon nicht viel mehr, als dass ein lebenslang bearbeitetes Feld nunmehr durch den so verdienstvollen Gelehrten zu einem recht glücklichen Abschluss gelangt sei. ${ }^{31}$

Wie üblich in den ,Mittelalterlichen Backstein-Bauwerken` leitete Adler seine Erläuterungen zur Klosterkirche mit historischen Anmerkungen ein, fasste aber nur lange schon Bekanntes wie das Erscheinen der Franziskaner in der Stadt (bald vor 1250), die Überlassung des für ihren Klosterbau geeigneten Grundstücks durch Markgraf Otto (1271), die Schenkung einer Ziegelei durch Jacob von Nybede am Westrand des heutigen Kreuzbergs (1290) und die von allen früheren Forschern bereits interpretierte Chorgestühlinschrift der Zeit um 1500 zusammen. ${ }^{32}$ Am Ende dieser historischen Anmerkungen wiederholte er sein Bedauern, dass durch die Wiederherstellung unter der Leitung seines Freundes Ferdinand von Quast (1842-44) die Vorderfront der Kirche unter Hinzufügung der beiden Treppentürme mit Zinkhelmen und des Firsttürmchens ihren bis dahin bewahrten alten schlichten Kunstcharakter leider eingebüßt habe. ${ }^{33} 1877$ hatte er schon vergleichbar formuliert: Eine mehrjährige Restauration (nach 1840) hat das Aeußere mit zwei Treppenthürmen und einem Giebelreiter mehr bereichert als verschönert. Das Innere ist intakter geblieben. ${ }^{34}$ 1861, noch zu Lebzeiten Ferdinand von Quasts und Theodor August Steins als den maßgeblich Eingebundenen, hatte er sich noch der Kritik enthalten, wohl aber auf die Grandiosität des wertvollsten und gediegensten Bauwerks des mittelalterlichen Berlin verwiesen. ${ }^{35}$ Durch die Adoptirung des Backsteins [habe] für Berlin und Cölln erst eine höhere Entwicklung in der Baukunst begonnen. ${ }^{36}$ Niemals sei man über den trefflichen Bau der Franziskaner hinausgegangen, zumal die Klosterkirche

30 Gerhard Bronisch, Die Franziskaner-Klosterkirche in Berlin, in: Mitteilungen des Vereins für die Geschichte Berlins 50 (1933), S. 89-142.

31 Gegenübergestellt seien hier nur: Karl Schnaase, Mittelalterliche Backstein-Bauwerke des Preussischen Staates, in: Zeitschrift für Bauwesen 9 (1859), S. 131 f. und Hans Lutsch, Rezension zu Mittelalterliche Backstein-Bauwerke des Preussischen Staates, in: Zentralblatt der Bauverwaltung 18 (1898), S. 562 f.

32 Die Bedeutung der Ziegelei ist noch unerforscht. Sie lag westlich des Kreuzbergs auf ,Kriegersfelde' an der heutigen Katzbachstraße, wurde bis ins 19. Jahrhundert betrieben und um 1900 mit Wohnhäusern überbaut. Zu den historischen Quellen siehe Adler, Mittelalterliche Backstein-Bauwerke, Bd. 2, S. 40; zuletzt: Winfried Schich, Die Markgrafen von Brandenburg und die Ansiedlung der Franziskaner in den Städten östlich der Elbe im 13. Jahrhundert, in: Landesdenkmalamt Berlin, Kirchenruine des Grauen Klosters in Berlin, S. 13-21.

33 Adler, Mittelalterliche Backstein-Bauwerke, Bd. 2, S. 40.

34 Architekten-Verein, Berlin und seine Bauten, T. 1, S. 120.

35 Adler, Die Baugeschichte von Berlin, S. 9.

36 Ebd. 
durch einen 1335 hinzugefügten polygonalen Chor einen architektonischen Schmuck empfangen hatte, der sie den edelsten Bauwerken der Mark ebenbürtig macht. ${ }^{37}$ Die Charakterisierung in seinem Abschlusswerk von 1898 klingt abgeklärter, so sei die Kirche eine durch Klarheit und Uebersichtlichkeit des Raumes, durch maassvolle Schönheit der Verhältnisse, durch wirkungsvolle Beleuchtung und durch originelle Detailbildung eine hervorragende Bauanlage. ${ }^{38}$ Auch den weiteren Erläuterungen ist anzumerken, dass ihnen eine längere Beschäftigung mit der Klosterkirche oder auch Vakanz vorausging und in der Tat belegte ja schon seine ,Baugeschichte' im Kontext der Stadtbefestigung aus der Zeit um 1860, dass er sie in einem weiter zu fassenden Zusammenhang sah.

Typologische Ableitungen von den Domen Magdeburgs und Brandenburgs und die enge Verwandtschaft mit der kulminierenden märkischen Backsteinkunst im Kloster Chorin betonend, sah Adler im dreigliedrigen Berliner Franziskanerbau zwei Bauphasen: das frühgotische, im Grundriss einem Quadrat angenäherte Langhaus mit Langchor und das hochgotische Chorhaupt. Die in der äußeren Nordmauer vorgesetzten Findlinge sprächen darüber hinaus höchstwahrscheinlich für ein inkorporiertes noch markgräfliches Gebäude, was Rückschlüsse auf die ursprüngliche Bestimmung des Grundstückes zuließe. Dezidiert würdigte er die Besonderheiten, etwa die Gestaltung und ungewöhnliche Anordnung der Langhausstützen, deren floral geschmückte Kapitelle, das schön proportionierte und detaillierte Westportal und nicht zuletzt die außerordentliche Qualität der in Backstein skulptierten Dienstkonsolen im Langchor. Das Hauptaugenmerk lenkte er jedoch auf das Chorpolygon, das mit seinen sieben Seiten des Zehnecks die unvergleichbare Wirkung und Stimmung im Inneren erzeuge.

Schon in seinen genannten Veröffentlichungen um 1860 hatte Adler konsequent die Ansicht vertreten, dass dieses weite und lichte 7/10 Chorpolygon stilistisch und zeitlich nicht zum altertümlicheren Charakter des Langhauses gehöre, was er, davon abweichende Meinungen reflektierend, wiederholt mit starken Worten untermauerte. Denn erst dieser Chorabschluss mache das Bauwerk so singulär. Während das Langhaus mit den überlieferten Daten und Dokumenten in Übereinstimmung stünde, sei das Chorhaupt in seinen harmonischen Proportionen, angesichts der durch die herrlichen Fenster hervorgerufenen Lichtstimmung und aufgrund der Details wesentlich jünger. Danach datierte er das Langhaus mit einem ursprünglich gerade geschlossenen Chor in die Zeit zwischen 1271 und 1300. Das Chorpolygon empfand er als Bereicherung des frühgotischen Baus und glaubte, seine Entstehung in die Jahre zwischen 1340 und 1345 legen zu müssen. Für den auch bei Bettelordenskirchen üblichen platt geschlossenen Chor führte Adler drei vermeintliche Belege an, seinen Freund Ferdinand von Quast, eine vertikale Baunaht zwischen nördlichem Langchor und Polygon und die das bestehende Chorhaupt bogenartig umlaufende Stadtmauer. Von Quast, der allerdings wie auch Franz Kugler im Gegensatz zu Adler schon an eine ungefähre Zeitgleichheit der Bauglieder glaubte, habe ihn 1856 mit den Ergebnissen früherer Grabungen im Chorinneren vertraut gemacht. ${ }^{39}$ Sie hätten zwar vordringlich den Gräbern der Markgrafenfamilien gegolten, aber eben auch die Fundamente des ursprünglichen geraden Chor-

37 Ebd.

38 Architekten-Verein, Berlin und seine Bauten, T. 1, S. 119.

39 Kugler war Autor der ersten ausführlichen Abhandlung zur Klosterkirche und mit Adler später durch den Architektenverein im Austausch. Franz Kugler, Die Klosterkirche zu Berlin, in: Allgemeines Archiv für die Geschichtskunde des preußischen Staates 4 (1831), S. 257-272. 
schlusses belegt. Diese vermeintlichen Fundamentreste wie auch die von Autoren wie Richard Borrmann und Ernst Rosstäuscher geleugnete oder zumindest anders interpretierte Baunaht waren es vordringlich, die die späteren Kontroversen um die Entstehungszeit des Polygons auslösen sollten. ${ }^{40}$ Das dritte von Adler zur Stützung seiner Argumentation angeführte Moment zielte auf die an der rückwärtigen Neuen Friedrichstraße den Chor umlaufende alte Stadtmauer. Adler galt neben Friedrich Holtze und Ernst Friedel als der beste Kenner der mittelalterlichen Fortifikation der Doppelstadt. ${ }^{41}$ Als gesichert galt, dass die aus Feld- und Backsteinen bestehende Stadtmauer Berlin bereits um 1320 umschlossen hatte. Holtze beschrieb 1861 ihren zumeist schnurgeraden Verlauf, aber wo sie an die Klosterkirche herantritt, zeigt sie [...] einen wunderlichen, den Linien der Hinterwand des Kirchgebäudes [...] folgenden Vorsprung. Wäre dieser nicht vorhanden, so würde die Mauer die hintere Kirchenwand durchschneiden. Offenbar also ist die Mauer der Kirche halber herausgerückt. Man wüsste jetzt - und hier verwies er auf Adler -, dass die Klosterkirche anfangs ohne das erst später hinzugefügte Chorpolygon errichtet worden sei. ${ }^{42}$ Holtze und Adler waren sich also einig, dass die zuvor auf den gerade geschlossenen Chor ausgerichtete Stadtmauer für das neu konzipierte Chorhaupt wieder abgebrochen und nach Osten verschoben worden sei. Auch dieses, gemessen am ungewöhnlichen Stadtmauerverlauf an sich recht plausible Motiv hielt späteren Ansichten nicht stand, wenn auch erst jüngste archäologische Befunde die sicheren Gegenbeweise lieferten. ${ }^{43}$ Zunehmend verdichteten sich die Annahmen, dass das Chorpolygon und die westlichen Bauteile zeitlich enger zusammengehören als es Adler glaubte. Es ist aber nicht zu übersehen, wie sich dessen ja wesentlich auf Stilinterpretation stützende Meinung bis in die jüngsten Publikationen hinein behauptete. ${ }^{44}$ Heute geht die Forschung von einer relativen Gleichzeitigkeit der Bauteile aus. Die dennoch vielfach voneinander abweichenden Datierungen zum Polygon und die hinter ihnen stehenden Interpretationen wie unterbrochene Bauphasen oder im laufenden Bauprozess vollzogene Planänderungen wurden 2007 im Sammelband zur Berliner Franziskanerkirche in mehreren Beiträgen vorbildlich dokumentiert. ${ }^{45}$

Wesentlich aber bleiben auch die bereits angesprochene detailreiche Abhandlung zur noch unzerstörten Klosterkirche durch Gerhard Bronisch und dessen Auslassungen über Friedrich Adler. ${ }^{46}$ Die 1933 veröffentliche Dissertation basierte auf mehrjährigen örtlichen Untersuchungen, archäologischen Grabungen im Chorinneren sowie im östlichen Umfeld und entstand offenbar im Zusammenhang mit umfassenden Restaurierungsarbeiten zwischen 1926 und 1935. Sie schlossen auch eine Beseitigung der ,Zutaten' der 1840er-Jahre ein. Bronisch war der Ansicht,

40 Richard Borrmann, Die Bau- und Kunstdenkmäler von Berlin, Berlin 1893, S. 188; Ernst Rosstäuscher, Kirchen, in: Architekten-Verein zu Berlin (Hrsg.), Berlin und seine Bauten, T. 2, Berlin 1896, S. 148.

41 Architekten-Verein, Berlin und seine Bauten, T. 1, S. 27.

42 Friedrich Holtze, Geschichte der Befestigung von Berlin, in: Märkische Forschungen 7 (1861), S. 1-101, hier S. 15; siehe dazu auch: Adler, Zur Geschichte der Befestigung Berlins, S. 213-220.

43 Uwe Michas, Archäologische Untersuchungen an der Berliner Franziskaner-Klosterkirche, in: Landesdenkmalamt Berlin, Kirchenruine des Grauen Klosters, S. 88-98.

44 Die jüngere Literatur und Diskussionen sind zusammengefasst in: Landesdenkmalamt Berlin, Kirchenruine des Grauen Klosters.

45 Siehe insbesondere Petra Marx, Zur Geschichte der bauhistorischen Forschung und denkmalpflegerischen Bemühungen - ein fachgeschichtlicher Rückblick, in: ebd., S. 31-49 und Stefan Breitling, Die Franziskaner-Klosterkirche in Berlin: Ergebnisse der bauhistorischen Untersuchungen 1999-2004, in: ebd., S. 99-126. 
dass abgesicherte Resultate nur durch hochspezialisierte, in die Tiefe gehende Baumonografien zum mittelalterlichen Backsteinbau zu erzielen seien. Danach qualifizierte er Adler als einen eben nur an der Oberfläche agierenden Autor ab. Es ermangele ihm an jeglicher Kompetenz, er biege sich „erfundene“ Resultate zurecht, streue wissenschaftlich falsche Fakten und Tatsachen. Speziell zur Klosterkirche attestierte er ihm Fehler und Fahrlässigkeiten - Adler habe die von Ferdinand von Quast mitgeteilten Grundlagen jedenfalls nicht nur uminterpretiert, sondern „nicht richtig verstanden“. ${ }^{47}$ Das offenbare insbesondere seine These vom geraden Chorabschluss auf Höhe des zweiten Langchorjochs. Der Verriss Bronischs blieb in seiner Schärfe singulär, auch wenn Schmoll gen. Eisenwerth drei Jahrzehnte später Adlers märkische Mittelalterforschung gleichfalls in generaliter abqualifizierte. ${ }^{48}$ Gleichwohl darf angemerkt werden, dass auch deren Um- und Neuinterpretationen zur Architektur der Askanier im Allgemeinen und zu Chorin und der Berliner Franziskanerkirche im Besonderen nicht die angestrebten Schlusspunkte setzten und nach wie vor einen Gegenstand der Forschung bilden.

\section{Anmerkungen zur Restaurierung der Klosterkirche in den 1840er-Jahren}

Die zwischen 1841 und 1845 durchgeführte, restauratorische“ Wiederherstellung der Franziskanerklosterkirche ist wiederholt, zuletzt 2007, ausführlich erörtert worden. ${ }^{49}$ Interessanterweise hatten sich die seinerzeit an den Arbeiten beteiligten Hauptakteure, Stadtbaurat Friedrich Wilhelm Langerhans, Landbauinspektor Wilhelm Berger, Bauführer und nachmals Konservator Ferdinand von Quast und Landbauinspektor Theodor August Stein kaum oder auch nur zu Nebenaspekten in der Fachöffentlichkeit geäußert. ${ }^{50}$ Dennoch sind wir über die einzelnen Schritte, den Fortgang, die Zuständigkeiten durch Personen und Behörden recht gut unterrichtet. Zu Recht wird Ferdinand von Quast mit den Wiederherstellungsarbeiten in Verbindung gebracht, denn richtig ist daran zumindest, dass er, der noch zu den Schülern Schinkels gehörte und auch dessen hohes Vertrauen genoss, früh in die Thematik der dringend erforderlichen Sicherungsarbeiten an der Klosterkirche eingebunden wurde. Dass aber immer wieder er es war, dem man die Hauptrolle bei den Entscheidungen und baulichen Umsetzungen zuordnete, rief 1906 den schon genannten Adler-Vertrauten Julius Kohte auf den Plan. Ein Aufsatz sollte von Quasts wahren An-

47
Ebd., S. 89.

Josef A. Schmoll, gen. Eisenwerth, Das Kloster Chorin und die askanische Architektur in der Mark Brandenburg 1260-1320 (Veröffentlichungen der Berliner Historischen Kommission beim Friedrich-Meinecke-Institut der Freien Universität Berlin, Bd. 2), Berlin 1961.

9 Zu dieser jüngsten Bearbeitung mit diversen Verweisen auf die neuere Literatur siehe Stefan Breitling, Ferdinand von Quast und die Franziskaner-Klosterkirche in Berlin. Ein Beitrag zur Geschichte der Denkmalpflege im 19. Jahrhundert, in: Landesdenkmalamt Berlin/Schinkel-Zentrum für Architektur, Stadtforschung und Denkmalpflege der TU Berlin/Architekturmuseum der TU Berlin in der Universitätsbibliothek (Hrsg.), Auch die Denkmalpflege hat Geschichte. Ferdinand von Quast (1807-1877). Konservator zwischen Trier und Königsberg (Beiträge zur Denkmalpflege in Berlin, Bd. 29), Berlin/Petersberg 2008, S. 77-87.

Von Quast hat offenbar mehrere Werkberichte in die Spenersche Zeitung gebracht, nur Bauleiter Stein lieferte später einen wichtigeren Beitrag: Theodor August Stein, Über den Bau eiserner Thurmspitzen, in: Zeitschrift für Bauwesen 10 (1860), Sp. 481-490, hier Sp. 485-487. Zu Stein siehe Ingeborg Schild, Theodor August Stein, Das Lebenswerk eines Ingenieur-Architekten im 19. Jahrhundert, Habilitationsschrift Technische Hochschule Aachen 1970; zum 50-jährigen Berufsjubiläum Steins siehe Deutsche Bauzeitung 9 (1875), Nr. 50, S. 249. 
teil an den Maßnahmen belegen. ${ }^{51}$ Julius Kohte: „Die neueren Veröffentlichungen, die die Klosterkirche, das wichtigste mittelalterliche Bauwerk der Stadt Berlin, behandeln, nennen Ferdinand v. Quast als den Leiter der 1842 bis 1844 stattgehabten Wiederherstellung, wobei sie nicht unterlassen, ihr Mißfallen über diese auszusprechen." Und Kohte vermutete wohl nicht zu Unrecht, dass „die Überlieferung“ in ihm den „Urheber“ erblickte, weil er „die bekannteste der an dem Bau beteiligten Persönlichkeiten war" ${ }^{52}$ Den Anstoß zu Kohtes Abhandlung gab die auch von ihm abgelehnte Umgestaltung der Westfront mit den in durchbrochenen Zinkgussspitzen endenden oktogonalen Treppentürmen, mit der - wie schon Adler beklagte - das alte klösterliche Erscheinungsbild beeinträchtigt, wenn nicht gar zerstört worden sei. Die tatsächlichen Hintergründe der Veränderung mit den bekannt gewordenen Entwürfen, Modellen und Zeichnungen Cantians, auch Schinkels, vor allem aber denen vom König goutierten Bergers nachzeichnend, konstatierte er: „Sommer 1843 geschah die Ausführung der drei Türme der Westfront, und an dieser bedenklichen Bereicherung war von Quast also ganz unbeteiligt “. ${ }^{33}$ Kohte legte seine auf gründlicher Durchsicht des vom Architekturmuseum der Technischen Hochschule betreuten Von-QuastNachlasses und amtlicher Dokumente basierenden Erkenntnisse vor, die zusammengefasst lauten: Von Quast war zwar der unermüdliche Anreger der überfälligen Kirchen-Restaurierung, sein Einfluss auf die jeweiligen Entscheidungen jedoch war dermaßen marginal, dass er sich bald aus dem Unternehmen zurückzog. Die Auflistung der durchgeführten Arbeiten, vor allem die im Inneren, ist aber auch bei Kohte bisweilen widersprüchlich. Unstrittig bleibt, dass sich der ,Kunstgelehrte' von Quast spätestens seit seiner Einschaltung in die Erhaltungsmaßnahmen mit der Bau- und Planungsgeschichte befasste. Frühe Belege etwa sind Kopien bereits 1813 vorgelegter Schinkelentwürfe für Umgestaltungen des Kircheninneren. Durch sie erst sind wir mit der Art und dem Umfang der erstaunlich massiv in die Substanz und den Charakter des Bauwerks eingreifenden Ideen ihres Urhebers vertraut. ${ }^{54}$ Ferdinand von Quasts durch Kohte akribisch dokumentierte Versuche, sowohl aufgedeckte Chormalereien als auch ebenso noch mittelalterliche Lettnerelemente zu retten, scheiterten nach langem Bemühen und beschleunigten seinen Rückzug. Diese Vorgänge kontrastierte allerdings seine Berufung zum ersten Konservator der preuBischen Kunstdenkmale vom 22. Juli 1843, die fraglos als Anerkennung seiner so umfangreichen Fachkompetenzen zu werten ist. Abschließend äußerte sich Julius Kohte zum wirkungsvollsten Neubauelement im Stadtraum an der Klosterstraße, dem so gar nicht mittelalterlich anmutenden Bogengang. ${ }^{55}$ Er sollte eine wenig ansehnliche Massivmauer aus dem 18. Jahrhundert ersetzen. „Im Jahre 1844 entstand der Bogengang, der den Vorplatz der Kirche an der Klosterstraße begrenzt. Auch an diesem Bauwerk hat v. Quast keinen Anteil genommen. Allerdings hatte er sich einmal, vermutlich im Sommer 1842, als er noch hoffte, auf die Gestaltung der Westfront einen Einfluß zu gewinnen, mit dem Gedanken beschäftigt, den tiefen Vorplatz mit in der Höhe der Straße gelegenen, gewölbten Bogengängen zu umschließen, etwa im Sinne des Vorhofs von S. Ambrogio in Mailand, und damit den Bau von ein oder zwei Türmen zu versuchen, die mit

51 Julius Kohte, Ferdinand von Quast und die Wiederherstellung der Klosterkirche in Berlin, in: Die Denkmalpflege 3 (1906), S. 20-24, $28 \mathrm{f}$.

52 Ebd., S. 20.

53 Ebd., S. 21.

54 Rave, Karl Friedrich Schinkel. Berlin, T. 1, S. 345-355.

55 Kohte, Ferdinand von Quast, S. 29. 
der Kirche selbst nicht in Verbindung getreten wären. Diesen Gedanken hat er in zwei anmutigen farbigen Skizzen dargestellt, obwohl zu deren Verwirklichung sich gar keine Aussicht bot. " ${ }^{6}$ Diese doch auch vagen Hinweise Kohtes von 1906 verhinderten es offenbar nicht, weiterhin in von Quast den Haupthandelnden der 1840er-Aktionen zu sehen. Es ist aber auch nicht erwiesen, dass Theodor August Stein, der die zumindest bautechnisch beachtenswerten Zinkgussspitzen für die beiden Treppentürme entworfen und konstruiert hatte, Autor dieses „recht hübschen“ Bogengangs war. ${ }^{57}$ Friedrich Adler, der sich doch so eng mit von Quast verbunden fühlte, hatte noch 1877 verkündet: Um die stattgefundene Strassenerhöhung architektonisch zu begrenzen, ist längs der Kloster-Straße ein rundbogiger Arkadengang mit Seitennischen nach Entwürfen von v. Quast erbaut worden. ${ }^{58}$

Julius Kohte, dessen Aufsatz mit Lobpreisungen Ferdinand von Quasts als des weit vorausschauenden Begründers der modernen Denkmalpflege ausklingt, vermeldete abschließend: „Am 13. April 1845 endlich wurde die Klosterkirche dem Gottesdienst zurückgegeben. So lebhaftes Interesse v. Quast ihrer Wiederherstellung entgegengebracht hatte, bedeutete diese für ihn doch nur eine schwere Enttäuschung." ${ }^{\text {"59 }}$

\section{Schlussbemerkung}

Adlers während der zweiten Hälfte des 19. Jahrhunderts entwickelten bauhistorischen Ansätze, Analysen und Schlussfolgerungen gelten generell durch seither erfolgte Spezialuntersuchungen und die alle Bereiche der Bauforschung betreffenden Fortschritte weitgehend als überholt. Im Eigentlichen spiegeln sie nur noch eine Sequenz Wissenschaftsgeschichte, die, wenn man tiefer in sie eindringt, auch Faszinierendes bietet. Unter welchen Voraussetzungen und Bedingungen seine Arbeiten und auch die seiner ambitionierten Zeitgenossen entstanden, sollte mit in die Betrachtungen einbezogen werden. ${ }^{60}$ Gleichwohl hatte seine Forschergeneration noch den beneidenswerten Vorteil, die - wenn auch mühsamer erreichbaren - Monumente in oft noch wenig oder gar unzerstörten Zuständen vorzufinden. Die Dokumentation dieser Zustände machen nicht zuletzt auch Adlers Werk für die fortschreitende Forschung noch immer wertvoll. Für seine Zeit aber und die noch durch ihn ausgebildete nachfolgende Generation galt auch seine Methodik der alle historischen, politischen, merkantilen und kulturellen Quellen ausschöpfenden Ganzheitlichkeit als bahnbrechend und vorbildlich.

56 Ebd.

57 Rave, Karl Friedrich Schinkel. Berlin, T. 1, S. 355.

58 Adler in: Architekten-Verein, Berlin und seine Bauten, T. 1, S. 120.

59 Kohte, Ferdinand von Quast, S. 29.

60 Und wenn man sich seine so weit aufgefächerten Tätigkeiten, die Forschungsreisen, das Schreiben, sein Lehramt an der Bauakademie und an der Technischen Hochschule, die zahlreichen Vorträge im Architekten- und Archäologenkreis in den Geschichtsvereinen, seine sich beständig steigernde Privatbautätigkeit et cetera vor Augen führt, überrascht es kaum noch, dass er 1858, also schon ,sehr früh; auch den international ausgeschriebenen Wettbewerb um das Berliner Rathaus gewinnen konnte. Wäre er mit dessen Ausführung beauftragt worden, hätte sich sein Wirken möglicherweise anders gestaltet. 



\section{Wolfgang Schäche}

\section{Aufbruch in das 20. Jahrhundert. Der Umbau und die Erweiterung des Gymnasiums zum Grauen Kloster durch Ludwig Hoffmann}

Zentraler thematischer Gegenstand der vorliegenden bauhistorischen Betrachtung sind der Umbau und die Erweiterung des Gymnasiums zum Grauen Kloster durch Ludwig Hoffmann. ${ }^{1}$ Einstmals an geschichtsträchtigem Ort im Herzen der Stadt lokalisiert, blieben die Baulichkeiten der Schule im Allgemeinen wie die zu Beginn des 20. Jahrhunderts vorgenommene architekturräumliche Neuordnung im Besonderen aus der bau-, respektive stadtgeschichtlichen Rezeption der Nachkriegszeit weitgehend ausgeblendet. Und auch das im Zweiten Weltkrieg so arg geschundene und in der Nachkriegszeit vernachlässigte Klosterviertel, in dessen Mitte sich in Zuordnung zur Klosterkirche das Gymnasium befand, erfuhr über Jahrzehnte keine nennenswerte stadtbaugeschichtliche Beachtung. Erst nach der Wiedervereinigung rückte die alte Mitte Berlins nach und nach in den Fokus stadtgesellschaftlicher Betrachtungen und mit ihr das in Vergessenheit geratene Klosterviertel sowie der unkenntlich gemachte Molkenmarkt. Die 2016 erfolgte förmliche Festlegung eines Bebauungsplans schuf dann die Voraussetzung für eine städtebauliche Wiederherstellung und funktionale Revitalisierung der genannten Stadtbereiche. In der Diskussion über Art, Charakter und Typus der hierzu zu entwickelnden Überbauung stellte sich die grundlegende Frage nach dem Umgang mit den historischen Hinterlassenschaften. Das führte schließlich zu einer umfassenden wissenschaftlichen Thematisierung der Geschichte und Bedeutung des Grauen Klosters und den sich mit dem einstmaligen Ort und der Kirchenruine verbindenden potenziellen Perspektiven.

Die folgenden Einlassungen widmen sich explizit dem zwischen 1900 und 1904 vorgenommenen Um- und Ausbau des Berlinischen Gymnasiums zum Grauen Kloster. Er stellte die erste umfassende Baumaßnahme nach den Erweiterungen der späten 1850er-Jahre dar und war zugleich die letzte nennenswerte vor den kruden Zerstörungen des Zweiten Weltkriegs. Ihre Notwendigkeit ergab sich aus der stetig wachsenden Schülerzahl des Gymnasiums, ${ }^{2}$ das sich - ob seiner Tradition und Bedeutung als älteste höhere Lehranstalt der Stadt - seit der Reichsgründung bei den in großer Zahl in die Hauptstadt zugezogenen bürgerlichen Eliten einer außerordentlichen Beliebtheit erfreute. Es galt dabei vor allem, den durch den regen Schülerzulauf im letzten Jahr-

1 Der Beitrag stützt sich im Wesentlichen auf folgende Quellen und Literatur: Ludwig Hoffman (Hrsg.), Neubauten der Stadt Berlin, Bd. 1-11, Berlin 1902-1912; ders., Lebenserinnerungen eines Architekten, bearb. und aus dem Nachlass hrsg. von Wolfgang Schäche, mit einem Vorwort von Julius Posener (Die Bauwerke und Kunstdenkmäler von Berlin, Beih. 10), Berlin 1983; Julius Posener, Vorlesungen zur Geschichte der Neuen Architektur II - Die Geschichte der Reform (1900-1924), in: Arch+ 53 (1980); Hans J. Reichhardt/Wolfgang Schäche (Hrsg.), Ludwig Hoffmann in Berlin. Die Wiederentdeckung eines Architekten. Eine Ausstellung des Landesarchivs Berlin, Berlin 1987; Wolfgang Schäche (Hrsg.), Das Stadthaus. Geschichte, Bestand und Wandel eines Baudenkmals, Berlin 2000; Dorte Döhl, Ludwig Hoffmann. Bauen für Berlin 1896-1924, Berlin 2004.

2 Zitat aus Otto Sarrazin/Friedrich Schultze, Die Um- und Erweiterungsbauten des berlinischen Gymnasiums zum Grauen Kloster, in: Zentralblatt der Bauverwaltung 24 (1904), S. 577-579, hier S. 577. 
zehnt vor der Jahrhundertwende entstandenen signifikanten Flächenbedarf zu decken. Die bauliche Umsetzung der damit verbundenen Erweiterungsplanungen wurde schließlich durch den Verkauf eines der ,Kommunitätskasse‘ des Gymnasiums gehörigen ehemaligen Ackergrundstücks an der Greifswalder Straße ermöglicht, welches eine erhebliche Wertsteigerung erfahren hatte, da es zwischenzeitlich zu Bauland geworden war.

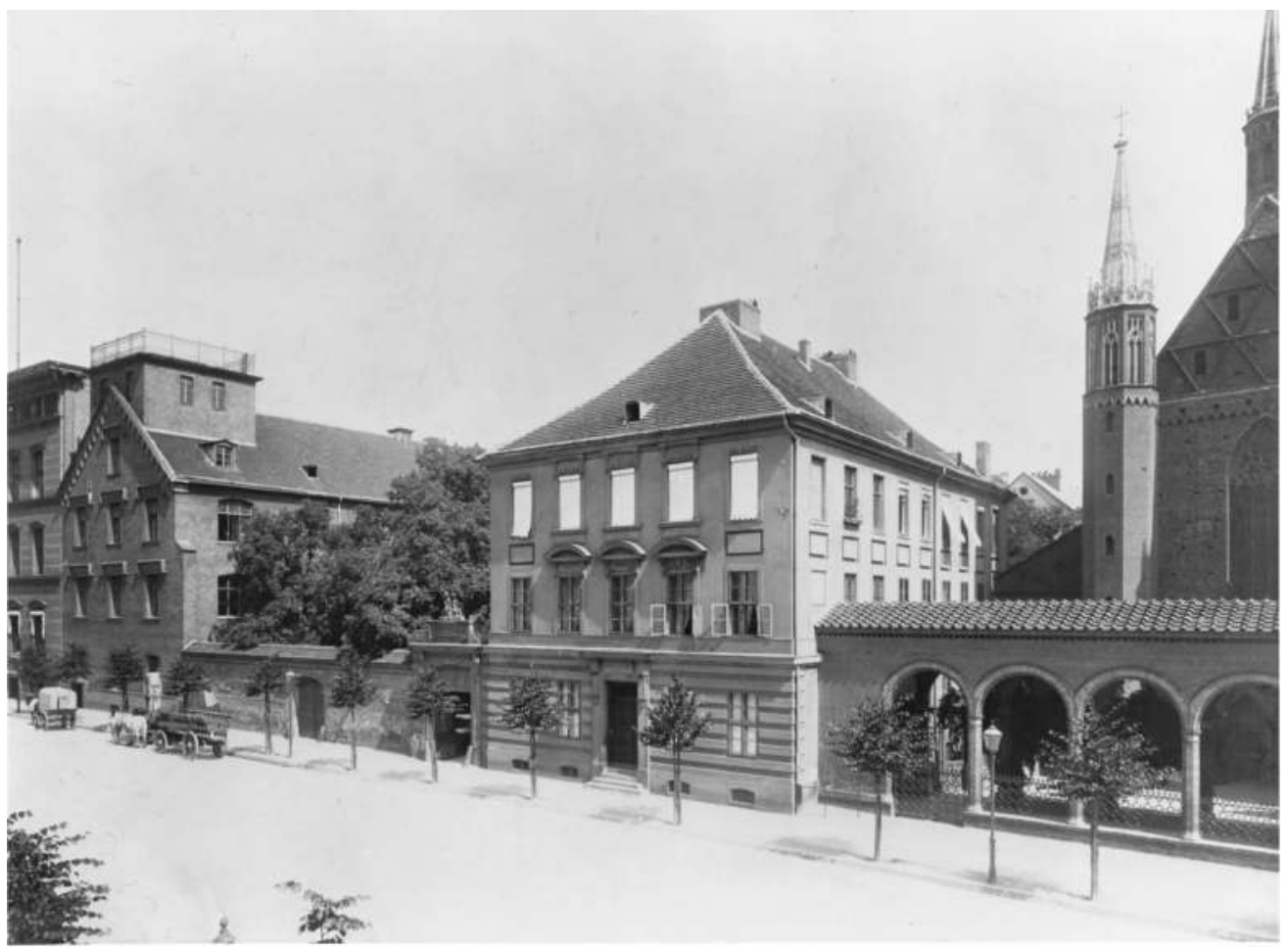

Abb. 1: Gymnasium zum Grauen Kloster an der Klosterstraße, Aufnahme um 1890.

Das ab Sommer 1897 entwickelte Bauprogramm umfasste die Erweiterung des Schulhauses zur Aufnahme neuer Klassen- und Fachräume, den Bau eines repräsentativen Direktoren- und Lehrerhauses mit Räumlichkeiten für das Alumnat sowie einen Turnhallenbau, über den das Gymnasium bis dahin noch nicht verfügte und der ausschließlich aus städtischen Mitteln finanziert wurde. Die Gebäudeplanung und Bauausführung oblag dem Städtischen Hochbauamt, dessen Leitung Ludwig Hoffmann innehatte. Er war 1896 zum Stadtbaurat von Berlin gewählt worden und sollte dieses Amt bis 1924 ausführen. Stadtbauräte, zumal in der prosperierenden Hauptstadt des Kaiserreiches, mussten damals - im Gegensatz zu heute - über ausgewiesene Fachkompetenz verfügen und so wurde Hoffmann, dem zuvor durch den Bau des Reichsgerichts in Leipzig große nationale wie internationale Anerkennung zuteil geworden war, vor allem als planender und bauender Architekt in diese hochbegehrte Position berufen. Ihm unterstand eine erfahrene Bauabteilung, die die Planung und Durchführung sämtlicher kommunaler Baumaßnahmen zu verantworten hatte, so auch die Erweiterung des Berlinischen Gymnasiums zum Grauen Kloster. 


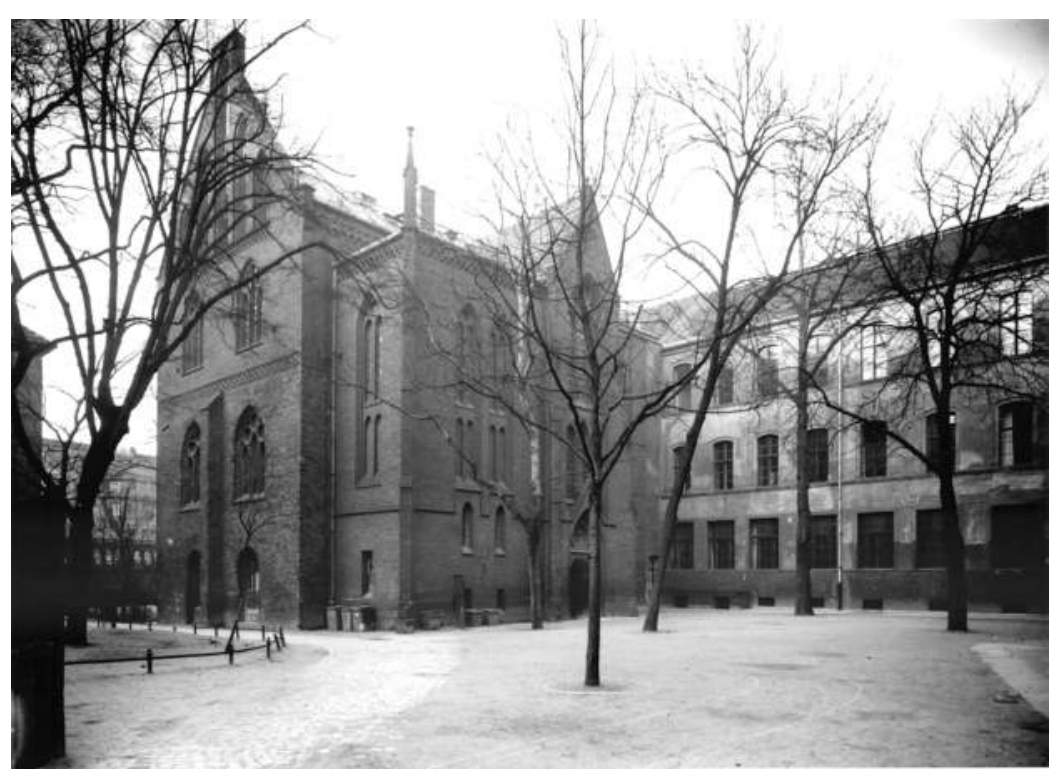

Abb. 2: Blick auf das Schulhaus von 0sten gesehen, ohne Datierung.

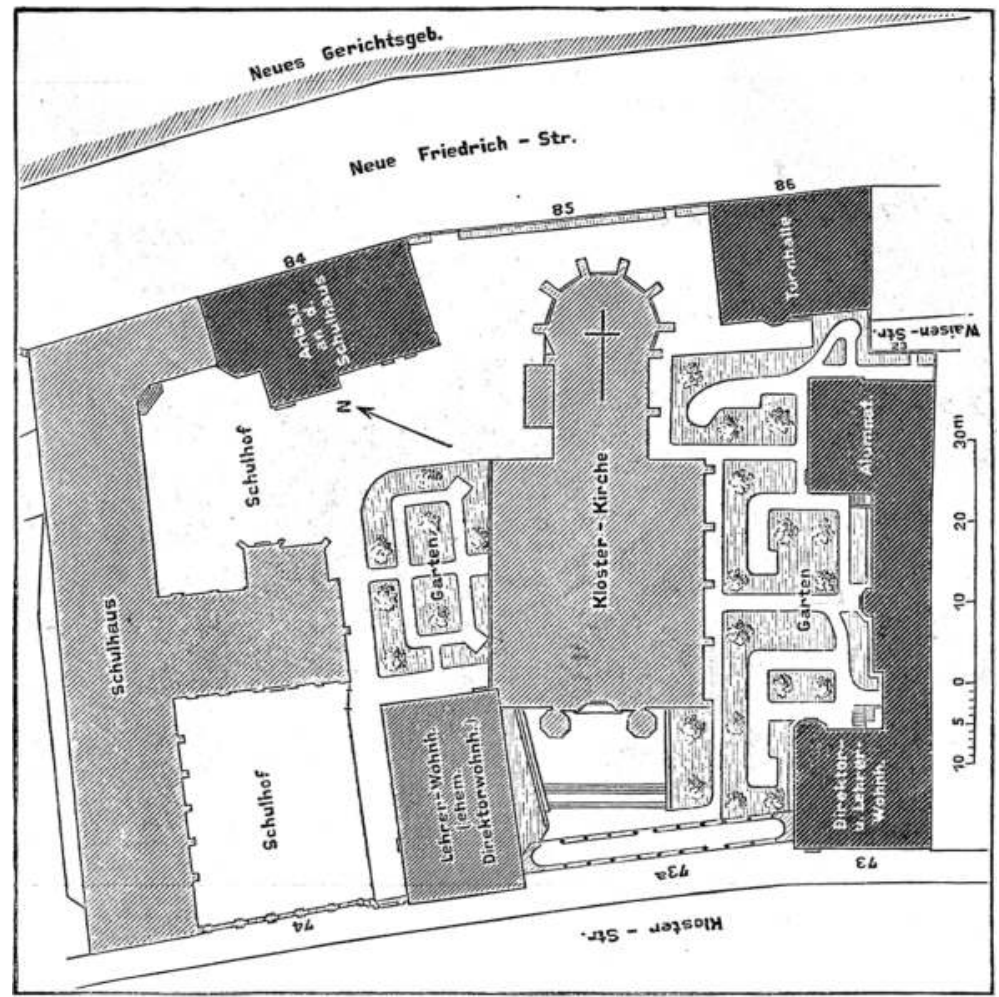

Abb. 3: Lageplan des Gymnasiums mit den Erweiterungsbauten von 1900-1902 unter Leitung von Ludwig Hoffmann. 


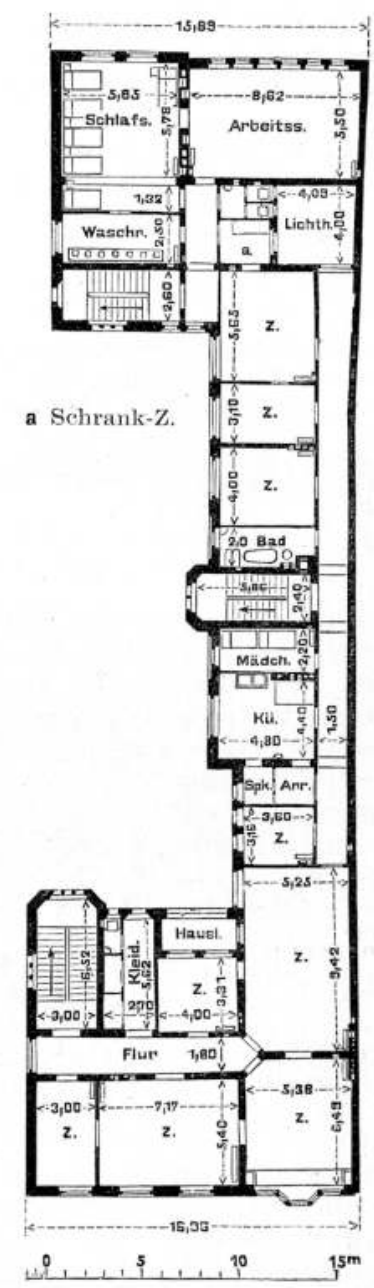

Abb. 4: Grundriss des ersten Obergeschosses des Direktorenwohnhauses und Alumnates von Emil Högg.

Sein Um- und Ausbau stellte eine der ersten Bauaufgaben dar, die das Hochbauamt unter Hoffmanns Leitung zu bearbeiten hatte. Er selbst behielt sich den Entwurf des Turnhallengebäudes vor, das - wie erwähnt - in toto von der Stadt finanziert wurde, während er die anderen Gebäudeplanungen für das Gymnasium leitenden Mitarbeitern übertrug, denen er in künstlerischen Fragen - wie es in einem zeitgenössischen Artikel des Zentralblatts der Bauverwaltung bedeutungsvoll hieß - mit guten Ratschlägen die Richtung wies. ${ }^{3}$

Der erste Neubau, der im Rahmen des Ausbaus des Gymnasiums realisiert wurde, war das 1900/01 auf dem ein Jahr zuvor erworbenen Grundstück Klosterstraße 73 errichtete Direkto- 
ren- und Oberlehrerwohnhaus mit Alumnatflügel. Den Entwurf hierfür fertigte Emil Högg, ${ }^{4}$ einer der talentiertesten Mitarbeiter Ludwig Hoffmanns, der dann später über verschiedene Karrierestationen den Ruf als Ordentlicher Professor für Raumkunst und Ingenieurbaukunst an die angesehene Technische Hochschule in Dresden erhielt, wo er neben seiner Arbeit als Architekt von 1911 bis 1933 in der Lehre tätig war.

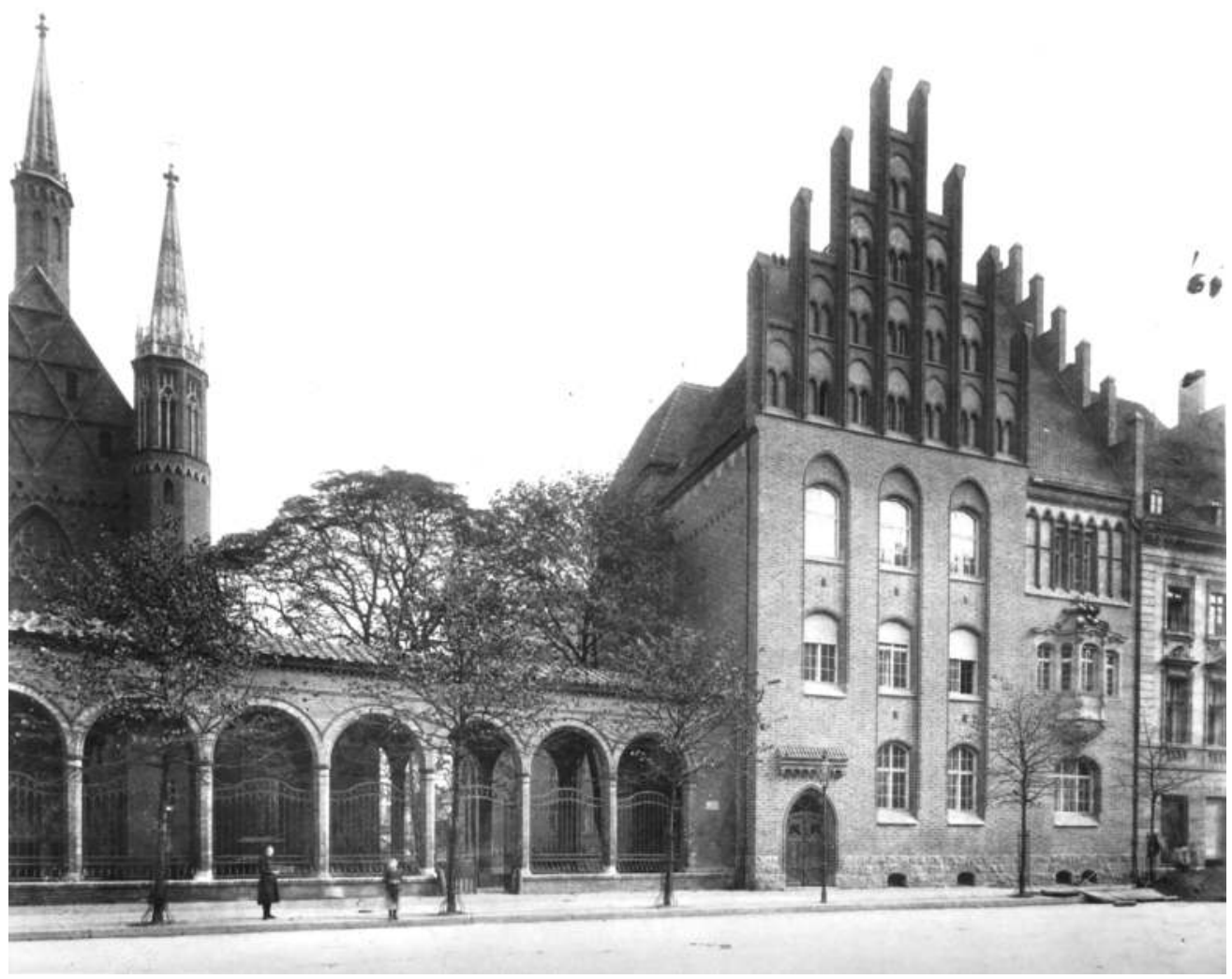

Abb. 5: Ansicht des Direktoren- und Lehrerhauses an der Klosterstraße, Aufnahme 1903.

Unmittelbar nach Bezug des von Högg geplanten Gebäuderiegels, der sich in Material und Stilistik an den Duktus der Klosterkirche anlehnte (so wurden unter anderem rötlicher handgestrichener Backstein in Klosterformat für die Gebäudehülle verwandt und naturrote Bieberschwänze Nürnberger Formats für die Dacheindeckung), begann im Herbst 1901 der grundlegende Umbau des zum Ende des 18. Jahrhunderts fertiggestellten alten Direktoren-Wohnhauses an der Klosterstraße sowie der städtebaulich wie architektonisch maßstabsgebundene Neubau des Turnhallengebäudes an der Neuen Friedrichstraße, welcher bis ins Detail von Ludwig Hoffmann konzipiert wurde.

4 Emil Högg (1867 bis 1954) studierte Architektur an der Technischen Hochschule Stuttgart und arbeitete danach in einigen bekannten Architekturbüros - wie u. a. bei Eisenlohr \& Weigle in Stuttgart und Bruno Schmitz in Berlin - ehe er 1898 in die Bauverwaltung von Berlin unter Stadtbaurat Ludwig Hoffmann als Stadtbaumeister eintrat. Schon im April 1904 verließ er Berlin und wechselte nach Bremen, wo er zum Direktor des Gewerbemuseums berufen wurde. 


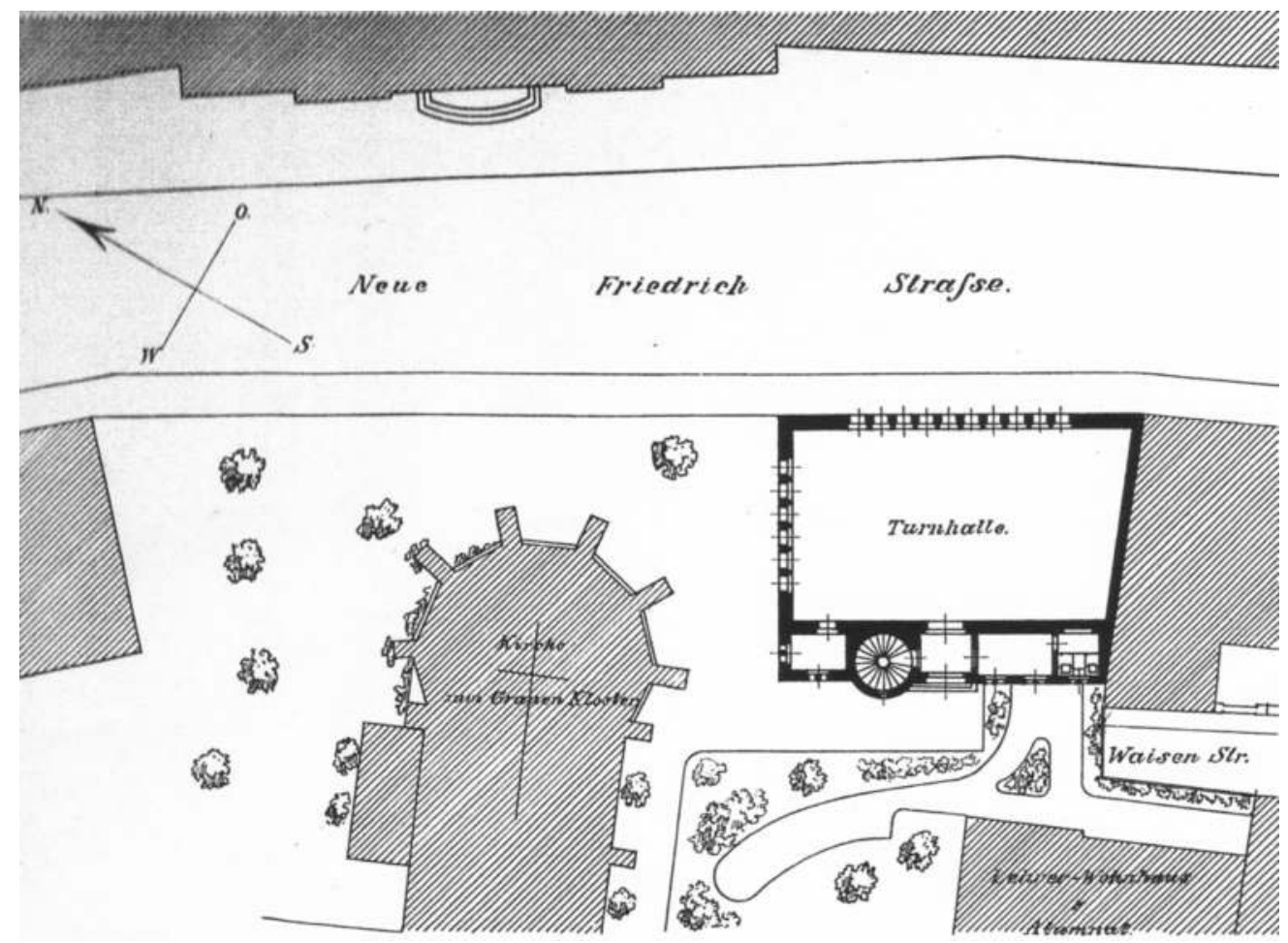

Abb. 6: Lageplanausschnitt mit der Turnhalle nach Entwurf von Ludwig Hoffmann.

Dieser sah hierfür einen auf nahezu rechteckiger Grundfläche errichteten kompakten zweigeschossigen Baukörper mit steilem Satteldach vor, der die vorhandene Randbebauung an der Neuen Friedrichstraße nach Norden fortsetzte und in respektvollem Abstand zum Chor des mittelalterlichen Kirchenbaues mit einer wohlproportionierten Stirnwand mit mächtigem Stufengiebel abschloss. Im Erdgeschoss befand sich die eigentliche Turnhalle. Ihr waren gartenseitig ein Lehrerzimmer, der Garderoben- und Waschraum, eine darüber liegende Zuschauergalerie sowie ein Treppenturm angefügt. Das Obergeschoss über der Turnhalle und den Nebenräumen mit Galerie war den Sammlungsgegenständen des Gymnasiums sowie dem Archiv vorbehalten. In seiner ausgewogenen Gestalt und architektonischen Gestik erwies sich der Turnhallenbau für die neuen Gebäude des Gymnasiums, die sich in pittoresker Anordnung um den bauzeitlich nahezu unverändert überkommenen Kirchenbau gruppierten und ihn damit stadträumlich in das Zentrum der mehrteiligen Schulanlage rückten, gleichsam als akzentsetzender Leitbau. 

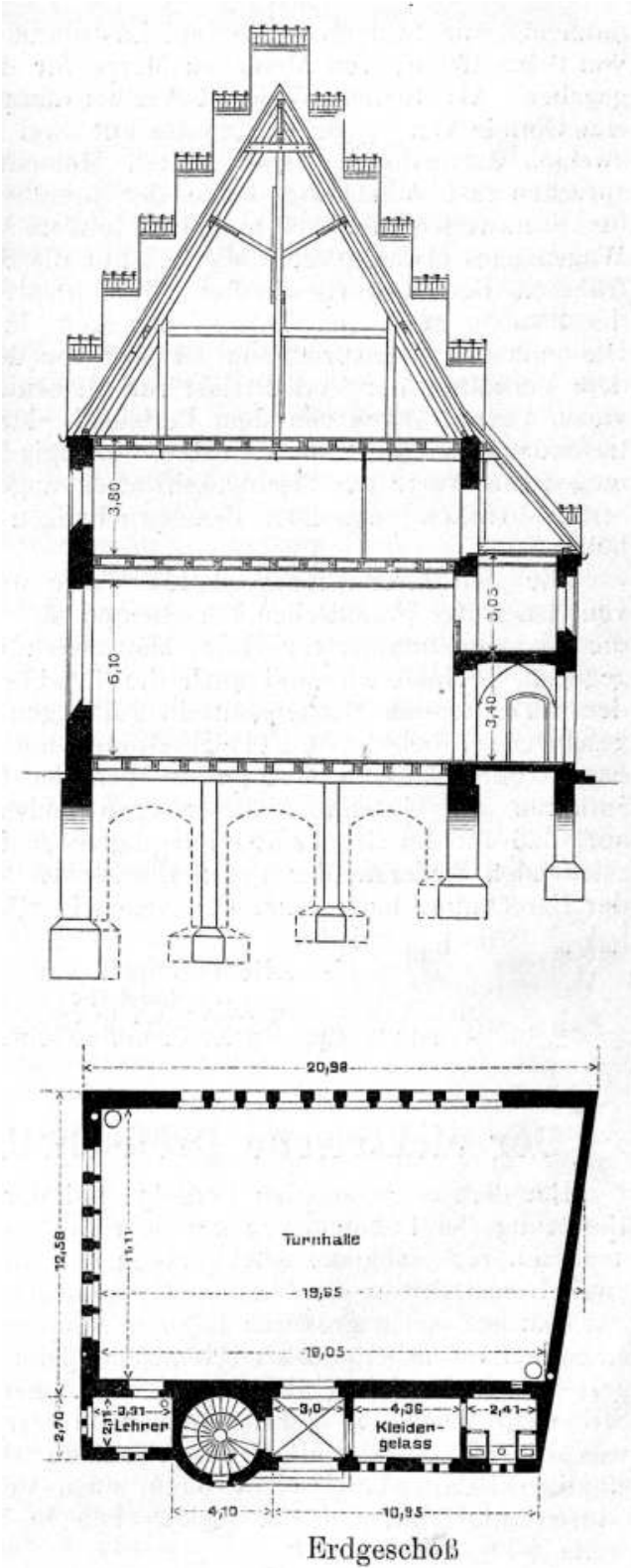

Abb. 7: Gebäudeschnitt und Grundriss der Turnhalle. 


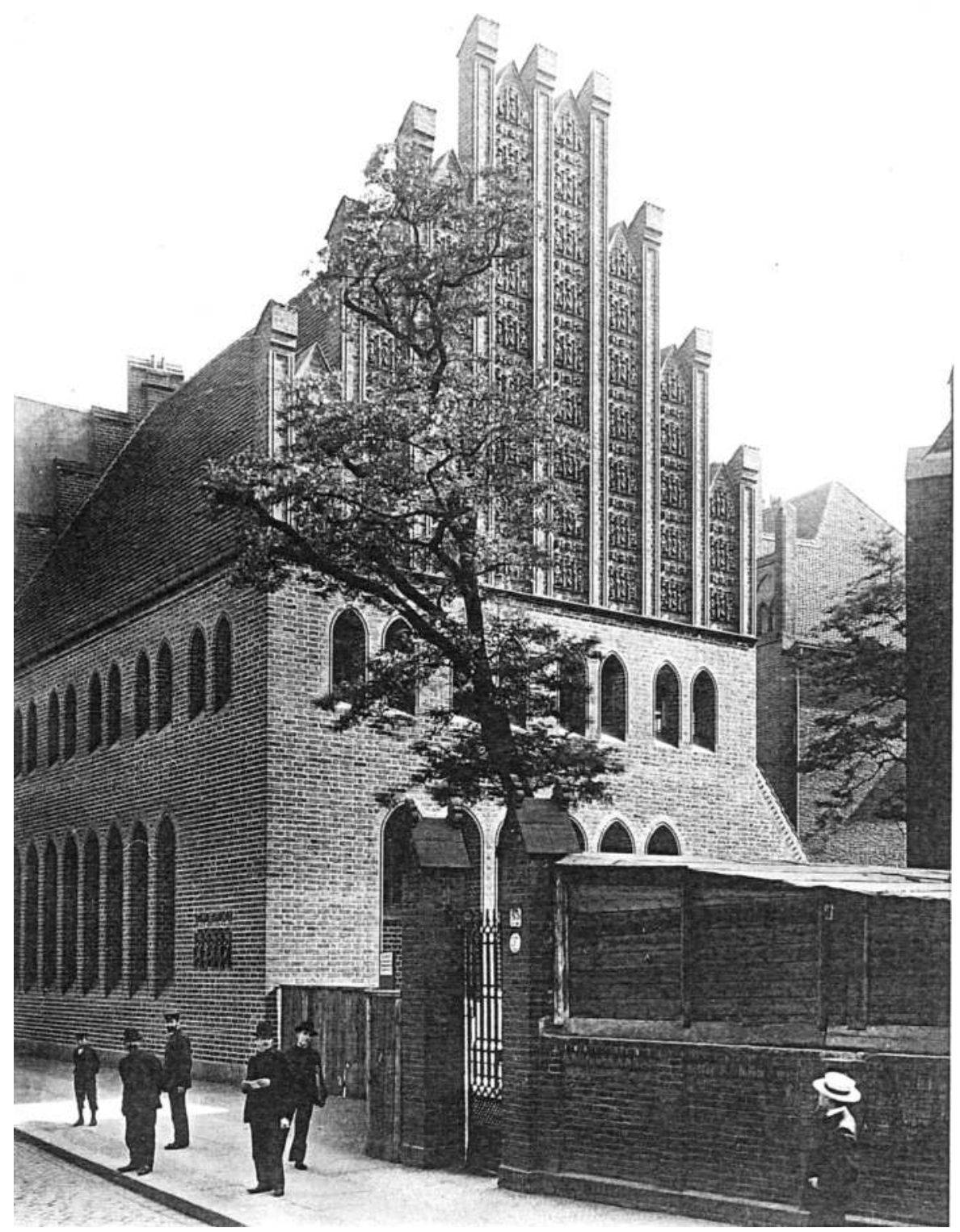

Abb. 8: Turnhalle des Gymnasiums an der Neuen Friedrichstraße, Aufnahme um 1903/04.

Auf den Turnhallenbau nahm auch der dritte Neubauteil - die Erweiterung des Schulhauses in seiner städtebaulichen Platzierung und architektonischen Gestaltung unmittelbaren Bezug. Seine Errichtung erfolgte nach Abschluss der Arbeiten am Turnhallengebäude im Spätsommer 1902. Zuvor musste der an dieser Stelle bis dahin bestandene Gebäudeflügel des Schulhauses an der Neuen Friedrichstraße, in dem sich die Lehrerwohnungen befanden, abgebrochen werden. Die entwurfliche Bearbeitung des neuen Bauteils hatte Hoffmann dem ebenfalls in seinem Amt tätigen Stadtarchitekten Carl Roemert übertragen. Er schloss den Gebäudeflügel an das alte, in 
Teilen auf den Klostermauern erbaute Schulhaus an und verband deren Grundrisse in allen drei Geschossen miteinander. Im Erdgeschoss und im ersten Obergeschoss des neuen Flügels waren die so dringend benötigten zusätzlichen Unterrichtsräume vorgesehen; so im Erdgeschoss zwei Klassenräume für je 40 Schüler und eine geräumige Abortanlage sowie im ersten Obergeschoss eine Zeichenklasse mit anschließendem Modellzimmer und eine Chemieklasse nebst Vorbereitungs- und Apparatezimmer, ${ }^{5}$ während das gesamte zweite Obergeschoss der umfangreichen Bibliothek des Gymnasiums vorbehalten war.

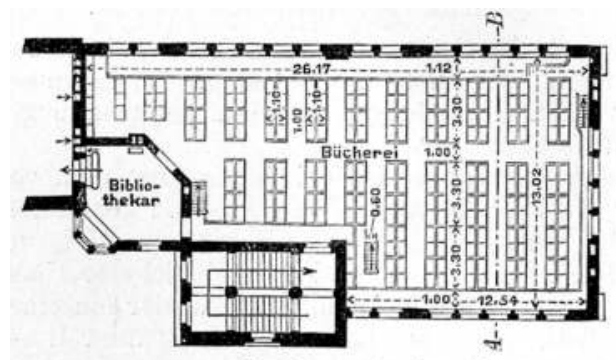

Zweites Stockwerk

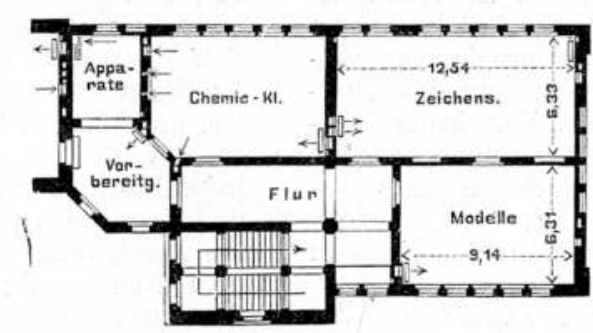

Erstes Stockiwerk

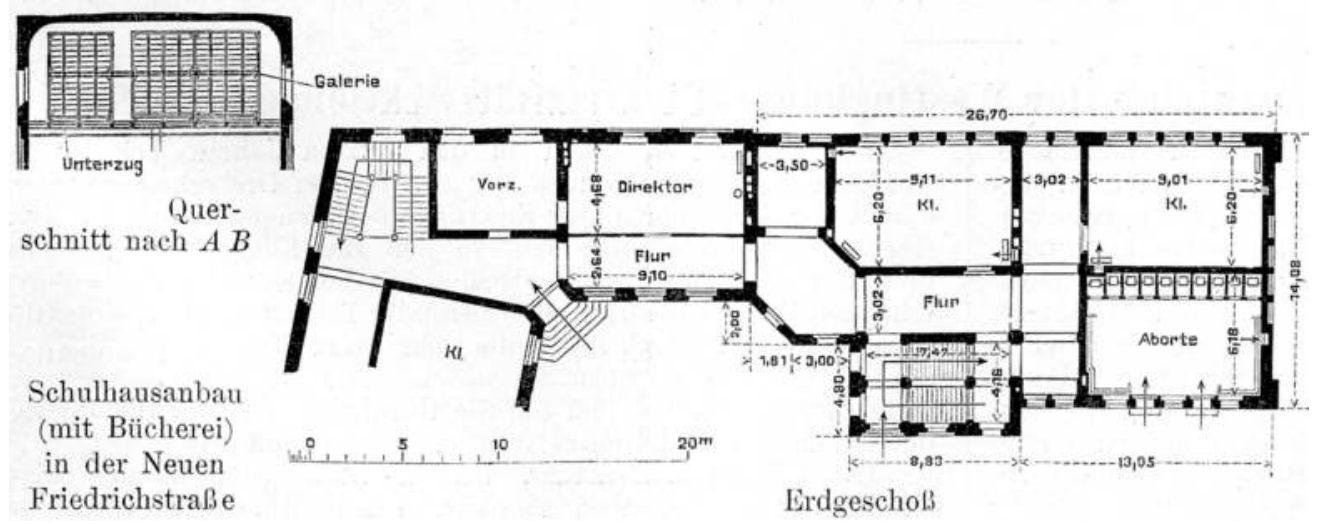

Abb. 9: Grundrisse des Schulhausanbaues von Stadtarchitekt Carl Roemert.

Als im Oktober 1903 auch dieser Bauteil in Nutzung genommen werden konnte, folgte als letzte Baumaßnahme die sukzessive Instandsetzung des alten Schulhauses. Die damit verbundenen Arbeiten erstreckten sich noch über den ganzen Winter bis in das Frühjahr des nächsten Jahres. Am 11. Mai 1904 fand schließlich die feierliche Einweihung der Neubauten in Gegenwart der Königlichen und städtischen Behörden ${ }^{6}$ statt. Die Baukosten beliefen sich einschließlich des aus städtischen Mitteln bezahlten Turnhallenbaus auf insgesamt 690.000 Goldmark. Der Kubikmeterpreis des umbauten Raumes lag bei den einzelnen Bauten je nach ihrem Ausbaustandard zwischen 11,30 Mark (Umbau des alten Direktorenhauses) und 22,00 Mark (Neubau des Direktorenwohnhauses). 


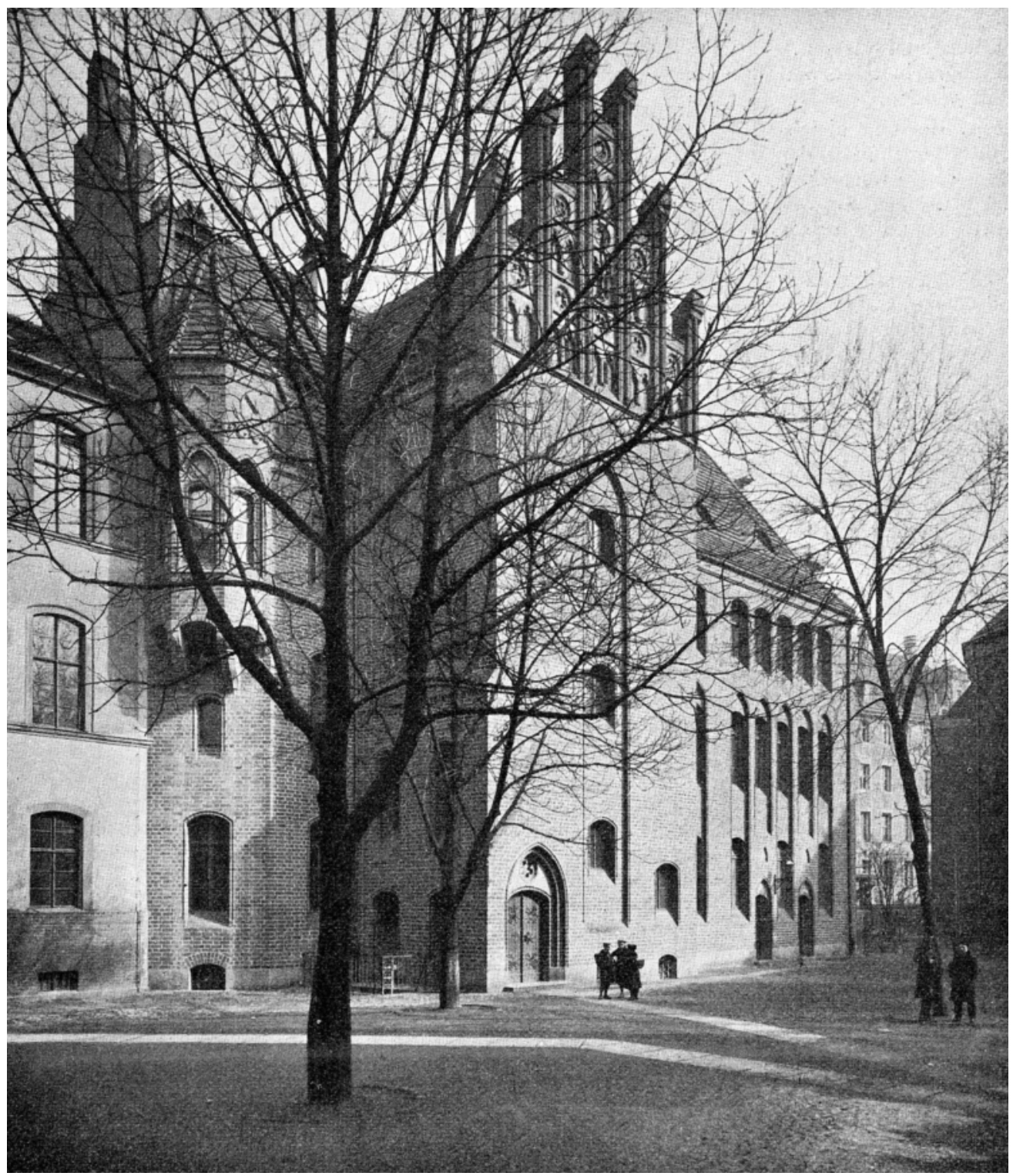

Abb. 10: Hofansicht des Schulhausanbaus an der Neuen Friedrichstraße, Aufnahme 1903.

Fragt man nach derWirkung und Bedeutung der Neubauten des Gymnasiums zum Grauen Kloster, so stellte das durch sie erweiterte Gebäudeensemble ohne Frage nicht nur die Revitalisierung und Festigung des traditionsreichen Schulstandortes dar, sondern bewirkte für das aus der Frühzeit der Stadt überkommene und in der Stadtentwicklung des 19. Jahrhunderts mehr und mehr ins Abseits geratene Klosterviertel eine deutliche stadträumliche Aufwertung wie architektonische Nobilitierung. An der Schwelle zum 20. Jahrhundert wies die auf Balance und Harmonie bedachte bauliche Synthese zwischen Mittelalter und Neuzeit dem Viertel gleichsam eine in die Zukunft 
gerichtete Perspektive, ohne seine identitätsstiftenden historischen Charakteristika in Frage zu stellen. Der architektonisch imposante Turnhallenbau von Ludwig Hoffmann verkörperte in seiner räumlichen Positionierung zur Klosterkirche und der auf die spezifische Zweckbestimmung zugeschnittenen eigenständigen Gestaltung dabei im Besonderen den kompositorischen Anspruch, Alt und Neu in einem spannungsreichen Dialog erfahrbar zu machen. Dabei griff Hoffmann jedoch nicht die Motivik der die Gebäudeanlage bestimmenden Klosterkirche auf, sondern orientierte sich bewusst an anderen Gestaltungsmustern der Backsteingotik und suchte sie in freier Interpretation auf sein Turnhallengebäude zu übertragen. So liest man in seinen

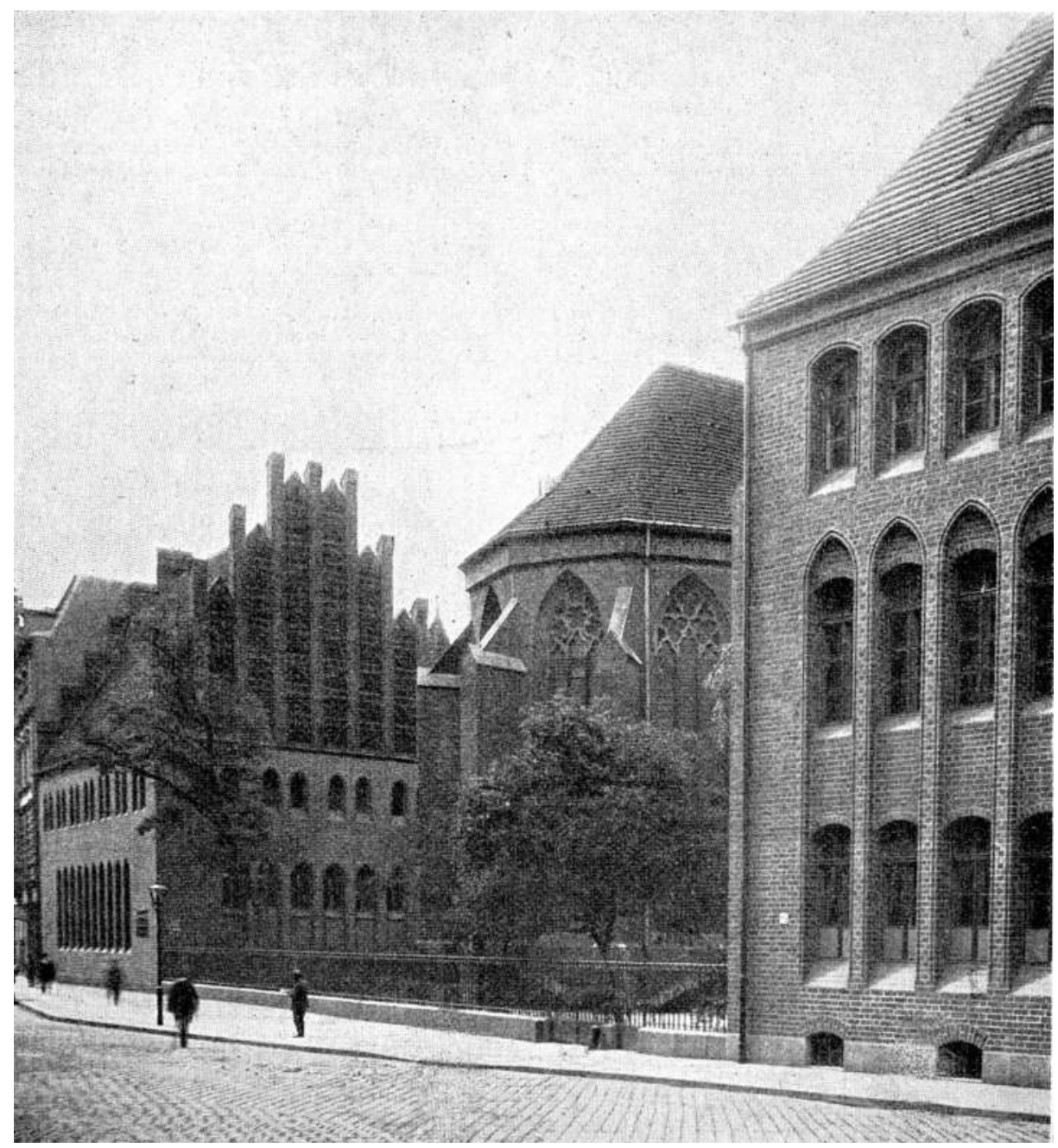

Abb. 11: Blick auf die Neubauten an der Neuen Friedrichstraße, links die Turnhalle, rechts der Schulhausanbau, Aufnahme 1903. 
,Lebenserinnerungen'7 dass er schon im Jahr 1897 Rostock, Lübeck und Wismar sowie Güstrow, Doberan, Lüneburg und Ratzeburg besuchte, um dort die formalen Besonderheiten der Backsteinarchitektur zu studieren und sich für seine ersten Bauaufgaben - zu denen das Märkische Museum und eben der Turnhallenbau des Gymnasiums zum Grauen Kloster gehörten - tektonische, motivische wie formale Anregungen zu holen, um sie auf die Gegenwart zu übersetzen. Für die dekorative Ausgestaltung seines pittoresken Stufengiebels ließ er sich dabei explizit vom Duktus des Südgiebels des Querhauses von Sankt Nikolai in Wismar inspirieren und versah den zwölf Meter breiten Giebel des Turnhallenbaus, wie in Wismar, ebenfalls mit Terrakotten. Seine Begründung hierfür war vergleichsweise pragmatisch, wenn er ausführte: So kam die 75 Quadratmeter große Fläche bis auf einige schmale aufstrebende Lisenen durch die zahlreichen kleinen, sich stets wiederholenden Terrakotten, auf welchen in starkem Relief Bären ihre Turnkünste zeigen, zu reichem Schmuck! Bei nur zehn kleinen Modellen hielten sich die Kosten in bescheidenen Grenzen, auch wurde durch die vielfache Verwendung desselben Terrakottenmotivs bei aller Lebhaftigkeit eine lästig unruhige Wirkung vermieden. ${ }^{8}$

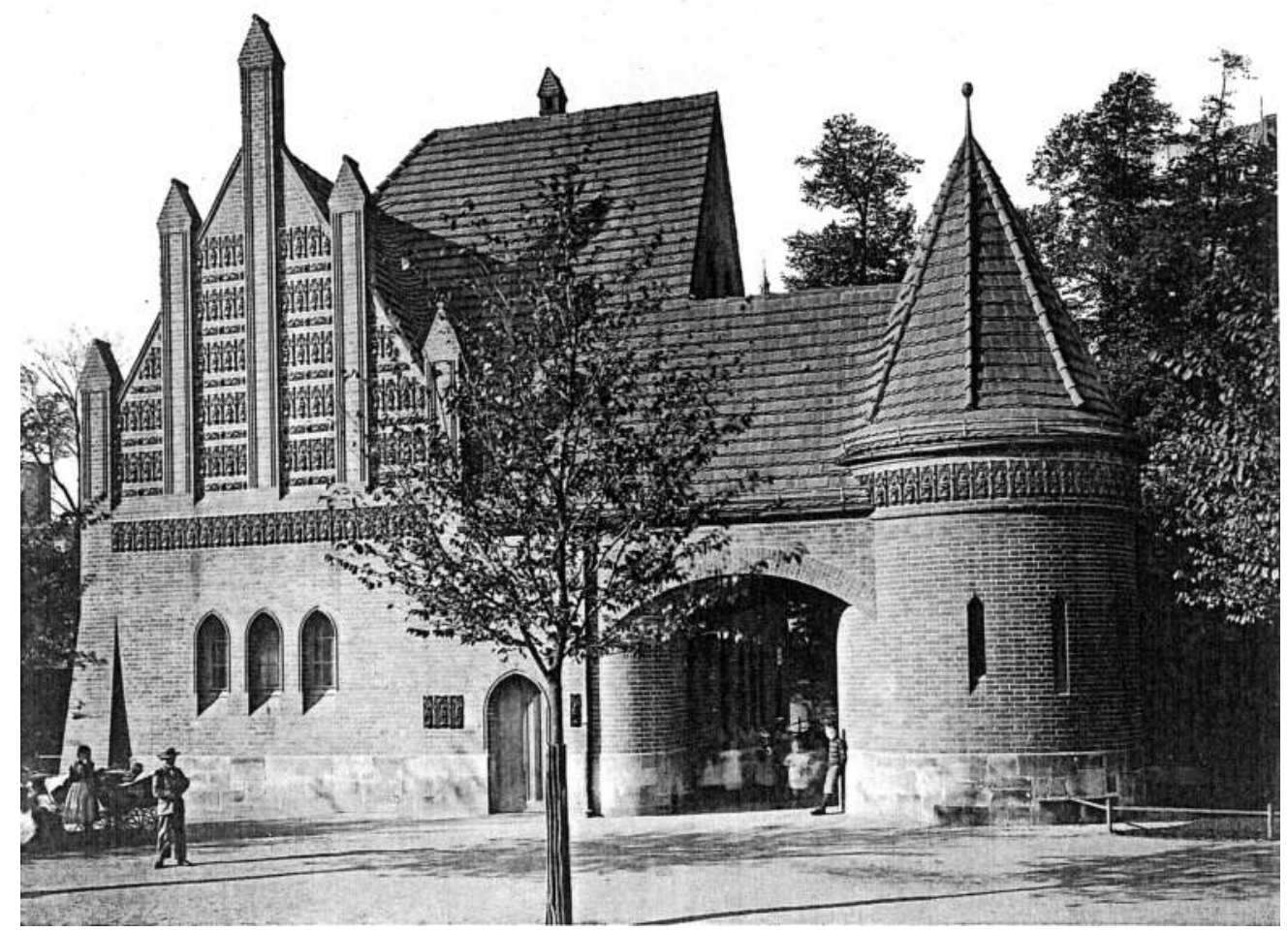

Abb. 12: Straßenreinigungsdepot im Köllnischen Park nach Entwürren von Ludwig Hoffmann, Aufnahme 1902.

7 Hoffmann, Lebenserinnerungen eines Architekten, S. 128.

8 Ebd. S. 129. 
Bemerkenswert erscheint, dass er sich von der architektonischen Wirkung des Ziergiebels erst im kleineren Maßstab am 1900/01 im Köllnischen Park erbauten Straßenreinigungsdepot - dem nachmaligen ,Bärenzwinger - eine genaue Anschauung verschaffte, ehe er den Turnhallenbau mit dem beherrschenden Stufengiebel der Klosterkirche selbstbewusst gegenüberstellte.

Will man vor diesem Hintergrund Hoffmanns architektonisches Selbstverständnis und seine damit einhergehende Entwurfsmethodik festmachen, so wird deutlich, dass er seine Architektur vor allem aus der eigenen Anschauung historischer Vorbilder entwickelte. Über das visuelle und haptische Erlebnis vertiefte er seine Erkenntnisse, indem er die Bauten, die er studierte, in der Regel zeichnerisch festhielt. Seine unzähligen Reiseskizzen vermitteln exakte Aufnahmen von Proportionen, Maßstäblichkeiten und Raumeindrücken von Bauten und ihren Beziehungen im urbanen wie naturräumlichen Kontext. Julius Posener vermutete, dass er zweierlei aus seinen Beobachtungen zu gewinnen trachtete: „Authentizität und Freiheit für die eigene Arbeit“.9 Das schloss bei seinen Kompositionen eben auch das bewusste Nachahmen einzelner Teile ein, wenn es die Gesamtwirkung seinem Verständnis nach erforderte. Den Inhalten funktional Rechnung tragend, suchten sich seine Bauten stets mit ihrer Umgebung zu arrangieren, ohne sich unterzuordnen. Jeder Bau, jede Gebäudekonstellation offenbarte sich in der Gestaltung als ein neuer Versuch, die ,richtige Lösung' zu finden. Bei Hoffmann wiederholte sich im Grunde nichts. Als historisch gebildeter Eklektiker schöpfte er immer wieder kreativ und neu. Seine ,Handschrift definierte sich deshalb nicht allein in der variablen Anwendung bestimmter wiederkehrender Formen, sondern in der Gewissenhaftigkeit und Sorgfalt für das Detail und damit in der Stimmigkeit des Ganzen. Auf die Wirkung seiner Bauten kam es ihm an; ihr galt sein künstlerisches Hauptinteresse, nicht der Entwicklung eines durchgängigen ,Stils. Was er von der Geschichte lernen wollte, war die richtige Wahl und der richtige Einsatz der architektonischen Mittel. Kunst ist Takt, schrieb er in seinen ,Lebenserinnerungen' und an anderer Stelle Kunst will Wahrheit. ${ }^{10}$ Das war die architektonische Doktrin, die seine Arbeit determinierte. Ihm ging es um die ,Verherrlichung der Schönheit', die damit verbundene Wirkung des Bauwerkes auf den Betrachter sowie den Sinn für harmonische Proportionen und die sorgfältig ausbalancierte Beziehung des Einzelnen zum Ganzen. Hoffmann entwarf eben nicht nur, sondern er komponierte seine Bauten beziehungsweise Gebäudegruppen im Kleinen wie im Großen und stellte sie in einen unauflösbaren Zusammenhang. Indem er sich gleichermaßen um das konstruktive Detail wie um den räumlichen Kontext bekümmerte, hatte er stets die ,Einheit der Dinge' im Auge. Und sie bestimmte letztlich auch die Gestaltung des Turnhallengebäudes, für die es bis zu diesem Zeitpunkt keine typologischen Vorbilder gab, den räumlichen Dialog mit der Klosterkirche sowie seine Einflussnahme auf die Platzierung und Gebäudeplanung der durch die Mitarbeiter entworfenen Neubauten. Insofern war das städtebaulich und architektonisch neugefasste Quartier des Gymnasiums eingedenk der Klosterkirche in seiner programmatischen Klarheit und stilistischen Vielfalt - wie es Julius Posener einmal pointierte - „unverwechselbar hoffmannsch, impressio-

9 Posener, Vorlesungen zur Geschichte der Neuen Architektur II, S. 11.

10 Widmung eines Portraitfotos von Ludwig Hoffmann, datiert November 1908. Das Foto befindet sich im Besitz des Verfassers. 
nistisch, fortschrittlich, beruhigend und (im Sinne des gesellschaftlichen Selbstverständnisses) dabei durchaus autoritär". ${ }^{11}$
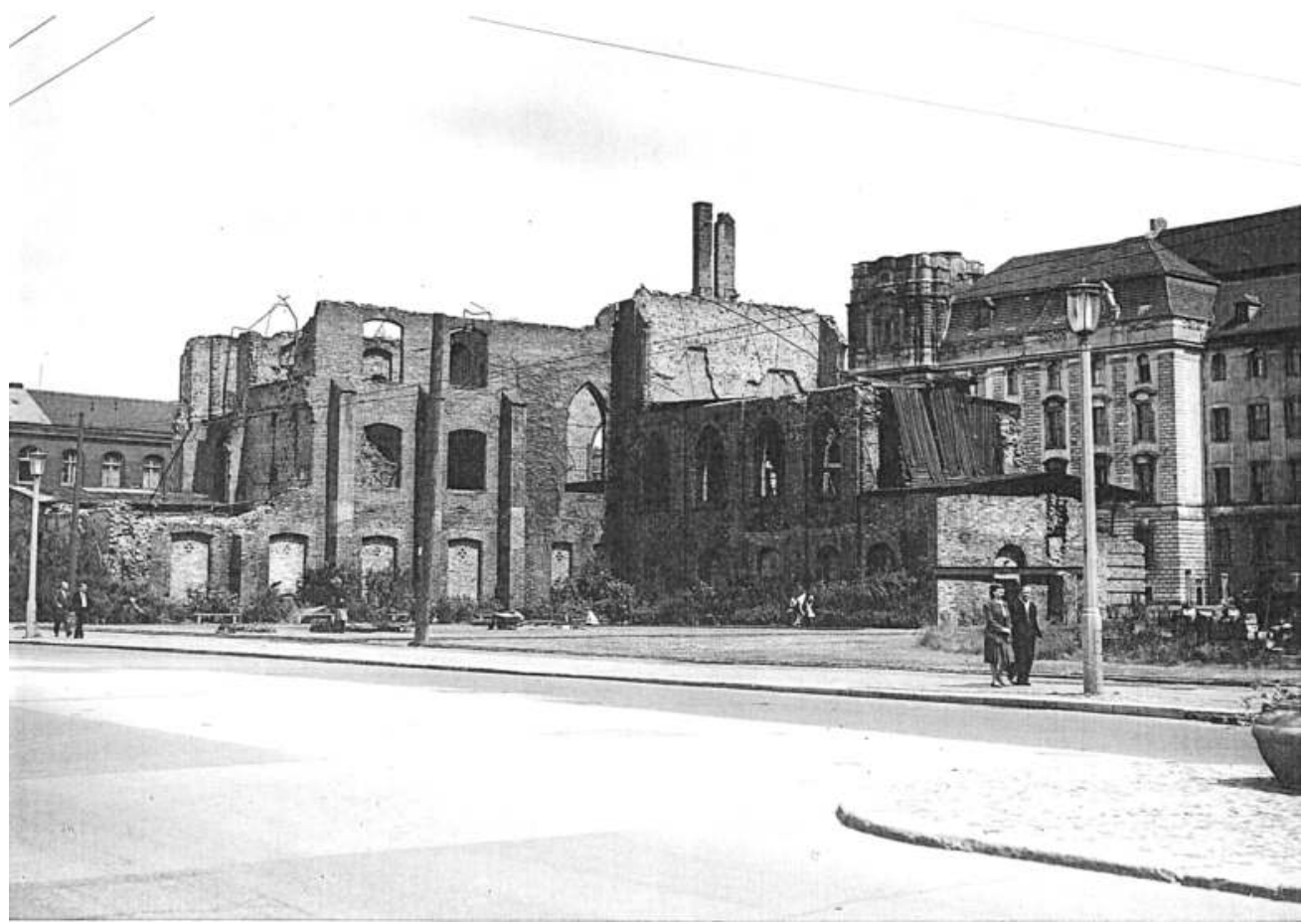

Abb. 13: Gebäudereste des Schulhauses von der Klosterstraße gesehen, Aufnahme 1959.

Das von Ludwig Hoffmann so unverwechselbar geprägte Gebäudeensemble des Gymnasiums zum Grauen Kloster existiert nicht mehr. Die letzten beschädigten und wiederaufbaufähigen Gebäudeteile, die den Bombenkrieg und die rigorosen Geschichtstilgungen der Nachkriegszeit noch überdauert hatten, wurden Anfang der 1960er-Jahre zugunsten der stadtzerstörenden Schneise der Grunerstraße mit ihrer maßstabslosen Tunnelführung beseitigt. Allein die ob ihrer hohen handwerklichen Qualität noch als Ruine beeindruckende Klosterkirche ist auf die Gegenwart überkommen und verlangt in ihrer unwirtlichen wie schamlosen Freistellung nach stadträumlicher Einbettung. Insofern sollte die nun gebotene Chance wahrgenommen werden, das Gymnasium im Rahmen der anstehenden Neubebauung des Klosterviertels und des Molkenmarkts an seinen einstmaligen historischen Ort zurückzubringen und in räumlicher Korrespondenz zur Ruine der Klosterkirche - gleichsam als Geschichtsanker - wieder erstehen zu lassen. Seine städtebauliche Restituierung würde angesichts seiner für die Stadtgeschichte so hohen Bedeutung - wie die geplante Wiederherstellung des Jüdenhofs - somit ein bewusstes Zeichen der 
Versöhnung von Vergangenheit und Gegenwart setzen. Der historische Bezug sollte dabei jedoch primär an den architekturräumlichen Charakteristika der einstmaligen Gebäudekonfiguration des die Kirche umgebenden Gymnasiums orientiert sein; das heißt an deren Proportion, Maßstäblichkeit, Massenverteilung und Materialität, nicht aber an der einstmaligen architektonischen Gestaltung in Form einer Rekonstruktion. So könnte im produktiven Dialog von Alt und Neu die Geschichte in die Zukunft fortgeschrieben werden. 

Sibylle Schulz

\section{Die Klosterkirche zu Berlin - Ruinendenkmal seit 1945}

\section{Einleitung}

In den Jahren 2002 bis 2005 fand die jüngste umfassende Sicherung und Restaurierung der Kirchenruine des Franziskanerklosters in Berlin statt, rund 20 Jahre nach der vorherigen. Bereits 1999 begannen die Vorbereitungen unter Leitung des Landesdenkmalamtes Berlin. Die Ergebnisse

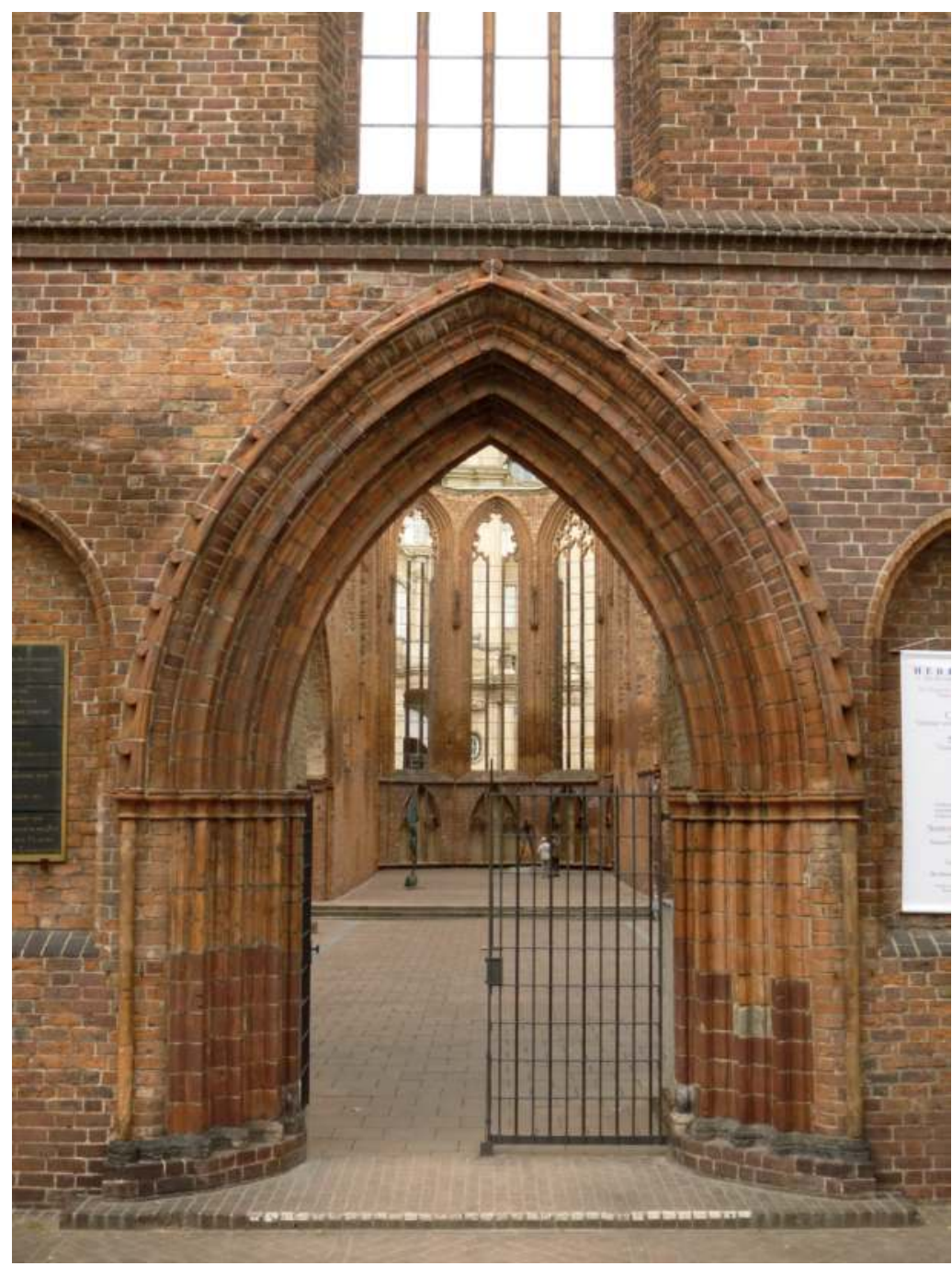

Abb. 1: Berlin-Mitte, Ruine der Franziskanerklosterkirche, Blick durch das Hauptportal an der Klosterstraße in die Ruine, 2013. 
von Quellenforschung, Bestands- und Schadensaufnahme, Voruntersuchungen, archäologischen Grabungen und die Sanierung sind zusammengefasst im 2007 vom Landesdenkmalamt Berlin herausgegebenen Sammelband zur ,Kirchenruine des Grauen Klosters in Berlin. Hierauf und auf den Erfahrungen der Autorin aus ihrer Tätigkeit als Denkmalpflegerin basiert dieser Beitrag. ${ }^{1}$

Ausgiebige Vorbereitungsarbeiten waren erforderlich, um die Aspekte zur Bedeutung dieses besonderen Denkmals in der Gegenwart und für die Zukunft herausarbeiten und das dafür verantwortbare denkmalpflegerische Konzept entwickeln zu können. Bereits nach den ersten Untersuchungen, die die Dringlichkeit praktischer Maßnahmen noch einmal deutlicher vor Augen führten, fanden Beratungen mit allen Beteiligten statt, deren Kreis sich mit dem Fortschreiten der Grundlagenermittlung und Planung erweiterte. Einbezogen wurden Vertreter des Bezirksamtes Mitte von Berlin als Eigentümer, des Fördervereins Klosterkirchenruine e. V. und des Fördervereins des Evangelischen Gymnasiums zum Grauen Kloster - Berlinisches Gymnasium in BerlinMitte e. V., die Senatsverwaltung für Stadtentwicklung, erfahrene Spezialisten aus Architektur, Denkmalpflege und Archäologie, Kunstgeschichte, Geschichte, Bauforschung und Restaurierung. Als nach und nach das Sanierungskonzept herausgearbeitet und Fördermittel akquiriert werden konnten, hatten auch die Förderer die Möglichkeit, die Entscheidungen zu verfolgen; ${ }^{2}$ es wurde ein vorbildliches interdisziplinäres Projekt der Berliner Denkmalpflege, das treuhänderisch als Eigentümervertreterin die S.T.E.R.N GmbH managte. ${ }^{3}$

\section{Zur Entscheidung für die Bewahrung als Ruinendenkmal am Anfang des 21. Jahrhunderts}

Der Weg zur Entscheidung für die Erhaltung des Klosterkirchenfragmentes als Ruinendenkmal in der überlieferten Form war langwierig. Viele Aspekte waren zu berücksichtigen und die möglichen Varianten auf ihre Vor- und Nachteile mit den Beteiligten zu prüfen. Dabei wurden verschiedene Lösungen der Präsentation und deren Folgen dargestellt, untersucht und diskutiert: die Überdachung der Ruine, ein teilweiser oder vollständiger Wiederaufbau der Kirche, die Bewahrung des Ensembles als Ruinendenkmal. Jede Variante hatte Befürworter und Gegner. Die Entscheidung musste auf eine wissenschaftliche Grundlage gestellt werden. ${ }^{4}$

Gegen die Bewahrung im ruinösen Zustand sprachen zunächst Bedenken im Hinblick auf die langfristige Erhaltung der historischen Substanz und auf den Aufwand der Baupflege. Der Austausch mit Kollegen und Kolleginnen aus anderen Bundesländern, in denen Ruinendenkmalpflege ein Teil des Alltags ist, zeigte schlüssige Lösungen. Nach einer eingehenden Schadensdokumentation und Ursachenforschung konnten die Bedenken ausgeräumt werden. Es stellte

1 Landesdenkmalamt Berlin (Hrsg.), Kirchenruine des Grauen Klosters in Berlin. Geschichte - Forschung - Restaurierung (Beiträge zur Denkmalpflege in Berlin, Bd. 23), Petersberg 2007.

2 Die Restaurierung von 2002 bis 2005 wurde finanziell unterstützt durch die Beauftragte für Kultur und Medien (BKM), Cornelsen-Stiftung, Stiftung Deutsche Klassenlotterie, Deutsche Stiftung Denkmalschutz, Förderverein Klosterkirchenruine e. V., Förderverein Evangelisches Gymnasium Graues Kloster Berlin Mitte e. V.

3 Federführend bei der S.T.E.R.N GmbH (Berlin) war Dipl.-Ing. Helmut Schermeyer.

4 Das Landesdenkmalamt Berlin führte zu diesen Varianten ein wissenschaftliches Kolloquium durch. Die Beiträge sind nachzulesen in: Landesdenkmalamt Berlin, Die Klosterruine. Eine Innenstadtruine mit Zukunft. Texte des Kolloquiums im Palais Podewil am 11.04.2002, Berlin 2002, unveröff. Typoskript. 
sich heraus, dass der Pflegeaufwand nicht höher ist als bei anderen Bauten, wenn die Sanierung denkmalpflegerisch sowie bautechnisch sachgerecht ausgeführt wurde.

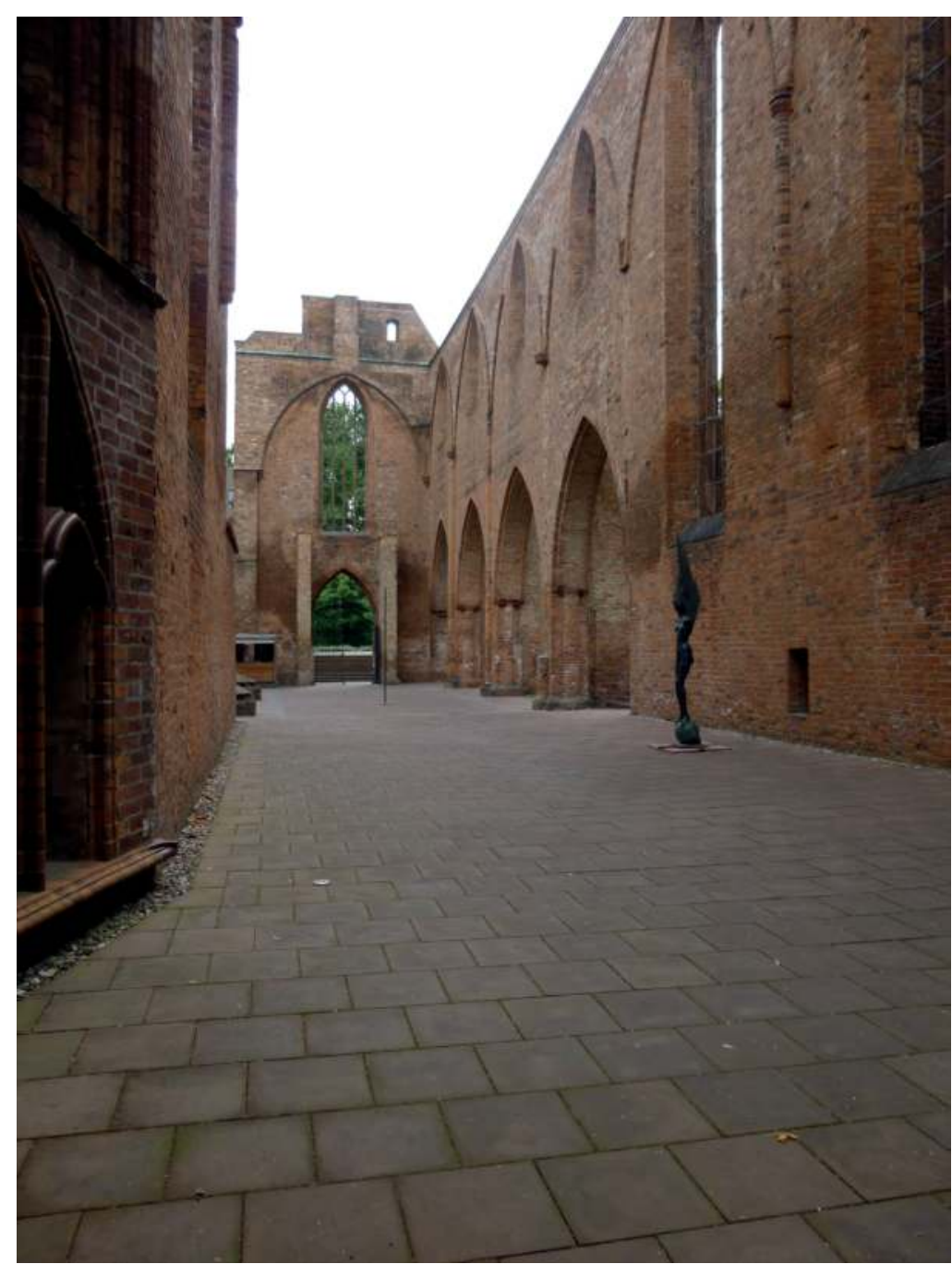

Abb. 2: Berlin-Mitte, Ruine der Franziskanerklosterkirche, Blick durch das Mittelschiff nach Westen zum Hauptportal, 2013.

Der teilweise oder vollständige Wiederaufbau der Kirche verlangt umfassende Nutzungs-, Finanzierungs- und Eigentümerkonzepte. Jede Nutzungserweiterung, die über die bisherige Nutzung als Veranstaltungsraum für Ausstellungen und Sommerkonzerte hinausgeht, zieht An-, Ein- und/ oder Umbauten nach sich. Der Erhaltungs- und Betreibungsaufwand erhöht sich. Im Raum stand auch die Frage, ob Berlin einen weiteren (wiederhergestellten) Kirchenbau mit teilweiser oder neuer Nutzung braucht, wenn etliche Gotteshäuser wegen kontinuierlich sinkender Mitgliederzahlen aufgegeben werden. Unweit des Klosterareals wurde der Neuaufbau der kriegszerstörten 
und nach 1945 beräumten Petrikirche vorgesehen. In unmittelbarer Nachbarschaft wurde die Parochialkirche mit viel Aufwand über Jahre hinweg in einen denkmalgerechten, pflegefähigen und nutzbaren Zustand gebracht, dessen dauerhafte Erhaltung für die Kirchengemeinde kaum leistbar ist. Die archäologischen Untersuchungen für das Klosterareal hatten noch nicht begonnen und der Weiterbau der Kirchenruine zum damaligen Zeitpunkt schien im Hinblick auf die offene Zukunft des Quartiers weder verantwortbar noch sinnvoll, da es kein ausgereiftes Entwicklungskonzept gab. Darüber hinaus sind Rekonstruktion und Ausbau keine denkmalpflegerische Aufgabe und an der Klosterkirche für die dauerhafte Bewahrung des historischen Fragmentes aus konservatorischen Gründen nicht erforderlich.

Ein Schutzdach, und hier waren sowohl ein Interims- als auch ein langjähriges in Betracht gezogen worden, hätte die notwendigen substanzerhaltenden Maßnahmen nicht ersetzt, jedoch zu einer enormen optischen Veränderung der vorhandenen Situation geführt. Es hätten beachtliche bautechnische Voraussetzungen geschaffen und Eingriffe in die archäologisch bedeutsamen Flächen inner- wie außerhalb der Gemäuer durchgeführt werden müssen.

Viele Menschen - unmittelbar Beteiligte, Berliner und Gäste der Stadt, Fachleute wie Kulturinteressierte - äußerten Vorstellungen und Wünsche, doch was wirklich verantwortbar war, musste erst sorgfältig herausgearbeitet werden. Am Anfang des Entscheidungsweges, bevor die Konsequenzen klar wurden, die ein Schutzdach bedeutet hätte, machte die Unterzeichnete als verantwortliche Denkmalpflegerin diese Version publik. Daraufhin kam die Diskussion auch teilweise öffentlich in Schwung.

Unabhängig von formalen, gestalterischen, baulichen oder finanziellen Fragen war zu klären, was uns - den Menschen heute, gleich ob vom Fach oder nicht - die Kirchenruine des Franziskanerklosters bedeutet. Es wurde verschiedenen Fragen nachgegangen, zum Beispiel, welchen Identifikationswert sie hat, welche besonderen Merkmale innerhalb der Denkmallandschaft von Berlin sie aufweist, wie der Dokumentationswert eingeschätzt wird und welche Wirkung über Berlin hinaus besteht. Wie kam es überhaupt zum heutigen Zustand?

\section{Vom Trümmerhaufen 1945 zum Ruinendenkmal und zur Großstadtruine}

Eine Rückschau in die Nachkriegsjahre macht die Entwicklung des ehemaligen Klosterareals zur gegenwärtigen Denkmalanlage mit Grünfläche sowie dessen Bedeutung innerhalb der heutigen Denkmallandschaft in Berlin verständlich. Dabei spielen denkmalpflegerisch-fachgeschichtliche Aspekte und die Aufbauideen für die zerstörte historische Mitte Berlins eine große Rolle.

Das Schulgebäude und die Kirche waren im April 1945 bis auf die Umfassungsmauern zerstört worden, sie waren Teil der Trümmerlandschaft im historischen Zentrum von Berlin. Seit der Zerstörung der Kirche hatten mehrere Einflüsse zu weiteren Substanzverlusten geführt, wie sich den handschriftlichen Aufzeichnungen und Fotos des Bodendenkmalpflegers Wolfgang Gehrke aus 


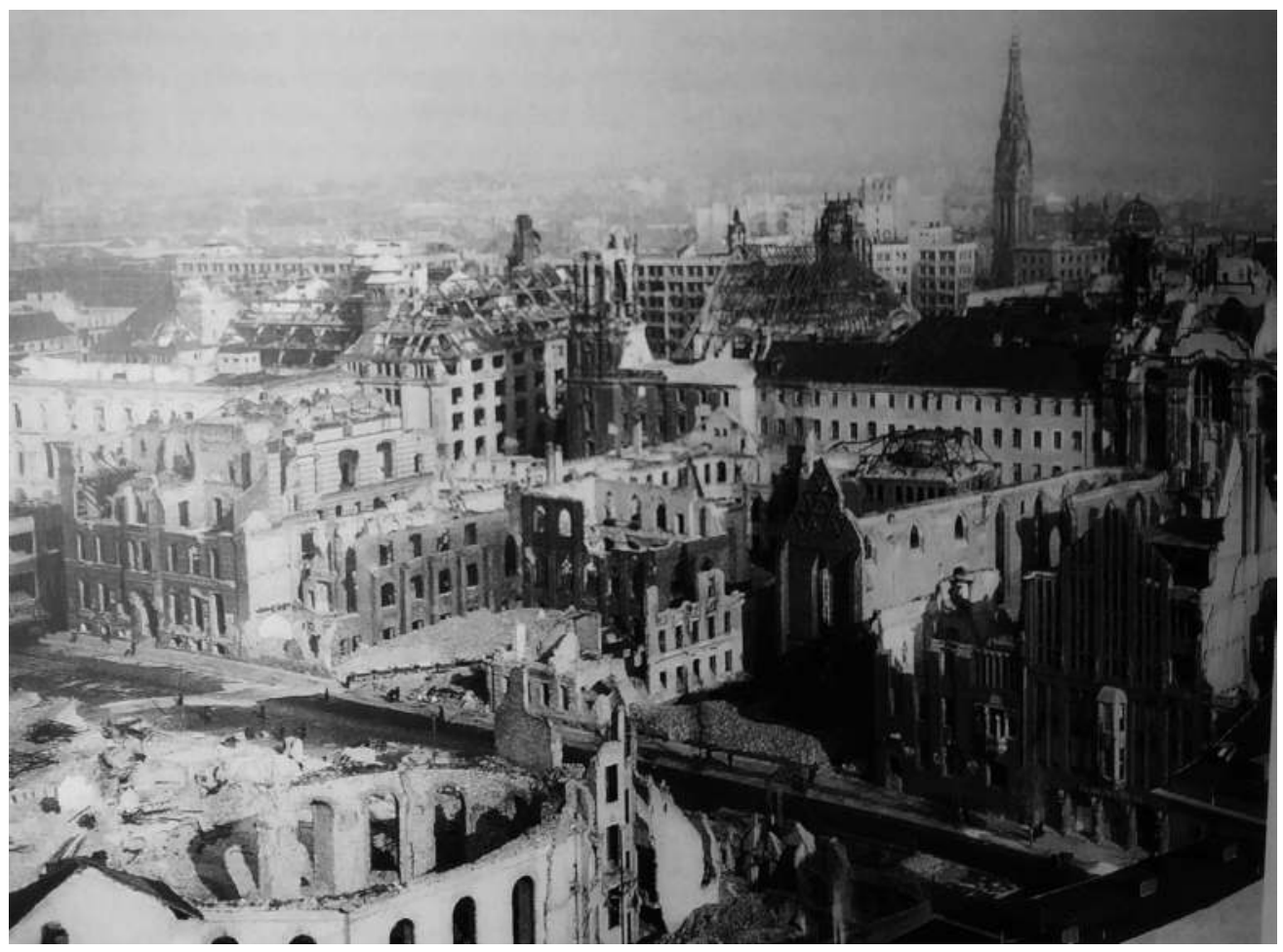

Abb. 3: Berlin-Mitte, die Trümmerlandschaft nach Kriegsende, 1947.

den Jahren 1949/50 entnehmen lässt. ${ }^{5}$ Die Menschen durchstöberten in ihrer Not die Trümmer nach Heizholz und so ging zum Beispiel das Gestühl komplett verloren. Ohne Kirchendach wurden die bemalten Putzreste im Chorbereich abgängig, ebenso die Bausubstanz. Manch ein Ausstattungsstück, zum Beispiel Grabmale, konnte ausgegraben und in den Bestand des Märkischen Museums überführt werden. Die klosterformatigen Backsteine der Kirche dienten als Material für den Umbau der Schlüter-Kanzel in der benachbarten Marienkirche.

Immer wieder wurden in den Folgejahren Sicherungen zur Schadensabwehr für Menschen durchgeführt. Mit diesen Arbeiten gingen kleinere Abrisse einher, insbesondere nachmittelalterlicher Substanz, der aus fachgeschichtlich-denkmalpflegerischer und kunsthistorischer Sicht damals noch nicht die heutige Anerkennung zukam. Einen großen Verlust bedeutete der Einsturz des fragilen Westgiebels im Zusammenhang mit dem Bau des U-Bahntunnels bis 1952 (dem sogenannten Klostertunnel), der nach der Spaltung der Stadt und der damit einhergehenden Trennung der Berliner Verkehrsbetriebe seitens Berlin (Ost) als erforderliche Maßnahme entschieden und realisiert worden war; Schäden an Gebäuden sind seit alters her leider immer wieder eine Begleiterscheinung bei Tiefbauarbeiten.

5 Wolfgang Gehrke, Die Klosterkirche im November 1949. Faksimile und Abschrift, in: Landesdenkmalamt, Kirchenruine des Grauen Klosters, S. 142-150. 
Auf Unverständnis heute trifft häufig der Zustand der Freifläche zwischen Ruine und Verkehrsader, die teilweise die Lage des Klosters abbildet. Moderne Städtebauvisionen des frühen 20. Jahrhunderts und Planungen für den Umbau Berlins zu einer verkehrsgerechten Stadt seit den 1930er-Jahren bringen hierzu Einblicke.

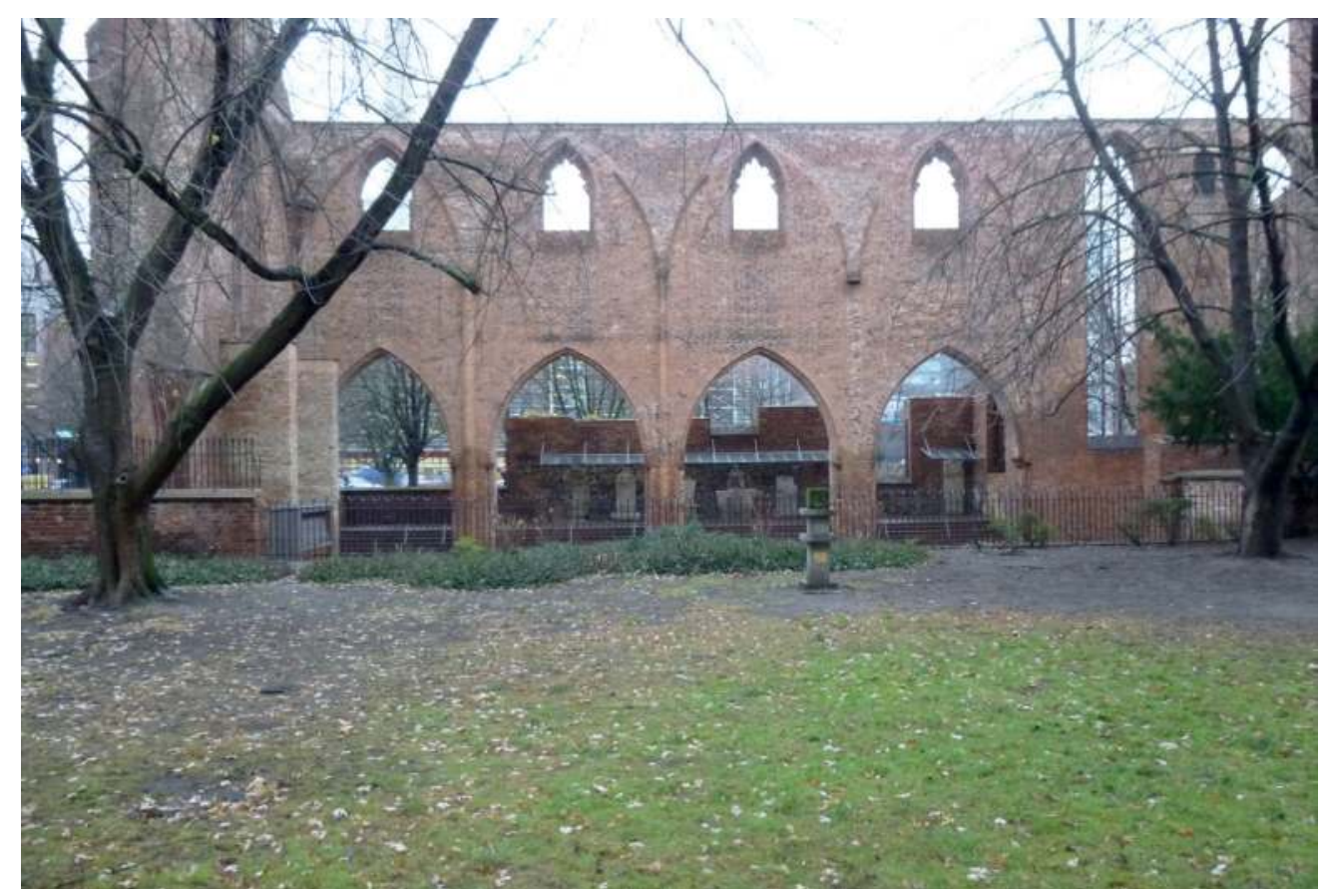

Abb. 4: Die Kirchenruine des Franziskanerklosters, von Süden betrachtet, 2018.

Nachdem Hans Scharoun am 17. Mai 1945 von der sowjetischen Militärregierung zum ersten Stadtbaudirektor Berlins nach Kriegsende berufen worden war und den Wiederaufbau zu konzipieren hatte, entstanden erste Aufbau-Pläne, die von Berlin als einheitlichem Stadtorganismus ausgingen, so auch der Kollektivplan 1945/46 von Scharoun und dessen Team. ${ }^{6}$ Ausgehend von der durch die Kriegszerstörungen aufgelockerten Stadt wurde eine Stadtlandschaft vorgeschlagen, die sogenannte Bänderstadt; es sollte auf den natürlichen Gegebenheiten der Lage im Urstromtal aufgebaut werden - die Verkehrsadern sollten als Tangenten am Zentrum um den Alexanderplatz herum verlaufen und die Ost-West-Achse sollte durchgezogen werden. Diese zwischen 1935 und 1943 unter Adolf Hitler entwickelte Achse war bereits Teil der Verkehrsplanung für Berlin als ,Welthauptstadt Germania', die auf Albert Speer als ,Generalbauinspektor für die Reichshauptstadt' (GBI) zurückgeht. Von der 50 Kilometer langen Verkehrsader zwischen Wustermark im Westen und der Frankfurter Allee im Osten wurde bis 1939 mit viel Umbauauf-

6 Dem Planungskollektiv gehörten die Architekten und Stadtplaner sowie Garten- und Landschaftsplaner Wils Ebert, Peter Friedrich, Ludmilla Herzenstein, Reinhold Lingner, Louise Seitz, Selman Selmanagić und Herbert Weinberger an. Andere wichtige Konzepte waren der Bonatz-Plan und der Zehlendorfer Plan. 
wand eine sieben Kilometer lange Teilstrecke realisiert, deren Kernstück die Siegessäule auf dem Großen Stern wurde. ${ }^{7}$

Der Kollektivplan sah die radikale Umgestaltung des historischen Stadtzentrums vor. Das Berlin der Nachkriegszeit sollte mit modernen Grundstrukturen das neue gesellschaftliche Konzept abbilden. Rücksicht auf vorhandene historisch gewachsene Strukturen wurde dabei nicht genommen, das teilweise sehr zerstörte Berlin wurde als Chance begriffen, Städtebau-Visionen der Moderne der 1920er-Jahre zu realisieren. ${ }^{8}$ Die Tatsache, dass dafür die unterirdische, für die Stadt unverzichtbare Infrastruktur nicht kriegszerstört war, jedoch völlig neu hätte erstellt werden müssen, verhinderte die radikale Abkehr vom gewachsenen Stadtgrundriss und trug wesentlich zu einem respektvolleren Umgang vor allem mit den Quartieren bei, die unmittelbar an die historische Mitte Berlins angrenzen, aber auch mit anderen Stadtbezirken. Gleichzeitig wurden historische Gebäude als Erinnerungsmonumente einbezogen. ${ }^{9}$

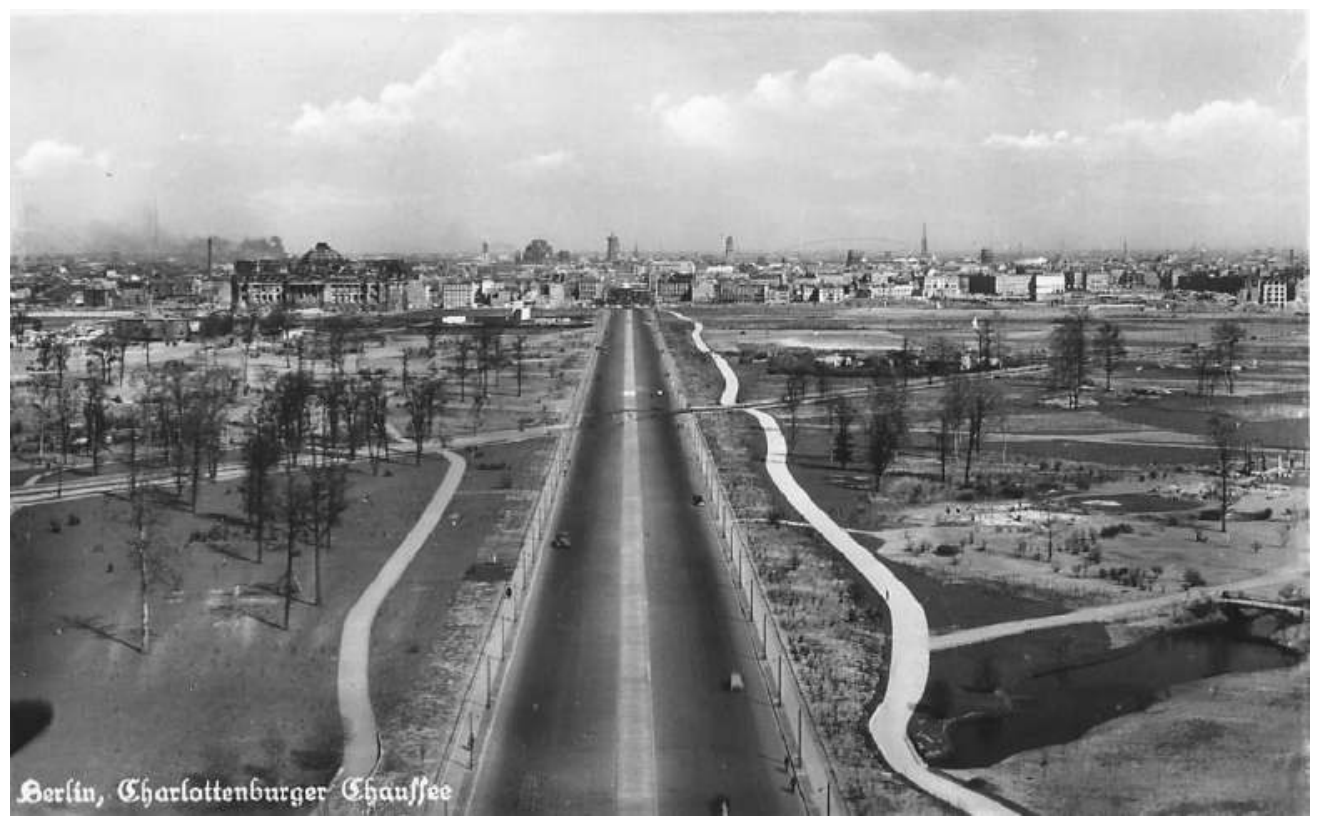

Abb. 5: Berlin, historisches Zentrum, Straße des 17. Juni nach 0sten, 1945.

$7 \quad$ Albert Speer, Das künftige Gesicht der Reichshauptstadt (1938), in: Vittorio Magnago Lampugnani/Katia Frey/ Eliana Perotti (Hrsg), Anthologie zum Städtebau, Bd. 2: Das Phänomen Großstadt und die Entstehung der Stadt der Moderne, T. 2, Berlin 2014, S. 1423.

8 Gabi Dolff-Bonekämper/Franziska Schmidt (Fotos), Das Hansaviertel. Internationale Nachkriegsmoderne in Berlin, Berlin 1999; Le Corbusier, Entretien avec les étudiants des écoles d’architecture, Paris 1943; Charta von Athen 1933, verabschiedet auf dem IV. Internationalen Kongress für neues Bauen in Athen. Der Kongress hatte das Thema ,Die funktionale Stadt‘

9 Sibylle Schulz, Das IBA-Ausstellungsgelände ,Hansaviertel' in Berlin, in: Vittorio Magnago Lampugnani/Konstanze Sylva Domhardt (Hrsg.), Die Stadt der Moderne. Strategien zu Erhaltung und Planung, Zürich 2016, S. $138-165$. 
Als 1949 mit der Gründung der beiden deutschen Staaten die Teilung Berlins besiegelt wurde, ging die Verkehrsplanung mit der durchgehenden Ost-West-Achse nicht mehr auf, der dritte Abschnitt mit der Straße Unter den Linden endete am Brandenburger Tor als Sackgasse. Die bisherigen Planungsansätze wurden nunmehr auf die neue Situation zugeschnitten und in den ,16 Grundsätzen des Städtebaus' vom 27. Juli 1950 definiert. ${ }^{10}$ Bereits im April in der Sowjetunion verfasst, waren sie das Leitbild für den Städtebau in der Deutschen Demokratischen Republik (DDR). Die Idealvorstellungen der, sozialistischen Stadt' orientierten sich am Vorbild der Sowjetunion und brachten für die erste Wiederaufbauphase den Stil des ,sozialistischen Klassizismus' hervor. Die heutige Karl-Marx-Allee im Bereich Strausberger Platz bis Frankfurter Tor ist stilistisch beispielhaft dafür.

Hierauf basierten die Grundsätze für die Neugestaltung der Berliner Innenstadt vom 23. August 1950, schließlich wurde am 6. September des Jahres das ,Gesetz über den Aufbau der Städte in der Deutschen Demokratischen Republik und der Hauptstadt Deutschlands, Berlin (Aufbaugesetz) verabschiedet, das die Durchführungsbestimmungen festlegte. ${ }^{11}$ Eine großzügige, in die Zukunft weisende Verkehrsregelung sollte die Verknüpfung des Zentrums mit den ausgedehnten Wohnquartieren, die im 19. Jahrhundert als ,Prenzlauer Berg' entstanden waren, gewährleisten. Die Verkehrsleitung entlang der Stralauer Straße in den Süden und die Option, die Leipziger Straße zu einer modernen Geschäftsstraße zu entwickeln, wurden festgeschrieben. Das führte 1964 bis 1969 zum Ausbau der Grunerstraße, mit deren Verbreiterung die Fahrbahnen an das Klosterareal stießen. ${ }^{12}$ Der östliche Abschnitt zwischen Frankfurter Tor und Strausberger Platz wurde mit der heutigen Karl-Marx-Allee als erstem Bauabschnitt ab 1952 realisiert und erfuhr eine Fortsetzung als breite Verkehrsmagistrale bis zum Alexanderplatz, wo die Hauptstraßen als Tangenten um das für die Zentrumsplanung der Hauptstadt der DDR abgesteckte Gebiet des ehemaligen historischen Zentrums zwischen heutiger Karl-Liebknecht-, Gruner- und Dircksenstraße und der Spree herumgeführt wurden. Für diesen Kernbereich mit Alexanderplatz und Marx-Engels-Forum (heute wieder Schloss-Komplex im westlichen Teil) entstanden ab 1950 verschiedene Entwürfe mit Höhenvarianten, die die Kirchenbauten von Sankt Marien und von Sankt Nikolai als Solitäre einbezogen, wohingegen auf den Berliner Dom in manchen Darstellungen verzichtet worden war. Der Hauptstadt-Wettbewerb 1964 brachte die Entscheidung für den Entwurf mit Fernsehturm von Hermann Henselmann und Kollektiv. Aus diesen Planungen wurde endgültig klar, dass die natürlich gewachsenen Wege zum Kloster-Quartier nicht weiter Bestand haben würden.

Es gab Versuche, die Tragweite der neuen Planung in Bezug auf das Kloster zu mildern. 1954 schlug Bodo Köttler den Wiederaufbau für eine Schule vor, jedoch nicht als akribische Rekonstruktion einer bestimmten Zeitschicht über den Grundmauern. Das zeigt der Vergleich mit dem Trümmerfeld des Areals nach Kriegsende, mit älteren Aufnahmen oder auch mit dem rekonstruierten Grundriss des Klosters auf der Grundlage eines Lageplans um 1700. Beispielsweise wurde auf die

10 Lothar Bolz, Von deutschem Bauen. Reden und Aufsätze, Berlin (Ost) 1951, S. 32-52.

11 Gesetz über den Aufbau der Städte in der Deutschen Demokratischen Republik und der Hauptstadt Deutschlands, Berlin (Aufbaugesetz) vom 6. September 1950, in: Gesetzblatt der Deutschen Demokratischen Republik, Jahrgang 1950, Nr. 104 vom 14. September 1950.

12 Thomas Topfstedt, Städtebau in der DDR 1955-1971 (Seemann-Beiträge zur Kunstwissenschaft), Leipzig 1988, S. 70 . 


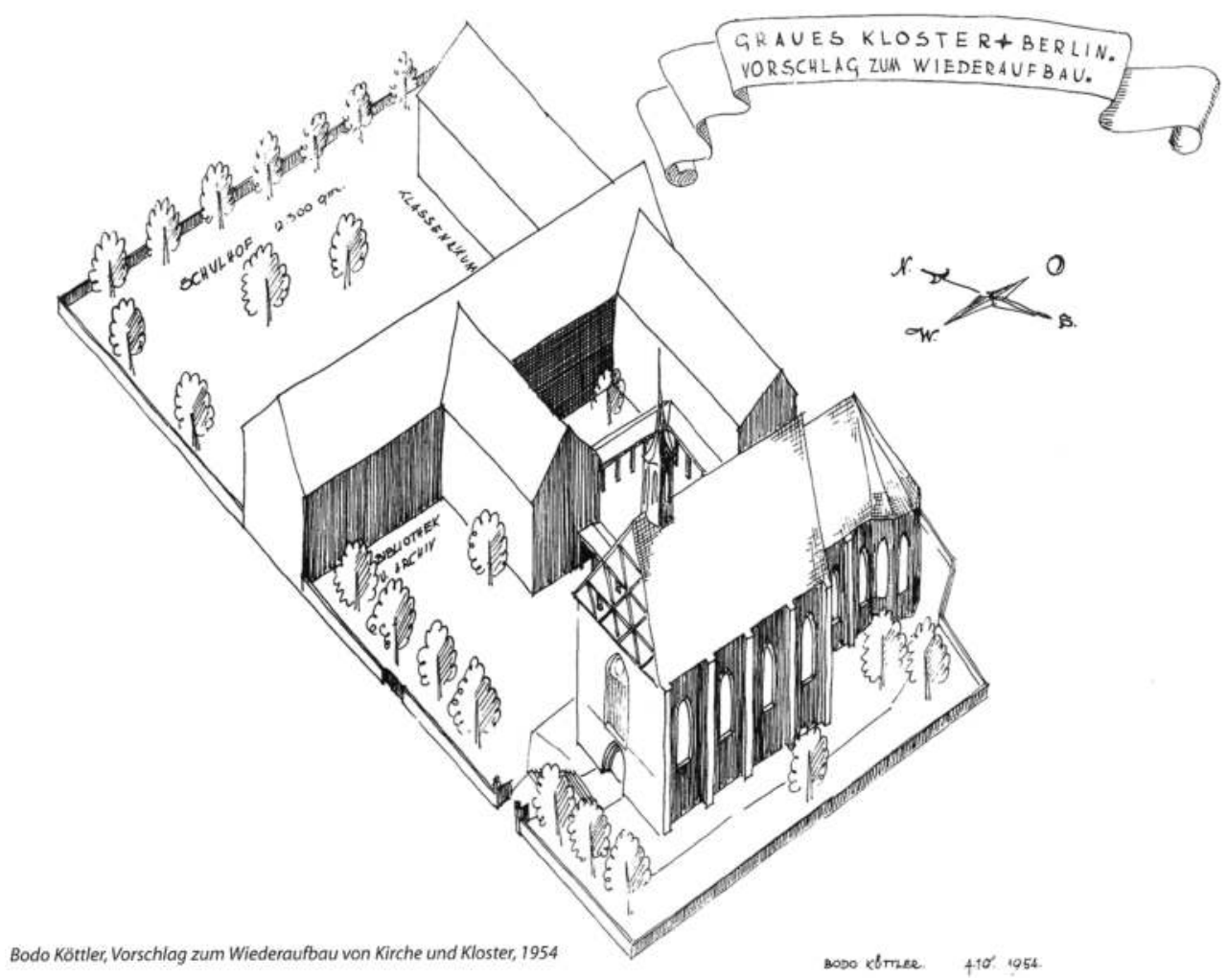

Abb. 6: Bodo Köttler, Vorschlag zum Wiederaufbau von Kirche und Kloster, 1954.

langen Gebäude an der Nordseite und an der Klosterstraße verzichtet wie auch auf die Wiederherstellung der städtebaulich prägnanten Stülerschen Säulenhalle aus dem 19. Jahrhundert.

Das Kloster-Areal stand jenseits des Planungszentrums und am Rande der Aufmerksamkeit, jedoch schien seine Erhaltung unstrittig, denn auch hier wurden bereits unter Scharoun Sicherungen durchgeführt. Auf dem Quartier lag kein Nutzungsdruck, die Schule zum Grauen Kloster hatte neue Domizile im östlichen und dann auch im westlichen Teil von Berlin gefunden. Ohne Anspruch auf eine wirtschaftliche Nutzung und in Anbetracht der Zentrums-Planungen war aus heutiger Sicht die Bewahrung der Klosterkirche als Ruinendenkmal mit Mahnmal-Funktion eine verantwortungsvolle, in die Gedenkkultur der zukünftigen Generationen reichende Entscheidung. ${ }^{13}$ Die Sicherung der Klosterkirchen-Ruine 1959 bis 1963 unter Leitung von Klaus Pöschk führte zur heutigen DenkmalRuine, hergerichtet als ,Mahnmal für die Schrecken des Krieges', eingebettet in eine Grünfläche. ${ }^{14}$

13 Heinz Seyer, Berlin im Mittelalter, Berlin 1987, S. 120: „Die Ruine der Klosterkirche ist seit mehr als drei Jahrzehnten Mahnmal für die Zerstörung Berlins durch anglo-amerikanische Bomber.; Archiv Landesdenkmalamt Berlin, Akte zum Vorgang ,Klosterkirche‘ 1945-1981.

14 Klaus Pöschk, Bauvorbereitende Untersuchungen der Franziskaner-Klosterkirchenruine, Bestandserfassung und Schadenskartierung, in: Landesdenkmalamt, Kirchenruine des Grauen Klosters, S. 168-179; Archiv Landesdenkmalamt Berlin, Akte zum Vorgang ,Klosterkirche‘ 1945-1981. 
Mit dem modernen Umbau des Zentrums von Ost-Berlin - zu verstehen auch als Symbol für die Überwindung von Krieg und Gewaltherrschaft - verschwanden die Ruinen und damit die historischen Strukturen, die (Welt-)Geschichte wurde in situ unlesbar. Diese Entwicklung stärkte die Mahnmal- und Erinnerungs-Funktion des ruinösen Kloster-Komplexes.

Nachdem 1968 die Reste der Schulgebäude abgetragen worden waren, erhielt die Grünfläche ihre heutige Gestaltung mit den zweireihig gepflanzten Bäumen, die die Gesamtanlage nach der Gruner- und der Littenstraße hin säumen und dem Ruinen-Denkmal einen schützenden Raum bieten, während die Erschließung an der Klosterstraße über eine Freitreppe hinab zum gotischen Hauptportal die mittelalterliche Höhenlage der Stadt erfahrbar macht. 1970 wurde das Denkmal für eine einfache Ruinennutzung hergerichtet, die über das Sommerhalbjahr Ausstellungen und Konzerte ermöglichte.

Die Instandsetzung in den Jahren 1982 bis 1990 wurde auf der Grundlage der denkmalpflegerischen Zielstellung ,Zur Erneuerung der Ruinensicherung' des Instituts für Denkmalpflege, Arbeitsstelle Berlin (Ost), durchgeführt. Die praktischen Maßnahmen leiteten sich aus dem Bauzustand sowie aus der historischen Bewertung des Denkmals her. Der Kunsthistoriker und Denkmalpfleger Ernst Badstübner stellte die Geschichte und Bewertung im Zusammenhang mit der Bedeutung des Grauen Klosters als Bildungsstätte für die Gesamtanlage und für Berlin dar. Der Mahnmal-Begriff wurde nicht benutzt. Bei der dringend erforderlichen Sicherung ging „das Institut für Denkmalpflege davon aus, dass die Integration der gesicherten und gepflegten Ruine der mittelalterlichen Kirche in den städtebaulichen Rahmen der neuzeitlichen und jüngsten Zentrumsbebauung gelungen ist. Bei den Instandsetzungen soll deshalb auf die Beibehaltung dieses Konzepts der Erhaltung und Denkmalpräsentation orientiert werden." ${ }^{15}$ - Das Klosterkirchen-Fragment war zu der Zeit längst eine ,anerkannte Ruine' geworden. Die politischen Gremien respektierten das denkmalpflegerische Ziel und es wurde auf den Ausbau zu einem wirtschaftlichen Denkmal verzichtet.

\section{Zur Bedeutung der Klosterkirchenruine}

Die im letzten Drittel des 13. Jahrhunderts errichtete Bettelordenskirche ist einer der ersten vollständig in Backstein ausgeführten Bauten in Berlin und steht im Raum Berlin-Brandenburg mit seinen repräsentativen Merkmalen stilistisch am Anfang der gotischen Backsteinkunst. ${ }^{16}$ Mit den Zerstörungen im Zweiten Weltkrieg versank auch das ehemalige Franziskanerkloster, dem das historische Klosterviertel seinen Namen verdankt, in Schutt und Asche. Das Fragment der Klosterkirche wird seither als Ruinendenkmal und Großstadtruine präsentiert. Es erinnert an die Klosteranlage als Kultur-, Kunst- und Bildungszentrum, dessen religiöser Mittelpunkt der Kirchenbau einst war. Es stellt ein eindrückliches historisches Denkmal für die jüngere Geschichte Deutschlands und der ehemaligen Hauptstadt der DDR dar; die Ruine ist ein Mahnmal des Krieges, sie erinnert an dessen Grauen, Zerstörungen und Folgen. Ein Pendant im Westteil Berlins bietet die Turmruine der Kaiser-Wilhelm-Gedächtniskirche (1891 bis 1895, Architekt Franz

15 Archiv Landesdenkmalamt Berlin, Akte zum Vorgang, Klosterkirche‘ 1982-1990.

16 Ernst Badstübner, Kirchen der Bettelorden, in: Landesdenkmalamt, Kirchenruine des Grauen Klosters, S. 23-30, hier S. 30; Jörg Haspel, Die Berliner Klosterkirchenruine - eine Zukunft für unsere Vergangenheit (Vorwort), ebd., S. 8-12, hier S. 8. 
Schwechten), die nach Kriegsende der Neugestaltung Charlottenburgs als Zentrum weichen sollte. Der Protest Berliner Bürgerinnen und Bürger gegen den Abriss führte zur Umplanung; der Turm wurde in Verbindung mit dem modernen Neubau (1959 bis 1963, Architekt Egon Eiermann) neu in Szene gesetzt und so zu einem städtebaulich signifikanten Mahnmal des Krieges sowie zu einem Symbol der Überwindung seiner Schrecken.

Die Klosterkirche bietet darüber hinaus ein exzellentes Beispiel für die Geschichte der Denkmalpflege. Ihre spannende Erhaltungsgeschichte überliefert den Sanierungs- und Reparaturbedarf des Gebäudes über die Jahrhunderte hinweg. Während der Besatzung Berlins durch napoleonische Truppen, die 1796 einmarschiert waren, litt das Gotteshaus erheblich. Aufgrund der kollektiven schlechten Erfahrung mit Besatzung und Krieg während der Franzosenzeit besannen sich die Menschen Anfang des 19. Jahrhunderts auf die eigenen, die historischen Werte und auf die alten nationalen Monumente. In Berlin beschwerten sich Bürger bei König Friedrich Wilhelm III. über den baulichen Zustand und den verwahrlosten Eindruck der Klosterkirche. 1813 gab Karl Friedrich Schinkel mit seinen Zeichnungen Impulse für die Auseinandersetzung mit der Wiederherstellungsund Umbauplanung des Kirchendenkmals. ${ }^{17}$ Fortan widmete die sich entwickelnde staatliche Denkmalpflege dem Bauwerk Aufmerksamkeit. Es folgten weitere Planungsvorschläge, ehe es 1842 bis 1845, unter König Friedrich Wilhelm IV., zu umfassenden Renovierungs- und Umbauarbeiten kam, in die bereits Ferdinand von Quast, ab 1843 erster preußischer Staatskonservator, involviert war. ${ }^{18}$ Die Vorschläge zum Umgang mit der Klosterkirche im 19. Jahrhundert sahen verschiedene Konzepte und praktische Maßnahmen zu Bewahrung, Veränderung und Präsentation vor.

Das Ruinendenkmal mitten im Herzen Alt-Berlins ist eingebettet in eine einfach und klar strukturierte Grünanlage, die Teile des ehemaligen Klosterareals markiert. Die Freifläche überrascht heute umso mehr, als sich die Metropole seit dem ausgehenden 20. Jahrhundert durch Investitions- und Entwicklungsdruck erneuert hat. Die innerstädtischen Freiflächen, oft auch Grünflächen oder kleine Parkanlagen anstelle von Baulücken, die durch Kriegszerstörung, Schuttberäumung oder Neugestaltung entstanden waren, wurden zu kostbarem Bauland zwischen den historischen Gebäuden. Auch funktionierende Neubauten aus der Nachkriegszeit weichen größeren und höheren Gebäuden. Damit gehen eine neue Maßstäblichkeit und ein enormer Verdichtungsdruck einher. Für das Bau- und Bodendenkmal Klosterkirche - ein Kulturdenkmal von nationaler Bedeutung - werden neue Präsentations- und Nutzungsforderungen formuliert, die den gegenwärtigen Zustand infrage stellen. ${ }^{19}$ Bisweilen entsteht der Eindruck, dass sich die moderne neue alte Hauptstadt schwer tut, authentische Erinnerungsmale mit Prägung und Dokumentationswert aus verschiedenen Zeitschichten, vor allem aus der Zeit nach 1945, insbesondere der DDR-Zeit, zu respektieren. Das erinnert an die frühe

17 Zeittafel zu den Bau- und Restaurierungsphasen der Franziskaner-Klosterkirche, in: Landesdenkmalamt, Kirchenruine des Grauen Klosters, S. 50-53; Petra Marx, Zur Geschichte der bauhistorischen Forschung und denkmalpflegerischen Bemühungen - ein fachgeschichtlicher Rückblick, in: ebd., S. 31-49.

18 Stefan Breitling, Die Franziskaner-Klosterkirche in Berlin: Ergebnisse der bauhistorischen Untersuchungen 1999-2004, in: Landesdenkmalamt, Kirchenruine des Grauen Klosters, S. 99-126. Siehe hierzu auch den Beitrag von Peter Lemburg in diesem Band.

19 Die Einstufung der Klosterkirchenruine als ,Denkmal von nationaler Bedeutung erfolgte durch die Bundesbeauftragte für Kultur und Medien (BKM) auf der Grundlage eines wissenschaftlich begründeten Antrages des Landesdenkmalamts Berlin, autorisiert durch Gabi Dolff-Bonekämper, Jörg Haspel und Sibylle Schulz. 
Nachkriegszeit in Berlin, Deutschland und anderen Ländern Europas, als in den kriegszerstörten historischen Zentren neben historisch orientierten Rekonstruktionen auch verkehrsgerechte moderne Umbauten als Grundlage des Wiederaufbaus zum Tragen kamen, wobei Baudenkmale und historisch gewachsene Stadtstrukturen nachrangig behandelt wurden. ${ }^{20}$

In Berlin zeigt sich das auch im Umgang mit den Sakralbauten des 13. bis 19. Jahrhunderts, die nahezu alle beschädigt wurden. In den Folgejahrzehnten nach Kriegsende erfuhren sie Abriss und Überbauung oder Neubau, Reparatur, teilweisen Wiederaufbau, Rekonstruktion, Ruinensicherung, Modernisierung, Umnutzung oder Funktionserweiterung. Beispielsweise musste der beschädigte, ursprünglich neugotische Bau der Kaiser-Friedrich-Gedächtniskirche im Alten Hansaviertel (1892 bis 1895, Architekt Johannes Vollmer) einem modernen Neubau (1957, Architekt Ludwig Lemmer) weichen. Der war Teil des Neuen Hansaviertels, das im Rahmen der Interbau 1957 entstand und zum Symbol eines neuen demokratischen Berlin (West) wurde.

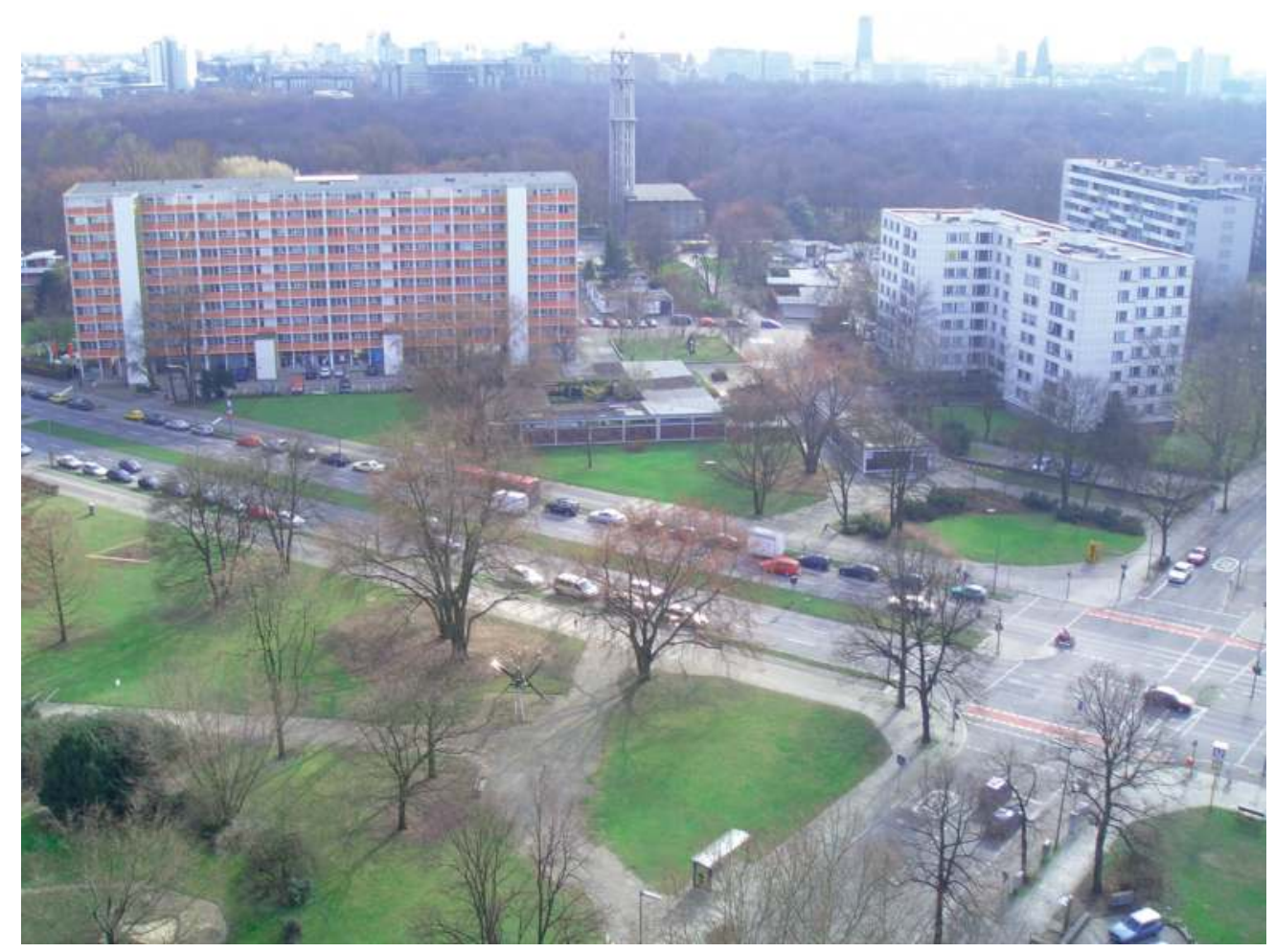

Abb. 7: Berlin, Hansaviertel. Blick vom Hochhaus Bartningallee 5 nach Süden zur Kaiser-Friedrich-Gedächtniskirche, 2007.

20 Vittorio Magnago Lampugnani/Konstanze Sylva Domhardt (Hrsg.), Die Stadt der Moderne. Strategien zu Erhaltung und Planung, Zürich 2016. Der Band umfasst Beiträge von Historikern, Vertretern aus den Bereichen Bauforschung und Inventarisation, von praktischen Denkmalpflegern, Architekten und Stadtplanern. Es geht um die Möglichkeit, städtebauliche Zeugnisse des 20. Jahrhunderts in Gegenwart und in Zukunft als ,erlebbares Ganzes' zu erhalten. Dafür werden neun Fallbeispiele zu europäischen Städten, Ensembles und Siedlungen analysiert. 
Der barocke Rundbau der Böhmischen Kirche an der Mauerstraße in Berlin-Mitte wurde 1943 bis auf die Grundmauern zerstört und die Fläche nach der Sprengung der Ruine 1963 beräumt. Seit 2012 erinnert die Stahlskelett-Rekonstruktion von Juan Garaizábal an den historischen Ort. Im Herzen der Luisenstädtischen Vorstadt befindet sich die Katholische Kirche Sankt Michael (1851 bis 1856, Architekt August Soller). Noch in den letzten Kriegswochen 1945 zerstört, konnte das Querhaus mit Apsis und Sakristei bis 1953 wiederaufgebaut werden, während das Langhaus bis heute Ruine ist. Gesichert und restauriert ist sie ein besonderer Veranstaltungsort im Bewusstsein der Menschen.

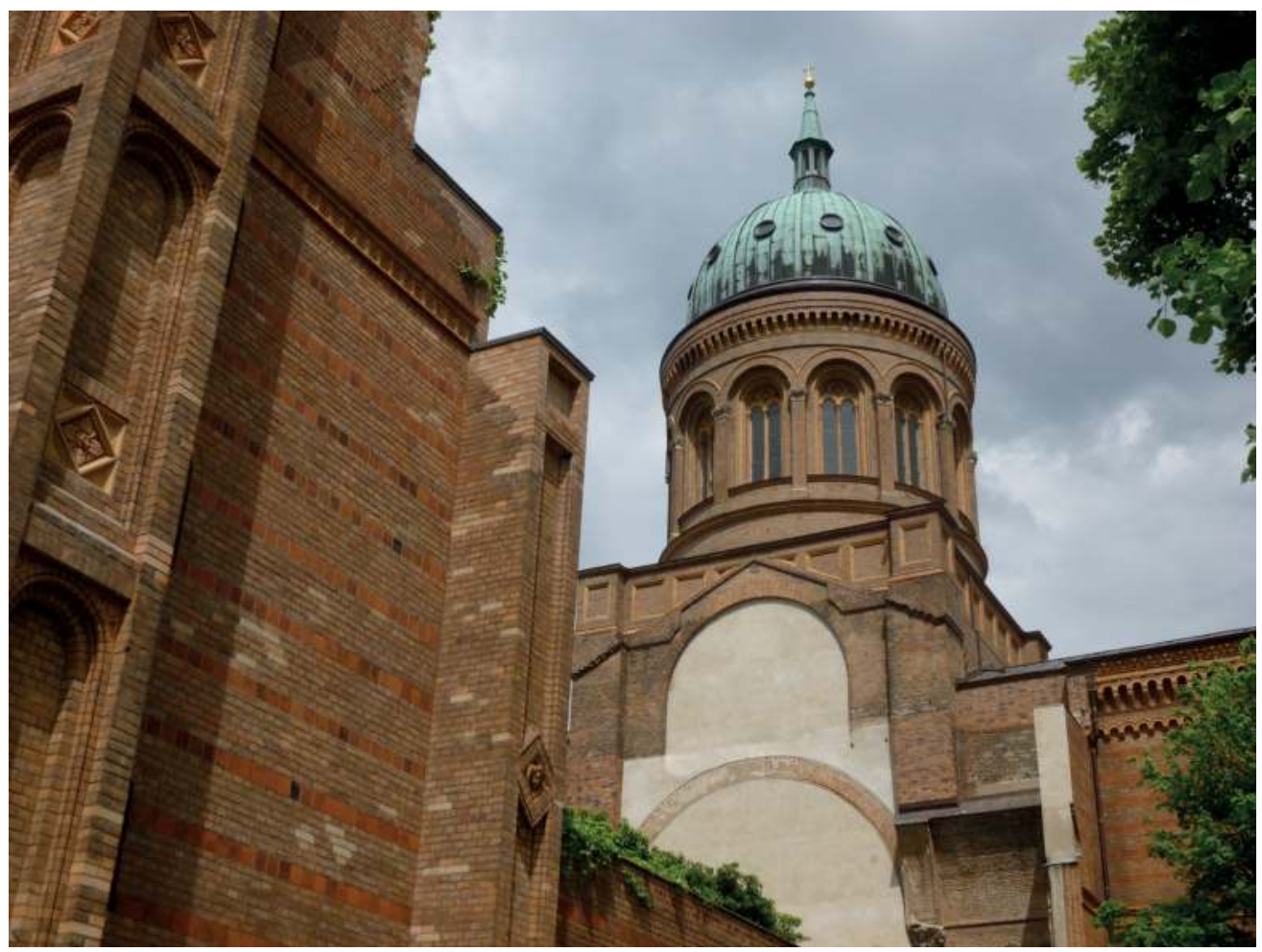

Abb. 8: Berlin-Mitte, Michaelkirchplatz, Ruine der Katholischen Kirche Sankt Michael, 2013.

Einige Monumente im Planungszentrum erfuhren aufgrund ihres Alters, der künstlerischen Bedeutung oder der Zukunftsfunktion die erforderliche Wertschätzung, die den respektvollen Umgang mit ihnen sicherte. So kam der mittelalterlichen Marienkirche der damaligen Evangelischen Kirchengemeinde Sankt Marien und Sankt Nikolai die Funktion der zentralen Kirche zu. Sie hatte den Krieg relativ unbeschadet überstanden und wurde bereits kurz nach Kriegsende 1945 unter der Mitwirkung von Hans Scharoun für kirchliche Zwecke wiederhergestellt. Dahingegen blieb die Nikolaikirche im Besitz des Magistrats von Groß-Berlin als Ruine bestehen, um im Zusammenhang mit dem für später geplanten Ausbau der Leipziger Straße zur Nutzung als Museum rekonstruiert zu werden, was zur 750-Jahr-Feier Berlins 1987 gelang. Andere Gebäude 


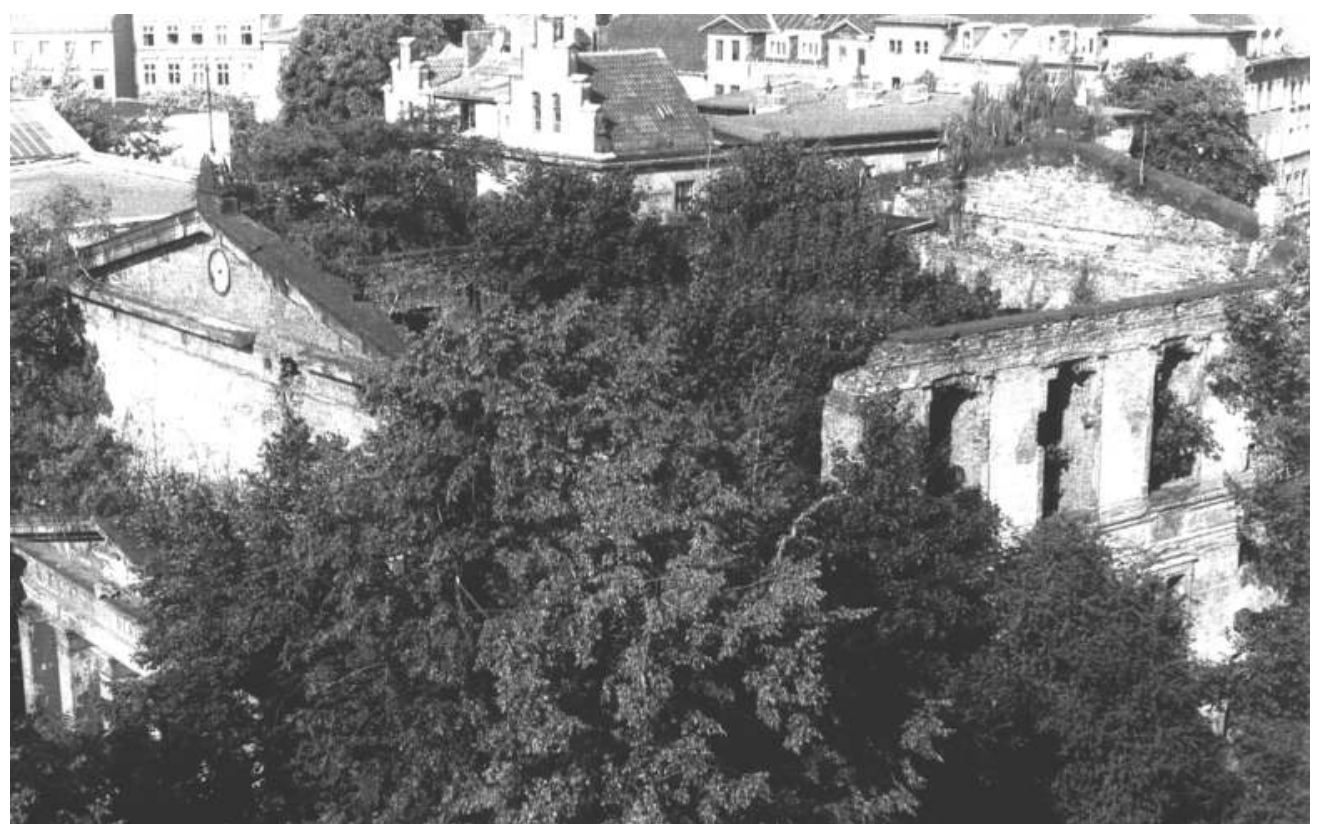

Abb. 9: Sankt Elisabethkirche, 1990.

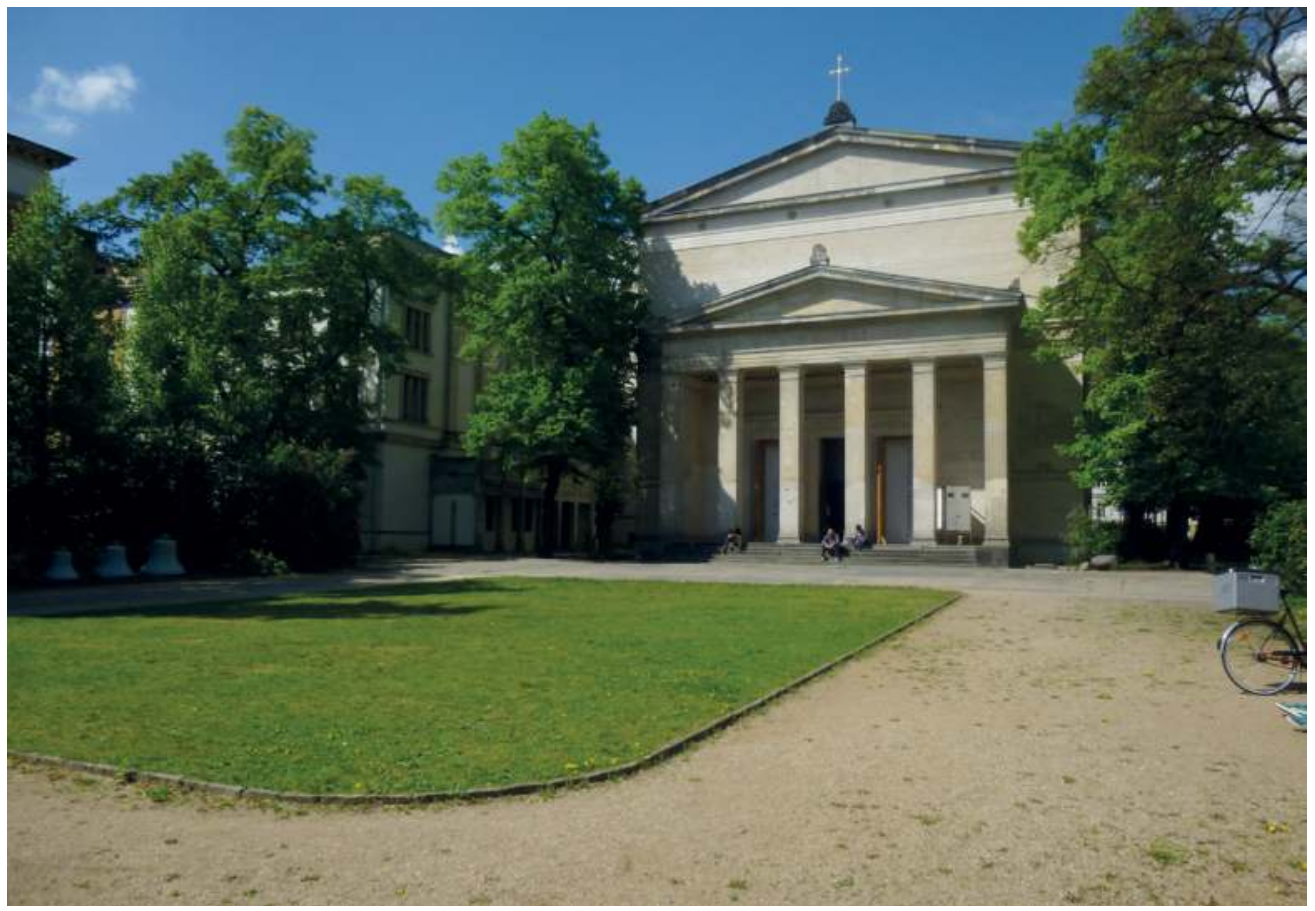

Abb. 10: Sankt Elisabethkirche, 2018. 
lagen außerhalb des Planungsdruckes, es fehlte die materiell-technische Basis für den Wiederaufbau. Die Menschen hatten ihre Kirche verloren und einigen Kirchengemeinden im historischen Zentrum fehlten nach der Teilung der Stadt die Gemeindemitglieder, für die die Gotteshäuser hätten wieder hergerichtet werden sollen. Deshalb blieben sie zunächst Ruinen und erfuhren erst mit dem Wandel des Zeitgeistes sowie auch der gesellschaftlichen Voraussetzungen einen späten Wiederaufbau. Dazu zählt die Sankt Elisabethkirche (1832 bis 1835, Architekt Karl Friedrich Schinkel) an der Invalidenstraße, die seit 1990 dank Sicherung, Restaurierung und Ausbau (Architekt Klaus Block, Berlin) nachhaltig wiederhergestellt wurde und eine kulturelle und kirchliche Nutzung erhielt.

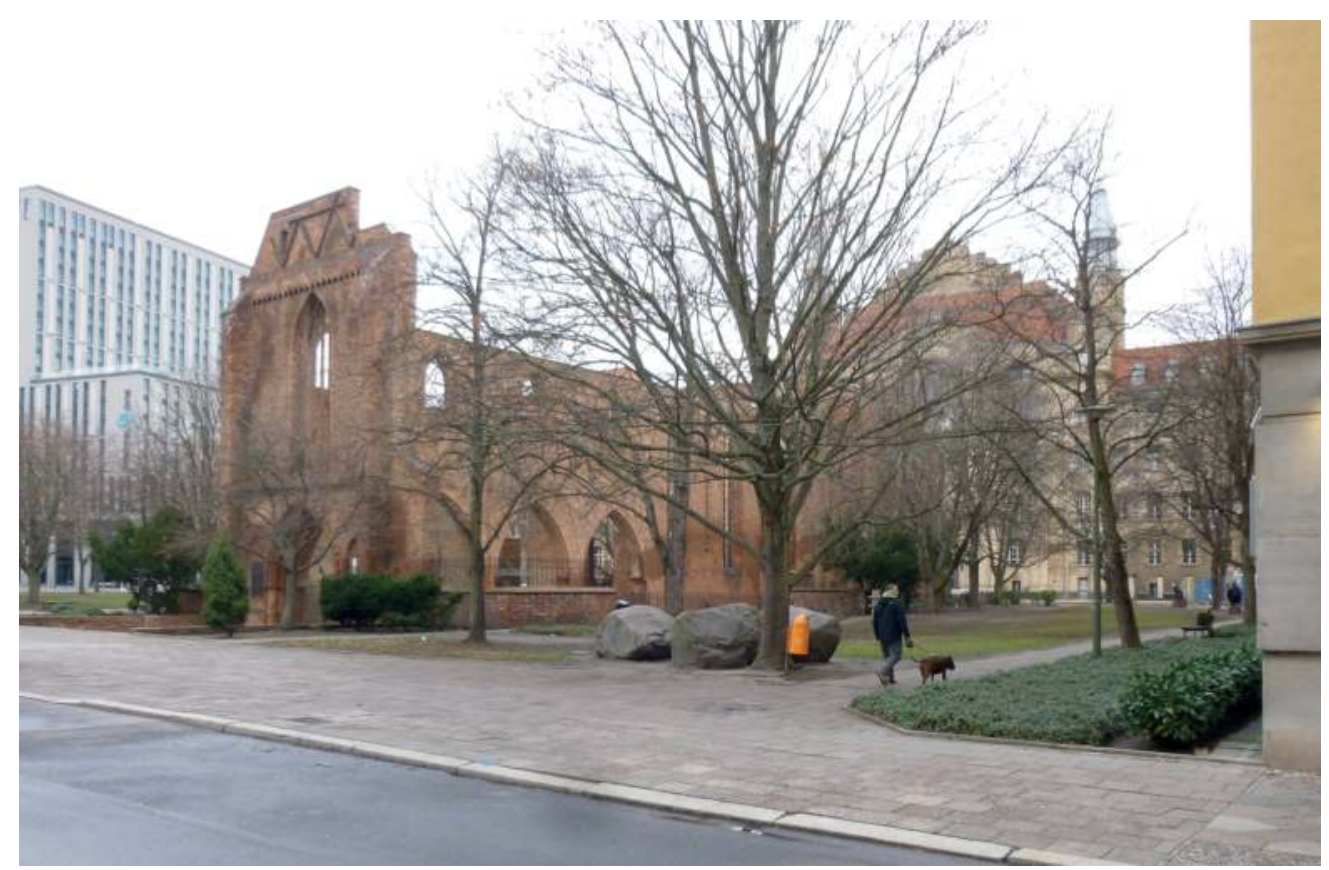

Abb. 11: Berlin-Mitte, Ruine der Franziskanerklosterkirche, 2018.

\section{Resümee}

Der Zweite Weltkrieg war eine traumatische kollektive Erfahrung von Gewalt und Zerstörung mit nachfolgenden Verlusten an historischen Orten, die den Menschen Identifizierungsmöglichkeiten nahmen. Die Entwicklung des ehemaligen Areals des Franziskanerklosters mag als tragisch gelten, jedoch bietet sie eine große Chance, denn unter der Grasnarbe befinden sich die authentischen Dokumente eines der ältesten erhaltenen Orte Berlins. Dort sind sie auch für nachfolgende Generationen gesichert und wir haben die einzigartige Möglichkeit, diesem besonderen Bodendenkmal weiterhin jeglichen Schutz zu bieten.

In der Gesamtschau auf die Denkmallandschaft Berlin stellt die Klosterkirche zwar nicht das einzige Ruinen-Denkmal eines Gotteshauses dar, jedoch ist sie einzigartig. Ihre Bestimmung zum 
Mahnmal mitten in der sich unter einem unvergleichlichen Bauboom und Investitionsdruck wandelnden Metropole scheint innerhalb des wieder geeinten Berlin heute umso bedeutender, als hier einerseits für vergangene Generationen ein mentaler Erinnerungsort erhalten bliebe, der andererseits zukünftigen Generationen ein authentisches bauliches Geschichtsdokument in situ bieten würde, weil respektvoll mit den Leistungen der Kriegs- und Nachkriegsgeneration umgegangen wird.

Die Präsentation dieses besonderen Denkmals mag an Kirchenruinen in Eldena oder Oybin erinnern und Kunstwerke der Romantiker, allen voran Caspar David Friedrichs, vor Augen rufen. Der sentimental-romantische Aspekt des frühen 19. Jahrhunderts hält sich hier in Grenzen, wiederum bedingt durch die Lage im tosenden Zentrum und teilweise umgeben von Zweck- und Monumentalbauten wie dem mächtigen Alten Stadthaus (1902 bis 1911, Stadtbaurat Ludwig Hoffmann) und dem benachbarten Neuen Stadthaus (um 1935, Kurt Starck/Franz Arnous).

Gleichermaßen unerwartet wie selbstverständlich steht hier das Denkmal mit seiner klaren Botschaft, beeindruckend durch die Baukunst und die sepulkralgeschichtlichen Dokumente. Es ist ein auratischer Raum, der berührt und Geschichte lesbar authentisch überliefert.

Ruinen sind unwirtschaftliche Denkmale, das mag zu Begehrlichkeiten in Richtung Wiederaufbau führen. Ein Blick über die Grenzen von Berlin und Deutschland hinaus zeigt, mit welcher Selbstverständlichkeit anderswo Ruinen akzeptiert, gepflegt und ortsgerecht genutzt werden, man denke zum Beispiel an Visby. Schließlich bringt jede Rekonstruktion oder Überbauung weitere Verluste an Originalsubstanz mit sich. Die praktische Erhaltung von Ruinen ist unproblematisch, wenn - wie an anderen Bauwerken ebenso erforderlich - die Objektpflege regelmäßig durchgeführt wird.$^{21}$ Ein entsprechendes Pflegewerk für die Franziskanerklosterkirche ist mit der letzten Restaurierung durch das Landesdenkmalamt Berlin erarbeitet worden. Es gibt ausreichend Erfahrungen in der Ruinendenkmalpflege.

Die Vielfalt der Bedeutungsschichten an diesem historischen Ort anhand der vorhandenen Denkmalanlage mit der Ruine als Bau sowie der Freifläche als Bodendenkmal für Kinder, Jugendliche und Erwachsene zu visualisieren und so weiter ins Bewusstsein der Berliner und der Besucher zu rücken, könnte ein denkmalgerechtes stadtplanerisches Ziel sein.

21 Günther Stanzl, Konservierung von Burg- und Klosterruinen: Fallbeispiele aus Rheinland-Pfalz, in: Landesdenkmalamt, Kirchenruine des Grauen Klosters, S. 163-167. 


\section{Guido Hinterkeuser}

\section{Zum Umgang mit Ruinen kriegszerstörter Kirchen nach 1945 in Deutschland}

Eine Ruine ist im Kern immer Ausdruck von Zerstörung und Gewalt. Ruinen zeigen an, dass etwas nicht in Ordnung ist, sie mahnen oder fordern zur Erinnerung auf. Sie regen zum Nachdenken an und verlangen eine Stellungnahme. Ruinen lassen niemanden gleichgültig. Man muss sich ihnen gegenüber verhalten, Position beziehen. Diese Position wird nicht allein von der Ruine bestimmt, sondern wesentlich von dem Kontext, der sie bedingt und in dem sich der Betrachter befindet. Dazu zählen sowohl die Umstände, die zur Beschädigung des Gebäudes führten und es zur Ruine werden ließen, als auch die Entscheidungen, die später über seine Zukunft getroffen wurden. Ohne diese Kontexte sind Ruinen nicht zu verstehen, denn die Steine allein teilen sie nicht mit.

Eine Ruine wie diejenige der in Thüringen gelegenen Klosterkirche in Paulinzella wird von uns heute neben ihrem architekturhistorischen Wert vorrangig als Stimmungsträger wahrgenommen. ${ }^{1}$

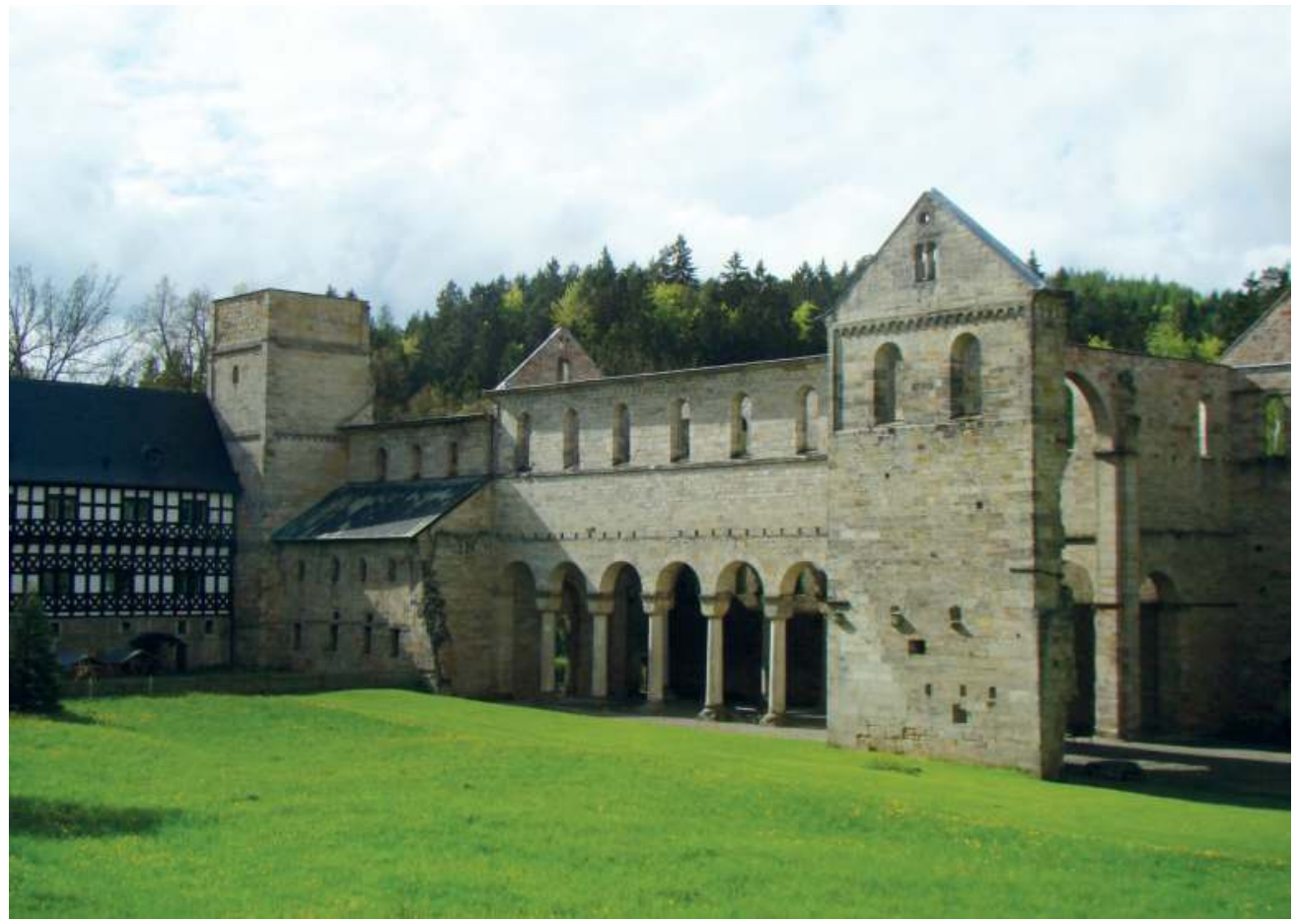

Abb. 1: Paulinzella, Klosterruine, Aufnahme 2013.

1 Verena Friedrich/Lutz Unbehaun/Doris Fischer, Kloster Paulinzella (Amtlicher Führer der Stiftung Thüringer Schlösser und Gärten), 2. vollst. überarb. Aufl., Rudolstadt/München 2019, S. 4-6, 17-21. 
Wir haben uns hier den Blick der Romantiker zu Eigen gemacht, die sich derartigen Ruinen seit dem 18. Jahrhundert näherten, und wir haben diesen Blick bis heute beibehalten und das damit einhergehende Empfinden verinnerlicht. Dass es sich bei dem 1124 geweihten Bau um ein Nachbild der Abteikirche in Hirsau handelt, interessiert vor allem den Architekturhistoriker. Gut vierhundert Jahre war die Klosterkirche in Funktion, ehe in der Folge der Reformation ein kontinuierlicher Verfallsprozess einsetzte, dem erst gegen Ende des 18. Jahrhunderts Einhalt geboten wurde. Romantikern galten derartige Ruinen als Schlüssel zu einer verschütteten Vergangenheit, zugleich wurden sie als Mahnungen an die Vergänglichkeit allen irdischen Lebens geschätzt, wozu ihre Einbettung in die Natur wesentlich beitrug. Nicht umsonst bildeten in dieser Zeit künstlich geschaffene Ruinen ein beliebtes Motiv zur Ausstattung von Landschaftsgärten, allen voran in Dessau, Wörlitz, Potsdam, Schwetzingen oder Kassel. ${ }^{2}$

Deutlich wird dieser Aspekt auch bei der Ruine der Zisterzienserklosterkirche Eldena, die über einen langen Zeitraum hinweg im 13. und 14. Jahrhundert entstanden war, ebenfalls in der Reformation säkularisiert wurde und anschließend verfiel. Heute sind nur noch unzusammenhängende Teile des Kirchenschiffs erhalten. Caspar David Friedrich entdeckte die Ruine und machte sie zum Motiv für mehrere seiner Werke, darunter das berühmte, 1809 entstandene Gemälde der Abtei im Eichwald, in dem er die Ruine ebenso stimmungsvoll mit einer Winterlandschaft und einem Begräbnis kombiniert wie auf einer bereits einige Jahre früher entstandenen Sepiazeichnung. ${ }^{3}$ Dem besonderen Charakter der Ruine trug wiederum Peter Joseph Lenné ab 1828 Rechnung, indem er sie in einen Landschaftspark einbettete. Desgleichen war schon ab 1826 in Heisterbach bei Königswinter geschehen, wo die sagenumwobene Chorruine nach den Plänen des königlichen Gartenbaudirektors Maximilian Friedrich Weyhe wirkmächtige Staffage innerhalb eines Landschaftsgartens wurde, und zwar als Endpunkt eines von Baumgruppen gesäumten Pleasuregrounds. ${ }^{4}$ Wurden also einerseits im 18. und frühen 19. Jahrhundert künstliche Ruinen als Genremotiv für Gartenanlagen eigens konzipiert und errichtet, regten umgekehrt reale Ruinen zur Umgestaltung ihrer Umgebung in ebensolche Landschaftsgärten an.

Dass allerdings schon im 19. Jahrhundert längst nicht jede Ruine als Stimmungsträger taugte, machen Theodor Fontanes Äußerungen über das Kloster Chorin und seine Kirchenruine deutlich, die er 1873 im Band ,Ost-Havelland' seiner ,Wanderungen durch die Mark Brandenburg' publizierte: Leider geht dieser baulich schönen Ruine, wie gesagt, das eigentlich Malerische ab. Ruinen, wenn sie nicht bloß, als nähme man ein Inventarium auf, nach Pfeiler- und Fensterzahl beschrieben

2 Vgl. Jürgen Obmann/Derk Wirtz/Philipp Groß, ,Ruinirt Euch, um Ruinen zu machen'. Antikisierende Ruinenarchitekturen in deutschen Gärten des 18. und frühen 19. Jahrhunderts (Mitteilungen der Pückler-Gesellschaft e. V., N. F., Bd. 30), Weimar 2016, S. 20-23, 70-72, 75-79, 83-88, 92-95.

3 Siehe dazu: Friedrich Möbius, Caspar David Friedrichs Gemälde ,Abtei im Eichwald' und die frühe Wirkungsgeschichte der Ruine Eldena bei Greifswald. Zu aktuellen Aspekten des Denkmalbegriffs und der Denkmalpflege (Abhandlungen der Sächsischen Akademie der Wissenschaften zu Leipzig, Philologisch-Historische Klasse), Berlin 1980, S.3-14; Peter Rautmann, Ruinen-Landschaften von Caspar David Friedrich. Montage als Konstruktion von Erinnerung, in: Richard Faber (Hrsg.), Arkadische Kulturlandschaft und Gartenkunst. Eine Tour d'Horizon, Würzburg 2010, S. 201-225, hier S. 209-219.

4 Christoph Keller, Kloster Heisterbach in Königswinter (Rheinische Kunststätten, H. 505), Köln 2008, S. 7-11. 


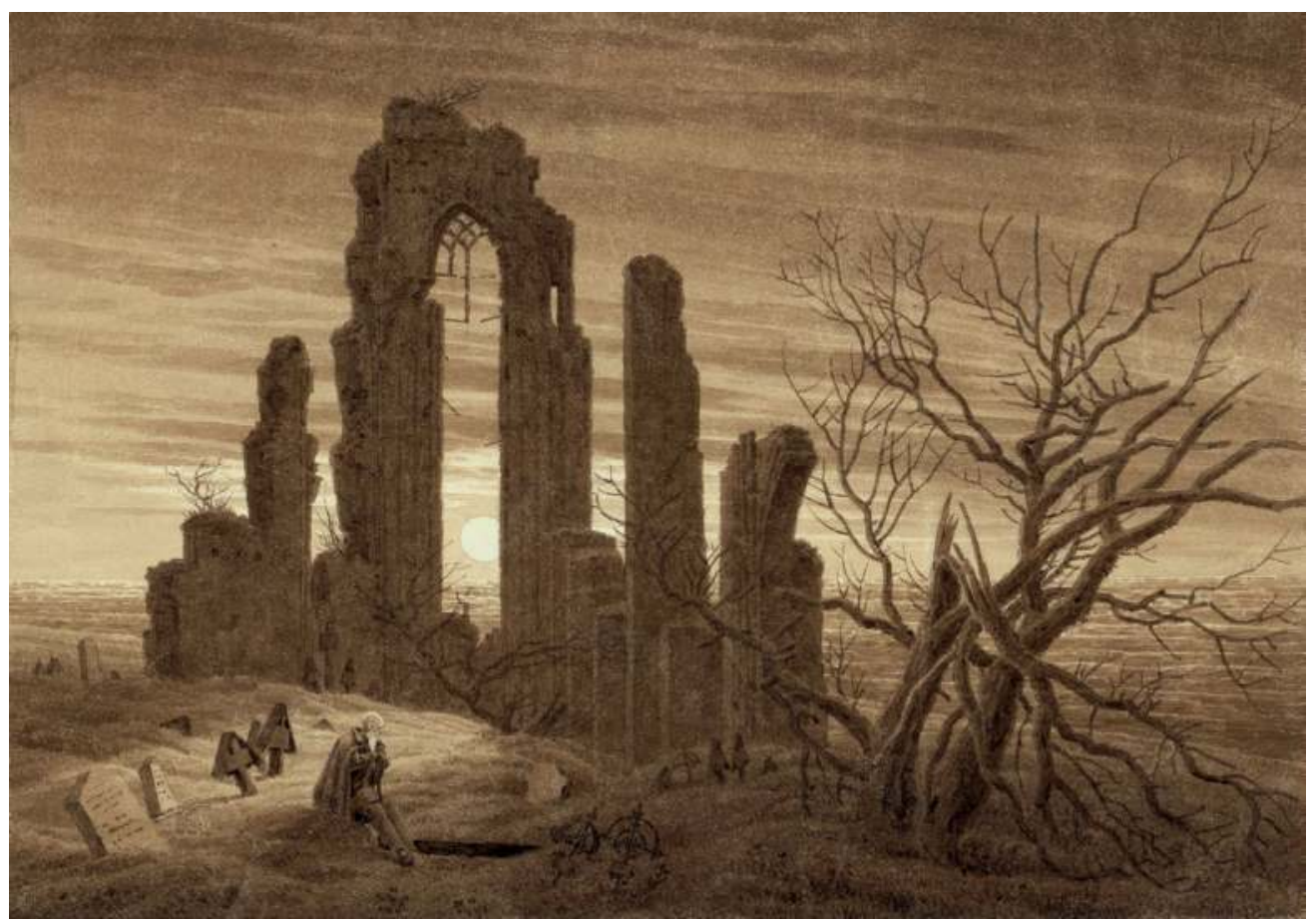

Abb. 2: Caspar David Friedrich, Klosterruine Eldena im Winter (Der Winter - Die Nacht - Alter und Tod), 1803, Zeichnung in Sepia.

werden sollen, müssen zugleich ein Landschafts- oder auch ein Genrebild sein. In einem oder im andern, am besten in der Zusammenwirkung beider wurzelt ihre Poesie. Chorin aber hat wenig oder nichts von dem allen; es gibt sich fast ausschließlich als Architekturbild. Alles fehlt, selbst das eigentlich Ruinenhafte der Erscheinung, so daß, von gewisser Entfernung her gesehen, das Ganze nicht anders wirkt wie jede andere gotische Kirche, die sich auf irgendeinem Marktplatz irgendeiner mittelalterlichen Stadt erhebt. Nur fehlt leider der Marktplatz und die Stadt. ${ }^{5}$

Außerdem wurden zu allen Zeiten, und selbstredend auch im 18. und 19. Jahrhundert, Kirchenruinen meist dann nicht als positiv erfahren, wenn die Zerstörung des Bauwerks, sei es durch Krieg oder ein sonstiges Unglück, unmittelbar vorangegangen und nicht etwa weit zurück in einer historisch abgeschlossenen Periode erfolgt war (in dieser Hinsicht unterscheidet sich die Heisterbacher Chorruine von den Klosterruinen in Paulinzella und Eldena). Vor allem aber konnte der romantisch-melancholische Blick auf Kirchenruinen in den Jahren während und nach dem Zweiten Weltkrieg nicht funktionieren, als mit einem Mal viele Kirchen, oft parallel auf engem Raum in einer Stadt und zudem gleichzeitig in vielen Städten, Zerstörungen in einem bis dahin unvorstellbaren Ausmaß erlitten hatten. Denn vor dem Hintergrund der eigenen Kriegserfahrungen erweckten Ruinen von Bauwerken, die man zuvor sein ganzes Leben lang nur in unversehrtem

5 Zitiert nach: Theodor Fontane, Wanderungen durch die Mark Brandenburg, Bd. 2: Havelland ' Spreeland, hrsg. von Helmuth Nürnberger, München 1997, S. 98. 
Zustand gekannt hatte, keine positiven Emotionen, wie dies die romantische Sichtweise ermöglicht hatte. Zudem waren die Kriegsruinen nicht stimmungsvoll in die Vegetation eines Parks eingebettet, sondern gehörten oftmals zu einem unendlich erscheinenden Ruinenfeld.

Nach 1945 wurde lebhaft und kontrovers diskutiert, wie mit den Kriegszerstörungen von Kirchen und anderen Kulturdenkmälern umzugehen sei - während sich bei Wohn-, Geschäfts- und anderen Nutzbauten diese Fragen weniger stellten. Stellvertretend sei hier an die in Köln 1946 und 1947 durchgeführte Vortragsreihe erinnert, deren Beiträge 1948 unter dem Titel ,Kirchen in Trümmern. Zwölf Vorträge zum Thema was wird aus den Kölner Kirchen' veröffentlicht wurden. ${ }^{6}$ Auch wenn sich unter den Referenten Stimmen erhoben, die Ruinen anzunehmen und zu akzeptieren - ähnliche Mahnungen gab es in der Debatte um die Rekonstruktion des Goethe-Hauses in Frankfurt ${ }^{7}$-, so setzte sich schließlich doch eine Haltung durch, gerade auch bei den zahlreichen Zuhörern, die für die Wiederherstellung der Kirchen eintrat: Die Diskussion des letzten Abends brachte es klar zum Ausdruck. Man will und man kann die Kirchen nicht verloren geben, man will und man kann auf sie nicht verzichten. In ihnen war unsere gesamte Geschichte Gestalt geworden. Mit ihnen verlören wir den Boden, in dem unsere Kultur wurzelt. Die Optimisten, die an die Möglichkeiten einer fast völligen Wiederherstellung des Alten glaubten, hatten die Menge für sich. Die Warner und Mahner, die nur das Verbliebene zu erhalten suchten, das Vernichtete aber durch Neues in Geist und Form ersetzen wollten, liefen bisweilen Gefahr, verkannt zu werden. Aber alle waren sich einig: Nichts darf mehr verloren gehen. Wo jemals eine Kirche stand, und sei sie nur in kleinen Resten erhalten, muß eine neue entstehen, die wenn immer möglich, den durch Jahrhunderte geheiligten Raum in seiner großen und einmaligen Ausdruckskraft erneut verwirklicht. ${ }^{8}$

Bis 1985 wurden nicht nur die zwölf großen Kölner romanischen Kirchen allesamt wiederhergestellt, wobei in keinem Fall daran gedacht war, exakt den Vorkriegszustand zu rekonstruieren. ${ }^{9}$ Die Reparatur galt meist allein dem Außenbau, während im Inneren auch behutsam ausgeführte zeitgenössische Lösungen oder Purifizierungen zum Einsatz kamen und auf die Rekonstruktion später eingefügter barocker und historistischer Ausstattungen fast immer verzichtet wurde. Das Kölner Beispiel lässt sich, grob gesprochen, auf die meisten westdeutschen Städte übertragen, wobei reine Barockkirchen oftmals ganzheitlicher betrachtet und deshalb, wie beispielsweise die Clemenskirche in Münster oder Sankt Anna im Lehel in München, auch im Inneren wieder weitgehend in den Originalzustand versetzt wurden. ${ }^{10}$

6 Gesellschaft für Christliche Kultur (Hrsg.), Kirchen in Trümmern. Zwölf Vorträge zum Thema was wird aus den Kölner Kirchen, Köln 1948 (ND in Hiltrud Kier/Ulrich Krings [Hrsg.], Köln. Die Romanischen Kirchen in der Diskussion 1946/47 und 1985 [Stadtspuren - Denkmäler in Köln, Bd. 4], Köln 1986, S. 19-126).

7 So Walter Dirks in seinem berühmten Aufsatz, Mut zum Abschied. Zur Wiederherstellung des Frankfurter Goethehauses', in dem er die Zerstörungen als „Spruch der Geschichte“ deutet, der endgültig sei und den es anzunehmen gelte (Walter Dirks, Mut zum Abschied. Zur Wiederherstellung des Frankfurter Goethehauses, in: Frankfurter Hefte. Zeitschrift für Politik und Kultur 2 [1947], S. 819-828).

8 Gesellschaft für Christliche Kultur, Kirchen in Trümmern, Vorwort [zitiert nach Kier/Krings, Köln, S. 20 f.].

9 Zum Wiederaufbau der Kölner Romanischen Kirchen umfassend: Kier/Krings, Köln.

10 Hartwig Beseler/Nils Gutschow, Kriegsschicksale deutscher Architektur. Verluste - Schäden - Wiederaufbau. Eine Dokumentation für das Gebiet der Bundesrepublik Deutschland, 2 Bde., Neumünster 1988, Bd. 1, S. 649651; Bd. 2, S. 1377 f. 
Anders lag der Fall in der Sowjetischen Besatzungszone (SBZ) beziehungsweise in der Deutschen Demokratischen Republik (DDR), wo Kirchen und ihren Trägern aufgrund des neu eingeführten sozialistischen Gesellschaftssystems mit großem Misstrauen begegnet wurde, sodass ihnen staatlicher- und kommunalerseits längst nicht die Unterstützung gewährt wurde, die die Wiederaufbauten in Westdeutschland erfuhren. Zwar wurden selbstverständlich auch im Osten Deutschlands zahlreiche Kirchen repariert und instandgesetzt, zumal wenn es sich um bedeutende Kulturdenkmäler handelte. Auf der anderen Seite wurden jedoch ebenso bedeutende Kirchen auch abgerissen, etwa weil sie dem sozialistischen Stadtaufbau im Wege standen - und dies, obwohl ihre Ruinen durchaus hätten wiederhergestellt werden können. Erinnert sei hier nur stellvertretend für zahlreiche andere Bauten an die Ulrichskirche in Magdeburg, abgerissen 1956, an die Sophienkirche in Dresden, abgerissen 1962/63, und an die Potsdamer Garnisonkirche, abgerissen 1968. ${ }^{11}$ Deren Abriss geschah übrigens parallel zum Abbruch der Leipziger Universitätskirche Sankt Pauli, die im Krieg gar nicht zerstört worden war - woraus man ermessen mag, welcher ideologische Druck auf so mancher Kirchenruine lastete. ${ }^{12}$

Wird der Blick erneut nach Westdeutschland gerichtet, wird deutlich: Je erfolgreicher der Wiederaufbau der Städte voranschritt, desto schärfer kristallisierte sich in ausgewählten Fällen der Wunsch heraus, die eine oder andere Kirche bewusst als Ruine zu belassen. Zu dieser Haltung trug wesentlich bei, dass in einem Umfeld der Moderne und Unversehrtheit eine Ruine, die die Spuren und Narben ihrer Zerstörung offen zur Schau trägt, eine besondere Wirkung entfalten kann, und zwar als Mahnmal und Gedenkort, der dauerhaft an die Schrecken der Vergangenheit zu erinnern vermag. Etwas unfreiwillig, doch dafür umso erfolgreicher, übernahm in West-Berlin diese Rolle Franz Schwechtens neoromanische Kaiser-Wilhelm-Gedächtniskirche, deren ruinöse Vorhalle samt Hauptturm schließlich konserviert und als eigenständiger Baukörper in Egon Eiermanns ab 1959 realisierten Gesamtentwurf einer neuen Kirchenanlage integriert wurde. ${ }^{13} \mathrm{Al}$ lerdings war diese Lösung das Ergebnis eines Kompromisses, nachdem beim Wettbewerb von 1957 sowohl der Senator für Bau- und Wohnungswesen und der Architekt als auch Städteplaner und Architekturkritiker die völlige Beseitigung der Ruine favorisiert hatten, was nur durch lautstarken Protest der Berliner Bevölkerung verhindert werden konnte. Umgekehrt jedoch hatten Pläne einer Wiederherstellung des 1895 eingeweihten und im November 1943 stark beschädigten Baus ab dieser Zeit ebenfalls keine Chance mehr, sodass die übrige Ruine, darunter der Chor mit einem der noch gut erhaltenen Flankentürme, abgetragen wurde. Nach der Einweihung des Neubaus 1961 entwickelte sich die Kaiser-Wilhelm-Gedächtniskirche rasch zu einer Ikone der City West, die bis heute gleichermaßen für Erinnerung an die Zerstörungsgewalt des Krieges und Aufbruch in die Moderne steht.

11 Götz Eckardt, Schicksale deutscher Baudenkmale im zweiten Weltkrieg. Eine Dokumentation der Schäden und Totalverluste auf dem Gebiet der Deutschen Demokratischen Republik, 2 Bde., Berlin 1978, Bd. 1: Berlin. Hauptstadt der DDR, Bezirke Rostock, Schwerin, Neubrandenburg, Potsdam, Frankfurt/Oder, Cottbus, Magdeburg, S. 148 f., 254 f.; Bd. 2: Bezirke Halle, Leipzig, Dresden, Karl-Marx-Stadt, Erfurt, Gera, Suhl, S. 378.

12 Vgl. Birk Engmann, Der große Wurf. Vom schwierigen Weg zur neuen Leipziger Universität, Beucha 2008, S. 11-35.

13 Wolfgang Pehnt, Die Grenzen der Regeln. Egon Eiermanns Gedächtniskirche in ihrer Zeit, in: Kristin Feireiss (Hrsg.), Egon Eiermann - Die Kaiser-Wilhelm-Gedächtnis-Kirche. Mit Texten von Wolfgang Pehnt und Peter Haupt, Berlin 1994, S. 7-15. 


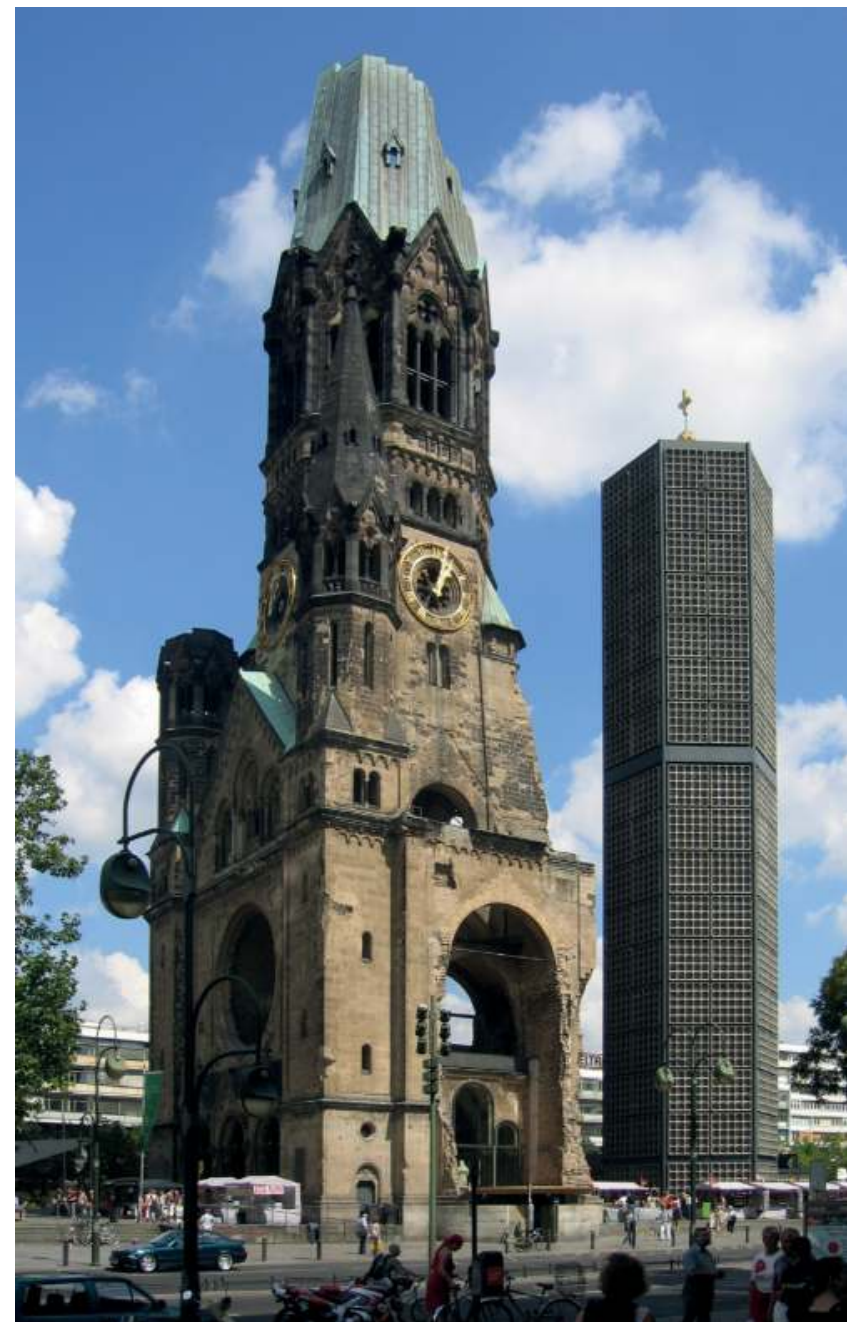

Abb. 3: Berlin-Charlottenburg, Kaiser-Wilhelm-Gedächtniskirche, Aufnahme 2004. Vorhalle mit Hauptturm (1891-1895) von Franz Schwechten und Glockenturm (1959-1961) von Egon Eiermann.

Dass man in Köln dafür die im Kern ebenfalls romanische Kirche Sankt Alban als Mahnmal auserwählte, die im Krieg schwer beschädigt worden war und beispielsweise ihr Dach und sämtliche Gewölbe verloren hatte, ${ }^{14}$ hat sicherlich verschiedene Gründe. Zum einen lag sie im Herzen des städtischen Repräsentationsareals, nämlich in der Nähe des Renaissance-Rathauses und neben dem Gürzenich, dem Festsaal der Bürgerschaft, an den sie unmittelbar anschloss. Zum anderen gehörte Sankt Alban nicht zu den ,Premium-Kirchen', denn aufgrund mehrfacher Umbauten waren ihre romanischen Ursprünge zuletzt kaum mehr zu erkennen. Der Innenraum war in der 


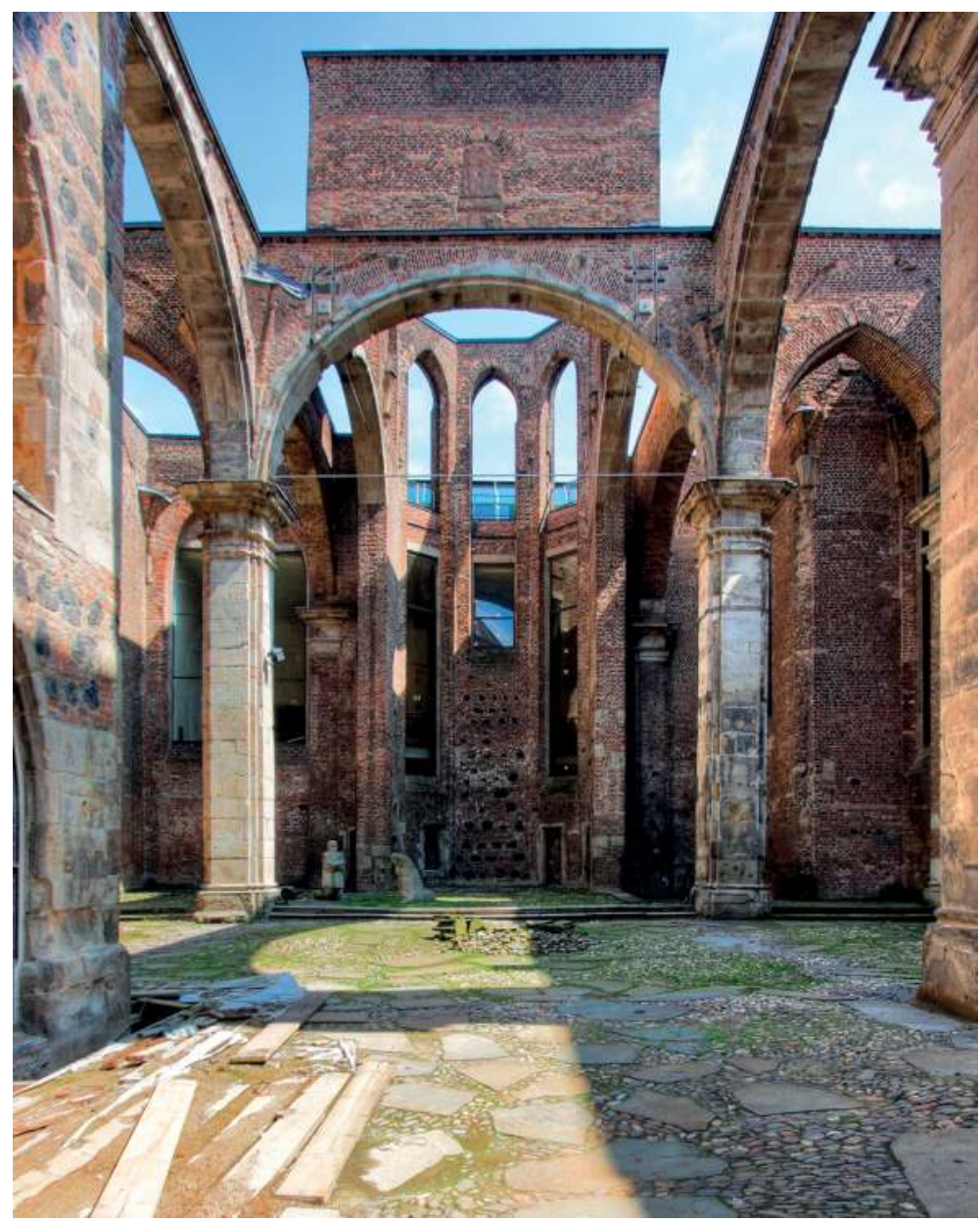

Abb. 4: Köln, Ruine von Alt Sankt Alban, Aufnahme 2009.

zweiten Hälfte des 17. Jahrhunderts umfassend neu gestaltet worden, und die Westfassade stammte gar erst aus dem Jahr $1896 .{ }^{15}$ Letztere wurde denn auch im Zuge der Sicherung der Ruine gerne geopfert und vollständig beseitigt. Beim Wiederaufbau von Sankt Alban kam es also zur Sicherung einer zuvor bereinigten Ruine, wobei man bewusst auf das Aufsetzen eines Dachs und das Einsetzen von Fenstern verzichtete. Am 23. Dezember 1954 wurde von Kardinal Frings die Genehmigung zur Profanierung erteilt, damit die Ruine künftig der Erinnerung an die Toten der Weltkriege diene.

15 Wilhelm Ewald/Hugo Rahtgens (Bearb.), Die Kirchlichen Denkmäler der Stadt Köln I: St. Alban - St. Andreas Antoniterkirche - St. Aposteln - St. Cäcilia - St. Columba - St. Cunibert - Elendskirche - St. Georg (Die Kunstdenkmäler der Rheinprovinz. Die Kunstdenkmäler der Stadt Köln, Bd. 6, Abt. IV), Düsseldorf 1916, S. 1-19. 
Seit dem Wiederaufbau des Gürzenichs, der mit einer modernen Erweiterung nach Norden einherging, stoßen dessen neues Treppenhaus und Foyer direkt an die Kirche und erlauben den Besuchern Einblicke in die Ruine. ${ }^{16}$ Ansonsten ist diese normalerweise nicht zu betreten, sondern lediglich durch vergitterte Öffnungen im Westen einzusehen. Dabei schaut man auf eine im Chorbereich aufgestellte Kopie des ,Trauernden Elternpaares', das von Käthe Kollwitz 1932 für den in Flandern befindlichen deutschen Soldatenfriedhof Esen-Roggeveld geschaffen worden war (und 1956 auf den Soldatenfriedhof von Vladslo versetzt wurde). Vorn am Eingang wurde außerdem ein schmiedeeisernes Mahnmal zur Erinnerung an die Kriegsgefangenen aufgestellt: ,Noch warten Kriegsgefangene auf ihre Heimkehr, steht auf der an Ketten befestigten Tafel geschrieben. Am 21. Mai 1959 wurde die Gedenkstätte in Anwesenheit von Bundespräsident Theodor Heuss eingeweiht, was den hohen Rang unterstreicht, den man ihr zuerkannte. Rudolf Schwarz, der Architekt des Neuen Gürzenichs, hat die Situation schon 1955 eindrücklich beschrieben: Der Gürzenich wird wieder die gute Stube der Bürgerschaft sein, wie er es eh und je war. Zu den alten Anlässen, die dort begangen wurden, ist noch ein neuer, weihevoller hinzugekommen: das Gedächtnis der Toten. Ihm dient die Ruine von St. Alban. Sie soll für alle Zeiten in Trümmern bleiben, ihr Boden wird nur mit Steinen belegt und nicht mit versöhnlichem Grün geschmückt, und irgendwo darin wird das Elternpaar der Käthe Kollwitz knien, seinem sinnlosen Leid überlassen. ${ }^{17}$ In diesem Zustand wird die Kirche bis heute gepflegt, als "gestaltete Kirchenruine“, ${ }^{18}$ und es ist keine Frage, dass diese Ruine im Zusammenhang mit ihrer Umgebung zu einem Denkmal von hoher Aussagekraft wurde, das nicht angetastet werden darf.

Desgleichen gilt für die gotische Ägidienkirche in Hannover, die 1943 schwer beschädigt wurde und im Inneren nahezu gänzlich ausbrannte. ${ }^{19}$ Auch in diesem Fall traf man die Entscheidung gegen eine Wiederherstellung, die leicht möglich gewesen wäre, und beließ den Bau bis heute als Ruine, die an die Zerstörung Hannovers und als Mahnmal für die Opfer von Krieg und Gewalt dient. Die mittelalterlichen Umfassungsmauern umschließen einen offenen Raum, behutsame Einbauten und Erinnerungstafeln unterstreichen dabei den Mahnmalcharakter und helfen auch heute noch, den Bau, der anders als Sankt Alban in Köln von jedermann betreten werden darf, entsprechend einzuordnen. So erfährt man auf einer Bronzetafel über die Geschichte der Kirche: ,Am 27. Oktober 1951 wurde die Ruine als Gedenkstätte für die Opfer der Kriege und der Gewalt eingeweiht.' Der Chor wird von einem Altartisch und einem hohen Kreuz beherrscht, davor ist eine steinerne Platte mit der Widmung ,Unseren Toten' in den Boden eingelassen. Eine ausführliche Inschrift findet sich zudem auf einer links vom Chor angebrachten weiteren Bronzetafel: ,Krieg und Katastrophe forderten das Leben vieler Einwohner unserer Stadt, an der Front und in der Heimat. 12628 fielen 1914-1918, 1939-1945 fielen 11360, 7000 wurden von Bomben getötet.

16 Rudolf Schwarz, Der Neue Gürzenich, in: Johann Jakob Hässlin (Hrsg.), Der Gürzenich zu Köln. Dokumente aus fünf Jahrhunderten, München 1955, S. 173-200; Angela Pfotenhauer/Elmar Lixenfeld, Festarchitektur der fünfziger Jahre. Der Gürzenich und St. Alban in Köln, Köln 1997.

17 Schwarz, Der Neue Gürzenich, S. 183.

18 Dieser Terminus wird verwendet von Pfotenhauer/Lixenfeld, Festarchitektur der fünfziger Jahre, S. 56.

19 Hinrich Hermann Leonhardt, Die St.-Aegidien-Kirche zu Hannover im Wandel von sechs Jahrhunderten. Zum Gedächtnis der Grundsteinlegung des Gotteshauses am 28. September 1347, Hannover 1947, S. 30-35; Beseler/ Gutschow, Kriegsschicksale deutscher Architektur, Bd. 1, S. 252-255. 


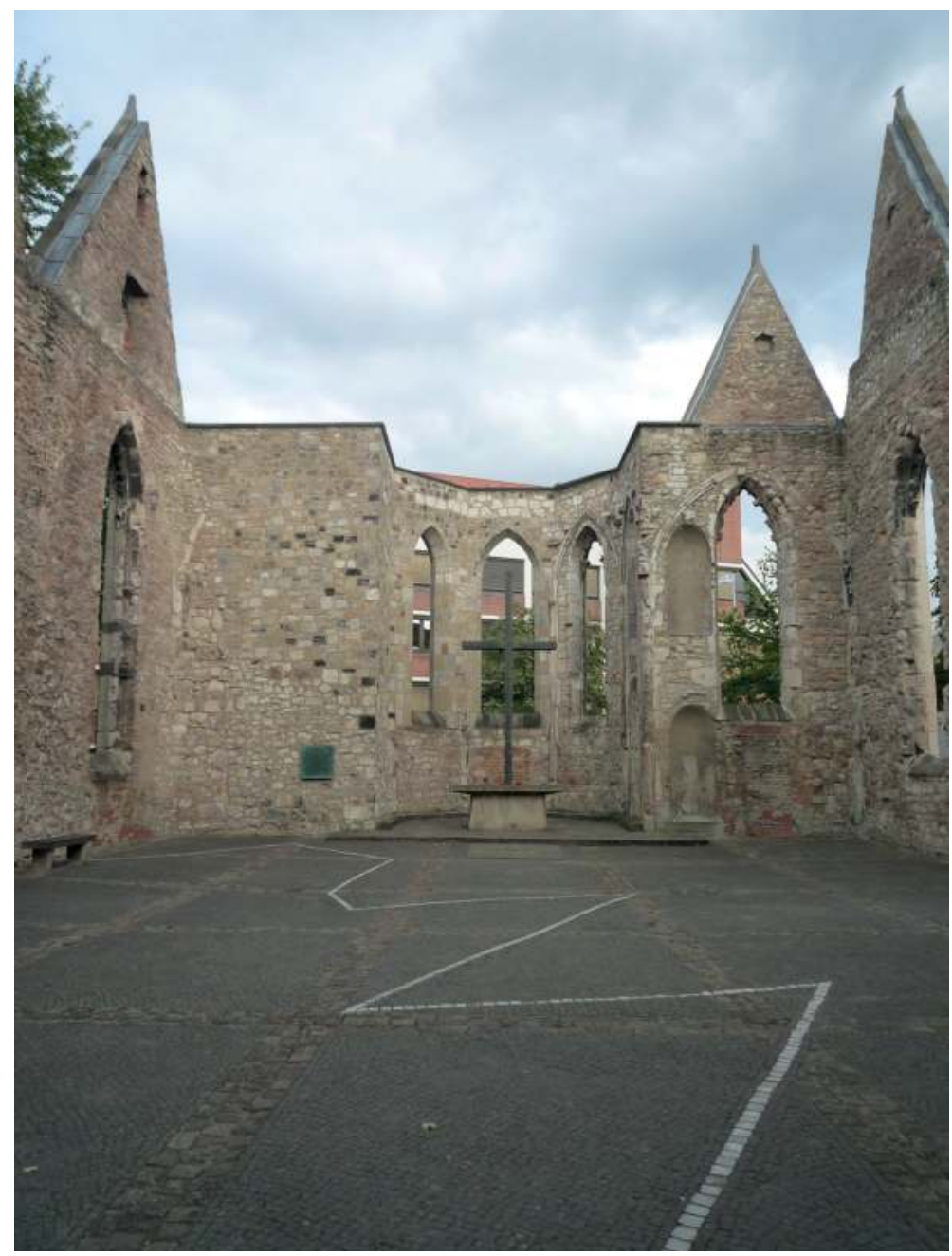

Abb. 5: Hannover, Ruine der Ägidienkirche, Aufnahme 2018.

6700 werden vermisst. Unzählige starben in Lagern und Gefängnissen und auf der Flucht.' Aufgrund all dieser Zusätze wird der Sinn der Ruine begriffen und man erkennt daran, wie wichtig die Kontextualisierung, das ,Labeling ist. Denn selbstredend ist nicht jede Kirchenruine ein Mahnmal. 1958 wurde der Turmstumpf, der nach wie vor als städtische Dominante fungiert, mit einem modernen Glockenspiel erhöht, und seit den achtziger Jahren wird zusätzlich an den Atombombenabwurf auf Hiroshima, Hannovers Partnerstadt, erinnert.

In den Fällen von Sankt Alban in Köln und der Ägidienkirche in Hannover wird die Ruine regelrecht inszeniert und bis heute aufwendig gepflegt und unterhalten. Dies unterscheidet sie von der - inzwischen bekanntlich zugunsten einer vollständigen Rekonstruktion wieder beseitigten Ruine der Dresdner Frauenkirche, wo neben den wenigen aufrecht stehenden Wandabschnitten vor allem ein großer Schutt- und Trümmerberg blieb, der zwar 1966 offiziell zu einem Mahnmal 


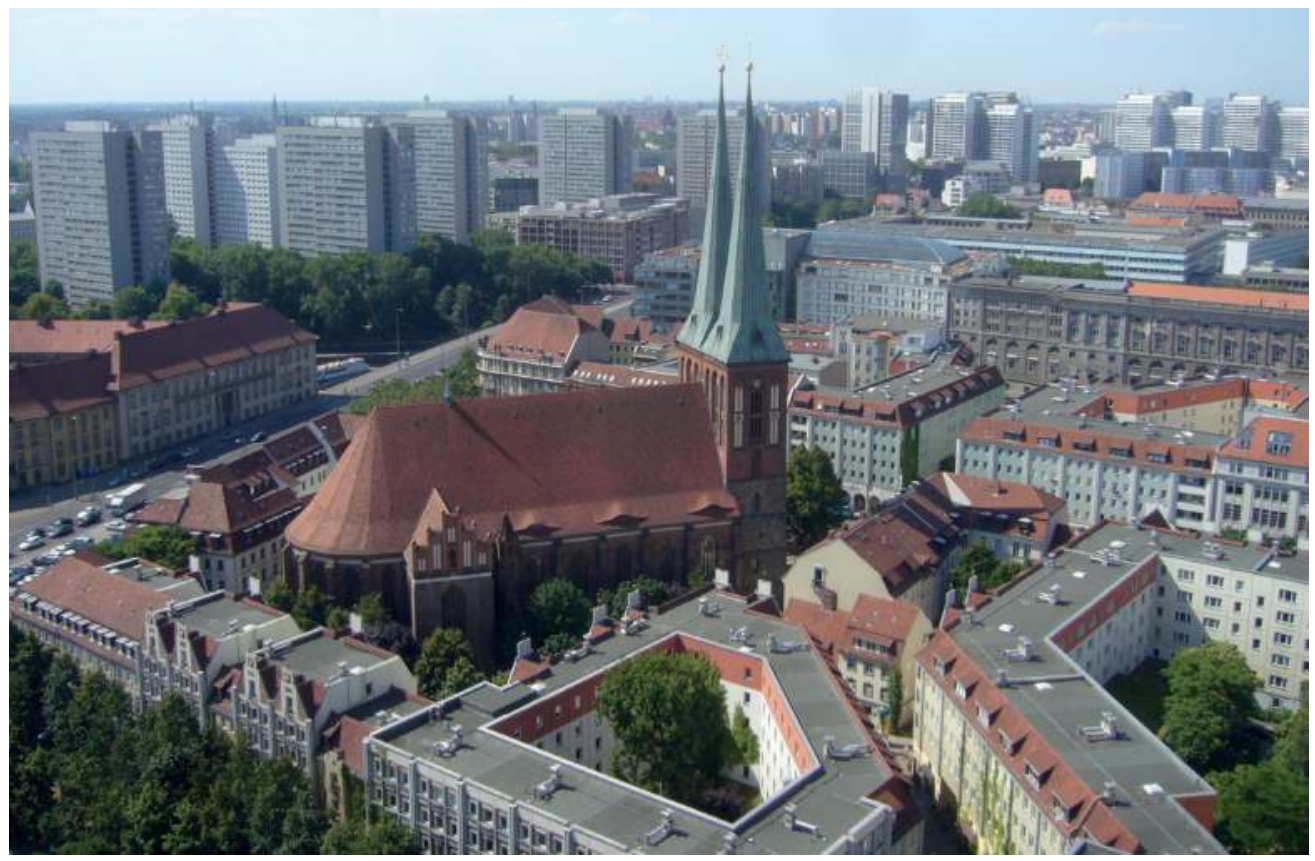

Abb. 6: Berlin, Blick vom Fernsehturm auf das Nikolaiviertel und die Nikolaikirche, Aufnahme 2010.

gegen Krieg und Gewalt deklariert, ansonsten jedoch sich selbst überlassen wurde. ${ }^{20}$ Andererseits führte im Osten Deutschlands der zunehmend hervortretende wirtschaftliche Mangel dazu, dass selbst in der Spätzeit der DDR viele Ruinen noch nicht wiederhergestellt waren, obwohl ihr Aufbau grundsätzlich nicht in Frage gestellt war. Ein prominentes Beispiel für einen sehr späten Wiederbau ist die Kirche Sankt Nikolai in Berlin, die im Krieg bis auf die monumentale Turmfront und die Umfassungsmauern zerstört worden war. Mit ihrer Wiederherstellung als Leitbau, nach außen weithin sichtbar durch das hohe Dach und die beiden Turmhelme, ging die Rekonstruktion eines ganzen Stadtquartiers einher, das, je länger die Zeit voranschreitet, als eine herausragende Leistung der DDR-Denkmalpflege erkannt wird. ${ }^{21}$ Der Krieg war dort also erst 1987, pünktlich zum Jubiläum der 750-Jahr-Feier, vorüber, wobei der Kirchenruine zu keiner Zeit eine bewusste Mahnmalfunktion zugedacht gewesen war.

Bis heute eine Ruine ist dagegen, um nur ein Beispiel zu nennen, die gotische Kirche Sankt Nikolai im anhaltinischen Zerbst, die in den letzten Kriegstagen, am 16. April 1945, durch einen amerikanischen Luftangriff zerstört worden war. ${ }^{22}$ Dass Ruinen dieser Art 1989 noch standen und eben nicht abgerissen worden waren, ist der Tatkraft von Denkmalpflegern zu verdanken,

20 Eckardt, Schicksale deutscher Baudenkmale im zweiten Weltkrieg, Bd. 2, S. 378-381.

21 Günter Stahn, Das Nikolaiviertel am Marx-Engels-Forum. Ursprung, Gründungsort und Stadtkern Berlins. Ein Beitrag zur Stadtentwicklung, Berlin 1985, S. 20-29; Günter Stahn, Berlin. Das Nikolaiviertel. Ein städtebaulicher Wegweiser, Berlin 2003 (Kleine Schriftenreihe der Historischen Kommission zu Berlin, Sonderh. 1), S. 21-28.

22 Eckardt, Schicksale deutscher Baudenkmale im zweiten Weltkrieg, Bd. 1, S. 276 f. 


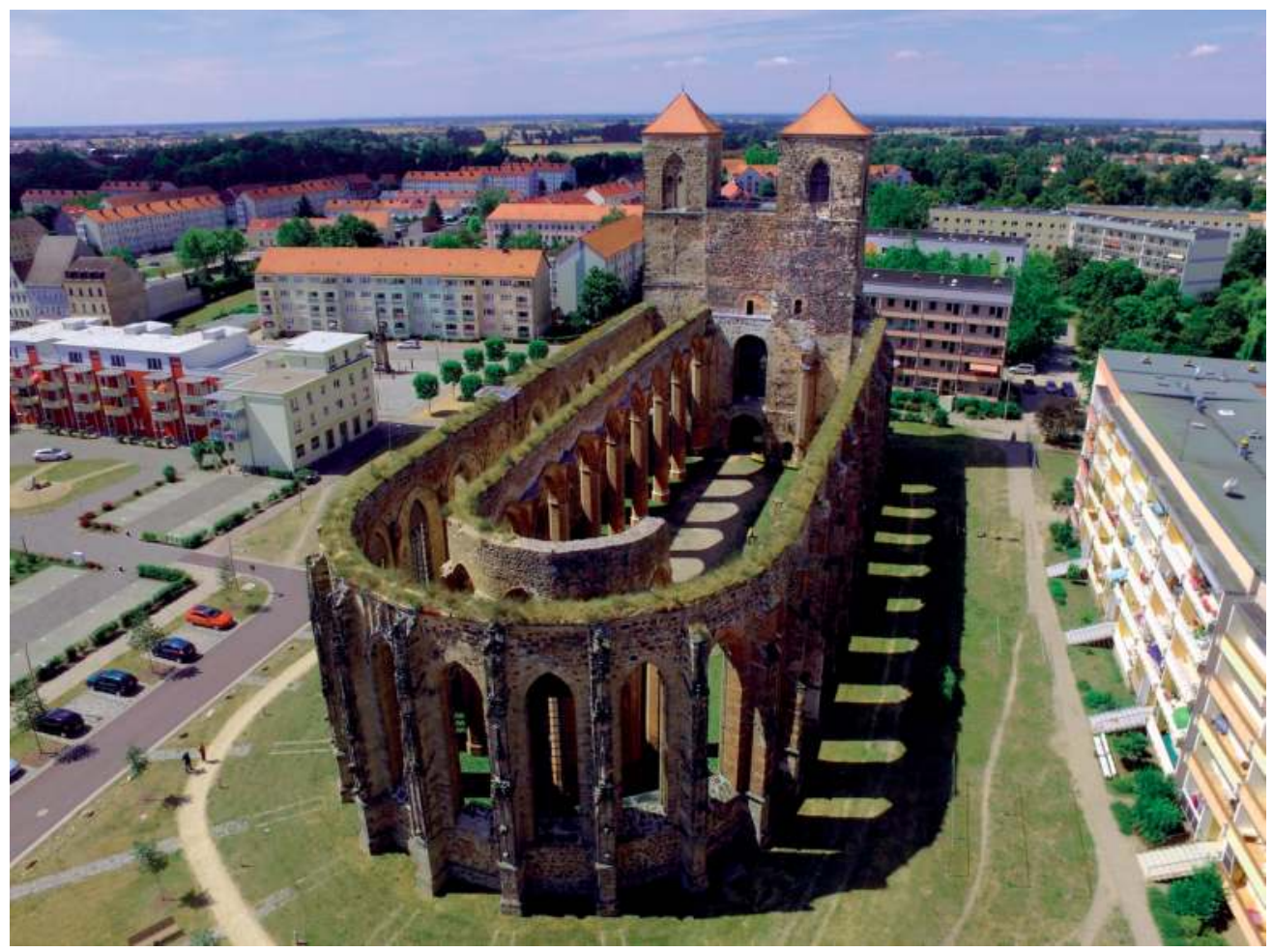

Abb. 7: Zerbst/Anhalt, Ruine von Sankt Nikolai, Aufnahme 2016.

die sich dennoch Verkennung der realen Gegebenheiten - von westlichen Stimmen den Vorwurf anhören mussten, wieso denn eine Ruine nach über vierzig Jahren immer noch in diesem $\mathrm{Zu}$ stand und nicht wiederhergestellt sei. Immerhin liegt die Wiedervereinigung inzwischen auch schon wieder dreißig Jahre zurück, und die Wiederherstellung so mancher Ruine ist nach wie vor nicht erfolgt beziehungsweise wird aufgrund gesellschaftlicher, religiöser und demografischer Entwicklungen auch nicht mehr angestrebt. Zwar kümmert sich in Zerbst seit der Wende ein Förderverein um den Erhalt der Ruine. Doch wie oftmals bei derartigen Projekten zu beobachten, muss man sich mit dem Eindecken von ausgewählten Bauteilen, in diesem Falle den beiden Türmen, begnügen und kann eventuell noch einen Turmaufstieg ermöglichen, während die Eindeckung des gesamten Schiffes schlicht nicht zu leisten ist. Ähnlich gelagerte Beispiel sind die Marienkirche in Wriezen oder die spätbarocke Pfarrkirche in Vierraden. ${ }^{23}$

Dieser Trend lässt sich auch auf der anderen Seite der Oder, im heutigen Polen, erkennen, wo sich in Königsberg in der Neumark (Chojna) und Guben (Gubin) vergleichbare Bauwerke, nämlich große, gegen Ende des Krieges zerstörte gotische Kirchen befinden. Während man in Königsberg sogar noch kurz vor der politischen Wende von 1989 in einem deutsch-polnischen Gemeinschaftsprojekt begann, die Kirchenruine wiederherzustellen, was zumindest äußerlich mit dem hohen Dach, das inzwischen sogar bereits ein zweites Mal wieder eingedeckt wurde, und der 
Turmsanierung gelang, ${ }^{24}$ so scheint man in Guben für eine derartige Herangehensweise nicht mehr den Willen und die Kraft aufzubringen. ${ }^{25}$ Stattdessen werden hier Überlegungen angestellt, die Ruine zu sichern und eine neue Nutzung mittels eines modernen Einbaus zu ermöglichen. Als Gotteshäuser werden beide Kirchen insofern nicht mehr benötigt, als die nach 1945 dort neu erstarkte katholische Kirche dafür andere Gebäude auswählte.

In diesem Zusammenhang sei der Blick nochmals auf Köln gerichtet, wo es neben Sankt Alban noch eine zweite Kirche gab, die man lange Zeit als Ruine beließ: nämlich Sankt Kolumba, einst eine der größten und bedeutendsten Pfarrkirchen der Stadt, deren Ursprünge sogar in ottonische Zeit zurückreichen und die in der Gotik zu einer fünfschiffigen Hallenkirche erweitert wurde, ehe sie in der Barockzeit und im 19. Jahrhundert weitere Veränderungen erfuhr. ${ }^{26} \mathrm{Nach}$ der fast völligen Vernichtung der Kirche im Jahr 1943 blieb neben Teilen der spätmittelalterlichen Außenmauern vor allem eine Marienstatue erhalten, der sofort besondere kultische Verehrung zuwuchs. Man entschied daher, dafür einen modernen Ersatzbau zu schaffen, den der junge Architekt Gottfried Böhm von 1947 bis 1950 in die stark kriegszerstörte Kirche Sankt Kolumba hineinsetzte. ${ }^{27}$ Die auf achteckigem Grundriss errichtete und mit einem zeltartigen Dach versehene eingeschossige Marienkapelle erhielt im Volksmund rasch den Namen ,Madonna in den Trümmern' - und zwar in doppelter Bedeutung, war doch die Madonnenstatue aus den Trümmern geborgen worden und befand sich deren Kapelle nun in den übriggebliebenen Trümmern der einstigen Kirche. Die neue Kapelle wurde zu einem Ort tiefer Volksfrömmigkeit, der insbesondere in der Nachkriegszeit, als viele Menschen noch unmittelbar von den Folgen des Krieges betroffen waren, stark besucht wurde und im Verbund mit den unmittelbar benachbarten Ruinen der ehemaligen Pfarrkirche, die lediglich gesichert wurden, eine eigentümliche Wirkung aus Mahnung und Trost entfaltete. Die Verquickung zwischen Ruine und Neubau zeigte sich zudem im Eingangsbereich, der im Stumpf des Turmes untergebracht und mit Trümmersteinen ergänzt wurde, um an die mittelalterliche Kirche zu erinnern.

Seit einigen Jahren allerdings ist die Kapelle im Neubau des Diözesanmuseums aufgegangen, das von 2003 bis 2007 nach den Entwürfen des Schweizer Architekten Peter Zumthor errichtet wurde. ${ }^{28}$ Spätestens damit ging sie auch ihres Mahnmalcharakters verlustig, auch wenn weder die Substanz der Kapelle noch die bis dahin erhaltenen Ruinen der alten Kolumbakirche angetastet wurden. Vielmehr wurden Letztere durch den Neubau auch dauerhaft gesichert. Hinzu kommt, dass die Kapelle auf dem weiten Kirchengelände nur einen vergleichsweise geringen Raum einnahm und dieses ansonsten jahrzehntelang ungenutzt und ungestaltet brachgelegen hatte. In Sankt Kolumba wurde also eine Ruine in modernen Formen ,weitergebaut.

24 Reinhard Schmook, Erfahrungen beim Wiederaufbau der Marienkirche in Chojna-Königsberg/Neumark - ein deutsch-polnisches Stiftungsprojekt, in: Wolfgang Michalka/Reinhard Schmook (Hrsg.), Schwierige Nachbarn? 300 Jahre deutsch-polnische Nachbarschaft. Groß Neuendorfer Grenzgespräche 2006. Vorträge und Diskussionen, Berlin 2007, S. 135-141.

25 Vgl. dazu auch Andreas Peter, Die Stadt- und Hauptkirche in Guben, Gubin: eine Bau- und Kulturgeschichte, Guben 2007, S. 91-94.

26 Ewald/Rahtgens, Die Kirchlichen Denkmäler der Stadt Köln I, S. 194-230.

27 Beseler/Gutschow, Kriegsschicksale deutscher Architektur, Bd. 1, S. $541 \mathrm{f}$.

28 Wolfgang Pehnt, Ein Haus für Sinn und Sinne: Diözesanmuseum Kolumba in Köln, Peter Zumthor, in: Baumeister 11 (2007), S. 48-63. 


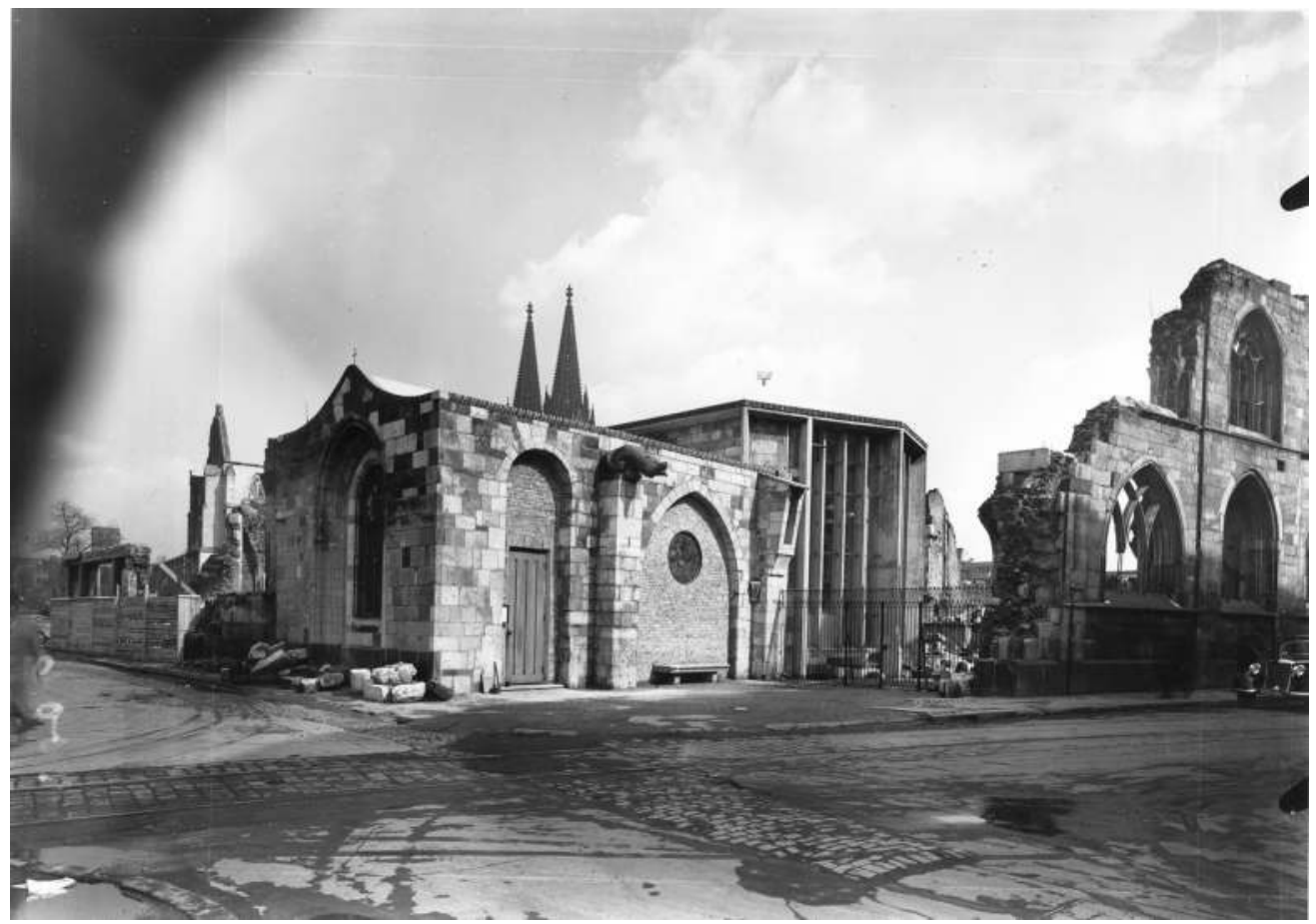

Abb. 8: Köln, Ruine von Sankt Kolumba mit Gottfried Böhms Neubau von Madonna in den Trümmern (1947-1950), Aufnahme 1951.

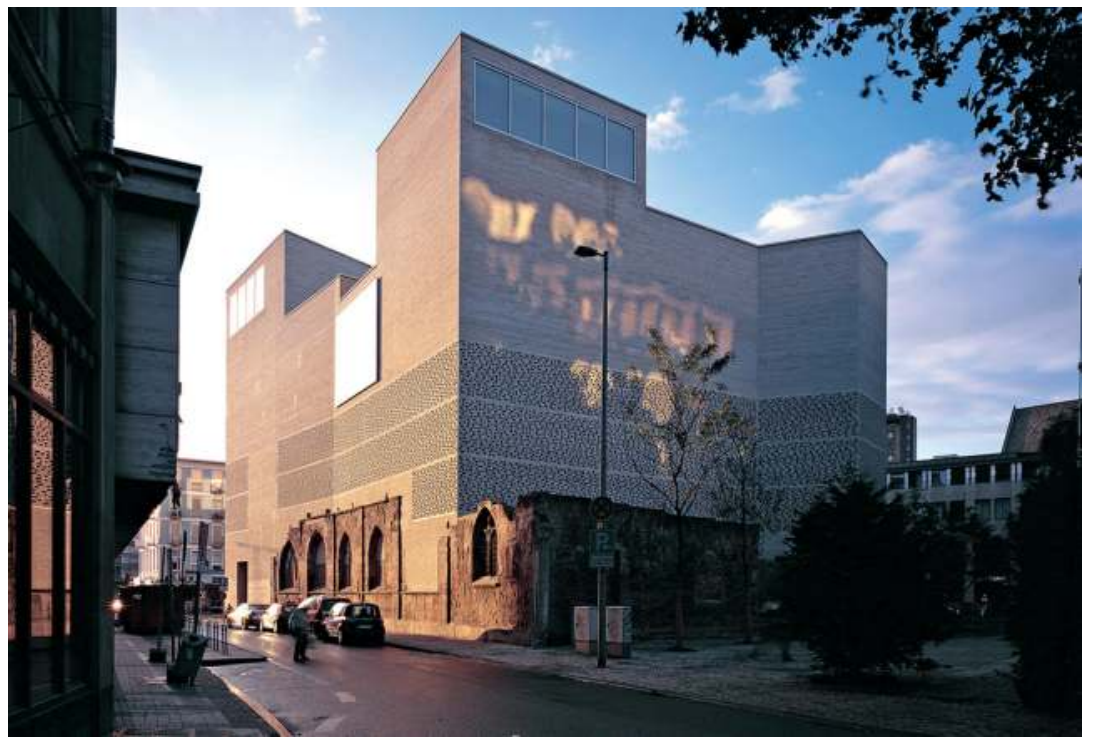

Abb. 9: Köln, Ruine von Sankt Kolumba mit Peter Zumthors Erweiterung zum Diözesanmuseum (2003-2007), Aufnahme 2008. 


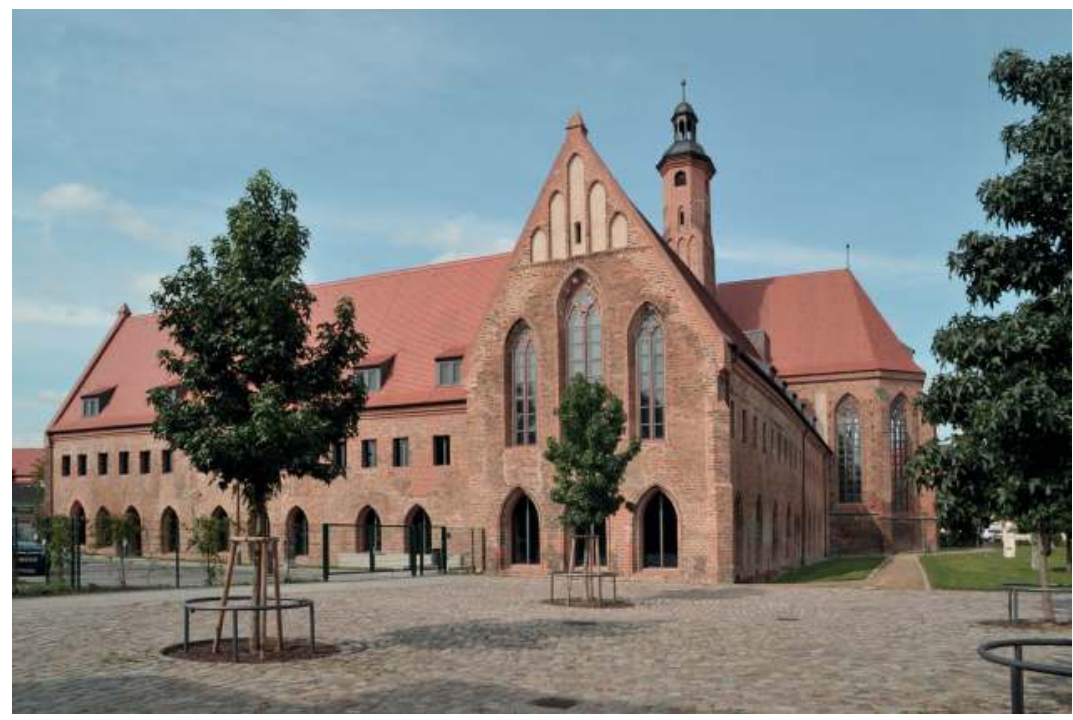

Abb. 10: Brandenburg an der Havel, Kloster Sankt Pauli nach der Wiederherstellung 2008, Aufnahme 2008.

Behutsamer ging man hingegen bei der annähernd gleichzeitig erfolgten Wiederherstellung von zwei Kirchenruinen in Brandenburg an der Havel vor. Beide Beispiele mögen zum Abschluss verdeutlichen, wie sich unsere Gesellschaft heute und in dieser Region mit dieser Problematik auseinandersetzt. Seit seiner 2008 erfolgten Einweihung als Archäologisches Landesmuseum zeigt sich das Paulikloster nach außen hin wieder in seiner ursprünglichen Gestalt. Die Anlage hatte bei der Eroberung Brandenburgs durch die Rote Armee, Ende April 1945, Feuer gefangen, sodass von der Kirche nur noch die Umfassungsmauern, der Turmstumpf und der Westgiebel übriggeblieben und auch die Klostergebäude, trotz zeitweiliger Sicherungsmaßnahmen nach dem Krieg, ihrer Dächer beraubt waren. ${ }^{29}$ Erst im Zuge der 2004 einsetzenden Sanierung erhielten sämtliche Bautrakte einschließlich der Kirche ihre historischen Dachformen zurück, zudem wurden an der Kirche der Ostgiebel, die südliche Pfeilerreihe und der Turmaufsatz rekonstruiert, während im Inneren auf eine Wiederherstellung der Gewölbe verzichtet wurde.

Die nahegelegene Johanniskirche hatte schon beim amerikanischen Bombenangriff auf Brandenburg vom 31. März 1945 ihr westliches Joch verloren, ehe schließlich 1986 aufgrund unzureichender Sicherungsmaßnahmen ihr Dach samt den Gewölben einstürzte. Eine umfassende Wiederherstellung gelang bis 2014 im Rahmen der ,BUGA 2015 Havelregion', bei welcher sie als Blumenhalle diente. ${ }^{30}$ Das heutige Dach weist die ursprüngliche Form auf, allerdings wurde

29 Eckardt, Schicksale deutscher Baudenkmale im zweiten Weltkrieg, Bd. 1, S. 138 f.; Marcus Cante, Führer durch das Paulikloster Brandenburg an der Havel, Zossen 2010, S. 23-27.

30 Eckardt, Schicksale deutscher Baudenkmale im zweiten Weltkrieg, Bd. 1, S. 138; Katrin Witt, St. Johannis. Von der Klostergründung zur Blumenhalle der BUGA 2015 Havelregion - Eine bewegte Vorgeschichte, in: Marcus Cante/Joachim Müller (Hrsg.), Johanniskirche Brandenburg an der Havel. Erforschung - Sicherung - Restaurierung (Arbeitshefte des Brandenburgischen Landesamtes für Denkmalpflege und Archäologischen Landesmuseums, Nr. 43), Worms 2017, S. 15-29, hier S. 23-28. 


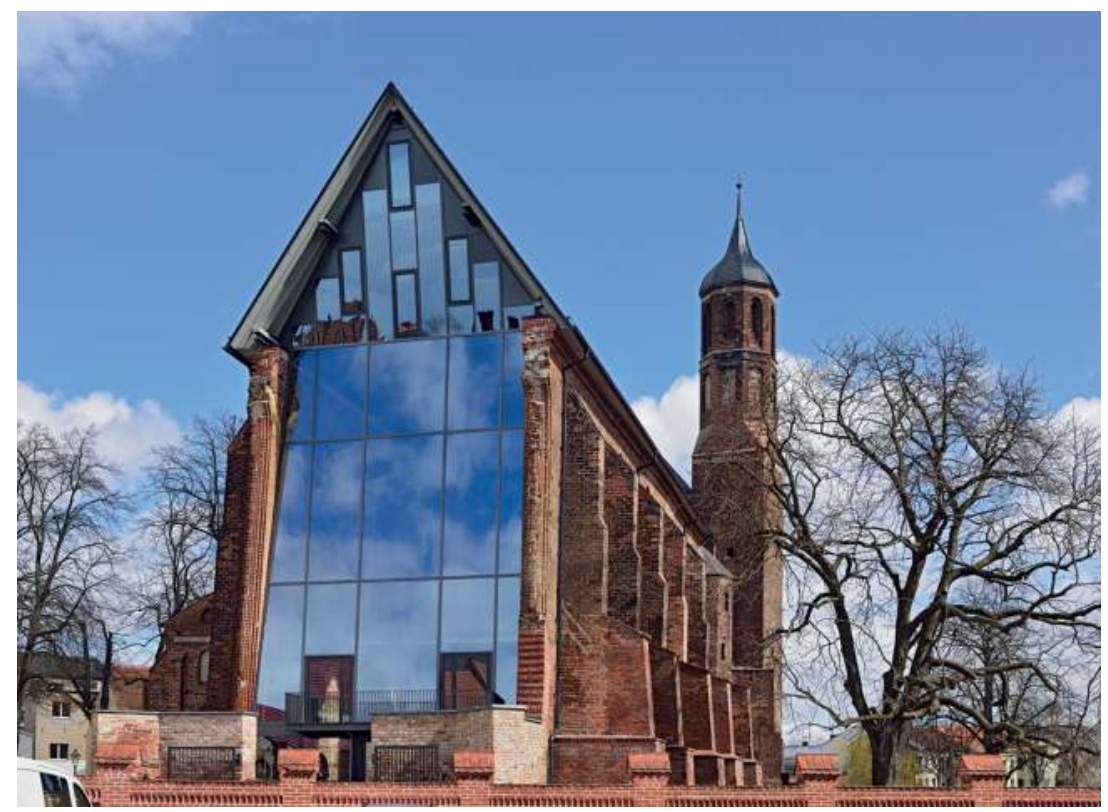

Abb. 11: Brandenburg an der Havel, Westfassade der Johanniskirche nach der Wiederherstellung durch Krekeler Architekten, Aufnahme 2015.

mit Kupfer eine bewusst vom historischen Ziegeldach abweichende Deckung gewählt, um über diese Art von Verfremdung auf die Zerstörungsgeschichte der Kirche aufmerksam zu machen. ${ }^{31}$ Weit drastischer geschieht dies freilich an der Westfront, wo die Abbruchkante des fehlenden Jochs sichtbar belassen und die offene Bresche lediglich durch eine monumentale Stahl-GlasFront geschlossen wurde. Seit dem Ende der Bundesgartenschau wird die Kirche für kulturelle Veranstaltungen der Stadt genutzt und steht außerdem der reformierten Gemeinde für Gottesdienste zur Verfügung.

Man könnte noch zahlreiche weitere Sakralbauten anfügen, doch mögen die skizzierten Beispiele ausreichen, um einen Begriff von den verschiedenen Möglichkeiten im Umgang mit Ruinen kriegszerstörter Kirchen zu vermitteln. Sicherlich ist jeder Fall anders gelagert, zumal wenn die stets entscheidende Frage der Nutzung mit hinzukommt. Was nun den künftigen Umgang mit der Ruine der Franziskanerkirche in Berlin anbelangt, so bedarf es zunächst einmal einer Vergewisserung und Verständigung über die Kontexte, in denen sie sich befindet. Handelt es sich hierbei, verkürzt gesagt, eher um Sankt Nikolai in Zerbst - oder um Sankt Alban in Köln? Wäre eine Herangehensweise - und Nutzung - wie bei Sankt Kolumba in Köln denkbar? Oder sollte sich das einstige Berliner Franziskanerkloster an Maßstäben orientieren, wie sie jüngst in Brandenburg an der Havel gesetzt wurden? Erst die Beantwortung dieser Fragen kann zu einem verantwortungsvollen Umgang mit der Ruine führen.

31 Sandra Nehiba/Alexander Wesch, St. Johanniskirche Brandenburg. Ikonographie eines Fragments, in: Cante/ Müller (Hrsg.), Johanniskirche Brandenburg an der Havel, S. 139. 



\section{Autorenverzeichnis}

Bulach, Doris; Dr. phil.; seit 2006 Mitarbeiterin der Regesta Imperii, Ludwig der Bayer; Forschungsschwerpunkte: Geschichte des Spätmittelalters, vergleichende Landesgeschichte, Klostergeschichte.

Heimann, Heinz-Dieter (geb. 1949); Prof. Dr.; von 1992/94 bis 2015 Professor für Mittelalterliche Geschichte an der Universität Potsdam; Forschungsschwerpunkte: Geschichte des europäischen Spätmittelalters, vergleichende Landes- und Kulturgeschichte, Geschichte der Franziskanergemeinschaften.

Hinterkeuser, Guido (geb. 1967); Dr. phil.; Studium der Kunstgeschichte, Geschichte und Italianistik in Köln, Bonn, Florenz und Berlin, Promotion 2002 mit einer Arbeit über ,Andreas Schlüter und das Berliner Schloß` an der Humboldt-Universität zu Berlin, von 1998 bis 2003 wissenschaftlicher Mitarbeiter in der Stiftung Preußische Schlösser und Gärten Berlin-Brandenburg in Potsdam und der Stiftung Schloss und Park Benrath in Düsseldorf, seit 2004 freiberuflich tätig als Kunsthistoriker und Publizist.

Knackmuß, Susanne; Studium unter anderem der Geschichte und Bibliothekswissenschaft in Berlin und Wien; betreut und erschließt für die Streitsche Stiftung zu Berlin die Sammlungen des Berlinischen Gymnasiums zum Grauen Kloster; Veröffentlichungen zur Ordens-, Kloster- und Schulgeschichte, Sammlungshistorie und Provenienzforschung mit dem Schwerpunkt auf der frühneuzeitlichen Geschichte, Editionen.

Lemburg, Peter (geb. 1946); Dr. phil.; Architektur- und Kunsthistoriker, Gutachter und denkmalpflegerischer Kontaktarchitekt, vornehmlich in Berlin; Schwerpunkte: Industrie- und Kirchenbau des 19. und 20. Jahrhunderts; Autor unter anderem von ,Denkmaltopographien'; Vorstand des Architekten- und Ingenieur-Vereins zu Berlin-Brandenburg.

Malliaris, Michael (geb. 1964); Dr. phil.; Projektleiter der Ausgrabungen des Landesdenkmalamtes Berlin am Molkenmarkt in Berlin-Mitte; Forschungsschwerpunkte: mittelalterliche und frühneuzeitliche Stadtkultur in Nordostdeutschland.

Nath, Gunnar (geb. 1967); geprüfter Grabungstechniker; seit 1990 Mitarbeiter in der Berliner Bodendenkmalpflege, zuerst an der Arbeitsstelle für Bodendenkmalpflege beim Märkischen Museum, danach beim Archäologischen Landesamt Berlin und seit 1995 Mitarbeiter des Landesdenkmalamtes Berlin.

Schäche, Wolfgang (geb. 1948); Prof. Dr. Ing.; Architekturhistoriker und Architekt, 1988 Berufung zum Professor für Baugeschichte und Architekturtheorie sowie zum Leiter des Labors für Baugeschichte und Bauerhaltung an der Beuth Hochschule für Technik Berlin; Forschungsschwerpunkte: Architektur- und Stadtgeschichte des 19. und 20. Jahrhunderts, Denkmalpflege; mehr als 250 Veröffentlichungen im In- und Ausland, davon 42 Buchpublikationen. 
Schulz, Sibylle (geb. 1957); Diplomkunsthistorikerin; 1980 bis 2009 Mitarbeiterin in der Berliner Denkmalpflege, zunächst im Institut für Denkmalpflege der DDR/Arbeitsstelle Berlin, danach im Landesdenkmalamt Berlin.

Schumann, Dirk (geb. 1964); Kunsthistoriker und Bauarchäologe; Forschungsschwerpunkte: Mittelalterliche Backsteinarchitektur in Norddeutschland, mittelalterliche und frühneuzeitliche Kunst- und Architekturgeschichte der Mark Brandenburg.

Stegmann, Andreas (geb. 1975); Dr. theol.; Privatdozent für Kirchengeschichte an der Theologischen Fakultät der Humboldt-Universität zu Berlin; Forschungsschwerpunkte: Kirchengeschichte der Frühen Neuzeit und des 20. Jahrhunderts, brandenburgische Kirchengeschichte.

Wemhoff, Matthias (geb. 1964); Prof. Dr.; von 1992 bis 2006 Leiter des Museums in der Kaiserpfalz in Paderborn, 2002 bis 2008 Gründungsdirektor des Westfälischen Landesmuseums für Klosterkultur in Kloster Dalheim, seit 2008 Direktor des Museums für Vor- und Frühgeschichte der Staatlichen Museen zu Berlin und Landesarchäologe von Berlin; Forschungsschwerpunkte: Archäologie des Mittelalters und der Neuzeit (speziell Kirchen und Klöster), Archäologie der Moderne. 


\section{Abbildungsnachweise}

\section{Heimann, per totum orbem longe lateque diffudit}

Abb. 1-2: Diözesanarchiv Berlin, Bildnummern 14995,23 und 14995,28; Fotos: Frank Vetter.

Abb. 3: Heinz-Dieter Heimann u. a. (Hrsg.), Brandenburgisches Klosterbuch. Handbuch der Klöster, Stifte und Kommenden bis zur Mitte des 16. Jahrhunderts (Brandenburgische Historische Studien, Bd. 14), 2 Bde., 1. Aufl., Berlin 2007, Bd. 1, S. 158; Entwurf und Zeichnung: Ellen Franke 2006.

Abb. 4-7: Brandenburgisches Landesamt für Denkmalpflege und Archäologisches Landesmuseum (BLDAM), Bildarchiv, Negativ-Nr. 38 m 11/5671.50, 38 m 12/5671.51, 38 m 13/5671.52

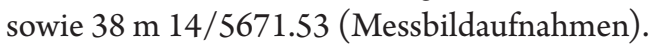

\section{Bulach, Das Franziskanerkloster in Berlin}

Abb. 1: Rosemarie Jung.

Abb.2-3: Evangelische Kirche Berlin-Brandenburg-schlesische Oberlausitz; Foto: Claudia Rückert.

Abb. 4, 6-12: Doris Bulach.

Abb. 5: Peter Knüvener.

\section{Knackmuß, >Klostergeist〈-Kontinuum in situ}

Abb. 1: Streitsche Stiftung zu Berlin, GK1 Archiv NL Wolfram Schulz.

Abb. 2-3, 5: Sammlungen des Berlinischen Gymnasiums zum Grauen Kloster (Streitsche Stiftung zu Berlin).

Abb. 4: Streitsche Stiftung zu Berlin.

\section{Schumann, Die Berliner Franziskanerklosterkirche}

Abb. 1, 3: Julius Kohte, Das Hohe Haus in Berlin, in: Forschungen zur brandenburgischen und preußischen Geschichte 48 (1936), S. 148-163, hier S. 149, 151 und 155.

Abb. 2: Richard Borrmann (Bearb.), Klosterkirche, in: Magistrat der Stadt Berlin (Hrsg.), Die Bau- und Kunstdenkmäler von Berlin, Berlin 1893, S. 190.

Abb. 4, 7, 9-10, 12-14, 18-20: Dirk Schumann.

Abb. 5: Dirk Schumann nach Sigrid Teichert, in: Rainer Szczesiak, Die baulichen Anfänge des Neubrandenburger Franziskanerklosters unter sakralen und weltlichen Aspekten, in: Dirk Schumann (Hrsg.), Brandenburgische Franziskanerklöster und norddeutsche Bettelordensbauten, Berlin 2010, S. 369-389, hier S. 374.

Abb. 6, 15: Paul Eichholz/Friedrich Solger (Bearb.), Die Kunstdenkmäler der Provinz Brandenburg, Bd. 3, T. 3: Kreis Angermünde, Berlin 1934, Tafel 4 und S. 59. 
Abb. 8: Paul Eichholz/Theodor Goecke (Bearb.), Die Kunstdenkmäler der Provinz Brandenburg, Bd. 2, T. 3: Brandenburg Stadt und Dom, Berlin 1912, S. 35.

Abb. 11: Josef Adolf Schmoll gen. Eisenwerth, Das Kloster Chorin und die Askanische Architektur in der Mark Brandenburg 1260-1320 (Veröffentlichungen der Berliner Historischen Kommission beim Friedrich-Meinecke-Institut der Freien Universität Berlin, Bd. 2), Berlin 1961, S. 30.

Abb. 16: Petra Marx, Zur Geschichte der bauhistorischen Forschung und denkmalpflegerischen Bemühungen - ein fachgeschichtlicher Überblick, in: Landesdenkmalamt Berlin (Hrsg.), Kirchenruine des Grauen Klosters in Berlin. Geschichte - Forschung - Restaurierung (Beiträge zur Denkmalpflege in Berlin, Bd. 23), Petersberg 2007, S. 31-53, hier S. 45.

Abb. 17: Dirk Schumann, Die Franziskaner-Klosterkirche und der Dekor - Formsteine und Formsteinsysteme einer repräsentativen askanischen Architektur, in: Landesdenkmalamt Berlin (Hrsg.), Kirchenruine des Grauen Klosters in Berlin. Geschichte - Forschung - Restaurierung (Beiträge zur Denkmalpflege in Berlin, Bd. 23), Petersberg 2007, S. 127-140, hier S. 138.

\section{Nath, Archäologische Bestandsaufnahme des Grauen Klosters}

Abb. 1-5, 8-12: Landesdenkmalamt Berlin; Foto oder Plan: Gunnar Nath.

Abb. 6: Landesdenkmalamt Berlin; Foto: Wolfgang Gehrke.

Abb. 7: Archiv Landesdenkmalamt Berlin, 1-S02-08-105-6.

\section{Malliaris, Klostergründungen in Berlin}

Abb. 1, 3, 6: Landesdenkmalamt Berlin; Foto: Michael Malliaris.

Abb. 2, 4-5: Entwurf: Michael Malliaris; Grafik: Ulrich Haarlammert (Maßwerke, Münster).

\section{Lemburg, Klostergründungen in Berlin}

Abb. 1: Friedrich Adler, Mittelalterliche Backstein-Bauwerke des Preussischen Staates, Bd.2, Berlin 1898.

\section{Schäche, Aufbruch in das 20. Jahrhundert}

Abb. 1: Landesarchiv Berlin, F Rep. 290-01-01, Nr. 679; Foto: Friedrich Albert Schwartz.

Abb. 2: Landesarchiv Berlin, F Rep. 290, Nr. II 4235; Foto: keine Angabe.

Abb. 3-4, 7, 9-11: Zentralblatt der Bauverwaltung 24 (1904), Nr. 93, S. 578-581.

Abb. 5: Landesarchiv Berlin, F Rep. 290-01-01, Nr. 684; Foto: Friedrich Albert Schwartz.

Abb. 6: Ludwig Hoffmann (Hrsg.), Neubauten der Stadt Berlin, Bd. 3, Berlin 1904, S. I.

Abb. 8: Ludwig Hoffmann (Hrsg.), Neubauten der Stadt Berlin, Bd. 3, Berlin 1904, Tafel 2; Foto: Ernst von Brauchitsch.

Abb. 12: Ludwig Hoffmann (Hrsg.), Neubauten der Stadt Berlin, Bd. 1, Berlin 1902, Tafel 17; Foto: Ernst von Brauchitsch.

Abb. 13: Landesarchiv Berlin, F Rep. 290, Nr. 65665; Foto: Herbert Kraft. 


\section{Schulz, Die Klosterkirche zu Berlin}

Abb. 1-2, 4, 8, 10-11: Sibylle Schulz

Abb. 3, 5: Archiv Landesdenkmalamt Berlin; Foto: keine Angabe.

Abb. 6: Archiv Landesdenkmalamt Berlin.

Abb. 7: Felix Lohrmann.

Abb. 9: Klaus Block Architekt BDA.

\section{Hinterkeuser, Zum Umgang mit Ruinen kriegszerstörter Kirchen}

Abb. 1: CC-BY-SA-3.0 (via Wikimedia Commons); Foto: Peter Schmelzle.

Abb. 2: Staatliche Museen zu Berlin, Kupferstichkabinett, KdZ 29942; Foto: Jörg P. Anders.

Abb. 3: CC-BY-SA-3.0 (via Wikimedia Commons); Foto: GerardM.

Abb. 4: CC-BY-SA-4.0 (via Wikimedia Commons); Foto: Raimond Spekking.

Abb. 5: Guido Hinterkeuser.

Abb. 6: Stiftung Stadtmuseum Berlin, CC BY-SA 3.0; Foto: Tobias Böhm.

Abb. 7: CC-BY-SA-4.0 (via Wikimedia Commons); Foto: Bodo Witzke.

Abb. 8: Rheinisches Bildarchiv Köln, rba_136940.

Abb. 9: Kolumba Köln; Foto: Hélène Binet.

Abb. 10: Brandenburgisches Landesamt für Denkmalpflege und Archäologisches Landesmuseum; Foto: Detlef Sommer.

Abb. 11: Krekeler Architekten Generalplaner GmbH; Foto: Stefan Melchior. 


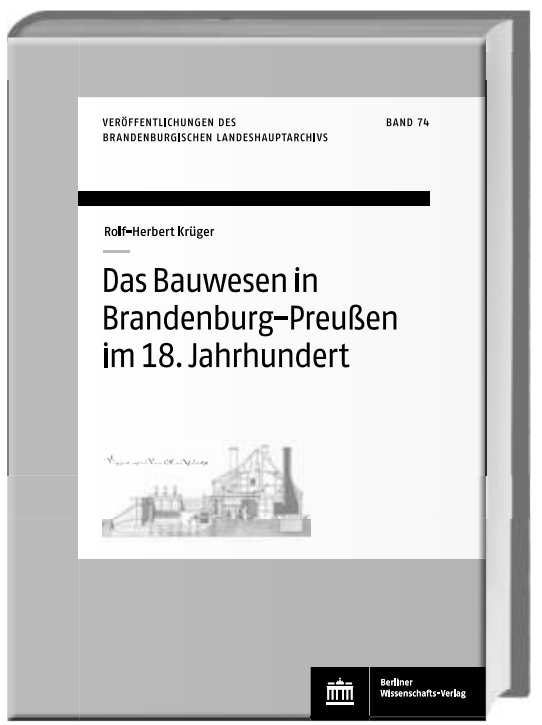

\section{DER AUTOR}

Dr.-Ing. Rolf-Herbert Krüger, geb. 1941, Maurergeselle 1959, Studium zum Bau-Ing. in Berlin \& zum Dipl.-Ing. an der TU Dresden 1972. Ab 1964 Bauund Prüf-Ing. für Statik/Konstruktion, ab 1972 Mitarbeit an Projekten für Neu- und historische Bauten im Zentrum Berlins, 1987 Chef-Ing., 1990 Promotion an der TU Dresden, 1990-2005 Inhaber eines Ing.-Büros, Beratender Ing. Seit 1985 div. Publikationen zu bauhistorischen Themen.

\section{AUS DEM INHALT}

Geschichte der ersten zivilen Bauverwaltung | Vom Bau-Comptoir zum Königlichen OberHofbauamt | Die Berliner Baukommissionen im 17. und 18. Jahrhundert | Brandschutz, Feuerordnungen und Feuersozietäten | Die Schlossbaumeister, das Bauamt in Berlin | Ausbildung, Qualifikation, Besoldung und emigrierte Baubeamte | Planungsordnung, Vereidigungen, Baureglements und Zunftgesetze | Straßen- und Wegebau | Bautechnik und Baustatik in Preußen | Veröffentlichungen zu Architektur- und Bauproblemen

\section{Rolf-Herbert Krüger}

\section{Das Bauwesen in}

\section{Brandenburg-Preußen} im 18. Jahrhundert

Die Baugeschichte Brandenburg-Preußens ist zugleich Teil der Geschichte des Königreichs Preußen während seines Aufstiegs zur europäischen Großmacht im 18. Jahrhundert. Rolf-Herbert Krüger erläutert hier erstmals das Entstehen derVerwaltungsstrukturen und der Organisation des Bauwesens sowie die Besonderheiten der Berliner Baukommission, die für den Ausbau der Hauptstadt Berlin verantwortlich war.

Besonderen Fokus legt er auf die praktische Arbeit der Architekten, Ingenieure und Bauausführenden, ihre soziale Stellung, Qualifizierung und Bezahlung sowie die technischen Hilfsmittel, mit denen die Bauten errichtet wurden, bevor statische Berechnungen möglich waren. Dabei geht er auch auf Fehlschläge und Einsturzkatastrophen wie die des Münz-Turms, des Petri-Kirchturms und des Deutschen Doms ein.

Weitere Schwerpunkte bilden das Verhältnis der Baubeteiligten zu den Königen, fehlerhafte zeitgenössische und spätere Darstellungen der Aufgabengebiete sowie Leistungen der Baubeamten und deren Wissenstransfer durch selbst verfasste Fachbücher.

2020, 448 S., 93 s/w Abb., 15 s/w Fotos, geb., $69,-€, 978-3-8305-3965-0$

eBook PDF 978-3-8305-4128-8

(Veröffentlichungen des Brandenburgischen Landeshauptarchivs, Bd. 74) 


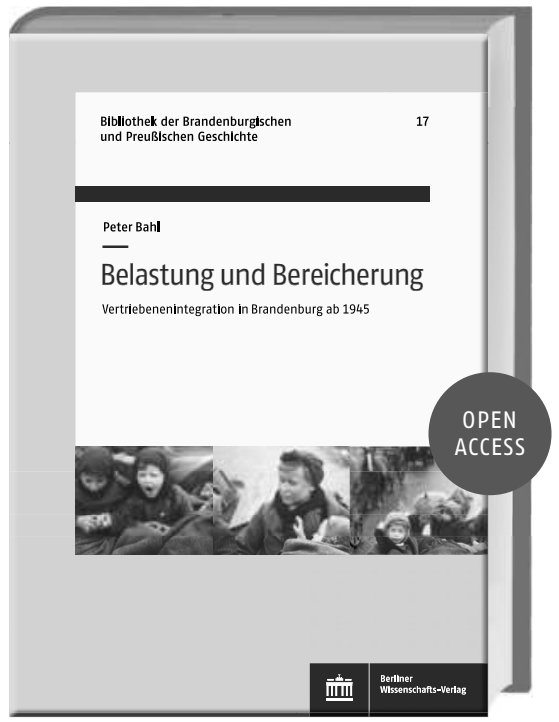

\section{DER AUTOR}

Dr. Peter Bahl, geb. 1963, Studium der Geschichte und Lateinischen Philologie in Bielefeld und Berlin (FU), 2001 Promotion an der FU Berlin, freier Historiker in Berlin. Forschungsschwerpunkte: Landesgeschichte Berlins, Brandenburgs, Preußens und Schlesiens, Personengeschichte, Historische Hilfswissenschaften.

\section{AUS DEM INHALT}

Ziele und Methoden | Forschungsstand und Stellenwert des Themas in der Erinnerungskultur | Quellenlage | Voraussetzungen und Abläufe | Flucht und Vertreibung | Ankunft und Erstaufnahme | Herkunftsgebiete - landsmannschaftliche Differenzierung | Materielle AspekteFürsorge und Integration durch Assimilation | Spätzeit - Entwicklungen nach 1989 | Fazit - Vertriebene in der brandenburgischen Gesellschaft der Gegenwart | Ortsdokumentation. Historische Stätten der Vertriebenenintegration in Brandenburg | Quellenedition

\section{Peter Bahl}

\section{Belastung und Bereicherung}

Vertriebenenintegration in Brandenburg ab 1945

Flüchtlinge und Vertriebene aus den ehemaligen deutschen Ostgebieten und anderen Siedlungsräumen in Ostmittel- und Osteuropa kamen ab 1945 in sehr großer Zahl auch nach Brandenburg. Bis Ende 1946 nahm das Land mehr als 616.000 Menschen auf, was die Bevölkerung nicht nur erheblich vergrößerte, sondern auch in ihrer Zusammensetzung stark veränderte.

Das weitere Schicksal der Betroffenen in der DDR ist jedoch kaum bekannt. Peter Bahl zeichnet erstmals auf breiter Quellenbasis ihre Ankunft und Integration sowie die Erinnerungskultur bis zur Gegenwart nach. Neben Akten lässt er dabei vielfach Zeitzeugen sowohl aus dem Kreis der Vertriebenen als auch dem der Einheimischen zu Wort kommen.

An die Darstellung der Ereignisgeschichte schließt er eine Dokumentation für alle Städte und ausgewählte Landgemeinden mit handbuchartigen Informationen zur konkreten lokalen Entwicklung in 340 Orten an. In einem Editionsteil sind ferner 261 Quellentexte aus den Jahren 1945-2018 abgedruckt, die sich für eine vertiefende Beschäftigung mit dem Thema in Bildungsarbeit und Wissenschaft eignen.

2020, 1736 S., 12 s/w Tab., geb.,

125, - €, 978-3-8305-5016-7

eBook PDF 978-3-8305-4186-8

(Bibliothek der Brandenburgischen und

Preußischen Geschichte, Bd. 17)

Berliner Wissenschafts-Verlag | Behaimstr. 25 | 10585 Berlin

Tel. 0308417 70-0 | Fax 0308417 70-21

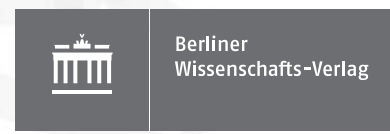



Das Graue Kloster in Berlin hat seine einstige Bedeutung eingebüßt und ist gegenwärtig nur noch ein, gebrochener Erinnerungsort'. Es fristet als Ruinendenkmal an der viel befahrenen Grunerstraße ein Schattendasein und die von ihm einst ausgegangene Lebendigkeit und Vielfalt drohen der Vergessenheit anheim zu fallen. Doch mit der anstehenden Neugestaltung des Klosterviertels, dem das Graue Kloster seinen Namen gab, rücken Fragen an die Geschichte des Klosters in den Fokus.

Welche Bedeutung hatte das Kloster im Mittelalter? Wie wirkte das Berlinische Gymnasium zum Grauen Kloster, das nahezu 400 Jahre innerhalb der einstigen Klostermauern für Bildung und Kultur stand? Auf welche Weise strahlten Kloster und Gymnasium in das umgebende Viertel sowie die Stadt Berlin aus? Wie ist der gegenwärtige interdisziplinäre Forschungsstand zu diesem Areal? Vom landesherrlichen Beginn im Mittelalter bis zum heutigen Schicksal des Klostergeländes und seiner möglichen Zukunft: Die hier versammelten Beiträge bilden ein Panorama, das die herausragende Stellung des Areals in der Berliner Stadtgeschichte einem größeren Publikum erschließt. 